\title{
Determinants of Child Development in India
}

\author{
Dissertation in order to acquire the doctoral degree \\ from the Faculty of Economic Sciences, \\ at the Georg-August-Universität Göttingen
}

\author{
Submitted by \\ Liza von Grafenstein \\ Born in Erlangen, Germany
}

Göttingen, 2021 
Supervision and examination committee:

First Supervisor: $\quad$ Professor Stephan Klasen, $\mathrm{PhD}$

Second Supervisor: Professor Dr. Sebastian Vollmer

Third Supervisor: $\quad$ Professor John Hoddinott, PhD

Date of disputation: $\quad 25.6 .2020$ 
For the benefit of all beings 
Die schnellste Art der Entwicklung ist die, seine guten Eigenschaften in die Welt zu tragen.

[The fastest way to develop is to bring one's own good qualities into the world.] 


\section{Acknowledgements}

I thank the German Research Foundation (Deutsche Forschungsgemeinschaft) for funding the Research Training Group [RTG] 1666 "GlobalFood” - Transformation of Global Agri-Food Systems of which I was a member and for the funding of my data collection. I also thank the SWAGATA Consortium to grant me a scholarship for my research stay at the Jawaharlal Nehru University.

I would like to express my sincere gratitude to my advisor Prof. Stephan Klasen, $\mathrm{PhD}$, for the continuous support of my doctoral study and research, for his patience, encouragement, and immense knowledge. I thank Prof. Dr. Sebastian Vollmer for his supervision. I feel very grateful that he entrusted me with the conduction and data collection of a large-scale RCT. I am thankful for the very valuable feedback of my third supervisor Prof. John Hoddinott, $\mathrm{PhD}$, who inspired me to pursue this PhD during my Master studies at Cornell University.

I want to thank Prof. Dr. Claudia Mähler for her engagement to cooperate beyond disciplines. I feel very grateful to have been part of the vibrant research community at Göttingen University. I want to thank Professor Marcela Ibanez-Diaz, PhD, Junior Professor Dr. Holger Rau, and Professor Dr. Andreas Landmann for their valuable advice. I also want to thank Professor Prabhu Pingali, PhD, and Professor Dr. Faisal Abbas who encouraged me to strive for a PhD. I owe gratitude to Abhijeet Kumar for conducting the data collection in India with me. I thank Bianca Dülken, Thea Eyting, Lena Gempke, Dara Krolpfeifer, Maximilian Köster, Tabea Recksiek, and Carmen Steinmetz for excellent research assistance in the field and in the office. I want to thank Rahul Kumar and Deeraj Kumar as well as the data collection supervisors and teams for their engagement and team spirit.

I would like to express my gratitude to the members of the RTG 1666 "GlobalFood”, members of the Chair of Professor Dr. Sebastian Vollmer, and the Development Economics PhD and PostDoc community. Thank you for your support, great scientific and non-scientific discussions. I especially thank Pooja Balasubramanian, Sarah Khan, Anette Ruml, Maximilian Späth, and Ann-Charline Weber.

I want to thank the over 2,300 families and 60 schools for sharing their experience and opinion 
with me for my data collection. I wish to use my research to benefit you all especially.

I want to thank the Diamond Way Buddhist Sangha in Göttingen and Aspasia Werner for inspiring me to keep questioning what is really important in life.

Last but not least, I would like to express my deepest gratitude to my parents Carmen von Grafenstein and Edgar Renner and my partner Nawang Gyatso Lachenpa for their endless love, support, and encouragement. I would not have reached here without you. 


\section{Declaration for admission to the doctoral examination according to $\S 12$ of Prüfungs- und Studienordnung des}

Promotionsstudiengangs "Wirtschaftswissenschaften" der Georg-August-Universität Göttingen

I confirm

1. that the dissertation "Determinants of Child Development in India" that I submitted was produced independently without assistance from external parties, and not contrary to high scientific standards and integrity,

2. that I have adhered to the examination regulations, including upholding a high degree of scientific integrity, which includes the strict and proper use of citations so that the inclusion of other ideas in the dissertation are clearly distinguished,

3. that in the process of completing this doctoral thesis, no intermediaries were compensated to assist me neither with the admissions or preparation processes, and in this process,

- No remuneration or equivalent compensation were provided

- No services were engaged that may contradict the purpose of producing a doctoral thesis

4. that I have not submitted this dissertation or parts of this dissertation elsewhere.

I am aware that false claims (and the discovery of those false claims now, and in the future) with regards to the declaration for admission to the doctoral examination can lead to the invalidation or revoking of the doctoral degree.

24.5.2020

Signature

Date 



\begin{abstract}
To overcome poverty, strengthening human development is crucial. However, today 250 million children younger than 5 years in low-income and middle-income countries are likely not to attain their full development potential. To overcome the obstacles to optimal human development, this dissertation examines the effect of determinants on the child, parent, school, or country level that determine child development.

The first essay questions the robustness of parental preferences as the main determinants of the height gap between children in India and sub-Saharan Africa as Jayachandran \& Pande (2017) [J+P] claim. In this replication and extension, we conduct a sensitivity analysis of J+P's model considering more recent data, weights, and additional controls: macro-determinants such as female education, household prosperity, open defecation, and the consumption of animal sourced foods. We show that the birth order gradient is shallower and can only explain a small share of the height difference using data from around 2015 or weights. The additional macro-determinants contribute to explaining the height gap.

The second essay poses the question if timing and duration of the use of fortified foods in school lunches determine child development. This essay presents the results of a follow-up study to a randomized controlled trial of a nutrition intervention that provides double-fortified salt [DFS] to government schools in Bihar. We find that children who receive DFS for almost 4 years have higher hemoglobin levels. Children with DFS exposure only in early childhood have also increased hemoglobin levels and reduced likelihood of suffering from moderate or severe anemia than children who only receive DFS briefly for 4 months in later childhood. The results show that a public nutrition intervention can determine child health outcomes.

The third essay investigates how market returns to investments and parentsâ perception thereof interacted with child endowments determine parental investments in children in India. Though research has examined the effects and causes of son preference in India widely, studies fail to cleanly identify the underlying reasons for lower parental investments in daughters. Our lab-in-the-field experiment reveals that parents react to different market settings: parents invest almost 10 percent less of the initial endowment in their children under competition. Further, parentsâ investments decrease by more than a quarter of the initial endowment once their own child competes against a boy. Market returns determine parental investments in children and so child development.
\end{abstract}




\section{Zusammenfassung}

Um Armut zu bekämpfen, muss die menschliche Entwicklung gestärkt werden. Allerdings werden heute 250 Millionen Kinder unter 5 Jahren in Ländern mit niedrigem und mittlerem Einkommen wahrscheinlich nicht ihr volles Entwicklungspotenzial erreichen. Um Hindernisse für eine optimale menschliche Entwicklung zu beseitigen, untersucht diese Dissertation die Wirkung von Determinanten kindlicher Entwicklung auf der Ebene des Kindes, der Eltern, der Schule oder des Landes.

Der erste Aufsatz stellt die Robustheit der elterlichen Präferenzen als Hauptdeterminanten der Größenunterschiede zwischen Kindern in Indien und Subsahara-Afrika in Frage, wie Jayachandran \& Pande (2017) [J+P] behaupten. In dieser Replikation und Erweiterung führen wir eine Sensitivitätsanalyse des Modells von J+P. Wir verwenden aktuellere Daten, Gewichte und zusätzliche Kontrollvariablen von Makro-Determinanten wie weibliche Bildung, Haushaltswohlstand, Defäkation unter freiem Himmel und der Konsum von Nahrungsmitteln tierischer Herkunft. Unter Verwendung von Daten um das Jahr 2015 und Gewichtung ist der Gradient der Geburtenreihenfolge flacher und der Höhenunterschieds weniger durch elterlichen Präferenzen erklärbar. Die Makro-Determinanten tragen zur Erklärung des Größenunterschieds bei.

Der zweite Aufsatz stellt die Frage, ob Zeitpunkt und Dauer der Verwendung von angereicherten Lebensmitteln in der Schulspeisung die kindliche Entwicklung bestimmen. Dieser Aufsatz präsentiert Ergebnisse einer Folgestudie zu einer randomisierten kontrollierten Studie einer Ernährungsintervention, die doppelt angereichertes Salz [DFS] für staatliche Schulen in Bihar bereitstellt. Unsere Ergebnisse zeigen, dass Kinder, die mindestens 3 Jahre lang in der frühen Kindheit DFS erhalten haben, höhere Hämoglobinwerte aufweisen. Kinder, die nur in der frühen Kindheit mit DFS versorgt wurden, haben zudem eine geringere Wahrscheinlichkeit, an moderater oder schwerer Anämie zu leiden, als Kinder, die nur kurzzeitig für 4 Monate in der späteren Kindheit DFS erhalten. Eine staatliche Ernährungsintervention scheint bestimmend für Kindergesundheit zu sein.

Der dritte Aufsatz untersucht, wie Marktrenditen für Investitionen und die Wahrnehmung der Eltern derer Investitionen in Kinder in Indien bestimmen. Obwohl die Forschung die Auswirkungen und Ursachen der Sohn-Präferenz in Indien umfassend untersucht hat, sind die zugrundeliegenden Ursachen für geringere elterliche Investitionen in Töchter nicht klar identifiziert. Unser Lab-in-the-Field Experiment zeigt, dass Eltern auf Marktbedingungen reagieren: Eltern investieren unter Wettbewerb fast 10 Prozent weniger des Startkapitals in ihre Kinder. Außerdem sinken die Investitionen der Eltern um mehr als ein Viertel des Startkapitals, sobald ihr Kind gegen einen Jungen antritt. Marktrenditen bestimmen die elterlichen Investitionen in Kinder und damit die kindliche Entwicklung. 


\section{Table of Contents}

1 Introduction 1

1 Context for Investigating Determinants of Child Development in India . . . . . 1

2 Conceptual Models for Determinants of Child Health and Development . . . . 2

2.1 An Economics Conceptual Model: Theory of the Transmission of Earnings, Assets, and Consumption from Parents to Descendants . . . . . 3

2.2 A Public Policy Conceptual Model: UNICEF (1990) Framework of Causes of Malnutrition and Death . . . . . . . . . . . 4

2.3 A Public Health Conceptual Model: Framework for Actions to Achieve Optimal Fetal and Child Nutrition and Development . . . . . . . 6

2.4 Comparison of the Conceptual Models . . . . . . . . . . . . . . 7

2.5 Contextualizing the Dissertation . . . . . . . . . . . . 9

$2.5 .1 \quad$ Essay $1 \ldots \ldots \ldots \ldots \ldots$

2.5.2 Essay $2 \ldots \ldots \ldots \ldots \ldots \ldots \ldots$

2.5.3 Essay $3 \ldots \ldots \ldots \ldots \ldots$

2.5.4 Conclusion of Contextualization . . . . . . . . . 13

3 Summary of the Essays . . . . . . . . . . . . . . . . . . . 14

$3.1 \quad$ Essay $1 \ldots \ldots \ldots \ldots \ldots$

$3.2 \quad$ Essay $2 \ldots \ldots \ldots \ldots \ldots \ldots$

$3.3 \quad$ Essay $3 \ldots \ldots \ldots \ldots \ldots$

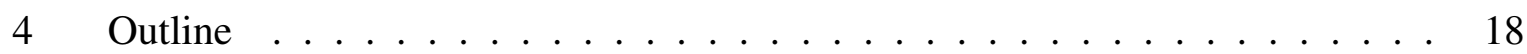

2 Essay 1: "Why are Indian Children So Short? The Role of Birth Order and Son Preference" - Replication and Extension 19

$1 \quad$ Introduction . . . . . . . . . . . . . . . . . . . 20

2 Background and Literature Review . . . . . . . . . . . . . . . 21

$2.1 \quad$ Son Preference in India . . . . . . . . . . . . . . . . . 22

2.2 Emerging Macro-Determinants Affecting Child Health . . . . . . . . 23 
3 Data and Methodology . . . . . . . . . . . . . . . 26

$3.1 \quad$ Sample Description . . . . . . . . . . . . . . . . 26

3.2 Estimation Strategy . . . . . . . . . . . . . . . 30

3.3 Measures of the Four Macro-Determinants . . . . . . . . . . . 31

$4 \quad$ Replication Results (2011-2017) vs (2004-2010): Unweighted . . . . . . . . . 32

$4.1 \quad$ Summary Statistics . . . . . . . . . . . . . . . . 32

4.2 India's Differential Birth Order Gradient in Child Height and Related

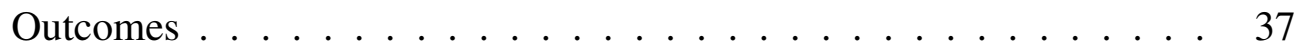

$4.3 \quad$ Child Health Inputs . . . . . . . . . . . . . . . . . 41

$4.4 \quad$ Child Gender and the Birth Order Gradient in Height . . . . . . . . . 44

4.5 Impact on Average Height - Accounting exercise . . . . . . . . . . 47

$5 \quad$ Replication Results (2004-2010): Weighted . . . . . . . . . . . . . . . . 50

5.1 Summary Statistics . . . . . . . . . . . . . 50

5.2 Summary of Results for India's Differential Birth Order Gradient and Gender for Child Health and Related Outcomes . . . . . . . . . . . . . 52

6 Extension Macro-Determinants (2011-2017) vs (2004-2010): Weighted . . . 56

$6.1 \quad$ Summary Statistics . . . . . . . . . . . . . . . . 56

6.2 Summary of Regression Results Using Macro-Determinants _ . . . . 59

6.2.1 India and Birth Order as Determinants . . . . . . . . 59

6.2.2 Emerging Macro-Determinants ........... . 59

6.2.3 Reassessment of the Main Predictions and Accounting Exercise 61

$7 \quad$ Discussion . . . . . . . . . . . . . . . . . . 64

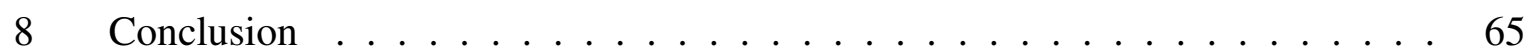

3 Essay 2: Long-Term Evidence of a Cluster Randomized Controlled Trial: Double Fortified Salt Usage for Health and Human Capital Acquisition of School Children $\begin{array}{ll}\text { in Rural Bihar } & 67\end{array}$

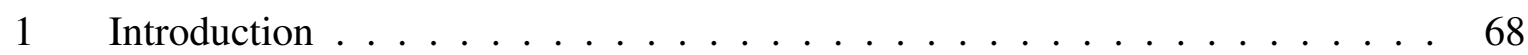

2 Background and Literature Review . . . . . . . . . . . . . . . 70

$3 \quad$ Study Design and Data . . . . . . . . . . . . . . . . . 72

3.1 Study Site and Sample Selection . . . . . . . . . . . . . 72

3.2 Data Collection . . . . . . . . . . . . . 76

3.3 Outcome and Covariate Measures . . . . . . . . . . . . . 76 
3.3.1 Health Measures . . . . . . . . . . . . . . . 76

3.3.2 Cognition Measures . . . . . . . . . . . . 77

3.3.3 Education Measures . . . . . . . . . . . . . . 77

3.3.4 Covariate Measures . . . . . . . . . . . . . 78

4 Estimation Strategy . . . . . . . . . . . . . . . . . . 79

$4.1 \quad$ Compliance . . . . . . . . . . . . . . . 79

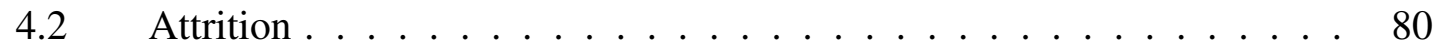

4.2.1 Reasons for Sample Attrition . . . . . . . . . . . . . 80

4.2.2 Extent of Sample Attrition . . . . . . . . . . . . 81

$4.3 \quad$ Pre-Intervention Balance . . . . . . . . . . . . . . 82

$4.4 \quad$ Empirical Specification . . . . . . . . . . . . . . . 83

$5 \quad$ Results ......................... 85

$5.1 \quad$ Health Outcomes . . . . . . . . . . . . . 85

$5.2 \quad$ Cognition and Education Outcomes . . . . . . . . . . . 89

5.2.1 Cognition Index Score . . . . . . . . . . . . . . . . 89

$5.2 .2 \quad$ Education Outcomes . . . . . . . . . . . . . 92

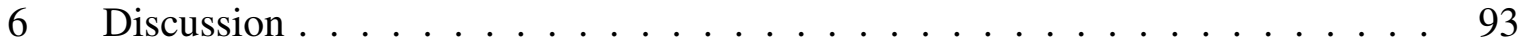

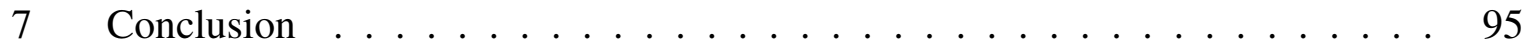

4 Essay 3: Parental Beliefs and Investment Decisions under Competition 97

$1 \quad$ Introduction . . . . . . . . . . . . . . . . . . . . 98

2 Background and Literature Review . . . . . . . . . . . . . . . . . . . . . 99

$2.1 \quad$ Input Factors in Parental Investment in Children _ . . . . . . . . . 100

$2.1 .1 \quad$ Becker's Identified Inputs . . . . . . . . . . . . . 100

2.1.2 Becker's Assumptions . . . . . . . . . . . . . . 103

$2.2 \quad$ Beyond Becker: Other Inputs _ . . . . . . . . . . . . . . . 104

2.3 Behavior under Competition . . . . . . . . . . . . . . 105

2.3.1 Behavior under Competition in the Lab . . . . . . . . . 105

2.3.2 Children's Behavior Under Competition _. . . . . . . . 108

3 Conceptual Framework . . . . . . . . . . . . . . . . . . . . 108

3.1 Investment under Non-Competition . . . . . . . . . . . . . 109

3.2 Investment under Competition . . . . . . . . . . . . . 113

3.3 Differential Investment between Non-Competition and Competition . . 119 
4 Experimental Design and Procedures . . . . . . . . . . . . . . 120

$4.1 \quad$ Experimental Procedures . . . . . . . . . . . . . . . 121

4.1.1 Experimental Sequence for Parents . . . . . . . . . . . 122

4.1.2 Experimental Sequence for Children . . . . . . . . . . . 124

4.2 Key Measures and Understanding . . . . . . . . . . . . . . . . . 125

4.2.1 Investment . . . . . . . . . . . . . . . 125

4.2.2 Beliefs ................... 127

$4.3 \quad$ Empirical Specification . . . . . . . . . . . . . . . 131

4.3.1 Belief Outcomes . . . . . . . . . . . . . . 131

4.3.2 Investment Outcome . . . . . . . . . . . . . . 132

4.3.3 Reduced Form Regression for Investment Outcome . . . . . 133

$5 \quad$ Experimental Results . . . . . . . . . . . . . . . . . . . . . . . 134

$5.1 \quad$ Sample Characteristics: Summary Statistics . . . . . . . . . . . . . 134

$5.2 \quad$ Formation of Parental Belief . . . . . . . . . . . . . . . 136

5.2.1 Descriptive Assessment of Accuracy of Beliefs . . . . . . . 136

5.2.2 Assessment of Parental Belief by Child and Competitor Endowment ....................... 139

5.2.3 Predictors of Believed Own Child Ability . . . . . . . . . 143

5.2.4 Predictors of Believed Probability to Win . . . . . . . . . 144

$5.3 \quad$ Parental Investment Decisions under Competition . . . . . . . . . . 148

5.3.1 Are Parents Purely Utility Maximizing? . . . . . . . . . . . 148

5.3.2 Do Parents Invest Less in Competitive Games? . . . . . . . . 148

5.3.3 Test of Hypotheses Investment 1 to $5 \ldots \ldots$

$5.4 \quad$ Reduced Form Regression - Bringing Investment and Beliefs together . 155

6 Discussion . . . . . . . . . . . . . . . . . 158

$7 \quad$ Conclusion $\ldots \ldots \ldots \ldots \ldots \ldots 1 \ldots \ldots \ldots \ldots$

$\begin{array}{lll}\text { Appendix A } & \text { Introduction } & 187\end{array}$

$\begin{array}{llr}\text { Appendix B } & \text { Essay 1 } & 189\end{array}$

1 Results (2004-2010) by J+P and Replicated Results (2004-2010): Same Methodology and Data from the Same Time Period . . . . . . . . . . . . . . . . 189

$1.1 \quad$ Summary Statistics . . . . . . . . . . . . . . . . . . 189 
1.2 India's Differential Birth Order Gradient in Child Height and Related Outcomes ........................... 191

$1.3 \quad$ Child Health Inputs . . . . . . . . . . . . . . . . . . . . 193

1.4 Cultural Norms and Child Height: Within-India Evidence . . . . . . . 194

1.5 Child Gender and the Birth Order Gradient in Height . . . . . . . . . 196

1.6 Impact on Average Height - Accounting exercise . . . . . . . . . . 197

2 Replicated Results (2004-2010) and Replicated Results (2011-2017): Same Methodology and Data from the More Recent Time Period . . . . . . . . . . . 199

$2.1 \quad$ Summary Statistics . . . . . . . . . . . . . . . . . . . 199

2.2 India's Differential Birth Order Gradient in Child Height and Related

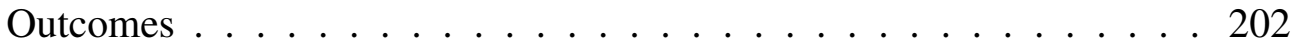

$2.3 \quad$ Child Health Inputs . . . . . . . . . . . . . . . . . . . . . 205

2.4 Cultural Norms and Child Height: Within-India Evidence . . . . . . 206

2.5 Child Gender and the Birth Order Gradient in Height . . . . . . . . . . 209

2.6 Impact on Average Height - Accounting exercise . . . . . . . . . . . 210

3 Replicated Results (2004-2010): Adjusted Methodology and Data from the Same Time Period . . . . . . . . . . . . . . . . . . . . . . . . . . 212

$3.1 \quad$ Summary Statistics . . . . . . . . . . . . . . . . . . . . 212

3.2 India's Differential Birth Order Gradient in Child Height and Related Outcomes .......................... 217

$3.3 \quad$ Child Health Inputs . . . . . . . . . . . . . . . . . . . . . 221

3.4 Cultural Norms and Child Height: Within-India Evidence . . . . . . 223

3.5 Child Gender and the Birth Order Gradient in Height . . . . . . . . 225

3.6 Impact on Average Height - Accounting exercise . . . . . . . . . . . 227

$4 \quad$ Replicated Results (2004-2010) and Replicated Results (2011-2017): Adjusted Methodology and Data from the More Recent Time Period . . . . . . . . . . . 230

$4.1 \quad$ Summary Statistics . . . . . . . . . . . . . . 230

4.2 India's Differential Birth Order Gradient in Child Height and Related

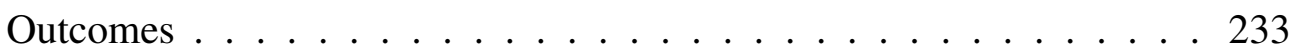

$4.3 \quad$ Child Health Inputs . . . . . . . . . . . . . . . . 236

4.4 Cultural Norms and Child Height: Within-India Evidence . . . . . . 237

4.5 Child Gender and the Birth Order Gradient in Height . . . . . . . . . . 240 
4.6 Impact on Average Height - Accounting exercise . . . . . . . . . . 241

$5 \quad$ Replicated Results (2004-2010) and Replicated Results (2011-2017): Adjusted

Methodology and Three Macro-Determinants with Data from the More Recent

Time Period . . . . . . . . . . . . . . . . . . . . . . 243

$5.1 \quad$ Summary Statistics . . . . . . . . . . . . . . . . . . 243

5.2 India's Differential Birth Order Gradient in Child Height and Related

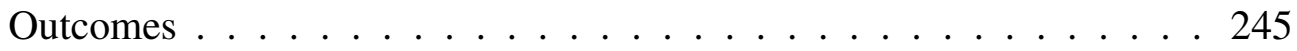

$5.3 \quad$ Child Health Inputs . . . . . . . . . . . . . . . . . . . . 247

5.4 Child Gender and the Birth Order Gradient in Height . . . . . . . . . . 248

5.5 Impact on Average Height - Accounting exercise . . . . . . . . . 250

6 Replicated Results (2004-2010) and Replicated Results (2011-2017): Adjusted

Methodology and Four Macro-Determinants with Data from the More Recent

Time Period . . . . . . . . . . . . . . . . . . . . 253

6.1 India's Differential Birth Order Gradient in Child Height and Related

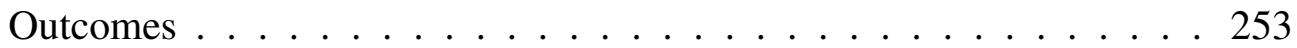

6.2 Child Gender and the Birth Order Gradient in Height . . . . . . . . . 256

6.3 Impact on Average Height - Accounting exercise . . . . . . . . . 258

7 Additional Descriptive Evidence . . . . . . . . . . . . . . . . . 261

7.1 Summary Statistics: Assets of Wealth Index . . . . . . . . . . . . 261

7.2 Summary Statistics: Child Survival _ . . . . . . . . . . . . 263

7.3 Child Inputs by Birth Order, Gender, Time, and Country . . . . . . . 264

$\begin{array}{llr}\text { Appendix C } & \text { Essay 2 } & 267\end{array}$

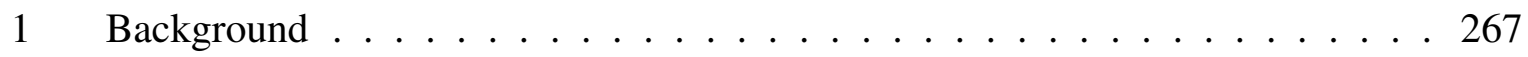

1.1 India's School-Feeding Program . . . . . . . . . . . . . . 267

1.2 Prevalence, Causes, and Consequences of Iron Deficiency in India . . . 268

2 Study Design and Data . . . . . . . . . . . . . . . . . 269

2.1 Causal Pathway of the Intervention . . . . . . . . . . . 269

$2.2 \quad$ School Types Across Survey Waves . . . . . . . . . . . . . . 271

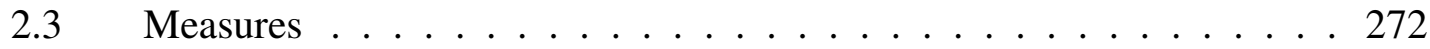

$2.3 .1 \quad$ Outcomes ..................... 272

2.3.2 Covariates ........................ 274

3 Internal Validity Threats $\ldots \ldots \ldots \ldots \ldots$ 


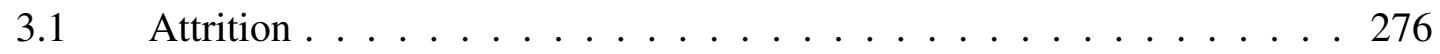

3.1.1 Illustration of Attrition over Time Using the Health Outcomes Sample . . . . . . . . . . . . . 276

3.1.2 Examining Correlation between Attrition and DFS Exposure 277

3.1.3 Balancing Tables by Attrition Status Using wave I Data . . . 279

3.1.4 Balancing Tables by Attrition Status Using Data of Previous Time Period Data . . . . . . . . . . . . . . 289

3.1.5 Balancing Tables of Attrited by Exposure Group . . . . . . . 299

3.2 Additional Balancing Tables by Exposure Groups . . . . . . . . . . . . 309

3.3 Inverse Probability Weighting . . . . . . . . . . . . . 313

3.3.1 Health Outcomes . . . . . . . . . . . . . 313

3.3.2 Cognition Outcomes . . . . . . . . . . . . . 315

3.3.3 Education Outcomes . . . . . . . . . . . . . 317

$3.4 \quad$ Lee Bounds for Outcomes . . . . . . . . . . . . . . . . . . . . . . . . 319

3.4.1 Health Outcomes . . . . . . . . . . . . . . . . 319

3.4.2 Cognition Outcomes . . . . . . . . . . . . . . 321

3.4.3 Education Outcomes . . . . . . . . . . . . . . . 324

3.5 Multiple Hypothesis Corrected Sharpened q-Values . . . . . . . . . 326

3.5.1 Health Outcomes . . . . . . . . . . . . . . 326

3.5.2 Cognition Outcomes . . . . . . . . . . . . 327

3.5.3 Education Outcomes . . . . . . . . . . . . . . . 328

$3.6 \quad$ Ceiling Effects . . . . . . . . . . . . . . . . . . 329

4 Heterogeneous Effects . . . . . . . . . . . . . . . . 330

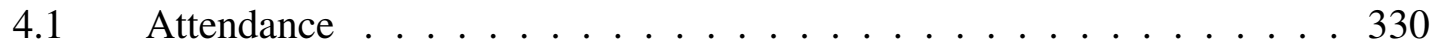

4.1.1 Health Outcomes . . . . . . . . . . . . . 330

4.1.2 Cognition Outcomes . . . . . . . . . . . . . . 334

4.1.3 Education Outcomes . . . . . . . . . . . . . . . 339

$\begin{array}{lll}\text { Appendix D } & \text { Essay } 3 & 342\end{array}$

1 Comparison Believed and Measured Probabilities of Competitors . . . . . . . . 342

2 Robustness Checks: Regressions . . . . . . . . . . . . . . . . . . . . 344 


\section{List of Figures}

1.1 UNICEF (1990) Conceptual Model of Causes of Malnutrition and Death . . . . 5

1.2 Framework for Actions to Achieve Optimal Fetal and Child Nutrition and Development ............................... 6

2.1 GDP for India and Sub-Saharan Africa . . . . . . . . . . . . . . . . . 24

2.2 Child Height versus National GDP (2004-2010) vs (2011-2017): Unweighted . 36

2.3 Child Height in India and Africa, by Child's Birth Order (2004-2010) vs (20112017): Unweighted . . . . . . . . . . . . . . . . . . . 40

2.4 Child Height in India and Africa, by Child's Birth Order (2004-2010): Unweighted vs Weighted . . . . . . . . . . . . . . 55

3.1 DFS Supply to Schools over Time . . . . . . . . . . . . . . . . . . . 74

3.2 Child Treatment over Time . . . . . . . . . . . . . . . . . . . 75

3.3 Marginal Affects for Hemoglobin by Level of Attendance . . . . . . . . . . . . 91

4.1 Simplified Decision Tree for Non-Competition . . . . . . . . . . . . 111

4.2 Simplified Decision Tree for Competition . . . . . . . . . . . . . . 116

4.3 Experimental Sequence . . . . . . . . . . . . . . . . 121

4.4 Relative Frequency of Correct Answers of Test Questions for Investment Game 126

4.5 Relative Frequency of Prompts and Changes for Test Questions for Believed Probability of an Event . . . . . . . . . . . . . . . . . . 128

4.6 Relative Frequency of Using Ten Beans for Believed Distribution of a Series of Events . . . . . . . . . . . . . . . . . . 130

4.7 Histogram of Relative Frequency of Probability of Solving Any One Task by Gender of Own Child Comparing Believed and Measured Values . . . . . . . . 137

4.8 Histogram of Relative Frequency of Probability of Own Child Winning against a Competitor with Different Gender Comparing Believed and Measured Values 138

4.9 Box Plots on Probability to Win by Own Child by Gender Combinations . . . . 141

4.10 Average Invested Amount over Number of Solved Tasks by Competition . . . . 149 
4.11 Box Plots of Parental Investment in the Child Account by Competition . . . . 149

4.12 Box Plots of Parental Investment in the Child Account over Solved Tasks by Competition . . . . . . . . . . . . . . . . . 150

4.13 Average Invested Amount over Number of Solved Tasks by Competition . . . . 151

A.1 Conceptual Framework Depicting Causes of Malnutrition and Links between Women's Empowerment and Nutrition _. . . . . . . . . . . . . 188

B.1 Child Height versus National GDP (2004-2010) vs (2011-2017): Unweighted . 201

B.2 Child Height in India and Africa, by Child's Birth Order (2004-2010) vs (20112017): Unweighted . . . . . . . . . . . . . . . . . . . 204

B.3 Child Height versus National GDP (2004-2010): Unweighted vs Weighted . 215

B.4 Child Height versus National GDP (2004-2010): Weighted . . . . . . . . . . 216

B.5 Child Height in India and Africa, by Child's Birth Order (2004-2010): Unweighted vs Weighted . . . . . . . . . . . . . . 220

B.6 Child Height in India and Africa, by Child's Birth Order (2004-2010): Weighted 221

B.7 Child Height versus National GDP (2004-2010) vs (2011-2017): Weighted . 232

B.8 Child Height in India and Africa, by Child's Birth Order (2004-2010) vs (20112017): Weighted . . . . . . . . . . . . . . . 235

C.1 Logical Framework of DFS Intervention . . . . . . . . . . . . . 270

C.2 Frequency of Age of School Children by Survey Wave . . . . . . . . . . . . . 272

C.3 Flowchart of School and Child Attrition over Time for Health Outcomes . . . . 276

C.4 Frequency of Math Score of School Children by Survey Wave . . . . . . . 329

C.5 Frequency of Reading Score of School Children by Survey Wave . . . . . . . 329

C.6 Marginal Affects for Hemoglobin by Level of Attendance . . . . . . . . . . . . 330

C.7 Marginal Affects for Any Anemia by Level of Attendance . . . . . . . . . . . 330

C.8 Marginal Affects for Mild Anemia by Level of Attendance . . . . . . . . . . 331

C.9 Marginal Affects for Moderate and Severe Anemia by Level of Attendance . . 331

C.10 Marginal Affects for Block Design by Level of Attendance . . . . . . . . . . . 334

C.11 Marginal Affects for Digit Span Forward by Level of Attendance . . . . . . . . 334

C.12 Marginal Affects for Digit Span Backward by Level of Attendance . . . . . . . 335

C.13 Marginal Affects for Raven's Progressive Matrices by Level of Attendance . . . 335

C.14 Marginal Affects for Stroop Test by Level of Attendance . . . . . . . . . . . 336 
C.15 Marginal Affects for Cognition Index by Level of Attendance . . . . . . . . . 336

C.16 Marginal Affects for Math Score by Level of Attendance . . . . . . . . . . . 339

C.17 Marginal Affects for Reading Score by Level of Attendance . . . . . . . . . 339 


\section{List of Tables}

1.1 Comparison of the Conceptual Models . . . . . . . . . . . . 8

1.2 Contextualizing the Essays Given Three Seminal Conceptual Models . . . . . . 10

2.1 State Sample Share of NFHS 3 and NFHS $4 \ldots \ldots$. . . . . . . . . 27

2.2 Sample Comparison . . . . . . . . . . . . . . . . . . . . . . . . . . . 29

2.3 Summary Statistics $(2004-2010) \ldots \ldots \ldots$. . . . . . . . . . . . 34

2.4 Summary Statistics $(2011-2017) \ldots \ldots \ldots$

2.5 India's Differential Birth Order Gradient in Child Height and Related Outcomes

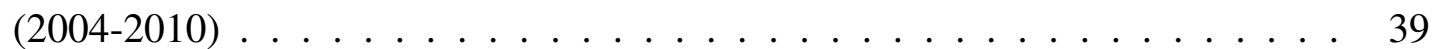

2.6 India's Differential Birth Order Gradient in Child Height and Related Outcomes

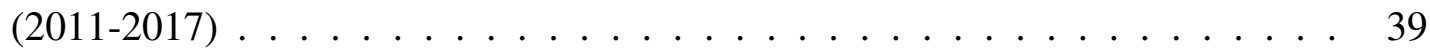

2.7 Child Health Inputs $(2004-2010) \quad \ldots \ldots \ldots$

2.8 Child Health Inputs $(2011-2017) \ldots \ldots$. . . . . . . . . . . . . . 43

2.9 Child Gender and the Birth Order Gradient in Height (2004-2010) . . . . . . 46

2.10 Child Gender and the Birth Order Gradient in Height (2011-2017) . . . . . 46

2.11 Accounting Exercise Part 1: Sample Comparison (2004-2010) . . . . . . . . . 48

2.12 Accounting Exercise Part 1: Sample Comparison (2011-2017) . . . . . . . . . 48

2.13 Accounting Exercise Part 2: Sample Comparison (2004-2010) _ . . . . . . . . 49

2.14 Accounting Exercise Part 2: Sample Comparison (2010-2017) _ . . . . . . . 49

2.15 Summary Statistics (2004-2010): Unweighted . . . . . . . . . . . . . 51

2.16 Summary Statistics (2004-2010): Weighted ． . . . . . . . . . . . 52

2.17 India's Differential Birth Order Gradient in Child Height and Related Outcomes (2004-2010): Unweighted . . . . . . . . . . . . . . . . 54

2.18 India's Differential Birth Order Gradient in Child Height and Related Outcomes (2004-2010): Weighted India . . . . . . . . . . . . . . . . . . 54

2.19 Summary Statistics (2004-2010): Weighted Macro-Determinants . . . . . . . 58

2.20 Summary Statistics (2011-2017): Weighted Macro-Determinants . . . . . . . 58 
2.21 India's Differential Birth Order Gradient in Child Height and Related Outcomes (2004-2010): Weighted Macro-Determinants

2.22 India's Differential Birth Order Gradient in Child Height and Related Outcomes (2011-2017): Weighted Macro-Determinants . . . . . . . . . . . 63

3.1 Correlation between Attrition and DFS Exposure Status . . . . . . . . . . 81

3.2 Baseline Summary Statistics for Health Outcomes Sample (Balance Check) at Wave III Using Wave I Data as Baseline . . . . . . . . . . . . . . . . 83

3.3 Effects on Hemoglobin and Anemia Using Inverse Probability Weighting . . 86

3.4 Sharpened Lee Bounds for Effects on Health, Cognition, and Education Outcomes 87

3.5 Multiple Hypothesis Corrected Sharpened q-Values for Inverse Probability Weighted Effects . . . . . . . . . . . . . . . . . 88

3.6 Effects on Cognition and Education Using Inverse Probability Weighting . . . . 90

4.1 Payout Table for Non-Competition . . . . . . . . . . . . . . . . . 112

4.2 Payout Table for Competition . . . . . . . . . . . . . . . . . . 118

4.3 Summary Statistics of Selected Variables . . . . . . . . . . . . . . . . . 135

4.4 Mean Comparison of Believed and Measured Values . . . . . . . . . . . . 138

4.5 Mean Comparison of Beliefs by Gender of Own Child ～. . . . . . . . . . . . 140

4.6 Mean Comparison of Beliefs by Gender of Competitor . . . . . . . . . . . . . 142

4.7 Regression Results for Belief of Own Child Solving Any One Task . . . . . . . 143

4.8 Regression Results Parental Belief about Probability of Own Child to Win . . . 145

4.9 Comparison of the Investments by Child Ability and Competition . . . . . . 151

4.10 Regression Results for Parental Investment in Child Account . . . . . . . . . 153

4.11 Reduced Form Regression Results for Parental Investment in Child Account . 156

B.1 Summary Statistics (2004-2010): Original . . . . . . . . . . . . . . . 189

B.2 Summary Statistics (2004-2010): Unweighted ． . . . . . . . . . . . 190

B.3 India's Differential Birth Order Gradient in Child Height and Related Outcomes (2004-2010): Original . . . . . . . . . . . . . . . . . . . . 191

B.4 India's Differential Birth Order Gradient in Child Height and Related Outcomes (2004-2010): Unweighted . . . . . . . . . . . . . . . . . . 192

B.5 Child Health Inputs (2004-2010): Original . . . . . . . . . . . . . . . . . 193

B.6 Child Health Inputs (2004-2010): Unweighted . . . . . . . . . . . . . . 193 
B.7 Cultural Norms and Child Height: Within-India Evidence (2004-2010): Original 194

B.8 Cultural Norms and Child Height: Within-India Evidence (2004-2010): Unweighted . . . . . . . . . . . . . . . . . . 195

B.9 Child Gender and the Birth Order Gradient in Height (2004-2010): Original . 196

B.10 Child Gender and the Birth Order Gradient in Height (2004-2010): Unweighted 196

B.11 Accounting Exercise Part 1: Sample Comparison (2004-2010): Original ․ . . 197

B.12 Accounting Exercise Part 1: Sample Comparison (2004-2010): Unweighted . . 197

B.13 Accounting Exercise Part 2: Sample Comparison (2004-2010): Original ․ . . 198

B.14 Accounting Exercise Part 2: Sample Comparison (2004-2010): Unweighted . 198

B.15 Summary Statistics (2004-2010) . . . . . . . . . . . . . . . . 199

B.16 Summary Statistics $(2011-2017)$. . . . . . . . . . . . . . . . 200

B.17 India's Differential Birth Order Gradient in Child Height and Related Outcomes

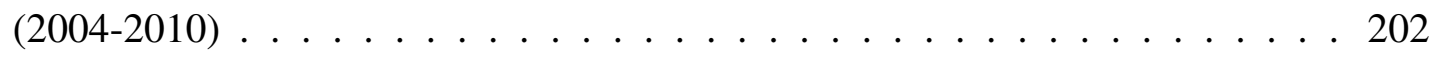

B.18 India's Differential Birth Order Gradient in Child Height and Related Outcomes

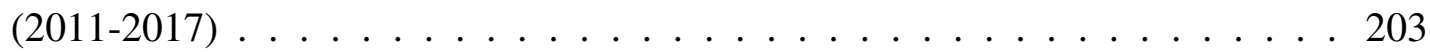

B.19 Child Health Inputs (2004-2010) ～. . . . . . . . . . . . . . 205

B.20 Child Health Inputs (2011-2017) ～. . . . . . . . . . . . . 205

B.21 Cultural Norms and Child Height: Within-India Evidence (2004-2010) . . . . . 206

B.22 Cultural Norms and Child Height: Within-India Evidence (2004-2017) . . . . . 207

B.23 Cultural Norms and Child Height: Within-India Evidence (2015/6) . . . . . . 208

B.24 Child Gender and the Birth Order Gradient in Height (2004-2010) . . . . . 209

B.25 Child Gender and the Birth Order Gradient in Height (2011-2017) . . . . . . . 209

B.26 Accounting Exercise Part 1: Sample Comparison (2004-2010) . . . . . . . 210

B.27 Accounting Exercise Part 1: Sample Comparison (2011-2017) . . . . . . . . 210

B.28 Accounting Exercise Part 2: Sample Comparison (2004-2010) . . . . . . . . . 211

B.29 Accounting Exercise Part 2: Sample Comparison (2010-2017) . . . . . . . . . 211

B.30 Summary Statistics (2004-2010): Unweighted . . . . . . . . . . . . . 212

B.31 Summary Statistics (2004-2010): Weighted India ～. . . . . . . . . . . 213

B.32 Summary Statistics (2004-2010): Weighted ． . . . . . . . . . . 214

B.33 India's Differential Birth Order Gradient in Child Height and Related Outcomes (2004-2010): Unweighted . . . . . . . . . . . . . . . . 217 
B.34 India's Differential Birth Order Gradient in Child Height and Related Outcomes (2004-2010): Weighted India . . . . . . . . . . . . . . . . . 218

B.35 India's Differential Birth Order Gradient in Child Height and Related Outcomes (2004-2010): Weighted . . . . . . . . . . . . . . . . 219

B.36 Child Health Inputs (2004-2010): Unweighted . . . . . . . . . . . . . . 221

B.37 Child Health Inputs (2004-2010): Weighted India . . . . . . . . . . . . 222

B.38 Child Health Inputs (2004-2010): Weighted ． . . . . . . . . . . . . . . . 222

B.39 Cultural Norms and Child Height: Within-India Evidence (2004-2010): Unweighted . . . . . . . . . . . . . . . . . . 223

B.40 Cultural Norms and Child Height: Within-India Evidence (2004-2010): Weighted India . . . . . . . . . . . . . . . . . . . . . 224

B.41 Child Gender and the Birth Order Gradient in Height (2004-2010): Unweighted 225

B.42 Child Gender and the Birth Order Gradient in Height (2004-2010): Weighted India . . . . . . . . . . . . . . . . . . . 225

B.43 Child Gender and the Birth Order Gradient in Height (2004-2010): Weighted . 226

B.44 Accounting Exercise Part 1: Sample Comparison (2004-2010): Unweighted . 227

B.45 Accounting Exercise Part 1: Sample Comparison (2004-2010): Weighted India 227

B.46 Sample Comparison (2004-2010): Weighted . . . . . . . . . . . . . . . 228

B.47 Accounting Exercise Part 2: Sample Comparison (2004-2010): Unweighted . . 229

B.48 Accounting Exercise Part 2: Sample Comparison (2004-2010): Weighted India 229

B.49 Accounting Exercise Part 2: Sample Comparison (2004-2010): Weighted . . . 229

B.50 Summary Statistics (2004-2010): Weighted ． . . . . . . . . . . . 230

B.51 Summary Statistics (2011-2017): Weighted . . . . . . . . . . . . 231

B.52 India's Differential Birth Order Gradient in Child Height and Related Outcomes (2004-2010): Weighted . . . . . . . . . . . . . . 233

B.53 India's Differential Birth Order Gradient in Child Height and Related Outcomes (2011-2017): Weighted . . . . . . . . . . . . . . . . 234

B.54 Child Health Inputs (2004-2010): Weighted ． . . . . . . . . . . . . . . 236

B.55 Child Health Inputs (2011-2017): Weighted ～. . . . . . . . . . . . . 236

B.56 Cultural Norms and Child Height: Within-India Evidence (2004-2010): Weighted237 B.57 Cultural Norms and Child Height: Within-India Evidence (2004-2017): Weighted238 B.58 Cultural Norms and Child Height: Within-India Evidence (2015/6): Weighted . 239 
B.59 Child Gender and the Birth Order Gradient in Height (2004-2010): Weighted . 240

B.60 Child Gender and the Birth Order Gradient in Height (2010-2017): Weighted 240

B.61 Accounting Exercise Part 1: Sample Comparison (2004-2010): Weighted . . . 241

B.62 Accounting Exercise Part 1: Sample Comparison (2011-2017): Weighted . . 241

B.63 Accounting Exercise Part 2: Sample Comparison (2004-2010): Weighted . . 242

B.64 Accounting Exercise Part 2: Sample Comparison (2010-2017): Weighted . . 242

B.65 Summary Statistics (2004-2010): Weighted Macro-Determinants . . . . . . . . 243

B.66 Summary Statistics (2011-2017): Weighted Macro-Determinants . . . . . . . . 244

B.67 India's Differential Birth Order Gradient in Child Height and Related Outcomes (2004-2010): Weighted 3 Macro-Determinants . . . . . . . . . . . 245

B.68 India's Differential Birth Order Gradient in Child Height and Related Outcomes (2011-2017): Weighted 3 Macro-Determinants . . . . . . . . . . . . . 246

B.69 Child Health Inputs (2004-2010): Weighted Macro-Determinants . . . . . . . . 247

B.70 Child Health Inputs (2011-2017): Weighted Macro-Determinants . . . . . . . . 247

B.71 Child Gender and the Birth Order Gradient in Height (2004-2010): Weighted 3 Macro-Determinants . . . . . . . . . . . . . . . . . . . 248

B.72 Child Gender and the Birth Order Gradient in Height (2010-2017): Weighted 3 Macro-Determinants . . . . . . . . . . . . . . . . . . 249

B.73 Accounting Exercise Part 1: Sample Comparison (2004-2010): Weighted 3 Macro-Determinants . . . . . . . . . . . . . . 250

B.74 Accounting Exercise Part 1: Sample Comparison (2011-2017): Weighted 3 Macro-Determinants . . . . . . . . . . . . . . . 251

B.75 Accounting Exercise Part 2: Sample Comparison (2004-2010): Weighted 3 Macro-Determinants . . . . . . . . . . . . . . . 252

B.76 Accounting Exercise Part 2: Sample Comparison (2010-2017): Adjusted Methodology and 3 Macro-Determinants with Data from the More Recent Time Period

B.77 India's Differential Birth Order Gradient in Child Height and Related Outcomes (2004-2010): Weighted 4 Macro-Determinants . . . . . . . . . . . . 254

B.78 India's Differential Birth Order Gradient in Child Height and Related Outcomes (2011-2017): Weighted 4 Macro-Determinants . . . . . . . . . . . 255

B.79 Child Gender and the Birth Order Gradient in Height (2004-2010): Weighted 4 Macro-Determinants ...................... 256 
B.80 Child Gender and the Birth Order Gradient in Height (2010-2017): Weighted 4 Macro-Determinants . . . . . . . . . . . . . . . . . . 257

B.81 Accounting Exercise Part 1: Sample Comparison (2004-2010): Weighted 4 Macro-Determinants . . . . . . . . . . . . . . . 258

B.82 Accounting Exercise Part 1: Sample Comparison (2011-2017): Weighted 4 Macro-Determinants . . . . . . . . . . . . . . . . . 259

B.83 Accounting Exercise Part 2: Sample Comparison (2004-2010): Weighted 4 Macro-Determinants . . . . . . . . . . . . . . . . 260

B.84 Accounting Exercise Part 2: Sample Comparison (2011-2017): Weighted 4 Macro-Determinants . . . . . . . . . . . . . . . . 260

B.85 Wealth Index Summary Statistics (2004-2010): Unweighted . . . . . . . . . 261

B.86 Wealth Index Summary Statistics (2011-2017): Unweighted . . . . . . . . . 262

B.87 Share of Ever Born Children and Survival Rate by Gender, Birth Order, Country, and Time: Weighted . . . . . . . . . . . . . . . . 263

B.88 Summary Statistics of Inputs by Birth Order: Weighted Means . . . . . . . . 264

B.89 Summary Statistics of Inputs by Birth Order for Girls: Weighted Means . . . 265

B.90 Summary Statistics of Inputs by Birth Order for Boys: Weighted Means . . . . 266

C.1 Frequency and Treatment Periods of Schools Included at the Three Data Collection Waves . . . . . . . . . . . . . . . . . . . 271

C.2 Number of Anemia Cases by Treatment and Survey Wave . . . . . . . . . . . 272

C.3 Sources Used for Cognitive Tests in Wave III . . . . . . . . . . . . . . 273

C.4 Overview Covariates . . . . . . . . . . . . . . . . . 275

C.5 Correlation between Attrition and DFS Exposure Status . . . . . . . . . . . 278

C.6 Panel A: Balancing Table by Attrition and Time Period Using Wave I Data for Health Outcomes . . . . . . . . . . . . . . . . . . . . . 280

C.7 Panel B: Balancing Table by Attrition and Time Period Using Wave I Data for Health Outcomes . . . . . . . . . . . . . . . . . . . 281

C.8 Panel C: Balancing Table by Attrition and Time Period Using Wave I Data for Health Outcomes . . . . . . . . . . . . . . . . . . 282

C.9 Panel A: Balancing Table by Attrition and Time Period Using Wave I Data for Cognition and Education Outcomes 
C.10 Panel B: Balancing Table by Attrition and Time Period Using Wave I Data for Cognition and Education Outcomes _ . . . . . . . . . . . . . . . . . 284

C.11 Panel C: Balancing Table by Attrition and Time Period Using Wave I Data for Cognition and Education Outcomes _. . . . . . . . . . . . . . 285

C.12 Panel A: Balancing Table by Attrition and Time Period Using Wave I Data for Attendance Outcome . . . . . . . . . . . . . . . . . . . 286

C.13 Panel B: Balancing Table by Attrition and Time Period Using Wave I Data for Attendance Outcome . . . . . . . . . . . . . . . . . . 287

C.14 Panel C: Balancing Table by Attrition and Time Period Using Wave I Data for Attendance Outcome . . . . . . . . . . . . . . . . . . . 288

C.15 Panel A: Balancing Table by Attrition over Time Using Data for Health Outcomes290

C.16 Panel B: Balancing Table by Attrition over Time Using Data for Health Outcomes291

C.17 Panel C: Balancing Table by Attrition over Time Using Data for Health Outcomes292

C.18 Panel A: Balancing Table by Attrition over Time Using Data for Cognition and Education Outcomes _. . . . . . . . . . . . . . . . . . 293

C.19 Panel B: Balancing Table by Attrition over Time Using Data for Cognition and Education Outcomes . . . . . . . . . . . . . . . . . . . . . . 294

C.20 Panel C: Balancing Table by Attrition over Time Using Data for Cognition and Education Outcomes _. . . . . . . . . . . . . . . . . . 295

C.21 Panel A: Balancing Table by Attrition over Time Using Data for Attendance Outcome . . . . . . . . . . . . . . . . . . . 296

C.22 Panel B: Balancing Table by Attrition over Time Using Data for Attendance Outcome . . . . . . . . . . . . . . . . . . . . . . 297

C.23 Panel C: Balancing Table by Attrition over Time Using Data for Attendance Outcome . . . . . . . . . . . . . . . . . . . . . 298

C.24 Balancing Table of Attrited Members of Exposure Group Using Wave I Data for Health Outcomes ～. . . . . . . . . . . . . . . . . . . . . . . 300

C.25 Balancing Table of Attrited Members of Exposure Group Using Wave I Data for Health Outcomes . . . . . . . . . . . . . . . . . . . . . 301

C.26 Balancing Table of Attrited Members of Exposure Group Using Wave II Data for Health Outcomes ～. . . . . . . . . . . . . . . . . . . . . . . 302 
C.27 Balancing Table of Attrited Members of Exposure Group Using Wave I Data for Cognition and Education Outcomes

C.28 Balancing Table of Attrited Members of Exposure Group Using Wave I Data for Health Outcomes ～. . . . . . . . . . . . . . . . . . . . . . . . 304

C.29 Balancing Table of Attrited Members of Exposure Group Using Wave II Data for Health Outcomes

C.30 Balancing Table of Attrited Members of Exposure Group Using Baseline Data for Attendance Outcome . . . . . . . . . . . . . . . . . . . 306

C.31 Balancing Table of Attrited Members of Exposure Group Using Wave I Data for Health Outcomes ～. . . . . . . . . . . . . . . . . . . . . 307

C.32 Balancing Table of Attrited Members of Exposure Group Using Wave II Data for Health Outcomes ． . . . . . . . . . . . . . . . . . . 308

C.33 Baseline Mean Characteristics by Exposure Groups - Sample for Health Outcomes 310

C.34 Baseline Mean Characteristics by Exposure Groups - Sample for Cognition and Education Outcomes

C.35 Baseline Mean Characteristics by Exposure Groups - Sample for Attendance Outcome . . . . . . . . . . . . . . . . . . . . . 312

C.36 Inverse Probability Weighted Effects on Hemoglobin and Anemia . . . . . . 314

C.37 Inverse Probability Weighted Effects on Cognition . . . . . . . . . . . . . . 316

C.38 Inverse Probability Weighted Effects on Education and Attendance . . . . . . . 318

C.39 Hemoglobin $(\mathrm{g} / \mathrm{dL}) \ldots \ldots \ldots$. . . . . . . . . . . . . . . . 319

C.40 Any anemia . . . . . . . . . . . . . . . . . . . . 319

C.41 Mild anemia . . . . . . . . . . . . . . . . . . . . 320

C.42 Moderate/severe anemia . . . . . . . . . . . . . . . . 320

C.43 Block design . . . . . . . . . . . . . . . . . . 321

C.44 Digit span forward . . . . . . . . . . . . . . . . 321

C.45 Digit span backward . . . . . . . . . . . . . . . . 322

C.46 Progressive matrices . . . . . . . . . . . . . . . 322

C.47 Stroop test . . . . . . . . . . . . . . . . . . 323

C.48 Cognitive score index . . . . . . . . . . . . . . . . 323

C.49 Math score . . . . . . . . . . . . . . . . . . . . . 324

C.50 Reading score . . . . . . . . . . . . . . . . . . . . . . . 324 
C.51 School attendance . . . . . . . . . . . . . . . . . . 325

C.52 Multiple Hypothesis Corrected Sharpened q-Values for Inverse Probability Weighted Effects on Hemoglobin and Anemia . . . . . . . . . . . . . . . 326

C.53 Multiple Hypothesis Corrected Sharpened q-Values for Inverse Probability Weighted Effects on Cognition Outcomes . . . . . . . . . . . . . . . . . 327

C.54 Multiple Hypothesis Corrected Sharpened q-Values for Inverse Probability Weighted Effects on Education Outcomes . . . . . . . . . . . . . . . . . . . 328

C.55 Heterogeneous Effects by Attendance Terciles on Hemoglobin and Anemia . 332

C.56 Heterogeneous Effects by High Attendance Groups on Hemoglobin and Anemia 333

C.57 Heterogeneous Effects by Attendance Terciles on Cognition . . . . . . . . . 337

C.58 Heterogeneous Effects by High Attendance Groups on Cognition . . . . . . . . 338

C.59 Heterogeneous Effects by Attendance Terciles on Education and Attendance . . 340

C.60 Heterogeneous Effects by High Attendance Groups on Education and Attendance341

D.1 Mean Comparison of Believed and Measured Values by Number of Solved Task for Competing Child Without Known Gender . . . . . . . . . . . . . . . . 342

D.2 Mean Comparison of Believed and Measured Values by Number of Solved Task for Competing Girl . . . . . . . . . . . . . . . . . . . . 343

D.3 Mean Comparison of Believed and Measured Values by Number of Solved Task for Competing Boy . . . . . . . . . . . . . . . . . . . . 343

D.4 Regression Results for Parental Investment in Child Account With Additional Main Effect of Believed Ability of Own Child to Win . . . . . . . . . . . . . 345 


\title{
List of Abbreviations
}

\author{
ANCOVA ...... Analysis of covariance \\ ASER ........ Annual Status of Education Report \\ ATE $\ldots . . \ldots$... Average treatment effect \\ BMI ......... Body mass index \\ DFS ......... Double-fortified salt \\ DHS ........ Demographic and Health Survey \\ GDP $\ldots \ldots \ldots$ Gross domestic product \\ HFA z-score ... Standardized height-for-age score \\ IDHS ......... IPUMS Demographic and Health Surveys \\ IFA $\ldots \ldots \ldots$ Iron-folic acid \\ INR ......... Indian Rupee \\ ITT $\ldots \ldots \ldots$ Intention-to-treat \\ J+P ........ Jayachandran \& Pande (2017) \\ MDM $\ldots . . \ldots$ Midday-Meal-Scheme \\ MS .......... Middle school \\ NFHS ....... National Family and Health Survey \\ OLS ......... Ordinary least squares \\ PDS ......... Public Distribution System \\ PS $\ldots \ldots \ldots$ Primary school \\ PSU ......... Primary sampling unit
}


Randomized controlled trial

SA

South Asia

sd

Standard deviation

SSA

Sub-Saharan Africa

UNDP

United Nations Development Programme

UNICEF ..... United Nations International Children's Emergency Fund

WFA z-score ... Standardized weight-for-age scores

WHO ........ World Health Organization

WIFS

Weekly iron-folic acid supplementation program 


\section{Introduction}

\section{Context for Investigating Determinants of Child Develop- ment in India}

Around 600 million people in the world live in extreme income poverty, on less than $\$ 1.90$ a day (United Nations Development Programme [UNDP], 2019). When using a different poverty measure such as the Multidimensional Poverty Index even more people live in extreme poverty, 1.3 billion (UNDP, 2019). As this is an unacceptably high number for the global community, the first of the Sustainable Development Goals of the United Nations demands to "end poverty in all its forms everywhere" by 2030 (General Assembly resolution, 2015).

To overcome poverty, strengthening human development is crucial (UNDP, 2019). However, today 250 million children younger than 5 years in low-income and middle-income countries are likely not to attain their full potential, i.e. competencies to make accomplishments in academic, behavioral, socio-emotional, and economic areas (M. M. Black et al., 2017).

Whether children reach their developmental potential is to a large degree determined before their birth (Currie \& Almond, 2011; Deaton, 2003). Parental resources such as maternal education, maternal health, and income or community resources like sanitation or safety affect brain development, nutritional status, and health in early childhood (M. M. Black et al., 2017). Growth failure due to malnutrition below primary-school age is associated with lower schooling, lower test performance, lower household per capita expenditure, and a higher probability of living in poverty as an adult (Alderman et al., 2006; Hoddinott et al., 2013). As deprivations during childhood carry through to adulthood, poverty is transmitted from one generation to another.

Children are a good target group to stop the vicious cycle because they have not yet completed their human development. Interventions in childhood or early adolescence allow to catch up to prior foregone development to a certain degree (Jee et al., 2014).

India is an interesting study region for enhancing child development in an adverse setting be- 
cause India is home to about 18.69 percent of children between 0 and 14 years of age in the world, 366 million (World Bank, 2019). At the same time, 21.2 percent of India's population lives under extreme income poverty with less than $\$ 1.90$ a day (UNDP, 2019). To learn how to overcome the transmission of poverty by strengthening human development, India is an ideal setting.

The description of the intergenerational transmission of poverty already shows that the determinants of child development root in multiple disciplines. To do justice to this multidisciplinary research area, I want to relate the examined determinants of child development in this dissertation to the disciplines of economics, public policy, and public health. For this, I introduce three seminal models to capture the essence of the multidisciplinary approaches and match the three essays in this dissertation with these conceptual models. In this way, I want to show how this dissertation contributes to progress in each discipline.

\section{Conceptual Models for Determinants of Child Health and Development}

To find remedies for intergenerational poverty, it is helpful to consult existing conceptual models on the formation of child development because determinants, causes, and influencing factors are spread across multiple levels and dimensions linked to several disciplines, such as economics, public policy, and public health. To do justice to the interdisciplinary character of the research on this topic, I introduce three seminal conceptual models: the intergenerational transmission theory by Becker \& Tomes (1979) and Becker \& Tomes (1986), the "Framework of Causes of Malnutrition and Death" by the United Nations International Children's Emergency Fund [UNICEF] (1990), and the"Framework for actions to achieve optimal fetal and child nutrition and development" by R. E. Black et al. (2013). After a brief summary of each model and a brief comparison, I show which pathways in these conceptual models are captured in the three different essays of my dissertation. I focus on the used dependent and independent variables. 


\subsection{An Economics Conceptual Model: Theory of the Transmission of Earnings, Assets, and Consumption from Parents to Descendants}

In the model of the transmission of earnings, assets, and consumption from parents to descendants by Becker \& Tomes (1979) and Becker \& Tomes (1986) the focus lies on the parents' utility function that derives from own parental consumption and wealth of children in the future period. We consider the income of children in the future as the measured outcome of child development. Parents face a maximization problem in which they have to choose the optimal investments in the human capital development of children subject to family income constraints. All parents independent of their financial present income can contribute to the production of wealth of children by investing in their human capital development giving up their own consumption. We consider the demand function for the income of children by Becker \& Tomes (1979) to learn about what factors matter for child wealth in the future. We use the equation even though it is a simplification of reality because it does not account for the quantity of children, only the overall wealth of all children in the family.

$$
I_{t+1}=\alpha w_{t+1}(1-h+f) \bar{e}_{t}+\beta_{t} I_{t}+a h w_{t+1} e_{t}+\alpha w_{t+1} v_{t+1}+\alpha w_{t+1} u_{t+1}
$$

with

$$
\begin{array}{ll}
I_{t+1} & \text { wealth of children in future } t+1 \\
\alpha & \text { fraction of family income spent on children } \\
w_{t+1} & \text { real income per unit of capital to children in } t+1 \\
(1-h+f) \bar{e}_{t} & \text { cultural or social environment } \\
e_{t} & \text { parental endowment } \\
h & \text { constant fraction of } e_{t} \text { inherited by children } \\
\bar{e}_{t} & \text { average endowment in generation } t \\
f & \text { rate of growth of } \bar{e}_{t} \\
\beta_{t} & \text { warents' propensity to invest in children } \\
I_{t} & \text { wealth of children at time } t
\end{array}
$$




$$
\begin{array}{ll}
v_{t+1} & \text { exogenous component in the endowment of children } \\
u_{t+1} & \text { market returns to child capital }
\end{array}
$$

The demand function reveals that the income of children in the future $I_{t+1}$, a measured outcome of child development, depends on factors related to the parents, family, or the child itself. These are the share of income spent on children $\alpha$, the income returns to developed capital of children $w_{t+1}$, the parental endowment $e_{t}$, the fraction of inherited endowment of parents $h$, parents' propensity to invest in children $\beta_{t}$, the wealth of children at time $t$, and idiosyncratic shocks $v_{t+1}$. The demand function also depends on factors beyond the family. These apply for whole communities or societies: the cultural or social environment $(1-h+f) \bar{e}_{t}$, the average endowment in generation $t \bar{e}_{t}$, the rate of growth of the average endowment $f$, covariate shocks $v_{t+1}$, and the market returns to investments $u_{t+1}$ shaped by the current market situation. Becker $\&$ Tomes (1979) extend the model and also include further factors like economic growth, taxes, or subsidies.

\subsection{A Public Policy Conceptual Model: UNICEF (1990) Framework of Causes of Malnutrition and Death}

Moving from the economists' perspective to the political arena, we introduce the "UNICEF (1990) Framework of Causes of Malnutrition and Death" as the second seminal conceptual model (Figure 1.1). This conceptual model reflects the multisectoral nature of child survival, growth, and development, especially the nutritional status. Its goal is to bring all possible causes together to allow an exchange between different professions. It is explicitly not predictive.

The framework considers three levels of causes that generate the manifestations: immediate, underlying, and basic causes. Immediate causes are the health status and dietary intake of the child. These are rooted in the underlying causes that represent unmet basic needs of children and women and belong to one of the following three groups: household food security, care for children and women, or health services and healthy environment.

Underlying causes are triggered by basic causes that include multiple levels. The first level consists of potential resources of production of a community or society. In the second level, the political and ideological superstructure and the economic structure are introduced that restrict the potential resources. This is reflected in the third level, in the real allocation of human, economic, and organizational resources as well as control. The ability to use the available potential 
Figure 1.1: UNICEF (1990) Conceptual Model of Causes of Malnutrition and Death

\section{Figure II: Causes of Malnatrition and Death}

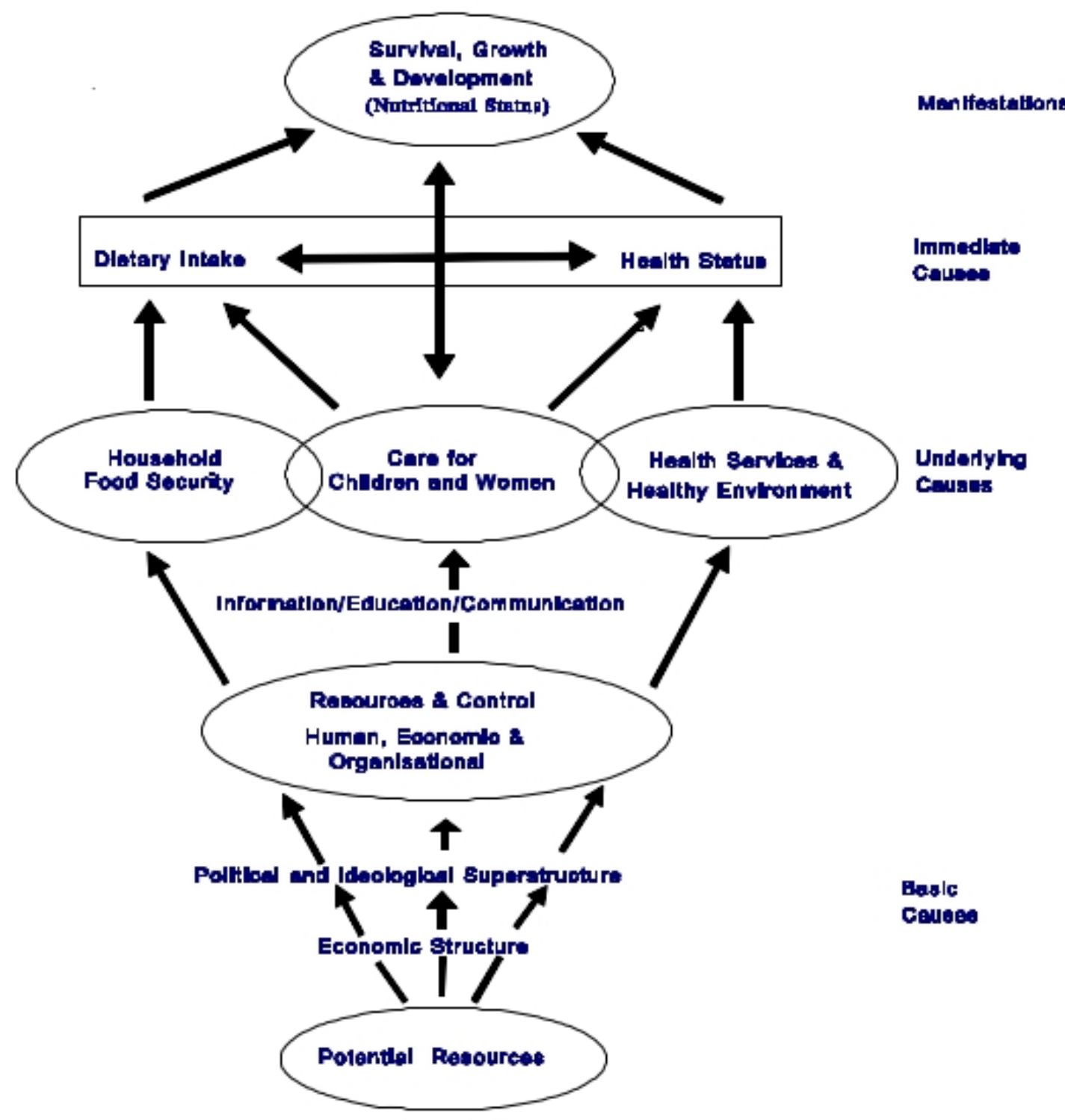

Source: UNICEF (1990) 
is moderated by information, education, or communication of households. This channels the real allocation to the underlying causes.

The model has also been adapted and modified (see for example the adaptation by van den Bold et al. (2013) in the appendix).

\subsection{A Public Health Conceptual Model: Framework for Actions to Achieve Optimal Fetal and Child Nutrition and Development}

We turn now from the policy perspective to a public health framework that aims at informing about viable intervention options. We consider the "Framework for actions to achieve optimal fetal and child nutrition and development" by R. E. Black et al. (2013) (Figure 1.2).

It differs from the conceptual model introduced before because instead of looking at causes of

Figure 1.2: Framework for Actions to Achieve Optimal Fetal and Child Nutrition and Development

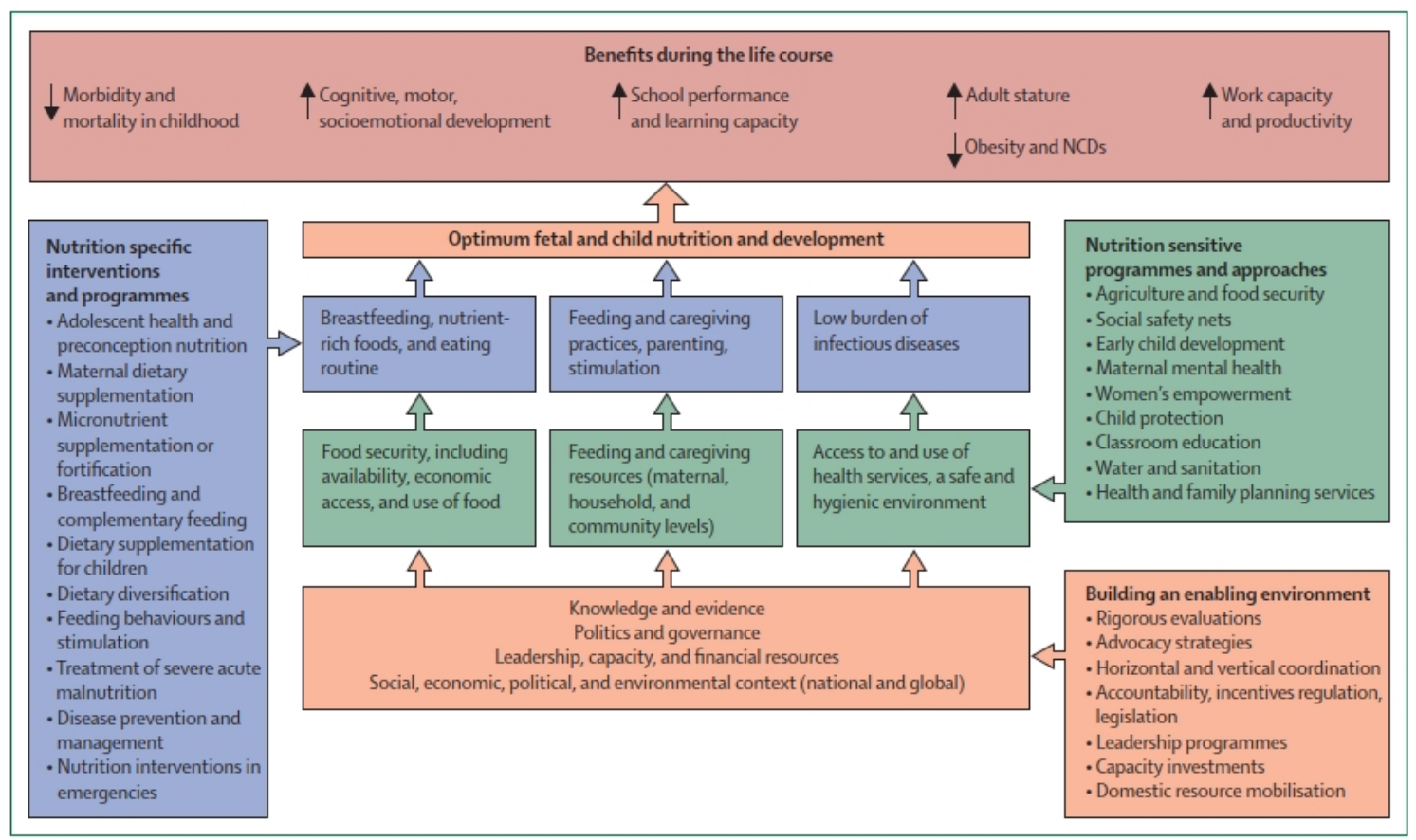

Figure 1: Framework for actions to achieve optimum fetal and child nutrition and development

Source: R. E. Black et al. (2013)

undernutrition it displays pathways to reach optimal fetal and child development. The possible benefits during the life course of this are displayed at the top of the diagram.

Optimal development builds on "dietary, behavioural, and health determinants" (R. E. Black et al., 2013). They are affected by underlying causes of dietary determinants, behavioral determinants, and health determinants. 
Causes of the dietary determinants are related to food security, causes of the behavioral determinants to caregiving resources, and causes of health determinants to environmental conditions regarding health.

These causes in turn rely on a broader context base that includes knowledge and evidence, politics and governance, leadership, capacity, and the financial resources, and also the overall social, economic, political, and environmental context on a national and global level.

Further, this framework points out possible pathways to intervene in all three levels of the model. Interventions listed in "building an enabling environment" aim to improve the context base for the causes of the determinants (R. E. Black et al., 2013). Nutrition sensitive programs and approaches focus on the underlying causes of the development determinants whereas nutrition specific interventions and programs target the development determinants.

\subsection{Comparison of the Conceptual Models}

After the brief introduction, I want to highlight the key differences and similarities of the introduced conceptual models in Table 1.1. The three conceptual models derive from different disciplines and have distinct goals. The economic conceptual model by Becker \& Tomes (1979) and Becker \& Tomes (1986) aims at predicting the transmission of earnings, assets, and consumption from parents to descendants. The "UNICEF (1990) Framework of Causes of Malnutrition and Death" is explicitly not predictive. Its goal is to facilitate an exchange between different professions that are related to child development. The"Framework for actions to achieve optimal fetal and child nutrition and development" by R. E. Black et al. (2013) intends to inform about viable intervention options.

The style, outcomes, and input factors considered in the conceptual models are quite similar in the models by UNICEF (1990) and R. E. Black et al. (2013). Both represent multi-level frameworks. The outcome for both models is explicitly child development that includes the nutritional status. Both identify basic or a base that influences causes that affect either determinants or immediate causes of the outcome. Basic causes in the UNICEF (1990) framework and the base of causes by R. E. Black et al. (2013) include the broader economic, human, organizational, political, ideological, social, and environmental context, knowledge, and resources. Causes of the determinants in the framework by R. E. Black et al. (2013) look at the same aspects as the UNICEF (1990) framework: food security, care for children and women, as well as health services and hygienic environment. The basic causes in the UNICEF (1990) framework 


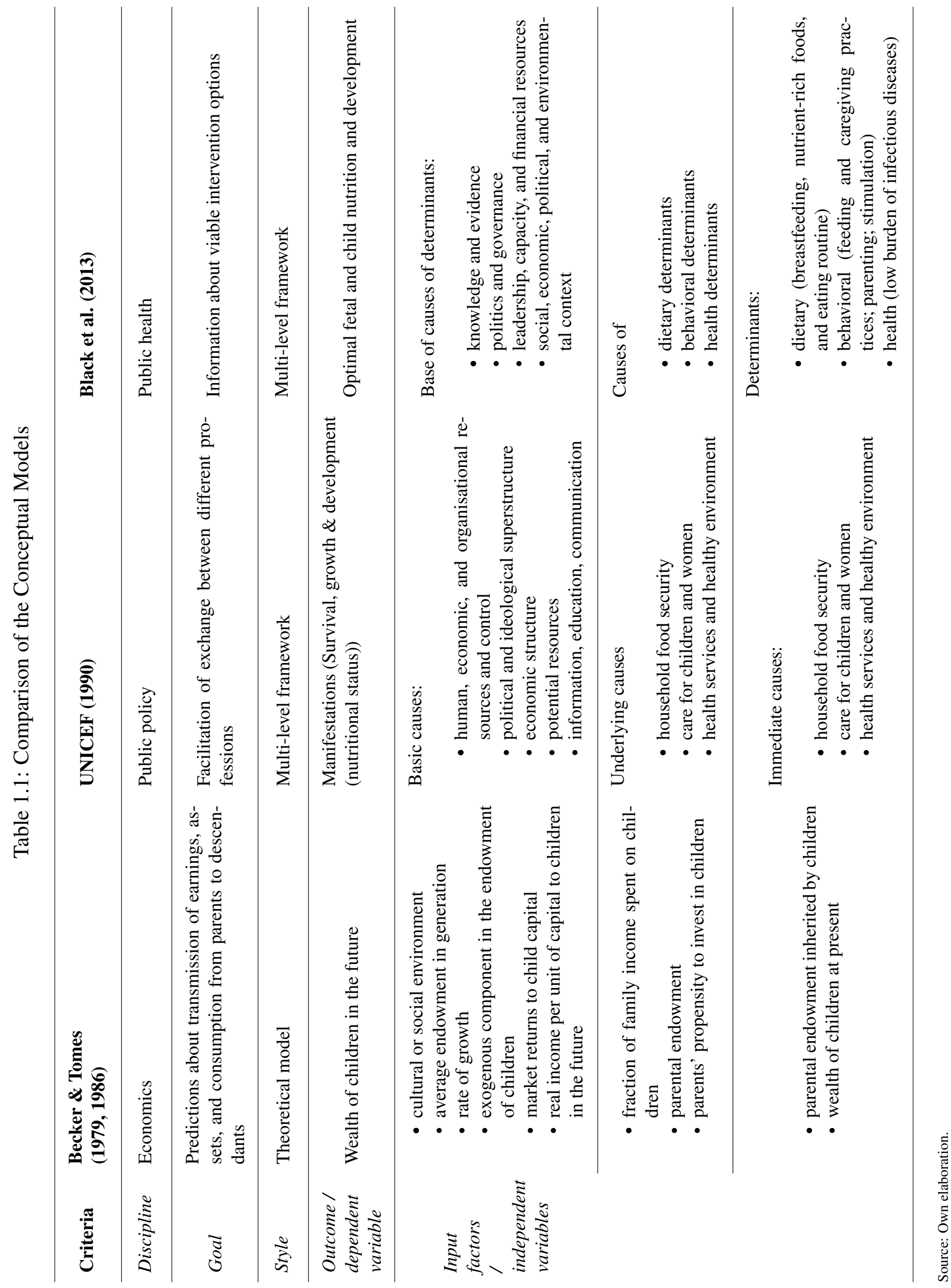


are defined more broadly because it only considers dietary intake and health status compared to the framework by R. E. Black et al. (2013). In this model dietary intake is included but also behavioral determinants like parenting and health determinants such as the low burden of infectious diseases.

The theoretical model by Becker \& Tomes (1979) and Becker \& Tomes (1986) follows a different approach. It considers the wealth of children in the future as the outcome in the demand function for the income of children. The input factors are not hierarchical. It considers the wealth of children in terms of monetary income though we interpret wealth here as development. Unlike the two other frameworks, Becker \& Tomes (1979) and Becker \& Tomes (1986) explicitly consider two time periods and include how parental beliefs about the future could affect present behavior.

The demand function depends on parameters that focus on the context like economic growth, market returns to child capital, exogenous components in the endowment of children, real income per unit of capital to children in the future, the cultural or social environment, or the average endowment in a generation. This is similar to the basic or base of causes in the two multi-level frameworks. Parameters like parental endowments, the fraction of family income spent on children, or parents' propensity to invest in children captures the underlying causes or causes of dietary and behavioral determinants such as food security via household income or care for children. The theoretical model also uses child endowments like the wealth of the child at present and inherited endowments of parents that are represented as health status, a basic cause, in the UNICEF (1990) framework.

Even though the three presented seminal models pursue different goals, derive from different disciplines, and have a different style, they roughly fit together regarding the considered links for child development.

\subsection{Contextualizing the Dissertation}

This a good starting point to examine the considered determinants in the three essays of this dissertation in the light of the conceptual models. I create an overview table by listing the matching concepts in the model with the dependent and independent variables of each essay in Table 1.2. 
Table 1.2: Contextualizing the Essays Given Three Seminal Conceptual Models

$\begin{array}{lll}\text { Essay } & \text { Variable } & \begin{array}{l}\text { Becker \& Tomes } \\ (1979,1986)\end{array}\end{array} \quad$ UNICEF (1990) Black et al. (2013)

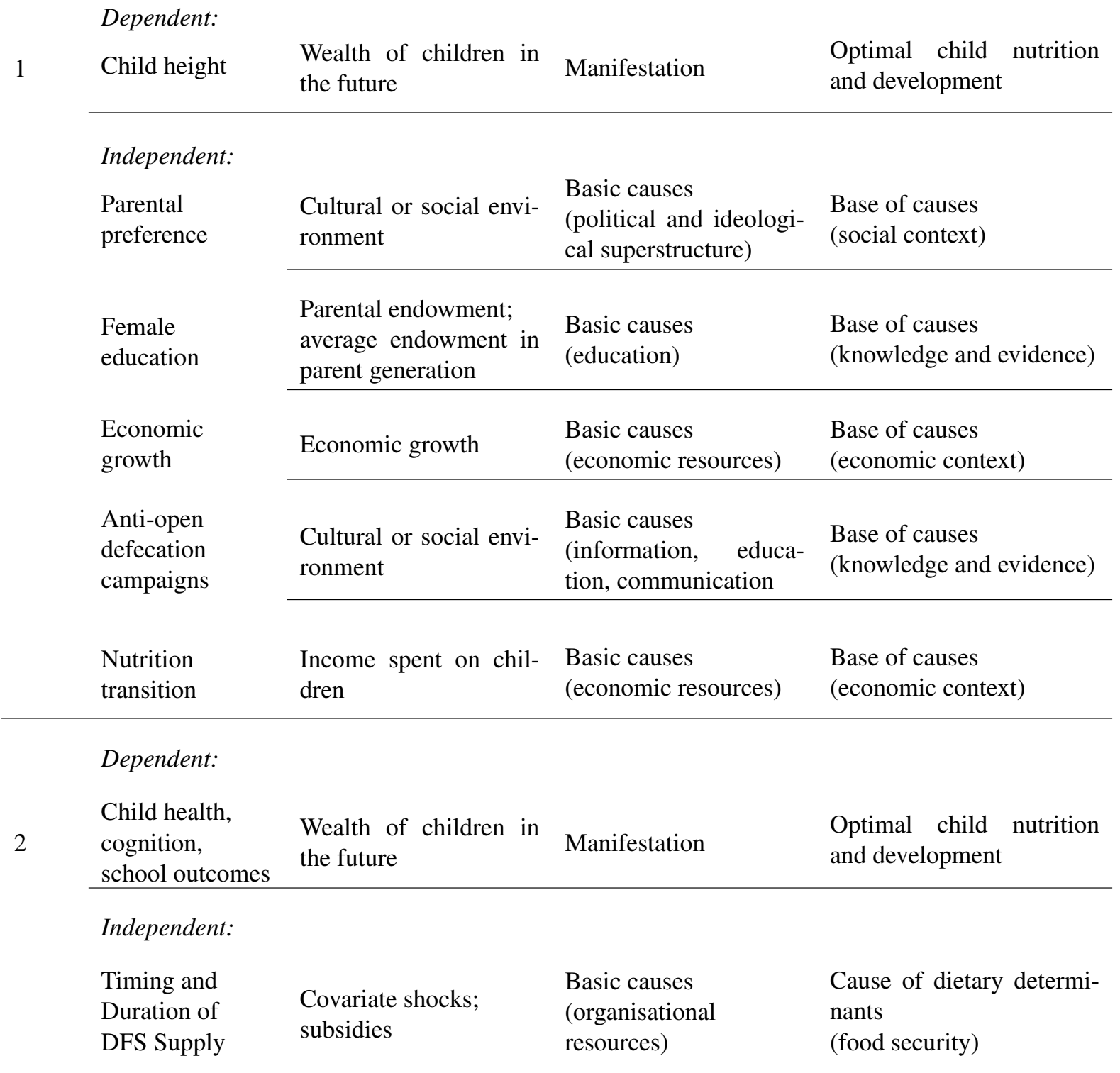

Dependent:

Cause of behavioral determinants

(caregiving resources on the maternal and household level)

Independent:

Market returns to child

Competitive capital;

labor market exogenous components

Basic causes

Base of causes in the endowment of (economic structure) (economic context) children 


\subsubsection{Essay 1}

The first essay examines the sensitivity of parental preferences as the main determinants of the height gap between children in India and sub-Sahara Africa [SSA]. One robustness check is the inclusion of recent macro-determinants. The focus lies on parental preferences for the eldest son or generally sons in India and macro-determinants like female literacy, economic growth, anti-open defecation campaigns, and the nutrition transition that have developed differently in India compared to SSA. We examine how these determinants influence the height of children below 5 years of age.

In the perspective of the model of the transmission of earnings, assets, and consumption from parents to descendants by Becker \& Tomes (1979) and Becker \& Tomes (1986) the outcome variable of interest is child wealth in the future. The explanatory variables parental preferences and anti-open defecation campaigns can be counted to the cultural or social environment. Economic growth has been examined by Becker \& Tomes (1979) as a potential determinant for future child wealth. The explanatory variable female literacy is reflected in the parental endowment but also in the average endowment in the parent generation. Another macro-determinant, the nutrition transition, represents an increase in the real income spent on children. The nutrition transition is a change in the dietary pattern of the population. It is accompanied by decreasing prices for staple foods. Via the income effect of decreasing prices parents purchasing power increases and they can afford to buy more calories with a fixed nominal income spent on children. When we use the UNICEF (1990) framework to contextualize this essay, we find that most explanatory variables fall into the level of basic causes. Parental preferences belong to the political and ideological superstructure. Economic growth and the nutrition transition as a change in the availability and access of foods count to the economic resources. Female literacy and anti-open defecation campaigns change the information, education, or communication of how resources and control of these are used by the households. This moderates how the basic causes affect the underlying causes. The explanatory variables determine the underlying causes that in turn affect immediate causes and so the manifestation of interest, the height of children.

In the framework of R. E. Black et al. (2013) most of the explanatory variables of the gap of child height between India and SSA count to the base of causes of the development determinants. Parental preferences belong to the social context, economic growth and the nutrition transition to the economic context, female literacy, and anti-open defecation campaigns to knowledge. So the explanatory variables determine the underlying causes of the development 
determinants that shape the optimal child nutrition and development. Parental preferences, female literacy, and economic growth affect food security, feeding and caregiving resources, and access to health services, all three domains of the underlying causes. The nutrition transition influences only food security and the anti-open defecation campaigns the hygienic environment. The considered outcome, the height of children, is represented by the optimum child nutrition and development in the framework.

\subsubsection{Essay 2}

The second essay poses the question if timing and duration of the use of double-fortified salt [DFS] in the school lunch determine child development. This essay presents the results of a nutrition intervention that bridges a supply chain gap. Even though schools are obligated to use iron and iodine fortified salt, DFS, in the Midday-Meal-Scheme [MDM], the Indian school feeding program, by law, they do not adhere because DFS is not widely available in the market. We start providing DFS to schools at different times and follow up with children leaving the treatment schools to learn about the determining character of timing and duration of DFS usage on children's health, cognition, and school attainment.

In the perspective of the model of the transmission of earnings, assets, and consumption from parents to descendants by Becker \& Tomes (1979) and Becker \& Tomes (1986) this nutrition intervention represents either a covariate shock or a type of subsidy because children receive investments in their human capital development apart from their parents. The considered outcomes, children's health, cognition, and school attainment, are represented as child wealth in this model.

When we consider the UNICEF (1990) framework, our intervention targets basic causes because we add to the organizational resources by working as a supplier of DFS to schools. This has an impact on the underlying causes because the care for children is increased. This affects the immediate cause of dietary intake and so manifests in child development.

Using the framework by R. E. Black et al. (2013), we have to refine the type of our intervention. Our intervention has the character of a nutrition sensitive program because it improves food security, i.e. the economic access of schools to the fortified product. By strengthening the access to foods, a cause of the dietary determinants, we contribute to children's intake of nutrient rich foods, a dietary determinant to improve children's health, cognition, and school attainment. The outcomes reflect the goal in the framework: optimal child nutrition and development. 


\subsubsection{Essay 3}

The third essay investigates how market returns to investment and parents' perception thereof interacted with child endowments determine parental investments in children. The outcome is here not child development but one step before: the provision of investments used for building up child development.

The logic of this paper follows the theory of the transmission of earnings, assets, and consumption from parents to descendants by Becker \& Tomes (1979) and Becker \& Tomes (1986) closely. The link between this essay and the model is explained in more detail in the essay itself. The design used in the essay artificially changes the market situation. In this ways, we cleanly identify how these changes affect parents' propensity to invest in their children. The considered child endowments like gender and ability are captured by the exogenous components in the endowment of children in the demand function for child wealth in the future. The endowment might moderate the parental propensity to invest.

In terms of the UNICEF (1990) framework, this study manipulates a basic cause, the economic structure, because it changes the market returns to investment for parents. The market structure affects the human and economic resources and control within the basic causes. These influence the underlying cause of care for children, parental investment in this essay.

In the light of the framework by R. E. Black et al. (2013), a change in the market returns to investment is reflected in the economic context of the base for the causes of child determinants. This directly affects the caregiving resources of a household, a behavioral determinant, that represents the outcome of interest of the essay in this framework.

\subsubsection{Conclusion of Contextualization}

The contextualization reveals how this dissertation adds to the broad field of determinants of child development across disciplines. We provide further evidence for the Public Health community by showing how the base of causes (Essay 1) or causes of dietary determinants (Essay 2) influence optimal child nutrition and development following the framework by R. E. Black et al. (2013). Essay 3 looks at how the base of causes affects causes of behavioral determinants. Considering the UNICEF (1990) framework all essays look at the effect of basic causes. However, the first two essays consider the manifestations of child development as outcomes while the outcome of the third essay belongs to underlying causes.

In the light of the theory of the transmission of earnings, assets, and consumption from parents 
to descendants by Becker \& Tomes (1979) and Becker \& Tomes (1986) the first two essays deal with the generation of wealth of children in the future as the outcome. They look at different explanatory variables: essay 1 at the cultural or social environment, parental endowment, average endowment in parent generation, economic growth, as well as income spent on children, and essay 2 at covariate shocks or subsidies. The third essay examines the effect of market returns to capital and exogenous components in the endowments of children on parents' propensity to invest in children.

The explored determinants as well as the considered outcomes have relevance for economics, public policy, and public health.

\section{Summary of the Essays}

The contextualization has already provided a brief introduction to the three essays of the dissertation. In the following, I summarize the essays about determinants of child development in India in more detail.

\subsection{Essay 1}

The first essay is co-authored by Professor Stephan Klasen and reassesses a puzzle in science: the "Asian Enigma". It describes the contradiction of greater progress in indicators like gross domestic product [GDP], food supply, education, and health services and remaining higher child malnutrition in South Asia [SA] compared to SSA (Smith et al., 2003; Ramalingaswami et al., 1996; Klasen, 2008; Headey et al., 2012).

The literature offers a broad range of possible determinants for this puzzle like women's status, sanitation, urbanization, agricultural development, or measurement errors due to genetic differences in growth potential (Smith, 2003; Headey et al., 2012; Klasen, 2008; de Haen et al., 2011; Spears, 2018). Jayachandran \& Pande (2017) make the case for another possible determinant: parental eldest son preference. The study by Jayachandran \& Pande (2017), henceforth J+P, has been quite influential and triggered more research concentrating on cultural preferences of birth order and gender shaping health outcomes for children.

The wide use of cultural preference for sons as a determinant for health outcomes of children demand a sensitivity analysis. Providing future researchers insights into the sensitivity of J+Ps models constitutes the main contribution of this essay. After the publication of the study by $\mathrm{J}+\mathrm{P}$, 
data for about 10 years later has become available. During that time four major trends emerged that could impact child health outcomes between India and SSA largely: greater female education, further economic growth, anti-open defecation campaigns, and the nutrition transition.

As a starting point for our sensitivity analysis, the same methodology by $\mathrm{J}+\mathrm{P}$ is used but with more recent data from around 2015 considering a similar SSA sample. The data derive from the Demographic and Health Surveys [DHS], either directly from the platform in the case of the India samples or from the IPUMS Demographic and Health Surveys [IDHS] project for the SSA sample. Further, we use different methodology but similar data used by J+P from around 2005. At first, we only adjust the methodology by weighting the data to make it nationally representative. We show that the birth order effect can only explain a small share of the difference in height between African and Indian children when using either more recent data or weighting. Moreover, we bring in new determinants of the height gap that have developed differently over time. Still using weights, we examine to what extent the consequences of the macro-determinants - female education, household prosperity, open defecation, and the consumption of animal proteins - can account for the height difference. We find that the emerging macro-determinants are drivers of the difference in height between African and Indian children and so help to explain the "Asian Enigma".

\subsection{Essay 2}

The second essay is joint work with Abhijeet Kumar, Santosh Kumar, and Sebastian Vollmer. We conduct a follow-up study to the RCT by Krämer et al. (2020) that supplies DFS to schools. This mimics the implementation of a directive by the Indian Ministry of Women and Child Development that postulates all government run schools to use DFS in the MDM (Ministry of Human Resource Development, 2015). However, this policy is hardly implemented due to a lack in supply of DFS. Facilitating the availability of DFS at schools, we want to investigate the impact of this policy on child health, cognition, and school outcomes in the long run. By examining whether timing and duration of a nutrition sensitive intervention determine child development we complement the literature about long-term treatments and food fortification in school programs.

Examining the consequences of long-term treatments is in accordance with the recent article by Bouguen et al. (2018) who call for looking beyond short-term treatment effects of randomized controlled trials [RCT]. Like Chhabra et al. (2019) we are interested in the policy-relevant ef- 
fects of a program but we focus on only one cohort and long-term treatment with an immediate follow-up.

Further, pure DFS has been used as a treatment in the MDM at a large scale only by Krämer et al. (2020) before. They assess the effect of DFS over a period of 1 year at government-funded schools in two blocks of the district Jehanabad in Bihar. The RCT covers 54 randomly selected treatment schools that receive the DFS and 53 control schools that use iodized salt. The assessed outcomes are the change in hemoglobin levels, educational achievements, and cognitive ability of 2,000 children.

By using data collected after almost 4 years of treatment, we examine the effect of DFS use for four different exposure groups and so come close to possible real-world implementations: children who receive DFS in their MDM since third or fifth grade and continued receiving it or stopped at the end of fifth grade. Thus, this essay contributes to the literature by considering the so far longest treatment period of DFS of a maximum treatment period of almost 4 years, by examining different treatment periods and duration, and by investigating how a childhood intervention (in third grade) unfolds in outcomes for young adolescents (in sixth grade).

For the data analysis, the RCT structure is exploited to measure the policy-relevant intention-totreat [ITT] effects. We use analysis of covariance [ANCOVA] estimation techniques to assess the difference in means of the health, cognition, and education outcome variables of four different exposure groups of DFS.

Our results show that compared to a child group that is hardly exposed to the DFS treatment in the MDM, children who receive DFS for almost 4 years have on average a higher hemoglobin level of $0.260 \mathrm{~g} / \mathrm{dL}$. Even treatment in only early childhood increases the hemoglobin level by the same amount and reduces the likelihood of a child being moderate or severe anemic by 8.6 percentage points compared to the children who are only exposed to DFS for 4 months in later childhood.

The results show that a public nutrition intervention - short-or-long-term - can determine child health outcomes and so the overall development of children.

\subsection{Essay 3}

The third paper, co-authored by Sebastian Vollmer, investigates how a competitive labor market and parents' belief thereof in combination with child endowments determine parental investment in children in India. Though there is evidence available about how changes in the 
labor market influence investment decisions of parents, studies fail to cleanly identify the effect because of the use of retrospective studies. The real-world setting does not allow to isolate the effect of market returns to investment from other input factors like human capital returns to investment or child endowment (Carranza, 2014; Rosenzweig \& Schultz, 1982; Munshi \& Richard Rosenzweig, 2006; Heath \& Mushfiq Mobarak, 2012; Jensen, 2010; Jensen \& Miller, 2010)

Only Durante et al. (2015) offer a cleaner identification. They use a discrete-choice experiment in a lab-like setting to examine how different economic situations shape the spending behavior of consumers towards female or male children. However, they investigate investment behavior in general in different market settings, not for the particular relationship of parental investment in children.

Our study combines both approaches using a lab-in-the-field experiment with sixth grade students and their parents in rural Bihar. In this way, we cleanly isolate one effect and capture the particular real-world relationship. We use the strategy method to elicit the investment of parents for two different market returns to investment: a non-competitive setting with a piece-rate payment scheme depending on the performance of the participants' own child and a competitive setting with a contest payment scheme depending on the absolute and relative performance of the own child in a tournament against either a girl, a boy, or a child with unknown gender. We use ordinary least squares [OLS] regressions with cluster robust standard errors to test hypotheses about parents' investment and beliefs derived from a conceptual framework.

Our lab-in-the-field experiment reveals that parents react to different market returns to investment. We find that parents invest about 10 percent less of the initial endowment in their children when exposed to market returns that are based on a competition with others. Parents' belief about the probability of their own child winning against a competitor has a positive association with investing in their children. Though the effect magnitude does not outweigh the decrease in investment due to competition. Irrespective of the gender of the own child, parents invest less in the tournament setting when their own child competes against a girl or a boy. Parents' investments decrease by more than a quarter of the initial endowment once the competitor is a boy.

We make contributions to two strains of literature. We add to the experimental literature with evidence about the influence of competition on the investment behavior of participants in risky settings. We also show how the gender dynamics of competitors matter for a third party that is 
not involved in the competition itself. Additionally, we contribute to the examination of input factors of parental investment decision by isolating the effect of market returns to investment and its interaction with child endowment in a lab-in-the-field experiment.

We conclude that market returns to investment and parents' beliefs thereof determine child investments, the base for child development.

\section{Outline}

The rest of this dissertation about determinants of child development in India is organized as follows: Chapter 2 presents the first essay about the sensitivity of parental preferences as determinants of the gap of child height between India and SSA. In chapter 3, the second essay is presented. It investigates the effect of timing and duration of a nutrition intervention on children's health, cognition, and school outcomes. The third essay follows in chapter 4. It cleanly identifies how competitive markets and parents' beliefs thereof determine investments in children. The Appendix contains chapters for each essay with further information regarding data collection, data analysis, results, or robustness checks. 


\title{
$2 \mid \quad$ Essay 1: "Why are Indian Children So Short? The Role of Birth Order and Son Preference" - Repli- cation and Extension
}

\begin{abstract}
Using data from about 2005, Jayachandran \& Pande (2017), henceforth J+P, argue that most of the difference in height between African and Indian children is due to the worse treatment of higher birth order children, particularly girls. In this replication and extension, we conduct a sensitivity analysis of J+P's model considering more recent data, weights, and macro-determinants s additional controls. We show that the birth order effect can only explain a small share using data from around 2015. When weighing the 2005 Indian data used by $\mathrm{J}+\mathrm{P}$ to make them nationally representative, the birth order effect can also only explain a small share of the height difference. In both of these analyses, the Indian birth order gradient is much shallower than in J+P's results. We then investigate the robustness of J+P's model to the inclusion of female education, household prosperity, open defecation, and the consumption of animal sourced foods. We find that these factors matter and contribute to explaining the height gap between African and Indian children. We discuss other potential reasons for the height difference.
\end{abstract}

\footnotetext{
${ }^{1}$ This paper is co-authored by Stephan Klasen.
} 


\section{Introduction}

Since the 1990s scientists examine the "Asian Enigma", the contradiction of greater progress in indicators like gross domestic product [GDP], food supply, education, and health services and remaining higher child malnutrition in South Asia [SA] compared to sub-Saharan Africa [SSA] (Smith et al., 2003; Ramalingaswami et al., 1996; Klasen, 2008). Headey et al. (2012) see the "Asian Enigma" as a particular puzzle for India because despite a dramatic increase in GDP between 1998/99 and 2005/6 child stunting and underweight of women hardly declines.

Smith et al. (2003) conclude that women's status, sanitation, and urbanization contribute to ex-

plaining this puzzle. Spears (2018) finds that difference between India and SSA in sanitation with the background of different population densities of open defecation can account for the height difference. He uses a demographic projection of the average height of Indian children given the exposure to sanitation like in SSA.

A cross-country comparison Klasen (2008) finds that the high rates of stunting in SA can be partially explained by the used child growth reference standard. The used standard might not fit with the actual growth pattern of SA children because in the study by the World Health Organization [WHO] to establish a worldwide reference standard Indian children are smaller than the sample average (WHO Multicentre Growth Reference Study Group, 2006). Indian children could be smaller due to genetic differences in growth potential or delayed impacts of past undernutrition of their mothers (Klasen, 2008; Prendergast \& Humphrey, 2014). So, the level of stunting in South Asia could be overestimated.

More recently Jayachandran \& Pande (2017), henceforth J+P, have added to this discussion by showing that Indian children are shorter than their peers in SSA due to parental preferences regarding birth order and gender. The favoritism of eldest sons determines the height of children because these preferences shape fertility behavior, family size, and investment decisions in child health. Eldest son preference especially in Hindu families is triggered by religious, cultural, and economic reasons. The study by $\mathrm{J}+\mathrm{P}$ has been quite influential and triggered more research concentrating on cultural preferences of birth order and gender shaping health outcomes for children.

Yet, authors like Spears et al. (2019) challenge that Indian parents decrease the health investments necessary for growth into higher birth order children and so cause the height gap between African and Indian children because of eldest son preference. Our objective is to guide future 
research on the appropriate inclusion of measures of the health investment in the form of eldest son preference when analyzing resource allocation of parents to children. We conduct a sensitivity analysis of J+P's model by considering a more recent time period. $\mathrm{J}+\mathrm{P}$ focus on data collected between 2004 and 2010. Since then, however, four major macro-determinants emerged that could impact child health outcomes largely: greater female education, further economic development, anti-open defecation campaigns, and the nutrition transition. We want to test whether J+P's eldest son preference hypothesis is robust to the inclusion of these changes. For this, the results by $\mathrm{J}+\mathrm{P}$ are replicated using data from around 2015 in the first step while considering a similar SSA sample. The data derive from the Demographic and Health Survey [DHS], either directly from the platform in the case of the India samples or from the IPUMS Demographic and Health Surveys [IDHS] project for the SSA sample. We show that the birth order effect can only explain a small share of the difference in height between African and Indian children. Further, we weigh the 2005 Indian data used by $\mathrm{J}+\mathrm{P}$ to make them nationally representative. We stay with the data from the original sample but adapt the methodology. Birth order effects can now only explain a small share of the height difference in this time period. Moreover, we extend the replication by assessing whether J+P's hypothesis still holds when including female education, household prosperity, open defecation, and the consumption of animal proteins. The four emerging macro-determinants are important drivers of child height.

Thus, this study contributes to the literature by conducting a sensitivity analysis of the hypothesis of eldest son preference as the driver of the "Asian Enigma".

This paper is structured as follows: the next section will provide a brief overview of evidence for the eldest son hypotheses as well as the effect of the recent macro-determinants. Section three looks at the data and the empirical strategy whereas section four presents the results for the replication using data of around 2015. In section five the original time period is reassessed weighing the data to become nationally representative. Section six is dedicated to the results of the extension of the replication by adding the four emerging macro-determinants. Section seven discusses the results and section eight concludes.

\section{Background and Literature Review}

To explain the discrepancy between good progress in development indicators but worse child health outcomes in India compared to SSA, the literature offers a broad range of possible con- 
tributing factors like women's status, sanitation, urbanization, agricultural development, or measurement errors due to genetic differences in growth potential (Smith, 2003; Headey et al., 2012; Klasen, 2008; de Haen et al., 2011; Spears, 2018). J+P make the case for another possible determinant: parental eldest son preference.

\subsection{Son Preference in India}

Social, economic, and cultural reasons shape this preference (Arnold et al., 1998; Jayachandran, 2015). Socially, many families, particular in North India have a patrilineal descent where only sons are accepted hers (Arnold et al., 1998; M. D. Gupta, 1987a; Pande, 2003). Sons have economic utility because they can participate in agricultural production, earn wages, guarantee dowry payments, and represent security for the parents during sickness and old age (Arnold et al., 1998; Rosenblum, 2017; Jayachandran, 2015). For Hindu families, sons also play a key role for religious functions like post-death rituals (Arnold et al., 1998; Jayachandran, 2015).

This son preference affects the fertility behavior of parents. Couples are likely to adopt a differential stopping behavior and continue reproduction until attaining a certain sex composition of children, i.e. the desired number of sons (Clark, 2000; Jensen, 2003; Rosenblum, 2013). Consequently, the differential stopping behavior leads to a high proportion of sons in a family when sons are born early or a low proportion when sons are born later (Clark, 2000).

By determining the number of siblings, son preference also influences the allocation of resources in the households indirectly because in larger families children have to share limited resources with more siblings (Anukriti et al., 2016). This indirect channel and the direct favoritism of sons contribute to a discrimination against daughters in education (Jensen, 2003), nutrition (Anukriti et al., 2016; Jayachandran \& National Bureau of Economic Research, 2009; Behrman, 1988b), and health (Anukriti et al., 2016; Arnold et al., 1998; Bharadwaj \& Lakdawala, 2013; V. Gupta et al., 2016; Oster, 2009; Pande, 2003; Rosenzweig \& Schultz, 1982; Asfaw et al., 2010).

Budget constraints of parents seem to worsen discrimination. Asfaw et al. (2010) show that when parents have no other means but have to borrow, sell assets, or receive help from friends, boys are more likely to be hospitalized than girls. Behrman (1988b) finds a bias in food allocation towards sons in Indian families during lean seasons. Older children independent of gender are also favored during lean seasons (Behrman, 1988a). Harris-Fry et al. (2017) conclude in their review that female household members aged 15 and older receive less food during severe 
or unexpected food insecurity.

Based on the literature formulate their J+P's hypotheses: the birth order gradient, i.e. declining parental investment, for children and especially girls should be more pronounced in India due to eldest son preference. Recently Spears et al. (2019) have reassessed the eldest son hypotheses by J+P. They focus on the contradictory findings by Coffey \& Spears (2019) who report that later birth order children are more likely to survive early-life using the same DHS data. Spears et al. (2019) conclude that correlations between the number of siblings and household wellbeing differ between India and the same SSA countries selected by J+P. The omitted variable bias driven by the number of siblings constitutes the birth order effects. The robustness checks conducted by JP, i.e. considering a sample with completed fertility or mother fixed effect, are misleading due to the given data structure of the DHS data set according to Spears et al. (2019). These authors also show that alone recoding of birth order puts the results under doubt, i.e. they exclude children without siblings in their analysis or look at last and second-last born children only. They find that last-born children in India are better off than their African counterparts. In our replication study, we bring in another perspective by considering a later period in time and the national representativeness of the data. Another novel aspect is testing the robustness of the hypothesis considering macro-determinants that might influence the height gap between India and SSA.

\subsection{Emerging Macro-Determinants Affecting Child Health}

Menon et al. (2018) examine the differences in stunting prevalence between low and high burden districts using population-weighted regressions and regression-based decomposition. We want to have a closer look at four of the five most important determinants of the difference (education, children's adequate diet, assets, and open defecation) that might weaken the effect of eldest son preference of Indian parents on child height. Three of the listed determinants have also been identified as key drivers for child height in SA: greater material well-being, increased female education, and improved sanitation (Headey et al., 2016).

The first we want to consider is female education. It is linked to lower fertility, lower child mortality, and higher quality care for children (Klasen, 2016). In India, the access to public schools has widely improved and so the gender gap in overall school enrollment and completion has almost disappeared, whereas in SSA primary, secondary, and tertiary education gender gaps persist (Klasen, 2016; Sahoo \& Klasen, 2018). This might be an advantage for India because 
greater female education allows for higher quality care and/or decreased family sizes that would increase available resources of parents to invest in their children.

Changes in income via economic development are one of the major macro-determinants that widened between India and SSA between 2004 and 2018 even more (Figure 2.1). Within India analysis show that economic growth is significantly correlated with stunting prevalence, stunting, and body mass index [BMI] (Headey et al., 2011; Bhagowalia et al., 2012; Klasen, 2008). Higher per capita income increases the budget of households and so the available resources of parents for investing in their children.

Figure 2.1: GDP for India and Sub-Saharan Africa

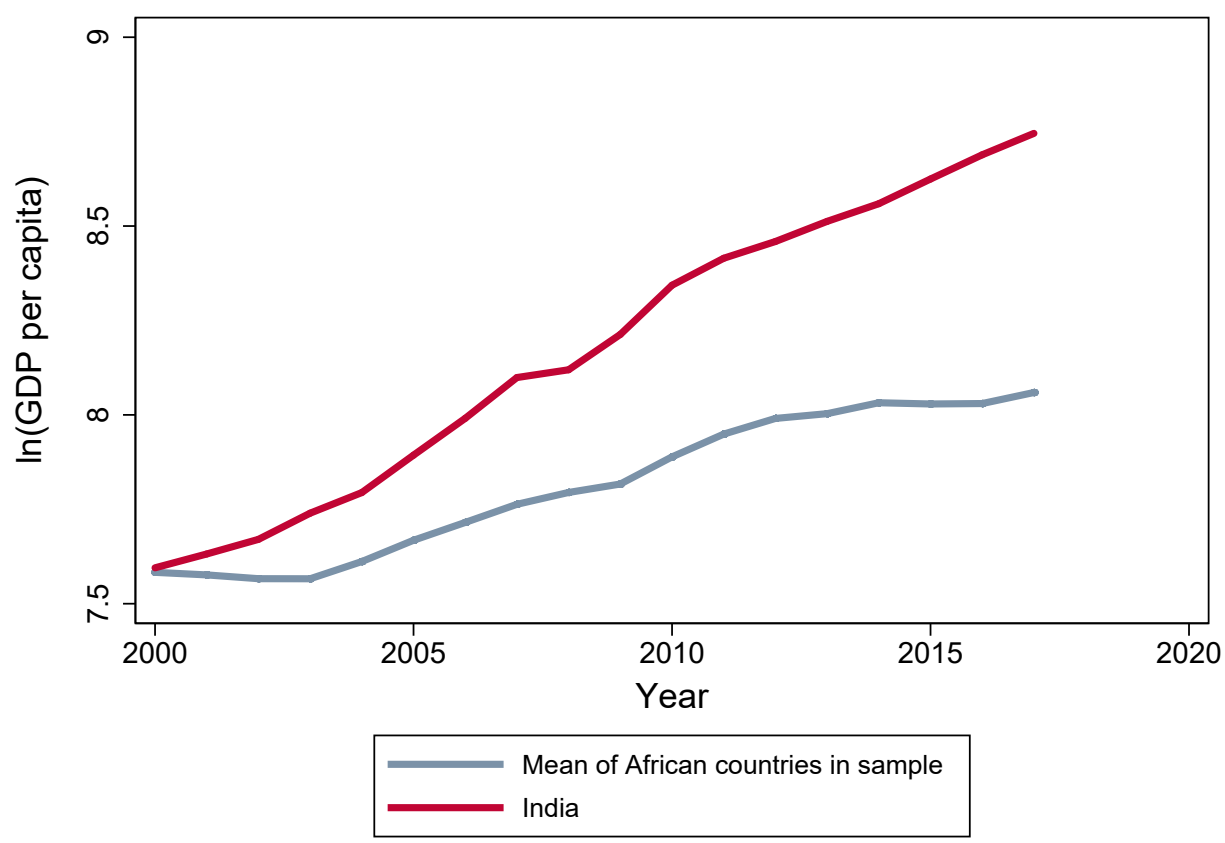

Notes: The GDP is the real GDP in constant prices of 2001 US\$. The African countries include all African countries listed in Table 2.2. Source: Own calculations using data from Penn World Table 9.1 Robert C. Feenstra (2019)

Other macro-determinants in the past years like campaigns against open defecation and the nutrition transition might also play a key role in the difference of health outcomes of Indian children and their SSA peers.

Spears (2018) shows that open defecation in India is a major contributing factor for the height gap between Indian and SSA children. Open defecation is such a major determinant of child health because it increases the disease environment for children via fecal-oral transmission (Larsen et al., 2017; Clasen et al., 2014). Diseases causing diarrhea or transmission of helminths impair child health and so the growth of children (Spears et al., 2013; Hammer \& Spears, 2016). This is particularly the case for densely populated regions where the externalities of 
open defecation have a larger impact on child health outcomes (Hathi et al., 2017; Geruso \& Spears, 2018). Spears et al. (2013) find that differences in open defecation can explain the differences in stunting between low-performing and high-performing Indian districts. In 2014 the Indian government has started the Swachh Bharat Mission to eliminate open defecation by 2019 (A. Gupta et al., 2019). The program includes public awareness campaigns and financial benefits when building new latrines. This governmental impulse could have decreased open defecation in India. While this government mission has increased toilet ownership, it has limited effects on the adoption of the use of these improved sanitation facilities (Clasen et al., 2014; A. Gupta et al., 2019). Adding open defecation or more so the ownership of toilets is a crucial macro-determinant that differs between India and SSA. The active awareness campaigns are very unique. Though India has a particular outstanding level of open defecation, it is also practiced in SSA (Pickering et al., 2015; Abubakar, 2018). Abubakar (2018) show that at least 25.1 percent of the population in Nigeria practices open defecation.

The last macro-determinant, the nutrition transition, favors an increase in animal sourced foods intake and so the trend away from underweight to obesity. The nutrition transition is defined as the shift away from traditional diets based on staples towards increased consumption of wheat, high protein and energy-dense food products, and temperate vegetable and fruits (Pingali, 2007). In this more westernized diet, the intake of processed foods rich in sugar, salt, and fat has particularly increased (Baker \& Friel, 2014). Drivers of the diet change are economic and income growth, urbanization, and globalization of agri-food systems (Pingali, 2007; Qaim, 2017). These factors increase the accessibility of non-traditional food products by relatively decreasing costs for the consumer.

Shetty (2002) shows that the nutrition transition is associated with chronic non-communicable diseases and Meenakshi (2016) finds that the diet quality, i.e. a low intake of vegetables, dairy, and meat, is associated with malnutrition. Even though undernutrition related to macronutrients is losing its importance, micronutrient deficiencies remain high. Overweight is increasing in urban and rural areas over time with related non-communicable diseases. Meenakshi (2016) claims that the Indian poor face greater challenges to increase diet quality and micronutrient intake because the relative price of micronutrient-rich foods compared to cereals has increased more quickly than for the rich. The trend of increasing weight is prevalent in both SA and SSA; in SA the BMI of children and adolescents has accelerated particularly from 1975 to 2016 (Jaacks et al., 2015; Abarca-Gómez et al., 2017). This is striking as consumption of animal 
sourced foods, one element of the nutrition transition, during periods of growth are important to cover nutrient requirements for optimal attainment of height (C. Neumann et al., 2002; Murphy \& Allen, 2003; C. G. Neumann et al., 2003; Iannotti et al., 2017). Children are less likely to be stunted when consuming animal sourced foods (Dror \& Allen, 2011; Headey et al., 2018; Krebs et al., 2011). Thus, the nutrition transition might affect the reliability of anthropometric measures as indicators of nutritional status because it increases the macronutrient intake and so weight but not micronutrient intake in the same way (de Haen et al., 2011). In an extreme case, children could be obese and stunted at the same time. So, the nutrition transition will challenge the identification of undernourished children and so might weaken the effect of eldest son preference. These four emerging macro-determinants call for a reassessment of the Indian Enigma because of their huge impact on the health outcomes of children.

\section{Data and Methodology}

To compare the results of $\mathrm{J}+\mathrm{P}$, the employed sample, cleaning procedures and analyses follow their paper closely.

\subsection{Sample Description}

The data sets for India are all four available DHS waves including the latest National Family and Health Survey [NFHS] 4 that had been conducted in 2015/2016 (ICF, 2004). Unlike the previous three waves of the NFHS data, the sampling procedures are readjusted to collect data that is representative on the district level, not only state level. The latest round also includes union territories like Andaman and Nicobar Islands, Chandigarh, Dadra and Nagar Haveli, Daman and Diu, Lakshadweep, and Puducherry. Therefore, the sample size has increased largely leading to more precise measures. If we compare the shares of each Indian state in of NFHS 3 to NFHS 4 like in Table 2.1, states like Bihar, Jharkhand, Madhya Pradesh, Rajasthan, Uttar Pradesh take up an at least one percent larger share of observations and states like Andhra Pradesh, Delhi, Goa, Kerala, Maharashtra, Manipur, Nagaland, or West Bengal bring in fewer observations (with at least a one percent difference). States like Madhya Pradesh, Rajasthan, Uttar Pradesh with a higher sex ratio gain additional weight whereas states with low sex ratios such as Andhra Pradesh, Goa, Kerala, Manipur, Nagaland, and West Bengal lose weight. The sex ratio is defined as low if the ratio of boys and girls under five years of age is smaller than the median ratio 


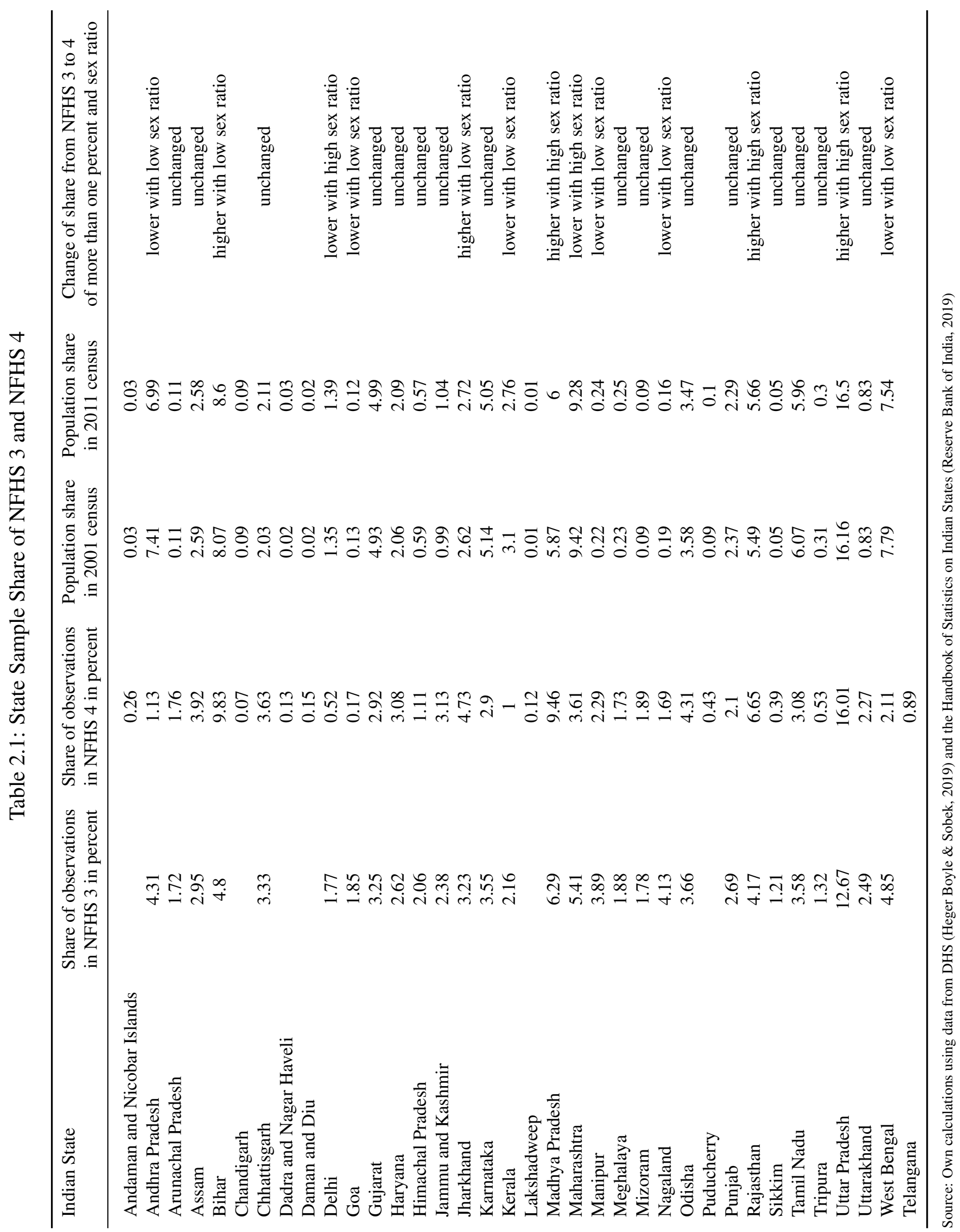


using Indian census data of 2011. The sample differences of the NFHS 3 and NFHS 4 lead to diverging outcomes as shown in the next section. This difference hinders the direct comparability of the two samples and so conclusions from a replication study as we would like to undertake. This is why we adjust these samples by the suggested mother sample weights of DHS to make the samples representative on the population level and overcome possible sampling procedure differences. The different results of the original study and the results of the weighted data from 2004 to 2010 will be presented and discussed in the appendix. We will use the weighted data for both time periods when we extend the replication with the four emerging macro-determinants. For the sample of SSA, surveys are chosen that have been conducted four years previous to and up to two years after the Indian survey in 2015/6, i.e. from 2011 to 2017. This is a similar time period of seven years as the original sample by $\mathrm{J}+\mathrm{P}$. The included countries are all available data sets on IPUMS DHS in the given time period for all the countries that had been included in the study by J+P: 13 countries are represented in both samples with each one survey. Due to lack of data, seven countries are only included in the sample from 2004 to 2010. Among these are five countries that do not fulfill the inclusion criteria of the original sample: a higher GDP per capita than half of India's GDP per capita in the respective survey year. Only two excluded countries, Sao Tome and Principe and Swaziland, would have met the criteria. Further, the samples differ in the number of surveys included for five countries. Following 25 surveys are used for the new sample: Cameroon 2011, Congo Democratic Republic 2013-14, Ethiopia 2011, Ethiopia 2016, Ghana 2014, Guinea 2012, India 2015-16, Kenya 2014, Lesotho 2014, Malawi 2016, Mali 2012, Namibia 2013, Niger 2012, Nigeria 2013, Rwanda 2014, Senegal 2010-11, Senegal 2012-13, Senegal 2012-13, Senegal 2015, Senegal 2016, Senegal 2017, Tanzania 2015, Uganda 2011, Uganda 2016, Zambia 2013, and Zimbabwe 2015. The data is downloaded from IPUMS DHS that harmonizes the different surveys (Heger Boyle \& Sobek, 2019). Table 2.2 provides an overview of the different SSA samples used in the original and the replication study. In the following, the sample of SSA will be referred to as African. To ensure comparability the African surveys are weighted by the suggested mother sample weights of DHS or IDHS. The weights of the countries that have conducted n surveys, i.e. more than one survey, in one of the given time periods will be adjusted to $1 / \mathrm{n}$ times. Robustness checks will be conducted to ensure that this procedure is not distorting the results. 
Table 2.2: Sample Comparison

\begin{tabular}{|c|c|c|}
\hline & Original (2004-2010) & Replication (2011-2017) \\
\hline Cameroon & 2004 & 2011 \\
\hline Congo Democratic Republic & 2007 & 2013-14 \\
\hline Republic of the Congo (Brazzaville) & 2005 & \\
\hline Chad & 2004 & \\
\hline Ethiopia & 2005 & $2011 \& 2016$ \\
\hline Ghana & 2008 & 2014 \\
\hline Guinea & 2005 & 2012 \\
\hline Kenya & $2008-9$ & 2014 \\
\hline Lesotho & $2004 \& 2009$ & 2014 \\
\hline Liberia & 2007 & \\
\hline Madagascar & 2003 & \\
\hline Malawi & 2004 & 2016 \\
\hline Mali & 2006 & 2012 \\
\hline Namibia & 2006 & 2013 \\
\hline Niger & 2006 & 2012 \\
\hline Nigeria & 2008 & 2013 \\
\hline Rwanda & 2005 & 2014 \\
\hline Sao Tome and Principe & $2008-9$ & \\
\hline Senegal & 2005 & $2010-11 \& 2012-13 \& 2015 \& 2016 \& 2017$ \\
\hline Sierra Leone & 2008 & \\
\hline Swaziland & 2006-7 & \\
\hline Tanzania & $2004 \& 2010$ & 2015 \\
\hline Uganda & 2006 & $2011 \& 2016$ \\
\hline Zambia & 2007 & 2013 \\
\hline Zimbabwe & $2005-6$ & 2015 \\
\hline Total & 27 & 24 \\
\hline
\end{tabular}




\subsection{Estimation Strategy}

Not only the data is supposed to be as similar to the original study as possible but also the methodology. We have used the published do-files from $\mathrm{J}+\mathrm{P}$ for cleaning and analysis for both data sets: the one for around 2005 and the other one for around 2015. The estimation strategies stay unchanged for the next section that focuses on the same methods but more recent data. The first three pair of regression output tables use the following estimation equation from $\mathrm{J}+\mathrm{P}$ :

$$
\begin{aligned}
H F A_{i m c}= & \alpha_{1} I_{c}+\alpha_{2} I_{c} \times 2 n d \text { Child }_{i m c}+\alpha_{3 c} \times 3 r d+\text { Child }_{i m c} \\
& +\beta_{1} 2 n d C h i l d_{i m c}+\beta_{2} 3 r d+\text { Child }_{i m c}+\gamma X_{i m c}+\epsilon_{i m c}
\end{aligned}
$$

$H F A$ represents the outcome variables, mostly the standardized height-for-age score [HFA zscore]. It is a measure of the deviation to a reference standard of height at a given age. A standard deviation of smaller than -2 is judged as impaired growth, stunting. Other considered outcomes in Table 2.5 and 2.6 are wasting measured as standardized weight-for-age scores [WFA z-score], hemoglobin level in the blood adjusted by altitude, and death. Table 2.7 and 2.8 consider child health inputs as outcomes, whereas in Table 2.9 and 2.10 HFA z-score and WFA z-scores are considered. The outcome variable has index $i, m$, and $c$ standing for the $i$-th child born to mother $m$ in country $c . I_{c}$ represents the indicator for Indian children; the coefficient $\alpha_{1}$ measures the India gap for first-born children, the omitted birth order category. $\alpha_{2}$ and $\alpha_{3}$ represent the gap for second-born children and third-and-higher birth order children in India. $\beta_{1}$ and $\beta_{2}$ for second-born children and third-and-higher birth order children show the gap to first-born children in general. $X$ represents a changing number of control variables on the child, mother, or primary sampling unit [PSU] level to overcome endogeneity concerns. Due to the sampling procedure of DHS that includes families that have or have not completed their fertility and only collects anthropometric data for children below five years of age, family size cannot be controlled for so that birth order could also capture the effects of high-fertility families (Jayachandran \& Pande, 2017). One strategy of $\mathrm{J}+\mathrm{P}$ to address endogeneity is the use of covariates like PSU fixed effects, maternal literacy, maternal age, child age, and interactions with an India dummy. ${ }^{2}$ Each table pair in the result sections will give details about all used variables. In all regressions, standard errors are clustered at the mother level and child age dummy variables

\footnotetext{
${ }^{2} \mathrm{~J}+\mathrm{P}$ in the original paper provide a more detailed discussion on endogeneity issues that will not be repeated here.
} 
(in months) are included to allow for nonlinear patterns of z-scores and age. In the extension section, we add the macro-determinants, that are interacted or not with the India dummy, to $X$. The last table pair is estimated with an extended estimation equation from $\mathrm{J}+\mathrm{P}$ :

$$
\begin{array}{r}
Y_{i m c}=\alpha_{1} I_{c}+\delta_{1} I_{c} \times \text { Girl }+\delta_{2} I_{c} \times \text { Girl } \times 2 n d C h i l d_{i m c}+\delta_{2} I_{c} \times \text { Girl } \times 3 r d+\text { Child }_{i m c} \\
+\beta_{1} 2 n d C h i l d_{i m c}+\beta_{2} 3 r d+\text { Child }_{i m c} \\
+\beta_{3} \text { Girl } \times 2 \text { ndChild } \text { imc }_{i m c}+\beta_{4} \text { Girl } \times 3 r d+\text { Child }_{i m c}+\beta_{5} \text { Girl }_{i m c} \\
+\alpha_{2} I_{c} \times 2 n d C h i l d_{i m c}+\alpha_{3} I_{c} \times 3 r d+\text { Child }_{i m c}+\gamma X_{i m c}+\epsilon_{i m c}
\end{array}
$$

Apart from the already defined vectors, a variable indicating the gender of the child enters the equation. This includes the interaction of Girl with India $\delta_{1}$, with Indian second-born children $\delta_{2}$, with Indian third-and-higher born children $\delta_{3}$, with first-born children $\beta_{3}$, with second-born children $\beta_{4}$, with third-and-higher born children $\beta_{5}$. In the extension part, we include the macrodeterminants with or without interaction with the India dummy into $X$.

\subsection{Measures of the Four Macro-Determinants}

In the following, we will explain the measures of the four macro-determinants . We use the partially imputed measure for literacy that $\mathrm{J}+\mathrm{P}$ use in their set of control variables but only keep values that are either 0 or 1 . It is a dummy variable that turns to one when the mother can at least read part of a sentence in the literacy test or it is imputed based on the country-specific literacy rate given the mother's completed number of school years.

To measure the influence of economic well-being of households on child health outcomes, we use wealth quantiles constructed based on a wealth index on the household level as additional control variables. The available DHS data does not provide any information regarding income or expenditure but allows to calculate a wealth index. We prepare the wealth index for each sample guided by the DHS procedures (Rutstein, n.d.). As the wealth index should be comparable across the two periods of time and include only information that had been asked for in all the surveys, only 34 dummy variables are used for the factor analysis. In the appendix, we present summary statistics for the included factors, the wealth index score, and wealth quantiles separately for India and the selected African countries.

For open defecation, we use again the same measure as in $\mathrm{J}+\mathrm{P}$. Practicing open defecation is measured as a dummy that turns to one if the household does not have a toilet facility. This 
should capture the essence of the Swacch Bharat Mission that has increased toilet ownership. However, this measure does not account for the adoption of the use of toilets or population density or open defecation practices within the village that might be a better measure to capture the negative externality of open defecation on child health (Spears, 2018).

For the nutrition transition, we use two dummy variables that turn to one when the child has been fed (a) eggs and/or meat or (b) dairy products the previous day. However, we substituted this information to whether the child has been fed in the past seven days if the information for the previous day is not available. This might potentially create bias as this is the case for five surveys conducted in Africa between 2004 and 2010.

This all should allow making the results of the original work and the replication most comparable. We compare the results of around 2005 to the results of around 2015 in the next section.

\section{Replication Results (2011-2017) vs (2004-2010): Unweighted}

In this section, we will compare the results by $\mathrm{J}+\mathrm{P}$ with the methodologically replicated results of the more recent time period. We display figure and table pairs, the first being the original results and the following the replicated ones. Throughout the replication and extension, we focus on the India-Africa health outcome gap. ${ }^{3}$

\subsection{Summary Statistics}

The two subsamples for the time period around 2005 (2004 to 2010) and around 2015 (2011 to 2017) differ mainly in their sample size (Table 2.3 and 2.4): the main sample of children for India increases from 42,069 to 230,220 and for Africa from 126,066 to 168,490 . The number of PSUs is greater in the later time period. India takes the lead this time with 28,215 PSUs compared to Africa with only 12,684 PSUs.

Considering the summary statistics of the previous time period and now, mother characteristics have generally improved. Mother's age at birth in years and mother's desire for more children have increased compared to the earlier time period. The number of born children by each mother and completion of fertility have slightly declined. Mother's desired fertility has decreased in India, whereas it has increased in Africa. Average mother's heights are unchanged.

\footnotetext{
${ }^{3} \mathrm{~J}+\mathrm{P}$ also conduct a within India analysis looking at different son preference proxies. We leave the results out in the main text but display the replication results in the appendix.
} 
Mother's literacy has improved from 58 percent to 67 percent in the Indian subsample but decreased from 49 percent to 48 percent in the African subsample. The gap between Africa and India has widened. Prenatal and postnatal health inputs like maternal iron supplementation, total tetanus shots, delivery at health facilities, postnatal checks within two months, and average pooled inputs have increased overall. The number of prenatal visits has gone up in India, too, but not in Africa. The average value in India is now surpassing the one in Africa in the percentage of deliveries at health facilities with 76 percent compared to 58 percent and average pooled inputs with 46 percent compared to 40 percent. The number of nonresident among children has slightly decreased for Africa but stagnated for India. The number of adult females in the household has increased overall with Africa surpassing India in the more recent time period. The log GDP per capita in a child's birth year has increased over time with the log GDP of 8.51 in India exceeding the log GDP in Africa of 7.75 in the time period around 2015.

Child characteristics have also changed except the gender distribution. Children in the India sample are slightly younger on average and African children older comparing the time period around 2005 to around 2015. The birth order of the sampled children is lower than previously. HFA z-scores, stunting, WFA z-scores, hemoglobin levels, and death incidents of children have improved. ${ }^{4}$ The average HFA z-score in India increases from -1.51 to -1.26 standard deviations and the one in Africa from -1.35 to -1.11 standard deviations. The gap between the Indian and African subsample has widened for children taking iron pills and the number of total vaccinations. In both India has higher reported values in the later time period, unlike Africa where numbers have decreased. The birth spacing in months has increased over time. Incidences of diarrhea are unchanged. Open defecation has decreased for both countries over time, though Africa has a greater reduction from 32 percent to 35 percent. In India, 46 percent of households in the sample of around 2005 and 44 percent around 2015 defecated in the open. Open defecation has not decreased more in Indian than in Africa.

Not only the per capita GDP in the child's birth year has increased but also the correlation between GDP and the HAZ z-score has become stronger for India comparing the original time

\footnotetext{
${ }^{4}$ The rate of diseased children has become more similar over time between India and Africa suggesting that Indian parents do not practice sex-selective abortion widely or to a larger degree than African parents. We examine the survival rate of all ever born children reported by the mother and whether the survival rate differs by birth order, gender, and country in the appendix. In general, we find that survival increases from earlier to later surveys and is higher in India. However, the survival rates do only differ up to 3 percent. The similarity between the India and Africa sample in the survival rate reduces the likelihood of more sex-selective abortion within India because we would expect a greater survival rate in particular for Indian girls. The ones who did not get aborted are wanted by the parents. This is not the case.
} 
period to the more recent one in Figure 2.2. However, the changes in the sampling strategy of the Indian sample might lead to an overestimation of the strength of the correlation. Even though India improved more than Africa in income per capita, education, and health inputs (except open defecation), India's stunting rate is not falling faster. The Indian Enigma seems to be still at play.

Table 2.3: Summary Statistics (2004-2010)

\begin{tabular}{|c|c|c|c|c|c|}
\hline & $\begin{array}{c}\text { India } \\
\text { subsample }\end{array}$ & $\begin{array}{c}\text { Africa } \\
\text { subsample }\end{array}$ & & $\begin{array}{c}\text { India } \\
\text { subsample }\end{array}$ & $\begin{array}{c}\text { Africa } \\
\text { subsample }\end{array}$ \\
\hline Mother's age at birth (years) & $\begin{array}{l}24.75 \\
{[5.23]}\end{array}$ & $\begin{array}{l}26.96 \\
{[6.86]}\end{array}$ & Child's age (months) & $\begin{array}{c}30.20 \\
{[16.90]}\end{array}$ & $\begin{array}{c}28.27 \\
{[17.06]}\end{array}$ \\
\hline Mother's total children born & $\begin{array}{c}2.74 \\
{[1.82]}\end{array}$ & $\begin{array}{c}3.88 \\
{[2.54]}\end{array}$ & Child is a girl & $\begin{array}{c}0.48 \\
{[0.50]}\end{array}$ & $\begin{array}{c}0.50 \\
{[0.50]}\end{array}$ \\
\hline Mother's desired fertility & $\begin{array}{c}2.47 \\
{[0.96]}\end{array}$ & $\begin{array}{c}4.62 \\
{[1.47]}\end{array}$ & Child's birth order & $\begin{array}{c}2.62 \\
{[1.80]}\end{array}$ & $\begin{array}{c}3.74 \\
{[2.48]}\end{array}$ \\
\hline Mother wants more children & $\begin{array}{c}0.34 \\
{[0.47]}\end{array}$ & $\begin{array}{c}0.67 \\
{[0.46]}\end{array}$ & Child's HFA z-score & $\begin{array}{l}-1.51 \\
{[1.81]}\end{array}$ & $\begin{array}{l}-1.35 \\
{[1.94]}\end{array}$ \\
\hline Mother completed her fertility & $\begin{array}{c}0.67 \\
{[0.47]}\end{array}$ & $\begin{array}{c}0.33 \\
{[0.47]}\end{array}$ & Child is stunted & $\begin{array}{c}0.40 \\
{[0.49]}\end{array}$ & $\begin{array}{c}0.38 \\
{[0.48]}\end{array}$ \\
\hline Mother is literate & $\begin{array}{c}0.58 \\
{[0.49]}\end{array}$ & $\begin{array}{c}0.49 \\
{[0.50]}\end{array}$ & Child's WFA z-score & $\begin{array}{l}-1.53 \\
{[1.33]}\end{array}$ & $\begin{array}{l}-0.88 \\
{[1.42]}\end{array}$ \\
\hline Mother's height (meters) & $\begin{array}{c}1.52 \\
{[0.06]}\end{array}$ & $\begin{array}{c}1.58 \\
{[0.07]}\end{array}$ & Child's hemoglobin level (g/dl) & $\begin{array}{l}10.28 \\
{[1.57]}\end{array}$ & $\begin{array}{l}10.15 \\
{[1.68]}\end{array}$ \\
\hline Mother took iron supplements & $\begin{array}{c}0.69 \\
{[0.46]}\end{array}$ & $\begin{array}{c}0.62 \\
{[0.49]}\end{array}$ & Child is deceased & $\begin{array}{c}0.05 \\
{[0.22]}\end{array}$ & $\begin{array}{c}0.07 \\
{[0.26]}\end{array}$ \\
\hline Mother's total tetanus shots & $\begin{array}{c}1.87 \\
{[0.94]}\end{array}$ & $\begin{array}{c}1.41 \\
{[1.20]}\end{array}$ & Child taking iron pills & $\begin{array}{c}0.06 \\
{[0.23]}\end{array}$ & $\begin{array}{c}0.11 \\
{[0.32]}\end{array}$ \\
\hline Total prenatal visits & $\begin{array}{c}4.04 \\
{[3.48]}\end{array}$ & $\begin{array}{c}3.85 \\
{[3.07]}\end{array}$ & Child's total vaccinations & $\begin{array}{c}6.61 \\
{[2.80]}\end{array}$ & $\begin{array}{c}6.24 \\
{[3.12]}\end{array}$ \\
\hline Delivery at health facility & $\begin{array}{c}0.45 \\
{[0.50]}\end{array}$ & $\begin{array}{c}0.47 \\
{[0.50]}\end{array}$ & Birth spacing (months) & $\begin{array}{c}36.16 \\
{[20.32]}\end{array}$ & $\begin{array}{c}38.69 \\
{[20.63]}\end{array}$ \\
\hline Postnatal check within 2 months & $\begin{array}{c}0.09 \\
{[0.29]}\end{array}$ & $\begin{array}{c}0.30 \\
{[0.46]}\end{array}$ & Diarrhea in last 2 weeks & $\begin{array}{c}0.09 \\
{[0.29]}\end{array}$ & $\begin{array}{c}0.16 \\
{[0.36]}\end{array}$ \\
\hline Average pooled inputs & $\begin{array}{c}0.33 \\
{[0.28]}\end{array}$ & $\begin{array}{c}0.38 \\
{[0.30]}\end{array}$ & Open defecation & $\begin{array}{c}0.46 \\
{[0.50]}\end{array}$ & $\begin{array}{c}0.32 \\
{[0.47]}\end{array}$ \\
\hline Percent non-resident among children & $\begin{array}{c}0.02 \\
{[0.04]}\end{array}$ & $\begin{array}{c}0.10 \\
{[0.08]}\end{array}$ & Number of PSUs & 3,822 & 10,366 \\
\hline Number of adult females in household & $\begin{array}{c}1.85 \\
{[1.09]}\end{array}$ & $\begin{array}{c}1.60 \\
{[1.06]}\end{array}$ & Main sample of children & 42,069 & 126,066 \\
\hline Log GDP per capita (in child's birth year) & $\begin{array}{c}7.78 \\
{[0.10]}\end{array}$ & $\begin{array}{c}7.36 \\
{[0.65]}\end{array}$ & & & \\
\hline
\end{tabular}

Notes: The means of the specified variables are calculated separately for the India and Africa subsamples. Standard deviations appear in brackets. The following variables are summarized at the mother level: total children born, mother's desired fertility, wants more children, mother completed her fertility, mother is literate, and mother's height. Total prenatal visits, mother took iron supplements, total tetanus shots, postnatal check within two months are also, in effect, summarized at the mother level because they are only available for the most recent birth. Variables summarized at the child level include: mother's age at birth, birth spacing (the birth interval between a child and his or her older sibling), delivery at health facility, average pooled inputs, all child variables (first ten variables in the second column), diarrhea in last two weeks, open defecation, percent nonresident among children, number of adult females in the household, and log GDP per capita in child's birth year.

Source: Adapted from J+P using data from DHS (Heger Boyle \& Sobek, 2019) 
Table 2.4: Summary Statistics (2011-2017)

\begin{tabular}{|c|c|c|c|c|c|}
\hline & $\begin{array}{c}\text { India } \\
\text { subsample }\end{array}$ & $\begin{array}{c}\text { Africa } \\
\text { subsample }\end{array}$ & & $\begin{array}{c}\text { India } \\
\text { subsample }\end{array}$ & $\begin{array}{c}\text { Africa } \\
\text { subsample }\end{array}$ \\
\hline Mother's age at birth (years) & $\begin{array}{l}25.12 \\
{[4.96]}\end{array}$ & $\begin{array}{l}27.23 \\
{[6.71]}\end{array}$ & Child's age (months) & $\begin{array}{c}30.14 \\
{[16.92]}\end{array}$ & $\begin{array}{c}28.90 \\
{[17.02]}\end{array}$ \\
\hline Mother's total children born & $\begin{array}{c}2.38 \\
{[1.49]}\end{array}$ & $\begin{array}{c}3.81 \\
{[2.48]}\end{array}$ & Child is a girl & $\begin{array}{c}0.48 \\
{[0.50]}\end{array}$ & $\begin{array}{c}0.50 \\
{[0.50]}\end{array}$ \\
\hline Mother's desired fertility & $\begin{array}{c}2.42 \\
{[0.99]}\end{array}$ & $\begin{array}{c}4.73 \\
{[1.41]}\end{array}$ & Child's birth order & $\begin{array}{c}2.26 \\
{[1.47]}\end{array}$ & $\begin{array}{c}3.70 \\
{[2.42]}\end{array}$ \\
\hline Mother wants more children & $\begin{array}{c}0.41 \\
{[0.47]}\end{array}$ & $\begin{array}{c}0.71 \\
{[0.44]}\end{array}$ & Child's HFA z-score & $\begin{array}{l}-1.26 \\
{[1.82]}\end{array}$ & $\begin{array}{l}-1.11 \\
{[1.73]}\end{array}$ \\
\hline Mother completed her fertility & $\begin{array}{c}0.61 \\
{[0.49]}\end{array}$ & $\begin{array}{c}0.28 \\
{[0.45]}\end{array}$ & Child is stunted & $\begin{array}{c}0.35 \\
{[0.48]}\end{array}$ & $\begin{array}{c}0.29 \\
{[0.45]}\end{array}$ \\
\hline Mother is literate & $\begin{array}{c}0.67 \\
{[0.47]}\end{array}$ & $\begin{array}{c}0.48 \\
{[0.50]}\end{array}$ & Child's WFA z-score & $\begin{array}{l}-1.43 \\
{[1.30]}\end{array}$ & $\begin{array}{c}-0.86 \\
{[1.31]}\end{array}$ \\
\hline Mother's height (meters) & $\begin{array}{c}1.52 \\
{[0.06]}\end{array}$ & $\begin{array}{c}1.58 \\
{[0.06]}\end{array}$ & Child's hemoglobin level (g/dl) & $\begin{array}{l}10.60 \\
{[1.51]}\end{array}$ & $\begin{array}{l}10.33 \\
{[1.63]}\end{array}$ \\
\hline Mother took iron supplements & $\begin{array}{c}0.77 \\
{[0.42]}\end{array}$ & $\begin{array}{c}0.76 \\
{[0.43]}\end{array}$ & Child is deceased & $\begin{array}{c}0.04 \\
{[0.20]}\end{array}$ & $\begin{array}{c}0.05 \\
{[0.22]}\end{array}$ \\
\hline Mother's total tetanus shots & $\begin{array}{c}1.91 \\
{[0.78]}\end{array}$ & $\begin{array}{c}1.42 \\
{[1.09]}\end{array}$ & Child taking iron pills & $\begin{array}{c}0.23 \\
{[0.42]}\end{array}$ & $\begin{array}{c}0.07 \\
{[0.25]}\end{array}$ \\
\hline Total prenatal visits & $\begin{array}{c}4.19 \\
{[3.86]}\end{array}$ & $\begin{array}{c}3.77 \\
{[2.92]}\end{array}$ & Child's total vaccinations & $\begin{array}{c}7.30 \\
{[2.70]}\end{array}$ & $\begin{array}{c}4.92 \\
{[3.55]}\end{array}$ \\
\hline Delivery at health facility & $\begin{array}{c}0.76 \\
{[0.43]}\end{array}$ & $\begin{array}{c}0.58 \\
{[0.49]}\end{array}$ & Birth spacing (months) & $\begin{array}{c}37.26 \\
{[21.45]}\end{array}$ & $\begin{array}{c}38.83 \\
{[20.79]}\end{array}$ \\
\hline Postnatal check within 2 months & $\begin{array}{c}0.36 \\
{[0.48]}\end{array}$ & $\begin{array}{c}0.49 \\
{[0.50]}\end{array}$ & Diarrhea in last 2 weeks & $\begin{array}{c}0.09 \\
{[0.29]}\end{array}$ & $\begin{array}{c}0.16 \\
{[0.36]}\end{array}$ \\
\hline Average pooled inputs & $\begin{array}{c}0.46 \\
{[0.25]}\end{array}$ & $\begin{array}{c}0.40 \\
{[0.29]}\end{array}$ & Open defecation & $\begin{array}{c}0.44 \\
{[0.50]}\end{array}$ & $\begin{array}{c}0.25 \\
{[0.43]}\end{array}$ \\
\hline Percent non-resident among children & $\begin{array}{c}0.02 \\
{[0.04]}\end{array}$ & $\begin{array}{c}0.09 \\
{[0.00]}\end{array}$ & Number of PSUs & 28,215 & 12,684 \\
\hline Number of adult females in household & $\begin{array}{c}1.91 \\
{[1.03]}\end{array}$ & $\begin{array}{c}1.94 \\
{[1.66]}\end{array}$ & Main sample of children & 230,220 & 168,490 \\
\hline Log GDP per capita (in child's birth year) & $\begin{array}{c}8.51 \\
{[0.08]}\end{array}$ & $\begin{array}{c}7.75 \\
{[0.68]}\end{array}$ & & & \\
\hline
\end{tabular}

Notes: The means of the specified variables are calculated separately for the India and Africa subsamples. Standard deviations appear in brackets. The following variables are summarized at the mother level: total children born, mother's desired fertility, wants more children, mother completed her fertility, mother is literate, and mother's height. Total prenatal visits, mother took iron supplements, total tetanus shots, postnatal check within two months are also, in effect, summarized at the mother level because they are only available for the most recent birth. Variables summarized at the child level include: mother's age at birth, birth spacing (the birth interval between a child and his or her older sibling), delivery at health facility, average pooled inputs, all child variables (first ten variables in the second column), diarrhea in last two weeks, open defecation, percent nonresident among children, number of adult females in the household, and log GDP per capita in child's birth year.

Source: Adapted from J+P using data from IPUMS DHS (ICF, 2004) and DHS (Heger Boyle \& Sobek, 2019) 
Figure 2.2: Child Height versus National GDP (2004-2010) vs (2011-2017): Unweighted Replication (2004-2010)

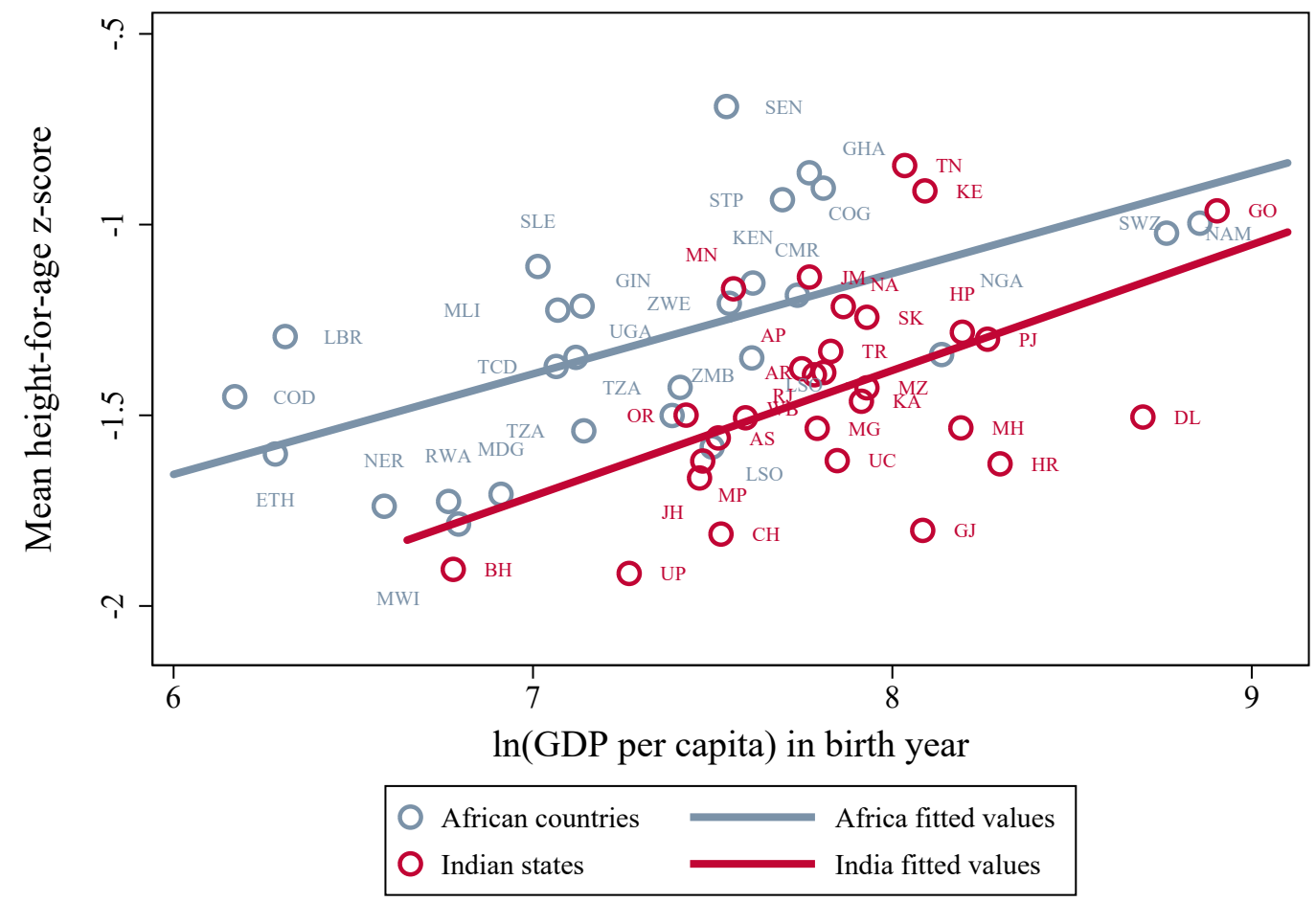

Replication (2011-2017)

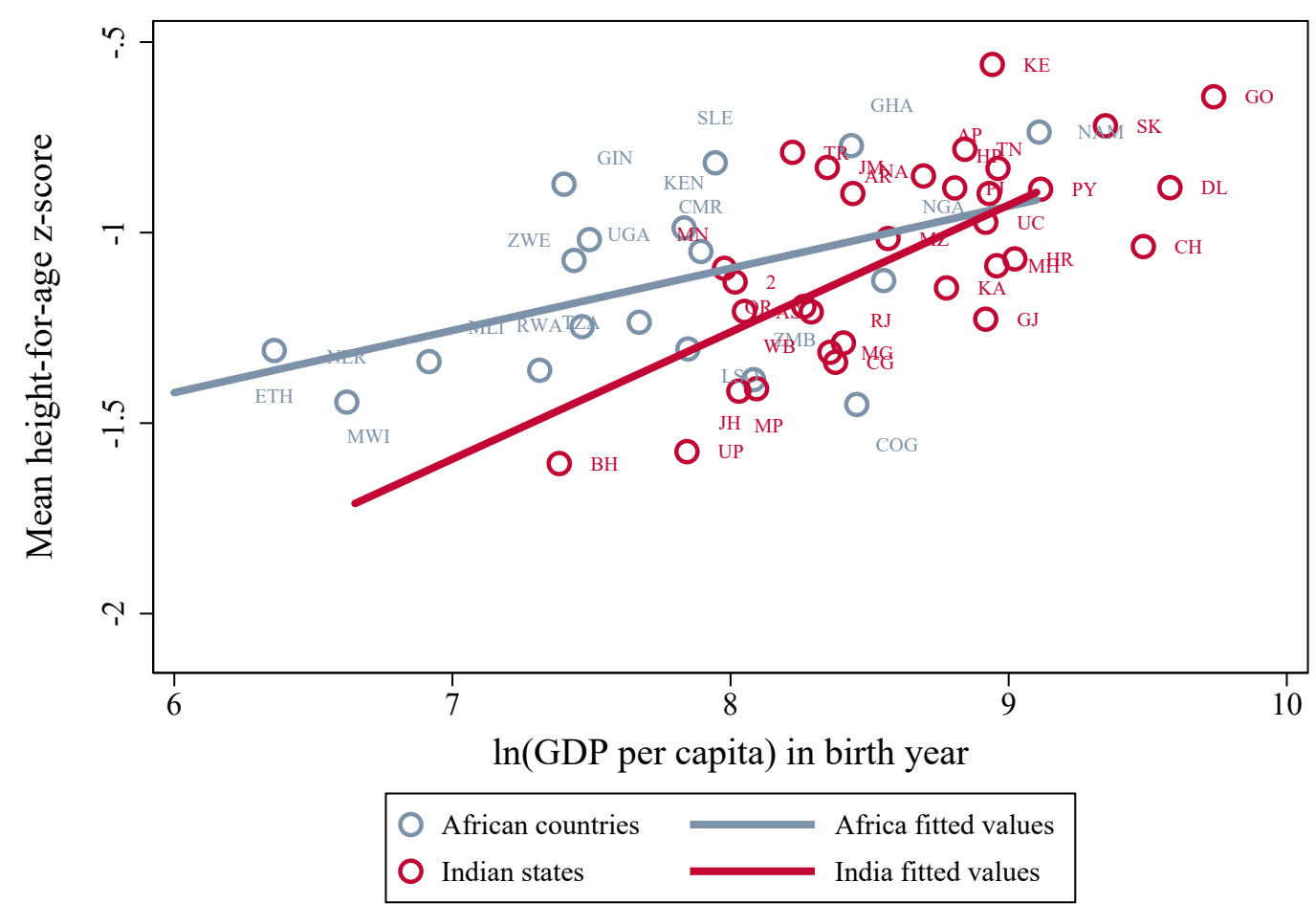

Notes: The light and dark circles represent sub-Saharan African countries and Indian states, respectively. The averages are calculated over all children less than 60 months old. The lines represent the best linear fit for each sample.

Source: Adapted from J+P using data from Penn World Table 9.0 (Robert C. Feenstra, 2016), Penn World Table 9.1 (Robert C. Feenstra, 2019), and the Handbook of Statistics on Indian States (Reserve Bank of India, 2019) 


\subsection{India's Differential Birth Order Gradient in Child Height and Re- lated Outcomes}

In the table pair Table 2.5 and 2.6, the pattern of HFA z-score is now analyzed using regressions. In the time period around 2015 (Table 2.6 column 1) we find that pooling all children Indians are on average 0.11 standard deviations shorter than Africans. This result is significant on the 1 percent significance level. The magnitude of the height difference to African children is larger using the new data compared to the original results by $\mathrm{J}+\mathrm{P}$. Children in India seem to be worse off compared to African children in recent years than before.

Next, we want to examine the differences in height based on the birth order. For this we want to assess the average HFA z-scores of Indian and African children per time graphically in a first step. In Figure 2.3, we assess the average child HFA z-scores for India and Africa by birth order. We observe that the Indian deficit does not only affect children of second-and-higher birth order anymore but also firstborns. Additionally, the gap between Indian and African children has widened for second birth order children but declined for third-and-higher birth order children. From 2011 to 2017 all children in India independent of their birth order are shorter than in Africa.

Starting with column 2 in the presented table pair, we use the introduced estimation strategy of equation (1) that disaggregates the results by birth order. Unlike for the period around 2005, the Indian height disadvantage affects all Indian children independent of their birth order in the time period around 2015. A first-born child in India is on average 0.02 standard deviations shorter than its African peer. This height disadvantage compared to African children (sum of main effect and interaction term) is even stronger for second-born Indian children with -0.11 and third-born ones with -0.27 . All coefficients are statistically significant at least on the 5 percent significance level. The birth order gradient is less steep in India in the more recent time period than before.

Column 3 adds now PSU fixed effects and control variables interacted with India like child's age dummies, mother's literacy, and mother's age at birth (linear and quadratic). This represents the main specification that is used also for column 6 following as well as for the next table pair in the following subsection. The effect magnitude for Indian children decreases with unchanged significance in the time period around 2005 and 2015. In the more recent sample, however, the addition of control variables increases the effect size and significance for second-and-higher 
birth order children in general. Column 4 uses the same specification as in column 3 but a sample that has already completed fertility and dummies for family size proxied by the observed number of children and interacted with India. ${ }^{5}$ The subsample includes all children whose mother has likely completed fertility. This is why the sample reduces to roughly 40 percent in the earlier time period and about less than 50 percent in the more recent time period. The coefficients are not significant anymore in the time period around 2015 and also the effect sizes change.

In column 5, another robustness check of the results is conducted by using mother fixed effects and so a within-family comparison that keeps family size constant. The sample only includes families with at least two children in one family. The sample sizes are reduced to 83,228 for the time period around 2005 and to 189,520 observations for the time period around 2015. All birth order gradients remain statistically significant but are larger in magnitude apart from the coefficient for third-or-higher born children that reduces in size. A key finding for $\mathrm{J}+\mathrm{P}$ is that "the birth order gradient in child height is twice as large in India as in Africa". Reassessing this finding with data from around 2015 the birth order gradient is not as large in India as before.

Columns 6 to 9 focus on other health outcomes that are also likely to be affected by birth order driven parental investment decisions. In column 6 the outcome variable is the incidence of stunting in children, a lower HFA z-score than 2 standard deviations above or below the mean. Indian second-born children perform 2 percentage points and Indian third-or-higher born children 3 percentage points lower than their African counterparts. The Indian birth order gradient is very shallow as the magnitudes of second-and-higher birth order children are quite similar in the time period around 2015. At least for stunting the additional gap in stunting for Indian and African children has halved for higher-birth order children.

Column 7 considers the WFA z-scores. The steep birth order gradient for India for the period around 2005 has flattened in the time period around 2015. For example, Indian secondborn children weigh now 0.09 standard deviations less compared to 0.15 standard deviations in the earlier sample. The effect sizes and birth order gradients for hemoglobin levels have also changed over time. In the time period around 2005, we see a steep birth order gradient for India. In contrast, around 2015 only the second-born Indian children have a statistically significant effect on hemoglobin levels that is smaller in magnitude than in the time period before. The outcomes for infant mortality in column 9 do not longer change for the Indian birth order

\footnotetext{
${ }^{5}$ We follow $\mathrm{J}+\mathrm{P}$ in their classification for completed fertility: Women have completed their fertility if they "stated they do not want any more children or [if they] have been sterilized".
} 
Table 2.5: India's Differential Birth Order Gradient in Child Height and Related Outcomes (2004-2010)

\begin{tabular}{|c|c|c|c|c|c|c|c|c|c|}
\hline & $\begin{array}{c}\text { HFA } \\
\text { Z- } \\
\text { score } \\
(1)\end{array}$ & $\begin{array}{l}\text { HFA } \\
\text { Z- } \\
\text { score } \\
(2)\end{array}$ & $\begin{array}{c}\text { HFA } \\
\text { Z- } \\
\text { score } \\
(3)\end{array}$ & $\begin{array}{l}\text { HFA } \\
\text { Z- } \\
\text { score } \\
(4)\end{array}$ & $\begin{array}{c}\text { HFA } \\
\text { z- } \\
\text { score } \\
(5)\end{array}$ & $\begin{array}{l}\text { Stunted } \\
(6)\end{array}$ & $\begin{array}{c}\text { WFA } \\
\text { Z- } \\
\text { score } \\
(7)\end{array}$ & $\begin{array}{c}\mathrm{Hb} \\
\text { level } \\
(8)\end{array}$ & $\begin{array}{l}\text { Deceased } \\
\text { (9) }\end{array}$ \\
\hline India & $\begin{array}{l}-0.083 \\
{[0.011]}\end{array}$ & $\begin{array}{l}0.092 \\
{[0.018]}\end{array}$ & & & & & & & \\
\hline India $\times 2$ nd child & & $\begin{array}{l}-0.144 \\
{[0.025]}\end{array}$ & $\begin{array}{l}-0.161 \\
{[0.027]}\end{array}$ & $\begin{array}{l}-0.110 \\
{[0.063]}\end{array}$ & $\begin{array}{l}-0.243 \\
{[0.048]}\end{array}$ & $\begin{array}{l}0.051 \\
{[0.007]}\end{array}$ & $\begin{array}{l}-0.147 \\
{[0.020]}\end{array}$ & $\begin{array}{l}-0.094 \\
{[0.030]}\end{array}$ & $\begin{array}{l}0.003 \\
{[0.004]}\end{array}$ \\
\hline India $\times 3$ rd + child & & $\begin{array}{l}-0.377 \\
{[0.024]}\end{array}$ & $\begin{array}{l}-0.228 \\
{[0.032]}\end{array}$ & $\begin{array}{l}-0.194 \\
{[0.092]}\end{array}$ & $\begin{array}{l}-0.436 \\
{[0.085]}\end{array}$ & $\begin{array}{l}0.064 \\
{[0.009]}\end{array}$ & $\begin{array}{l}-0.199 \\
{[0.024]}\end{array}$ & $\begin{array}{l}-0.158 \\
{[0.036]}\end{array}$ & $\begin{array}{l}0.002 \\
{[0.004]}\end{array}$ \\
\hline 2nd child & & $\begin{array}{l}0.024 \\
{[0.015]}\end{array}$ & $\begin{array}{l}-0.011 \\
{[0.017]}\end{array}$ & $\begin{array}{l}-0.096 \\
{[0.053]}\end{array}$ & $\begin{array}{l}-0.167 \\
{[0.027]}\end{array}$ & $\begin{array}{l}0.009 \\
{[0.004]}\end{array}$ & $\begin{array}{l}0.010 \\
{[0.012]}\end{array}$ & $\begin{array}{l}-0.010 \\
{[0.022]}\end{array}$ & $\begin{array}{l}-0.014 \\
{[0.002]}\end{array}$ \\
\hline $3 \mathrm{rd}+$ child & & $\begin{array}{l}-0.065 \\
{[0.013]}\end{array}$ & $\begin{array}{l}-0.117 \\
{[0.019]}\end{array}$ & $\begin{array}{l}-0.168 \\
{[0.074]}\end{array}$ & $\begin{array}{l}-0.334 \\
{[0.044]}\end{array}$ & $\begin{array}{l}0.036 \\
{[0.005]}\end{array}$ & $\begin{array}{l}-0.063 \\
{[0.014]}\end{array}$ & $\begin{array}{l}-0.038 \\
{[0.025]}\end{array}$ & $\begin{array}{l}-0.011 \\
{[0.003]}\end{array}$ \\
\hline Africa mean of outcome & -1.351 & -1.351 & -1.351 & -1.351 & -1.351 & 0.375 & -0.877 & 10.149 & 0.072 \\
\hline Child's age dummies $\times$ India & No & No & Yes & Yes & Yes & Yes & Yes & Yes & Yes \\
\hline Mother's literacy $\times$ India & No & No & Yes & Yes & No & Yes & Yes & Yes & Yes \\
\hline Mother's age at birth $\times$ India & No & No & Yes & Yes & No & Yes & Yes & Yes & Yes \\
\hline PSU FEs & No & No & Yes & Yes & No & Yes & Yes & Yes & Yes \\
\hline $\begin{array}{l}\text { Mother FEs } \\
\text { Africa mean } \\
\text { India mean }\end{array}$ & No & No & No & No & $\begin{array}{c}\text { Yes } \\
-0.023 \\
0.078\end{array}$ & No & No & No & No \\
\hline $\begin{array}{l}\text { Completed fertility sample } \\
\text { Observations }\end{array}$ & $\begin{array}{l}\text { No } \\
168,135\end{array}$ & $\begin{array}{l}\text { No } \\
168,135\end{array}$ & $\begin{array}{l}\text { No } \\
167,765\end{array}$ & $\begin{array}{c}\text { Yes } \\
66,574\end{array}$ & $\begin{array}{c}\text { No } \\
83,243\end{array}$ & $\begin{array}{l}\text { No } \\
167,765\end{array}$ & $\begin{array}{l}\text { No } \\
167,765\end{array}$ & $\begin{array}{c}\text { No } \\
88,893\end{array}$ & $\begin{array}{l}\text { No } \\
199,514\end{array}$ \\
\hline
\end{tabular}

Table 2.6: India's Differential Birth Order Gradient in Child Height and Related Outcomes (2011-2017)

\begin{tabular}{|c|c|c|c|c|c|c|c|c|c|}
\hline & $\begin{array}{c}\text { HFA } \\
\text { Z- } \\
\text { score } \\
(1)\end{array}$ & $\begin{array}{c}\text { HFA } \\
\text { Z- } \\
\text { score } \\
(2)\end{array}$ & $\begin{array}{c}\text { HFA } \\
\text { z- } \\
\text { score } \\
(3)\end{array}$ & $\begin{array}{l}\text { HFA } \\
\text { Z- } \\
\text { score } \\
(4)\end{array}$ & $\begin{array}{c}\text { HFA } \\
\text { Z- } \\
\text { score } \\
(5)\end{array}$ & $\begin{array}{l}\text { Stunted } \\
\text { (6) }\end{array}$ & $\begin{array}{c}\text { WFA } \\
\mathrm{Z}^{-} \\
\text {score } \\
(7)\end{array}$ & $\begin{array}{c}\mathrm{Hb} \\
\text { level } \\
(8)\end{array}$ & $\begin{array}{l}\text { Deceased } \\
\text { (9) }\end{array}$ \\
\hline India & $\begin{array}{l}-0.107 \\
{[0.006]}\end{array}$ & $\begin{array}{l}-0.019 \\
{[0.010]}\end{array}$ & & & & & & & \\
\hline India $\times 2$ nd child & & $\begin{array}{l}-0.105 \\
{[0.014]}\end{array}$ & $\begin{array}{l}-0.073 \\
{[0.015]}\end{array}$ & $\begin{array}{l}-0.059 \\
{[0.055]}\end{array}$ & $\begin{array}{l}-0.168 \\
{[0.028]}\end{array}$ & $\begin{array}{l}0.024 \\
{[0.004]}\end{array}$ & $\begin{array}{l}-0.087 \\
{[0.011]}\end{array}$ & $\begin{array}{l}-0.039 \\
{[0.018]}\end{array}$ & $\begin{array}{l}-0.002 \\
{[0.002]}\end{array}$ \\
\hline India $\times 3 \mathrm{rd}+$ child & & $\begin{array}{l}-0.271 \\
{[0.013]}\end{array}$ & $\begin{array}{l}-0.112 \\
{[0.018]}\end{array}$ & $\begin{array}{l}-0.082 \\
{[0.076]}\end{array}$ & $\begin{array}{l}-0.326 \\
{[0.049]}\end{array}$ & $\begin{array}{l}0.028 \\
{[0.005]}\end{array}$ & $\begin{array}{l}-0.129 \\
{[0.014]}\end{array}$ & $\begin{array}{l}-0.013 \\
{[0.020]}\end{array}$ & $\begin{array}{l}-0.000 \\
{[0.002]}\end{array}$ \\
\hline 2nd child & & $\begin{array}{l}0.007 \\
{[0.012]}\end{array}$ & $\begin{array}{l}-0.049 \\
{[0.013]}\end{array}$ & $\begin{array}{l}-0.092 \\
{[0.053]}\end{array}$ & $\begin{array}{l}-0.178 \\
{[0.021]}\end{array}$ & $\begin{array}{l}0.011 \\
{[0.004]}\end{array}$ & $\begin{array}{l}-0.014 \\
{[0.010]}\end{array}$ & $\begin{array}{l}-0.026 \\
{[0.016]}\end{array}$ & $\begin{array}{l}-0.009 \\
{[0.002]}\end{array}$ \\
\hline $3 r d+$ child & & $\begin{array}{l}-0.104 \\
{[0.010]}\end{array}$ & $\begin{array}{l}-0.155 \\
{[0.014]}\end{array}$ & $\begin{array}{l}-0.129 \\
{[0.072]}\end{array}$ & $\begin{array}{l}-0.314 \\
{[0.033]}\end{array}$ & $\begin{array}{l}0.043 \\
{[0.004]}\end{array}$ & $\begin{array}{l}-0.082 \\
{[0.011]}\end{array}$ & $\begin{array}{l}-0.114 \\
{[0.018]}\end{array}$ & $\begin{array}{l}-0.009 \\
{[0.002]}\end{array}$ \\
\hline Africa mean of outcome & -1.110 & -1.110 & -1.110 & -1.110 & -1.110 & 0.289 & -0.858 & 10.332 & 0.049 \\
\hline Child's age dummies $\times$ India & No & No & Yes & Yes & Yes & Yes & Yes & Yes & Yes \\
\hline Mother's literacy $\times$ India & No & No & Yes & Yes & No & Yes & Yes & Yes & Yes \\
\hline Mother's age at birth $\times$ India & No & No & Yes & Yes & No & Yes & Yes & Yes & Yes \\
\hline PSU FEs & No & No & Yes & Yes & No & Yes & Yes & Yes & Yes \\
\hline $\begin{array}{l}\text { Mother FEs } \\
\text { Africa mean } \\
\text { India mean }\end{array}$ & No & No & No & No & $\begin{array}{c}\text { Yes } \\
-0.018 \\
0.015\end{array}$ & No & No & No & No \\
\hline Completed fertility sample & No & No & No & Yes & No & No & No & No & No \\
\hline Observations & 398,710 & 398,710 & 397,702 & 176,665 & 189,520 & 397,702 & 397,702 & 300,933 & 410,460 \\
\hline
\end{tabular}

Notes: Standard errors are clustered by mother and appear in brackets. HFA z-score is the child's height-for-age z-score, Stunted is defined as having an HFA z-score 2, WFA z-score is the child's weight-for-age z-score, and Hb level is the child's hemoglobin level; 2nd child is an indicator for children whose birth order is $2 ; 3 \mathrm{rd}+$ child is an indicator for children whose birth order is 3 or higher. Child age dummies are included in all columns. In columns 3- 4 and 6-9, the main effect India is absorbed by PSU fixed effects. In column 5, the main effect India is absorbed by mother fixed effects. Columns 3-4 and 6-9 include PSU fixed effects, a linear and a quadratic variable for mother's age at birth, mother's literacy, and mother's literacy, maternal age, and child age dummies interacted with India. In columns 3 and 5-9, the sample is restricted to PSUs with at least two children aged 1-59 months. In column 4, the sample is restricted to children whose mothers report that they do not want to have more children, are sterilized, or are infecund. Column 4 includes total fertility dummies, top-coded at 6 children, and total fertility dummies interacted with India. In column $8, \mathrm{Hb}$ level is $\mathbf{3}$ Qined for children 6 months or older and is not available for six surveys. In column 9, the sample consists of ever-born children aged 13-59 months. 
Figure 2.3: Child Height in India and Africa, by Child's Birth Order (2004-2010) vs (20112017): Unweighted

Replication (2004-2010)

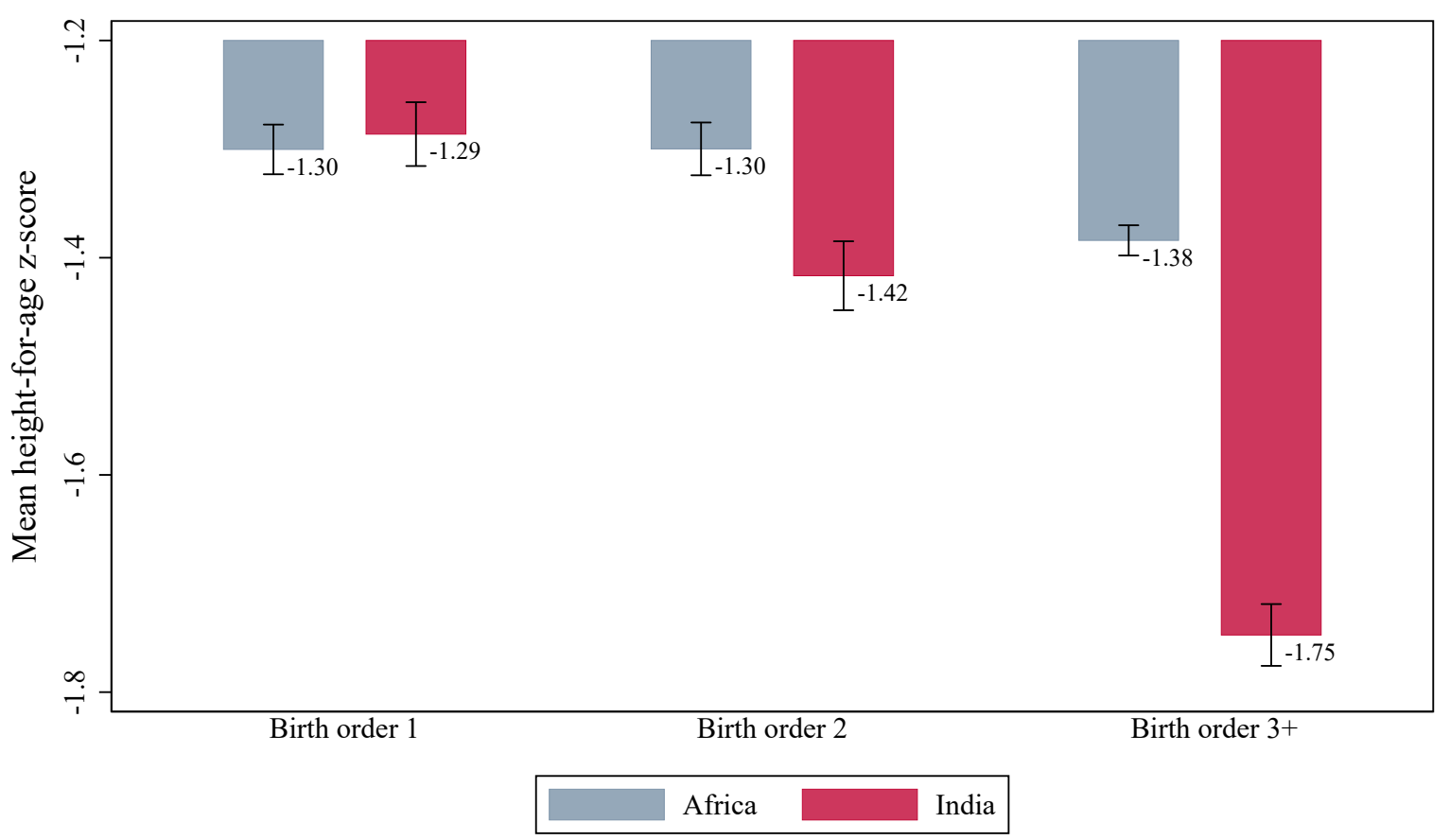

Replication (2011-2017)

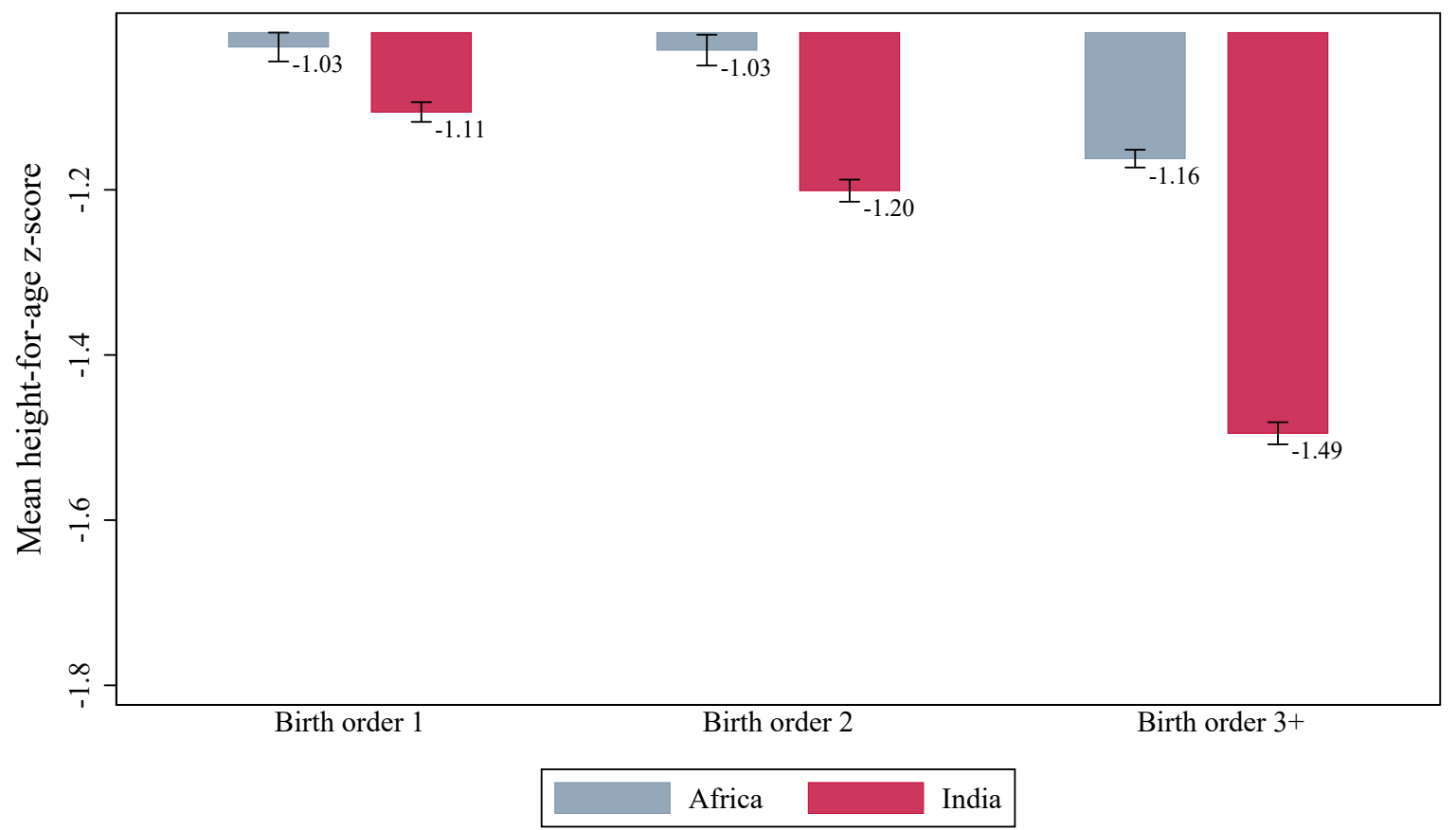

Notes: The figure depicts the mean child height-for-age z-scores for sub-Saharan Africa and India, by the birth order of the child. The mean is calculated over all children less than 60 months old.

Source: Adapted from J+P using data from DHS (ICF, 2004) and IPUMS DHS (Heger Boyle \& Sobek, 2019) 
gradient from positive in the time period around 2005 to negative in the time period around 2015. A preferential treatment regarding birth order is not visible. Overall, the steep birth order gradient found in the study by $\mathrm{J}+\mathrm{P}$ is much shallower in the new considered sample. A particular preference for Indian first-borns in form of a positive birth order effect is not detectable anymore. This puts a particular first-birth order preference of Indian parents into question.

\subsection{Child Health Inputs}

The next table pair, Table 2.7 and 2.8, focuses on the link between birth order gradients and prenatal and postnatal investments in child health. ${ }^{6}$ Considering the prenatal inputs, India has on average a higher outcome for the time period around 2005 (Table 2.7) than for the time period around 2015 (Table 2.8). India surpasses Africa in all outcomes in the time period around 2015 and in all but delivery at the health facility in the time period around 2005. In the later time period, the birth order gradient is not as clear for India anymore: in the case of mother's tetanus shots, the effect size is larger for third-or-higher born children than for second-born children. In the case of delivery at the health facility, second-born children are even more likely to be delivered at a health facility than their African counterparts; third-or-higher birth order children in India are negatively associated with delivery at a health facility again.

Turning to postnatal inputs, the African subsamples have higher outcomes in postnatal checks within two months, while the Indian subsamples show higher rates of child vaccinations overall. In the later considered period, India surpasses the African mean of children taking iron pills. In the time period around 2005 , there are no differential birth order gradients for postnatal checkups and iron pill consumption of children. However, around 2015 there are significant effects of third-born Indian children. For postnatal checks, they are even positive for thirdor-later-born children. Around 2005 a clear birth order gradient for Indian children is visible considering vaccinations. Around 2015 there is no birth order gradient detectable anymore for Indian children because all effects are insignificant.

Column 8 looks at average total inputs. This measure is composed of the seven prior health put indicators. The indicators with original multiple values (total prenatal visits, total tetanus shots, and total vaccines) are transformed into dummy variables that turn on if the measure of the original variable has a value larger than the sample median. In the earlier period, the birth order gradient in India is quite steep compared to around 2015 when only the third-or-higher-born

\footnotetext{
${ }^{6}$ The estimation strategy follows the one for Table 2.5 and 2.6 column 3 .
} 
children in India have a significant effect. Its magnitude is smaller than the prior effect size.

The child health inputs do not show a clear birth order preference of Indian parents but rather an increase of child health investments in India in the recent years that benefited all children independent of their birth order. 
Table 2.7: Child Health Inputs (2004-2010)

\begin{tabular}{|c|c|c|c|c|c|c|c|c|}
\hline & \multicolumn{4}{|c|}{ Prenatal inputs } & \multicolumn{3}{|c|}{ Postnatal inputs } & \multirow[b]{2}{*}{$\begin{array}{c}\text { Average } \\
\text { pooled } \\
\text { inputs } \\
\text { (8) }\end{array}$} \\
\hline & $\begin{array}{c}\text { Total } \\
\text { prenatal } \\
\text { visits } \\
\text { (1) }\end{array}$ & $\begin{array}{l}\text { Mother } \\
\text { took iron } \\
\text { supple- } \\
\text { ments } \\
\text { (2) }\end{array}$ & $\begin{array}{l}\text { Mother's } \\
\text { total } \\
\text { tetanus } \\
\text { shots } \\
\text { (3) }\end{array}$ & $\begin{array}{c}\text { Delivery } \\
\text { at health } \\
\text { facility } \\
\text { (4) }\end{array}$ & $\begin{array}{c}\text { Postnatal } \\
\text { check } \\
\text { within } 2 \\
\text { months } \\
\text { (5) }\end{array}$ & $\begin{array}{c}\text { Child } \\
\text { taking } \\
\text { iron pills } \\
(6)\end{array}$ & $\begin{array}{c}\text { Child's } \\
\text { total vac- } \\
\text { cinations } \\
\text { (7) }\end{array}$ & \\
\hline India $\times 2$ nd child & $\begin{array}{c}-0.525 \\
{[0.052]}\end{array}$ & $\begin{array}{c}-0.031 \\
{[0.008]}\end{array}$ & $\begin{array}{c}-0.019 \\
{[0.018]}\end{array}$ & $\begin{array}{c}-0.040 \\
{[0.006]}\end{array}$ & $\begin{array}{c}-0.008 \\
{[0.013]}\end{array}$ & $\begin{array}{c}-0.008 \\
{[0.005]}\end{array}$ & $\begin{array}{l}-0.204 \\
{[0.039]}\end{array}$ & $\begin{array}{c}-0.011 \\
{[0.003]}\end{array}$ \\
\hline India $\times 3$ rd + child & $\begin{array}{c}-1.011 \\
{[0.060]}\end{array}$ & $\begin{array}{c}-0.072 \\
{[0.009]}\end{array}$ & $\begin{array}{c}-0.036 \\
{[0.021]}\end{array}$ & $\begin{array}{c}-0.092 \\
{[0.008]}\end{array}$ & $\begin{array}{c}0.015 \\
{[0.014]}\end{array}$ & $\begin{array}{c}-0.010 \\
{[0.006]}\end{array}$ & $\begin{array}{c}-0.462 \\
{[0.051]}\end{array}$ & $\begin{array}{c}-0.033 \\
{[0.004]}\end{array}$ \\
\hline 2nd child & $\begin{array}{c}-0.182 \\
{[0.029]}\end{array}$ & $\begin{array}{c}-0.014 \\
{[0.005]}\end{array}$ & $\begin{array}{c}-0.111 \\
{[0.013]}\end{array}$ & $\begin{array}{c}-0.088 \\
{[0.004]}\end{array}$ & $\begin{array}{c}0.004 \\
{[0.010]}\end{array}$ & $\begin{array}{c}-0.004 \\
{[0.004]}\end{array}$ & $\begin{array}{c}-0.097 \\
{[0.025]}\end{array}$ & $\begin{array}{c}-0.044 \\
{[0.002]}\end{array}$ \\
\hline $3 r d+$ child & $\begin{array}{c}-0.432 \\
{[0.033]}\end{array}$ & $\begin{array}{c}-0.031 \\
{[0.005]}\end{array}$ & $\begin{array}{c}-0.207 \\
{[0.014]}\end{array}$ & $\begin{array}{c}-0.133 \\
{[0.004]}\end{array}$ & $\begin{array}{c}-0.023 \\
{[0.011]}\end{array}$ & $\begin{array}{c}-0.014 \\
{[0.005]}\end{array}$ & $\begin{array}{c}-0.207 \\
{[0.030]}\end{array}$ & $\begin{array}{c}-0.071 \\
{[0.003]}\end{array}$ \\
\hline Africa mean of outcome & 3.847 & 0.622 & 1.415 & 0.472 & 0.302 & 0.113 & 6.245 & 0.380 \\
\hline India mean of outcome & 4.041 & 0.689 & 1.872 & 0.450 & 0.090 & 0.055 & 6.607 & 0.334 \\
\hline Age \& other controls & Yes & Yes & Yes & Yes & Yes & Yes & Yes & Yes \\
\hline Observations & 115,364 & 117,707 & 117,219 & 167,405 & 35,902 & 91,964 & 122,922 & 167,752 \\
\hline
\end{tabular}

Table 2.8: Child Health Inputs (2011-2017)

\begin{tabular}{|c|c|c|c|c|c|c|c|c|}
\hline & \multicolumn{4}{|c|}{ Prenatal inputs } & \multicolumn{3}{|c|}{ Postnatal inputs } & \multirow[b]{2}{*}{$\begin{array}{l}\text { Average } \\
\text { pooled } \\
\text { inputs } \\
\text { (8) }\end{array}$} \\
\hline & $\begin{array}{c}\text { Total } \\
\text { prenatal } \\
\text { visits } \\
\text { (1) }\end{array}$ & $\begin{array}{l}\text { Mother } \\
\text { took iron } \\
\text { supple- } \\
\text { ments } \\
\text { (2) }\end{array}$ & $\begin{array}{l}\text { Mother's } \\
\text { total } \\
\text { tetanus } \\
\text { shots } \\
\text { (3) }\end{array}$ & $\begin{array}{c}\text { Delivery } \\
\text { at health } \\
\text { facility } \\
\text { (4) }\end{array}$ & $\begin{array}{l}\text { Postnatal } \\
\text { check } \\
\text { within } 2 \\
\text { months } \\
\quad(5)\end{array}$ & $\begin{array}{c}\text { Child } \\
\text { taking } \\
\text { iron pills } \\
(6)\end{array}$ & $\begin{array}{l}\text { Child's } \\
\text { total vac- } \\
\text { cinations } \\
\text { (7) }\end{array}$ & \\
\hline India $\times 2$ nd child & $\begin{array}{c}-0.208 \\
{[0.030]}\end{array}$ & $\begin{array}{c}-0.016 \\
{[0.004]}\end{array}$ & $\begin{array}{c}0.085 \\
{[0.011]}\end{array}$ & $\begin{array}{c}0.008 \\
{[0.003]}\end{array}$ & $\begin{array}{c}0.006 \\
{[0.005]}\end{array}$ & $\begin{array}{c}-0.002 \\
{[0.003]}\end{array}$ & $\begin{array}{c}0.035 \\
{[0.045]}\end{array}$ & $\begin{array}{c}-0.003 \\
{[0.002]}\end{array}$ \\
\hline India $\times 3$ rd + child & $\begin{array}{c}-0.418 \\
{[0.035]}\end{array}$ & $\begin{array}{c}-0.031 \\
{[0.005]}\end{array}$ & $\begin{array}{c}0.115 \\
{[0.013]}\end{array}$ & $\begin{array}{c}-0.007 \\
{[0.004]}\end{array}$ & $\begin{array}{c}0.016 \\
{[0.006]}\end{array}$ & $\begin{array}{c}-0.011 \\
{[0.004]}\end{array}$ & $\begin{array}{c}-0.030 \\
{[0.054]}\end{array}$ & $\begin{array}{c}-0.009 \\
{[0.002]}\end{array}$ \\
\hline 2nd child & $\begin{array}{c}-0.231 \\
{[0.023]}\end{array}$ & $\begin{array}{c}-0.012 \\
{[0.004]}\end{array}$ & $\begin{array}{c}-0.178 \\
{[0.010]}\end{array}$ & $\begin{array}{c}-0.082 \\
{[0.003]}\end{array}$ & $\begin{array}{c}-0.017 \\
{[0.004]}\end{array}$ & $\begin{array}{c}-0.002 \\
{[0.002]}\end{array}$ & $\begin{array}{c}-0.173 \\
{[0.043]}\end{array}$ & $\begin{array}{c}-0.041 \\
{[0.002]}\end{array}$ \\
\hline 3rd + child & $\begin{array}{c}-0.466 \\
{[0.026]}\end{array}$ & $\begin{array}{c}-0.025 \\
{[0.004]}\end{array}$ & $\begin{array}{c}-0.253 \\
{[0.011]}\end{array}$ & $\begin{array}{c}-0.136 \\
{[0.003]}\end{array}$ & $\begin{array}{c}-0.032 \\
{[0.005]}\end{array}$ & $\begin{array}{c}-0.001 \\
{[0.002]}\end{array}$ & $\begin{array}{c}-0.310 \\
{[0.051]}\end{array}$ & $\begin{array}{c}-0.066 \\
{[0.002]}\end{array}$ \\
\hline Africa mean of outcome & 3.767 & 0.760 & 1.423 & 0.582 & 0.490 & 0.068 & 4.920 & 0.405 \\
\hline India mean of outcome & 4.193 & 0.771 & 1.908 & 0.760 & 0.358 & 0.230 & 7.298 & 0.463 \\
\hline Age \& other controls & Yes & Yes & Yes & Yes & Yes & Yes & Yes & Yes \\
\hline Observations & 287,302 & 282,486 & 281,157 & 397,406 & 272,650 & 374,185 & 215,976 & 397,636 \\
\hline
\end{tabular}

Notes: Standard errors are clustered by mother and appear in brackets. Control variables included are child age dummies, mother's literacy, maternal age, PSU fixed effects, and child age dummies, mother's literacy, and maternal age interacted with India. The main effect India is absorbed by PSU fixed effects. Total prenatal visits, mother took iron supplements, mother's total tetanus shots, and postnatal check within 2 months are only available for the youngest living child in the family; postnatal check within 2 months is collected in only 13 African surveys in Table 2.7. Delivery at health facility, child taking iron pills, and total vaccinations are available for all births in the past five years; child taking iron pills is collected in only ten African surveys; total vaccinations uses children ages 13-59 months, as the recommended age for some is up to 1 year. In column 8 , the average across four prenatal and three postnatal inputs is used to create the outcome. The dummies are (i) total prenatal visits $>3$; (ii) mother took iron supplements; (iii) mother's total tetanus shots $>2$; (iv) child was delivered at a health facility; (v) child is taking iron pills; (vi) total vaccinations $>8$; (vii) child had postnatal check within two months of birth.

Source: Adapted from J+P using data from IPUMS DHS (ICF, 2004) and DHS (Heger Boyle \& Sobek, 2019) 


\subsection{Child Gender and the Birth Order Gradient in Height}

Tables 2.9 and 2.10 examine whether children's birth order gradient can be traced back to parent's eldest son preference. We use the second equation introduced in section 3 that considers gender-specific gradients. The regression should test in particular the two predictions made by $\mathrm{J}+\mathrm{P}$ :

PREDICTION 1: Relative to African counterparts, both boys and girls in India will exhibit a steeper birth order gradient.

PREDICTION 2: The India-Africa height gap will be more pronounced among girls.

Prediction 1 could be observed because preferring the eldest son over all other sons would cause a steep birth order gradient for boys directly. For girls eldest son preference would lead to a steeper birth order gradient because parents would concentrate spending their resources on her older brother. Girls are also more likely to live in larger families with more siblings to compete for resources against because parents will only stop reproduction when having at least one son. The second prediction derives from two reasons. If elder sons are preferred to any other siblings, on average all sons would be receiving more investments than the average daughter. Further, the desire of bearing a son in Indian mothers is higher than in African mothers who only have given birth to girls before (Jayachandran \& Pande, 2017). So families will exceed their planned family size and so lack adequate resources for their children with a given budget.

Columns 1 to 4 examine prediction 1 whereas columns 5 to 8 investigate prediction 2 . In the first specification in column 1 only age dummies and interactions with Girl and India are used as control variables. In the earlier period (Table 2.9), there is a steep birth order gradient for girls and boys in India. However, the interactions of India, higher birth orders, and girl dummy are both statistically insignificant, though negative in sign. Eldest daughters have a negative association with height, unlike eldest sons. The eldest sons are 0.15 standard deviations taller in India than in Africa around 2005 but only 0.03 standard deviations taller around 2015. For boys, the birth order gradient in India is shallower in the more recent period than in the earlier one.

In column 2 additional covariates are added and in column 3 mother fixed effects are used that change only the magnitude of the birth order gradient for sons but not the significance. For the later period in column 2, the triple interaction of India, higher birth order, and girl dummy turns significant. In the later time period in column 3 the birth order gradient for girls turns around 
reducing the effect of being later born. However, the effects are not statistically significant. Column 4 with the same specification as column 2 considers now weight as an outcome. The birth order gradient for boys and girls is again visible and significant for sons in both tables. Only in the later time period around 2015 Indian higher birth order daughters have a significant association with weight. Overall, the birth order gradient for sons has become shallower for columns 2 to 4 overtime. Unlike for girls whose birth order gradient has become steeper in column 2 and column 4.

Now we turn to prediction 2 looking at gender bias in India. Column 5 has similar controls like column 1, column 6 like column 2, and column 7 like column 3. Column 8 looks at WFA $\mathrm{z}$-score just like column 4. In the time period around 2005, the India dummy in column 5 is insignificant and small in magnitude and the interaction of India and Girls is negative and significant in columns 5 to 8 . In the later time period, Indian daughters are still shorter and weigh less than their African peers but the magnitude is reduced compared to the time period around 2005. However, column 5 in the later time period diverges from the results in the earlier one: Indian sons are 0.07 standard deviations shorter on the 1 percent significant level. The average mother fixed effects in column 6 have different signs than in column 3: We have a negative and rather stable mean for Indian mother fixed effects but a positive average for African mother fixed effects which increases over time. Without adjusting for birth order children born to Indian mothers are less tall than those born to African mothers in general.

Overall the birth order gradient for boys has become much shallower over time raising doubts on eldest son preference. The situation for higher birth order girls seems to have worsened for height and weight outcomes. The results on son preference show that on average sons in India are disadvantaged compared to their African counterparts. 
Table 2.9: Child Gender and the Birth Order Gradient in Height (2004-2010)

\begin{tabular}{|c|c|c|c|c|c|c|c|c|}
\hline & $\begin{array}{l}\text { HFA } \\
\text { Z-score } \\
\quad(1)\end{array}$ & $\begin{array}{l}\text { HFA } \\
\text { z-score } \\
\text { (2) }\end{array}$ & $\begin{array}{c}\text { HFA } \\
\text { z-score } \\
\text { (3) }\end{array}$ & $\begin{array}{l}\text { WFA } \\
\text { z-score } \\
\text { (4) }\end{array}$ & $\begin{array}{l}\text { HFA } \\
\text { z-score } \\
\text { (5) }\end{array}$ & $\begin{array}{l}\text { HFA } \\
\text { z-score } \\
(6)\end{array}$ & $\begin{array}{l}\text { HFA } \\
\text { z-score } \\
\text { (7) }\end{array}$ & $\begin{array}{c}\text { WFA } \\
\text { z-score } \\
(8)\end{array}$ \\
\hline India & $\begin{array}{c}0.148 \\
{[0.026]}\end{array}$ & & & & $\begin{array}{l}-0.011 \\
{[0.014]}\end{array}$ & & & \\
\hline India $\times$ Girl & $\begin{array}{c}-0.112 \\
{[0.036]}\end{array}$ & & & & $\begin{array}{l}-0.143 \\
{[0.020]}\end{array}$ & $\begin{array}{l}-0.147 \\
{[0.019]}\end{array}$ & $\begin{array}{c}-0.098 \\
{[0.032]}\end{array}$ & $\begin{array}{l}-0.116 \\
{[0.014]}\end{array}$ \\
\hline India $\times 2$ nd child & $\begin{array}{l}-0.107 \\
{[0.036]}\end{array}$ & $\begin{array}{l}-0.153 \\
{[0.040]}\end{array}$ & $\begin{array}{l}-0.228 \\
{[0.069]}\end{array}$ & $\begin{array}{l}-0.122 \\
{[0.030]}\end{array}$ & & & & \\
\hline India $\times 3$ rd + child & $\begin{array}{l}-0.352 \\
{[0.033]}\end{array}$ & $\begin{array}{l}-0.222 \\
{[0.047]}\end{array}$ & $\begin{array}{l}-0.414 \\
{[0.097]}\end{array}$ & $\begin{array}{l}-0.176 \\
{[0.035]}\end{array}$ & & & & \\
\hline India $\times 2$ nd child $\times$ Girl & $\begin{array}{l}-0.077 \\
{[0.053]}\end{array}$ & $\begin{array}{l}-0.045 \\
{[0.057]}\end{array}$ & $\begin{array}{l}-0.024 \\
{[0.101]}\end{array}$ & $\begin{array}{l}-0.047 \\
{[0.042]}\end{array}$ & & & & \\
\hline India $\times 3$ rd + child $\times$ Girl & $\begin{array}{l}-0.051 \\
{[0.047]}\end{array}$ & $\begin{array}{l}-0.048 \\
{[0.067]}\end{array}$ & $\begin{array}{l}-0.030 \\
{[0.092]}\end{array}$ & $\begin{array}{l}-0.063 \\
{[0.049]}\end{array}$ & & & & \\
\hline 2nd child & $\begin{array}{c}0.023 \\
{[0.022]}\end{array}$ & $\begin{array}{l}-0.005 \\
{[0.026]}\end{array}$ & $\begin{array}{l}-0.202 \\
{[0.041]}\end{array}$ & $\begin{array}{c}0.006 \\
{[0.019]}\end{array}$ & & & & \\
\hline $3 r d+$ child & $\begin{array}{l}-0.057 \\
{[0.019]}\end{array}$ & $\begin{array}{l}-0.113 \\
{[0.029]}\end{array}$ & $\begin{array}{l}-0.355 \\
{[0.052]}\end{array}$ & $\begin{array}{l}-0.069 \\
{[0.021]}\end{array}$ & & & & \\
\hline Africa mean of outcome & -1.351 & -1.351 & -1.351 & -0.877 & -1.351 & -1.351 & -1.351 & -0.877 \\
\hline Age \& other controls & No & Yes & No & Yes & No & Yes & No & Yes \\
\hline $\begin{array}{l}\text { Mother FEs } \\
\text { Africa mean } \\
\text { India mean }\end{array}$ & No & No & $\begin{array}{c}\text { Yes } \\
-0.031 \\
0.102\end{array}$ & No & No & No & $\begin{array}{c}\text { Yes } \\
0.028 \\
-0.092\end{array}$ & No \\
\hline Observations & 168,135 & 165,623 & 83,243 & 165,623 & 168,135 & 167,765 & 83,243 & 167,765 \\
\hline
\end{tabular}

Table 2.10: Child Gender and the Birth Order Gradient in Height (2011-2017)

\begin{tabular}{|c|c|c|c|c|c|c|c|c|}
\hline & $\begin{array}{l}\text { HFA } \\
\text { z-score } \\
(1)\end{array}$ & $\begin{array}{l}\text { HFA } \\
\text { z-score } \\
\text { (2) }\end{array}$ & $\begin{array}{l}\text { HFA } \\
\text { z-score } \\
\text { (3) }\end{array}$ & $\begin{array}{l}\text { WFA } \\
\text { Z-score } \\
\text { (4) }\end{array}$ & $\begin{array}{l}\text { HFA } \\
\text { z-score } \\
\text { (5) }\end{array}$ & $\begin{array}{l}\text { HFA } \\
\text { z-score } \\
\text { (6) }\end{array}$ & $\begin{array}{c}\text { HFA } \\
\text { z-score } \\
(7)\end{array}$ & $\begin{array}{c}\text { WFA } \\
\text { z-score } \\
(8)\end{array}$ \\
\hline India & $\begin{array}{c}0.028 \\
{[0.014]}\end{array}$ & & & & $\begin{array}{l}-0.068 \\
{[0.008]}\end{array}$ & & & \\
\hline India $\times$ Girl & $\begin{array}{l}-0.091 \\
{[0.020]}\end{array}$ & & & & $\begin{array}{c}-0.076 \\
{[0.011]}\end{array}$ & $\begin{array}{c}-0.072 \\
{[0.010]}\end{array}$ & $\begin{array}{l}-0.055 \\
{[0.018]}\end{array}$ & $\begin{array}{c}-0.044 \\
{[0.008]}\end{array}$ \\
\hline India $\times 2$ nd child & $\begin{array}{c}-0.100 \\
{[0.021]}\end{array}$ & $\begin{array}{l}-0.043 \\
{[0.023]}\end{array}$ & $\begin{array}{l}-0.181 \\
{[0.040]}\end{array}$ & $\begin{array}{c}-0.062 \\
{[0.017]}\end{array}$ & & & & \\
\hline India $\times 3 r d+$ child & $\begin{array}{l}-0.271 \\
{[0.019]}\end{array}$ & $\begin{array}{l}-0.066 \\
{[0.027]}\end{array}$ & $\begin{array}{c}-0.349 \\
{[0.056]}\end{array}$ & $\begin{array}{l}-0.090 \\
{[0.020]}\end{array}$ & & & & \\
\hline India $\times 2$ nd child $\times$ Girl & $\begin{array}{c}-0.011 \\
{[0.030]}\end{array}$ & $\begin{array}{l}-0.057 \\
{[0.033]}\end{array}$ & $\begin{array}{c}0.029 \\
{[0.057]}\end{array}$ & $\begin{array}{l}-0.048 \\
{[0.025]}\end{array}$ & & & & \\
\hline India $\times$ 3rd + child $\times$ Girl & $\begin{array}{c}-0.002 \\
{[0.026]}\end{array}$ & $\begin{array}{l}-0.094 \\
{[0.038]}\end{array}$ & $\begin{array}{c}0.054 \\
{[0.053]}\end{array}$ & $\begin{array}{l}-0.074 \\
{[0.028]}\end{array}$ & & & & \\
\hline 2nd child & $\begin{array}{c}0.023 \\
{[0.017]}\end{array}$ & $\begin{array}{l}-0.049 \\
{[0.019]}\end{array}$ & $\begin{array}{c}-0.156 \\
{[0.031]}\end{array}$ & $\begin{array}{l}-0.010 \\
{[0.015]}\end{array}$ & & & & \\
\hline $3 \mathrm{rd}+$ child & $\begin{array}{l}-0.067 \\
{[0.014]}\end{array}$ & $\begin{array}{l}-0.144 \\
{[0.021]}\end{array}$ & $\begin{array}{c}-0.286 \\
{[0.039]}\end{array}$ & $\begin{array}{l}-0.074 \\
{[0.016]}\end{array}$ & & & & \\
\hline Africa mean of outcome & -1.110 & -1.110 & -1.110 & -0.858 & -1.110 & -1.110 & -1.110 & -0.858 \\
\hline Age \& other controls & No & Yes & No & Yes & No & Yes & No & Yes \\
\hline $\begin{array}{l}\text { Mother FEs } \\
\text { Africa mean } \\
\text { India mean }\end{array}$ & No & No & $\begin{array}{c}\text { Yes } \\
-0.039 \\
0.034\end{array}$ & No & No & No & $\begin{array}{c}\text { Yes } \\
0.100 \\
-0.086\end{array}$ & No \\
\hline Observations & 398,710 & 390,071 & 189,520 & 390,071 & 398,710 & 397,702 & $\begin{array}{l}-0.000 \\
189,520\end{array}$ & 397,702 \\
\hline
\end{tabular}

Notes: Standard errors are clustered by mother and appear in brackets. Child age dummies are included in all regressions. Columns 2, 4, 6, and 8 additionally include mother's literacy, maternal age, and PSU fixed effects. In columns 2 and 4, child age dummies, maternal age, and mother's literacy are interacted with Girl, India, and India $\times$ Girl and PSU fixed effects are interacted with Girl. In columns 3 and 7, the main effect India is absorbed by mother fixed effects. In columns 2 and 4, the main effects India and India $\times$ Girl are absorbed by PSU fixed effects and their interactions with Girl. In columns 6 and 8, the main effect of India is absorbed by PSU fixed effects. The main effect of Girl is included in all regressions but not shown. In columns 1-3, coefficients for 2nd child and 3rd+ child, 2nd child $\times$ Girl, and 3rd + child $\times$ Girl are included in the regression but not shown.

Source: Adapted from J+P using data from IPUMS DHS (ICF, 2004) and DHS (Heger Boyle \& Sobek, 2019) 


\subsection{Impact on Average Height - Accounting exercise}

Just like $\mathrm{J}+\mathrm{P}$ we turn now from an examination of the inequality across children to two backof-the-envelope calculations. We assess to what degree the birth order gradient in general and the birth order gradient driven by eldest son preference explain the average height gap between India and Africa. J+P generate two gradient proxies.

The first is the average height gap between first-borns and children with birth order two or higher that is weighted by the observed country-specific or region-specific birth order distribution (Table 2.11 and 2.12 column 2). The second gradient proxy is defined as the regression coefficient of a linear birth order variable (with the highest value three for third or higher birth order children) when estimating height for each country or region separately (column 3). Age dummies as well as GDP per capita in the child's birth year are included as control variables. The second approach comes closest to the presented regression tables, however, it implies linearity unlike the first approach.

Comparing the two different time periods, we find that the magnitude for India in column 1 has increased and the magnitude of the gradient proxy in column 2 has slightly increased over time. The magnitude of the gradient proxy in column 3 has halved in the later compared to the earlier time period but is not significant around 2015 .

The estimates are then used to calculate the share explained by birth order gradient in general and by birth order gradient rooted in eldest son preference in Table 2.13 and 2.14. ${ }^{7}$

The height gap, the explained amount of the height gap by the birth order gradient and by the birth order gradient driven via son preference have decreased in both accounting exercises. In the earlier period (Table 2.13), the birth order gradient accounts for 67 percent of the height gap but in the later time period only for 33 percent. The birth order gradient rooted in eldest son preference also loses its explanatory power over time from 33 percent to 19 percent. A similar decrease is visible in Accounting Exercise 2, however, the proxy estimated in the later time period column 3 is not significant.

The accounting exercises emphasize our finding that the eldest son preference hypothesis is not as clearly visible as in the period around 2005. This is why we first want to reassess whether the differing sampling strategy of NFHS 3 to NFHS 4 might play a role in the diverging outcomes. Thus, we weigh the data as described in section 3 to make data sets representative on the national and world level.

\footnotetext{
${ }^{7} \mathrm{~J}+\mathrm{P}$ provide a more detailed explanation of the calculation exercise.
} 
Table 2.11: Accounting Exercise Part 1: Sample Comparison (2004-2010)

\begin{tabular}{|c|c|c|c|}
\hline & & $\begin{array}{l}\text { Accounting } \\
\text { Exercise } 1\end{array}$ & $\begin{array}{l}\text { Accounting } \\
\text { Exercise } 2\end{array}$ \\
\hline & $\begin{array}{c}\text { HFA z-score } \\
\text { (1) }\end{array}$ & $\begin{array}{c}\text { HFA z-score } \\
\text { (2) }\end{array}$ & $\begin{array}{c}\text { HFA z-score } \\
\text { (3) }\end{array}$ \\
\hline India & $\begin{array}{c}-0.162 \\
{[0.017]}\end{array}$ & & \\
\hline Gradient proxy & & $\begin{array}{c}0.412 \\
{[0.069]}\end{array}$ & $\begin{array}{c}0.704 \\
{[0.131]}\end{array}$ \\
\hline \multicolumn{4}{|l|}{ Mean of gradient proxy } \\
\hline India & & -0.331 & -0.234 \\
\hline Africa & & -0.066 & -0.037 \\
\hline Kerala \& Northeast & & -0.229 & -0.155 \\
\hline Rest of India & & -0.358 & -0.257 \\
\hline Log GDP per capita & Yes & Yes & Yes \\
\hline Sample & Full & Africa & Africa \\
\hline Observations & 168,135 & 126,066 & 126,066 \\
\hline
\end{tabular}

Table 2.12: Accounting Exercise Part 1: Sample Comparison (2011-2017)

\begin{tabular}{|c|c|c|c|}
\hline & & $\begin{array}{l}\text { Accounting } \\
\text { Exercise } 1\end{array}$ & $\begin{array}{l}\text { Accounting } \\
\text { Exercise } 2\end{array}$ \\
\hline & $\begin{array}{c}\text { HFA z-score } \\
\text { (1) }\end{array}$ & $\begin{array}{c}\text { HFA z-score } \\
\text { (2) }\end{array}$ & $\begin{array}{c}\text { HFA z-score } \\
\text { (3) }\end{array}$ \\
\hline India & $\begin{array}{c}-0.186 \\
{[0.015]}\end{array}$ & & \\
\hline Gradient proxy & & $\begin{array}{c}0.431 \\
{[0.123]}\end{array}$ & $\begin{array}{c}0.375 \\
{[0.187]}\end{array}$ \\
\hline \multicolumn{4}{|l|}{ Mean of gradient proxy } \\
\hline India & & -0.251 & -0.192 \\
\hline Africa & & -0.107 & -0.070 \\
\hline Kerala \& Northeast & & -0.182 & -0.142 \\
\hline Rest of India & & -0.264 & -0.203 \\
\hline Log GDP per capita & Yes & Yes & Yes \\
\hline Sample & Full & Africa & Africa \\
\hline Observations & 398,710 & 168,490 & 168,490 \\
\hline
\end{tabular}


Table 2.13: Accounting Exercise Part 2: Sample Comparison (2004-2010)

Accounting Accounting

Exercise $1 \quad$ Exercise 2

Calculation 1: Share explained by birth order gradient

- India-Africa gap in birth order gradient $\quad-0.265$

$-0.197$

- India-Africa gap in birth order gradient $\times$ Gradient coeff

$-0.109 \quad-0.139$

- Explained share of India-Africa level gap in height (shown in column 1)

$67 \%$

$86 \%$

Calculation 2: Share explained by birth order gradient rooted in eldest son preference

- Rest of India - Kerala \& NE gap in birth order gradient

$-0.129-0.102$

- Rest of India - Kerala \& NE gap in birth order gradient $\times$ Gradient coff

$-0.053$

$-0.072$

- Explained share of India-Africa level gap in height (shown in column 1)

$33 \%$

$44 \%$

Table 2.14: Accounting Exercise Part 2: Sample Comparison (2010-2017)

Accounting Accounting

Exercise 1

Exercise 2

Calculation 1: Share explained by birth order gradient

- India-Africa gap in birth order gradient

$-0.144$

$-0.122$

- India-Africa gap in birth order gradient $\times$ Gradient coeff

$-0.062$

$-0.046$

- Explained share of India-Africa level gap in height (shown in column 1)

$33 \%$

$25 \%$

Calculation 2: Share explained by birth order gradient rooted in eldest son preference

- Rest of India - Kerala \& NE gap in birth order gradient

- Rest of India - Kerala \& NE gap in birth order gradient $\times$ Gradient coff

$-0.035$

$-0.023$

- Explained share of India-Africa level gap in height (shown in column 1)

$19 \%$

$12 \%$

Source: Adapted from J+P using data from IPUMS DHS (ICF, 2004) and DHS (Heger Boyle \& Sobek, 2019) 


\section{Replication Results (2004-2010): Weighted}

In this section, we will focus on new methodology but the same sample of J+P 2004 to 2010. We compare the results for the time period of 2004 to 2010 that are weighted by the suggested DHS mother sample weight for India for the regression analysis. Weighing matters and the importance of birth order diminishes. We also show the regression results weighing both India and Africa in the appendix. When using summary statistics in this section we adjust both the Indian and African sample to mother sampling weights and the number of surveys included. ${ }^{8}$ We concentrate on reporting the most important results here; all other results of the new methodology using the data of the original time period around 2005 are only shown in the appendix.

\subsection{Summary Statistics}

Even when we only consider the time period of 2004 to 2010, the values of the selected summary statistics for India and Africa differ in the unweighted sample (Table 2.15) to the weighted sample (Table 2.16). After weighing and adjusting mother's age at birth, mother's literacy, mother's total prenatal visits, child's HFA z-score, child's WFA z-score, child's hemoglobin level, child's number of vaccinations, and birth spacing have decreased in the Indian sample. For the number of prenatal visits, India is not surpassing Africa as in the unweighted data and for mother's literacy, and child's hemoglobin level India has now only a 0.01 larger value than the African sample. In the Indian sample values for mother's total children born, child's birth order, and open defecation are higher in the weighted than in the unweighted sample. The increase is particularly dramatic for open defecation: in the unweighted sample 46 percent of children live in households without any sanitation facility; in the weighted sample this is the case for 63 percent. For the African sample, only child's total vaccination and birth spacing are 0.01 units lower than in the unweighted sample. Adjusting the sample with weights draws a less rosy picture of India in 2004 to 2010.

\footnotetext{
${ }^{8}$ You can find the only India weighted data in the appendix for the summary statistics and the figures in this chapter.
} 
Table 2.15: Summary Statistics (2004-2010): Unweighted

\begin{tabular}{|c|c|c|c|c|c|}
\hline & $\begin{array}{c}\text { India } \\
\text { subsample }\end{array}$ & $\begin{array}{c}\text { Africa } \\
\text { subsample }\end{array}$ & & $\begin{array}{c}\text { India } \\
\text { subsample }\end{array}$ & $\begin{array}{c}\text { Africa } \\
\text { subsample }\end{array}$ \\
\hline Mother's age at birth (years) & $\begin{array}{l}24.75 \\
{[5.23]}\end{array}$ & $\begin{array}{l}26.96 \\
{[6.86]}\end{array}$ & Child's age (months) & $\begin{array}{c}30.20 \\
{[16.90]}\end{array}$ & $\begin{array}{c}28.27 \\
{[17.06]}\end{array}$ \\
\hline Mother's total children born & $\begin{array}{c}2.74 \\
{[1.82]}\end{array}$ & $\begin{array}{c}3.88 \\
{[2.54]}\end{array}$ & Child is a girl & $\begin{array}{c}0.48 \\
{[0.50]}\end{array}$ & $\begin{array}{c}0.50 \\
{[0.50]}\end{array}$ \\
\hline Mother's desired fertility & $\begin{array}{c}2.47 \\
{[0.96]}\end{array}$ & $\begin{array}{c}4.62 \\
{[1.47]}\end{array}$ & Child's birth order & $\begin{array}{c}2.62 \\
{[1.80]}\end{array}$ & $\begin{array}{c}3.74 \\
{[2.48]}\end{array}$ \\
\hline Mother wants more children & $\begin{array}{c}0.34 \\
{[0.47]}\end{array}$ & $\begin{array}{c}0.67 \\
{[0.46]}\end{array}$ & Child's HFA z-score & $\begin{array}{l}-1.51 \\
{[1.81]}\end{array}$ & $\begin{array}{l}-1.35 \\
{[1.94]}\end{array}$ \\
\hline Mother completed her fertility & $\begin{array}{c}0.67 \\
{[0.47]}\end{array}$ & $\begin{array}{c}0.33 \\
{[0.47]}\end{array}$ & Child is stunted & $\begin{array}{c}0.40 \\
{[0.49]}\end{array}$ & $\begin{array}{c}0.38 \\
{[0.48]}\end{array}$ \\
\hline Mother is literate & $\begin{array}{c}0.58 \\
{[0.49]}\end{array}$ & $\begin{array}{c}0.49 \\
{[0.50]}\end{array}$ & Child's WFA z-score & $\begin{array}{l}-1.53 \\
{[1.33]}\end{array}$ & $\begin{array}{c}-0.88 \\
{[1.42]}\end{array}$ \\
\hline Mother's height (meters) & $\begin{array}{c}1.52 \\
{[0.06]}\end{array}$ & $\begin{array}{c}1.58 \\
{[0.07]}\end{array}$ & Child's hemoglobin level (g/dl) & $\begin{array}{c}10.28 \\
{[1.57]}\end{array}$ & $\begin{array}{c}10.15 \\
{[1.68]}\end{array}$ \\
\hline Mother took iron supplements & $\begin{array}{c}0.69 \\
{[0.46]}\end{array}$ & $\begin{array}{c}0.62 \\
{[0.49]}\end{array}$ & Child is deceased & $\begin{array}{c}0.05 \\
{[0.22]}\end{array}$ & $\begin{array}{c}0.07 \\
{[0.26]}\end{array}$ \\
\hline Mother's total tetanus shots & $\begin{array}{c}1.87 \\
{[0.94]}\end{array}$ & $\begin{array}{c}1.41 \\
{[1.20]}\end{array}$ & Child taking iron pills & $\begin{array}{c}0.06 \\
{[0.23]}\end{array}$ & $\begin{array}{c}0.11 \\
{[0.32]}\end{array}$ \\
\hline Total prenatal visits & $\begin{array}{c}4.04 \\
{[3.48]}\end{array}$ & $\begin{array}{c}3.85 \\
{[3.07]}\end{array}$ & Child's total vaccinations & $\begin{array}{c}6.61 \\
{[2.80]}\end{array}$ & $\begin{array}{c}6.24 \\
{[3.12]}\end{array}$ \\
\hline Delivery at health facility & $\begin{array}{c}0.45 \\
{[0.50]}\end{array}$ & $\begin{array}{c}0.47 \\
{[0.50]}\end{array}$ & Birth spacing (months) & $\begin{array}{c}36.16 \\
{[20.32]}\end{array}$ & $\begin{array}{c}38.69 \\
{[20.63]}\end{array}$ \\
\hline Postnatal check within 2 months & $\begin{array}{c}0.09 \\
{[0.29]}\end{array}$ & $\begin{array}{c}0.30 \\
{[0.46]}\end{array}$ & Diarrhea in last 2 weeks & $\begin{array}{c}0.09 \\
{[0.29]}\end{array}$ & $\begin{array}{c}0.16 \\
{[0.36]}\end{array}$ \\
\hline Average pooled inputs & $\begin{array}{c}0.33 \\
{[0.28]}\end{array}$ & $\begin{array}{c}0.38 \\
{[0.30]}\end{array}$ & Open defecation & $\begin{array}{c}0.46 \\
{[0.50]}\end{array}$ & $\begin{array}{c}0.32 \\
{[0.47]}\end{array}$ \\
\hline Percent non-resident among children & $\begin{array}{c}0.02 \\
{[0.04]}\end{array}$ & $\begin{array}{c}0.10 \\
{[0.08]}\end{array}$ & Number of PSUs & 3,822 & 10,366 \\
\hline Number of adult females in household & $\begin{array}{c}1.85 \\
{[1.09]}\end{array}$ & $\begin{array}{c}1.60 \\
{[1.06]}\end{array}$ & Main sample of children & 42,069 & 126,066 \\
\hline Log GDP per capita (in child's birth year) & $\begin{array}{c}7.78 \\
{[0.10]}\end{array}$ & $\begin{array}{c}7.36 \\
{[0.65]}\end{array}$ & Main sample of children & 42,069 & 126,066 \\
\hline
\end{tabular}

Notes: The means of the specified variables are calculated separately for the India and Africa subsamples. Standard deviations appear in brackets. Please consider the notes in Table 2.3 for further explanations.

Source: Adapted from J+P using data from DHS (Heger Boyle \& Sobek, 2019) 
Table 2.16: Summary Statistics (2004-2010): Weighted

\begin{tabular}{|c|c|c|c|c|c|}
\hline & $\begin{array}{c}\text { India } \\
\text { subsample }\end{array}$ & $\begin{array}{c}\text { Africa } \\
\text { subsample }\end{array}$ & & $\begin{array}{c}\text { India } \\
\text { subsample }\end{array}$ & $\begin{array}{c}\text { Africa } \\
\text { subsample }\end{array}$ \\
\hline Mother's age at birth (years) & $\begin{array}{l}24.25 \\
{[5.19]}\end{array}$ & $\begin{array}{l}26.95 \\
{[6.85]}\end{array}$ & Child's age (months) & $\begin{array}{c}30.18 \\
{[17.01]}\end{array}$ & $\begin{array}{c}28.26 \\
{[17.05]}\end{array}$ \\
\hline Mother's total children born & $\begin{array}{c}2.87 \\
{[1.91]}\end{array}$ & $\begin{array}{c}3.90 \\
{[2.55]}\end{array}$ & Child is a girl & $\begin{array}{c}0.48 \\
{[0.50]}\end{array}$ & $\begin{array}{c}0.50 \\
{[0.50]}\end{array}$ \\
\hline Mother's desired fertility & $\begin{array}{c}2.45 \\
{[0.89]}\end{array}$ & $\begin{array}{c}4.62 \\
{[1.46]}\end{array}$ & Child's birth order & $\begin{array}{c}2.74 \\
{[1.88]}\end{array}$ & $\begin{array}{c}3.75 \\
{[2.48]}\end{array}$ \\
\hline Mother wants more children & $\begin{array}{c}0.34 \\
{[0.47]}\end{array}$ & $\begin{array}{c}0.67 \\
{[0.46]}\end{array}$ & Child's HFA z-score & $\begin{array}{l}-1.67 \\
{[1.80]}\end{array}$ & $\begin{array}{l}-1.36 \\
{[1.96]}\end{array}$ \\
\hline Mother completed her fertility & $\begin{array}{c}0.67 \\
{[0.47]}\end{array}$ & $\begin{array}{c}0.33 \\
{[0.47]}\end{array}$ & Child is stunted & $\begin{array}{c}0.45 \\
{[0.50]}\end{array}$ & $\begin{array}{c}0.38 \\
{[0.49]}\end{array}$ \\
\hline Mother is literate & $\begin{array}{c}0.49 \\
{[0.50]}\end{array}$ & $\begin{array}{c}0.48 \\
{[0.50]}\end{array}$ & Child's WFA z-score & $\begin{array}{l}-1.70 \\
{[1.30]}\end{array}$ & $\begin{array}{l}-0.89 \\
{[1.44]}\end{array}$ \\
\hline Mother's height (meters) & $\begin{array}{c}1.52 \\
{[0.06]}\end{array}$ & $\begin{array}{c}1.58 \\
{[0.07]}\end{array}$ & Child's hemoglobin level (g/dl) & $\begin{array}{l}10.10 \\
{[1.56]}\end{array}$ & $\begin{array}{l}10.11 \\
{[1.70]}\end{array}$ \\
\hline Mother took iron supplements & $\begin{array}{c}0.66 \\
{[0.47]}\end{array}$ & $\begin{array}{c}0.62 \\
{[0.49]}\end{array}$ & Child is deceased & $\begin{array}{c}0.06 \\
{[0.23]}\end{array}$ & $\begin{array}{c}0.07 \\
{[0.26]}\end{array}$ \\
\hline Mother's total tetanus shots & $\begin{array}{c}1.86 \\
{[0.95]}\end{array}$ & $\begin{array}{c}1.41 \\
{[1.21]}\end{array}$ & Child taking iron pills & $\begin{array}{c}0.05 \\
{[0.21]}\end{array}$ & $\begin{array}{c}0.13 \\
{[0.34]}\end{array}$ \\
\hline Total prenatal visits & $\begin{array}{c}3.49 \\
{[3.32]}\end{array}$ & $\begin{array}{c}3.87 \\
{[3.28]}\end{array}$ & Child's total vaccinations & $\begin{array}{c}6.42 \\
{[2.75]}\end{array}$ & $\begin{array}{c}6.14 \\
{[3.17]}\end{array}$ \\
\hline Delivery at health facility & $\begin{array}{c}0.39 \\
{[0.49]}\end{array}$ & $\begin{array}{c}0.47 \\
{[0.50]}\end{array}$ & Birth spacing (months) & $\begin{array}{c}35.43 \\
{[19.42]}\end{array}$ & $\begin{array}{c}38.43 \\
{[20.43]}\end{array}$ \\
\hline Postnatal check within 2 months & $\begin{array}{c}0.08 \\
{[0.28]}\end{array}$ & $\begin{array}{c}0.32 \\
{[0.47]}\end{array}$ & Diarrhea in last 2 weeks & $\begin{array}{c}0.09 \\
{[0.29]}\end{array}$ & $\begin{array}{c}0.16 \\
{[0.37]}\end{array}$ \\
\hline Average pooled inputs & $\begin{array}{c}0.30 \\
{[0.27]}\end{array}$ & $\begin{array}{c}0.38 \\
{[0.31]}\end{array}$ & Open defecation & $\begin{array}{c}0.63 \\
{[0.48]}\end{array}$ & $\begin{array}{c}0.32 \\
{[0.47]}\end{array}$ \\
\hline Percent non-resident among children & $\begin{array}{c}0.02 \\
{[0.03]}\end{array}$ & $\begin{array}{c}0.09 \\
{[0.08]}\end{array}$ & Number of PSUs & 3,822 & 10,366 \\
\hline Number of adult females in household & $\begin{array}{c}1.89 \\
{[1.11]}\end{array}$ & $\begin{array}{c}1.59 \\
{[1.05]}\end{array}$ & Main sample of children & 42,069 & 126,066 \\
\hline Log GDP per capita (in child's birth year) & $\begin{array}{c}7.77 \\
{[0.10]}\end{array}$ & $\begin{array}{c}7.35 \\
{[0.67]}\end{array}$ & Main sample of children & 42,069 & 126,066 \\
\hline
\end{tabular}

Notes: The means of the specified variables are calculated separately for the India and Africa subsamples. Standard deviations appear in brackets. Please consider the notes in Table 2.3 for further explanations.

Source: Adapted from J+P using data from DHS (Heger Boyle \& Sobek, 2019)

\subsection{Summary of Results for India's Differential Birth Order Gradient and Gender for Child Health and Related Outcomes}

The pattern of HFA z-score is now analyzed using regressions to be able to compare the differences in the unweighted sample (Table 2.17) and the weighted sample (Table 2.18). The weighted and unweighted results in column 1 are the same. Children in India seem worse off compared to African children.

If we examine the differences in height based on the birth order (weighing also the Africa sample), we see in Figure 2.4 that the Indian deficit does not only affect children of second-andhigher birth order but also firstborns in the weighted data. Additionally, the gap between Indian and African children is wider for second birth and higher birth order children in the weighted 
sample. In the weighted sample first-born African children are not as tall as their second-born siblings but shorter. Weighing the data reveals that all children in India, not even the eldest child, independent of their birth order are shorter than in Africa.

When disaggregating the regression results by birth order, we find that the Indian height disadvantage affects all Indian children independent of their birth order. Even a firstborn in India is on average 0.09 standard deviations shorter than its African peer, not 0.09 standard deviations taller than in the unweighted model (Table 2.17). This height disadvantage is even stronger for second-born Indian children with -0.11 and third-born ones with -0.36 in the weighted model. All coefficients are statistically significant on the 1 percent significance level. However, the birth order gradient is less steep in India in the weighted model compared to the unweighted one.

Similarly, the main specification in column 3 shows a slightly more muted birth order gradient for India in the weighted sample compared to the unweighted one.

Column 4 hardly changes when weighing the data whereas the Indian birth order gradient increases in the model with mother fixed effects in column 5.

Columns 6 to 9 focus on other health outcomes that are also likely to be affected by birth order driven parental investment decisions. The birth order gradient is more muted in the likelihood of stunting and WFA z-scores, is slightly increased for hemoglobin, and is absent for deceased as an outcome.

Overall, the steep birth order gradient found in the study by $\mathrm{J}+\mathrm{P}$ is usually shallower in the weighted sample. A particular preference for Indian first-borns in form of a positive birth order effect is not detectable. This puts a particular first-birth order preference of Indian parents into question, even for the time period around 2005.

Further, changes for child health inputs when weighing the data do not follow a clear pattern but introduce only slight changes in magnitude. ${ }^{9}$

Moreover, we also reassess the two predictions that hypothesize differential effects for girls and boys. ${ }^{10}$ We find that the India dummy is always negative for the weighted data and Indian girls are generally worse of than their African peers. The birth order effect of second birth order children reduces in magnitude and the one of third-or-higher born children increases. The general Indian birth order changes for the specification of completed fertility and mother fixed effects just like for the displayed table pair.

\footnotetext{
${ }^{9}$ The results are displayed in the appendix.

${ }^{10}$ The regression results can be found in the appendix.
} 
Table 2.17: India's Differential Birth Order Gradient in Child Height and Related Outcomes (2004-2010): Unweighted

\begin{tabular}{|c|c|c|c|c|c|c|c|c|c|}
\hline & $\begin{array}{l}\text { HFA } \\
\text { Z- } \\
\text { score } \\
(1)\end{array}$ & $\begin{array}{l}\text { HFA } \\
\text { Z- } \\
\text { score } \\
(2)\end{array}$ & $\begin{array}{l}\text { HFA } \\
\text { Z- } \\
\text { score } \\
(3)\end{array}$ & $\begin{array}{l}\text { HFA } \\
\text { Z- } \\
\text { score } \\
(4)\end{array}$ & $\begin{array}{l}\text { HFA } \\
\text { Z- } \\
\text { score } \\
(5)\end{array}$ & $\begin{array}{l}\text { Stunted } \\
\text { (6) }\end{array}$ & $\begin{array}{l}\text { WFA } \\
\text { Z- } \\
\text { score } \\
(7)\end{array}$ & $\begin{array}{l}\mathrm{Hb} \\
\text { level } \\
(8)\end{array}$ & $\begin{array}{l}\text { Deceased } \\
\text { (9) }\end{array}$ \\
\hline India & $\begin{array}{l}-0.083 \\
{[0.011]}\end{array}$ & $\begin{array}{c}0.092 \\
{[0.018]}\end{array}$ & & & & & & & \\
\hline India $\times 2$ nd child & & $\begin{array}{l}-0.144 \\
{[0.025]}\end{array}$ & $\begin{array}{l}-0.161 \\
{[0.027]}\end{array}$ & $\begin{array}{l}-0.110 \\
{[0.063]}\end{array}$ & $\begin{array}{l}-0.243 \\
{[0.048]}\end{array}$ & $\begin{array}{c}0.051 \\
{[0.007]}\end{array}$ & $\begin{array}{l}-0.147 \\
{[0.020]}\end{array}$ & $\begin{array}{l}-0.094 \\
{[0.030]}\end{array}$ & $\begin{array}{c}0.003 \\
{[0.004]}\end{array}$ \\
\hline India $\times 3$ rd + child & & $\begin{array}{l}-0.377 \\
{[0.024]}\end{array}$ & $\begin{array}{l}-0.228 \\
{[0.032]}\end{array}$ & $\begin{array}{l}-0.194 \\
{[0.092]}\end{array}$ & $\begin{array}{l}-0.436 \\
{[0.085]}\end{array}$ & $\begin{array}{c}0.064 \\
{[0.009]}\end{array}$ & $\begin{array}{l}-0.199 \\
{[0.024]}\end{array}$ & $\begin{array}{l}-0.158 \\
{[0.036]}\end{array}$ & $\begin{array}{c}0.002 \\
{[0.004]}\end{array}$ \\
\hline 2nd child & & $\begin{array}{c}0.024 \\
{[0.015]}\end{array}$ & $\begin{array}{l}-0.011 \\
{[0.017]}\end{array}$ & $\begin{array}{l}-0.096 \\
{[0.053]}\end{array}$ & $\begin{array}{l}-0.167 \\
{[0.027]}\end{array}$ & $\begin{array}{c}0.009 \\
{[0.004]}\end{array}$ & $\begin{array}{c}0.010 \\
{[0.012]}\end{array}$ & $\begin{array}{l}-0.010 \\
{[0.022]}\end{array}$ & $\begin{array}{l}-0.014 \\
{[0.002]}\end{array}$ \\
\hline $3 r d+$ child & & $\begin{array}{l}-0.065 \\
{[0.013]}\end{array}$ & $\begin{array}{l}-0.117 \\
{[0.019]}\end{array}$ & $\begin{array}{l}-0.168 \\
{[0.074]}\end{array}$ & $\begin{array}{l}-0.334 \\
{[0.044]}\end{array}$ & $\begin{array}{l}0.036 \\
{[0.005]}\end{array}$ & $\begin{array}{l}-0.063 \\
{[0.014]}\end{array}$ & $\begin{array}{l}-0.038 \\
{[0.025]}\end{array}$ & $\begin{array}{l}-0.011 \\
{[0.003]}\end{array}$ \\
\hline Africa mean of outcome & -1.351 & -1.351 & -1.351 & -1.351 & -1.351 & 0.375 & -0.877 & 10.149 & 0.072 \\
\hline Child's age dummies $\times$ India & No & No & Yes & Yes & Yes & Yes & Yes & Yes & Yes \\
\hline Mother's literacy $\times$ India & No & No & Yes & Yes & No & Yes & Yes & Yes & Yes \\
\hline Mother's age at birth $\times$ India & No & No & Yes & Yes & No & Yes & Yes & Yes & Yes \\
\hline PSU FEs & No & No & Yes & Yes & No & Yes & Yes & Yes & Yes \\
\hline $\begin{array}{l}\text { Mother FEs } \\
\text { Africa mean } \\
\text { India mean }\end{array}$ & No & No & No & No & $\begin{array}{c}\text { Yes } \\
-0.023 \\
0.078\end{array}$ & No & No & No & No \\
\hline $\begin{array}{l}\text { Completed fertility sample } \\
\text { Observations }\end{array}$ & $\begin{array}{l}\text { No } \\
168,135\end{array}$ & $\begin{array}{l}\text { No } \\
168,135\end{array}$ & $\begin{array}{l}\text { No } \\
167,765\end{array}$ & $\begin{array}{c}\text { Yes } \\
66,574\end{array}$ & $\begin{array}{c}\text { No } \\
83,243\end{array}$ & $\begin{array}{l}\text { No } \\
167,765\end{array}$ & $\begin{array}{l}\text { No } \\
167,765\end{array}$ & $\begin{array}{c}\text { No } \\
88,893\end{array}$ & $\begin{array}{l}\text { No } \\
199,514\end{array}$ \\
\hline
\end{tabular}

Table 2.18: India's Differential Birth Order Gradient in Child Height and Related Outcomes (2004-2010): Weighted India

\begin{tabular}{|c|c|c|c|c|c|c|c|c|c|}
\hline & $\begin{array}{l}\text { HFA } \\
\text { z- } \\
\text { score } \\
(1)\end{array}$ & $\begin{array}{l}\text { HFA } \\
\text { Z- } \\
\text { score } \\
(2)\end{array}$ & $\begin{array}{l}\text { HFA } \\
\text { Z- } \\
\text { score } \\
(3)\end{array}$ & $\begin{array}{l}\text { HFA } \\
\text { Z- } \\
\text { score } \\
(4)\end{array}$ & $\begin{array}{l}\text { HFA } \\
\text { z- } \\
\text { score } \\
(5)\end{array}$ & $\begin{array}{l}\text { Stunted } \\
\text { (6) }\end{array}$ & $\begin{array}{l}\text { WFA } \\
\text { Z- } \\
\text { score } \\
(7)\end{array}$ & $\begin{array}{c}\mathrm{Hb} \\
\text { level } \\
(8)\end{array}$ & $\begin{array}{l}\text { Deceased } \\
\text { (9) }\end{array}$ \\
\hline India & $\begin{array}{l}-0.083 \\
{[0.011]}\end{array}$ & $\begin{array}{l}-0.086 \\
{[0.021]}\end{array}$ & & & & & & & \\
\hline India $\times 2$ nd child & & $\begin{array}{l}-0.108 \\
{[0.029]}\end{array}$ & $\begin{array}{l}-0.138 \\
{[0.032]}\end{array}$ & $\begin{array}{l}-0.110 \\
{[0.068]}\end{array}$ & $\begin{array}{l}-0.275 \\
{[0.057]}\end{array}$ & $\begin{array}{c}0.047 \\
{[0.009]}\end{array}$ & $\begin{array}{l}-0.136 \\
{[0.024]}\end{array}$ & $\begin{array}{l}-0.094 \\
{[0.035]}\end{array}$ & $\begin{array}{l}-0.005 \\
{[0.005]}\end{array}$ \\
\hline India $\times 3$ rd + child & & $\begin{array}{l}-0.360 \\
{[0.029]}\end{array}$ & $\begin{array}{l}-0.203 \\
{[0.039]}\end{array}$ & $\begin{array}{l}-0.197 \\
{[0.102]}\end{array}$ & $\begin{array}{l}-0.471 \\
{[0.102]}\end{array}$ & $\begin{array}{c}0.059 \\
{[0.011]}\end{array}$ & $\begin{array}{l}-0.190 \\
{[0.029]}\end{array}$ & $\begin{array}{l}-0.163 \\
{[0.042]}\end{array}$ & $\begin{array}{l}-0.005 \\
{[0.006]}\end{array}$ \\
\hline 2nd child & & $\begin{array}{c}0.024 \\
{[0.015]}\end{array}$ & $\begin{array}{l}-0.011 \\
{[0.017]}\end{array}$ & $\begin{array}{l}-0.096 \\
{[0.053]}\end{array}$ & $\begin{array}{l}-0.167 \\
{[0.027]}\end{array}$ & $\begin{array}{c}0.009 \\
{[0.004]}\end{array}$ & $\begin{array}{c}0.010 \\
{[0.012]}\end{array}$ & $\begin{array}{l}-0.010 \\
{[0.022]}\end{array}$ & $\begin{array}{l}-0.014 \\
{[0.002]}\end{array}$ \\
\hline 3rd + child & & $\begin{array}{l}-0.065 \\
{[0.013]}\end{array}$ & $\begin{array}{l}-0.117 \\
{[0.019]}\end{array}$ & $\begin{array}{l}-0.168 \\
{[0.074]}\end{array}$ & $\begin{array}{l}-0.334 \\
{[0.044]}\end{array}$ & $\begin{array}{c}0.036 \\
{[0.005]}\end{array}$ & $\begin{array}{l}-0.063 \\
{[0.014]}\end{array}$ & $\begin{array}{l}-0.038 \\
{[0.025]}\end{array}$ & $\begin{array}{l}-0.011 \\
{[0.003]}\end{array}$ \\
\hline Africa mean of outcome & -1.351 & -1.351 & -1.351 & -1.351 & -1.351 & 0.375 & -0.877 & 10.149 & 0.072 \\
\hline Child's age dummies $\times$ India & No & No & Yes & Yes & Yes & Yes & Yes & Yes & Yes \\
\hline Mother's literacy $\times$ India & No & No & Yes & Yes & No & Yes & Yes & Yes & Yes \\
\hline Mother's age at birth $\times$ India & No & No & Yes & Yes & No & Yes & Yes & Yes & Yes \\
\hline PSU FEs & No & No & Yes & Yes & No & Yes & Yes & Yes & Yes \\
\hline $\begin{array}{l}\text { Mother FEs } \\
\text { Africa mean } \\
\text { India mean }\end{array}$ & No & No & No & No & $\begin{array}{c}\text { Yes } \\
0.014 \\
-0.041\end{array}$ & No & No & No & No \\
\hline Completed fertility sample & No & No & No & Yes & No & No & No & No & No \\
\hline Observations & 168,135 & 168,135 & 167,765 & 66,574 & 83,243 & 167,765 & 167,765 & 88,893 & 199,514 \\
\hline
\end{tabular}


Figure 2.4: Child Height in India and Africa, by Child's Birth Order (2004-2010): Unweighted vs Weighted

Replication (2004-2010): Unweighted

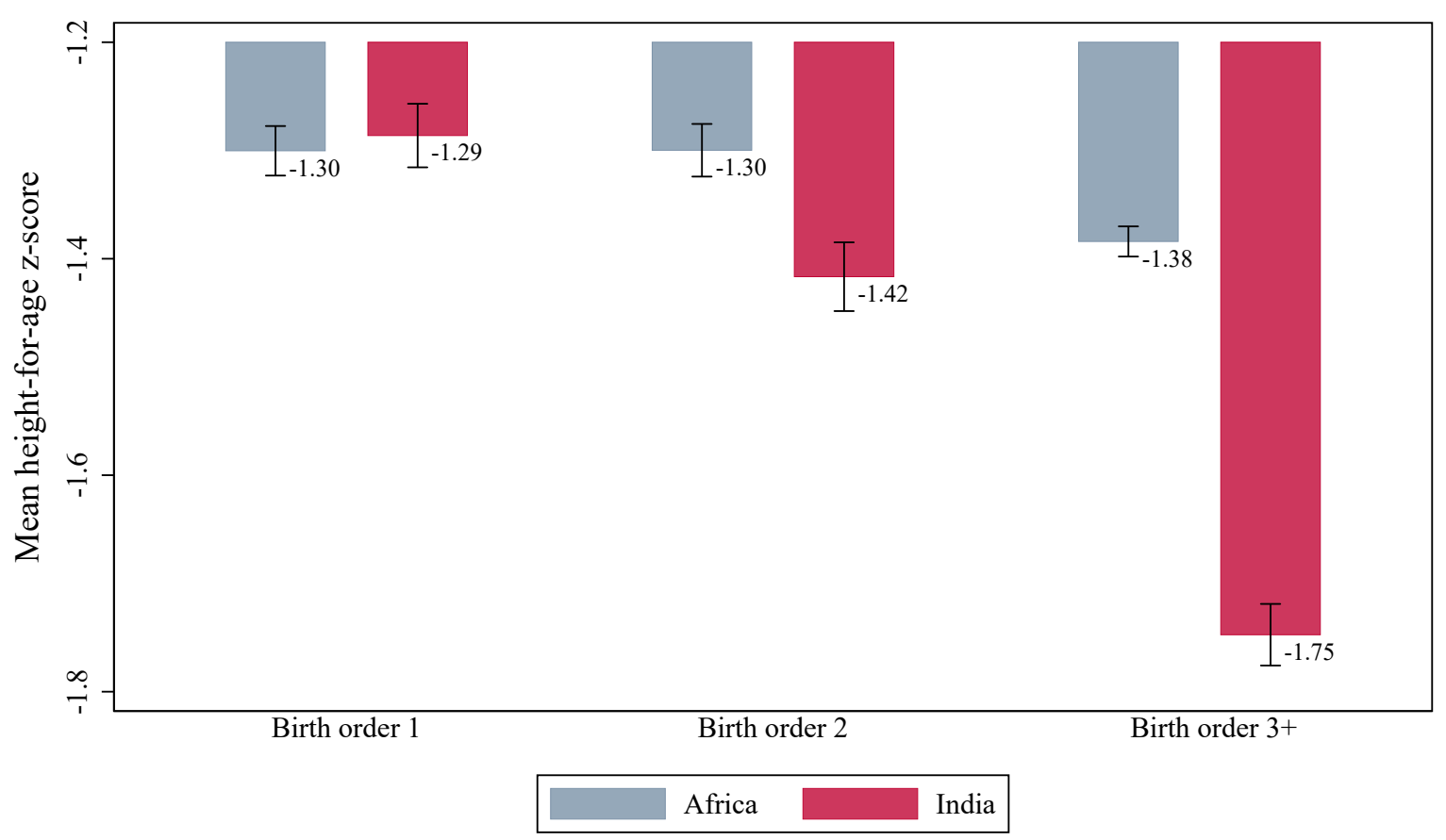

Replication (2004-2010): Weighted

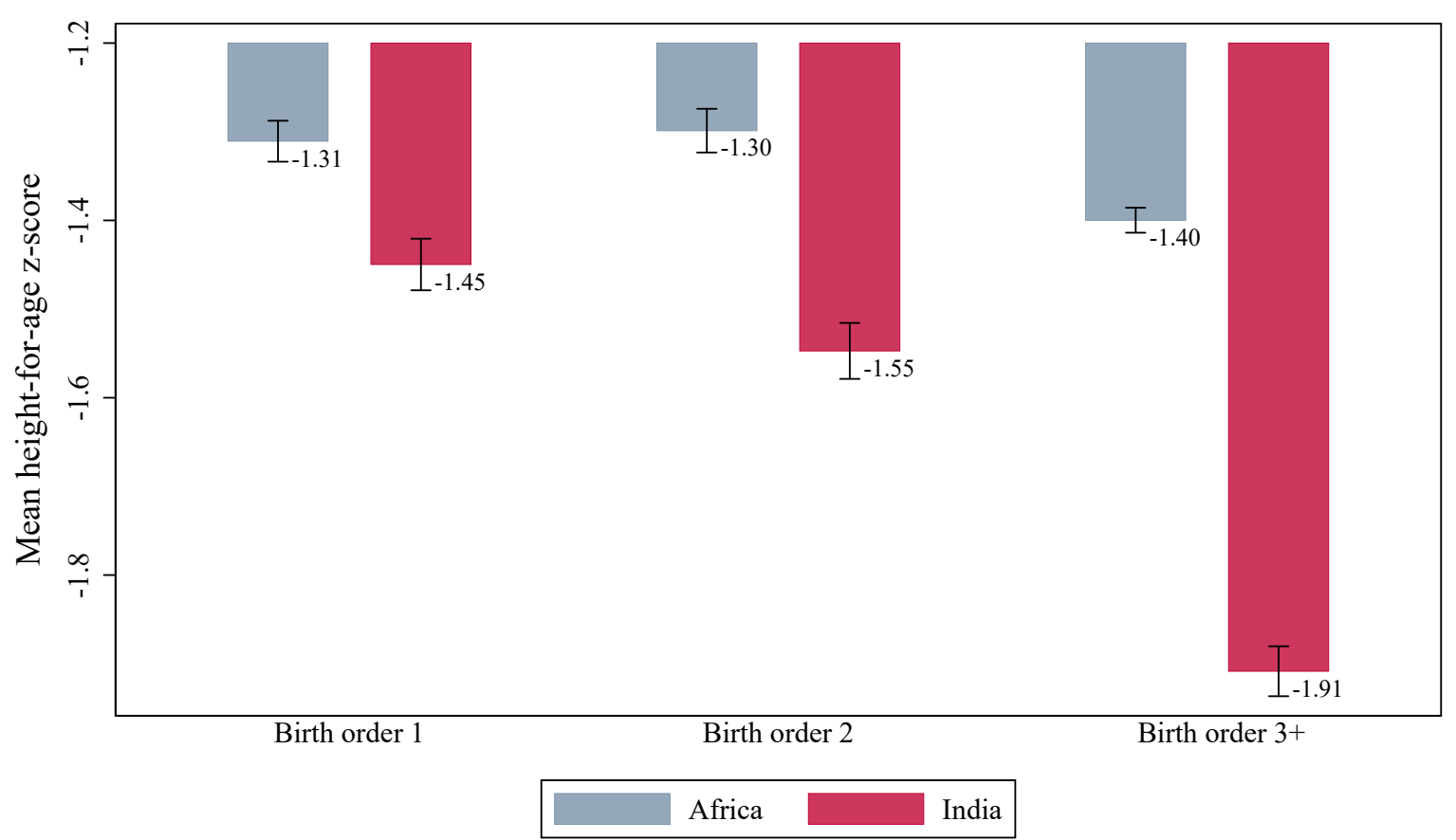

Notes: The figure depicts the mean child height-for-age z-scores for sub-Saharan Africa and India, by the birth order of the child. The mean is calculated over all children less than 60 months old. Please consider the notes in Figure 2.3 for further explanations.

Source: Adapted from J+P using data from DHS (ICF, 2004) and IPUMS DHS (Heger Boyle \& Sobek, 2019) 
Considering the back-of-the-envelope calculations, we find that the birth order gradient can explain the height gap between African and Indian children less. The explained share reduces by at least 35 percentage points in each of the two accounting exercises compared to the unweighted data. The birth order gradient rooted in eldest son preference can explain even less in the weighted data, between 11 and 14 percent.

\section{Extension Macro-Determinants (2011-2017) vs (2004-2010): Weighted}

In the replication part of this paper, we first have used the same methodology but more recent data and then different methodology but the same time period around 2015. We bring now both together, new methodology and more recent data. Apart from weighting, we expose J+P's specification to additional covariates. We examine the sensitivity of the gap between Indian and African children using four emerging macro-determinants: mother's education, economic growth, anti-open defecation campaigns, and the nutrition transition. ${ }^{11}$

As data of food consumption is only available for the last born child of each family, the sample is reduced by half in the later time period and almost by two-thirds in the earlier time period.

${ }^{12}$ We weigh all the samples to be nationally representative. Countries with multiple surveys in the periods are weighted so that each survey receives the weight of $1 / \mathrm{n}$ for $\mathrm{n}$ surveys. ${ }^{13}$

\subsection{Summary Statistics}

We want to briefly describe the means of the considered macro-determinants for the time period around 2005 (Table 2.19) and around 2015 (Table 2.20).

Literacy increases for both India and Africa though India has the largest growth in literacy just as we hypothesized.

Noteworthy is the wealth distribution that mirrors the larger economic growth in India: 23 percent of the Indian households in our sample in the period around 2005 and 12 percent in the

\footnotetext{
${ }^{11}$ In the appendix we look at different average inputs like consumption of meat and eggs by gender and birth order to get a first idea about whether these inputs are distributed differently.

${ }^{12}$ This is why we also estimate the regressions with all macro-determinants but the nutrition transition for greater power. The results are in the appendix and similar to the ones shown in the main body of this text.

${ }^{13} \mathrm{We}$ also analyze the time period around 2005 and 2015 using weights but without macro-determinants in the appendix.
} 
later time period are in the poorest quantile whereas African households are represented with 23 percent and 43 percent, respectively. Looking at the richest quantile we find that 27 percent of the Indian households in our sample in the earlier time period and 29 percent in the later time period are in the richest quantile whereas African households are only represented with 16 percent and 4 percent, respectively. The wealth gap has widened between India and Africa over time. More African households are in the poorest and second poorest wealth quantile and less in the third, fourth poorest, and richest wealth quantile than Indian ones in the more recent time period.

Open defecation has overall decreased: 63 percent of Indian households in the time period around 2005 and 47 percent in the time period around 2015 have no sanitation facilities; African households have decreased open defecation from 32 percent to 23 percent.

The gap in consumption of animal products has decreased over time: In the time period around 2005, 12 percent of the Indian children and 43 percent of the African children have consumed meat or eggs in the past 7 days. In the later period, 14 percent and 30 percent have eaten meat or egg, respectively. More children consume dairy products. The consumption increases from 11 to 13 percent and in Africa from 16 to 20 percent over time. Possible explanations of the diverging meat and egg consumption of the African sample could be measurement errors. In the survey for the period around 2005, we also include measures about the consumption of animal products in the past 24 hours for the Africa sample when measures for the consumption in the past 7 days are not available. This might increase the likelihood of consumption. However, this trend might also reflect the gap in economic growth leading to decreasing purchasing power of rather expensive animal sourced foods for the African population compared to India.

Considering the presence of the four macro-determinants, we observe mixed evidence. The increased level of maternal literacy mirrors the greater improvements in female education in India than in Africa. In the period between 2004 and 2017 India has grown much faster than Africa. This is reflected in the wealth of the households in our sample. Indian households are represented more in higher wealth quantiles. The dramatic improvement in India in open defecation could reflect the increased awareness and construction of sanitation facilities. Nevertheless, the decrease in open defecation in India is not large enough to catch up with Africa. Children's consumption of animal sourced foods has increased in India but not clearly in Africa. We want to assess now in the next section how these macro-determinants are related to the height gap between African and Indian children. Is the eldest son preference specification by $\mathrm{J}+\mathrm{P}$ sensitive 
to the addition of the selected macro-determinants?

Table 2.19: Summary Statistics (2004-2010): Weighted Macro-Determinants

\begin{tabular}{|c|c|c|c|c|c|}
\hline & $\begin{array}{c}\text { India } \\
\text { subsample }\end{array}$ & $\begin{array}{c}\text { Africa } \\
\text { subsample }\end{array}$ & & $\begin{array}{c}\text { India } \\
\text { subsample }\end{array}$ & $\begin{array}{c}\text { Africa } \\
\text { subsample }\end{array}$ \\
\hline Mother is literate & $\begin{array}{c}0.49 \\
{[0.50]}\end{array}$ & $\begin{array}{c}0.48 \\
{[0.50]}\end{array}$ & Open defecation & $\begin{array}{c}0.63 \\
{[0.48]}\end{array}$ & $\begin{array}{c}0.32 \\
{[0.47]}\end{array}$ \\
\hline Poorest wealth quantile & $\begin{array}{c}0.23 \\
{[0.42]}\end{array}$ & $\begin{array}{c}0.23 \\
{[0.42]}\end{array}$ & Meat or eggs consumed & $\begin{array}{c}0.12 \\
{[0.33]}\end{array}$ & $\begin{array}{c}0.43 \\
{[0.50]}\end{array}$ \\
\hline 2 nd poorest wealth quantile & $\begin{array}{c}0.09 \\
{[0.28]}\end{array}$ & $\begin{array}{c}0.24 \\
{[0.43]}\end{array}$ & Dairy products consumed & $\begin{array}{c}0.11 \\
{[0.31]}\end{array}$ & $\begin{array}{c}0.16 \\
{[0.37]}\end{array}$ \\
\hline 3rd poorest wealth quantile & $\begin{array}{c}0.20 \\
{[0.40]}\end{array}$ & $\begin{array}{c}0.20 \\
{[0.40]}\end{array}$ & Number of PSUs & 3,822 & 10,366 \\
\hline 4 th poorest wealth quantile & $\begin{array}{c}0.21 \\
{[0.41]}\end{array}$ & $\begin{array}{c}0.18 \\
{[0.38]}\end{array}$ & Main sample of children & 42,069 & 126,066 \\
\hline Richest wealth quantile & $\begin{array}{c}0.27 \\
{[0.45]}\end{array}$ & $\begin{array}{c}0.16 \\
{[0.36]}\end{array}$ & & & \\
\hline
\end{tabular}

Table 2.20: Summary Statistics (2011-2017): Weighted Macro-Determinants

\begin{tabular}{|c|c|c|c|c|c|}
\hline & $\begin{array}{c}\text { India } \\
\text { subsample }\end{array}$ & $\begin{array}{c}\text { Africa } \\
\text { subsample }\end{array}$ & & $\begin{array}{c}\text { India } \\
\text { subsample }\end{array}$ & $\begin{array}{c}\text { Africa } \\
\text { subsample }\end{array}$ \\
\hline Mother is literate & $\begin{array}{c}0.68 \\
{[0.47]}\end{array}$ & $\begin{array}{c}0.55 \\
{[0.50]}\end{array}$ & Open defecation & $\begin{array}{c}0.47 \\
{[0.50]}\end{array}$ & $\begin{array}{c}0.23 \\
{[0.42]}\end{array}$ \\
\hline Poorest wealth quantile & $\begin{array}{c}0.12 \\
{[0.32]}\end{array}$ & $\begin{array}{c}0.43 \\
{[0.49]}\end{array}$ & Meat or eggs consumed & $\begin{array}{c}0.14 \\
{[0.35]}\end{array}$ & $\begin{array}{c}0.30 \\
{[0.46]}\end{array}$ \\
\hline 2nd poorest wealth quantile & $\begin{array}{c}0.19 \\
{[0.39]}\end{array}$ & $\begin{array}{c}0.23 \\
{[0.42]}\end{array}$ & Dairy products consumed & $\begin{array}{c}0.13 \\
{[0.34]}\end{array}$ & $\begin{array}{c}0.20 \\
{[0.40]}\end{array}$ \\
\hline 3rd poorest wealth quantile & $\begin{array}{c}0.19 \\
{[0.39]}\end{array}$ & $\begin{array}{c}0.15 \\
{[0.36]}\end{array}$ & Number of PSUs & 28,215 & 12,684 \\
\hline 4 th poorest wealth quantile & $\begin{array}{c}0.22 \\
{[0.41]}\end{array}$ & $\begin{array}{c}0.14 \\
{[0.35]}\end{array}$ & Main sample of children & 230,220 & 168,490 \\
\hline Richest wealth quantile & $\begin{array}{c}0.29 \\
{[0.45]}\end{array}$ & $\begin{array}{c}0.04 \\
{[0.21]}\end{array}$ & & & \\
\hline
\end{tabular}

Notes: The means of the specified variables are calculated separately for the India and Africa subsamples. Standard deviations appear in brackets. The following variable is summarized at the mother level: mother is literate. Meat or eggs consumed and dairy products consumed are also, in effect, summarized at the mother level because they are only available for the most recent birth. Variables summarized at the child level include: open defecation and the wealth quantiles.

Source: Adapted from J+P using data from IPUMS DHS (ICF, 2004) and DHS (Heger Boyle \& Sobek, 2019) 


\subsection{Summary of Regression Results Using Macro-Determinants}

We present now regression results including the identified macro-determinants to explain the height gap between Indian and African children. We also reassess the two main predictions of $\mathrm{J}+\mathrm{P}$ and the accounting exercises.

\subsubsection{India and Birth Order as Determinants}

We consider the table pair - Table 2.21 and Table 2.22 - for an in-depth description of regression results. The India dummy is significant and negative in column 1 and column 2 in the time period around 2005 (Table 2.21) and around 2015 (Table 2.22). The magnitude is larger in the later time period than in the earlier time period. The effect size is also greater than the weighted model without the macro-determinants but smaller than the weighted models with only three macro-determinants excluding animal sourced foods.

The Indian birth order gradient is shallower in the later period in time because the magnitude of the effects decreases for all outcomes.

\subsubsection{Emerging Macro-Determinants}

The literacy dummy interacted with India is significant for the HFA z-scores without controls and for WFA z-scores for both time periods. Literacy of mothers in India benefits children additionally in the later time period in the HFA z-scores main specification, stunting, and likelihood to decease. The interaction term is positively associated with improved health outcomes (except for the fertility sample in the earlier time period). The magnitude of the interaction of India and literacy increases for the models of HFA z-score without controls over time.

The literacy dummy is significant for all outcomes in both time periods. Literacy is positively correlated with improved health outcomes as expected (apart from deceased in the later time period). The magnitude of the dummy literacy increases for the first three columns for the HFA $\mathrm{z}$-scores but decreases for all other outcomes.

The wealth quantiles are positively associated with improved health outcomes for all but deceased for which evidence is mixed. In general, richer households are associated with healthier children because the effect sizes usually increase from the second poorest wealth quantile over the third and fourth poorest quantile to the richest wealth quantile. The richest wealth quantile has a significant and positive relationship with improved health outcomes but deceased. All 
wealth quantiles do not have a significant association with deceased overall. The fourth and third poorest wealth quantiles have a significant and positive relationship with all improved health outcomes but hemoglobin in the time period around 2005. The second poorest wealth quantile does not seem to differ too much from the poorest wealth quantile, the reference category, because significant effects can only be found for one specification for HFA z-score and WFA z-scores in the earlier time period. Around 2015 the second poorest wealth quantile has more significant correlations with health outcomes (three of the four HFA z-score specifications, stunting, and WFA z-scores). There is not a clear time trend.

Open defecation interacted with India has negative associations with improved health outcomes (apart from hemoglobin outcomes in the time period around 2005 and the third specification of HFA z-scores as well as deceased in the later time period). The coefficients in the first specification for HFA z-scores are significant in both time periods. The coefficient for the outcome WFA z-scores, the second specification of HFA z-scores and deceased have significant effects for the later time period. A clear time trend is not detectable.

Open defecation alone has the expected negative relationship for stunting, weight-for-age zscores, and hemoglobin in both time periods as well as for deceased in the later time period. Only in the main specification for HFA z-scores open defecation has the expected sign. This shows the importance of adding PSU fixed effects that include characteristics of each PSU like population density and disease environment that moderate the negative externality of open defecation on child health. The dummy is significant for the first specification of HFA z-scores in both tables and the second specification in the later time period. These effects vanish once including PSU fixed effects. Further, around 2005 we find significant effects for WFA z-scores. The consumption of animal products should be positively associated with improved health outcomes. We consider two different outcomes: the consumption of dairy products as well as of meat and egg together. We look at the interactions with the India dummy, too. The interaction of meat and egg consumption with India is only significant for hemoglobin outcomes in the earlier time period. In general, the interaction is correlated with improved health outcomes. Only in the later period, this relationship is not positive in two specifications for the HFA z-scores. Meat and egg consumption in India provides in most cases an additional benefit for children. The dummy meat and egg consumption has the expected positive association with health outcomes. It is significant for specifications in columns 1 to 3 for HFA z-scores, WFA z-scores, and stunting in both tables. 
The interaction of dairy products and India does not show any significant effects (apart from diseased in the time period around 2015). The small effect sizes and the changes in signs imply that consumption of dairy products in India is not creating additional benefits for the health outcomes of children.

The consumption of dairy products has significant positive associations with improved health outcomes for HFA z-scores (apart from the specification of the fertility sample), stunting, WFA z-scores, and deceased in both time periods. Hemoglobin has the expected sign and significance only in the earlier time period.

From our assessment of emerging macro-determinants of the height gap between children in India and Africa we draw the following conclusions. Literacy plays a key role in health outcomes. There is a gap between India and Africa. For India, the interaction term helps to improve health outcomes even further. Wealth plays a key role in the improvement of health outcomes apart from death. In the models without controlling for PSU fixed effects, the effects for open defecation for India and Africa seem to be quite distinct. Defecating in the open in India damages health outcomes additionally. There does not seem to be a particular difference for Africa and India for the consumption of animal sourced products because most of the coefficients of the interaction terms with India are not significant and vary in signs. The consumption of animal sourced foods improves health outcomes overall. The macro-determinants are jointly significant in models but deceased in the earlier time period. Adding the macro-determinants increases the general height gap of children between India and Africa.

\subsubsection{Reassessment of the Main Predictions and Accounting Exercise}

When examining the two predictions deriving from eldest son preference, we have similar findings. Additionally, we observe negative -though over time- decreasing effects of girls in India on child health outcomes relative to their African peers. Interactions of girl, India, and birth order are positive in the time period around 2005 when adding the macro-determinants. However, these signs turn negative in the later time period.

We again perform the two back-of-the-envelope calculations. This time we additionally control for the macro-determinants. In the time period around 2005, the explained share by the birth order gradient is even lower than for the weighted sample: between 18 and 9 percent. There is also a reduction for the later time period, however, the accounting exercise fails. Due to weighting the data the average first-born child in Africa is taller than the second-born child, so 
Table 2.21: India's Differential Birth Order Gradient in Child Height and Related Outcomes (2004-2010): Weighted Macro-Determinants

\begin{tabular}{|c|c|c|c|c|c|c|c|c|}
\hline & $\begin{array}{c}\text { HFA } \\
\text { Z- } \\
\text { score } \\
(1)\end{array}$ & $\begin{array}{c}\text { HFA } \\
\text { Z- } \\
\text { score } \\
(2)\end{array}$ & $\begin{array}{c}\text { HFA } \\
\text { Z- } \\
\text { score } \\
(3)\end{array}$ & $\begin{array}{c}\text { HFA } \\
\text { Z- } \\
\text { score } \\
(4)\end{array}$ & $\begin{array}{l}\text { Stunted } \\
\text { (5) }\end{array}$ & $\begin{array}{c}\text { WFA } \\
\text { Z- } \\
\text { score } \\
(6)\end{array}$ & $\begin{array}{c}\mathrm{Hb} \\
\text { level } \\
(7)\end{array}$ & $\begin{array}{l}\text { Deceased } \\
\text { (8) }\end{array}$ \\
\hline India & $\begin{array}{l}-0.158 \\
{[0.036]}\end{array}$ & $\begin{array}{l}-0.142 \\
{[0.057]}\end{array}$ & & & & & & \\
\hline India $\times 2$ nd child & & $\begin{array}{l}-0.117 \\
{[0.052]}\end{array}$ & $\begin{array}{l}-0.179 \\
{[0.060]}\end{array}$ & $\begin{array}{l}-0.732 \\
{[0.605]}\end{array}$ & $\begin{array}{c}0.051 \\
{[0.015]}\end{array}$ & $\begin{array}{l}-0.184 \\
{[0.043]}\end{array}$ & $\begin{array}{l}-0.085 \\
{[0.072]}\end{array}$ & $\begin{array}{c}0.003 \\
{[0.002]}\end{array}$ \\
\hline India $\times 3 \mathrm{rd}+$ child & & $\begin{array}{l}-0.170 \\
{[0.048]}\end{array}$ & $\begin{array}{l}-0.222 \\
{[0.070]}\end{array}$ & $\begin{array}{l}-1.374 \\
{[0.775]}\end{array}$ & $\begin{array}{c}0.065 \\
{[0.018]}\end{array}$ & $\begin{array}{l}-0.161 \\
{[0.050]}\end{array}$ & $\begin{array}{l}-0.121 \\
{[0.083]}\end{array}$ & $\begin{array}{c}0.006 \\
{[0.003]}\end{array}$ \\
\hline 2nd child & & $\begin{array}{c}0.092 \\
{[0.033]}\end{array}$ & $\begin{array}{c}0.052 \\
{[0.039]}\end{array}$ & $\begin{array}{c}1.500 \\
{[0.351]}\end{array}$ & $\begin{array}{l}-0.005 \\
{[0.009]}\end{array}$ & $\begin{array}{c}0.079 \\
{[0.028]}\end{array}$ & $\begin{array}{c}0.046 \\
{[0.055]}\end{array}$ & $\begin{array}{c}0.002 \\
{[0.001]}\end{array}$ \\
\hline $3 r d+$ child & & $\begin{array}{c}0.055 \\
{[0.028]}\end{array}$ & $\begin{array}{l}-0.048 \\
{[0.044]}\end{array}$ & $\begin{array}{c}2.426 \\
{[0.531]}\end{array}$ & $\begin{array}{c}0.014 \\
{[0.010]}\end{array}$ & $\begin{array}{l}-0.003 \\
{[0.031]}\end{array}$ & $\begin{array}{c}0.033 \\
{[0.062]}\end{array}$ & $\begin{array}{c}0.002 \\
{[0.001]}\end{array}$ \\
\hline India $\times$ Mother's literacy & $\begin{array}{c}0.157 \\
{[0.034]}\end{array}$ & $\begin{array}{c}0.154 \\
{[0.043]}\end{array}$ & $\begin{array}{c}0.081 \\
{[0.052]}\end{array}$ & $\begin{array}{l}-0.026 \\
{[0.084]}\end{array}$ & $\begin{array}{l}-0.025 \\
{[0.014]}\end{array}$ & $\begin{array}{c}0.094 \\
{[0.037]}\end{array}$ & $\begin{array}{c}0.001 \\
{[0.061]}\end{array}$ & $\begin{array}{c}0.003 \\
{[0.002]}\end{array}$ \\
\hline Mother's literacy & $\begin{array}{c}0.100 \\
{[0.019]}\end{array}$ & $\begin{array}{c}0.082 \\
{[0.023]}\end{array}$ & $\begin{array}{c}0.082 \\
{[0.031]}\end{array}$ & $\begin{array}{c}0.151 \\
{[0.061]}\end{array}$ & $\begin{array}{l}-0.023 \\
{[0.007]}\end{array}$ & $\begin{array}{c}0.123 \\
{[0.021]}\end{array}$ & $\begin{array}{c}0.098 \\
{[0.045]}\end{array}$ & $\begin{array}{l}-0.003 \\
{[0.001]}\end{array}$ \\
\hline 2nd poorest wealth quantile & $\begin{array}{c}0.077 \\
{[0.025]}\end{array}$ & $\begin{array}{c}0.017 \\
{[0.030]}\end{array}$ & $\begin{array}{c}0.018 \\
{[0.036]}\end{array}$ & $\begin{array}{l}-0.016 \\
{[0.062]}\end{array}$ & $\begin{array}{l}-0.012 \\
{[0.009]}\end{array}$ & $\begin{array}{c}0.061 \\
{[0.025]}\end{array}$ & $\begin{array}{c}0.027 \\
{[0.044]}\end{array}$ & $\begin{array}{l}-0.001 \\
{[0.001]}\end{array}$ \\
\hline 3rd poorest wealth quantile & $\begin{array}{c}0.229 \\
{[0.025]}\end{array}$ & $\begin{array}{c}0.184 \\
{[0.029]}\end{array}$ & $\begin{array}{c}0.140 \\
{[0.038]}\end{array}$ & $\begin{array}{c}0.175 \\
{[0.064]}\end{array}$ & $\begin{array}{l}-0.030 \\
{[0.010]}\end{array}$ & $\begin{array}{c}0.110 \\
{[0.026]}\end{array}$ & $\begin{array}{c}0.014 \\
{[0.046]}\end{array}$ & $\begin{array}{l}-0.001 \\
{[0.001]}\end{array}$ \\
\hline 4 th poorest wealth quantile & $\begin{array}{c}0.363 \\
{[0.025]}\end{array}$ & $\begin{array}{c}0.314 \\
{[0.029]}\end{array}$ & $\begin{array}{c}0.188 \\
{[0.043]}\end{array}$ & $\begin{array}{c}0.295 \\
{[0.071]}\end{array}$ & $\begin{array}{l}-0.057 \\
{[0.011]}\end{array}$ & $\begin{array}{c}0.217 \\
{[0.030]}\end{array}$ & $\begin{array}{c}0.066 \\
{[0.052]}\end{array}$ & $\begin{array}{l}-0.000 \\
{[0.001]}\end{array}$ \\
\hline Richest wealth quantile & $\begin{array}{c}0.690 \\
{[0.028]}\end{array}$ & $\begin{array}{c}0.672 \\
{[0.034]}\end{array}$ & $\begin{array}{c}0.401 \\
{[0.056]}\end{array}$ & $\begin{array}{c}0.570 \\
{[0.092]}\end{array}$ & $\begin{array}{l}-0.107 \\
{[0.014]}\end{array}$ & $\begin{array}{c}0.413 \\
{[0.039]}\end{array}$ & $\begin{array}{c}0.264 \\
{[0.070]}\end{array}$ & $\begin{array}{c}0.001 \\
{[0.002]}\end{array}$ \\
\hline India $\times$ Open defecation & $\begin{array}{l}-0.205 \\
{[0.035]}\end{array}$ & $\begin{array}{l}-0.073 \\
{[0.044]}\end{array}$ & $\begin{array}{l}-0.116 \\
{[0.068]}\end{array}$ & $\begin{array}{l}-0.019 \\
{[0.106]}\end{array}$ & $\begin{array}{c}0.038 \\
{[0.018]}\end{array}$ & $\begin{array}{l}-0.086 \\
{[0.048]}\end{array}$ & $\begin{array}{c}0.009 \\
{[0.077]}\end{array}$ & $\begin{array}{c}0.002 \\
{[0.003]}\end{array}$ \\
\hline Open defecation & $\begin{array}{c}0.050 \\
{[0.021]}\end{array}$ & $\begin{array}{c}0.004 \\
{[0.025]}\end{array}$ & $\begin{array}{l}-0.061 \\
{[0.038]}\end{array}$ & $\begin{array}{c}0.002 \\
{[0.074]}\end{array}$ & $\begin{array}{c}0.009 \\
{[0.009]}\end{array}$ & $\begin{array}{l}-0.060 \\
{[0.027]}\end{array}$ & $\begin{array}{l}-0.076 \\
{[0.053]}\end{array}$ & $\begin{array}{l}-0.002 \\
{[0.002]}\end{array}$ \\
\hline India $\times$ Meat or eggs consumed & $\begin{array}{c}0.059 \\
{[0.037]}\end{array}$ & $\begin{array}{c}0.068 \\
{[0.048]}\end{array}$ & $\begin{array}{c}0.092 \\
{[0.060]}\end{array}$ & $\begin{array}{c}0.167 \\
{[0.095]}\end{array}$ & $\begin{array}{l}-0.027 \\
{[0.017]}\end{array}$ & $\begin{array}{c}0.026 \\
{[0.044]}\end{array}$ & $\begin{array}{c}0.158 \\
{[0.066]}\end{array}$ & $\begin{array}{c}0.000 \\
{[0.002]}\end{array}$ \\
\hline Meat or eggs consumed & $\begin{array}{c}0.199 \\
{[0.020]}\end{array}$ & $\begin{array}{c}0.204 \\
{[0.024]}\end{array}$ & $\begin{array}{c}0.134 \\
{[0.030]}\end{array}$ & $\begin{array}{c}0.094 \\
{[0.061]}\end{array}$ & $\begin{array}{l}-0.029 \\
{[0.007]}\end{array}$ & $\begin{array}{c}0.120 \\
{[0.020]}\end{array}$ & $\begin{array}{c}0.031 \\
{[0.039]}\end{array}$ & $\begin{array}{l}-0.000 \\
{[0.001]}\end{array}$ \\
\hline India $\times$ Dairy products consumed & $\begin{array}{c}0.048 \\
{[0.044]}\end{array}$ & $\begin{array}{l}-0.020 \\
{[0.056]}\end{array}$ & $\begin{array}{l}-0.058 \\
{[0.067]}\end{array}$ & $\begin{array}{c}0.165 \\
{[0.108]}\end{array}$ & $\begin{array}{l}-0.005 \\
{[0.018]}\end{array}$ & $\begin{array}{c}0.058 \\
{[0.048]}\end{array}$ & $\begin{array}{l}-0.075 \\
{[0.072]}\end{array}$ & $\begin{array}{c}0.001 \\
{[0.002]}\end{array}$ \\
\hline Dairy products consumed & $\begin{array}{c}0.101 \\
{[0.025]}\end{array}$ & $\begin{array}{c}0.126 \\
{[0.030]}\end{array}$ & $\begin{array}{c}0.126 \\
{[0.038]}\end{array}$ & $\begin{array}{l}-0.025 \\
{[0.078]}\end{array}$ & $\begin{array}{l}-0.030 \\
{[0.009]}\end{array}$ & $\begin{array}{c}0.080 \\
{[0.027]}\end{array}$ & $\begin{array}{c}0.135 \\
{[0.047]}\end{array}$ & $\begin{array}{l}-0.002 \\
{[0.001]}\end{array}$ \\
\hline Africa mean of outcome & -1.363 & -1.363 & -1.363 & -1.363 & 0.381 & -0.889 & 10.107 & 0.074 \\
\hline Child's age dummies $\times$ India & No & No & Yes & Yes & Yes & Yes & Yes & Yes \\
\hline Mother's age at birth $\times$ India & No & No & Yes & Yes & Yes & Yes & Yes & Yes \\
\hline PSU FEs & No & No & Yes & Yes & Yes & Yes & Yes & Yes \\
\hline Completed fertility sample & No & No & No & Yes & No & No & No & No \\
\hline p-Value of joint significance test & 0.000 & 0.000 & 0.000 & 0.000 & 0.000 & 0.000 & 0.000 & 0.437 \\
\hline Observations & 64,785 & 64,785 & 63,635 & 24,638 & 63,635 & 63,635 & 28,297 & 47,835 \\
\hline
\end{tabular}

Notes: Standard errors are clustered by mother and appear in brackets. Please consider the notes in Table 2.6 for further explanations. Source: Adapted from J+P using data from DHS (Heger Boyle \& Sobek, 2019) 
Table 2.22: India's Differential Birth Order Gradient in Child Height and Related Outcomes (2011-2017): Weighted Macro-Determinants

\begin{tabular}{|c|c|c|c|c|c|c|c|c|}
\hline & $\begin{array}{c}\text { HFA } \\
\text { Z- } \\
\text { score } \\
(1)\end{array}$ & $\begin{array}{c}\text { HFA } \\
\mathrm{Z}^{-} \\
\text {score } \\
(2)\end{array}$ & $\begin{array}{c}\text { HFA } \\
\text { Z- } \\
\text { score } \\
(3)\end{array}$ & $\begin{array}{c}\text { HFA } \\
\text { Z- } \\
\text { score } \\
(4)\end{array}$ & $\begin{array}{l}\text { Stunted } \\
\text { (5) }\end{array}$ & $\begin{array}{c}\text { WFA } \\
\text { Z- } \\
\text { score } \\
(6)\end{array}$ & $\begin{array}{c}\mathrm{Hb} \\
\text { level } \\
(7)\end{array}$ & $\begin{array}{l}\text { Deceasec } \\
\text { (8) }\end{array}$ \\
\hline India & $\begin{array}{l}-0.309 \\
{[0.021]}\end{array}$ & $\begin{array}{l}-0.202 \\
{[0.040]}\end{array}$ & & & & & & \\
\hline India $\times 2$ nd child & & $\begin{array}{l}-0.076 \\
{[0.037]}\end{array}$ & $\begin{array}{l}-0.098 \\
{[0.044]}\end{array}$ & $\begin{array}{c}0.231 \\
{[0.781]}\end{array}$ & $\begin{array}{c}0.023 \\
{[0.010]}\end{array}$ & $\begin{array}{l}-0.059 \\
{[0.032]}\end{array}$ & $\begin{array}{l}-0.104 \\
{[0.051]}\end{array}$ & $\begin{array}{c}0.001 \\
{[0.001]}\end{array}$ \\
\hline India $\times 3$ rd + child & & $\begin{array}{l}-0.166 \\
{[0.034]}\end{array}$ & $\begin{array}{l}-0.187 \\
{[0.051]}\end{array}$ & $\begin{array}{l}-0.128 \\
{[0.900]}\end{array}$ & $\begin{array}{c}0.040 \\
{[0.012]}\end{array}$ & $\begin{array}{l}-0.123 \\
{[0.037]}\end{array}$ & $\begin{array}{l}-0.030 \\
{[0.057]}\end{array}$ & $\begin{array}{c}0.002 \\
{[0.001]}\end{array}$ \\
\hline 2nd child & & $\begin{array}{c}0.068 \\
{[0.029]}\end{array}$ & $\begin{array}{c}0.033 \\
{[0.035]}\end{array}$ & $\begin{array}{c}0.604 \\
{[0.638]}\end{array}$ & $\begin{array}{l}-0.006 \\
{[0.008]}\end{array}$ & $\begin{array}{c}0.035 \\
{[0.025]}\end{array}$ & $\begin{array}{c}0.064 \\
{[0.044]}\end{array}$ & $\begin{array}{l}-0.002 \\
{[0.001]}\end{array}$ \\
\hline 3rd + child & & $\begin{array}{c}0.077 \\
{[0.024]}\end{array}$ & $\begin{array}{c}0.012 \\
{[0.039]}\end{array}$ & $\begin{array}{c}1.183 \\
{[0.716]}\end{array}$ & $\begin{array}{c}0.000 \\
{[0.009]}\end{array}$ & $\begin{array}{c}0.003 \\
{[0.028]}\end{array}$ & $\begin{array}{l}-0.022 \\
{[0.048]}\end{array}$ & $\begin{array}{l}-0.002 \\
{[0.001]}\end{array}$ \\
\hline India $\times$ Mother's literacy & $\begin{array}{c}0.102 \\
{[0.021]}\end{array}$ & $\begin{array}{c}0.073 \\
{[0.029]}\end{array}$ & $\begin{array}{c}0.082 \\
{[0.038]}\end{array}$ & $\begin{array}{c}0.052 \\
{[0.081]}\end{array}$ & $\begin{array}{l}-0.024 \\
{[0.009]}\end{array}$ & $\begin{array}{c}0.087 \\
{[0.027]}\end{array}$ & $\begin{array}{c}0.041 \\
{[0.042]}\end{array}$ & $\begin{array}{l}-0.002 \\
{[0.001]}\end{array}$ \\
\hline Mother's literacy $=1$ & $\begin{array}{c}0.122 \\
{[0.014]}\end{array}$ & $\begin{array}{c}0.167 \\
{[0.020]}\end{array}$ & $\begin{array}{c}0.104 \\
{[0.028]}\end{array}$ & $\begin{array}{c}0.119 \\
{[0.068]}\end{array}$ & $\begin{array}{l}-0.018 \\
{[0.007]}\end{array}$ & $\begin{array}{c}0.085 \\
{[0.021]}\end{array}$ & $\begin{array}{c}0.083 \\
{[0.034]}\end{array}$ & $\begin{array}{c}0.002 \\
{[0.001]}\end{array}$ \\
\hline 2 nd poorest wealth quantile & $\begin{array}{c}0.096 \\
{[0.016]}\end{array}$ & $\begin{array}{c}0.086 \\
{[0.021]}\end{array}$ & $\begin{array}{c}0.051 \\
{[0.026]}\end{array}$ & $\begin{array}{c}0.132 \\
{[0.052]}\end{array}$ & $\begin{array}{l}-0.013 \\
{[0.006]}\end{array}$ & $\begin{array}{c}0.052 \\
{[0.019]}\end{array}$ & $\begin{array}{c}0.048 \\
{[0.030]}\end{array}$ & $\begin{array}{c}0.000 \\
{[0.001]}\end{array}$ \\
\hline 3rd poorest wealth quantile & $\begin{array}{c}0.225 \\
{[0.016]}\end{array}$ & $\begin{array}{c}0.217 \\
{[0.022]}\end{array}$ & $\begin{array}{c}0.113 \\
{[0.031]}\end{array}$ & $\begin{array}{c}0.183 \\
{[0.060]}\end{array}$ & $\begin{array}{l}-0.023 \\
{[0.007]}\end{array}$ & $\begin{array}{c}0.109 \\
{[0.022]}\end{array}$ & $\begin{array}{c}0.119 \\
{[0.034]}\end{array}$ & $\begin{array}{c}0.001 \\
{[0.001]}\end{array}$ \\
\hline 4th poorest wealth quantile & $\begin{array}{c}0.410 \\
{[0.017]}\end{array}$ & $\begin{array}{c}0.400 \\
{[0.023]}\end{array}$ & $\begin{array}{c}0.270 \\
{[0.036]}\end{array}$ & $\begin{array}{c}0.326 \\
{[0.069]}\end{array}$ & $\begin{array}{l}-0.065 \\
{[0.009]}\end{array}$ & $\begin{array}{c}0.223 \\
{[0.026]}\end{array}$ & $\begin{array}{c}0.168 \\
{[0.039]}\end{array}$ & $\begin{array}{c}0.001 \\
{[0.001]}\end{array}$ \\
\hline Richest wealth quantile & $\begin{array}{c}0.655 \\
{[0.019]}\end{array}$ & $\begin{array}{c}0.690 \\
{[0.028]}\end{array}$ & $\begin{array}{c}0.461 \\
{[0.047]}\end{array}$ & $\begin{array}{c}0.522 \\
{[0.085]}\end{array}$ & $\begin{array}{l}-0.100 \\
{[0.011]}\end{array}$ & $\begin{array}{c}0.416 \\
{[0.032]}\end{array}$ & $\begin{array}{c}0.269 \\
{[0.047]}\end{array}$ & $\begin{array}{c}0.001 \\
{[0.001]}\end{array}$ \\
\hline India $\times$ Open defecation & $\begin{array}{l}-0.180 \\
{[0.023]}\end{array}$ & $\begin{array}{l}-0.151 \\
{[0.032]}\end{array}$ & $\begin{array}{c}0.010 \\
{[0.048]}\end{array}$ & $\begin{array}{l}-0.147 \\
{[0.099]}\end{array}$ & $\begin{array}{c}0.008 \\
{[0.011]}\end{array}$ & $\begin{array}{l}-0.086 \\
{[0.035]}\end{array}$ & $\begin{array}{l}-0.013 \\
{[0.054]}\end{array}$ & $\begin{array}{l}-0.002 \\
{[0.001]}\end{array}$ \\
\hline Open defecation & $\begin{array}{c}0.084 \\
{[0.017]}\end{array}$ & $\begin{array}{c}0.122 \\
{[0.023]}\end{array}$ & $\begin{array}{l}-0.030 \\
{[0.035]}\end{array}$ & $\begin{array}{c}0.134 \\
{[0.083]}\end{array}$ & $\begin{array}{c}0.005 \\
{[0.008]}\end{array}$ & $\begin{array}{l}-0.003 \\
{[0.027]}\end{array}$ & $\begin{array}{l}-0.056 \\
{[0.045]}\end{array}$ & $\begin{array}{c}0.001 \\
{[0.001]}\end{array}$ \\
\hline India $\times$ Meat or eggs consumed & $\begin{array}{c}0.009 \\
{[0.025]}\end{array}$ & $\begin{array}{l}-0.059 \\
{[0.037]}\end{array}$ & $\begin{array}{c}0.011 \\
{[0.047]}\end{array}$ & $\begin{array}{l}-0.069 \\
{[0.093]}\end{array}$ & $\begin{array}{l}-0.018 \\
{[0.011]}\end{array}$ & $\begin{array}{c}0.031 \\
{[0.033]}\end{array}$ & $\begin{array}{c}0.074 \\
{[0.046]}\end{array}$ & $\begin{array}{l}-0.000 \\
{[0.001]}\end{array}$ \\
\hline Meat or eggs consumed & $\begin{array}{c}0.183 \\
{[0.015]}\end{array}$ & $\begin{array}{c}0.187 \\
{[0.022]}\end{array}$ & $\begin{array}{c}0.134 \\
{[0.027]}\end{array}$ & $\begin{array}{c}0.123 \\
{[0.067]}\end{array}$ & $\begin{array}{l}-0.027 \\
{[0.007]}\end{array}$ & $\begin{array}{c}0.089 \\
{[0.019]}\end{array}$ & $\begin{array}{c}0.002 \\
{[0.031]}\end{array}$ & $\begin{array}{c}0.000 \\
{[0.001]}\end{array}$ \\
\hline India $\times$ Dairy products consumed & $\begin{array}{l}-0.050 \\
{[0.026]}\end{array}$ & $\begin{array}{l}-0.058 \\
{[0.038]}\end{array}$ & $\begin{array}{c}0.037 \\
{[0.046]}\end{array}$ & $\begin{array}{c}0.128 \\
{[0.093]}\end{array}$ & $\begin{array}{l}-0.000 \\
{[0.011]}\end{array}$ & $\begin{array}{c}0.006 \\
{[0.034]}\end{array}$ & $\begin{array}{c}0.006 \\
{[0.046]}\end{array}$ & $\begin{array}{c}0.003 \\
{[0.001]}\end{array}$ \\
\hline Dairy products consumed & $\begin{array}{c}0.209 \\
{[0.017]}\end{array}$ & $\begin{array}{c}0.174 \\
{[0.024]}\end{array}$ & $\begin{array}{c}0.095 \\
{[0.030]}\end{array}$ & $\begin{array}{c}0.105 \\
{[0.074]}\end{array}$ & $\begin{array}{l}-0.016 \\
{[0.007]}\end{array}$ & $\begin{array}{c}0.095 \\
{[0.022]}\end{array}$ & $\begin{array}{l}-0.018 \\
{[0.035]}\end{array}$ & $\begin{array}{l}-0.002 \\
{[0.001]}\end{array}$ \\
\hline Africa mean of outcome & -1.163 & -1.163 & -1.163 & -1.163 & 0.311 & -0.838 & 10.439 & 0.050 \\
\hline Child's age dummies $\times$ India & No & No & Yes & Yes & Yes & Yes & Yes & Yes \\
\hline Mother's age at birth $\times$ India & No & No & Yes & Yes & Yes & Yes & Yes & Yes \\
\hline PSU FEs & No & No & Yes & Yes & Yes & Yes & Yes & Yes \\
\hline Completed fertility sample & No & No & No & Yes & No & No & No & No \\
\hline $\mathrm{p}$-Value of joint significance test & 0.000 & 0.000 & 0.000 & 0.000 & 0.000 & 0.000 & 0.000 & 0.029 \\
\hline Observations & 145,957 & 145,957 & 139,245 & 43,381 & 139,245 & 139,245 & 84,690 & 75,570 \\
\hline
\end{tabular}

Notes: Standard errors are clustered by mother and appear in brackets. Please consider the notes in Table 2.6 for further explanations. Source: Adapted from J+P using data from IPUMS DHS (ICF, 2004) and DHS (Heger Boyle \& Sobek, 2019) 
the calculated gradient proxies for Africa are also negative just like in India. A negative proxy implies differences in height depending on the birth order favoring firstborns.

When we add up the coefficients of the macro-determinants for the accounting exercise, we find that the macro-determinants contribute to the explanation of the height gap between Indian and African children. ${ }^{14}$ To conclude, the results of this extension show that the emerging macro-determinants are drivers of child height, especially female literacy, economic growth, and the nutrition transition. Birth order and son preference are sensitive to the addition of the macro-determinants and so have less explanatory power in the extension.

\section{Discussion}

The results of this replication and extension study show that J+P's eldest son preference is sensitive to specification. Using weights or more recent data the birth order gradient is less steep. When interpreting the results we should have certain limitations in mind.

The presented evidence is overall descriptive, not causal evidence. We want to support our evidence with checks of our methodology and sample. To lend our results more credibility, we are planning to conduct placebo tests to check our methodology by using other outcomes that are not related to child development where we expect not to detect an effect. If we found an "effect", we would have to question the validity of our identification strategy (Jones, 2009). To ensure that our results are not driven by the selection of our sample of countries, we are planning to conduct Monte Carlo simulations to assess how a different African sample would influence our results just like Spears (2018). We will also conduct similar Monte Carlo simulations for different weighing options of the data.

The used data considers families that have or have not yet completed their fertility. So, the health outcomes of the children might not yet reveal the parents' birth order or gender preferences completely. They might only practice discriminatory behavior with completed fertility. We are also not controlling for the number of siblings that seems to be a crucial omitted variable when assessing child survival (Spears et al., 2019). We are not integrating this omitted variable because we want to focus on other methodological aspects. However, we are planning to conduct an additional robustness check including the omitted variable of the number of siblings as

\footnotetext{
${ }^{14}$ The accounting exercises can be found in the appendix. The simple extension of the back-of-the-envelope calculations allows us to report whether the macro-determinants provide additional explanatory power, however, the reported magnitude of the simple calculations are not meaningful.
} 
a next step.

The measures used for our analysis might have errors due to the data collection in different settings or the use of different survey questions in the case of the nutrition indicators we are using. Another concern is that we make the implicit assumption that the growth potential of Indian and African children based on gens or health endowments of parents is not distinct. We use the WHO standards to calculate the HFA z-scores and WFA z-scores. We are also only using the information of whether a household defecates in the open as a measure. This does not account for the disease environment or the externality of open defecation behavior of neighbors or residents in the same PSU (Spears, 2018).

Macro-determinants help to explain children's health outcomes but alone they do not bridge the difference between Indian and African children. The puzzle of the "Asian Enigma" has not been solved completely in our study because in regressions with only the emerging macrodeterminants the India dummy is still significant. However, other researchers, in particular, Spears (2018) offers a rather convincing explanation: the disease environment caused by the externality of open defecation. We only included a dummy in our study about the ownership of toilets but not about the behavior of neighboring households. The externality is captured in our study by the PSU fixed effects. The decomposition analysis of drivers of child stunting in South Asia by Headey et al. (2016) also provides more potential factors that might be important to consider. Other emerging macro-determinants that we do not focus on but might also be driving the health outcomes is the level of urbanization.

Our results should be interpreted keeping in mind the descriptive character of our study, the specific sample, the potential measurement errors in the data, and the selected determinants of the "Asian Enigma" in this study.

\section{Conclusion}

The results of this replication and extension study have several important implications for the cross-country assessment of health outcomes.

In our extension, we use emerging macro-determinants in the past ten years that evolved differently in India and Africa: mother's education, household prosperity, open defecation, and consumption of animal sourced foods. We find that the birth order gradient is not robust to the inclusion of these macro-determinants. The explanatory power of birth order gradients is 
reduced.

When testing the sensitivity of the eldest son preference hypothesis by $\mathrm{J}+\mathrm{P}$, we find that parental preferences seem to explain the "Asian Enigma" less in recent years or the weight-adjusted previous years. For this, we use first the same methodology but more recent data from around 2015 and then adjusted methodology and the data from the original time period. In both of these analyses, the eldest son preference or differences between the birth order of the children are not the key to explaining the differences in height for Indian and African children.

Using weights, we are not even able to conduct the same back-of-the-envelope calculations as $\mathrm{J}+\mathrm{P}$ for the time period around 2015 because it is based on the assumption that the birth order gradient is absent in Africa. This is not the case. Birth order gradients exist even beyond India and might be rooted more in gens or health endowments like mothers' height than of culture favoring a certain gender and birth order. Future research should work on the separation between health endowments and health investments like cultural birth order effects keeping the changing macro-determinants in mind. 


\title{
$3 \mid$ Essay 2: Long-Term Evidence of a Cluster Ran- domized Controlled Trial: Double Fortified Salt Usage for Health and Human Capital Acquisition of School Children in Rural Bihar
}

\begin{abstract}
To what degree timing and duration of exposure to a long-term nutrition intervention matter for child development is hardly considered in research. We provide evidence by examining the effectiveness of a follow-up to a randomized controlled trial delivering iron and iodine fortified salt for the school feeding program of 107 randomly selected governmental schools in Bihar, India. Using panel data of about 1,000 school children, we analyze the difference in means of the health, cognition, and education outcomes for four different exposure groups varying in onset and duration. Our results show on average higher hemoglobin levels for children who receive fortified salt at least in early childhood. Early childhood exposure matters especially because the likelihood of suffering from moderate and severe anemia in early adolescence is 8.6 percentage points lower compared to children who are hardly exposed to fortiï $\neg$ edsalt.
\end{abstract}

\footnotetext{
${ }^{1}$ This is joint work with Abhijeet Kumar, Santosh Kumar, and Sebastian Vollmer.
} 


\section{Introduction}

Many existing nutrition interventions evaluate the short-term effects on child health. The focus lies more on "if" exposure to a nutrition treatment matters for child health but less to what degree timing and duration of exposure to a long-term nutrition intervention improve child development.

This is why we strive to answer the following research question: Does timing and duration of the use of salt fortified with iron and iodine called double-fortified salt [DFS] in the Indian school lunch determine child development?

For this, we examine the effectiveness of a follow-up to a randomized controlled trial that is inspired by a directive issued by the Indian Ministry of Women and Child Development that postulates all government run schools to use DFS in the Midday-Meal-Scheme [MDM], the Indian school feeding program to improve children's diets (Ministry of Human Resource Development, 2015). Increasing the iron intake improves the development potential of children because 15 to 90 percent of Indian school children between 5 and 15 years of age are anemic and half of this stems from iron deficiency due to iron-poor diets (Allen et al., 2006; AlvarezUria et al., 2014). However, DFS is hardly available on the market, so schools cannot purchase and use it (Krämer et al., 2020). Therefore, we established a supply chain of DFS for up to 107 governmental schools in two blocks of the district Jehanabad in the state of Bihar, India. Half of the 107 randomly selected primary and middle schools are chosen by chance to receive DFS starting in 2015 or 2017 . Within each school, we randomly choose on average 20 students in second grade in 2014.

To capture the effect of onset and duration of this nutrition intervention, we follow up with the selected children even after they change to another governmental led middle school [MS]. So the sample has been enlarged by 16 untreated middle schools after the maximum treatment period of 4 years. Due to the variation in the start and the end of the treatment, we examine the intention-to-treat [ITT] effect of DFS use for four different exposure groups: a) children who receive DFS from third grade in 2015 onward, b) children who receive DFS from fifth grade in 2017 onward, c) children who receive DFS from third grad in 2015 to the end of fifth grade in 2018 , and d) children who are hardly exposed. The longest treatment period is about four years, 48 months (from August 2015 to July 2019).

This paper contributes to the literature by considering the so far longest treatment period of DFS 
in the MDM -a maximum treatment period of about 4 years-, by examining different treatment periods and duration, and by investigating how a childhood intervention (in third grade) unfolds in outcomes for young adolescents (in sixth grade).

Examining the consequences of long-term treatment is in accordance with the recent article by Bouguen et al. (2018) who call for looking beyond short-term treatment effects of RCTs. However, our study does not focus on the long-term impacts of short-term treatment, i.e. a short duration of treatment and a long duration between treatment end and follow-up. We rather consider the cumulative effect of treatment and whether an earlier or later onset determines child health, cognition, and education outcomes. Like Chhabra et al. (2019) we are interested in the policy-relevant effects of a program. These "full" effects of a program are distinct from "production function" effects that are early measurable outcomes of a program according to Glewwe \& Muralidharan (2016). Nevertheless, our study differs also from the study by Chhabra et al. (2019) because we do not examine differential program effects on later and early cohorts but we follow only one cohort over a long period of treatment time.

Further, we add to research about food fortification in school lunches for improved child nutrition by examining the effectiveness of four treatment periods within one study. We extend the study by Krämer et al. (2020) who assess the short-term effects of an intervention in the MDM after 1 year of DFS supplementation by providing evidence about how four different treatment periods varying in onset and duration of DFS exposure affect child development. Thus, we provide novel insights into the effectiveness of DFS in the MDM for possible implementation options.

The last contribution is linked to the long treatment duration that starts in one life stage but ends in another. The exposure to DFS starts in childhood when children are on average 8 years of age in third grade. Our measures collected after the treatment period of maximum of 4 years capture health and other human development outcomes of children with an average age of 11 years in sixth grade. This age group is in early adolescence. Thus, our study provides evidence of how exposure to DFS in one life stage, childhood, can affect another life phase, adolescence. In general, the unique duration and variation of the treatment contribute to the understanding of exposure effects of nutrition interventions.

As we build on the RCT supplying DFS for the Indian MDM by Krämer et al. (2020), we work with a panel data set of about 1,000 children after the treatment period of maximum of 4 years. The data collection includes a household survey, cognitive ability tests, health assessments, 
observations at the school level, administrative records of attendance as well as interviews of headmasters and school cooks.

For the data analysis, we measure the effectiveness of the introduced policy using ANCOVA estimation techniques corrected for attrition to assess the difference in means of the health, cognition, and education outcomes of the four exposure groups.

Our results show that compared to a child group that is hardly exposed to DFS in the MDM, children who receive DFS at least in early childhood (from third to fifth grade) have on average a higher hemoglobin level of $0.260 \mathrm{~g} / \mathrm{dL}$. Exposure in early childhood alone reduces the likelihood of a child being moderate or severe anemic by 8.6 percentage points compared to the children who are only exposed to DFS for 4 months in later childhood. Nevertheless, the exposure of about 4 years starting in early childhood in the third grade does not seem to suffice to improve cognitive ability or education outcomes in early adolescence in sixth grade.

The results have high policy relevance as they show the potential of fortified foods in school feeding programs to increase the health of adolescents without crowding out other interventions. The results highlight that early childhood exposure is long-lasting and so could benefit children even when schools are closed.

The paper proceeds as follows. The next section provides a more detailed description of the background and the literature. Section 3 describes the exposure groups, data collection, and measures of the panel data. In section 4 we propose our estimation strategy and discuss possible internal validity threats with a focus on attrition. We present the results in section 5 and discuss these in section 6 . Section 7 concludes.

\section{Background and Literature Review}

As our study focuses on the supply of DFS for use in the MDM at government schools, we provide a brief overview of the characteristics of the Indian school feeding program and the state of iron deficiency in India in the appendix. Here we only focus on the coverage of DFS interventions in the MDM in the scientific literature.

This paper contributes to the existing literature by examining a long-term nutrition intervention of DFS in a public distribution channel, by focusing on the effect of a childhood intervention for outcomes in early adolescents, and by considering different exposure periods within one study. Pure DFS has been used as a treatment in the MDM at a large scale only by Krämer et al. (2020) 
before. They assess the effect of DFS in the MDM over a period of 1 year at government-funded schools in two blocks of the district Jehanabad in Bihar, India. The RCT covers 54 randomly selected treatment schools that receive the DFS and 53 control schools that use iodized salt. The assessed outcomes are hemoglobin levels, cognitive ability, and educational achievements of 2,000 children in second grade at baseline. Krämer et al. (2020) conclude that the inclusion of DFS reduces the prevalence of any form of anemia by 20 percent. Treated children with higher school attendance more than 80 to 90 percent have even larger improvements in anemia and test scores.

Other rigorous studies using the same DFS formula in India focus on another public channel: the Public Distribution System [PDS]. A. Banerjee et al. (2013) find that only 13 percent of customers at the PDS shops and 33 percent of customers at private shops choose to buy subsidized DFS instead of conventional salt. The consumption of DFS declines after 2 to 3 years of the roll-out: only 10 percent of customers consume subsidized DFS. The provision of DFS free of costs to randomly selected households is examined by A. Banerjee et al. (2018). They find that despite the free delivery only 61 to 75 percent of households use the DFS. Nevertheless, the availability of DFS in shops or free delivery of DFS for a period of about 2 years benefits adolescents. Their hemoglobin levels increase slightly and the fraction of anemia of this age group decreases.

Further, some studies with school level treatment use multiple fortified salts for meals and find increases in hemoglobin levels and even in memory and attention for children between the age of 5 and 18 (Sivakumar et al., 2001; Kumar \& Rajagopalan, 2007; Vinodkumar \& Rajagopalan, 2009). However, the sample sizes are smaller than the one by Krämer et al. (2020) and the treatment period is 1 year, less than in A. Banerjee et al. (2018). The MDM is also used to provide other micronutrients or fortified rice in India like the study by Berry, Mehta, et al. (2020) in which the impact of the usage of a micronutrient mix to fortify the MDM in Odisha, India, is assessed. The authors do not find any effects on hemoglobin levels, child health, and subsequently human capital measures of cognitive or learning outcomes. Other studies using DFS find effects on hemoglobin levels, too (Radhika et al., 2011; Osei et al., 2010; Pinkaew et al., 2013). However, the sample sizes and exposure periods do not surpass the studies introduced at the beginning of this subsection.

Despite the evidence that longer-term iron supplementation has positive effects on the cognitive performance of children older than 2 years of age and adolescents, iron nutrient interventions 
targeting early adolescents in India are rare (Bryan et al., 2004). Exceptions are the evaluations of India's Adolescent Girls' Anaemia Control Programme or a study conducted by Deshmukh et al. (2008) that fails due to lack of compliance in taking iron supplements. More recently Berry, Mehta, et al. (2020) examine the usage of the MDM to provide iron folic acid [IFA] supplementation for adolescents. They provide evidence on the supplementation of IFA in Odisha, India, for primary school children who attend the first to the fifth grade, but not the sixth grade like in our study. They find that the IFA program has significant large effects for moderately anemic students in schools that are distributing tablets more recently compared to schools that run out of tablets.

Our study adds to the existing literature by looking at the until now longest treatment period of DFS in the MDM of up to 4 years, the effect of different exposure periods of DFS in one study, and how a childhood intervention starting in third grade unfolds in outcomes for young adolescents in the sixth grade.

\section{Study Design and Data}

In this section, we want to provide an overview of the study site and sample selection, the data collection methods, and the used measures. For the interested reader in the underlying causal pathway of the intervention, we recommend the study by Krämer et al. (2020) or the appendix.

\subsection{Study Site and Sample Selection}

For this study, Bihar is a suitable site because it is one of the poorest states in India. 34 percent of its population lived below the poverty line in 2012 with the second-largest share of India's poor (World Bank, 2016). It also ranks low in the Indian Health Index (NITI Aayog, n.d.). Anemia is also widespread 58.3 percent of women (age 15 to 49) are affected and 99.2 percent of girls (age 10 to 19) in 2015/2016 (George \& Ray, 2016). Jehanabad is chosen as the district in which the study is implemented. This district performs slightly better than Bihar on average regarding the share of anemic children below the age of 5 (61.5 percent of the district population) and anemic women in reproductive age (56.7 percent) (George et al., 2017).

We select our sample schools and children in the following way: Out of all 228 governmentfunded schools in two blocks (Kako and Modanganj) 54 schools are randomly selected to receive DFS since 2015 (See table in the appendix.). Among these are 31 primary schools [PS] 
that teach children from first to fifth grade and 23 middle schools [MS] that children can attend from first to at least eighth grade. The other 53 randomly selected schools (32 PS and 21 MS) are the schools that receive DFS since 2017. The different types of schools are not stratified. In this way, we create variation in the starting point of the DFS exposure.

Our target group is school children between 7 and 9 years of age because this age group has large potential to be affected in their cognitive abilities because of a particular developmental phase of the frontal lobes during this time (Thatcher, 1991). Thus, we select on average 20 children from second grade (April 2014 to March 2015) of each school. The sample of children with an average age of 6 years adds up to initially 2,000 (Krämer et al., 2020). As the MDM is prepared decentralized at own school kitchens and distributed directly to the children in this district, all school children when eating at school consume the DFS.

Apart from this random selection, we also include schools for the third data collection wave in a purposive way. We do this because 31 schools in our baseline sample are PS that only teach children until fifth grade. Thus, in April 2018 children attending a PS have to change to a MS to join the next highest grade, sixth grade. These schools are either a MS within or outside of our sample. The schools excluded in our sample could be either other governmental MS or private schools. In the data collection after the treatment period of maximum of 4 years children attend 20 PS and 23 MS which receive DFS since 2015 (referred to hereafter as early childhood) as well as 21 PS and 21 MS which receive DFS since 2017 (referred to hereafter as later childhood). To minimize attrition, we follow children who transition to 16 governmental schools that we subsequently include in the sample. Figure 3.1 visualizes the DFS delivery to the schools over time indicating the start of the supply and the wave of the data collection.

Due to the inclusion of both PS and MS in our sample, we have the chance to examine the effect of a long or short exposure duration. Children in fifth grade have to choose another school to continue their education. In Figure 3.2 we simplify the decision to either choosing to attend a school in our original sample (Group Always and Group Late) or not (Group Early and Group Hardly). In this way we have the advantage to observe the effect of DFS on four distinct exposure groups:

- Group Always contains all children who attend a school with the early start of DFS supply until fifth grade and any school (Early or Late) in our original sample after fifth grade. They receive DFS beyond fifth grade and so have the longest (48 months) and earliest exposure of the four groups. 
Figure 3.1: DFS Supply to Schools over Time
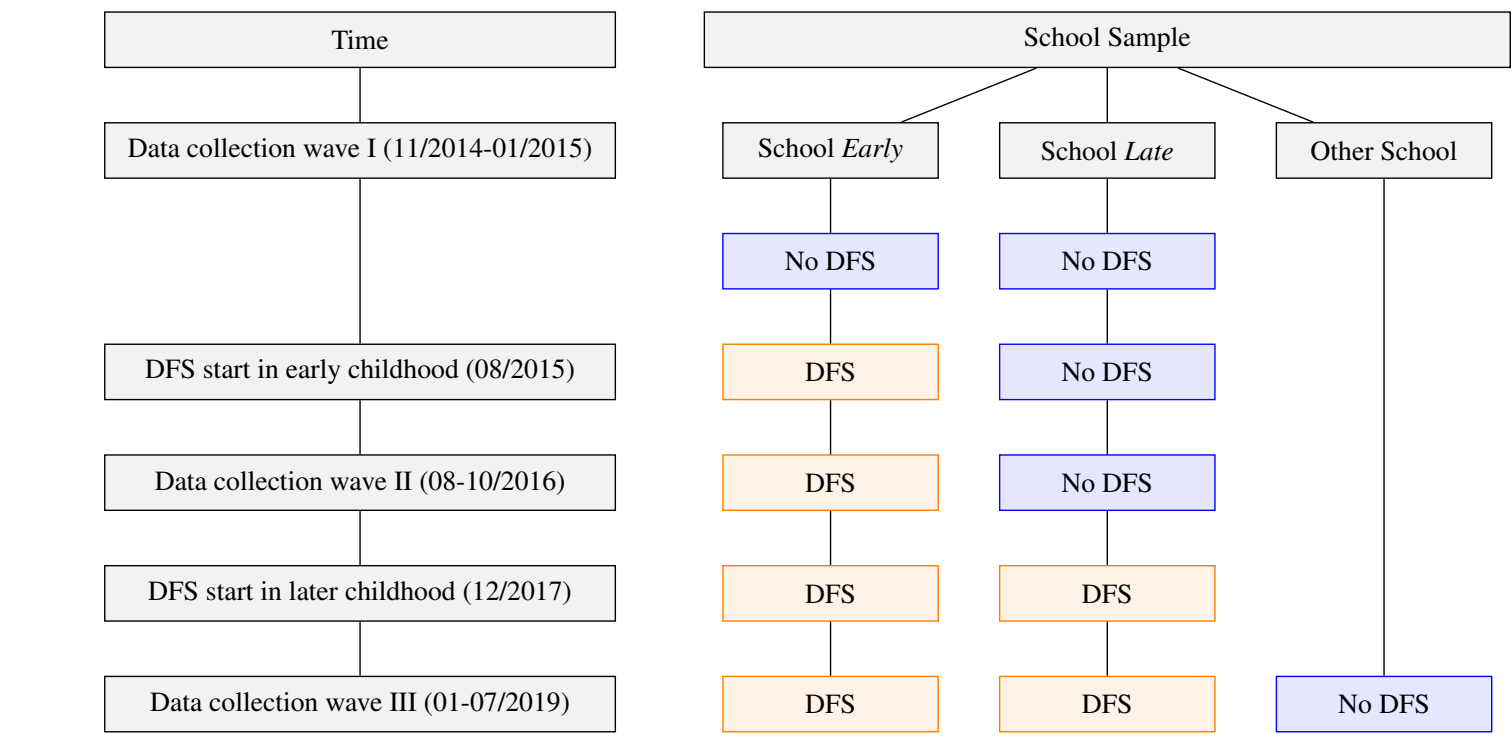

Notes: School Early indicates a start of the DFS supply in 2015 and school Late in 2017. Source: Own data.

- Group Early includes all children who attend a school with the early start of DFS supply until fifth grade and no school in our original sample after fifth grade. They receive DFS only until fifth grade and so have a short (32 months from August 2015 to March 2018) and early exposure to DFS (no exposure in the past 12 months August 2018 to July 2019).

- Group Late are all children who attend a school with the late start of DFS supply until fifth grade and any school in our original sample after fifth grade. They receive DFS starting at the end of fifth grade and so have a short (20 months from December 2017 to July 2019) and late exposure (exposure in the past 12 months August 2018 to July 2019).

- Group Hardly contains all children who attend a school with the late start of DFS supply until fifth grade and no school in our original sample after fifth grade. They receive DFS only briefly (4 months from December 2017 to March 2018) at the end of fifth grade and so have a late and the shortest exposure to DFS (no exposure in the past 12 months August 2018 to July 2019).

As the parents and children are not informed about the schools' supply with DFS, we are confident that the selection of the school after fifth grade is independent of the treatment status of the schools and so does not introduce selection bias. However, child and household characteristics might in general drive the selection of attending a certain type of school in any grade. 
Figure 3.2: Child Treatment over Time
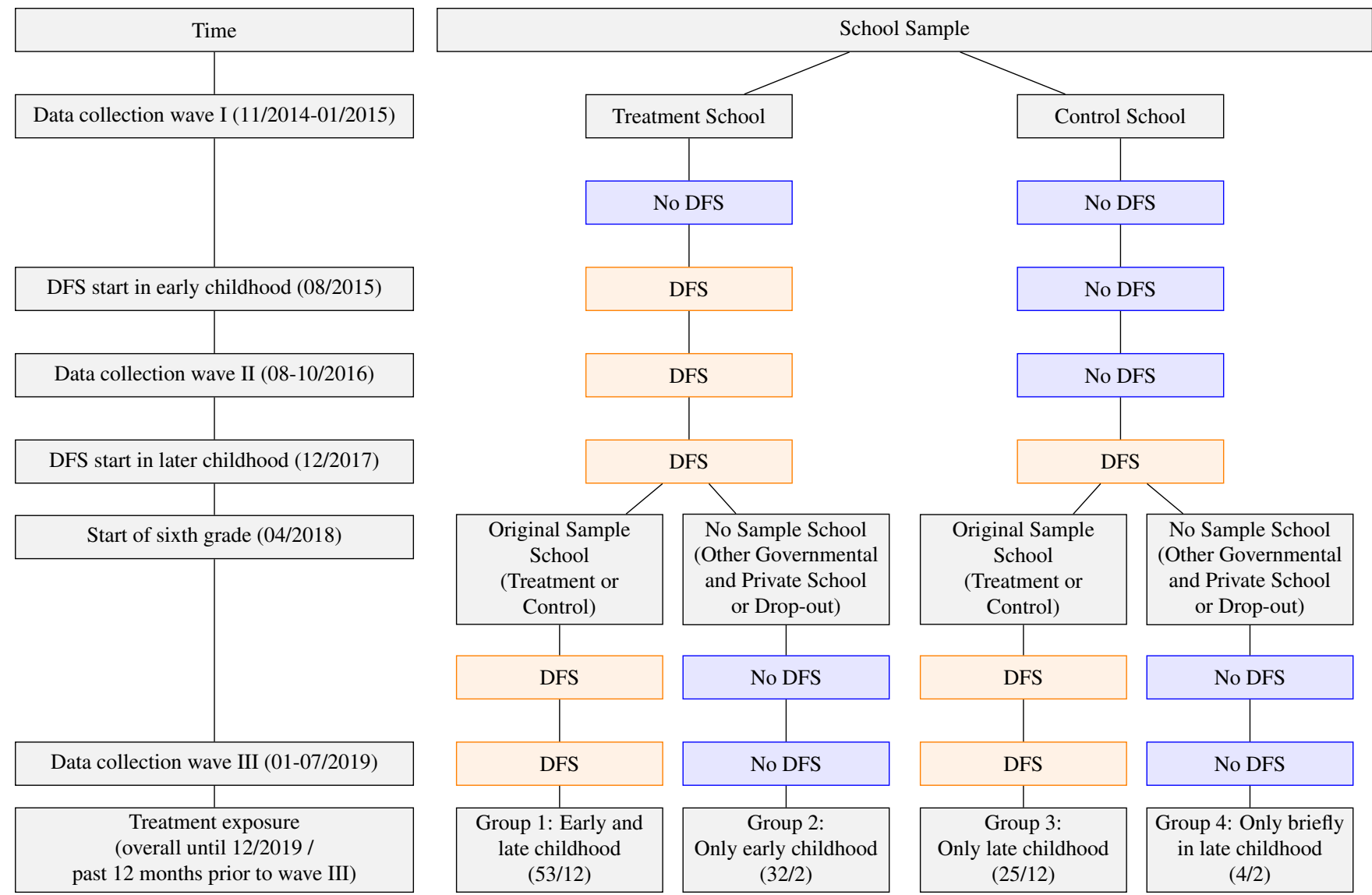

Source: Own data. 


\subsection{Data Collection}

To assess whether timing and duration of DFS matters, we have received ethical clearance for the intervention and the data collection by University Medical Center Göttingen and Georg August University of Göttingen. The intervention and data collection are also supported by the local administration, the Bihar Midday Meal Directorate and the local administration which have granted us access to the schools for the data collection waves and the delivery of DFS. The data collection waves follow the same procedure as described by Krämer et al. (2018). ${ }^{2}$

\subsection{Outcome and Covariate Measures}

For the assessment of the effects of DFS on children's health and human, we choose outcomes and covariates that are measured as consistently as possible across all three data collection waves. However, as we follow children over time, the cognitive ability tests are adjusted to be in line with the actual ability of the children and provide enough variability in the data. The focus in the following is to revise the chosen outcome variables by Krämer et al. (2018) briefly and to emphasize the differences of the measures in the third data collection wave. Krämer et al. (2018) provide a more detailed description.

\subsubsection{Health Measures}

The main health outcomes of interest are hemoglobin levels in $\mathrm{g} / \mathrm{dL}$, mild anemia status, moderate anemia status, and severe anemia status. ${ }^{3}$ Depending on the hemoglobin level we classify the anemia status of the children following the WHO (2011). ${ }^{4}$ As the age of the children varies within and across surveys, we have to apply different thresholds (see Figure in appendix). This adjustment is in particular necessary for the third data collection wave in which children are on

\footnotetext{
${ }^{2}$ However, there are some minor differences that we will mention in this footnote. Firstly, the duration of the questionnaires in the third wave is longer for the household interviews (on average 40 minutes) and the cognition and education tests (30 minutes). Secondly, in the last survey, an additional team plays a behavioral experiment with children and their parents at the schools. It follows the team conducting the cognition tests and precedes the medical staff. Thirdly, the third wave only includes MS for the headmaster, cook-cum-helper interviews, observations, and recording of attendance. These are the schools which children should attend in sixth grade. They are not permitted by law to stay at a PS after fifth grade.

${ }^{3}$ The hemoglobin levels are determined with the HemoCue ${ }^{\circledR} \mathrm{Hb} 301$ photometer (AB Leo Diagnostics, Helsinborg, Sweden) on-site because it only requires a drop of finger-prick blood for the test.

${ }^{4}$ Children between 5 and 11 years of age are considered severe anemic when their blood hemoglobin level is lower than $8 \mathrm{~g} / \mathrm{dL}$, moderate anemic with a level between $8 \mathrm{~g} / \mathrm{dl}$ to $10.9 \mathrm{~g} / \mathrm{dL}$, and mild anemic with a level between $11 \mathrm{~g} / \mathrm{dL}$ to $11.4 \mathrm{~g} / \mathrm{dL}$.
} 
average 11 years of age and 18 children are above 14 years of age. ${ }^{5}$ We also group moderate and severe anemia status because for severe anemia there are only eleven observations at the first data collection wave, one observation at the second wave, and three observations at the third wave (see table in the appendix). ${ }^{6}$

\subsubsection{Cognition Measures}

To assess cognitive ability and in particular executive functioning, we use a cognitive ability index based on five tests: block design, forward digit-span, backward digit-span, Raven's Colored Progressive Matrices, and a Stroop test (see table in the appendix). To account for a general increase in cognitive ability in the third data collection wave, we adjust or even employ new tests like the fruit/vegetable Stroop by Röthlisberger et al. (2010). ${ }^{7}$ Based on the five tests we use a principal component analysis to calculate a cognitive index. For the block design test and the Stroop test, we use the extended or new measures. The index is normalized by subtracting the baseline mean and dividing by the baseline standard deviation. The unit of the outcome is then standard deviations from the mean in the first data collection wave.

\subsubsection{Education Measures}

For examining the reading and math skills the Annual Status of Education Report [ASER] reading assessment tool and the ASER Math tool are used that are developed by the Indian Non-Governmental Organization Pratham (ASER Centre, 2014). However, the conduction of the test has been modified to accommodate the setting. ${ }^{8}$ The outcomes are normalized just like the cognition index.

School attendance is recorded from the official record books of the schools. The focus lies in

\footnotetext{
${ }^{5}$ The thresholds for moderate and severe anemia remain the same for children between 12 and 14 years of age, non-pregnant women aged 15 years and above, as well as men aged 15 years and above. Otherwise, the bounds for mild anemia widen for children above 12 and women to $11.9 \mathrm{~g} / \mathrm{dL}$ and men up to $12.9 \mathrm{~g} / \mathrm{dL}$. We adjust the anemia status according to age and gender.

${ }^{6}$ That includes all children that have taken the hemoglobin test and are in one of the four exposure groups.

${ }^{7}$ Adjustments to the previous data collection waves affect Raven's Colored Progressive Matrices, Block Design, and the Stroop test:The test matrices for the Raven's Colored Progressive Matrices are changed to avoid learning effects from previous rounds. For the block design we add two more pictures displaying a pattern in accordance to which the children are asked to arrange red and white colored blocks (Malin, 1969). When block design is used as an outcome in comparison with the previous surveys, the additional new patterns are censured. However, it remains uncensored in the calculation of the final cognition index. We provide more details about the fruit/vegetable Stroop in the appendix.

${ }^{8}$ At the first data collection wave the math exercises comprise of 13 , in the second wave of 15 , and in the third wave of 16. The scoring remains the same across waves except with additional chances to gain points in the math assessment due to the included exercises.
} 
particular on the past 12 months before the survey. The official records of many schools go only back for 12 months or to the start of the school year. The first data collection wave includes attendance data for the time between November 2013 and October 2014, the second wave for the time between August 2015 and July 2016, and the third wave for the time between January and December 2018. We calculate school attendance as the rate of the total number of days present of a child and the total number of days school is open for each time period.

\subsubsection{Covariate Measures}

We follow roughly the covariate choice by Krämer et al. (2018) for the health, cognition, and education outcomes but bring in school level covariates for all outcomes. We provide an overview table of the choice of our covariates in the appendix. For our empirical model, we use in particular the baseline data apart from three exceptions measured in the third data collection wave. We add another variable to account for the activities of the weekly IFA supplementation [WIFS] program. This governmental program provides once a week one IFA tablet containing $100 \mathrm{mg}$ elemental iron and $500 \mathrm{ug}$ folic acid for each child attending the sixth to the twelfth grade of government, government aided, or municipal schools (Ministry of Health \& Family Welfare, 2016). The provision is administered by the schools. The WIFS program has been introduced by India's Ministry of Health and Family Welfare in 2012 but only started again after the onset of our intervention (2014) in Bihar in late 2017. Only four schools have started distributing the tablets to children in 2018. In 2019 all but one school in our sample are actively participating in the WIFS. As the provision of IFA supplements could potentially bias our estimates, we add it as an additional control to the food intake covariates. IFA supplementation is measured as the number of days between the date the school starts providing IFA tablets to the child's grade and the date on which the health measurements of the child have been collected.

The other exceptions relate to the construction of the exposure groups. Two of the groups include children that only go to a private school or that have dropped out of school. Children attending private schools might perform better in cognition and education tests because of higher quality education. At private schools, more resources for more nutritious foods might be provided. This could increase the micronutrient status of the children. So, children attending government schools might be - independent of the DFS treatment - worse off than children attending private schools. Thus, we add a dummy of whether the child attends only a private school after fifth grade. Children who drop out of school do not receive any kind of free food 
or any kind of cognitive stimulation or educational input. They might be in general worse of than children attending government schools. Therefore, we also include a dummy for whether the child dropped out of school after fifth grade. ${ }^{9}$ This rich set of control variables related to socioeconomic, nutrition, health, and psychosocial interaction status ensures that other potential drivers of our child development outcomes are accounted for.

\section{Estimation Strategy}

To assess how timing and duration of exposure to DFS in the MDM affect health, cognition, and education outcomes of school children, we are discussing compliance, attrition, baseline balance, and the empirical specification in the following.

\subsection{Compliance}

In our study, we might face an internal validity threat by partial compliance on the school or the child level. Krämer et al. (2020) discuss potential compliance issues in more detail. We want to mention additional possible channels for partial compliance. On the child level children who are enrolled in a governmental school offering free lunch might not eat the MDM. At the third data collection wave, this is only the case for four children in our sample according to self-report by the tested children.

At school level, partial compliance might be a greater threat due to the switch of suppliers, strikes of cooks and helpers, and the production of DFS in Northern Bihar. Due to the lack of production, we had to switch the supplier for about 4 months in 2018. The interim supplier is a less known and so less accepted brand by the schools. We cannot fully overcome the concern that the treatment and control schools have not used another kind of salt during this time. The MDM has also not taken place in January and most of February in 2019 due to a strike of cookscum-helpers. In our study area, DFS has not been available and mostly unknown throughout the study region. Even though DFS has been started to be sold in Patna, the capital of Bihar, in early 2017, the production has been reduced or partly stopped due to low demand by our original supplier. Since 2018 a Bihari company manufactures also DFS and has started to supply districts in Northern Bihar. They have not spread the supply to Jehanabad district, though. So there is little chance that the school children receive DFS apart from the MDM. As compliance might

\footnotetext{
${ }^{9}$ Children who leave our original selected schools earlier than fifth grade are also captured by these variables if they continued this behavior during the third wave data collection.
} 
be impaired especially because of children's attendance, we measure the ITT effects and not the ATE.

\subsection{Attrition}

Another potential internal validity threat is attrition. In the following, we describe the causes and extent of attrition in our sample.

\subsubsection{Reasons for Sample Attrition}

When collecting the data in the third wave, we face additional challenges that decrease the number of complete information of participants. The first challenge is the revisit after more than 2 years that increases the likelihood of reallocation of households.

The children's life stage is also decisive because some parents might opt for private or boarding schools after children have completed PS and are considered old enough to be away from the family. The completion of PS increases the likelihood of the child to change the school. Another challenge is insufficient or contradictory information: Even though we have conducted the household interviews first, the available information about the attended school of the child remains often ambiguous. In few cases, children are reported to go to two schools, a governmental and a private school. Cases with missing or contradictory information of schools are considered incomplete and so increase the attrition by large. In the appendix, we illustrate with a flowchart at which stage children drop out of the health outcomes sample.

The different types of schools attended at baseline introduce differential attrition between the four exposure groups because children who attend MS until fifth grade only have to decide on their continuation of education if they want to attend private school, explicitly another school, or want to drop out. Instead, the children at PS until fifth grade do not have a default option to continue studying. For them a change to MS is mandatory. As there is no default for these children, ambiguous information does not allow to determine the attended school after fifth grade easily. Due to this, children going to PS until fifth grade are more likely to exit our analytical sample.

Children who attend PS until fifth grade are also more likely to continue education at a governmental or private school that is not in our original sample. Thus, they would mainly constitute group Early and Hardly with no exposure to DFS in later childhood. The selection into schools after fifth grade affects attrition. As our exposure groups are built on the attendance of certain 
Table 3.1: Correlation between Attrition and DFS Exposure Status

\begin{tabular}{lccc} 
Sample & Health Outcomes & $\begin{array}{c}\text { Cognition and } \\
\text { Education Outcomes }\end{array}$ & Attendance Outcome \\
\hline Group Always & $-0.105^{*}$ & $-0.208^{* *}$ & $-0.218^{*}$ \\
& {$[0.043]$} & {$[0.064]$} & {$[0.088]$} \\
Group Early & 0.022 & -0.008 & 0.083 \\
& {$[0.057]$} & {$[0.085]$} & {$[0.119]$} \\
Group Late & -0.074 & $-0.240^{* * *}$ & $-0.299^{* * *}$ \\
& {$[0.046]$} & {$[0.064]$} & {$[0.085]$} \\
\hline P-value: Group Always = Early & 0.006 & 0.003 & 0.003 \\
P-value: Group Always $=$ Late & 0.319 & 0.383 & 0.167 \\
P-value: Group Early $=$ Late & 0.049 & 0.001 & 0.000 \\
Attrition rate & & & \\
$\quad$ All & 0.211 & 0.308 & 0.349 \\
Group Always & 0.167 & 0.252 & 0.291 \\
Group Early & 0.294 & 0.453 & 0.592 \\
Group Late & 0.198 & 0.220 & 0.210 \\
$\quad$ Group Hardly & 0.272 & 0.460 & 0.509 \\
Observations & 1477 & 1477 & 1477 \\
& & & \\
\hline
\end{tabular}

Notes: Exposure group Hardly is used as reference category. Standard errors are clustered by PS-MS cluster and appear in brackets. *, **, *** denote significance at the $10 \%, 5 \%$ and $1 \%$ levels, respectively. The number of observations are all children we could group in one of the four exposure groups without ambiguity.

Source: Own Data

schools, the exposure groups are correlated with the combination of PS and MS attended by the children and so also associated with attrition. We argue that attrition depends on the school type and not the treatment because Krämer et al. (2020) show that the small treatment effect of DFS does not affect attrition for a shorter treatment period.

\subsubsection{Extent of Sample Attrition}

The attrition in our sample constitutes a challenge for the estimation of the exposure effects because it is high in frequency, differs between different exposure groups, and seems to be partly driven by observable baseline characteristics.

The attrition rate from baseline to the point in time after a treatment exposure of maximum of 4 years is 21.1 percent for health outcomes, 30.8 percent for cognition outcomes, maths and reading score, and 34.9 percent for the attendance outcome as Table 3.1 depicts. ${ }^{10}$ The attrition varies between the different exposure groups. Considering the health outcomes as an example the attrition varies between 16.7 percent in group Always to 29.4 percent in group Early (column

\footnotetext{
${ }^{10}$ In the appendix, we also depict the attrition rate considering different baselines.
} 
2). In general, groups Early and Hardly have larger attrition rates than groups Always and Late. This holds also for cognition and education samples and the attendance outcome sample. There are significant differences between the exposure groups related to attrition. For the health outcome samples the difference between group Always and Hardly, Always and Early, and Early and Late are statistically significant at the 5 percent significance level. For the other outcome samples there are statistically significant differences at least at the 10 percent significance level between group Always and Early, Always and Hardly, Early and Late, and Late and Hardly. This pattern reveals that attrition seems to be different in group Early and Hardly that transition out of the school with DFS supply due to school change compared to group Always and Late that mainly remain at schools with DFS supply. Overall, attrition of participants is correlated with the exposure group and so threatens internal validity.

In the appendix we examine differences in observable characteristics between the children in our analysis sample and those who dropped out and between drop-outs across the different exposure groups considering different baseline samples. We find statistically significant differences between the comparison groups. Thus, attrition is likely to bias our outcome estimates. As the exposure groups are correlated with attrition via the type of attended schools, we cannot exclude the possibility of differential or selective attrition. To correct for this selection bias, we use parametric and non-parametric attrition correction approaches. As a parametric attrition correction approach, we employ inverse probability weighting. We estimate the attrition weights with baseline characteristics and exposure group. As a non-parametric attrition correction approach, we use Lee bounds (Lee, 2009). These bounds create worst-case scenarios assuming that participants who select into the sample because of the treatment rank at the top or the bottom of the outcome distribution (Tauchmann, 2014). The group with less attrition is trimmed either from above or below. We report tightened Lee bounds in the text that use the baseline outcome and either quartiles, terciles, or dummies representing the group below or above the median of the outcome for more precise estimates. We report additional details and classical Lee bounds in the appendix.

\subsection{Pre-Intervention Balance}

Another interval validity threat is the pre-intervention imbalance of observable characteristics between the exposure groups. The random selection of schools into receiving DFS in early childhood for group Always and Early or in later childhood for group Late and Hardly at the 
beginning of the intervention should ensure that there are no systematic differences between these groups. However, as a change in schools is likely to be based on the child and household characteristics, that influences in which exposure group participating children fall into after the treatment period of maximum 4 years, differences at baseline between the four exposure groups are likely. When comparing baseline characteristics of the four exposure groups, our suspicion is confirmed: There are statistically significant differences between groups. We illustrate this by Table 3.2 which shows mean baseline outcomes and statistically significant differences between exposure groups for hemoglobin, any anemia, moderate or severe anemia, and reading score. We show extended baseline tables for covariates and other baselines in the appendix.

Due to the imbalance of the baseline means we control for the baseline characteristics that might influence the outcome following the outlined selection of covariates in the subsection about measures.

Table 3.2: Baseline Summary Statistics for Health Outcomes Sample (Balance Check) at Wave III Using Wave I Data as Baseline

\begin{tabular}{|c|c|c|c|c|c|c|c|c|c|c|c|}
\hline & \multirow[b]{2}{*}{$\begin{array}{l}\text { Obser- } \\
\text { vations }\end{array}$} & \multicolumn{4}{|c|}{ Means [Standard Deviations] } & \multicolumn{6}{|c|}{ p-value of difference } \\
\hline & & $\begin{array}{c}\text { Group } \\
\text { Al- } \\
\text { ways }\end{array}$ & Early & Late & Hardly & $\begin{array}{l}\text { Always- } \\
\text { Early }\end{array}$ & $\begin{array}{l}\text { Always- } \\
\text { Late }\end{array}$ & $\begin{array}{c}\text { - Always- } \\
\text { Hardly }\end{array}$ & $\begin{array}{l}\text { Early- } \\
\text { Late }\end{array}$ & $\begin{array}{l}\text { Early- } \\
\text { Hardly }\end{array}$ & $\begin{array}{l}\text { Late- } \\
\text { Hardly }\end{array}$ \\
\hline \multicolumn{12}{|c|}{ Panel A. Child level outcome variables } \\
\hline \multicolumn{12}{|c|}{ Health outcomes } \\
\hline Hemoglobin (g/dL) & 1,165 & $\begin{array}{l}11.401 \\
{[1.107]}\end{array}$ & $\begin{array}{l}11.458 \\
{[1.091]}\end{array}$ & $\begin{array}{l}11.586 \\
{[1.177]}\end{array}$ & $\begin{array}{l}11.709 \\
{[1.058]}\end{array}$ & 0.654 & 0.037 & 0.001 & 0.330 & 0.059 & 0.198 \\
\hline Any anemia & 1,165 & 0.501 & 0.493 & 0.430 & 0.373 & 0.887 & 0.033 & 0.002 & 0.271 & 0.052 & 0.161 \\
\hline Mild anemia & 1,165 & 0.208 & 0.204 & 0.184 & 0.155 & 0.907 & 0.289 & 0.135 & 0.559 & 0.268 & 0.427 \\
\hline Moderate/severe anemia & 1,165 & 0.293 & 0.289 & 0.246 & 0.218 & 0.943 & 0.157 & 0.024 & 0.451 & 0.210 & 0.400 \\
\hline \multicolumn{12}{|l|}{ Cognitive test outcomes } \\
\hline Cognitive score index & 1,135 & $\begin{array}{c}- \\
0.034 \\
{[1.009]}\end{array}$ & $\begin{array}{l}0.099 \\
{[0.950]}\end{array}$ & \begin{tabular}{l}
\multicolumn{1}{c}{} \\
0.071 \\
{$[0.976]$}
\end{tabular} & $\begin{array}{l}0.013 \\
{[1.012]}\end{array}$ & 0.365 & 0.740 & 0.730 & 0.280 & 0.622 & 0.569 \\
\hline \multicolumn{12}{|l|}{ Education outcomes } \\
\hline Math score & 1,138 & $\begin{array}{l}4.506 \\
{[3.841]}\end{array}$ & $\begin{array}{l}5.101 \\
{[3.657]}\end{array}$ & $\begin{array}{l}4.920 \\
{[3.679]}\end{array}$ & $\begin{array}{l}4.848 \\
{[3.675]}\end{array}$ & 0.372 & 0.427 & 0.527 & 0.797 & 0.724 & 0.902 \\
\hline Reading score & 1,138 & $\begin{array}{l}0.815 \\
{[1.118]}\end{array}$ & $\begin{array}{l}1.058 \\
{[1.205]}\end{array}$ & $\begin{array}{l}0.949 \\
{[1.166]}\end{array}$ & $\begin{array}{l}0.937 \\
{[1.089]}\end{array}$ & 0.099 & 0.273 & 0.441 & 0.498 & 0.525 & 0.945 \\
\hline School attendance & 1,112 & $\begin{array}{l}0.781 \\
{[0.172]}\end{array}$ & $\begin{array}{l}0.817 \\
{[0.138]}\end{array}$ & $\begin{array}{l}0.801 \\
{[0.157]}\end{array}$ & $\begin{array}{l}0.819 \\
{[0.139]}\end{array}$ & 0.124 & 0.363 & 0.116 & 0.395 & 0.921 & 0.361 \\
\hline
\end{tabular}

Notes: Columns 2-5 report baseline means by intervention arm for child in the study analysis. Columns 6-11 report p-values from tests on the equality of means for each variable.

Source: Own Data.

\subsection{Empirical Specification}

As already pointed out we will focus on estimating the ITT and not the ATE because of incomplete compliance on the child and school level. For the data analysis, we estimate the difference 
in means of the outcome variables of the four different exposure groups using analysis of covariance [ANCOVA]. It includes lagged baseline characteristics. We condition on the baseline level of outcomes because of two reasons: improving statistical power and controlling for baseline imbalance of the exposure groups (McKenzie, 2012). Our main estimation specification is the following:

$$
\begin{array}{r}
Y_{i s 1}=\alpha+\beta_{1} \text { Always }_{s}+\beta_{2} \text { Early }_{s}+\beta_{3} \text { Late }_{s}+\gamma_{0} Y_{i s 0} \\
+\gamma_{1} X_{i s 0}+\gamma_{2} W_{s 0}+\gamma_{3} X_{i s 1}+\mu_{s}+\epsilon_{i s}
\end{array}
$$

where $Y_{i s 1}$ represents the previously explained outcomes: hemoglobin level, anemia status, the cognitive ability index, reading scores, math scores, and school attendance. For the outcome anemia status, linear probability models are estimated. $i$ is used as a subscript indicating observations for child $i$ and $s$ for all combinations of PS and MS $s$. All standard errors are clustered at the school level, i.e. the PS-MS clusters. The subscript 1 indicates the time after the treatment period of maximum of 4 years.

$\alpha$ constitutes the intercept. Always $s_{s}$, Early $_{s}$, and Late $_{s}$ are dummy variables that turn to one when the PS-MS cluster is assigned to the respective group, it is zero otherwise. $\beta_{1}, \beta_{2}$, and $\beta_{3}$ represent the ITT estimators. The focus lies on the children who have observations for all three data collection waves. $Y_{i s 0}$ is the outcome of interest at baseline. To increase precision and to overcome baseline imbalance, we introduce control variables on the child level with the vector $X_{i s 0}$ and PS-MS cluster $W_{s 0}$ at baseline. We also include control variables that we measure in the same data collection wave as the outcome $X_{i s 1}$. This vector includes fixed effects for the test conductor of the child cognition and education tests, a private school dummy, a drop out dummy, and the number of days between the beginning of the IFA distribution to the child's grade and the day on which the medical tests are conducted. $\mu_{s}$ and $\epsilon_{i s}$ are independent and identically distributed errors across clusters and children within clusters.

We present the outcomes for three different estimation strategies. The first contains no control variables including the baseline outcome $Y_{i s 0}$. The second model includes the baseline outcome $Y_{i s 0}$ as a control variable. The last specification and main specification uses all discussed controls for the chosen outcome. To not only test whether there are statistically significant differences between the exposure group Always, Early, as well as Late and Hardly, we also conduct Wald tests of equality for differences between all other group combinations and report the p-values.

As attrition is correlated with school type and so the exposure groups, we address this issue 
by reporting results in the text using inverse probability weighting based on attrition status and tightened Lee-bounds for the treatment estimates.

To get to know more about how the exposure to DFS affects different groups, we conduct heterogeneous effects analysis using the same estimation strategy but using interaction terms or splitting the sample considering the attendance levels measured as the average attendance level in the fourth and sixth grade during the potential DFS exposure. For this, we plot marginal effects of the treatment exposure by attendance levels or we split the sample by different attendance levels (at least $60 \%, 70 \%$, or $80 \%$ ) or by attendance terciles.

\section{Results}

We use the empirical specification to measure the effects of timing and duration of exposure to DFS use in the MDM in child health, cognition, and education outcomes. We show results for a maximum treatment period of about 4 years adjusted for attrition and multiple hypotheses testing.

\subsection{Health Outcomes}

We find statistically significant differences between groups for hemoglobin for all three specifications comparing group Always to Hardly in Table 3.3 adjusting for attrition using IPW. Compared to a child group that is hardly exposed to DFS in the MDM, children who receive DFS for about 4 years have on average a higher hemoglobin level of $0.260 \mathrm{~g} / \mathrm{dL}$. For the specifications I and II, the comparison between group Late and Hardly also shows a significant difference at the 10 percent significance level. However, this effect is no longer significant in the main model (column 4). We also find a significant positive effect for group Early for specification III. Receiving DFS in early childhood only increases on average the hemoglobin level by $0.260 \mathrm{~g} / \mathrm{dL}$ compared to a group of children who is hardly exposed. This implies that exposure during early childhood and not so much in later childhood is important for higher hemoglobin levels.

We do not find statistically significant differences between groups for any form or mild anemia. Nevertheless, we find a statistically significant difference between group Late and Hardly in specifications I and II as well as for group Early and Hardly for specification III. There is also a significant difference between group Always and Early for specification III. On average, 


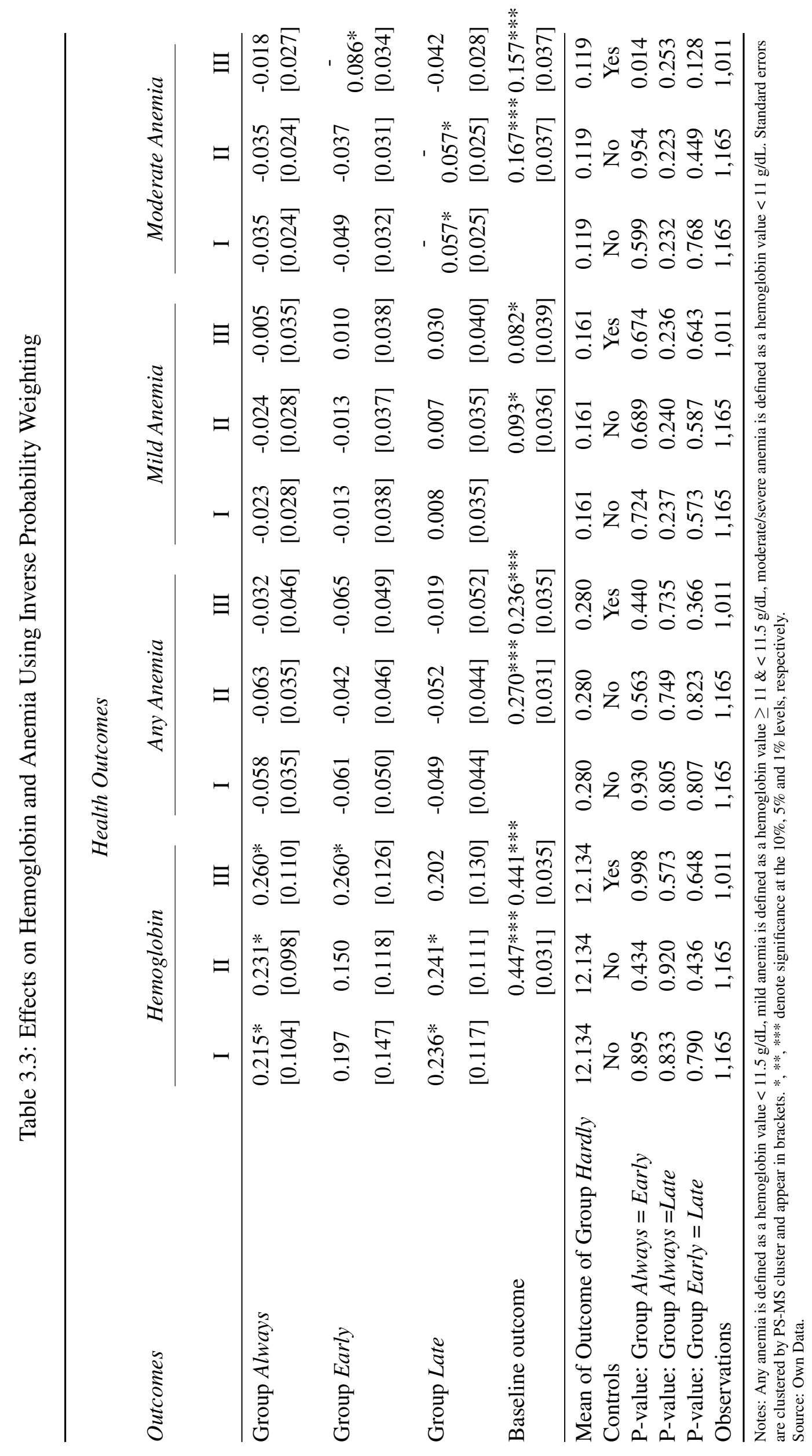




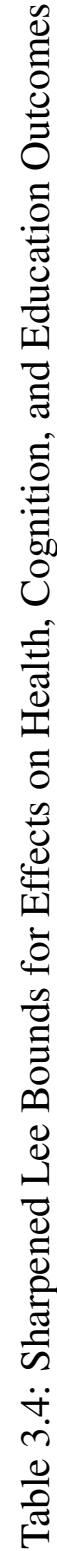

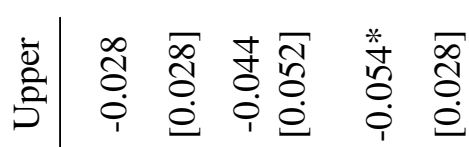

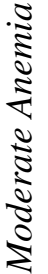

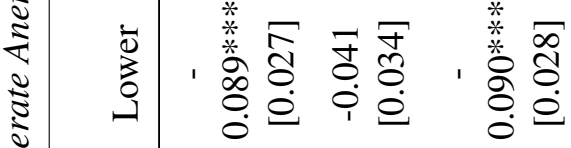

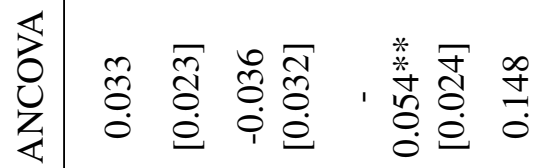

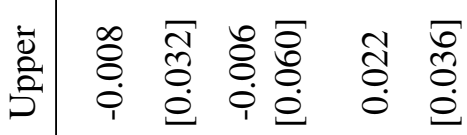

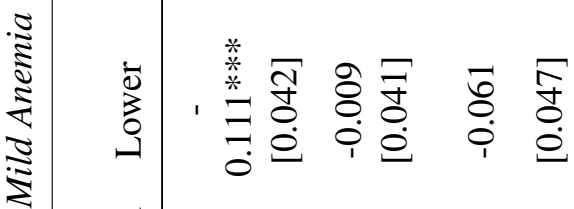

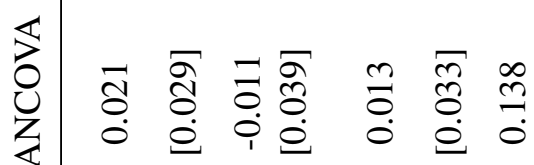

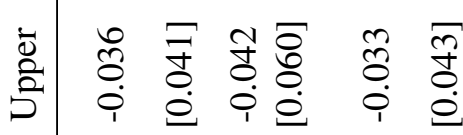

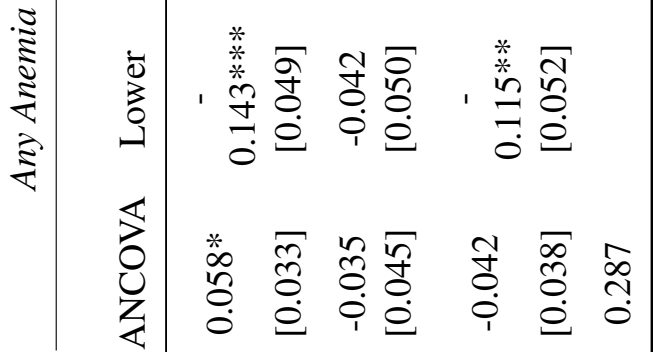

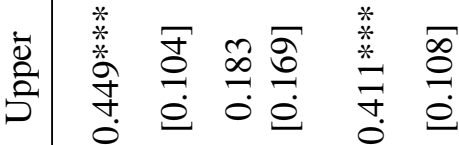

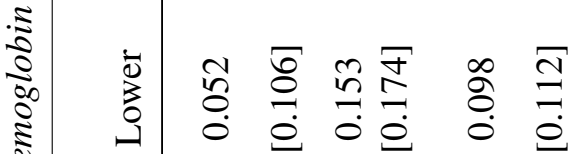

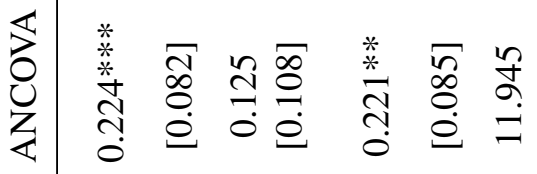

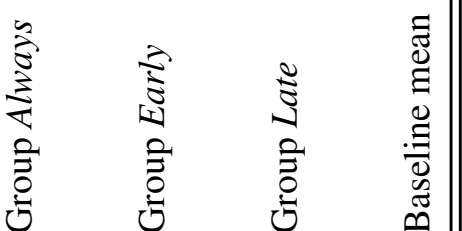

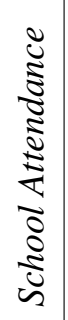

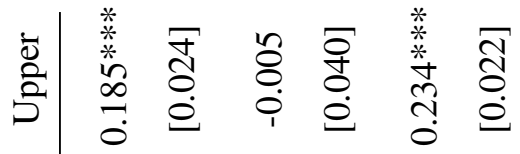

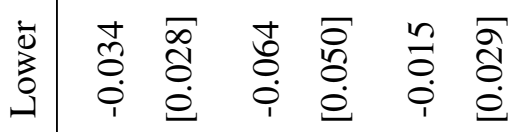

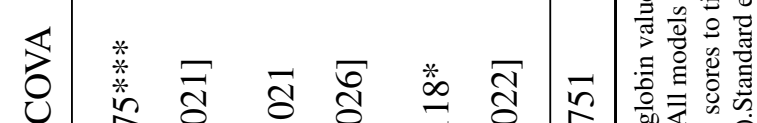

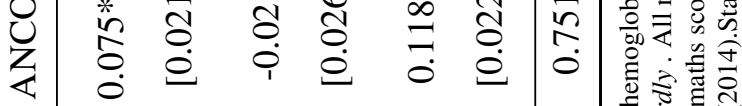

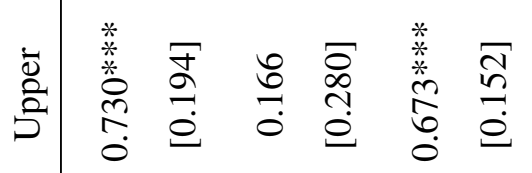

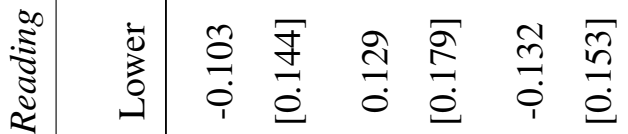

娄

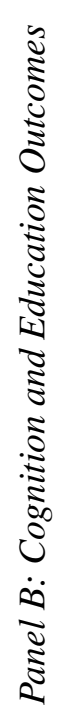

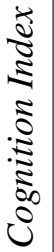

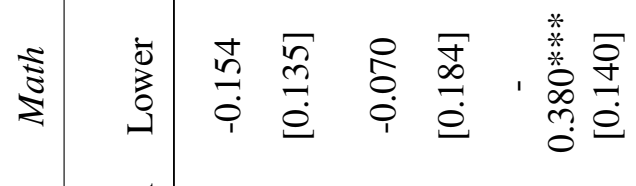

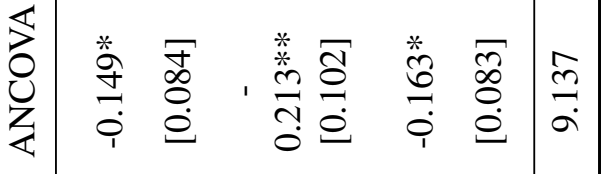

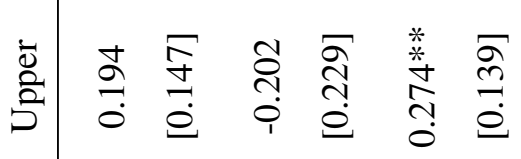

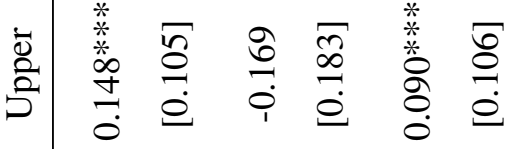

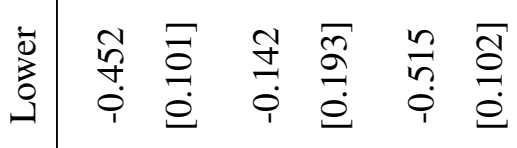

芆 * *

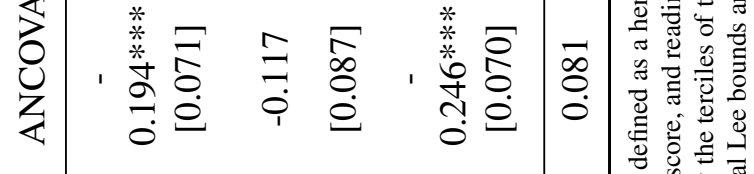

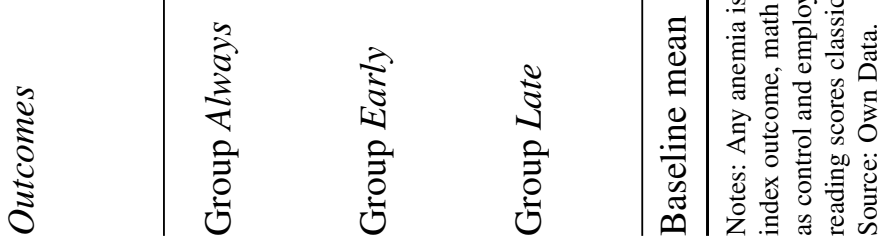




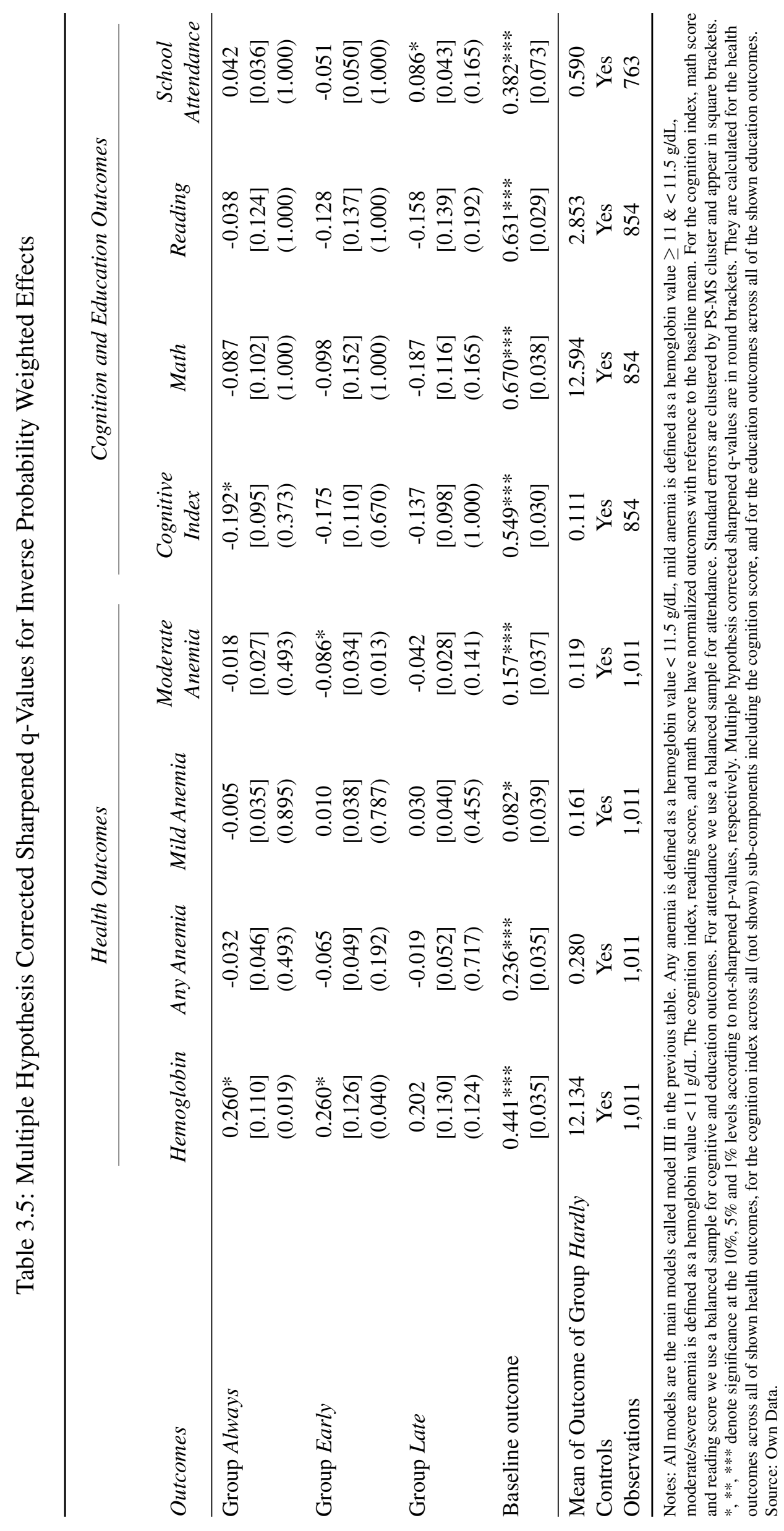


receiving DFS in early childhood reduces the likelihood of a child being moderate or severe anemic by 8.6 percentage points compared to children who receive DFS only briefly, less than 4 months. When we translate the significant effect into the prevalence of moderate/severe anemia, we find a reduction of 33 percent. ${ }^{11}$ We suppose that we are not able to observe improvements of moderate or severe anemia for group Always due to low power.

Regarding Lee bounds, we find no significant positive lower bounds for hemoglobin or negative upper bounds for anemia status in Table 3.4 Panel A that shows tightened Lee bounds. ${ }^{12}$

As testing for four different outcomes increases the probability of false rejection of at least one null hypothesis, we also correct standard errors for multiple hypothesis testing using the Benjamini-Hochberg method as a robustness check in Table 3.5 (Benjamini \& Hochberg, 1995; Benjamini et al., 2006). In the appendix, we report the sharpened q-values for further outcomes of the main specification. The estimated significant coefficients hold and have even smaller standard errors than in the main specification.

To examine the intensive margin of exposure to the treatment, we examine heterogeneous effects based on different attendance levels. However, the heterogeneity analysis is underpowered due to the small sample size. Though the intuition that greater attendance increases the effect sizes for health outcomes seems to hold, we hardly find statistically significant effects. To illustrate this issue, we show a margins plot for the outcome hemoglobin at different attendance levels in Figure 3.3. The 95 percent confidence intervals always include zero. Further evidence for all other outcomes is provided in the appendix.

\subsection{Cognition and Education Outcomes}

Next, we want to examine whether health effects transform into effects on cognition and education in Table 3.6.

\subsubsection{Cognition Index Score}

We start with describing the results for the cognition index. For specifications II and III, we find a statistically significant difference between group Always and Hardly suggesting that children who receive DFS for about 4 years have on average a 0.192 standard deviation lower score than children who consume it only briefly in later childhood, all else equal.

\footnotetext{
${ }^{11}$ This is the ratio of the coefficient divided by the baseline mean of non-attrited children after the treatment period of maximum 4 years: 8.6/26.

${ }^{12}$ We provide further details of the tightened and classical Lee bounds in the appendix.
} 


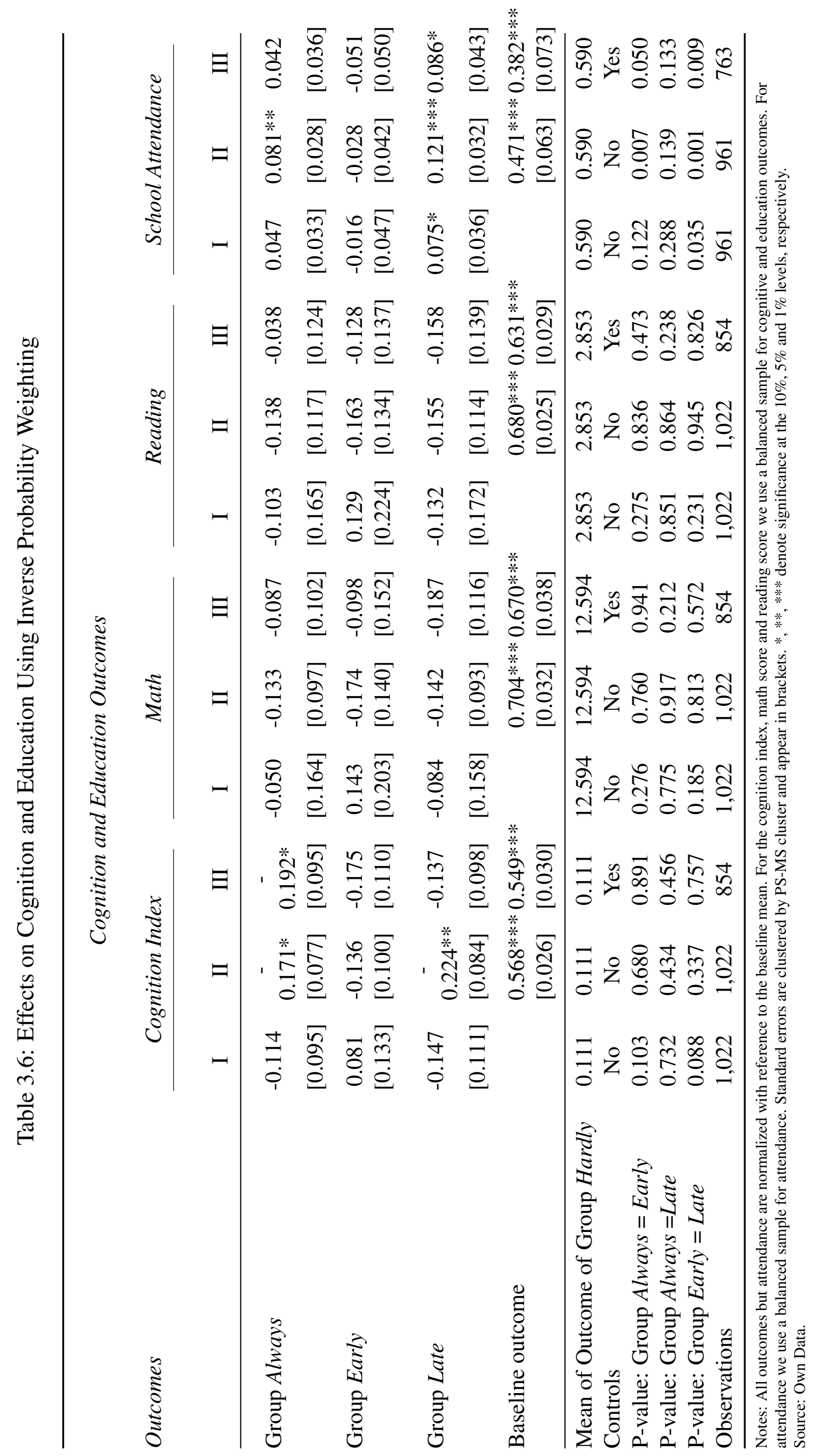


Figure 3.3: Marginal Affects for Hemoglobin by Level of Attendance

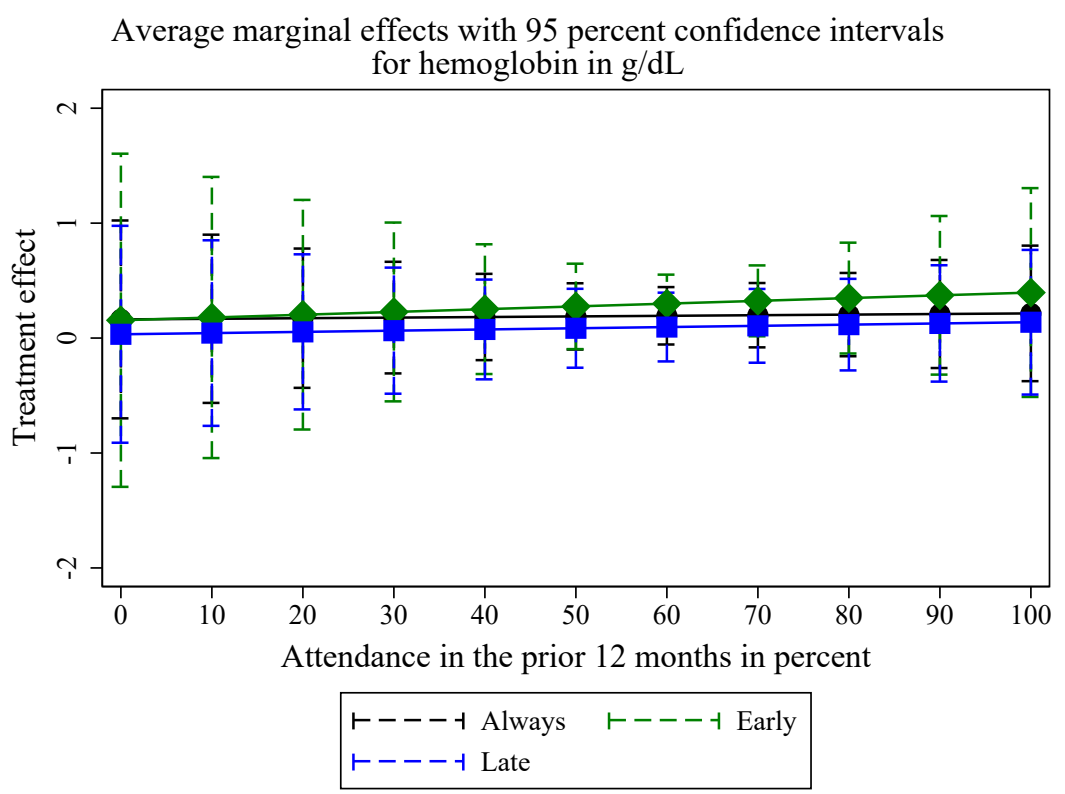

Note: Own Data.

The lower Lee bound is negative and statistically significant but the upper bound is not significant and also positive in Table 3.4 Panel B. Here the bounds are tightened with the cognition index split into terciles and the baseline outcome. We also conduct a robustness check of multiple hypotheses testing of all cognition related outcomes in the main specification in Table 3.5. The corrected standard errors for multiple hypothesis testing for the cognition index is no longer significant.

The unexpected sign might be driven by the adaptation of the tests to adjust to child development or a lack of other inputs for developing cognitive ability. Single test outcomes for the main specification do not show other statistically significant differences between groups (see tables in the appendix). The decrease in the cognition index might be due to the adaptation of the tests to adjust to the growing cognitive abilities of children over time. We have not tested the comparability of adapted and original tests. For example, we measure inhibition with the fruit/vegetable Stroop by Röthlisberger et al. (2010) instead of the Stroop like "Day-Night” test by Gerstadt et al. (1994). We have not tested the comparability of the two tests. The adaptation of the Stroop test might drive the difference in the performance of children in the cognitive index. Another explanation of this finding could be that for the cognitive ability to increase at different ages supplementary inputs apart from optimal nutrition are needed like psychosocial stimuli. The reference group, group Hardly, might have an advantage because next to children who drop out or go to another governmental school it also includes children who attend a private school 
after fifth grade. Assuming that the quality of psychosocial stimuli and other input factors for the development of cognitive ability is greater for group Hardly, it would not be surprising that children who only attend less equipped government schools perform lower (group Always).

Thus, the negative coefficient could be explained by the more cognitively developed exposure group or the different measures used to adapt to later childhood.

\subsubsection{Education Outcomes}

We do not find statistically significant differences between any two groups for the math or the reading score outcome. Ceiling effects could be the reason (Wang et al., 2008). We provide graphical evidence for this in the appendix. For example, in the conducted reading test it is relatively easy for children in sixth grade to score high so that the true extent of very wellperforming students cannot be determined. The highest level of assessment measures whether children can read a story fluently. Nevertheless, we find a statistically significant difference in school attendance for group Always and Hardly for specification II, between group Late and Hardly as well as between group Early and Late for all specifications, and between group Always and Early for specification II and III. This is quite puzzling because school attendance should not be directly affected by the treatment because children are not aware of the DFS usage, and children who do not eat the MDM regularly are not able to improve their health and, indirectly their school attendance through the treatment.

Lee bounds for education outcomes comparing group Late and Hardly as well as for reading score and attendance comparing group Always and Hardly have a significant and positive upper bound. The lower bound is not significant and negative. The Lee bounds for the reading scores are classical Lee bounds due to a lack in variation within the data. Correcting the standard errors for multiple hypotheses testing for the three education outcomes in the main specification in Table 3.5, there is no statistically significant difference in attendance between Group Late and Hardly anymore. The significant finding is not robust.

The correlation of our exposure groups and the school types might explain the effect of the treatment on attendance. First, in group Early and Hardly children exit our original selected schools to change to another school where we only have access to a limited amount of administrative records capturing their attendance. Second, children who attend PS until fifth grade are more likely to attend a school that is not in their own but a neighboring village or town. This implies that many children who could go to PS that is situated in their own village have to travel further 
to attend MS. The increased opportunity costs of traveling to reach further away schools might lead to children attending school less.

Despite treatment effects on hemoglobin and moderate anemia after the treatment period of maximum of 4 years, the results of treatment of about 4 years starting in early childhood does not seem to suffice to improve cognitive ability or education outcomes in early adolescence in sixth grade. We find an increase in hemoglobin for groups of children receiving DFS for about 4 years and in early childhood only. A reason for why exposure in early childhood appears to be more beneficial is that the requirement of daily intake of iron increases by age but that the intake of iron due to DFS does not increase at the same pace, i.e. depending on attended grade, not child age. ${ }^{13}$ DFS received in early childhood reduces the likelihood of moderate anemia in early adolescence compared to children with low exposure. However, we do not see improvements in cognition even after a duration of about 4 years. The considered outcome, a cognition index, has even an unexpected negative sign. We argue that cognitive ability has additional complementary factors that are essential to increase it. Thus, we conclude that supplementation of DFS alone might not be sufficient to increase cognition in early adolescence. Attendance has a positive association with different treatment groups though this effect might be traced back to the different school types in the exposure groups than the treatment itself.

\section{Discussion}

Overall, our results show that the implementation of the government directive postulating the use of DFS in the MDM has positive health outcomes. Our results have to be interpreted considering four limitations: partial compliance, attrition, age-adjusted measures, and school quality. As already explained before, we can not exclude partial compliance on the school and in particular the child level. Krämer et al. (2020) show that attendance of children represents a mediating factor. Children with higher attendance have larger treatment effects for health and cognition outcomes. This is why our study again does not look at the ATE but the ITT. The focus lies

\footnotetext{
${ }^{13}$ Children aged 4 to 6 years require $8 \mathrm{mg}$ of daily iron intake, children aged 7 to 9 years $10 \mathrm{mg}$, children aged 10 to 12 years $12 \mathrm{mg}$, and children aged 13 to 19 years $15 \mathrm{mg}$ (WHO, 1959). One $450 \mathrm{kcal}$ meal portion for primary school children (first to fifth grade) should contain $4 \mathrm{~g}$ of DFS per meal, i.e. $3.5 \mathrm{mg}$ of iron (Krämer et al., 2020; Bihar Government, 2017). Upper primary school children (from sixth grade onward) should receive a larger portion $700 \mathrm{kcal}$, so $6.222 \mathrm{~g}$ of DFS, i.e. $5.444 \mathrm{mg}$ of iron (Bihar Government, 2017). Thus, the iron intake due to DFS accounts for 43.75 percent of the required daily iron intake for children between age 4 and 6 years, 35 percent for children between age 7 to 9 years, and 29.167 percent for children between age 10 and 12 years considering the size of a meal for the first to the fifth grade. Considering the portion size at sixth grade, the iron intake due to DFS accounts for 45.367 percent of the required daily iron intake for children between age 10 and 12 .
} 
on the policy effectiveness of the intervention, not at the ATE that would have greater external validity.

Another limitation of our study is attrition. We face additional challenges after the treatment period of maximum of 4 years due to incomplete information. Attrition in our case threatens internal validity because exposure groups and attrition are correlated. We also show that there are significant differences between children within our analytical sample at the third data collection wave and those who dropped out. There are also significant differences in observable characteristics between the drop-outs of the different exposure groups.

However, we argue that the correlation between exposure groups and attrition is mainly driven by the school types that are included in the different exposure groups. Children who attend PS until fifth grade are more likely to leave the sample because additional information is needed to determine the newly attended school. Children attending MS until fifth grade have a default option that can be easily verified by checking attendance records. As the exposure groups are correlated with attrition via the type of attended schools, we use parametric and non-parametric attrition correction approaches.

Another limitation we want to draw attention to is the consistency of the cognition and education tests. Our study is following a cohort of children from second to sixth grade. During this time children are naturally developing greater cognitive ability and might also be exposed to more education. As we tried to be as consistent as possible, we conducted the same tests with only slight modifications for most tests. After the treatment period of maximum of 4 years this leads to less variability of the outcomes, a ceiling effect. For example, in the reading test hardly any participating child in sixth grade is not able to read single letters. For the outcome considering the ability of inhibition control we adopt a new test. The Stroop like "Day-Night" test by Gerstadt et al. (1994) used in the first two data collection waves to measure the ability of inhibition control is no longer appropriate for the new age group of the children in the third data collection wave. That is why we use an adapted version of the fruit/vegetable Stroop by Röthlisberger et al. (2010). We did not perform consistency checks or how performance in one test should be translated best to scores in the other. Instead, we convert the scores of the fruit/vegetable Stroop into points based on the outcome distribution. This might explain the puzzling negative treatment effects for the cognition index.

Another limitation is the influence of school quality on our outcome measures. So far we use a limited number of school characteristics at baseline as control variables like total school enroll- 
ment, number of children in the same grade as the child, distance to school, and student teacher ratio at the school level. However, this does not seem to suffice to capture the effect of school characteristics on our considered child development outcomes. The difference in education quality between schools might also be the reason why children who attend government schools that receive DFS during PS and MS score lower in the cognition index than those children who hardly consume DFS. Among the children who do not consume DFS are children who go to private schools where education quality is probably higher. We argue that education quality and so psychosocial stimuli are essential for child development. Even in the presence of adequate nutrition, the education quality could act as a constraint to child development.

These limitations - imperfect compliance, attrition, age-adapted measuring, and hardly controlled school quality - should be kept in mind when interpreting our findings.

\section{Conclusion}

Using panel data of about 1,000 school children we examine the effectiveness of a government directive. To model reality as close as possible we supply DFS to 107 randomly selected governmental schools in two blocks of the district of Jehanabad in the state of Bihar. We contribute to the literature by looking at one of the longest treatment periods of DFS in the MDM so far: about 4 years. Due to variation in onset and duration of DFS exposure we can examine the effectiveness of the salt across different exposure periods and observe how a childhood intervention starting in third grade unfolds in outcomes for young adolescents in sixth grade.

Employing an ANCOVA approach corrected for attrition we show that assigned usage of DFS during the preparation of the MDM increases the hemoglobin level by $0.260 \mathrm{~g} / \mathrm{dL}$ for the children who receive DFS at least in early childhood. Exposure in early childhood only reduces the likelihood of a child being moderate or severe anemic by 8.6 percentage points compared to the children who are only exposed to DFS for 4 months in later childhood. However, the improved health outcomes do not transform into cognition or education gains.

The results have high policy relevance as they show the potential of fortified foods in school feeding programs to increase the health of adolescents without crowding out other interventions. The results highlight that early childhood exposure is long-lasting and so could benefit children even when schools are closed.

We argue that optimal nutrition is only one important determinant for the development of cog- 
nitive ability and so school attainment. Another decisive factor is school quality that in our case might constraint the effects of the nutrition intervention. Therefore, we recommend a more holistic approach for future nutrition interventions at the school level. Apart from a treatment arm with only DFS supply, it would be advisable to complement it with measures improving the quality of education at schools.

Another interesting angle of our study is how an intervention in childhood unfolds in outcomes for early adolescents. It would be interesting to learn about the effects of DFS for girls before and after menarche that happens around early adolescents. We have not collected information on this even though menstruation leads to a regular blood and so iron loss for girls. Investigating the differential effects of the use of DFS for girls in this crucial life stage could show additional beneficial effects of the DFS in the MDM. 


\title{
4 Essay 3: Parental Beliefs and Investment Deci- sions under Competition
}

\begin{abstract}
Though research has examined the effects and causes of son preference in India widely, studies fail to cleanly identify the underlying reasons for lower parental investments in daughters. We examine how believed market returns to investment in children - one possible cause - affect parental investment decisions.

To isolate the effect of parents' believed market returns to investment, we conduct a lab-in-thefield experiment with sixth grade students and their parents in rural Bihar. We use the strategy method to elicit the investment of parents for two different market returns to investment: a non-competitive setting depending on the performance of the participants' own child and a competitive setting depending on the absolute and relative performance of the own child in a tournament against either a girl, a boy, or a child with unknown gender.

Our lab-in-the-field experiment reveals that parents react to different market returns to investment. We find that parents invest almost 10 percent less of the initial endowment in their children when exposed to a competitive market setting. Competing against a competitor with known gender reduces the investment. Parents invest about 27 percent less of the initial endowment into their children when competing against a boy compared to a non-competitive setting. We contribute to the experimental literature with evidence about the influence of competition on the investment behavior of participants in a competitive setting. We also show how the gender dynamics of competitors matter for a third party that is not involved in the competition itself. Additionally, we contribute to the examination of input factors of parental investment decision by isolating the effect of market returns to investment and its interaction with child endowment in a lab-in-the-field experiment.
\end{abstract}

\footnotetext{
${ }^{1}$ This paper is co-authored by Sebastian Vollmer.
} 


\section{Introduction}

A broad body of literature examines reasons and outcomes of daughter discrimination in India in areas like education, nutrition, and health. Yet, most studies fail to cleanly identify the underlying reasons for lower parental investments in daughters. We examine one possible underlying cause of parental differential investment in children - market returns to investment - with a labin-the-field experiment that allows clear isolation of the effect. We want to investigate how market returns to investment in combination with child endowments matter for parental investment decisions in their children.

To isolate the effect of parents' believed market returns to investment, we conduct a lab-in-thefield experiment with sixth grade students and their parents in rural Bihar. We keep income, family size, human capital returns to investment, effort costs, and time of investment fixed and vary the endowment of children and the market returns to investment. The within-subject-design or using control variables take care of parental heterogeneity in altruism, risk aversion, beliefs, and aspirations. We use the strategy method to elicit the investment of parents in two settings proxying two different market returns to investment: a non-competitive setting with a piece-rate payment scheme depending on the performance of the participants' own child and a competitive setting with a contest-like payment scheme depending on the absolute and relative performance of the own child in a tournament against either a girl, a boy, or a child with unknown gender. Beliefs about the probability of single events and probability distributions about multiple events are elicited using visual aids. This elicitation method has been inspired by Delavande \& Kohler (2009) and Giné et al. (2009). We use ordinary least squares [OLS] regressions with cluster robust standard errors to test hypotheses about parents' beliefs and investments derived from a conceptual framework.

In our first part of the analysis, we assess the belief formation of parents. We find that observable characteristics of own children like gender matter more than their real ability when parents form beliefs about the probability of their own child solving any one task of the game. However, when forming beliefs about how likely parents' own child is to win against a competitor, believed child ability matters. Parents believe that daughters have lower absolute and relative ability than sons. When we make the gender of the competitor salient, parents believe it is less likely for their own child to win.

In the second part of our analysis focusing on the parental investment decisions, we find that 
believed higher ability of children increases the investment of parents but does not matter more under competition. Parents invest less in daughters in general and discount their ability in the competitive setting. Regarding returns to market investment, we find that parents invest almost 10 percent of the initial endowment less in children when they are exposed to competition. The influence of social preferences seems negligible. Parents' belief about the probability of their own child winning against a competitor has a positive association with investing in their children. Though the effect magnitude does not outweigh the decrease in investment due to competition. Irrespective of the gender of the own child, parents invest less in the tournament setting when their own child competes against a girl or a boy. Parents' investments decrease by more than a quarter of the initial endowment once the competitor is a boy.

We make contributions to two strains of literature. We add to research on input factors of parental investment by cleanly identifying the influence of variation of market returns to investment and its interaction with child endowment with the help of a lab-in-the-field experiment. Further, we provide novel evidence about the influence of competition on the behavior of participants: investments are lower in a competitive compared to a non-competitive risky setting. We also show how the gender dynamics of competitors matter for a third party not involved in the competition itself.

The paper is organized as follows. Section 2 reviews the two different strains of literature this study connects. Section 3 derives the hypotheses from a conceptual framework of parents' investment in children. Section 4 describes the experimental design including the methodology for data collection and analysis. Section 5 presents the results and section 6 a brief discussion. Section 7 concludes.

\section{Background and Literature Review}

The objective of the study is to show how competitively framed market returns to investment evoke differential parental investments in children. We contribute to the literature on inputs into parental investment in children because we identify the influence of variation of market settings and its interaction with child endowment in a lab-in-the-field experiment. Further, we provide novel evidence for the experimental literature on competition because we investigate how a competitive setting shapes investment behavior and how gender dynamics influence the decisions of a third party. 
Our study draws from two strains of literature: input factors of the parental investment function in their children and experimental evidence about behavior under competition.

\subsection{Input Factors in Parental Investment in Children}

We start with reviewing input factors of parental investments in children. First, we describe the identified inputs in the parental investment of the intergenerational mobility and transmission theory of earnings, assets, and consumption by Becker \& Tomes $(1986,1979)$. Then, we bring in more recently discovered input factors omitted in this theory.

\subsubsection{Becker's Identified Inputs}

Becker \& Tomes (1979) consider the utility function of parents that derives from own consumption and wealth of children in the future period subject to own parental income, the inherited endowments of children, and expected endowed and market luck of children. All parents can contribute to the production of children's wealth by investing in their human capital development giving up their own consumption. ${ }^{2}$ The optimal investment in a child depends amongst others on income spent on children, the rates of return on investment in the child, the child endowment, the market luck of the child, and the family size (Becker \& Tomes, 1986, 1979). Parents have to form beliefs about the endowment of children, the rates of return on investments in children, and the market luck because they are not fully observable at the time of the investment decision. The authors assume that parents are perfectly informed about the human capital production function. Parents are also supposed to be utility maximizers, altruistic, and risk-neutral (Becker \& Tomes, 1979) .

Input Factor Income Empirical and theoretical results show that parents with higher income invest more and earlier in their children (Attanasio et al., 2017; Karagiannaki, 2017; Boneva $\&$ Rauh, 2018). This leads to human capital differences between children of low-income and high-income families.

In general, parents seem to be inequality averse, i.e. they aim at equal allocation of resources between siblings (Ejrnaes \& Portner, 2004; Behrman et al., 1982; Jurges, 2000; Del Bono et al., 2012; Berry, Dizon-Ross, \& Jagnani, 2020). Only income constraints force them to take up selective strategies (Glick \& Sahn, 2000; Majid, 2018; Ejrnaes \& Portner, 2004; Lundberg,

\footnotetext{
${ }^{2}$ Low-income parents are restricted to human capital investment whereas high-income parents can choose to also invest in non-human capital.
} 
2005; Behrman et al., 1982; Cardona, 2014; Rosenzweig \& Schultz, 1982). Lack of income or time does not allow parents to invest in their children equally (Ejrnaes \& Portner, 2004; Behrman et al., 1982). For instance, higher-income parents in India favor eldest sons less in terms of school enrollment than lower-income families (Kaul, 2018).

Input Factor Family Size Family size also affects parental investment in each child. Aizer \& Cunha (2012) find that larger families increase the investment in higher endowed children relative to their siblings. Kaul (2018) shows that larger Indian families invest less in all male children but focus on the eldest son.

Input Factor Child Endowment Becker \& Tomes (1979) assume that the expected endowment of children depends on the characteristics of parents, family members, and culture of family and society. The literature confirms that there is either reinforcing or compensating investment behavior of parents based on the endowment of their children (Yi et al., 2015; Ye \& Yi, 2017; Johnson \& Schoeni, 2011). As hinted at in the introduction, in India parents' investment decisions depend on the gender of their child. The preference for sons unfolds in areas like education (Jensen, 2003; Kaul, 2018), nutrition (Anukriti et al., 2016; S. Banerjee et al., 2011; Behrman, 1988c; Jayachandran \& National Bureau of Economic Research, 2009), and health (Anukriti et al., 2016; Arnold et al., 1998; Bharadwaj \& Lakdawala, 2013; M. D. Gupta, 1987b; Jayachandran \& Pande, 2017; Oster, 2009; Pande, 2003; Rosenzweig \& Schultz, 1982; Asfaw et al., 2010).

Next to gender, age (Behrman, 1988c), birth order (Kim, 2020; Kaul, 2018), health status (Restrepo, 2016; Datar et al., 2010), statue (Majid, 2018), ability (Akresh et al., 2012; Behrman et al., 1994; Berry, Dizon-Ross, \& Jagnani, 2020; Aizer \& Cunha, 2012), and school attainment (Dizon-Ross, 2019) play a role in parents' preferential treatment of children.

As the endowment of children is not completely observable, expectations are also formed based on the culture. In the setting of our study, India, cultural son favoritism and especially the preference for the eldest son are practiced. The main reasons are patrilocality, old-age support by eldest sons, dowry, patrilineality, religious rituals, safety and purity concerns, and persistence of gender norms (Jayachandran, 2015; Kaul, 2018).

Child endowment also includes the ability of parents to deliver investments. Parents with low capacity, lack in knowledge, or mental health issues are less able to provide investments for human capital development (Carneiro et al., 2019; Attanasio et al., 2017). 
As not all types of child endowment are clearly observable, parents might have inaccurate beliefs about observable characteristics like child performance at school (Bergman, 2015; Datta Gupta et al., 2016; Dizon-Ross, 2019). As parents rely on beliefs when making decisions regarding the endowment of their child, their investment might not be optimal. ${ }^{3}$

Input Factor Rates of Return to Investment In India rates of returns for daughters seem to be constrained for parents because it is harder for them to capture them due to patrilocality that forces daughters to leave their natal family and become part of the groom's family. Daughters' ability in terms of education is also valued less when the amount of dowry is determined (Maertens \& Chari, 2020; Rosenblum, 2017). As parents have to invest in their children before the returns of investments in building human capital are revealed, parents have to rely on their beliefs. The higher the anticipated returns the more parents invest (Cunha et al., 2013). As parents invest according to their beliefs they influence cognitive, socio-emotional, health, and school outcomes of children (Bhalotra et al., 2020; Attanasio et al., 2019; Cunha et al., 2013; Boneva \& Rauh, 2018). However, the beliefs are neither always accurate nor homogeneous across caregivers and can lead to non-optimal investment decisions. An example of an inaccurate belief in India is that parents believe that daughter's education has lower returns for their human capital formation as is the case (Emran et al., 2020).

Input Factor Market Luck Another input factor of parents' investment decision is market luck that is the key input in our study. Becker \& Tomes (1979) define that "the market luck of children, however, is determined by fluctuations in production possibilities and the prices of goods and factors of production that are often revealed only after children have received their education and much of their other training and entered the labor force [...]". We summarize evidence about how features of the labor market influence parental investments in children.

Durante et al. (2015) examine how different economic situations shape the spending behavior of consumers towards female or male children. The behavior seems to mirror evolutionary biology because girls - who have greater reproductive value in poor economic conditions - are favored in the scenarios of economic crisis. For their discrete-choice experiment, participants are first introduced to one of three economic situations. Then they have to decide how to allocate certain goods to either a female or male child when choosing the perspective of a parent.

\footnotetext{
${ }^{3}$ Ability of children seems to be rather hard to observe from outside. However, children also do not seem to be able to observe their ability as they seem to have inaccurate beliefs as well (R. Stinebrickner \& Stinebrickner, 2014; T. Stinebrickner \& Stinebrickner, 2012)
} 
Considering the labor market in India, girls face more challenges reducing the market returns to investment. Overall, there is low female employment, fewer labor opportunities for women, and boys are usually favored (Carranza, 2014; Jayachandran, 2015; Emran et al., 2020). However, labor market returns for investment in daughters and so investments can be increased by female employment opportunities (Carranza, 2014; Rosenzweig \& Schultz, 1982; Munshi \& Richard Rosenzweig, 2006; Heath \& Mushfiq Mobarak, 2012; Jensen, 2010). One of the few empirical studies on this topic by Jensen \& Miller (2010) uses a market luck shock in form of labor opportunities away from home combined with human capital returns to investment. It shows that the child, usually a son, parents have invested in in order to make him stay with them in their old age receives lower investments if labor opportunities away from home appear. Proximity enables parents to have greater decision-making power of the earnings of this child. That is why Jensen \& Miller (2010) find only for girls a significant increase in school enrollment by about 5 to 6 percentage points because parents assume that they will not be able to capture their returns of investments anyways due to female exogamy upon marriage and thus invest more in them for short-run higher family income.

As market luck is not observed but only anticipated, parental beliefs play again an important role. The overall economic situation seems to shape aspirations that influence parents' incentives to make investments. In turn, aspirations matter for economic growth (Genicot \& Ray, 2017). Attanasio \& Kaufmann (2014) find that mothers' expectations and risk perception of labor market returns determine schooling decisions, in particular for girls. Most of the studies examining the influence of market luck on the investment decisions of parents are retrospective studies. The real-world setting does not allow to isolate the effect of market returns to investment from other input factors like human capital returns to investment or child endowment. The presented study by Durante et al. (2015) uses a multiple-choice experiment in a lab-like setting. They examine investment behavior in different market settings in general, not for the particular relationship of parents and their children. Our study combines these approaches using a labin-the-field experiment to have both the ability to isolate one effect and capturing the particular real-world relationship.

\subsubsection{Becker's Assumptions}

When creating the theoretical model Becker \& Tomes $(1986,1979)$ make assumptions about parental behavior that is decisive for investment in children. Parents are supposed to be per- 
fectly informed about the human capital production function. Empirically, this is not the case and so misbelief leads to non-optimal allocations of investment (Bergman, 2015; Datta Gupta et al., 2016; Carneiro et al., 2019; Attanasio \& Kaufmann, 2017; Attanasio et al., 2019; Boneva \& Rauh, 2018; Dizon-Ross, 2019; Cunha et al., 2013; Bhalotra et al., 2020).

Another assumption is that parents are trying to maximize their utility. Becker et al. (2016) support this claim with the "Rotten Parent Theorem": parents invest in the human capital acquisition of children due to expectations of old-age support. Parents manipulate their children's preferences to ensure their old-age support. Berry, Dizon-Ross, \& Jagnani (2020) lend empirical support when investigating potential drivers of parents' preference for investing in their children. They conclude that parents have a slight preference for maximizing earnings.

Even though parents maximize their utility, Becker \& Tomes (1979) also assume that parents are altruistic. Field-experiments show that parental altruism becomes apparent in mothers' and fathers' investment behaviors, though differently (Beaulieu \& Bugental, 2008; Eswaran \& Kotwal, 2004; Vyrastekova et al., 2014).

The last assumption is parents' risk neutrality. It does not hold empirically. Risk aversion might decrease or increase parental investment in children (Checchi et al., 2014; Sovero, 2018; Tabetando, 2019). Sovero (2018) find that higher risk aversion of mothers is associated with higher spending on their son's school-related expenditure in Mexico. This triggers a gender gap in investments between siblings that is increasing with greater maternal risk aversion. Higher risk aversion of mothers' is also linked to higher weight-for-age and body mass index-for-age and overweight for boys. Further, Tabetando (2019) finds that overall parental risk aversion is positively associated with spending on educational expenditure of children in Uganda. The author shows that average risk aversion increases with wealth. However, when only considering poor households parental risk aversion is negatively correlated with spending on the educational expenditure for children.

\subsection{Beyond Becker: Other Inputs}

Recently other input factors for parental investment have emerged like the timing of the investment in early or late childhood (Cunha \& Heckman, 2007; Caucutt \& Lochner, 2012), effort costs of providing investments (Bhalotra et al., 2020), and parental aspirations (Favara, 2017; Ross, 2019; Beaman et al., 2012; Dercon \& Singh, 2013; Serneels \& Dercon, 2014).

Parents with higher aspirations for their children invest more in them. In India aspirations re- 
lated to education, marriage, and occupation are lower for girls than for boys (Dercon \& Singh, 2013; Beaman et al., 2012). The lower aspirations transform into lower human capital development of girls.

Using a lab-in-the-field experiment we keep certain assumptions and inputs constant and so identify to what degree market luck, the labor market returns of parental investments in children, matters. We keep the input factors of income, family size, human capital returns to investment, effort costs, and time of investment fixed and vary the endowment of children and the market luck. We control for parental heterogeneity in altruism, risk aversion, beliefs, and aspirations in our study by either using a within-subject design or using covariates in the regression analysis. We contribute to the literature on input factors of parental investment in children because we investigate the influence of variation of market luck and its interaction with child endowment in an ideal setting - a lab-in-the-field experiment.

\subsection{Behavior under Competition}

We define the market returns to investment as given by either a competitive or non-competitive setting with different competitors. This is another novelty of our study: We describe the behavior of participants exposed to a competitive setting in which they are not directly involved as they are not playing the game but have to make investments in regard to it. The participants for the elicitation of investment decisions are also unique: parents and their own children. We make the non-competitive and competitive setting more salient to the participants by letting their own children perform in a competitive or non-competitive game in line with the setting parents are exposed to. This allows us to conclude how different gender pairs of competitors influence the investment decisions of a third person. We now summarize research on how exposure to competition changes investments before we look at evidence about children's behavior under competition that might shape parental beliefs.

\subsubsection{Behavior under Competition in the Lab}

In general the literature examines changes in behavior exposed either to different features of competition, to non-competitive and competitive settings, or to the choice to participate in a competitive game. 
Behavior under Competition The survey article by Dechenaux et al. (2015) concludes that subjects deviate from the Nash equilibrium solution of tournaments because of non-monetary utility from winning, errors of the subjects, judgemental bias like non-linear probability weighting, or features of the experiment.

Features like the quantity and quality of competitors matter for the effort and performance of subjects. When competitors are perceived as stronger, players face the "discouragement effect" and perform less (Dechenaux et al., 2015; John, 2017). This affects in particular men.

Otherwise, Andreoni \& Brownback (2017) find mixed evidence. They theoretically derive and test in a lab experiment how different numbers of competitors in an auction affect exerted effort. When auction size increases, participants with low ability decrease their effort but ones with high ability increase their effort. Smaller group sizes increase the uncertainty of the participant in which percentile ranking of ability she falls in. Thus, in a larger group of competitors participants with lower ability have to exercise more effort to win and ones with higher ability can use less effort to maintain their position.

Other features of the game itself matter, too. When using noise parameters to obscure how effort translates into outcomes, Cason et al. (2010) observe that risk-aversion and utility of winning increase the deviation from theoretical optimal strategies in all contest types. Lower risk aversion and higher utility of winning increase effort. The task used for the competition explains the difference in the performance of female and male participants (Dreber et al., 2014; Shurchkov, 2012; Günther et al., 2010; De Paola \& Gioia, 2016).

Behavior under Competition vs Non-Competition Comparing the behavior under competition (competitive payment scheme) and non-competition (piece-rate payment scheme) the literature shows that subjects exercise on average more effort when exposed to competition although the variance of effort is larger (Eriksson et al., 2009; Bull et al., 1987). Self-selection into competition, the higher ability of the participant, and the lower difficulty of the task decrease the variance of performance in the competitive payment scheme (Eriksson et al., 2009; Vandegrift $\&$ Brown, 2003). Strategic uncertainty regarding the unknown performance of the competitor and greater complexity of the competitive payment function increase variance (Bull et al., 1987).

The evidence for sharing behavior under competition is mixed. When Krawczyk \& Le Lec (2010) elicit the investment decisions in variations of the dictator game, they find that even in competitive settings subjects share chances to win, though the shared amount is less. Further, 
the payment level seems to influence the beliefs of participants in a competitive game and in an employer-employee dictator game (Butler, 2016; Heinz et al., 2016). In the latter, employers act only gender neutral in case of competition but discriminate against female employees in case of a piece-rate remuneration scheme.

Behavior Shaped by Willingness to Compete and Risk An increase in the competitiveness of an environment further increases the performance of men overall (Gneezy et al., 2003). Women only increase their performance if they compete exclusively against other women.

Competitions are also linked to risk because they include uncertainty. Bull et al. (1987) explain that competition increases uncertainty because (a) a more elaborate strategy is needed than just maximizing behavior like in a piece-rate system and (b) strategic uncertainty related to the behavior of the competitor evolves. Higher risk exposure decreases giving in modified dictator games or trust games (Brock et al., 2013; Cettolin et al., 2017).

As the competitive setting of our lab-in-the-field experiment is unique, we can only draw from the evidence of modified dictator games, trust games, and different types of tournaments to infer behavior changes induced by competition. In general subjects in a tournament exert on average more effort. So, exposure to competition might increase investment due to non-monetary utility from winning, errors of the subjects, judgemental bias like non-linear probability weighting, higher payment levels, or features of the experiment.

Parents might invest less in competition when they believe competitors are stronger due to the "discouragement effect". As competition increases risk, risk-averse parents might invest less. Competition also reduces sharing that would point to lower parental investments in the competitive setting.

There are mixed results about how participants react in a tournament to the number of competitors, the gender of the competitor, or the type of tasks to be solved. Depending on the endowment of the participant these factors increase or decrease effort. Another example is that women only compete more against women, not against any competitor like men. Evidence of a modified dictator game show that only in a competitive setting a third party would discriminate less against women.

The mixed evidence does not yield clear predictions about investment behavior in a competitive setting like ours. 


\subsubsection{Children's Behavior Under Competition}

Now we look at how children or slightly older students react to competition. Parents might consider the behavior of children under competition when making their investment decisions. Under competition students with overconfidence about their own ability exercise less effort and children with realistic beliefs or low-self confidence score less (Brownback, 2018; Bedard \& Fischer, 2019). Children's willingness to compete is positively associated with parents' aspiration (Khadjavi \& Nicklisch, 2018). Competitiveness decreases for girls around puberty when they grow up in a patriarchal society (Andersen et al., 2012). Thus, for the age group of our children (on average 11 years of age) other endowments than gender should matter more for their performance.

Though the literature has started to investigate the influence of competition on the behavior of participants, we can make novel contributions by looking at the effects of competition on investments in a unique competitive setting and how the gender dynamics of competitors matter for a third party not involved in the competition itself.

\section{Conceptual Framework}

When we create our conceptual framework we can neglect the input family size, human capital returns to investment, effort costs, and time of investment because they are fixed in our experimental set-up. All parents receive the same kind of information and the same income endowment. So, they do not differ in available income and their degree of knowledge about the games as well as the optimal outcome maximizing strategy. In our experiment, we vary the endowment of children and the market luck. The competitive and non-competitive settings in our lab-in-the-field experiment constitute different market returns to investment, the overall market luck. As certain assumptions and inputs are parent-specific like altruism, risk aversion, or parental aspirations, we measure these possible heterogeneous factors to control for them. When comparing the competitive and the non-competitive setting we are even able to use a within-subject design that would take care of specific parent characteristics. To derive our hypotheses, we consider the following models explained below. 


\subsection{Investment under Non-Competition}

In the first step, we consider a non-competitive setting in which participants have to choose how to split their endowment into investments of a certain and another uncertain outcome. The uncertain outcome is the payout of a setting without competition. The outcome of the noncompetitive setting is based on the realization of the real ability of the participant's own child. We assume that parents know the real ability distribution of their child but are exposed to risk regarding the realization when eliciting the real ability only once.

We use the subscript $N C$ to indicate that the employed function applies for the case of noncompetition. Parents are assumed to maximize utility $U$ : a greater payout in the game increases utility. The utility derives from the realized payout $\pi_{N C}$ (with $\pi_{N C} \geq 0$ ) and social preferences or errors $s_{N C} \cdot{ }^{4}$

$$
U_{N C}=U\left(\pi_{N C}, s_{N C}\right)
$$

Participants might make a decision considering not only the optimal strategy to maximize outcome but also social norms, personal values, or feelings (Bénabou \& Tirole, 2006). They might also like to appear fair and so not reveal their real investment decisions (Andreoni \& Bernheim, 2009). In terms of social preferences, we focus on inputs or assumptions of parental investment in children: altruism, risk aversion, and aspirations.

In the investment game, the payout depends on the initial endowment $e$, the invested amount in the child account $I$, the amount remaining in the parental account $e-I$, and the real ability of the child to solve tasks $a$. The subscript $i$ is an indicator for own child.

$$
\pi_{N C}(e, I, a)
$$

Though the parent might know about the real ability distribution of their child, they cannot be sure what ability the child displays in only one game. Parents have to use their beliefs about the real ability $p$. This is why $p$ and not $a$ enters the expected payout equation:

$$
E\left[\pi_{N C}\right]=\pi_{N C}(e, I, p)
$$

\footnotetext{
${ }^{4} \mathrm{We}$ assume that economic incentives and social preferences are separable though this assumption has been contested Faravelli \& Stanca (2014).
} 
We assume that parents rely on more child endowments apart from ability when forming their beliefs. Parents might use observable characteristics of the own child $g$ like gender. The belief is based on uncertainty, so we also include social preferences $s_{p}$ because parents might have different degrees of risk aversion that shape their beliefs.

$$
p\left(a, g, s_{p}\right)
$$

We assume that $p$ does only indicate values of possible realized abilities $p \in[0 ; 6]$. It is the sum of the expected ability $E[a]$, the gender of the child $g$, and the product of these factors $g \times E[a]$.

$$
p\left(a, g, s_{p}\right)=\alpha_{1} E[a]+\alpha_{2} g+\alpha_{3} g \times E[a]+\alpha_{4} s_{p}
$$

We derive our first set of hypotheses from this:

Hypothesis Belief 1a: Greater ability of own child $a$ increases parental belief in the own child to solve more tasks $p$.

Hypothesis Belief 2a: When the own child is a girl (boy) $g$, parents believe that their child solves less (more) tasks $p$.

The social preferences and errors $s_{N C}$ do not depend on the invested amount in the child account $I$. We want to illustrate this by assuming that the utility function is a weighted sum of $\pi_{N C}$ and $s_{N C}$ with strictly positive weights $\beta_{1}, \beta_{2} \geq 0$ :

$$
U_{N C}=\beta_{1} \pi_{N C}+\beta_{2} s_{N C}
$$

The payout function of the non-competitive setting in this paper is defined as follows:

$$
\begin{aligned}
\pi_{N C}=a I+(e-I) \text { where } & e=100 \\
I & \in[0,10,20,30,40,50,60,70,80,90,100] \\
a & \in[0,1,2,3,4,5,6]
\end{aligned}
$$

The parental invested amount in the child account $I$ is multiplied by the real ability of the own child, the number of solved tasks $a$. In the played game children can solve up to six tasks. We endow the parents initially with Indian Rupee [INR] 100; they are only allowed to invest zero or multiple of INR 10 in the child account. Figure 4.1 shows the underlying decision tree. 
However, the expected payout function of the non-competitive setting deviates:

Figure 4.1: Simplified Decision Tree for Non-Competition

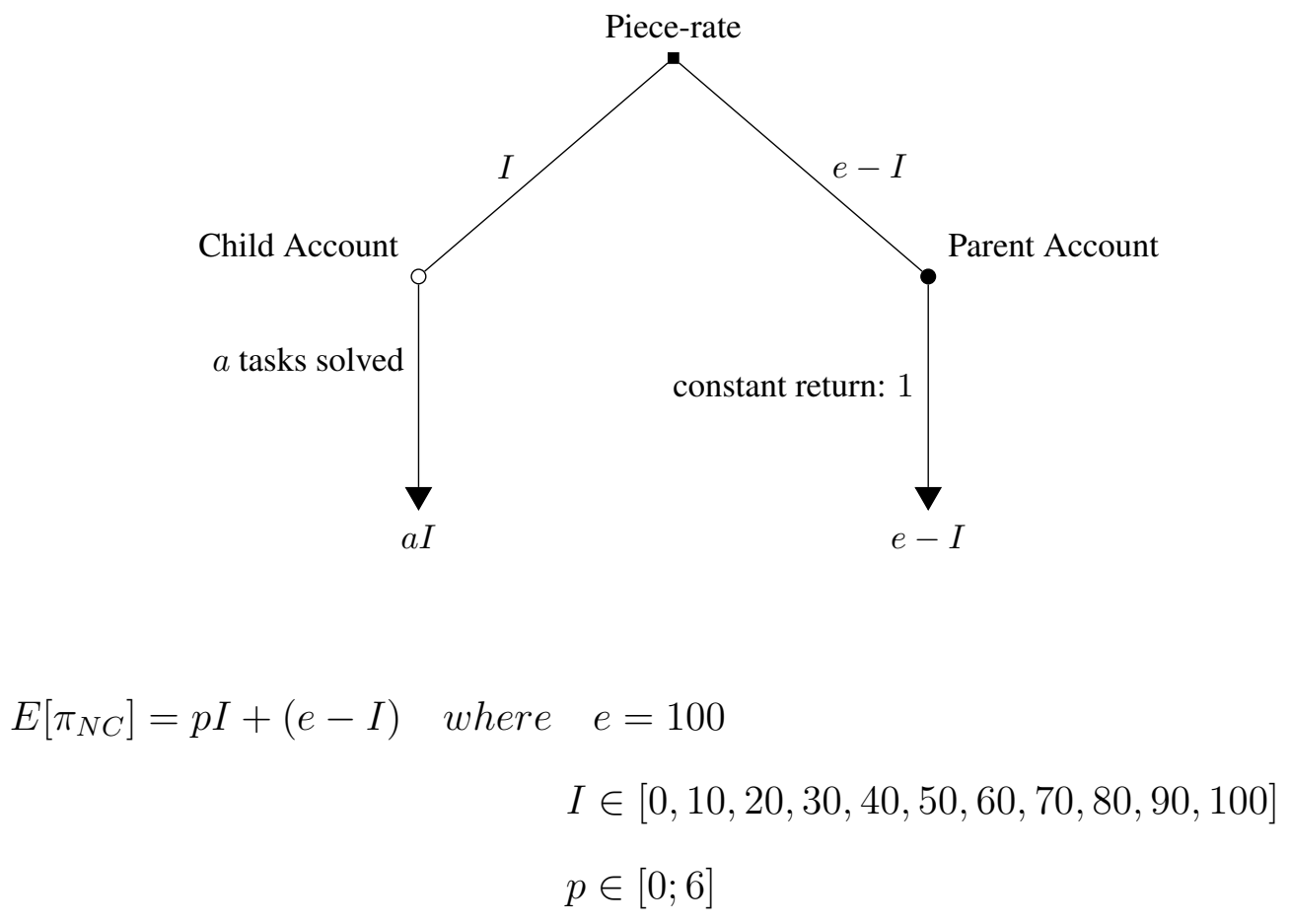

Each parent sets a piece-rate amount based on the belief of how many tasks the child solves $p$ before making their investment and determining $I$.

Given this payment scheme and assuming parents derive their utility only by increasing their income (adopting pure rational behavior), they would invest in their own child account when the expected utility of the payout is larger than keeping the amount in their own account:

$$
\begin{array}{r}
E\left[U\left(\pi_{N C}(I, p, e)\right)\right] \geq U(e) \\
p I+(e-I) \geq e \\
p \geq 1
\end{array}
$$

Once the child would have an expected ability $p$ of 1 or greater, parents increase their utility when investing only in the child account. We show this in Table 4.1 for the case $p \in$ $[0,1,2,3,4,5,6]$ and $e=100$. However, the believed ability and realized ability might differ $p \neq a$ because the beliefs are also based on the gender $g$ of the own child that might increase or discount believed ability and so investment. We assume that daughters' abilities are reduced by this in particular. This motivates our first hypothesis for investment decisions we want to test empirically: 
Table 4.1: Payout Table for Non-Competition

\begin{tabular}{|c|c|c|c|c|c|}
\hline $\begin{array}{l}\text { Believed } \\
\text { Ability } p\end{array}$ & $\begin{array}{l}\text { Investment in } \\
\text { child account } I\end{array}$ & $p I$ & $\begin{array}{l}\text { Investment in } \\
\text { parent account } \\
(e-I)\end{array}$ & $\begin{array}{l}\text { Expected Payout } \\
E\left[\pi_{N C}\right]\end{array}$ & $\begin{array}{l}\text { Investment } \\
\text { Strategy }\end{array}$ \\
\hline 0 & 0 & $0 \times 0=0$ & $100-0=100$ & 100 & Parent \\
\hline 1 & all rational & & & 100 & Both \\
\hline 2 & 100 & $2 \times 100=200$ & $100-100=0$ & 200 & Child \\
\hline 3 & 100 & $3 \times 100=300$ & $100-100=0$ & 300 & Child \\
\hline 4 & 100 & $4 \times 100=400$ & $100-100=0$ & 400 & Child \\
\hline 5 & 100 & $5 \times 100=500$ & $100-100=0$ & 500 & Child \\
\hline 6 & 100 & $6 \times 100=600$ & $100-100=0$ & 600 & Child \\
\hline
\end{tabular}

Hypothesis Investment 1a: Greater believed ability of own child $p$ increases parental investment in the child account $I$.

Hypothesis Investment 2a: When the own child is a girl (boy) $g$, parents invest less (more) in the child account $I$.

Otherwise, social preferences might matter for the investment decision:

$$
\begin{array}{r}
E\left[U\left(\pi_{N C}(I, p, e), s_{N C}\right)\right] \geq U\left(\pi_{N C}(0, p, e), s_{N C}\right) \\
\beta_{1}[p I+(e-I)]+\beta_{2} s_{N C} \geq \beta_{1} e+\beta_{2} s_{N C} \\
\beta_{1} p I \geq \beta_{1} I+\beta_{2}\left[s_{N C}-s_{N C}\right] \\
p \geq 1+\frac{\beta_{2}\left[s_{N C}-s_{N C}\right]}{\beta_{1} I} \\
p \geq 1
\end{array}
$$

When we use a within-subject-design $\left[s_{N C}-s_{N C}\right]=0$, the magnitude of the term $\frac{\beta_{2}\left[s_{N C}-s_{N C}\right]}{\beta_{1} I}$ is zero and so we have the same results as in a case without social preferences.

In our lab-in-the-field experiment parents have to maximize their expected utility choosing investment $I$ into the child account subject to a budget constraint $I \leq e$. They are exposed to uncertainty regarding the realization of the child's ability in a single game and so have to use 
the believed ability $p$ when making a decision. We receive the following results for optimal investments of $I_{N C}^{*}$ in a within-subject-design:

$$
\begin{array}{r}
\max _{I} E\left[U_{N C}\right]=\max _{I} U\left(E\left[\pi_{N C}\right], s_{N C}\right)= \\
\max _{I} \quad \beta_{1} p I+\beta_{1}(e-I)+\beta_{2} s_{N C} \\
\text { s.t. } \quad I \leq e
\end{array}
$$

First order condition $\left(F O C_{N C}\right)$ :

$$
\begin{array}{r}
\frac{\partial L}{\partial I}=\quad \beta_{1} p-\beta_{1}-\lambda=0 \\
\lambda \geq 0, \quad I \leq e \quad \text { and } \quad \lambda(I-e)=0
\end{array}
$$

$L$ represents the Lagrangian of the maximization problem, $\lambda$ is the Kuhn-Tucker multiplier indicating the shadow price of the constrain $I \leq e$. The optimal investment depends on the expected ability $p$ and the weight $\beta_{1}$ of the payout $\pi_{N C}$. We use the derived optimal investment $I_{N C}^{*}$ to learn how optimal investments under a non-competitive setting compare to a competitive one $I_{C}^{*}$.

\subsection{Investment under Competition}

Just like in the non-competitive setting, parents have to choose how to split their endowment into investments of a certain and an uncertain outcome in the competitive setting. The utility function is similar to the one under non-competition building on the realized payout $\pi_{C}$ (with $\pi_{C} \geq 0$ ) and social preferences or errors $s_{C}$. We use the subscript $C$ to indicate that the functions are used for the case of the competitive setting.

$$
U_{C}=U\left(\pi_{C}, s_{C}\right)
$$

The social preferences at the core of our study are the inputs or assumptions of parental investment in children: altruism, risk aversion, and aspirations. Compared to a non-competitive setting, parents face greater risk. They do not know about the revealed ability of their own child but also the ability of the potential competitor. An additional risk is involved because the difference in the ability between the own child and the competitor is unknown. Further, the parents might gain non-monetary utility from winning or have a different willingness to compete for 
themselves or their children. These factors could increase their spending on the child account (Dechenaux et al., 2015). The errors of participants when making decisions could also increase because a more elaborate strategy is needed than just maximizing behavior like in a piece-rate system (Bull et al., 1987). Thus, in a competitive setting the weight or the types of social preferences at play increase.

In the competitive setting the expected payout depends on the initial endowment $e$, the invested amount in the child account $I$, the remaining amount in the parental account $e-I$, the believed ability of the child to solve tasks $p$, and the parental belief about the probability that the own child solves more tasks than the competitor, i.e. wins the competition $w$.

$$
E\left[\pi_{C}\right]=\pi_{C}(e, I, p, w)
$$

Winning depends on the difference between the real ability of own child $a$ and competitor $b$ to solve tasks. However, the realized ability of the competing child in one game is uncertain, so the parents have to use their expectations about the real ability of the competing child to assess whether their own child or the competitor is more likely to solve more tasks.

We assume that parents consider also other endowments of children apart from ability when forming their beliefs. Parents might feel that performance under competition might vary by other child endowments. They might use observable characteristics of the own child $g$ and the competitor $h$ like gender. The literature review in the previous chapter indicates that gender could but might not determine performance in a tournament compared to a piece-rate schedule. Playing against a certain competitor might also shape the performance of the children. For example, Dechenaux et al. (2015) find that the "discouragement effect" decreases the effort of players in a game. This effect evolves when players are heterogeneous to a large degree. In our sample playing against another gender might increase the heterogeneity of the players and so discourage parents from investing in the child account and children to invest effort. Therefore, we assume that not just the gender of the own child and the competitor matter but also the combination in the competitive case. We will use gender to capture how observable characteristics could influence the beliefs of parents. As described in the literature review, parents in India value the educational achievements of their sons more than their daughters. This valuation might influence their formation of expectations.

We also include social preferences $s_{w}$ of parents because of possible different reactions to competition depending on the degree of risk aversion or competitiveness. 


$$
w\left(a, b, g, h, s_{w}\right)
$$

We assume that $w$ is linear and does only indicate positive probabilities: $w \in[0 ; 1]$. Apart from considering gender having possible effects on the performance under competition, we also treat gender as a discount factor for ability again.

$w\left(a, b, g, h, s_{w}\right)=\alpha_{5} E[a]+\alpha_{6} g+\alpha_{7} g \times E[a]+\alpha_{8} E[b]+\alpha_{9} h+\alpha_{10} h \times E[b]+\alpha_{11} g \times h+\alpha_{8} s_{w}$

We derive additional hypotheses from this:

Hypothesis Belief 1b: Greater ability of own child $a$ increases parental belief in the own child to win against a competitor $w$.

Hypothesis Belief 2b: When the own child is a girl (boy) $g$, parents believe in a lower (higher) probability to win against a competitor $w$.

Hypothesis Belief 1c: Lower believed ability of the competitor $b$ increases parental belief in the own child to win against a competitor $w$.

Hypothesis Belief 2c: When the competitor child is a girl (boy) $h$, parents believe in a higher (lower) probability of their own child to win $w$ compared to a competing child with unknown gender.

The social preferences and errors do not depend on the invested amount in the child account $I$ but whether the setting is competitive or not. Under competition social preferences $s_{C}$ like risk aversion and competitiveness gain greater emphasis.

To illustrate parental investment decisions, we assume that the expected utility function is a weighted sum of $E\left[\pi_{C}\right]$ and $s_{C}$ with strictly positive weights $\beta_{1}, \beta_{2} \geq 0$, just like in the case for non-competition.

$$
E\left[U_{C}\right]=\beta_{1} E\left[\pi_{C}\right]+\beta_{2} s_{C}
$$

The payout function is a function of nested decisions (Figure 4.2). First parents have to decide whether to contribute to the child account or the parent account. In this way, they define the piece-rate amount for every task the child solves like in the non-competitive setting. However, if parents decide to invest in the child account, they face an uncertain outcome with the probability $w$. When the real ability of the own child is greater than the competitor's ability $(a>b)$, then 
the parent receives the invested amount multiplied by the real ability of the own child $a$ and by the factor two. When the real ability of the own child is lower than or equal to the competitor's ability $(a \leq b)$, then the parent receives nothing from the child account because the invested amount is multiplied by the real ability of the own child $a$ and by the factor zero.

Figure 4.2: Simplified Decision Tree for Competition

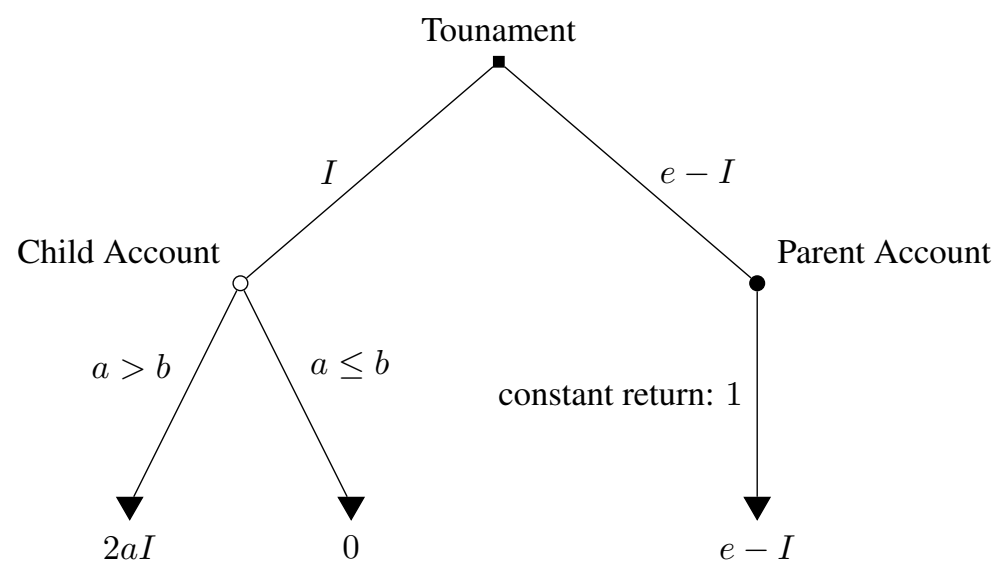

We can formalize the decision tree for the expected payment scheme. As the real ability of the own child $a$ is not known to the parents they have to use their beliefs $p$. Thus, the expected payout is represented as follows:

$$
\begin{array}{r}
E\left[\pi_{C}(e, I, p, w)\right]=w[2 p I+(e-I)]+(1-w)[0 p I+(e-I)] \\
\text { where } e=100 \\
I \in[0,10,20,30,40,50,60,70,80,90,100] \\
p \in[0,1,2,3,4,5,6]
\end{array}
$$

In the played game children can solve up to six tasks. We endow the parents initially with INR 100; they are only allowed to invest zero or multiple of INR 10 in the child account, just like in the non-competition game.

Given this competitive payment scheme and assuming parents derive their utility only by increasing their investment neglecting social preferences, they should invest in their own child account when the expected utility of the payout is larger than keeping the amount in their own account: 


$$
\begin{aligned}
E\left[U\left(\pi_{C}(e, I, p, w)\right)\right] & \geq U(e) \\
w[2 p I+(e-I)]+(1-w)[0 p I+(e-I)] & \geq e \\
w 2 p I+(e-I) & \geq e \\
w p & \geq 1 / 2 \\
p & \geq \frac{1}{2 w}
\end{aligned}
$$

Once the child's believed ability is $\frac{1}{2 w}$ or greater, parents increase their utility when they invest only in the child account. $w$ is the believed probability that the own child solves more tasks than a competitor. The greater the believed ability of the own child to win against a competitor $w$ the lower the believed ability of the child $p$ has to be for the parent to invest in the child account.

Hypothesis Investment 3: Higher believed probability of the own child to win against a competitor $w$ increases parental investment in the child account $I$ ( for competitive games).

To provide an example of the competitive payment scheme (Table 4.2), we assume that the believed chance of winning is $w=1 / 2, p=a$, and $e=100$. As the believed ability of the own child $p\left(a, g, s_{p}\right)$ depends again on the ability and gender of the own child, we adapt the first two hypotheses related to investment for the non-competitive game:

Hypothesis Investment 1b: Greater believed ability of own child $p$ increases parental investment in the child account $I$.

Hypothesis Investment 2b: When the own child is a girl (boy) $g$, parents invest less (more) in the child account $I$.

However, also social preferences might matter for the investment decision:

$$
\begin{array}{r}
E\left[U\left(\pi_{C}(e, I, p, w), s_{C}\right)\right] \geq U\left(\pi_{C}(e, 0, p, w), s_{C}\right) \\
\beta_{1}[w 2 p I+(e-I)]+\beta_{2} s_{C} \geq \beta_{1} e+\beta_{2} s_{C} \\
2 \beta_{1}[p I w] \geq \beta_{1} I+\beta_{2}\left[s_{C}-s_{C}\right] \\
p \geq \frac{1}{2 w}+\frac{\beta_{2}\left[s_{C}-s_{C}\right]}{2 \beta_{1} I w} \\
p \geq \frac{1}{2 w}
\end{array}
$$


Table 4.2: Payout Table for Competition

\begin{tabular}{llllll}
\hline $\begin{array}{l}\text { Believed } \\
\text { Ability } p\end{array}$ & $\begin{array}{l}\text { Investment in } \\
\text { child account } I\end{array}$ & $p I$ & $\begin{array}{l}\text { Investment in } \\
\text { parent account } \\
(e-I)\end{array}$ & $\begin{array}{l}\text { Expected Payout } \\
E\left[\pi_{C}\right]\end{array}$ & $\begin{array}{l}\text { Investment } \\
\text { Strategy }\end{array}$ \\
\hline 0 & 0 & $0 \times 0=0$ & $100-0=100$ & 100 & Parent \\
1 & all rational & $2 \times 100=200$ & $100-100=0$ & 200 & Both \\
2 & 100 & $3 \times 100=300$ & $100-100=0$ & 300 & Child \\
3 & 100 & $4 \times 100=400$ & $100-100=0$ & 400 & Child \\
4 & 100 & $5 \times 100=500$ & $100-100=0$ & 500 & Child \\
5 & 100 & $6 \times 100=600$ & $100-100=0$ & 600 & Child \\
6 & 100 & & & Child
\end{tabular}

Note: The table is based on the assumption of a pure utility maximizing individual with the utility function $U_{C}=\beta_{1} \times \pi_{C}$ with $\beta_{1}=1$. The payout function is defined as $\pi_{C}(e, I, p, w)=w \times[2 p I+(e-I)]+(1-w)[0 \times p I+(e-I)]$ where $e=100, p \in[0,1,2,3,4,5,6], \mathrm{I}$ $\in[0,10,20,30,40,50,60,70,80,90,100]$, and $\mathrm{w}=1 / 2$.

In the case of a within-subject design, the term $\left[s_{C}-s_{C}\right]$ cancels and social preferences can be ignored although social preferences are still in the probability to win $w$.

In our lab-in-the-field experiment, the parents have to maximize their expected utility by choosing investment $I$ :

$$
\begin{array}{r}
\max _{I} E\left[U_{C}\right]=\max _{I} \quad E\left[U\left(\pi_{C}, s_{C}\right)\right]= \\
\max _{I} \beta_{1} w 2 p I+\beta_{1} w(e-I)+\beta_{1}(1-w) 0 p I+\beta_{1}(1-w)(e-I)+\beta_{2} s_{C}= \\
\max _{I} \quad \beta_{1} 2 w p I+\beta_{1}(e-I)+\beta_{2} s_{C} \\
\text { s.t. } \quad I \leq e
\end{array}
$$

First order condition $\left(F O C_{C}\right)$ :

$$
\begin{array}{r}
\frac{\partial L}{\partial I}=\quad \beta_{1} 2 w p-\beta_{1}-\lambda=0 \\
\lambda \geq 0, \quad I \leq e \quad \text { and } \quad \lambda(I-e)=0
\end{array}
$$

$L$ represents the Lagrangian of the maximization problem, $\lambda$ is the Kuhn-Tucker multiplier indicating the shadow price of the constrain $I \leq e$. The optimal investment depends on the believed ability $p$, the believed probability to win $w$ and the weight $\beta_{1}$ of the payout $\pi_{C}$. We use the derived optimal investment $I_{C}^{*}$ under competition to compare it to the optimal investment 
under a non-competitive setting $I_{N C}^{*}$.

\subsection{Differential Investment between Non-Competition and Competition}

Introducing the first-order conditions for the non-competitive and competitive setting reveals why we believe parents might invest differently. We take the difference of the two first-order conditions to find the divergent terms that could explain the difference between these two situations:

$$
\begin{array}{r}
\Delta F O C=F O C_{N C}-F O C_{C}= \\
{\left[\beta_{1} 2 w p\right]-\quad\left[\beta_{1} p\right]=} \\
\beta_{1} p(2 w-1)
\end{array}
$$

The difference between the two first-order conditions shows that the believed probability to win $w$ matters for making the investment decisions. When $w=1 / 2$ or $p=0$, there would not be a difference in the optimal amount invested in the child account $I^{*}$. As $\beta_{1} \geq 0, p \in[0 ; 6]$, and $w[0 ; 1]$, the optimal amount invested in the child account is larger in competition than in noncompetition when $w>1 / 2$. When $w<1 / 2$ parents should invest more in the non-competitive than in the competitive setting.

Further, the believed ability of the own child $p$ is decisive for differential effects in the two settings. If the believed ability is $p=0$, there is no difference between the settings. The greater $p$ the larger the difference between the competitive and non-competitive setting because $p$ is a multiplicative factor. Thus, we come to the key hypothesis of our study:

Hypothesis Investment 4: Parents' investments in the child account depend on the market returns to investment: Parents invest differently when exposed to a competitive or a non-competitive payment scheme $(\triangle F O C \neq 0$ when $p \neq 0$ and $w \neq 1 / 2)$.

We could look at the differences of the first-order condition also in a reduced form replacing first $p\left(a, g, s_{p}\right)$ and then $w\left(a, b, g, h, s_{w}\right)$ with its function: 


$$
\begin{array}{r}
\Delta F O C=F O C_{N C}-F O C_{C}= \\
\beta_{1} p(2 w-1)= \\
\beta_{1}\left(\alpha_{1} E[a]+\alpha_{2} g+\alpha_{3} g \times E[a]+\alpha_{4} s_{p}\right)(2 w-1)= \\
\beta_{1}\left(\alpha_{1} E[a]+\alpha_{2} g+\alpha_{3} g \times E[a]+\alpha_{4} s_{p}\right)\left(2 \left(\alpha_{5} E[a]+\alpha_{6} g+\alpha_{7} g \times E[a]+\alpha_{8} E[b]+\right.\right. \\
\left.\left.\alpha_{9} h+\alpha_{10} h \times E[b]+\alpha_{11} g \times h+\alpha_{8} s_{w}\right)-1\right)
\end{array}
$$

This reduced form shows that social preferences $s_{p}$ and $s_{w}$ might matter for investment. Apart from the gender of the own child $g$, the gender of the competitor $h$ or its interaction with the gender of own child $g$ matter for parental investment decisions, too. This motivates our last set of hypotheses:

Hypothesis Investment 5: Social preferences like competitiveness and risk-seeking increase parental investments in the child account $I$ more in a competitive than in a noncompetitive market returns setting.

Hypothesis Investment 6: Lower believed ability of the competitor $h b$ increases parental investment in the own child $I$.

Hypothesis Investment 7: When the competitor child is a girl (boy) $h$, parents invest more (less) in the child account $I$ compared to a competing child with unknown gender.

This conceptual framework and the derived hypotheses guide the empirical specification in the next part.

\section{Experimental Design and Procedures}

Our goal is to identify how market luck affects parental investment decisions in children. We use a lab-in-the-field experiment to expose parents to two different settings reflecting different market returns of their invested amount in their children in the short run.

We use a within-subject design to measure the difference of parental investment exposed to competition or not and interactions with child endowments represented by ability and gender. To assess whether beliefs and investments are influenced not only by the gender of the own child but also of the competing child, we employ a between-subjects-design. Each parent participates with only one of her children and plays only one round of the competitive game against either 
Figure 4.3: Experimental Sequence
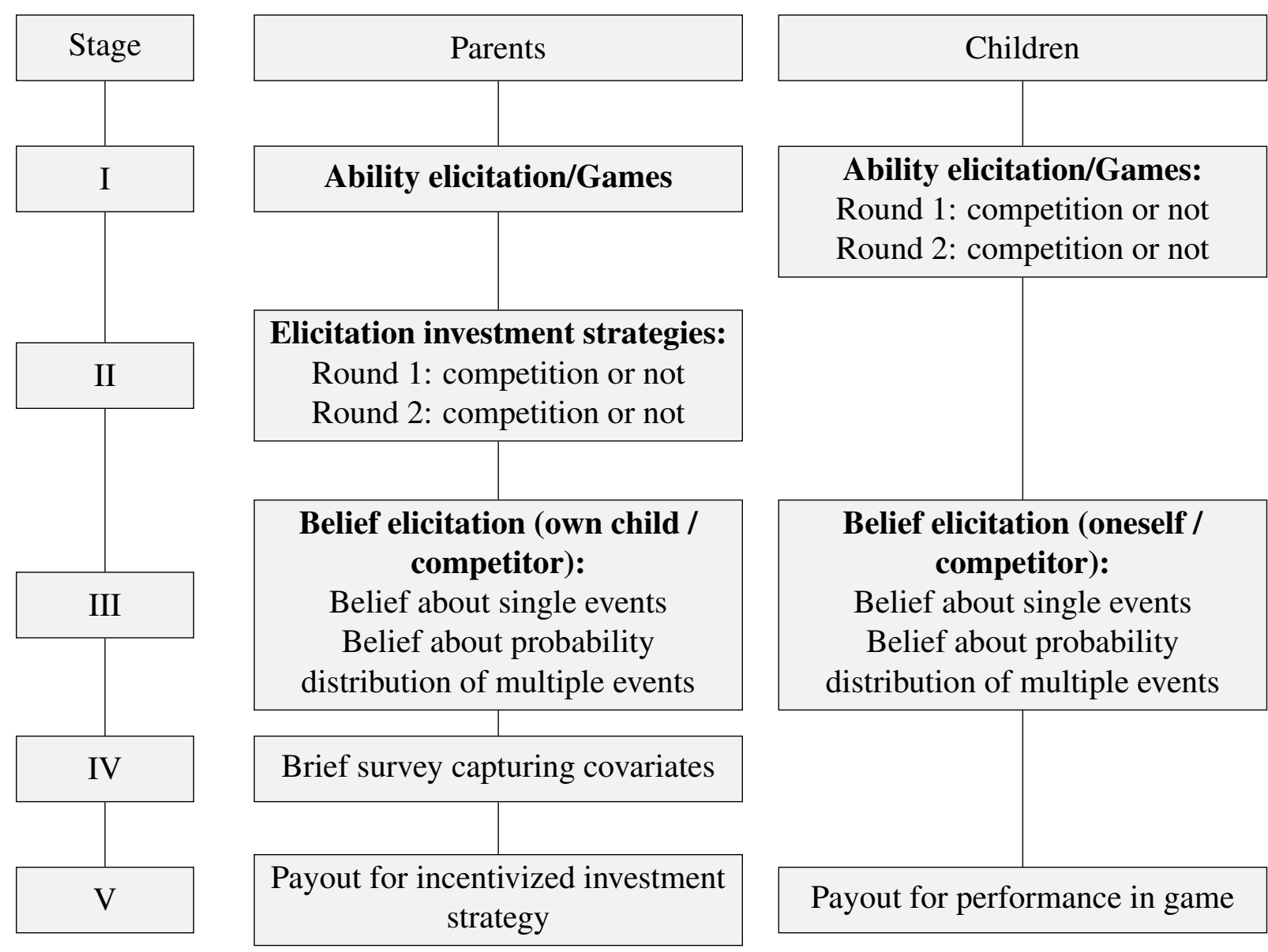

Source: Own data.

another child with unknown gender, a girl, or a boy.

We recruited roughly 400 parents with one child enrolled in the sixth grade in government led middle schools in rural Bihar, India. The selection from the same grade allows us to keep another child endowment, age, roughly constant because children of a certain age group usually attend a particular grade. We choose our sample from the randomly selected children of the cluster randomized controlled trial by Krämer et al. (2020) from January to March 2019.

\subsection{Experimental Procedures}

The lab-in-the-field experiment has been conducted as one session with multiple stages. Figure 4.3 presents the experimental sequence visually.

For the behavioral experiment, a preceding household survey team has invited the parents to a behavioral game at the child's school a few days or up to a week before the session. We have visited all schools where we have conducted the experiment at least one to five days before and 
told the children about the upcoming experiment. On the day of the experiment, children are asked to bring their parents from the village or fellow children and their parents if they have not attended school on this day. We conduct the experiment at two separate locations for parents and children. In this way, children and parents cannot observe each other but get a sense of how their decisions are interdependent.

After the arrival of parents and children pairs, we verify the identity to include only matching pairs of one parent and one child. Only one parent and one child of each family are allowed to participate. We group parents in groups of on average three participants. Children have larger groups of on average 12 children. The game is facilitated orally as some of the participants are illiterate. The results for the workshop are recorded on paper and for the short parental survey using tablets. We start with describing the sequence of the session for parents and then move to the session for children. A more detailed session protocol is provided upon request.

\subsubsection{Experimental Sequence for Parents}

In each group of the parents, one facilitator explains the instructions to the whole group. However, we facilitate the game in such a way that the answers of each participant are unknown to the other participants in the same group.

We first introduce the parents to the game the children will play: Raven's Colored Progressive Matrices. This game is supposed to be perceived as gender-neutral by the children and the parents. After explaining how to solve one of these tasks, each parent is asked to solve six of them.

Elicitation of Investment Strategy After this, we try to capture parents' investment strategies for two different market returns to investment: tournament and a piece-rate scheme. We randomize the order of the settings on the facilitator level. Thus, learning or order effects should not affect one setting more than the other. We also determine the type of competitor for each group randomly. Parents do not know the real competitor of their children. They only know that the competitor is either a child, girl, or boy of their own children's grade that is also taking part in the behavioral experiment.

In the first round, the facilitators explain the functioning of one of the market settings to the participants and check their understanding using visual aids including a payout schedule. After this parents are endowed with play money resembling the Indian currency to make the decision 
more salient. Parents are asked to decide on how much of their endowment they want to invest in their own account represented as a white envelope and a child account represented by a pink envelope. Parents can invest amounts of zero to INR 100 in steps of INR 10 of play money. Parents are asked to reveal their strategy for all possible seven outcomes of the game played with their child. They have to make seven decisions.

Each parent in the group makes the decision individually. As she puts the play money into an envelope other participants should not be able to observe it. This is meant to reduce socialdesirability bias because the pressure of the parent to make socially acceptable decisions is reduced due to secrecy.

After all participants of one group have revealed their investment strategies a second round is conducted covering the other market setting that has not been played before. The outcomes depend on the solved tasks by their own children.

Belief Elicitation In the next stage, we elicit parents' beliefs about the probability of single events and probability distributions of multiple events. As probability is a difficult concept that some of our participants without any formal education might not be able to understand, we use beans as the representation of chances. The facilitators explain how the participants can display their beliefs using beans. We provide visual aids for the explanation. The facilitator gives examples and checks the understanding of the participant before the beliefs about the probability of single events are recorded. To ensure secrecy parents receive two matchboxes, one with the stock of chances - ten beans - and one in which parents have to put their chances for each asked event. After each parent has provided their beliefs one after the other for single events, we proceed similarly for the elicitation of the probability distributions of multiple events. Beliefs are related to the absolute and relative ability of their own child and the competing child regarding the played game.

Survey and Payout Thereafter, facilitators conduct a small survey with each participant individually regarding their preferences, aspirations, and other aspects related to the behavioral experiment.

By the end of this session, children should also have completed playing the game. Depending on the elicited ability of the child and the randomized choice of the competitive or piece-rate payment scheme, we select the corresponding investment strategy of the parent for the payout. To this, a random payout is added in order to blur the child's performance. We also provide a 
minimum payout of INR 100 for all parents who participate until the end in cases the final payout is lower than INR 100. The maximum amount received is INR 1300. The median payout is INR 265. The average daily income of the district lies at about INR 300.

At the end of the interview, each parent is informed in privacy about their payout and receives a debriefing stressing that the payout is based mainly on luck. We do not reveal the children's real performance to anyone, including the parents. We take up these measures to ensure that disappointed parents who receive a lower payout than expected would blame their children. Further, we emphasize that the performance of the child is kept confidential and has no adverse consequences for the child's school or later life.

Thereafter, we offer the parents to either receive their whole payout in cash or to buy subsidized products with it. This is the end of the parental session.

\subsubsection{Experimental Sequence for Children}

At the same time, the children participate in their own session in a separate location. The experimental sequence for children follows a similar pattern as the session for the parents.

In stage one, the children take two times a shortened version of the Raven's Colored Progressive Matrices test in the group setting. The facilitator uses visual aids to explain the test and checks the children's understanding. Then, children are introduced to one of the two different schemes to win a certain amount of caramel bars: a piece-rate payment scheme or a competitive payment scheme. The number of solved tasks determines the payout for children and the payout for parents.

The order of the game or the competitor is randomly selected. Parent and child face the same competing child: a child with unknown gender, a girl, or a boy. Children do not know the real competitor their performance is compared to in the competitive game. They only know the group of children, i.e. one of the other participating children in the game. All participating children are usually from the same grade of the same school. Before the first round of the game, the facilitator checks the understanding of the child that more solved tasks increase the amount of paid caramel bars in case of the piece-rate payment scheme or a victory in the tournament. After completion of the first round, the second round is conducted immediately afterward. The procedures are the same.

In the next stage, the facilitators conduct the belief elicitation with beans in the same way as for parents. The only difference is that children are asked about the probability of one event or 
the probability distribution of multiple events about their own and the competitor's absolute and relative ability regarding the played game.

In the last stage, each child receives their in-kind payout. The final paid amount of caramel bars consists of the randomly selected round of the game, the number of solved tasks, and random addition of caramel bars to blur the real performance of the child. The facilitators give the children the caramel bars in an envelope to maintain secrecy about their performance. Throughout and after the game we do not share the child's performance with anyone. We also do not tell the children that their parents bet on their performance in the game. We do this to encounter possible sources of psychological pressure for the child.

\subsection{Key Measures and Understanding}

Now, we want to describe our key measures of investment and belief and show how we ensure the validity of the measures.

\subsubsection{Investment}

Measuring Investment Decisions We use two different payment scheme settings and the strategy method to elicit parents' investment in children. The design of the investment choices is closely linked to van Winden et al. (2011) and Hopfensitz \& Van Winden (2008) who present their decision problems not in the form of binary choice but a choice to allocate different amounts. Just like them, we ask the participants to choose how to allocate their endowment. They can choose between the parent account for a safe outcome or the child account for a risky one. The return of the safe outcome is always the chosen amount. The return from the risky account depends on the experimental condition. We have two conditions: a piece-rate or a competitive payment scheme.

Instead of a one-shot game, we use a variant of the strategy method (Selten, 1967). We ask the subjects in an incentive-compatible way how much they would like to allocate to the child account dependent on how much tasks their own child solves. We ask the subjects to indicate their investment for all seven possibilities for solving these tasks. To make every parental investment decision incentive compatible, every decision is potentially relevant for determining the actual payout. The performance of the child and random choice of the experimental condition selects one of the made decisions. According to this decision, we calculate the payout. This way of using the strategy method has been used for eliciting contributions in public good games (Fis- 
chbacher et al., 2012, 2001; Martinsson et al., 2014; Mullett et al., 2020), trust games (Falk \& Zehnder, 2013), hybrid public good games (Di Cagno et al., 2016), measuring the influence of emotions and punishment (Jordan et al., 2016), modified investment games (Güth et al., 2014), or to elicit complete or partial strategies (Brandts \& Charness, 2011). The strategy method is also a more economical data-collection process because instead of just only one data point, information about a whole strategy is collected (Brandts \& Charness, 2011).

Understanding of Investment Decisions For the competitive and non-competitive settings, the facilitators explain each parent the procedure, provide examples, and familiarize them with a payout table that parents can use when deciding about their investment. After this, the facilitators ask the parents one question about what is the final return given a certain ability level of their own child and the amount invested in the child account. In the case of a competitive setting, the facilitator brings in an additional condition for the test questions whether the child wins against the competitor. As a participant plays two rounds of the investment game with two different settings, the participant answers two questions. She can make up to two right or two wrong answers. If the participant has not given the right answer at first, the facilitator explains the participant the game again and asks again about the answer. So, we have also the answer option: correct at the second trial. Figure 4.4 shows that 34.54 percent of parents an-

Figure 4.4: Relative Frequency of Correct Answers of Test Questions for Investment Game

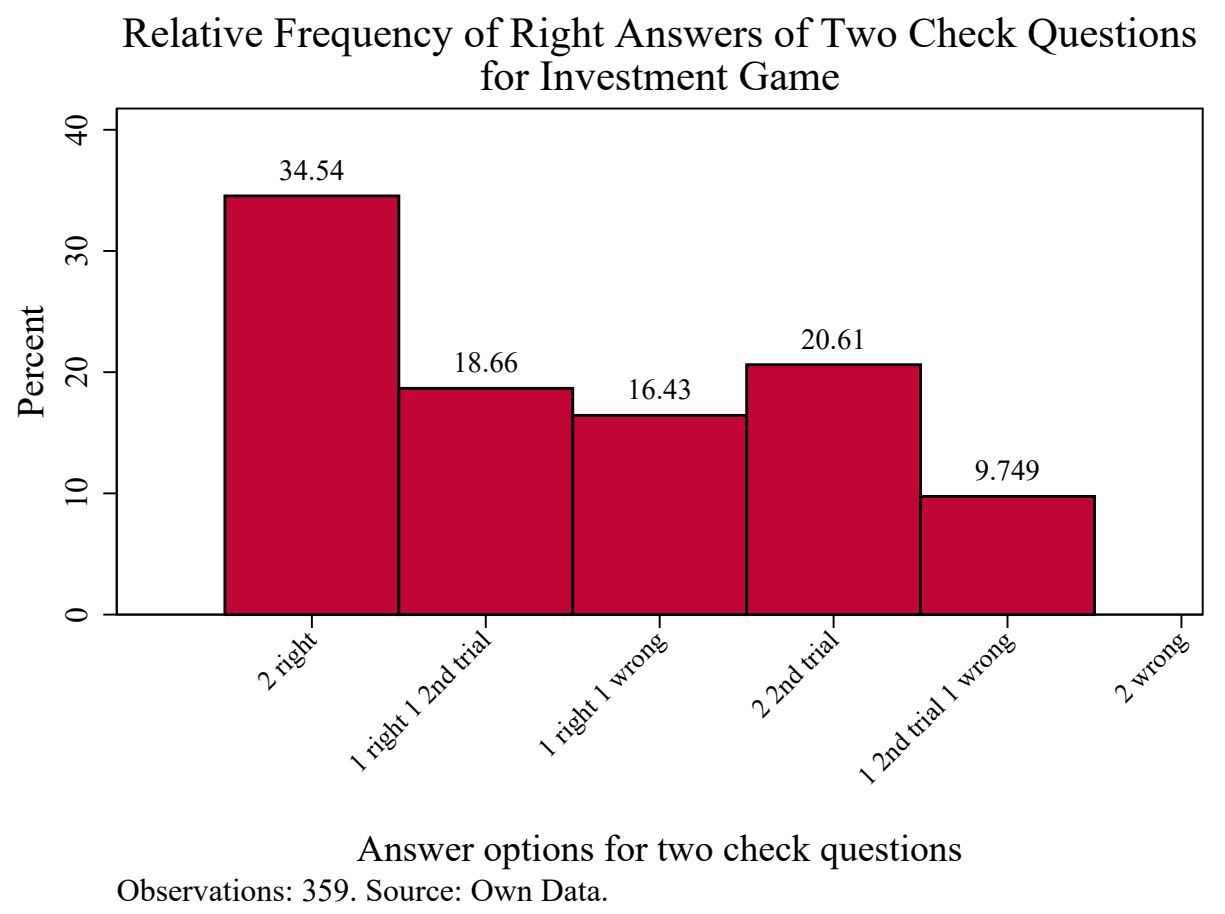


swer correctly right away in both rounds and 18.66 percent answer once right and once right on the second trial. Further, 20.61 percent of participants only answer correctly in both rounds at the second trial. A lower number of participants answer one question wrong but another right (18.66 percent) or right at the second trial ( 9.75 percent). No one in the sample has given two wrong answers. This shows that participants widely understand the investment game. Our measure seems to be a valid indicator of investment decisions of the participants.

\subsubsection{Beliefs}

Measuring Believed Probabilities We use two different ways to elicit participants' beliefs with visual aids. To get to know about the perceived likelihood of single events, we follow Delavande \& Kohler (2009) in procedure and text quite closely. Similarly, we ask respondents to express the likelihood that an event is realized by choosing up to ten beans and put them into an event box. As the elicitation is within a session, we try to create more secrecy for the decision and use boxes and not an open plate for the indication of probability.

We use two test questions to assess the understanding. The first comes from Delavande \& Kohler (2009) but is adapted to the context, i.e. "Pick the number of beans that reflects how likely you think it is that you will win if we play a game of Ludo after this interview". The second question tries to make the correspondent aware of the difference between frequency and probability. We ask them to indicate "how likely you think it is that it will rain today". We then ask them about the probability that their own child or a competitor solves any one task in the game and about the likelihood that their own child solves more tasks than a competitor.

To elicit the probability distribution of a number of events we adapt the elicitation method of Giné et al. (2009) who provide ten stones to participants and a sheet of paper with boxes indicating different time periods of the year. They instruct the respondent to put the stones in the different boxes depending on the perceived likelihood that the monsoon will start in the period indicated by the respective box. Instead, we provide seven boxes indicating the possibility of their own child or a competitor to solve none or all six tasks during the played game. We also use ten beans again as indicators of the likelihood of an event happening. Before this, we conduct an understanding check asking them about the likelihood of winning up to six games of Ludo.

We interpret the number of selected beans in the boxes indicating events as implied subjective probabilities ranging between 0 and 1 . Each bean indicates a probability of $0.1,10$ percent. 
We are positive that our visually aided elicitation of subjective beliefs is a valid measure of the real beliefs of the participants because we adapt previously validated methods (Delavande et al., 2011) and we check the understanding of the participants with test questions that give us more confidence in their understanding.

Checking the Understanding of Beliefs about a Single Event For the belief elicitation regarding the probability of single events, the facilitators ask two check questions. The considered events are winning one game of Ludo and rain today. When the participant decides to use zero or ten beans to indicate the probability, the facilitators prompt the participants by asking whether they are sure about the selected number of beans. We assume that choosing zero or ten beans indicates that the participants have not understood the concept of probability. After prompting the participants they have the chance to change their decision. In our sample 71.43 percent of Figure 4.5: Relative Frequency of Prompts and Changes for Test Questions for Believed Probability of an Event

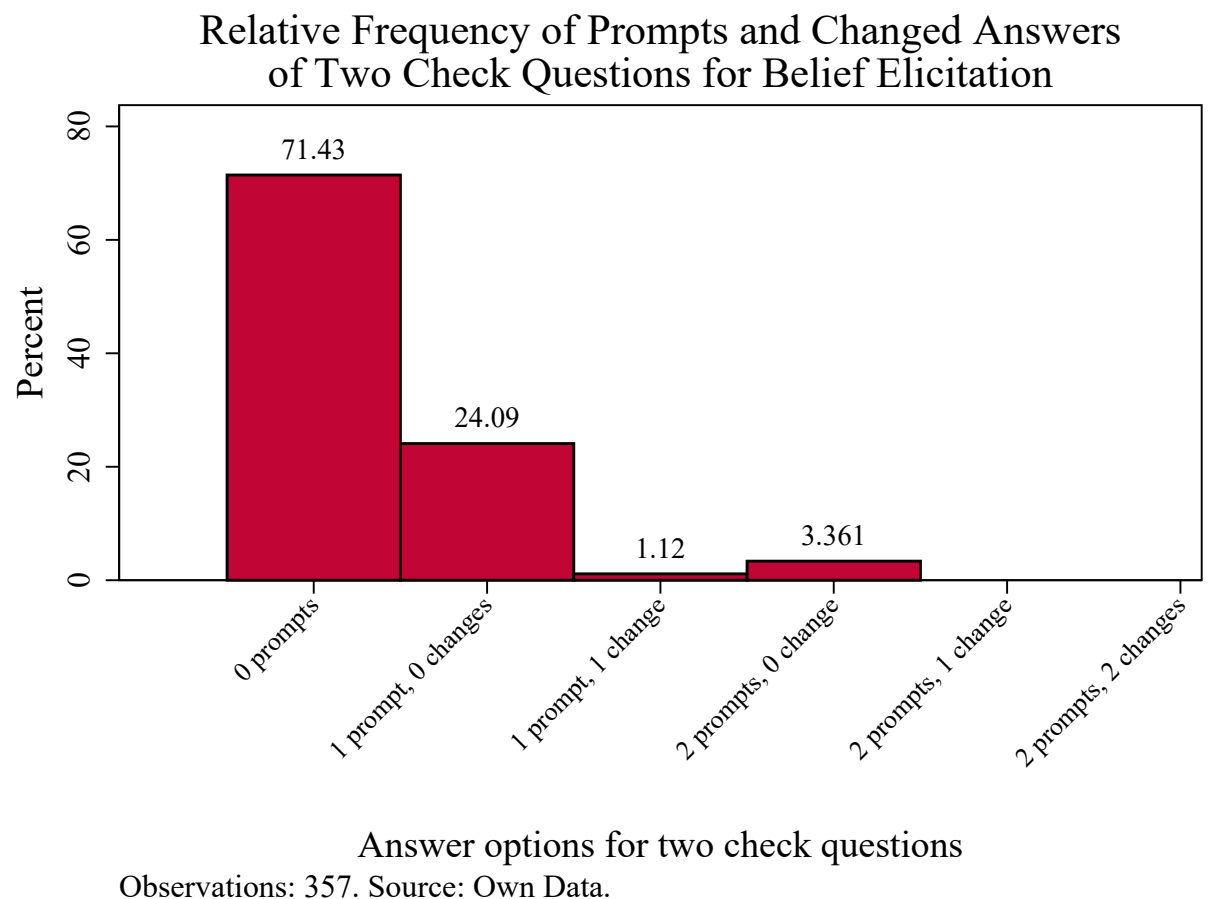

the participants do not choose zero or ten beans, thus, the facilitators do not give them a prompt (Figure 4.5). About a quarter of the participants (24.09 percent) is prompted once but does not change the decision. We see this as an indication that the participant has taken the decision deliberately. A smaller amount of participants (1.12 percent) receives one prompt and changes the allocation of beans after this. A small number of participants (3.36 percent) seems to have not 
grasped the idea of probability: they are prompted twice and do not change their allocation of beans. We exclude this group in our analysis sample because a lack of understanding threatens the validity of our results.

Checking the Understanding of Belief Distributions about Multiple Events For checking the elicitation of the probability distribution of a series of events, we ask the participant to distribute ten beans across the likelihood of winning zero to six games of Ludo when playing six games, one after the other. The facilitators instruct the participants to put the number of beans they would like to allocate for winning zero games, one game, etc., one by one into the respective boxes. After the facilitators have asked the participants for all possible numbers of winning a game, the facilitators show the participants how they have chosen to put their beans and whether they want to make changes to the distribution. When participants have spent all beans before the facilitator finishes asking the participant about all possible winning outcomes of Ludo, the facilitators prompt the participants. The facilitator asks whether the participant wants to reallocate beans to increase the likelihood of winning more games. However, the facilitator does not encourage the participant to spend all ten beans. We qualify using not all ten beans as a sign of lack of understanding. This is why we exclude these participants in our main sample. This is the case for 3.55 percent of our sample (Figure 4.6).

Overall, we exclude participants from our main sample who do not answer one single check question for the investment game correctly or do receive two prompts during the belief elicitation for the probability of one event, or do not use ten beans in the example belief distribution. 
Figure 4.6: Relative Frequency of Using Ten Beans for Believed Distribution of a Series of Events

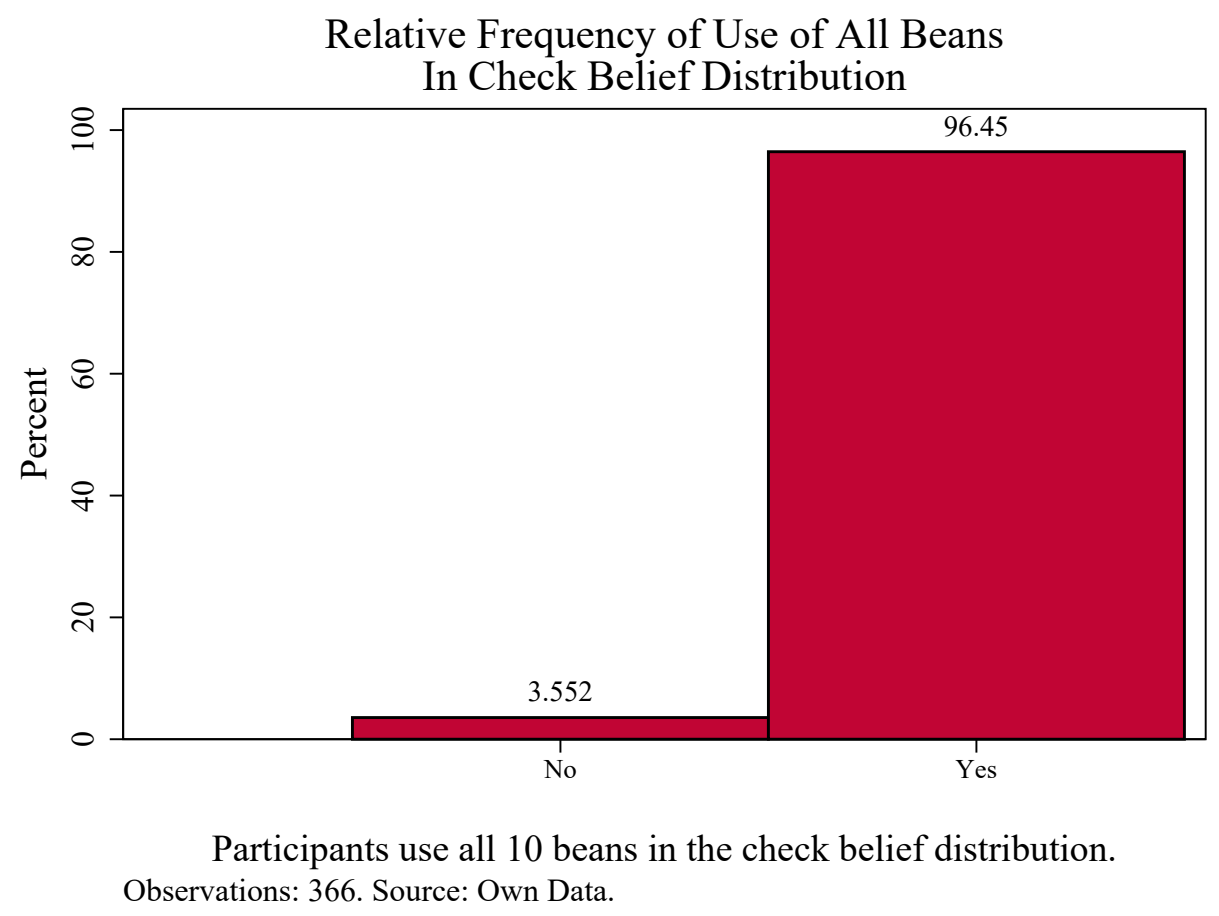




\subsection{Empirical Specification}

The empirical specification is based on the conceptual framework and additional considerations based on the data collection methodology.

\subsubsection{Belief Outcomes}

For the six hypotheses regarding parents' beliefs, we use two different specifications. One to learn about how believed ability of the own child is formed and another to assess the probability of their own child to solve more tasks than a competitor.

$$
p_{i}=\gamma_{1} a_{i}+\gamma_{2} g_{i}+\gamma_{3} g_{i} \times a_{i}+\gamma_{4} s_{i}+\gamma_{7} R_{i}+\gamma_{8} X_{i}+\varepsilon_{i}
$$

The outcome $p_{i}$ measures parents' believed probability that their own child is able to solve any one task in the game. The values range from 0 to 1 . The subscript $i$ is the indicator for parent $\mathrm{i}$. $a_{i}$ is the measured number of tasks the own child solved in the non-competition game. $g_{i}$ is the gender of the own child and enters the equation also as interaction with $a_{i}$. Social preferences $s_{i}$, here only risk aversion, are also included. We also bring in possible reference points about the difficulty of the game that parents might use to base their beliefs on: the vector $R_{i}$. It includes another input factor of child endowment, parental ability, and aspirations of the parents for their children. The parental endowment is measured as the number of correctly solved tasks of the participating parent. Parental aspirations are represented by the aspired number of completed years of education by the parents for their child.

The vector $X_{i}$ is also not included in the conceptual framework. It represents facilitator fixed effects. We use an error term $\varepsilon_{i}$ and cluster the standard errors at the school level. We use OLS regressions for the estimation.

For the second model regarding beliefs, we look at determinants that contribute to the development of the beliefs about the likelihood to win. We use the following estimation equation:

$$
\begin{array}{r}
w_{i}=\gamma_{1} a_{i}+\gamma_{2} b_{i}+\gamma_{3} g_{i}+\gamma_{4} h_{i}+\gamma_{5} a_{i} \times g_{i}+\gamma_{6} b_{i} \times h_{i}+\gamma_{7} g_{i} \times h_{i}+ \\
\gamma_{8} s_{i}+\gamma_{9} R_{i}+\gamma_{10} X_{i}+\varepsilon_{i}
\end{array}
$$

The outcome is the believed probability $w_{i}$ of the own child to win against a competitor . It is a ratio between 0 and 1 . Following our conceptual framework, it is determined by the believed 
ability of the own child $a_{i}$ that we measure here as the parental belief about the probability of the number of solved tasks in the non-competitive game. It is a probability between 0 and 1 . $b_{i}$ is the parental expectation about the performance of the competitor. As a measure, we use here the parental belief about the probability of the competitor to solve any one task. It is a probability between 0 and 1 .

$g_{i}$ is a dummy turning to one if the own child is a daughter. The reference category is a son. $h_{i}$ reveals the gender of the competitor. This vector contains two dummies indicating whether the competitor is a girl or a boy. The omitted category is another child with unknown gender. This will hint at whether parents take observable characteristics of the competitor into account when forming their beliefs. We also include an interaction term to learn how the combination of the gender of own child and competitor matter for the belief $g_{i} \times h_{i}$. We also include interactions of gender and ability for the own child $a_{i} \times g_{i}$ and the competitor $b_{i} \times h_{i}$.

Social preferences $s_{i}$ are also included: risk aversion and competitiveness for oneself and one's child. The subscript $i$ and parameters $R_{i}, X_{i}$, and $\varepsilon_{i}$ follow the estimation equation for the outcome $p_{i}$ We again cluster the standard errors at the school level and use OLS regressions for the estimation.

\subsubsection{Investment Outcome}

We want to examine the first five hypotheses regarding parental investment using the following estimation equation.

$$
\begin{array}{r}
I_{i t}=\gamma_{1} a_{i t}+\gamma_{2} g_{i} \times a_{i t}+\gamma_{3} g_{i}+\gamma_{4} c_{i t}+\gamma_{5} c_{i t} \times w_{i}+\gamma_{6} s_{i}+\gamma_{7} c_{i t} \times s_{i}+ \\
\gamma_{8} r_{i}+\gamma_{9} X_{i t}+\varepsilon_{i t}
\end{array}
$$

$I_{i t}$ is the outcome variable, the amount of INR a parent invests in the child account. As we elicit the parental investment with the strategy method, we ask them 14 times. Thus, the subscript $t$ indicates the number of the subsequent rounds. Unlike in the conceptual model, we are right away replacing the believed ability of children to solve a certain number of tasks $p$ with its components: $a$ and $g . a_{i t}$ is the known real ability of the child. It is the named number of solved tasks in the strategy method. $g_{i}$ is the gender of the own child and enters the equation as a dummy and an interaction with $a_{i t}$. $c_{i t}$ is a dummy variable that turns to one if the played game is competitive. We consider the interaction of competition and the parental belief about the probability that the own child solves more tasks than the competitor $c_{i t} \times w_{i}$. The probability 
is a ratio between 0 and 1 . The parameter is independent of the solved task by the own child. As social preference might be at play we include the vector $s_{i}$ and an interaction of it with competition $c_{i t} \times s_{i}$ for possible differential effects for competition and non-competition in the estimation equation. The preferences are assumed to stay constant across the elicitation period. We consider altruism and risk aversion derived from Becker's assumption for parental investment in children. We include parental aspirations as additional inputs for parental investment. We also add competitiveness for oneself and for children to account for possible influences on behavior due to the competitive setting.

We also include parental endowment $r_{i}$, i.e. the number of correctly solved tasks of the participating parent. Further, we include the vector $X_{i t}$ that contains variables related to the implementation of the experiment: facilitator fixed effects and time fixed effects of the taken decision. $\varepsilon_{i t}$ constitutes the error term.

We use clustered standard errors at the parent level because parental observations are not independent when made by the same parent. We run the regressions with OLS and check the results with a random effects model with standard error clustered at the school level and a random effects mixed model clustering at school level and facilitator level. To make full use of the information gathered by the strategy method we use a similar estimation strategy as Fischbacher \& Gachter (2010) and use every measured investment decision as one observation. As the belief about the probability of the own child to win against a competitor is conditional on parents' exposure to the competitive setting, we only include the interaction term of competition and belief. However, as this probability could be interpreted as the relative ability that could potentially also be a measure of child ability, we conduct robustness checks in the appendix where we include the main effect next to the interaction.

\subsubsection{Reduced Form Regression for Investment Outcome}

In the last step, we want to run a reduced form equation replacing the endogenous factor $w_{i t}$ in the introduced estimation equation of the investment outcome with the additional exogenous factors used to estimate $w_{i}: a_{i t}, b_{i}, g_{i}, h_{i}, a_{i t} \times g_{i}, b_{i} \times h_{i}, \mathbf{g}_{i} \times h_{i}$. 


$$
\begin{array}{r}
I_{i t}=\gamma_{1} a_{i t}+\gamma_{2} g_{i} \times a_{i t}+\gamma_{3} g_{i}+\gamma_{4} c_{i t}+ \\
\delta_{1} c_{i t} \times a_{i t}+{ }_{2} c_{i t} \times b_{i}+\delta_{3} c_{i t} \times g_{i}+\delta_{4} c_{i t} \times h_{i}+ \\
\delta_{5} c_{i t} \times a_{i t} \times g_{i}+\delta_{6} c_{i t} \times b_{i} \times h_{i}+\delta_{7} c_{i t} \times g_{i} \times h_{i}+ \\
+\gamma_{6} s_{i}+\gamma_{7} c_{i t} \times s_{i}+\gamma_{8} r_{i}+\gamma_{9} X_{i t}+\varepsilon_{i t}
\end{array}
$$

The own child ability variable is now again the number of solved tasks $a_{i t}$ parents are exposed to when revealing their investment strategy. All variables with the parameter $\gamma$ are using the same measures as in the model for estimating the investment outcome before. The parameters with $\delta$ in front are the same measures used for the belief estimation apart from $a_{i t}$.

We do not include the following variables in the regression to account for all main effects of the interaction because these variables are only specified in the competitive setting. We exclude them because they are not part of the conceptual model. Further, the value of these variables is conditional on the competitive setting. For a robustness check, we include the main effects. However, all of them are omitted as their value is zero when the setting is non-competitive. This is the case for the following variables and interactions: Competitor : child, Competitor : girl, Competitor : boy, Competitor : child $\times$ Competitorbelievedability, Competitor : girl $\times$ Competitorbelievedability, Competitor : boy $\times$ Competitorbelievedability, Daughter Child, Daughter - Girl, Daughter - Boy, Son - Child, Son - Girl, and Son - Boy.

\section{Experimental Results}

After explaining the underlying methodology of the analysis, we now show our empirical results.

\subsection{Sample Characteristics: Summary Statistics}

We start by describing the characteristics of our sample in Table 4.3. The described game has 266 participants for whom we have complete information on the invested amounts, beliefs, and the competing child. The sample includes only participants who have passed our understanding checks. Parents invest on average INR 56.61 in the non-competitive setting and INR 53.93 in the competitive setting.

Parents believe that their own child is able to solve any one task with a probability of 56.8 percent and to win against a competitor of 56.9 percent. However, when we measure the real 
Table 4.3: Summary Statistics of Selected Variables

\begin{tabular}{|c|c|c|c|}
\hline & Observations & Mean & Standard deviation \\
\hline \multicolumn{4}{|l|}{ Parental Investment } \\
\hline $\begin{array}{l}\text { No competition: Average investment by parents } \\
\text { (in INR) }\end{array}$ & 266 & 56.606 & 17.299 \\
\hline $\begin{array}{l}\text { Competition: Average investment by parents (in } \\
\text { INR) }\end{array}$ & 266 & 53.926 & 15.883 \\
\hline \multicolumn{4}{|l|}{ Parental beliefs about ability } \\
\hline $\begin{array}{l}\text { Believed: Probability own child solves any one } \\
\text { task }\end{array}$ & 266 & 0.568 & 0.237 \\
\hline $\begin{array}{l}\text { Believed: Probability own child solves more } \\
\text { tasks than competitor }\end{array}$ & 266 & 0.569 & 0.235 \\
\hline \multicolumn{4}{|l|}{ Measured ability } \\
\hline $\begin{array}{l}\text { Measured: Probability own child solves any one } \\
\text { task }\end{array}$ & 266 & 0.520 & 0.121 \\
\hline $\begin{array}{l}\text { Measured: Probability own child solves more } \\
\text { tasks than competitor }\end{array}$ & 266 & 0.222 & 0.266 \\
\hline $\begin{array}{l}\text { No competition: Number of solved tasks by } \\
\text { own child }\end{array}$ & 266 & 3.173 & 1.549 \\
\hline $\begin{array}{l}\text { Competition: Number of solved tasks by own } \\
\text { child }\end{array}$ & 263 & 3.297 & 1.626 \\
\hline Number of solved tasks by parent & 266 & 3.639 & 1.243 \\
\hline \multicolumn{4}{|l|}{ Parent characteristics } \\
\hline Participant: Mother & 266 & 0.782 & \\
\hline $\begin{array}{l}\text { Expected completed education of own child (in } \\
\text { years) }\end{array}$ & 265 & 12.045 & 1.313 \\
\hline Altruistic (0 to 10$)$ & 262 & 5.317 & 2.290 \\
\hline Willingness to take risks ( 0 to 10 ) & 257 & 5.451 & 2.590 \\
\hline Competitive for oneself & 250 & 0.720 & \\
\hline Competitive for own child & 260 & 0.500 & \\
\hline \multicolumn{4}{|l|}{ Child characteristics } \\
\hline Daughter & 266 & 0.549 & \\
\hline Competitor: child & 266 & 0.346 & \\
\hline Competitor: girl & 266 & 0.312 & \\
\hline Competitor: boy & 266 & 0.342 & \\
\hline \multicolumn{4}{|l|}{ Game: Own child vs competitor } \\
\hline Daughter - Child & 263 & 0.194 & \\
\hline Daughter - Girl & 263 & 0.167 & \\
\hline Daughter - Boy & 263 & 0.183 & \\
\hline Son - Child & 263 & 0.167 & \\
\hline Son - Child & 263 & 0.133 & \\
\hline Son - Child & 263 & 0.156 & \\
\hline
\end{tabular}

Source: Own Data. 
ability of their own children we find lower probabilities: Children are able to solve any one task with a probability of 52.0 percent and to win against a competitor of 22.2 percent. The stochastic likelihood of winning against a competitor is roughly 42.9 percent, i.e. of all 49 possible combinations of scored matrices the own child could win in 21 combinations. Thus, the average observed likelihood is lower than the stochastic likelihood. This might be likely due to the small sample size that does not allow to converge to the stochastic likelihood. Children solve on average 3.17 tasks under the piece-rate payment scheme and 3.29 under the competitive payment scheme. Parents solve on average 3.64 tasks. This shows that even though the task has been conceptualized for children below the age of 10 , the task is challenging for children and parents alike.

In the lab-in-the-field experiment, 78.2 percent of participants are mothers. On average parents aspire their own child to complete 12.04 years of education. This means they expect their children to complete school right before transitioning to higher education. On a scale from zero to ten participants see themselves on average on a level of 5.32 of altruism and of 5.45 of willingness to take risk. On average 72 percent are willing to enter a competition but only 50 percent are willing to let their child compete.

Our sample of children has slightly more girls than boys: 54.9 percent are girls. In our sample, 34.6 percent of children compete against another child with unknown gender, 31.2 percent against another girl , and 34.2 percent against another boy. The relative frequency of conducted combinations of own child gender and competitors ranges from 19.4 percent of games between daughter and child to 13.3 percent of games between son and child.

\subsection{Formation of Parental Belief}

One decisive factor for parental investment is parents' believed ability of own child $p$ or the probability to win against a competitor $w$. We want to examine in this section how accurate parental beliefs are and whether the identified input factors in the conceptual framework matter for belief formation.

\subsubsection{Descriptive Assessment of Accuracy of Beliefs}

Recent literature shows that parents' belief about their child's performance at school is often inaccurate (Bergman, 2015; Datta Gupta et al., 2016; Dizon-Ross, 2019). Thus, we check whether this applies also in our case. We examine the difference between believed and measured 
results. We first consider the relative frequency of believed and measured probability of solving any one task in Figure 4.7. Most frequently parents believe their child solves any one task with a Figure 4.7: Histogram of Relative Frequency of Probability of Solving Any One Task by Gender of Own Child Comparing Believed and Measured Values

Probability of own child solving any one task
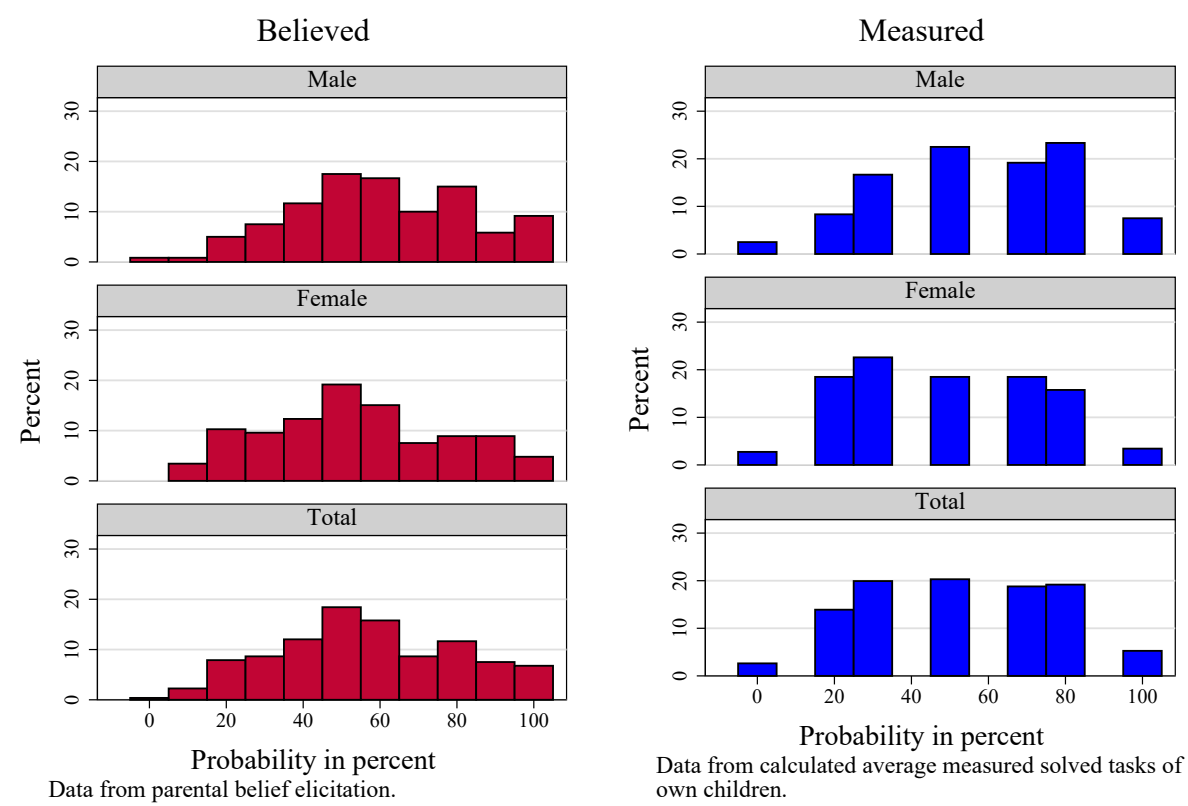

Source: Own Data

probability of almost 50 percent independent of gender. In reality, the most frequent probability for all children to solve any one task lies at 30 or 50 percent. The highest frequency measured for girls is a likelihood of 30 percent to solve any one task and for boys it is 80 percent.

Further, we examine graphically the differences between believed and measured probability of the own child to win against a competitor in Figure 4.8. Parents most frequently believe that their child has a chance of 50 percent to win. This also holds when the competitor is a child with unknown gender or a boy. When the competitor is a girl the most frequent believed probability of winning drops to 40 percent. When we look at the measured probability of winning against a competitor, we find a rather bleak picture. The most frequent probability for all, female, or male competitors is zero. Only when competing against another child the highest frequency of the probabilities to win is 20 percent.

In Table 4.4 we examine whether statistical tests of difference of means also capture our findings of the graphical assessment. Due to the small sample size and possible non-normal data, we also show the results for the Mann-Whitney rank-sum test or Wilcoxon signed-rank test. We examine the differences in believed and measured probability of solving any one task in the 
Figure 4.8: Histogram of Relative Frequency of Probability of Own Child Winning against a Competitor with Different Gender Comparing Believed and Measured Values

Probability of own child solving more tasks than competitior
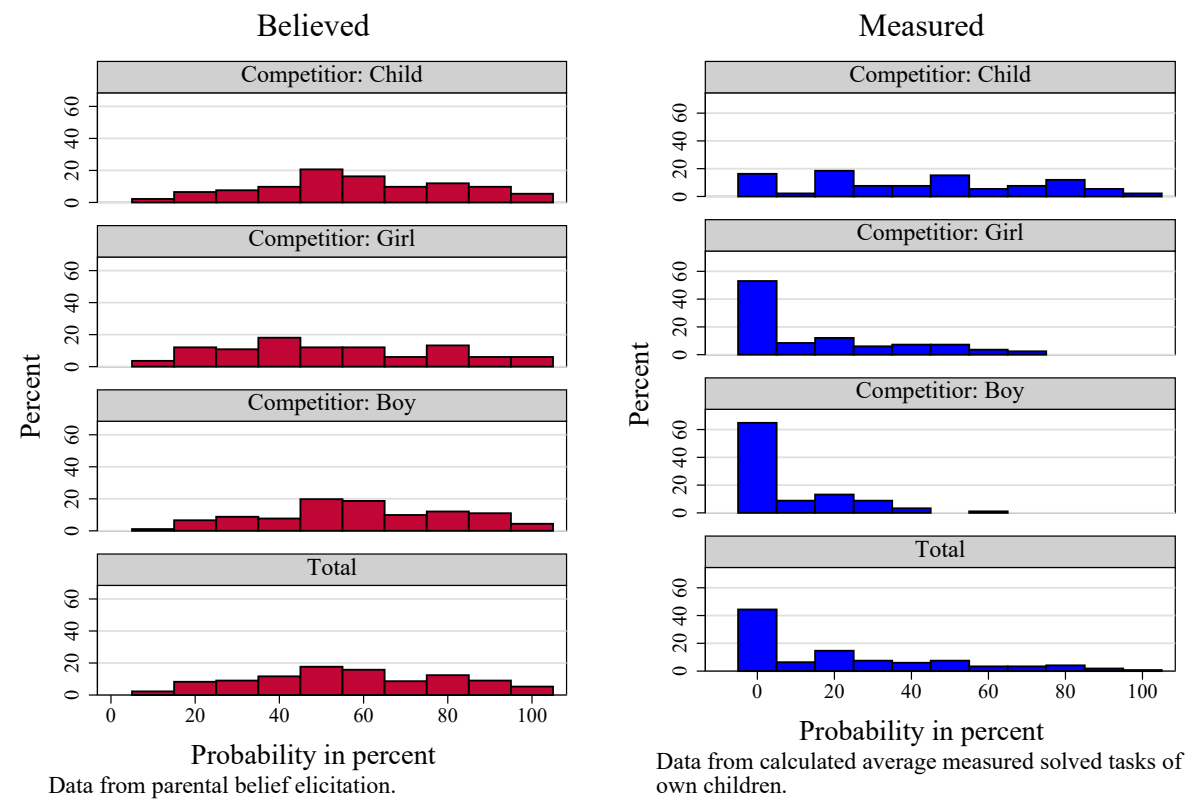

Source: Own Data

Table 4.4: Mean Comparison of Believed and Measured Values

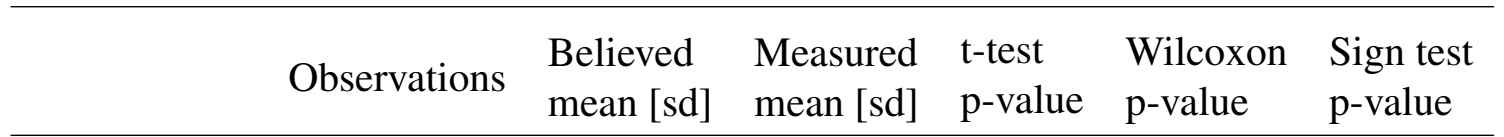

Probability of solving any one task

\begin{tabular}{lcccccc} 
Own child & 266 & 0.568 & 0.529 & 0.069 & 0.050 & 0.059 \\
\multirow{2}{*}{ Child } & & {$[0.237]$} & {$[0.258]$} & & & \\
& & 0.592 & 0.504 & 0.000 & 0.001 & 0.006 \\
\multirow{2}{*}{ Girl } & 83 & {$[0.220]$} & {$[0.091]$} & & & \\
& & 0.551 & 0.521 & 0.265 & 0.438 & 0.826 \\
Boy & 91 & $0.213]$ & {$[0.107]$} & & & \\
& & 0.626 & 0.534 & 0.002 & 0.008 & 0.208
\end{tabular}

Probability own child wins against

$\begin{array}{lcccccc}\text { Child } & 92 & 0.585 & 0.423 & 0.000 & 0.000 & 0.005 \\ & & {[0.229]} & {[0.295]} & & & \\ \text { Girl } & 83 & 0.528 & 0.155 & 0.000 & 0.000 & 0.000 \\ & & {[0.251]} & {[0.205]} & & & \\ \text { Boy } & 92 & 0.585 & 0.078 & 0.000 & 0.000 & 0.000 \\ & & {[0.230]} & {[0.128]} & & & \end{array}$


first panel in Table 4.4 and of the own child to win against different competitors in the second panel. $^{5}$

Believed and measured probability of the own child to solve any one task is only significant at the 10 percent significance level. The difference is rather small, less than 4 percent. Parents have inaccurate beliefs about the ability of a child with unknown gender and boys. They believe that they perform better than they do. The inaccuracies amount to a difference of slightly less than 9 percent. This is more than for the own child. Parents' beliefs about the ability of girls are accurate, believed and measured mean are not significantly different from zero. So, overall parents overestimate the performance for own children and competitors apart from competing girls.

In the lower panel of the table, we look at parental beliefs about the probability of their own child winning against a competitor. Believed and measured values are all statistically significant from zero. Parents overestimate the probability to win of their own child. They believe children have the lowest chance to win when playing against a girl, though the difference is only 5.7 percent.

\subsubsection{Assessment of Parental Belief by Child and Competitor Endowment}

The previous subsection already hinted at the influence of observable characteristics on the formation of parental beliefs about the ability of children. Now, we want to examine more closely how the gender of the own child, the gender of the competing child, and a combination of these matter for belief formation.

We first assess whether the means regarding belief are significantly differently between parents with a daughter or a son. As the number of observations is reduced to as low as 37 observations in one group, we not only run t-tests but also Wilcoxon rank-sum tests in Table 4.5. We assess the probability of solving any one task of the own child and the competitors, the own child winning against a competitor, and the probability of the own child to solve a certain amount of tasks. The only statistically significant difference at the 5 percent significance level is the probability of solving any one task of own child. Parents with a son believe that his average likelihood to solve any one task is 60.2 percent. Parents with a daughter believe that the probability to solve any one task is on average 54.0 percent, more than 6 percent less than for sons. The gender of the own child seems to matter for the belief formation of the parents.

\footnotetext{
${ }^{5}$ In the appendix, we also compare believed and measured probability of different numbers of solved tasks by the competitor.
} 
Table 4.5: Mean Comparison of Beliefs by Gender of Own Child

\begin{tabular}{|c|c|c|c|c|c|c|}
\hline & \multicolumn{2}{|c|}{ Daughter } & \multicolumn{2}{|c|}{ Son } & \multicolumn{2}{|c|}{ p-Values } \\
\hline & Observations & Mean [sd] & Observations & mean $[\mathrm{sd}]$ & t-test & Wilcoxon \\
\hline \multicolumn{7}{|c|}{ Probability of solving any one task } \\
\hline Own child & 146 & $\begin{array}{c}0.540 \\
{[0.239]}\end{array}$ & 120 & $\begin{array}{c}0.602 \\
{[0.232]}\end{array}$ & 0.036 & 0.035 \\
\hline Child & 50 & $\begin{array}{c}0.602 \\
{[0.213]}\end{array}$ & 42 & $\begin{array}{c}0.581 \\
{[0.230]}\end{array}$ & 0.650 & 0.529 \\
\hline Girl & 46 & $\begin{array}{c}0.585 \\
{[0.218]}\end{array}$ & 37 & $\begin{array}{c}0.508 \\
{[0.202]}\end{array}$ & 0.104 & 0.094 \\
\hline Boy & 50 & $\begin{array}{c}0.618 \\
{[0.235]}\end{array}$ & 41 & $\begin{array}{c}0.637 \\
{[0.222]}\end{array}$ & 0.702 & 0.825 \\
\hline \multicolumn{7}{|c|}{ Probability own child wins against } \\
\hline Child & 50 & $\begin{array}{c}0.550 \\
{[0.243]}\end{array}$ & 42 & $\begin{array}{c}0.626 \\
{[0.206]}\end{array}$ & 0.112 & 0.150 \\
\hline Girl & 46 & $\begin{array}{c}0.526 \\
{[0.246]}\end{array}$ & 37 & $\begin{array}{c}0.530 \\
{[0.260]}\end{array}$ & 0.948 & 0.923 \\
\hline Boy & 51 & $\begin{array}{c}0.547 \\
{[0.250]}\end{array}$ & 41 & $\begin{array}{c}0.632 \\
{[0.194]}\end{array}$ & 0.079 & 0.085 \\
\hline
\end{tabular}

Probability own child solves certain amount of tasks

\begin{tabular}{|c|c|c|c|c|c|c|}
\hline 0 & 146 & $\begin{array}{c}0.085 \\
{[0.103]}\end{array}$ & 120 & $\begin{array}{c}0.102 \\
{[0.108]}\end{array}$ & 0.198 & 0.157 \\
\hline 1 & 146 & $\begin{array}{c}0.135 \\
{[0.106]}\end{array}$ & 120 & $\begin{array}{c}0.134 \\
{[0.114]}\end{array}$ & 0.955 & 0.861 \\
\hline 2 & 146 & $\begin{array}{c}0.147 \\
{[0.094]}\end{array}$ & 120 & $\begin{array}{c}0.141 \\
{[0.094]}\end{array}$ & 0.621 & 0.571 \\
\hline 3 & 146 & $\begin{array}{c}0.168 \\
{[0.134]}\end{array}$ & 120 & $\begin{array}{c}0.174 \\
{[0.130]}\end{array}$ & 0.728 & 0.344 \\
\hline 4 & 146 & $\begin{array}{c}0.165 \\
{[0.107]}\end{array}$ & 120 & $\begin{array}{c}0.168 \\
{[0.117]}\end{array}$ & 0.813 & 0.832 \\
\hline 5 & 146 & $\begin{array}{c}0.147 \\
{[0.122]}\end{array}$ & 120 & $\begin{array}{c}0.125 \\
{[0.098]}\end{array}$ & 0.119 & 0.183 \\
\hline 6 & 146 & $\begin{array}{c}0.153 \\
{[0.158]}\end{array}$ & 120 & $\begin{array}{c}0.156 \\
{[0.163]}\end{array}$ & 0.903 & 0.751 \\
\hline
\end{tabular}


Next we consider the gender of the competitor (Table 4.6). We again run t-tests and Wilcoxon rank-sum tests to assess whether the beliefs about solving any one task or a certain amount of tasks or the own child to win against a certain competitor differ. Only the difference between girls and boys for the belief in solving any one task is statistically significant on the 5 percent significance level. Further, we only find statistically significant differences at the 5 percent level for a child with unknown gender and girl for the probability of solving three tasks.

We have seen that the gender of own child and the gender of the competing child evoke different parental beliefs. In the next step, we assess whether the combination of the gender of own child and the competing child matter for belief. Figure 4.9 shows box plots for the probability of winning of the own child against a certain competitor. It shows all six possible combinations. Whether the own child is a daughter or a son the median probability to win lies at 60 percent for

Figure 4.9: Box Plots on Probability to Win by Own Child by Gender Combinations

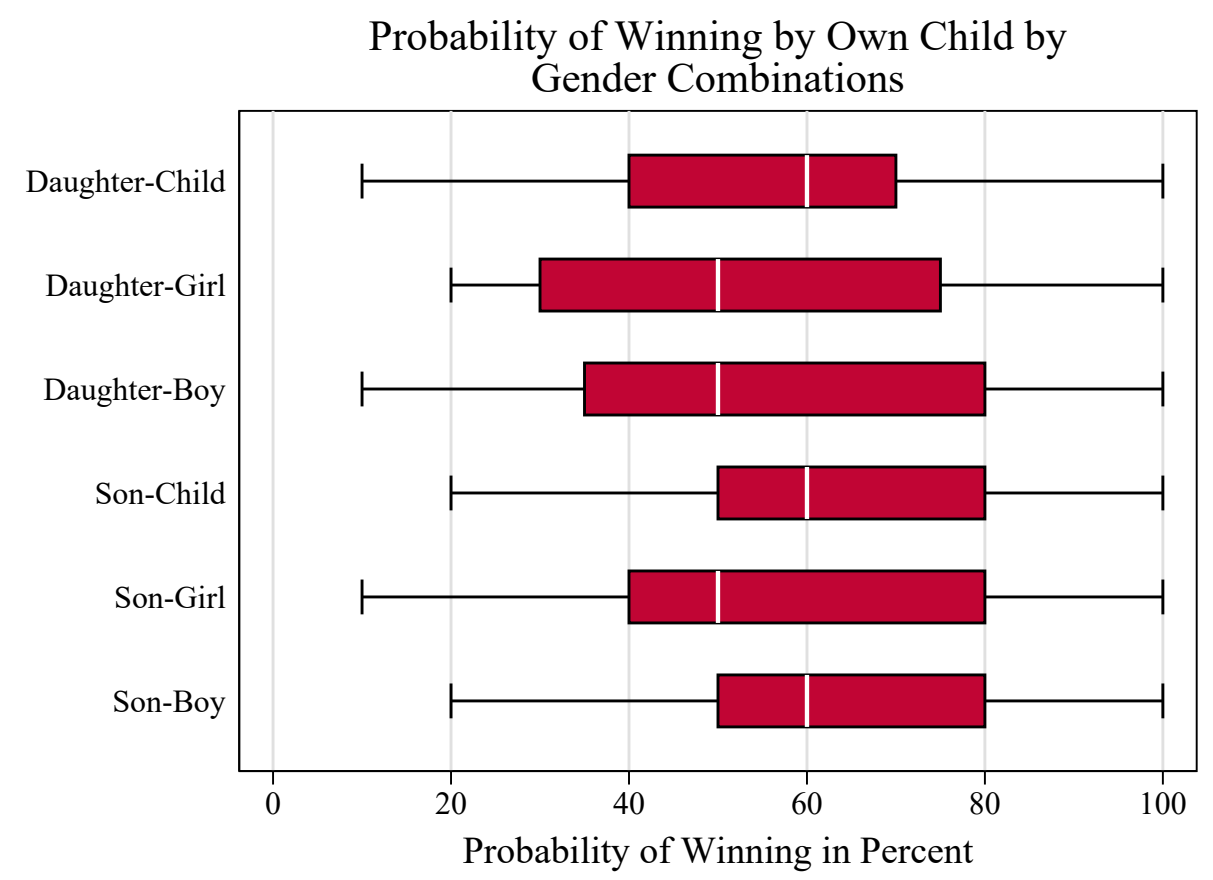

Source: Own Data.

competing against a child with unknown gender or at 50 percent for competing against a girl. The median probability to win lies at 50 percent for the combination daughter vs boy, but at 60 percent for son vs boy. The interquartile ranges are largest for the combination daughter vs boy. The interquartile ranges for the combinations with daughter include lower probabilities to win than with sons. 


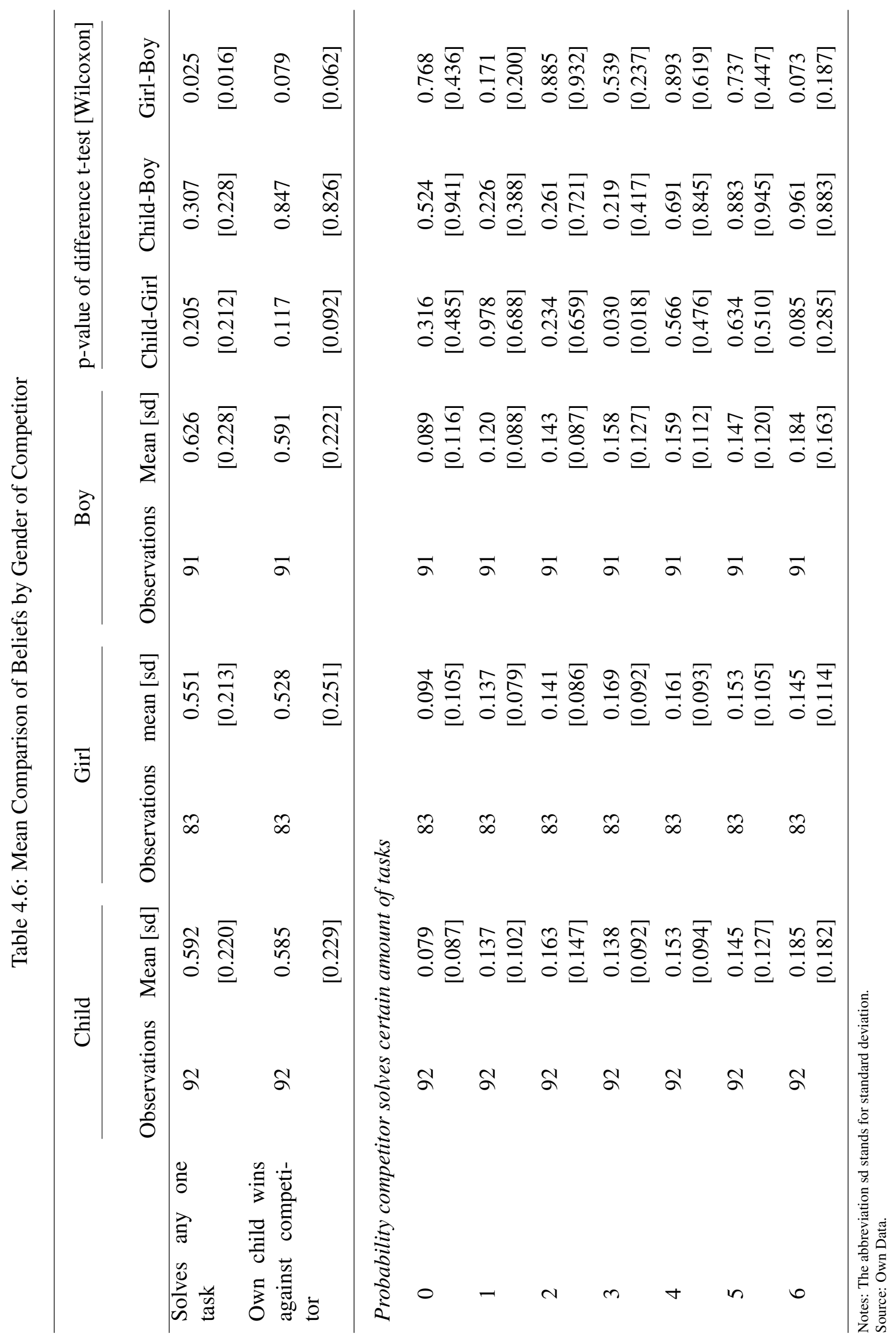




\subsubsection{Predictors of Believed Own Child Ability}

After our descriptive assessment of the effects of gender on parental beliefs, we assess now our first derived hypotheses from the conceptual framework considering predictors of the believed ability of the own child $p$ in Table 4.7 .

Table 4.7: Regression Results for Belief of Own Child Solving Any One Task

Believed Probability of Own Child Solving Any One Task

(1)

(2)

(3)

(4)

\begin{tabular}{|c|c|c|c|}
\hline Own child real ability & $\begin{array}{c}-0.008 \\
{[0.014]}\end{array}$ & & $\begin{array}{c}-0.016 \\
{[0.014]}\end{array}$ \\
\hline Daughter & & $\begin{array}{c}-0.061 * \\
{[0.027]}\end{array}$ & $\begin{array}{c}-0.092 \\
{[0.066]}\end{array}$ \\
\hline Daughter $\times$ Own child real ability & & & $\begin{array}{c}0.008 \\
{[0.019]}\end{array}$ \\
\hline
\end{tabular}

Expected completed education

(in years)

$-0.001$

[0.010]

Parent real ability

$0.028 *$

[0.011]

Willingness to take risks

$-0.001$

[0.007]

\begin{tabular}{lcccc}
\hline Mean Outcome & 0.568 & 0.568 & 0.568 & 0.568 \\
Controls & No & No & No & Yes \\
Observations & 266 & 266 & 266 & 257 \\
Subjects & 266 & 266 & 266 & 257
\end{tabular}

Notes: Standard errors appear in brackets and are clustered by parent. *,**,*** denote significance at the $10 \%, 5 \%$ and $1 \%$ levels, respectively.

Source: Own Data.

The table shows four OLS regressions with the outcome believed probability of own child solving any one task.

Hypothesis Belief 1a On average parents believe that their own children have a probability of 56.8 percent to solve any one task. As shown in the assessment of graphics and tests, the real ability of the child does not influence the belief. The coefficient is negative, small in magnitude, and not significant across the presented models. 
Hypothesis Belief 2a Other observable endowments of the child seem to matter more in the belief formation. When the own child is a girl, parents believe that on average a daughter is 6.1 percentage points less likely to solve any one task than a son (in column 2), ceteris paribus. Though the magnitude increases when adding covariates, the effect is no longer significant. The interaction of daughter and own child real ability is not significant and rather small in magnitude.

Parent Endowment as Significant Predictor When adding reference points to the model in column 4 such as parental ability and aspirations, we only find that parental real ability has a positive and significant association with the believed probability of the parent's own child to solve any one task. For every additional task the parent is able to solve, the parental belief about the own child to solve any one task increases on average by 2.8 percentage points, all else equal. In the next subsection, we assess the possible influence of observable endowments of children like gender on belief formation, this time related to the probability to win.

\subsubsection{Predictors of Believed Probability to Win}

We are testing the four left hypotheses regarding the parental belief formation derived from the conceptual framework using the second specified equation model for beliefs. Table 4.8 includes six different models. The first column focuses on endowments of the own child, the second on endowments of the competitor, the third on the believed ability of own child and competitor, and the fourth column on the gender of the own child, the competitor, and the combination of both. The second last model brings all predictors together and the last model includes control variables that have been specified in the empirical specification section.

Hypothesis Belief 1b We want to assess the hypothesis if greater believed ability of the own child increases parental belief in the own child to win against a competitor. The believed ability of own child is significant at least at the 5 percent significance level for all models in which it is included. The magnitude is largest in column one. Considering the main model in column 6 , the believed likelihood to win increases by 2.89 percentage points when the believed ability of the own child to solve any one task increases by 10 percentage points. This provides support to our hypothesis. 
Table 4.8: Regression Results Parental Belief about Probability of Own Child to Win

\begin{tabular}{|c|c|c|c|c|c|c|}
\hline & \multicolumn{6}{|c|}{ Believed Probability of Own Child to Win } \\
\hline & (1) & (2) & (3) & (4) & $(5)$ & $(6)$ \\
\hline Own child believed ability & $\begin{array}{c}0.384 * * * \\
{[0.090]}\end{array}$ & & $\begin{array}{c}0.233 * * \\
{[0.067]}\end{array}$ & & $\begin{array}{c}0.260 * * \\
{[0.089]}\end{array}$ & $\begin{array}{c}0.289 * * \\
{[0.103]}\end{array}$ \\
\hline Daughter & $\begin{array}{c}0.028 \\
{[0.078]}\end{array}$ & & & $\begin{array}{l}-0.073 * \\
{[0.032]}\end{array}$ & $\begin{array}{c}-0.038 \\
{[0.070]}\end{array}$ & $\begin{array}{c}-0.033 \\
{[0.077]}\end{array}$ \\
\hline Daughter $\times$ Own child believed ability & $\begin{array}{l}-0.107 \\
{[0.133]}\end{array}$ & & & & $\begin{array}{c}-0.047 \\
{[0.121]}\end{array}$ & $\begin{array}{c}-0.094 \\
{[0.116]}\end{array}$ \\
\hline Competitor believed ability & & $\begin{array}{c}0.179 \\
{[0.109]}\end{array}$ & $\begin{array}{c}0.281 * * \\
{[0.080]}\end{array}$ & & $\begin{array}{c}0.064 \\
{[0.121]}\end{array}$ & $\begin{array}{c}-0.095 \\
{[0.102]}\end{array}$ \\
\hline Competitor: girl & & $\begin{array}{c}-0.253^{*} \\
{[0.100]}\end{array}$ & & $\begin{array}{c}- \\
0.233 * * * \\
{[0.059]}\end{array}$ & $\begin{array}{c}- \\
0.403 * * * \\
{[0.103]}\end{array}$ & $\begin{array}{c}- \\
0.528 * * * \\
{[0.097]}\end{array}$ \\
\hline Competitor: boy & & $\begin{array}{l}-0.136 \\
{[0.113]}\end{array}$ & & $\begin{array}{c}- \\
0.274 * * * \\
{[0.075]}\end{array}$ & $\begin{array}{c}-0.263^{*} \\
{[0.106]}\end{array}$ & $\begin{array}{c}- \\
0.414 * * * \\
{[0.107]}\end{array}$ \\
\hline Competitor: girl $\times$ Competitor believed ability & & $\begin{array}{c}0.369^{*} \\
{[0.167]}\end{array}$ & & & $\begin{array}{c}0.439 * * \\
{[0.158]}\end{array}$ & $\begin{array}{c}0.472 * * \\
{[0.151]}\end{array}$ \\
\hline Competitor: boy $\times$ Competitor believed ability & & $\begin{array}{c}0.217 \\
{[0.156]}\end{array}$ & & & $\begin{array}{c}0.237 \\
{[0.148]}\end{array}$ & $\begin{array}{l}0.288^{*} \\
{[0.133]}\end{array}$ \\
\hline Daughter-Girl & & & & $\begin{array}{c}0.222 * * \\
{[0.071]}\end{array}$ & $\begin{array}{c}0.147 * * \\
{[0.052]}\end{array}$ & $\begin{array}{c}0.233 * * * \\
{[0.056]}\end{array}$ \\
\hline Daughter-Boy & & & & $\begin{array}{c}0.283 * * \\
{[0.081]}\end{array}$ & $\begin{array}{c}0.128 \\
{[0.063]}\end{array}$ & $\begin{array}{c}0.266^{* *} \\
{[0.082]}\end{array}$ \\
\hline Son-Girl & & & & $\begin{array}{c}0.149 * * \\
{[0.050]}\end{array}$ & $\begin{array}{c}0.101 * * \\
{[0.034]}\end{array}$ & $\begin{array}{c}0.140 * * \\
{[0.045]}\end{array}$ \\
\hline Son-Boy & & & & $\begin{array}{c}0.281 * * \\
{[0.082]}\end{array}$ & $\begin{array}{c}0.121 \\
{[0.061]}\end{array}$ & $\begin{array}{c}0.205^{* *} \\
{[0.073]}\end{array}$ \\
\hline Mean Outcome & 0.569 & 0.569 & 0.569 & 0.569 & 0.569 & 0.569 \\
\hline Controls & No & No & No & No & No & Yes \\
\hline Observations & 266 & 266 & 266 & 263 & 263 & 239 \\
\hline Subjects & 266 & 266 & 266 & 263 & 263 & 239 \\
\hline
\end{tabular}


Hypothesis Belief 1c Next, we want to assess whether lower believed ability of the competitor increases parental belief in the own child to win against a competitor. Surprisingly the sign of the coefficient for competitors' believed ability is positive. However, the magnitude and significance decrease when adding covariates. In the main model, the sign turns negative. The association of believed ability of a competitor and probability to win of the own child does not follow a clear pattern and so does not clearly support our hypothesis.

Hypothesis Belief 2b and 2c The last two hypotheses regarding parental belief formation assess the role of gender of the own child and the competitor. The dummy Daughter is only significant in models without own child believed ability. The coefficient is mostly negative, particularly in the main model. It is significant on the 10 percent significance level in column 4 suggesting that parents with a daughter compared to those with a son believe that their own child is 7.3 percent less likely to win against a competitor. The interaction of the dummy Daughter with the believed ability of own child represents a discount factor for girls. It is negative in sign but not significant.

Overall, we find that gender of the own child matters for the believed probability of the own child to win. Playing with a daughter has a negative association with belief in winning. The interaction of gender with the believed ability works as a discount factor for girls.

The last hypothesis regarding beliefs relates to the gender of the competitor. We claim when the competing child is a girl (boy), parents believe in a higher (lower) probability of their own child winning against a competitor compared to a competitor with unobserved gender. In our regression analysis, we include two dummy variables indicating that the competitor is a girl or a boy. The competitor with unknown gender is the reference category. Both dummies are largest in magnitude and significant on the 1 percent significance level for the main model in column 6. When the competitor is a girl compared to a child with unknown gender, parents believe that their child is on average 52.8 percentage points less likely to win, ceteris paribus. In the case of a boy as a competitor, the believed likelihood decreases by 41.4 percentage points.

That the magnitude for competing girls is largest is surprising in the context of India because parents value cognitive ability as revealed in our test less in girls than in boys. We would assume that parents would perceive boys to be a bigger threat than girls. Otherwise, our sample might be decisive for this parental belief. Higher performing sons are usually sent to private schools and so the average ability of sons at governmental schools could be lower than the average ability of girls. High-performing girls remain at governmental schools and so might raise 
the average performance of girls relative to the remaining boys. Parents might be aware of this and so see girls as a bigger threat and form the belief that their own child is less likely to win against a competing girl. However, this awareness might not influence parental beliefs in the likelihood of their own girl child to win in general because of the lower valuation of cognitive ability of girls.

The interaction of competitors' gender and ability are also significant in the main model. If parents believe that a competing girl is 10 percentage points more likely to solve any one task compared to a child of unknown gender, then the parental belief of their own child winning increases by 4.72 percentage points on average, ceteris paribus. In the case of a boy competitor, the increase is 2.88 percentage points.

We are also assessing the combinations of the gender of own child and the gender of the competitor. We include a dummy for each combination except for son vs child that is our reference category. The results for daughter vs child is omitted due to collinearity. All interactions are positive in sign and significant at least at the 5 percent significance level in column 4 and column 6. Parents playing the game daughter vs girl compared to the game son vs child believe that their own child is 23.3 percentage points more likely to win. When they play the game daughter vs boy the chance increases even more by 26.6 percentage points. The increase in ability is lower for the games son vs girl and son vs boy.

Parents believe that their own child is less likely to win if the competitor is a girl or a boy compared to a child with unknown gender. However, the believed ability of girls and boys discounts this because it has a positive association with the probability of winning. Looking at the combinations we observe the expected positive association of belief with the combination with son and girls and boy competitor. Though the magnitude is larger for competing against the same gender of the own child. For daughters, we see also positive effects, unlike our expectation. The magnitudes are even larger than for boys and largest for the case where daughters are competing against boys. We can only partly support our hypothesis because we find negative associations with probability to win with competitors of known gender and positive associations with own child and competing girl or boy.

To conclude, our empirical results show that the real ability of the own child and having a daughter are negatively associated with the belief about solving any one task though the findings are not statistically significant in the main model. Having a daughter has also a negative association with the believed probability to win. The believed ability of own child has a significant and 
positive association with the probability to win. The last two hypotheses regarding the competitor find mixed evidence. Competitor's believed ability does not have a clear association. For competing boys we find a negative association with belief to win but also for girls compared to children with unknown gender. We also find for both genders in the combination of own child and competitor a positive association. For the belief formation of parents, it seems to make a difference whether they know the gender of the competitor but not so much the gender itself.

\subsection{Parental Investment Decisions under Competition}

In this section, we come to the derived hypotheses for investment decisions of parents.

\subsubsection{Are Parents Purely Utility Maximizing?}

One assumption in the theoretical models of the intergenerational mobility and transmission of earnings, assets, and consumption by Becker \& Tomes $(1986,1979)$ is that parents are aiming at maximizing their utility. In the conceptual framework, we observe that social preferences matter not so much as a part of the utility function itself. Their influence on the belief formation of $p$ or $w$ seems more important. If we assume parents to only consider their expected payout for generating utility, the introduced payment schemes discourage parents to invest any money in case the child solves no task and encourages them to invest the whole endowment in case the child solves more than one task (if the probability to win is more than $w=1 / 2$ in the competitive game). When we look at the trend of investment over increasing numbers of solved tasks, we can detect a pattern though less sharp as predicted (Figure 4.10). On average parents invest more than INR 30 when the child solves no task. The investment is increasing. The investments seem to be usually higher for a non-competitive setting than for a competitive one. From this observation, we conclude that it is important to include social preferences in our estimation strategy because the investment behavior can not be explained alone by a payout maximizing strategy.

\subsubsection{Do Parents Invest Less in Competitive Games?}

This already introduces our main objective of this study: the influence of market luck in form of a competitive or non-competitive setting on parental investment decisions in their children. Considering the described trend in Figure 4.10 or the box plots of average parental investment by setting in Figure 4.11, we find that parents at the median invest less in their children when 
Figure 4.10: Average Invested Amount over Number of Solved Tasks by Competition

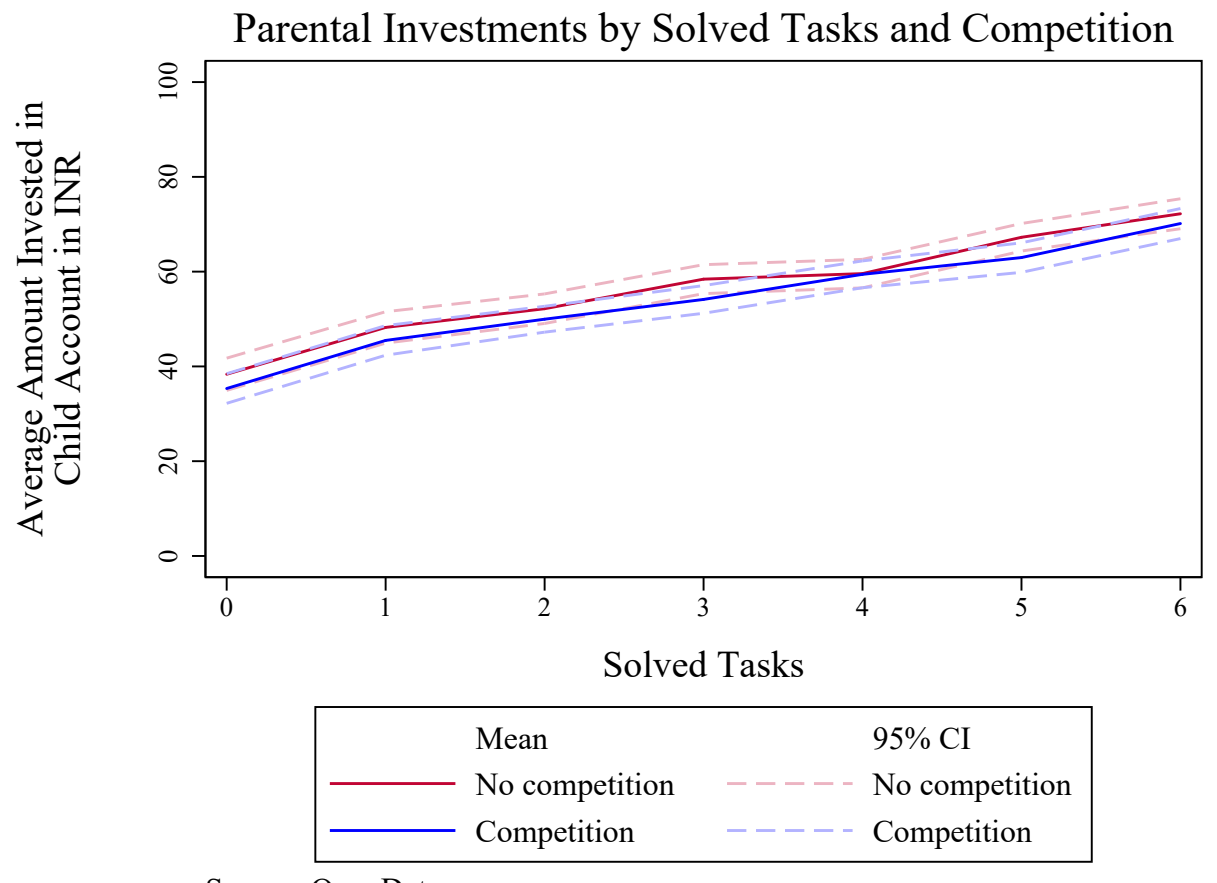

Source: Own Data.

exposed to competition. As we have elicited parental investment decisions with the strategy method we can have a closer look at the investment for each possible number of solved tasks like in Figure 4.12. The interquartile range is very similar for all possible solved tasks but

Figure 4.11: Box Plots of Parental Investment in the Child Account by Competition

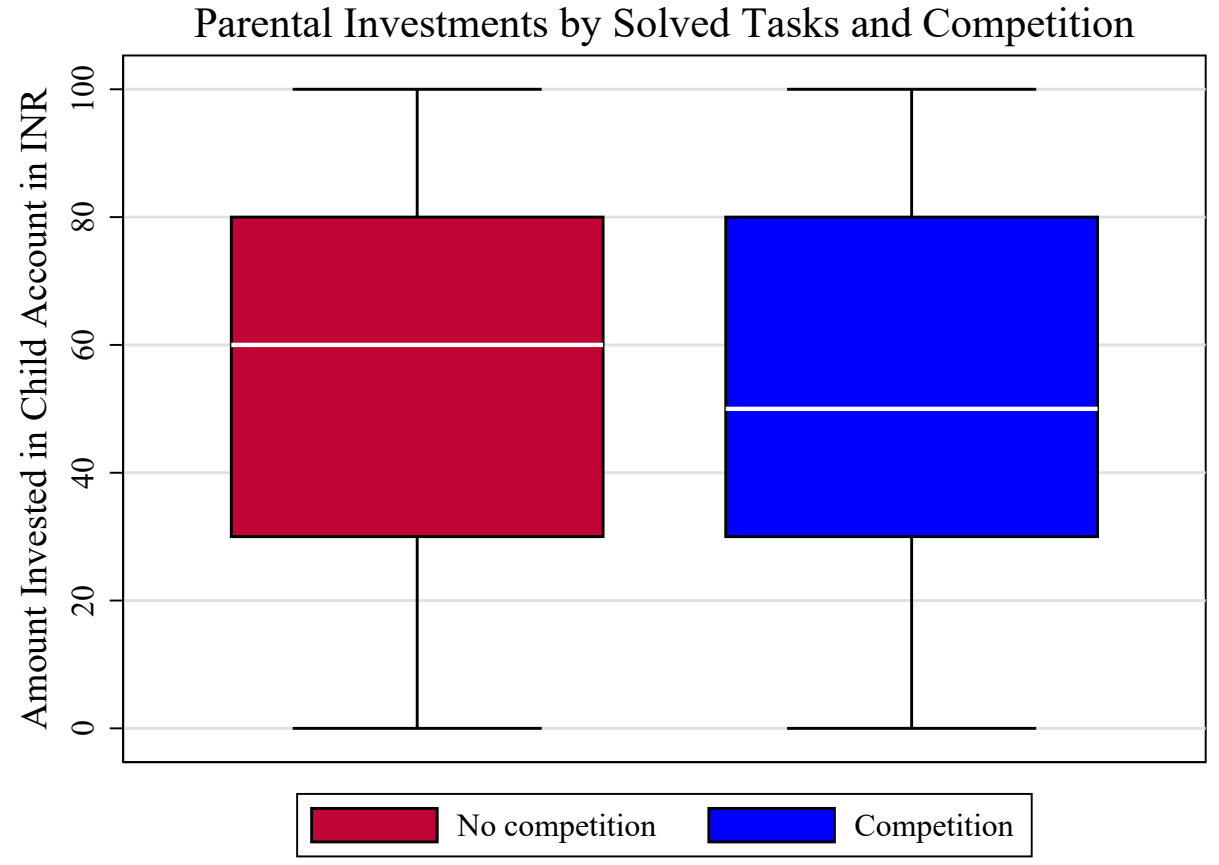

Source: Own Data. 
Figure 4.12: Box Plots of Parental Investment in the Child Account over Solved Tasks by Competition

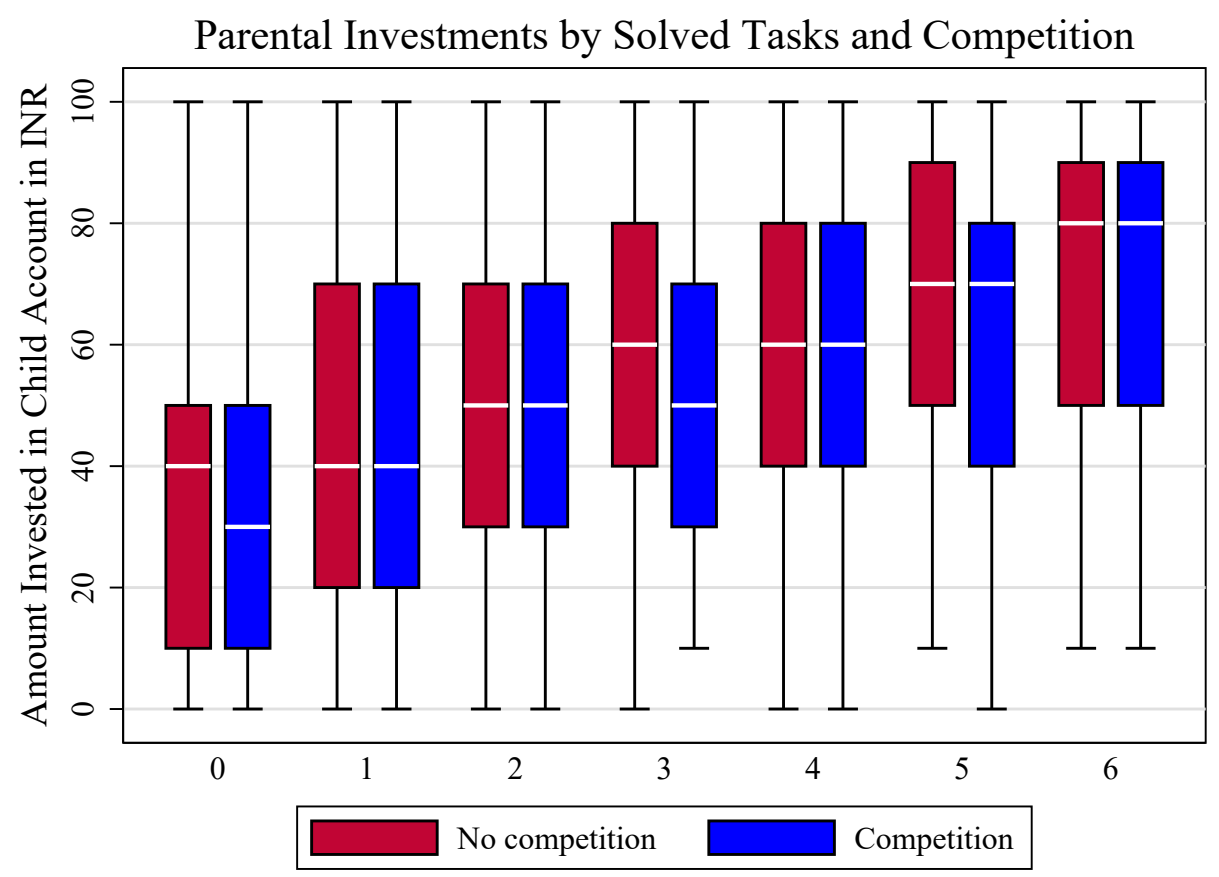

Source: Own Data.

three and five solved tasks. In these two cases, the interquartile range includes higher invested amounts for the non-competitive scenario compared to the competitive one. The median increases or remains the same with an increasing number of solved tasks. The median is also very similar for all possible solved tasks but solving nothing or three tasks. The median has a higher value in the non-competitive setting.

Next, we want to confirm our hunch that parents invest less in their children when exposed to competition by conducting t-tests of equality of means. As the assumption of normality is violated, we also report results of non-parametric tests like Mann-Whitney rank-sum test or Wilcoxon signed-rank test (Table 4.9). We find significant differences at the 5 percent level for all tests for solving three or five tasks. There is also a statistically significant difference between investments considering average spending. The overall mean investment is lower under competition. Standard deviations are usually smaller in the competitive setting until the possibility of the child to solve four tasks. Then the pattern changes and the standard deviation becomes smaller for the non-competitive setting.

We have just examined the investment decisions of parents based on the number of solved tasks of children by competition. Now we turn to another key independent variable, the believed probability of the own child to win against a competitor (Figure 4.13). When we look at box 
Table 4.9: Comparison of the Investments by Child Ability and Competition

\begin{tabular}{|c|c|c|c|c|c|c|}
\hline $\begin{array}{l}\text { Number of } \\
\text { Solved Tasks }\end{array}$ & Observations & $\begin{array}{l}\text { No Competition } \\
\text { mean }[\mathrm{sd}]\end{array}$ & $\begin{array}{l}\text { Competition } \\
\text { mean }[\mathrm{sd}]\end{array}$ & $\begin{array}{l}\text { t-test } \\
\text { p-value }\end{array}$ & $\begin{array}{l}\text { Wilcoxon } \\
\text { p-value }\end{array}$ & $\begin{array}{l}\text { Sign test } \\
\text { p-value }\end{array}$ \\
\hline 0 & 266 & $\begin{array}{c}38.346 \\
{[28.196]}\end{array}$ & $\begin{array}{c}35.338 \\
{[25.860]}\end{array}$ & 0.114 & 0.131 & 0.162 \\
\hline 1 & 266 & $\begin{array}{c}48.233 \\
{[27.463]}\end{array}$ & $\begin{array}{c}45.489 \\
{[25.858]}\end{array}$ & 0.152 & 0.073 & 0.066 \\
\hline 2 & 266 & $\begin{array}{c}52.180 \\
{[25.854]}\end{array}$ & $\begin{array}{c}49.962 \\
{[22.629]}\end{array}$ & 0.249 & 0.337 & 0.741 \\
\hline 3 & 266 & $\begin{array}{c}58.421 \\
{[25.279]}\end{array}$ & $\begin{array}{c}54.135 \\
{[24.189]}\end{array}$ & 0.022 & 0.011 & 0.014 \\
\hline 4 & 266 & $\begin{array}{c}59.586 \\
{[24.942]}\end{array}$ & $\begin{array}{c}59.436 \\
{[23.425]}\end{array}$ & 0.935 & 0.897 & 0.946 \\
\hline 5 & 266 & $\begin{array}{c}67.256 \\
{[24.067]}\end{array}$ & $\begin{array}{c}62.970 \\
{[25.782]}\end{array}$ & 0.019 & 0.026 & 0.101 \\
\hline 6 & 266 & $\begin{array}{c}72.218 \\
{[26.206]}\end{array}$ & $\begin{array}{c}70.150 \\
{[26.249]}\end{array}$ & 0.253 & 0.347 & 0.783 \\
\hline Mean & 266 & $\begin{array}{c}56.606 \\
{[17.299]}\end{array}$ & $\begin{array}{c}53.926 \\
{[15.883]}\end{array}$ & 0.015 & 0.041 & 0.029 \\
\hline
\end{tabular}

Notes: All tests are two-tailed. The abbreviation sd stands for standard deviation.

Source: Own Data.

Figure 4.13: Average Invested Amount over Number of Solved Tasks by Competition

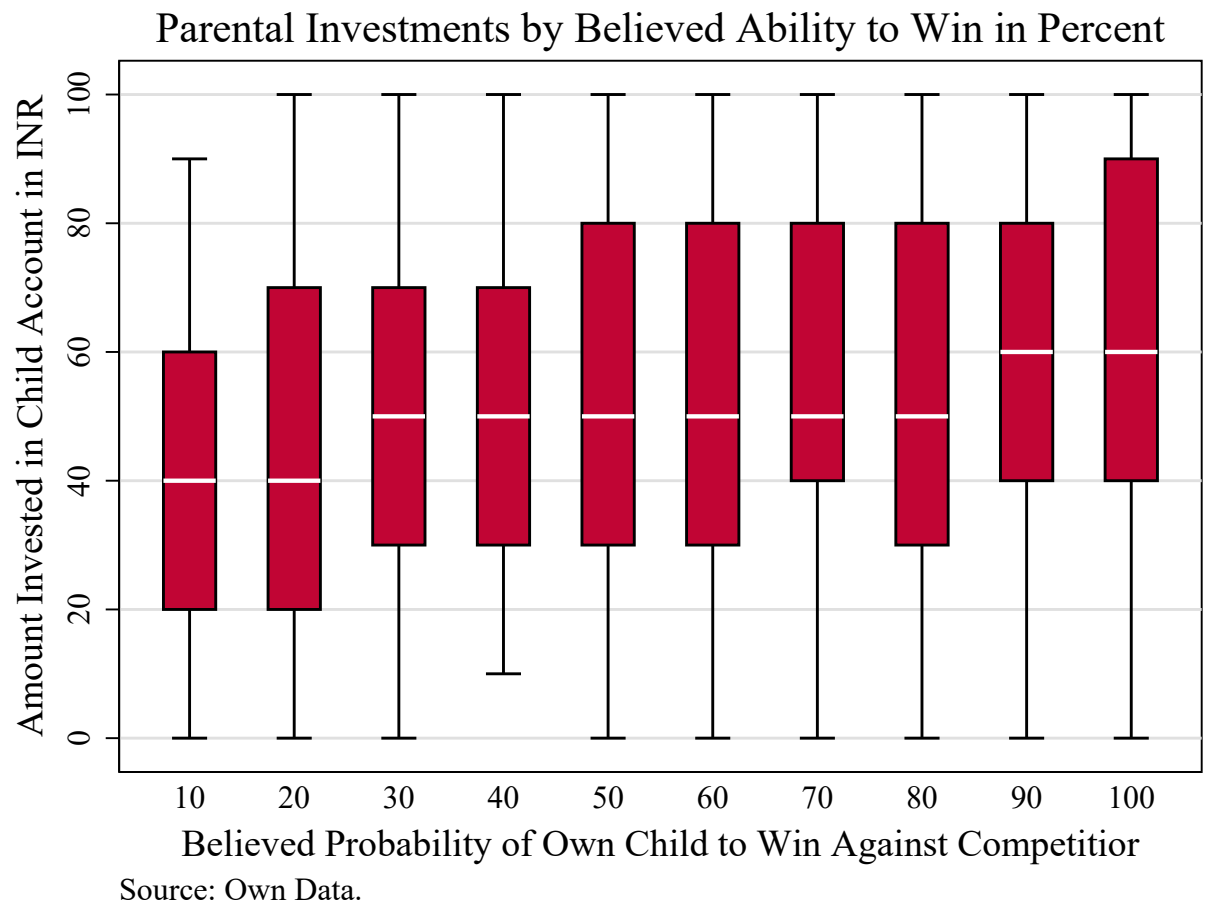


plots of parental investments in the child account by this key variable, we see that the median investment rises with increasing belief in the ability to win. The median parent who believes that the own child is 10 or 20 percent likely to win against a competitor invests INR 40. The median of parents who believe in a probability between 30 to 80 percent lies at INR 50. The median of parents with even higher believed probabilities is INR 60. The range of the median spending by believed probability to win contains a rather narrow bracket: INR 40 to INR 60. Our descriptive analysis shows that parents' investments are sensitive to market luck: they invest less under competition. Even parents who are sure that their own child wins against a competitor invest INR 60 (of possible INR 100) at the median.

\subsubsection{Test of Hypotheses Investment 1 to 5}

With the prior introduced empirical specification for the structural form regression equation, we estimate the effects of exposure to a competitive setting compared to a non-competitive one on investment in children (Table 4.10). The outcome is the invested amount in INR in the child account. We run the first eight models with OLS, the ninth with random effects, and the tenth with a random effects mixed model. Column 8 is the main model of our analysis, columns 9 and 10 serve as robustness checks.

The first seven columns include 3724 observations of 266 subjects. When we introduce covariates, the number of observations reduces to 3374 observations and 241 subjects. The average amount invested under non-competition is INR 56.61. Priorly displayed graphs show that parents invest between INR 0 and INR 100 with partly investments at the extreme. However, the interquartile range of the overall mean of investments covers INR 30 to INR 80 for both settings. We report the outcomes in INR and interpret them partly as a percent of the initial endowment to put the magnitude of the coefficients into perspective. We consider the endowment of the own children in general in the first three columns. Then we focus on competition and how child endowment, believed probability to win, and other covariates influence the overall spending behavior of parents. We present the findings for the first lot of hypotheses regarding investment (Hypotheses Investment 1a, 2a, 2b, 3, 4, 5) in the following.

Hypothesis Investment 1a Our findings support the hypothesis that greater ability of the own child increases parental investment in the child account. The effect is rather stable and always significant at the 1 percent level. For example, in column 8 parents invest on average INR 4.82 


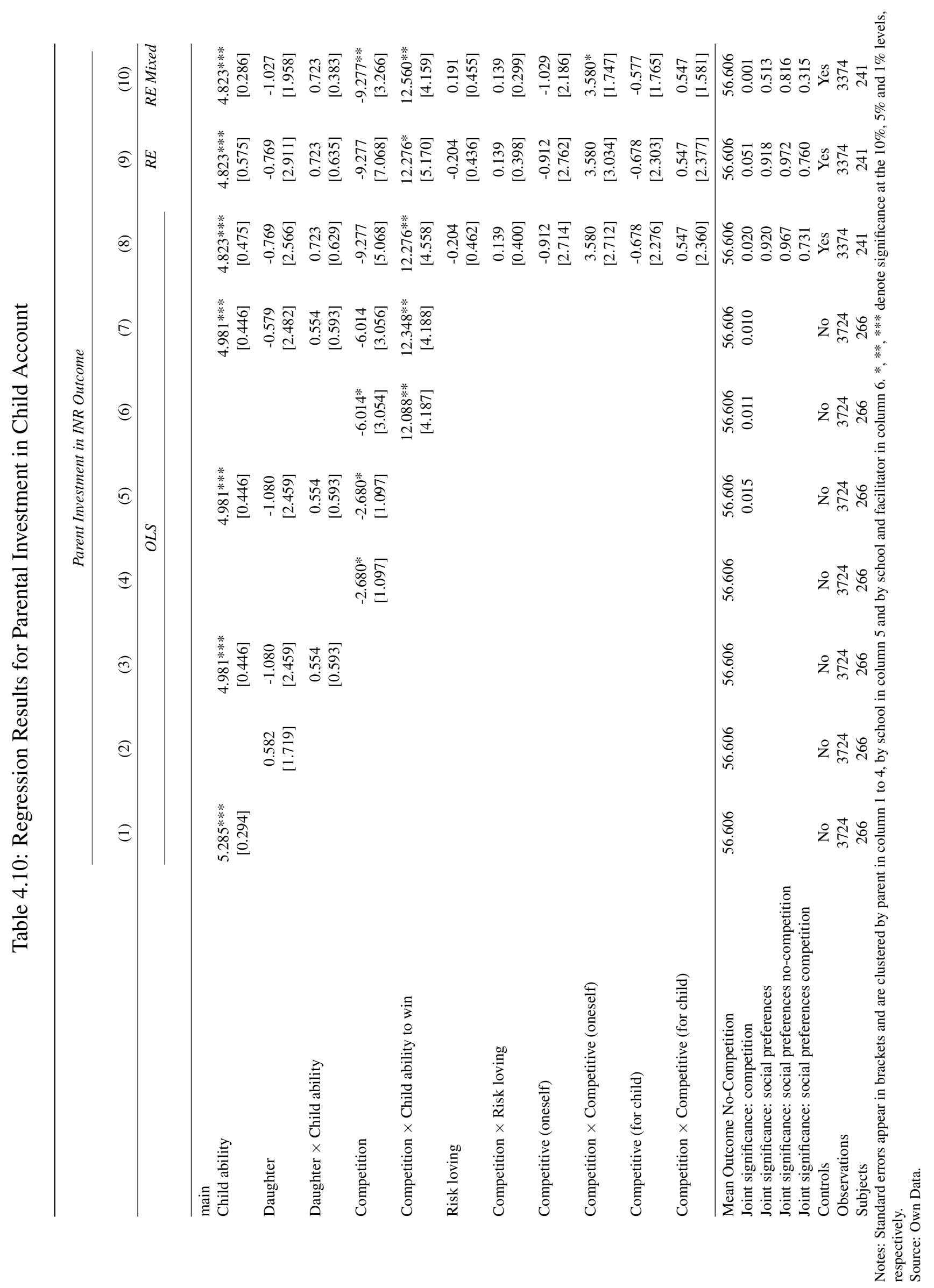


more in the child account when their child is able to solve one task more, ceteris paribus. That corresponds to 5 percent of the initial endowment. Our findings lend support to hypothesis 1a.

Hypothesis Investment 2a Now we consider the influence of the gender of own child for the investment decisions. Playing a game with a daughter has a negative association with investment in all columns but column 2. The gender of the child does not discount the real ability of daughters. The effects are not statistically significant and small in magnitude, each not more than INR 1 in our main model.

Hypothesis Investment 4 We turn now to our key independent variable to analyze whether market luck affects parental investment decisions in children. The result of column 4 reflects the conducted mean tests from before: Exposure to competition is associated with a decrease in investment in the child account by on average INR 2.68, ceteris paribus. This holds on the 10 percent significance level. When we add child endowments (real ability, gender of the own child, and their interaction) or the interaction of competition and the believed probability to win, the coefficient remains significant. It increases in size in column 6. For our main model in column 8 that includes all covariates, the magnitude is even larger. However, the effect is only significant in the random effects mixed model although the magnitude is stable in columns 8 to 10. On average parents invest INR 9.27 less in the child account when they are exposed to a competitive setting that is 9 percent of their initial endowment.

Hypothesis Investment 3 The third hypothesis we consider is whether a higher believed probability of the own child to win against a competitor increases parental investment in the child account. Our results in columns 6 to 10 show that the effect is positive and at least significant at the 10 percent significance level. The magnitude is rather stable. According to column 8 , parents invest on average INR 1.23 more in the child account when the parental belief regarding the probability of their own child to win against a competitor increases by 10 percentage points. That corresponds to 1 percent of the initial endowment. We check the robustness of this finding by adding also the main effect in the regression in the appendix. We find that the effect of parents' belief in the relative ability of their child, the probability to win against a competitor, is positive just as the interaction with competition. The effect size of the interaction term is reduced by half and is no longer significant. 
Hypothesis Investment 5 The fifth hypothesis claims that social preferences increase parental investments in the child account more in a competitive than in a non-competitive setting. Although interactions of competition with risk-seeking and competitiveness do have a positive sign in the regression analysis, only the interaction of competition and competitiveness for oneself is significant on the 10 percent significance level in column 10 . We conduct joint significance tests of either all included social preferences, only for the non-competitive, or only for the competitive setting. All tests are not significant rejecting our fifth hypothesis that the included social preferences matter significantly for the investment decision.

\subsection{Reduced Form Regression - Bringing Investment and Beliefs together}

We are now bringing the two equations of parental investment and belief formation together to estimate the results for a reduced form as specified in the methods section. Column 1 of Table 4.11 shows the results with the endogenous variable probability to win, the other columns are the reduced form equation. When we replace child ability to win with the parameters that generate this belief, we do this step-wise: column 2 considers own child endowments in the competitive setting, column 3 competitor's endowments, column 4 the gender combinations of own child and competitor, and column 5 to 8 include all exogenous parameters of the child ability to win against a competitor $w$. All parameters are interacted with competition. Our previous observations for child endowment hold.

Reassessment of Hypothesis Investment 4 The dummy competition remains negative but is smaller in magnitude and no more significant compared to the structural model. Parents still invest less in competition though the evidence is less striking.

Hypothesis Investment 6 We have slight evidence for our sixth hypothesis that believed lower ability of the competitor increases parental investment in the own child. The interaction of competition and competitor's believed ability is negative in sign and small in magnitude. It is not significant.

Hypothesis Investment 1b Our findings still support the hypothesis that greater ability of the own child increases parental investment in the child account for non-competition. However, there is no additional ability effect when exposed to competition because the interaction term is not significant and small in magnitude, though it is positive. 
Table 4.11: Reduced Form Regression Results for Parental Investment in Child Account

\begin{tabular}{|c|c|c|c|c|c|c|c|c|}
\hline & \multicolumn{8}{|c|}{ Parent Investment in INR Outcome } \\
\hline & (1) & (2) & (3) & (4) & $(5)$ & (6) & (7) & (8) \\
\hline & \multicolumn{6}{|c|}{$O L S$} & $R E$ & RE Mixed \\
\hline Child ability & $\begin{array}{c}4.981^{* * * *} \\
{[0.446]}\end{array}$ & $\begin{array}{c}4.762^{* * * *} \\
{[0.566]}\end{array}$ & $\begin{array}{c}4.981^{* * *} \\
{[0.446]}\end{array}$ & $\begin{array}{c}4.981 * * * \\
{[0.446]}\end{array}$ & $\begin{array}{c}4.762 * * * \\
{[0.567]}\end{array}$ & $\begin{array}{c}4.562 * * * \\
{[0.595]}\end{array}$ & $\begin{array}{c}4.552^{* * * *} \\
{[0.656]}\end{array}$ & $\begin{array}{c}4.552^{* * *} \\
{[0.400]}\end{array}$ \\
\hline Daughter & $\begin{array}{l}-0.579 \\
{[2.482]}\end{array}$ & $\begin{array}{l}-2.250 \\
{[3.098]}\end{array}$ & $\begin{array}{l}-1.013 \\
{[2.459]}\end{array}$ & $\begin{array}{l}-1.421 \\
{[2.828]}\end{array}$ & $\begin{array}{l}-2.159 \\
{[3.106]}\end{array}$ & $\begin{array}{l}-1.967 \\
{[3.131]}\end{array}$ & $\begin{array}{l}-1.882 \\
{[3.364]}\end{array}$ & $\begin{array}{l}-2.460 \\
{[2.383]}\end{array}$ \\
\hline Daughter $\times$ Child ability & $\begin{array}{c}0.554 \\
{[0.593]}\end{array}$ & $\begin{array}{c}0.894 \\
{[0.738]}\end{array}$ & $\begin{array}{c}0.554 \\
{[0.593]}\end{array}$ & $\begin{array}{c}0.617 \\
{[0.592]}\end{array}$ & $\begin{array}{c}0.894 \\
{[0.739]}\end{array}$ & $\begin{array}{c}1.121 \\
{[0.775]}\end{array}$ & $\begin{array}{c}1.118 \\
{[0.743]}\end{array}$ & $\begin{array}{l}1.118 * \\
{[0.540]}\end{array}$ \\
\hline Competition & $\begin{array}{l}-6.014 \\
{[3.056]}\end{array}$ & $\begin{array}{l}-4.158 \\
{[2.498]}\end{array}$ & $\begin{array}{c}2.476 \\
{[6.239]}\end{array}$ & $\begin{array}{l}-2.700 \\
{[2.712]}\end{array}$ & $\begin{array}{c}-0.130 \\
{[6.419]}\end{array}$ & $\begin{array}{l}-4.232 \\
{[7.421]}\end{array}$ & $\begin{array}{l}-2.419 \\
{[5.941]}\end{array}$ & $\begin{array}{l}-0.113 \\
{[4.711]}\end{array}$ \\
\hline Competition $\times$ Child ability to win & $\begin{array}{c}12.348^{* * *} \\
{[4.188]}\end{array}$ & & & & & & & \\
\hline Competition $\times$ Child ability & & $\begin{array}{c}0.438 \\
{[0.593]}\end{array}$ & & & $\begin{array}{c}0.438 \\
{[0.594]}\end{array}$ & $\begin{array}{c}0.513 \\
{[0.637]}\end{array}$ & $\begin{array}{c}0.507 \\
{[0.717]}\end{array}$ & $\begin{array}{c}0.507 \\
{[0.563]}\end{array}$ \\
\hline Competition $\times$ Daughter & & $\begin{array}{c}2.340 \\
{[3.242]}\end{array}$ & & & & & & \\
\hline Competition $\times$ Daughter $\times$ Child ability & & $\begin{array}{c}-0.680 \\
{[0.780]}\end{array}$ & & & $\begin{array}{l}-0.554 \\
{[0.786]}\end{array}$ & $\begin{array}{c}-0.650 \\
{[0.839]}\end{array}$ & $\begin{array}{c}-0.645 \\
{[0.879]}\end{array}$ & $\begin{array}{l}-0.644 \\
{[0.766]}\end{array}$ \\
\hline Competition $\times$ Competitor believed ability & & & $\begin{array}{l}-9.130 \\
{[9.401]}\end{array}$ & & $\begin{array}{l}-9.411 \\
{[9.274]}\end{array}$ & $\begin{array}{c}-7.040 \\
{[10.534]}\end{array}$ & $\begin{array}{l}-8.890 \\
{[8.062]}\end{array}$ & $\begin{array}{l}-9.148 \\
{[6.077]}\end{array}$ \\
\hline Competition $\times$ Competitor: girl $\times$ Competitor believed ability & & & $\begin{array}{c}14.634 \\
{[11.562]}\end{array}$ & & $\begin{array}{c}11.967 \\
{[11.617]}\end{array}$ & $\begin{array}{c}10.093 \\
{[12.767]}\end{array}$ & $\begin{array}{c}21.304 \\
{[12.212]}\end{array}$ & $\begin{array}{c}27.827 * * * \\
{[8.429]}\end{array}$ \\
\hline Competition $\times$ Competitor: boy $\times$ Competitor believed ability & & & $\begin{array}{c}23.194 \\
{[12.561]}\end{array}$ & & $\begin{array}{c}23.163 \\
{[12.534]}\end{array}$ & $\begin{array}{c}23.849 \\
{[12.748]}\end{array}$ & $\begin{array}{c}20.509 \\
{[11.200]}\end{array}$ & $\begin{array}{c}25.563 * * * \\
{[7.671]}\end{array}$ \\
\hline Competition $\times$ Competitor: girl & & & $\begin{array}{l}-10.720 \\
{[6.913]}\end{array}$ & & $\begin{array}{c}- \\
18.526^{* *} \\
{[6.764]}\end{array}$ & $\begin{array}{l}-14.909 \\
{[8.551]}\end{array}$ & $\begin{array}{c}- \\
19.820^{* *} \\
{[6.302]}\end{array}$ & $\begin{array}{c}- \\
24.001 * * \\
{[7.602]}\end{array}$ \\
\hline Competition $\times$ Competitor: boy & & & $\begin{array}{c}-17.784^{*} \\
{[8.113]}\end{array}$ & & $\begin{array}{c}- \\
30.201 * * * \\
{[8.428]}\end{array}$ & $\begin{array}{c}- \\
26.779^{* *} \\
{[9.904]}\end{array}$ & $\begin{array}{c}- \\
35.937 * * * \\
{[8.656]}\end{array}$ & $\begin{array}{c}- \\
40.161^{* * * *} \\
{[11.213]}\end{array}$ \\
\hline Competition $\times$ Daughter-Child & & & & $\begin{array}{c}2.903 \\
{[3.452]}\end{array}$ & $\begin{array}{c}4.362 \\
{[4.082]}\end{array}$ & $\begin{array}{c}4.144 \\
{[4.106]}\end{array}$ & $\begin{array}{c}3.916 \\
{[3.774]}\end{array}$ & $\begin{array}{l}4.076 \\
{[3.350]}\end{array}$ \\
\hline Competition $\times$ Daughter-Girl & & & & $\begin{array}{c}0.510 \\
{[3.682]}\end{array}$ & $\begin{array}{c}13.358^{* *} \\
{[4.236]}\end{array}$ & $\begin{array}{l}10.654 \\
{[5.615]}\end{array}$ & $\begin{array}{c}6.966 \\
{[8.455]}\end{array}$ & $\begin{array}{l}7.567 \\
{[6.888]}\end{array}$ \\
\hline Competition $\times$ Daughter-Boy & & & & $\begin{array}{l}-2.850 \\
{[3.767]}\end{array}$ & $\begin{array}{l}14.346^{*} \\
{[5.939]}\end{array}$ & $\begin{array}{l}11.720 \\
{[7.802]}\end{array}$ & $\begin{array}{l}23.788^{*} \\
{[9.447]}\end{array}$ & $\begin{array}{l}25.245^{*} \\
{[10.698]}\end{array}$ \\
\hline Competition $\times$ Son-Girl & & & & $\begin{array}{l}-0.526 \\
{[3.297]}\end{array}$ & $\begin{array}{c}10.684^{* * * *} \\
{[2.819]}\end{array}$ & $\begin{array}{l}9.307 * \\
{[4.502]}\end{array}$ & $\begin{array}{c}7.377 \\
{[6.260]}\end{array}$ & $\begin{array}{c}7.782 \\
{[6.397]}\end{array}$ \\
\hline Competition $\times$ Son-Boy & & & & $\begin{array}{c}0.025 \\
{[3.723]}\end{array}$ & $\begin{array}{c}15.463^{* *} \\
{[5.437]}\end{array}$ & $\begin{array}{l}14.062 * \\
{[7.091]}\end{array}$ & $\begin{array}{c}24.539 * * \\
{[7.514]}\end{array}$ & $\begin{array}{l}26.115^{*} \\
{[10.423]}\end{array}$ \\
\hline Mean Outcome No-Competition & 56.606 & 56.606 & 56.606 & 56.606 & 56.606 & 56.606 & 56.606 & 56.606 \\
\hline Joint significance: competition & 0.010 & 0.169 & 0.079 & 0.173 & 0.000 & 0.124 & 0.000 & 0.000 \\
\hline Joint significance: social preferences & & & & & & 0.954 & 0.903 & 0.536 \\
\hline Joint significance: social preferences no-competition & & & & & & 0.947 & 0.939 & 0.756 \\
\hline Joint significance: social preferences competition & & & & & & 0.784 & 0.789 & 0.347 \\
\hline Controls & No & No & No & No & No & Yes & Yes & Yes \\
\hline Observations & 3724 & 3724 & 3724 & 3703 & 3703 & 3353 & 3353 & 3353 \\
\hline Subjects & 266 & 266 & 266 & 266 & 266 & 241 & 241 & 241 \\
\hline $\begin{array}{l}\text { Notes: Standard errors appear in brackets and are cl } \\
\text { respectively. }\end{array}$ & red by & nt. *, * & $* *$ den & ignific & at the & $5 \%$ a & \% levels, & \\
\hline Due to collinearity following variables and interactio & $\mathrm{s}$ are omit & $\mathrm{d}$ : $C o m p$ & tition $\times$ & Daughte & n column & to 8 and & & \\
\hline $\begin{array}{l}\text { Competition } \times \text { Competitor }: \text { child } \times \text { Compet } \\
\text { Following variables are not displayed: } \text { Competitor }\end{array}$ & $\begin{array}{l}\text { orbelieve } \\
\text { elievedab }\end{array}$ & $\begin{array}{l}\text { lability a } \\
\text { lity in col }\end{array}$ & d Compe & ition $\times$ & mpetitc & child & lumn 3 & 5 \\
\hline
\end{tabular}


Hypothesis Investment 2b We stated in the second hypothesis that parents with a daughter invest less in the child account during competition. The interaction of competition and daughter is positive but not significant in column 2. Then the effect is omitted due to collinearity. The triple interaction of competition, daughter, and believed ability is a discounting factor for daughter's ability. It is also not significant and rather small in magnitude. The combinations of daughter and type of competitor interacted with competition are only significant for a girl competitor in column 5 or a boy competitor in column 5,7, and 8 at least at the 10 percent significance level. The reference group is no competition. The coefficient is positive just like the one for sons and its competitors in the models with other covariates, not in column 4 . The combinations of own son vs girl or boy have a similar magnitude like for daughters vs girl or boy. For own sons, we find significant effects for column 5 to 8 for competing against a boy and in column 5 and 6 for competing against a girl. Overall, the weak daughter discriminating tendencies for investments persist also in the competitive setting.

Hypothesis Investment 7 The last hypothesis looks at the gender of the competing child. Compared to the non-competitive setting, parents invest less in their child's account when the competitor is a girl and even less when the competitor is a boy. The effect for girls is significant for column 5 and the alternative specifications of our main model (columns 7 and 8). The effect for boys is significant at least on the 5 percent significance level throughout. When the own child competes against boys, parents invest on average INR 26.78 less in the child account (in our main model), all else equal. The reduction represents more than a quarter of the possible initial investment.

Compared to non-competition the coefficient of the believed ability of competing girls has a greater positive association with investment. The magnitude is larger for competing boys in the OLS models but similar in the alternative random effects specifications. The effects are both significant in the random effects mixed model. However, the magnitude is rather small: A 10 percentage point increase in the belief of the ability of a competing boy is associated with an increased investment of INR 2.38 on average, ceteris paribus (column 5). This corresponds to roughly 2 percent of the initial endowment.

When we consider the child combinations of own child and competitor interacted with competition, we see that parents invest more in the child account when the gender of the competitor is known. The investments are larger for boy competitors than for girl competitors. These effects do not outweigh the strong effects of the interaction of competition and the gender of the com- 
petitor. When we consider our main model (column 6) playing with a son against a girl has a combined effect of a lower investment of INR 5.6 (-14.91+9.31= -5.6) and against a boy of INR 12.72 less $(-26.78+14.06=-12.72)$ compared to a non-competitive setting. These findings are puzzling considering the results about the believed ability to win where parents' belief in their child to win is lower for competing girls than boys with competing child with unknown gender as the reference category. A possible explanation might be that parents follow heuristics, i.e. boys perform better than girls, than their own critical thinking about the ability of the children in the selected class when making the investment decision. We conclude that when the competitor child is either a girl and even more if it is a boy, parents invest less in the child account compared to non-competition.

We conclude that child endowments like ability and gender are decisive for parental investment in children. The general effect of ability is strengthened under competition. Parents invest less in daughters in general and discount their ability in the competitive setting. Considering market luck, we find that parents invest in children almost 10 percent of the initial endowment less when exposed to a competitive setting. Though their belief in their own child's ability to win increases investment, it can not outweigh the negative effect of the competitive setting itself. Social preferences seem negligible. In the future, we will conduct robustness checks to examine whether the results still hold when social preferences are omitted. When making the gender of the competing child salient, parents invest less in the child account. For competing boys, the magnitude of the effect is largest that is irrespective of the gender of the own child. Competing against boys reduces the investments by large, more than a quarter of the initial investment.

\section{Discussion}

Our results have to be interpreted with caution keeping certain assumptions in mind. In the following, we critically reflect on the made assumptions and future extensions of this study.

Our study relies on the elicitation of valid and reliable measures. However, as we are dealing with subjects with less education and likely lower cognitive ability, the measures might be biased. Less able subjects make random choices out of mistakes (Andersson et al., 2016). We have not validated our measures to learn about the importance of cognitive ability and education for making decisions. Nevertheless, the careful selection of our elicitation tools and understanding checks make us confident that participants have not made random choices. 
In our experimental setting, we have not asked the parents separately whether they want to invest at all in the child account and how much they would like to invest. Due to this, we are unable to distinguish whether investing INR 0 reflects extreme risk aversion to any uncertain setting or the exposure to the setting itself. However, we capture risk aversion as a control variable. This is why we are confident that our investment measure is not biased.

In the study, we have measured risk aversion but not ambiguity aversion. We assume that the participants have an accurate expectation of the potential of the competitors in the competition game. However, this assumption might not hold and participants have not perceived the competition game as only risky but also ambiguous because they have not had an expectation about the competitors' potential. As risk and ambiguity are distinct concepts and we are not controlling for ambiguity in our model, ambiguity might be driving the effect of the different investments in the non-competitive and the competitive game (Eisenberger \& Weber, 1995; Venkatraman et al., 2006). Nonetheless, we argue that the exposure to a familiar setting like the child's classmates makes ambiguity less of a concern because parents have been exposed to the ability distribution within the grade before. The ability distribution should not be ambiguous for the parents.

In our study, we also assume that participants' personality trades and emotions do not influence their investment behavior despite evidence of recent studies (Hajimoladarvish, 2018; Gambetti \& Giusberti, 2019; Hopfensitz \& Van Winden, 2008). As we have tried to maintain a similar atmosphere and setting in all sessions, there should not be any systematic differences in our experimental setting triggering emotions. To compare the competitive and non-competitive setting we use a within-subject design. In the case of constant emotions of parents within one session, the effects should be negligible.

When selecting our sample, we try to keep another child endowment, age, constant. We control for the age of children by only choosing participants of the same grade. However, the age bracket of children within one grade might vary because school enrollment, though mandatory for primary schools, is not enforced in India. There might be older children who have started school later in their childhood or younger children who are exceptionally intelligent who have moved to a higher grade with on average older classmates. This might affect parents' behavior because in the case of an older child than the average child in the grade they might believe that the endowment age is an advantage for the child to win the game because of her greater experience in her previous life. Otherwise, parents might believe that older children in the grade of more younger children might have lower ability as the others because this might be the reason 
why the child is in the grade with on average younger classmates. Considering the case of younger than average children in the grade parents might have opposing beliefs. Parents could believe that their child is exceptionally intelligent and thus more likely to win in a competition or that the child is less able to compete against more experienced fellow students. Nevertheless, these concerns are all linked to the parents' knowledge about the exact age of their children. We are not sure how likely it is that parents actually know about their child's exact age. In our survey, we also ask the parents about the birth date of their child and not many are able to give a prompt answer. Many parents do not attach importance to the age of their own child. Even if there are age differences, parents' belief is less likely to be influenced by it. We are planning to control for the age of children as an extension of our analysis.

When setting up our experiment, we endow parents all with the same amount to create equal budget constraints when making investment decisions. However, the amount parents could win in the game is likely to have a relatively higher value to parents from a poor household. This and the attitude towards making investments deriving from socialization at a certain household wealth level might alter social preferences and attitudes towards child endowments. For example, parents from wealthier households could be more risk-loving and so invest more in their child independent of child endowments due to the less relative importance of the possible income to be gained. Thus, our results might not apply to wealthier population groups. To get better insights into how decisive household wealth is for parental behavior, we will conduct a sub-sample analysis of households with different wealth levels.

In the analysis, we consider the gender combinations of own child and competitor but we do not look at the gender of the parent, a possible decisive parent endowment. Mothers and fathers might invest differently depending on the gender of their own child. The same gender might create the feeling of an in-group or greater connection. It might lead to parents behaving more competitively. We are planning to extend our analysis by including the gender of the parents as a possible factor that affects the investment decisions.

Another extension of our analysis we have in mind is to test our investment results employing a two-limit Tobit model because the dependent variable is doubly censored: the lowest possible investment is zero and the highest possible investment is the amount of the endowment. However, there is no accumulation of observations at the limits of the range of the outcome variable, so another check with the Tobit model is unlikely to bring about contradictory evidence.

Some of our underlying assumptions are critical for the interpretation of our results such as the 
absence of differential effects of parental cognitive ability, severe risk aversion, ambiguity aversion, and emotions. We are planning to extend our analysis by examining how a child's age, the parent's gender, and the censored variable investment affect our derived results.

\section{Conclusion}

Our lab-in-the-field experiment reveals that parents react to different market returns to investment. By holding other input factors of the investment function constant like income, family size, human capital returns to investment, effort costs, and time of investment, we find that parents invest almost 10 percent less of the initial endowment in their children when exposed to market returns that are based on competition. Competing against a competitor with known gender reduces the investment. The effect is largest for the competition against boys: Parents invest about 27 percent less compared to a non-competitive setting. Parents' belief about the probability of their own child winning against a competitor has a positive association with investing in their child. Yet, the effect magnitude does not outweigh the decrease in investment due to competition. In general playing with a daughter is associated with lower investment. In the competitive setting, parents discount their daughters' ability additionally. Higher ability of children increases the investment decisions of parents in general. We only have week evidence that social preferences matter in the competitive setting when conducting joint significant tests of all interactions with a dummy indicating the competitive setting.

Further, we investigate the belief formation of parents. We find that the observable characteristics of own children like gender matter more than their real ability when parents form beliefs about the probability of their own child solving any one task of the game. However, when forming beliefs about how likely a parent's own child is to win against a competitor, believed child ability matters. Parents believe that daughters have lower absolute and relative ability than sons. When we make the gender of the competitor salient, parents believe it is less likely for their own child to win.

Our results provide additional evidence for distinct strains of literature. We provide evidence about the influence of competition on the behavior of participants: compared to a non-competitive setting participants invest less in a competitive setting. We also show how the gender dynamics of competitors matter for a third party that is not involved in the competition itself. When gender is salient, the investments are reduced. Additionally, we contribute to the examination 
of inputs factors of parental investment decisions. We use a rather novel research design, a lab-in-the-field experiment, to cleanly identify the influence of variation of market returns to investment and its interaction with child endowments.

Our results show that parents are sensitive to the market returns to investment when investing in the human capital of their children. Potential policy implications of these findings are that if parents are fully informed about the market returns of their investment in children, they are likely to act upon it. Creating favorable market settings increases parental investment. A competitive setting of the market returns does not seem to be such a favorable option because parents reduce their investments in children. The reduction is particularly high when the competitor is a boy irrespective of the gender of the own child.

Future research could investigate further if other features or different degrees of competitiveness of labor market returns to investment apart from competition matter for parental investment. It would also be interesting to assess in a real-world setting how well parents are actually informed about labor market returns and how much they use this knowledge when investing in the human capital development of their children. 


\section{Bibliography}

Abarca-Gómez, L., Abdeen, Z. A., Hamid, Z. A., Abu-Rmeileh, N. M., Acosta-Cazares, B., Acuin, C., ... Ezzati, M. (2017). Worldwide trends in body-mass index, underweight, overweight, and obesity from 1975 to 2016: A pooled analysis of 2416 population-based measurement studies in 128.9 million children, adolescents, and adults. The Lancet, 390(10113), 2627-2642. doi: 10.1016/S0140-6736(17)32129-3

Abubakar, I. R. (2018). Exploring the determinants of open defecation in Nigeria using demographic and health survey data. Science of The Total Environment, 637-638, 1455-1465. doi: 10.1016/j.scitotenv.2018.05.104

Aizer, A., \& Cunha, F. (2012). The Production of Human Capital: Endowments, Investments and Fertility (Working Paper No. 18429). National Bureau of Economic Research. doi: $10.3386 / w 18429$

Akresh, R., Bagby, E., de Walque, D., \& Kazianga, H. (2012). Child Ability and Household Human Capital Investment Decisions in Burkina Faso. Economic Development and Cultural Change, 61(1), 157-186. doi: 10.1086/666953

Alderman, H., Hoddinott, J., \& Kinsey, B. (2006). Long term consequences of early childhood malnutrition. Oxford Economic Papers, 58(3), 450-474. doi: 10.1093/oep/gpl008

Allen, L., de Benoist, B., \& Hurrell, R. F. (Eds.). (2006). Guidelines on food fortification with micronutrients. World Health Organization, Food and Agricultural Organization of the United Nations.

Alvarez-Uria, G., Naik, P. K., Midde, M., Yalla, P. S., \& Pakam, R. (2014). Prevalence and Severity of Anaemia Stratified by Age and Gender in Rural India. Anemia, 2014, 176182. doi: $10.1155 / 2014 / 176182$

Andersen, S., Ertac, S., Gneezy, U., List, J. A., \& Maximiano, S. (2012). Gender, Competitiveness, and Socialization at a Young Age: Evidence From a Matrilineal and a Patri- 
archal Society. The Review of Economics and Statistics, 95(4), 1438-1443. doi: 10.1162/ REST_a_00312

Andersson, O., Holm, H. k. J., Tyran, J.-R., \& Wengström, E. (2016). Risk Aversion Relates to Cognitive Ability: Preference or Noise? Journal of the European Economic Association, 14(5), 1129-1154. doi: 10.1111/jeea.12179

Andreoni, J., \& Bernheim, B. D. (2009). Social Image and the 50-50 Norm: A Theoretical and Experimental Analysis of Audience Effects. Econometrica, 77(5), 1607-1636. (_eprint: https://onlinelibrary.wiley.com/doi/pdf/10.3982/ECTA7384) doi: 10.3982/ECTA7384

Andreoni, J., \& Brownback, A. (2017). All pay auctions and group size: Grading on a curve and other applications. Journal of Economic Behavior \& Organization, 137, 361-373. doi: 10.1016/j.jebo.2017.03.017

Anukriti, S., Bhalotra, R., \& Tam, H. (2016). On the Quantity and Quality of Girls: New Evidence on Abortion, Fertility, and Parental Investments (Tech. Rep. No. 10271). IZA.

Archibald, S. J., \& Kerns, K. A. (1999). Identification and Description of New Tests of Executive Functioning in Children. Child Neuropsychology, 5(2), 115-129. doi: 10.1076/ chin.5.2.115.3167

Arnold, F., Choe, M. K., \& Roy, T. K. (1998). Son Preference, the Family-Building Process and Child Mortality in India. Population Studies, 52(3), 301-315.

ASER Centre. (2014). Annual Status of Education Report. ASER.

Asfaw, A., Lamanna, F., \& Klasen, S. (2010). Gender gap in parents' financing strategy for hospitalization of their children: Evidence from India. Health Economics, 19(3), 265-279. doi: $10.1002 /$ hec. 1468

Attanasio, O., Cunha, F., \& Jervis, P. (2019). Subjective Parental Beliefs. Their Measurement and Role (Working Paper No. 26516). National Bureau of Economic Research. doi: 10.3386/ w26516

Attanasio, O., \& Kaufmann, K. M. (2014). Education choices and returns to schooling: Mothers' and youths' subjective expectations and their role by gender. Journal of Development Economics, 109, 203-216. doi: 10.1016/j.jdeveco.2014.04.003 
Attanasio, O., \& Kaufmann, K. M. (2017). Education choices and returns on the labor and marriage markets: Evidence from data on subjective expectations. Journal of Economic Behavior \& Organization, 140, 35-55. doi: 10.1016/j.jebo.2017.05.002

Attanasio, O., Meghir, C., Nix, E., \& Salvati, F. (2017). Human capital growth and poverty: Evidence from Ethiopia and Peru. Review of Economic Dynamics, 25, 234-259. doi: 10 $.1016 /$ j.red.2017.02.002

Baker, P., \& Friel, S. (2014). Processed foods and the nutrition transition: Evidence from Asia. Obesity Reviews, 15(7), 564-577. doi: 10.1111/obr.12174

Banerjee, A., Barnhardt, S., \& Duflo, E. (2013). Nutrition, Iron Deficiency Anemia, and the Demand for Iron-Fortified Salt: Evidence from an Experiment in Rural Bihar. Discoveries in the Economics of Aging, 343-384.

Banerjee, A., Barnhardt, S., \& Duflo, E. (2018). Can iron-fortified salt control anemia? Evidence from two experiments in rural Bihar. Journal of Development Economics, 133, 127146. doi: 10.1016/j.jdeveco.2017.12.004

Banerjee, S., Dias, A., Shinkre, R., \& Patel, V. (2011). Under-nutrition among adolescents: A survey in five secondary schools in rural Goa. National Medical Journal of India, 24(1), 8-11.

Beaman, L., Duflo, E., Pande, R., \& Topalova, P. (2012). Female Leadership Raises Aspirations and Educational Attainment for Girls: A Policy Experiment in India. Science (New York, N.y.), 335(6068), 582-586. doi: 10.1126/science.1212382

Beaulieu, D. A., \& Bugental, D. (2008). Contingent parental investment: An evolutionary framework for understanding early interaction between mothers and children. Evolution and Human Behavior, 29(4), 249-255. doi: 10.1016/j.evolhumbehav.2008.01.002

Becker, G. S., Murphy, K. M., \& Spenkuch, J. L. (2016). The Manipulation of Children's Preferences, Old-Age Support, and Investment in Children's Human Capital. Journal of Labor Economics, 34(S2), S3-S30. doi: 10.1086/683778

Becker, G. S., \& Tomes, N. (1979). An Equilibrium Theory of the Distribution of Income and Intergenerational Mobility. Journal of Political Economy, 87(6), 1153-1189. 
Becker, G. S., \& Tomes, N. (1986). Human Capital and the Rise and Fall of Families. Journal of Labor Economics, 4(3), S1-S39.

Bedard, K., \& Fischer, S. (2019). Does the response to competition depend on perceived ability? Evidence from a classroom experiment. Journal of Economic Behavior \& Organization, 159, 146-166. doi: 10.1016/j.jebo.2019.01.014

Behrman, J. (1988a). Intrahousehold Allocation of Nutrients in Rural India: Are Boys Favored? Do Parents Exhibit Inequality Aversion? Oxford Economic Papers, 40(1), 32-54.

Behrman, J. (1988b). Nutrition, health, birth order and seasonality. Journal of Development Economics, 28(1), 43-62. doi: 10.1016/0304-3878(88)90013-2

Behrman, J. (1988c). Nutrition, health, birth order and seasonality. Journal of Development Economics, 28(1), 43-62. doi: 10.1016/0304-3878(88)90013-2

Behrman, J., Pollak, R., \& Taubman, P. (1982). Parental Preferences and Provision for Progeny. Journal of Political Economy, 90(1), 52-73. (WOS:A1982NE02200003) doi: 10.1086/ 261039

Behrman, J., Rosenzweig, M. R., \& Taubman, P. (1994). Endowments and the Allocation of Schooling in the Family and in the Marriage Market: The Twins Experiment. Journal of Political Economy, 102(6), 1131-1174. doi: 10.1086/261966

Bénabou, R., \& Tirole, J. (2006). Incentives and Prosocial Behavior. American Economic Review, 96(5), 1652-1678. doi: 10.1257/aer.96.5.1652

Benjamini, Y., \& Hochberg, Y. (1995). Controlling the False Discovery Rate: A Practical and Powerful Approach to Multiple Testing. Journal of the Royal Statistical Society: Series B (Methodological), 57(1), 289-300. doi: 10.1111/j.2517-6161.1995.tb02031.x

Benjamini, Y., Krieger, A. M., \& Yekutieli, D. (2006). Adaptive linear step-up procedures that control the false discovery rate. Biometrika, 93(3), 491-507. doi: 10.1093/biomet/93.3.491

Bergman, P. (2015). Parent-Child Information Frictions and Human Capital Investment: Evidence from a Field Experiment (SSRN Scholarly Paper No. ID 2622034). Rochester, NY: Social Science Research Network. 
Berry, J., Dizon-Ross, R., \& Jagnani, M. (2020). Not Playing Favorites: An Experiment on Parental Fairness Preferences (Working Paper No. 26732). National Bureau of Economic Research. doi: 10.3386/w26732

Berry, J., Mehta, S., Mukherjee, P., Ruebeck, H., \& Shastry, G. K. (2020). Implementation and effects of India's national school-based iron supplementation program. Journal of Development Economics, 144, 102428. doi: 10.1016/j.jdeveco.2019.102428

Bhagowalia, P., Headey, D. D., \& Kadiyala, S. (2012). Agriculture, Income, and Nutrition Linkages in India: Insights from a Nationally Representative Survey: (Tech. Rep. No. 1195). International Food Policy Research Institute (IFPRI).

Bhalotra, S., Delavande, A., Gilabert, P. F., \& Maselko, J. (2020). Maternal Investments in Children: The Role of Expected Effort and Returns. (13056).

Bharadwaj, P., \& Lakdawala, L. K. (2013). Discrimination Begins in the Womb: Evidence of Sex-Selective Prenatal Investments. Journal of Human Resources, 48(1), 71-113. doi: 10.1353/jhr.2013.0004

Bihar Government. (2017). Mid-day meal plan - An Introduction. http://www.dopahar.org/dopahar/index.php.

Black, M. M., Walker, S. P., Fernald, L. C. H., Andersen, C. T., DiGirolamo, A. M., Lu, C., ... Grantham-McGregor, S. (2017). Early childhood development coming of age: Science through the life course. The Lancet, 389(10064), 77-90. doi: 10.1016/S0140-6736(16)31389 $-7$

Black, R. E., Victora, C. G., Walker, S. P., Bhutta, Z. A., Christian, P., de Onis, M., .. Uauy, R. (2013). Maternal and child undernutrition and overweight in low-income and middle-income countries. The Lancet, 382(9890), 427-451. doi: 10.1016/S0140-6736(13)60937-X

Bobonis, G. J. (2009). Is the Allocation of Resources within the Household Efficient? New Evidence from a Randomized Experiment. Journal of Political Economy, 117(3), 453-503. doi: $10.1086 / 600076$

Boneva, T., \& Rauh, C. (2018). Parental Beliefs about Returns to Educational Investments-The Later the Better? Journal of the European Economic Association, 16(6), 16691711. doi: 10.1093/jeea/jvy006 
Bouguen, A., Huang, Y., Kremer, M., \& Miguel, E. (2018). Using RCTs to Estimate Long-Run Impacts in Development Economics (Tech. Rep. No. 25356). National Bureau of Economic Research, Inc.

Brandts, J., \& Charness, G. (2011). The strategy versus the direct-response method: A first survey of experimental comparisons. Experimental Economics, 14(3), 375-398. doi: 10 $.1007 / \mathrm{s} 10683-011-9272-\mathrm{x}$

Brock, J. M., Lange, A., \& Ozbay, E. Y. (2013). Dictating the Risk: Experimental Evidence on Giving in Risky Environments. American Economic Review, 103(1), 415-437. doi: 10.1257/ aer.103.1.415

Brownback, A. (2018). A classroom experiment on effort allocation under relative grading. Economics of Education Review, 62, 113-128. doi: 10.1016/j.econedurev.2017.11.005

Bryan, J., Osendarp, S., Hughes, D., Calvaresi, E., Baghurst, K., \& van Klinken, J.-W. (2004). Nutrients for Cognitive Development in School-aged Children. Nutrition Reviews, 62(8), 295-306. doi: 10.1111/j.1753-4887.2004.tb00055.x

Bull, C., Schotter, A., \& Weigelt, K. (1987). Tournaments and Piece Rates: An Experimental Study. Journal of Political Economy, 95(1), 1-33. doi: 10.1086/261439

Butler, J. V. (2016). Inequality and Relative Ability Beliefs. The Economic Journal, 126(593), 907-948. doi: 10.1111/ecoj.12175

Cardona, A. (2014). Parental Choices and Children's Skills: An Agent-Based Model of Parental Investment Behavior and Skill Inequality Within and Across Generations. Jasss-the Journal of Artificial Societies and Social Simulation, 17(4), 8. (WOS:000346180800011) doi: 10 $.18564 /$ jasss. 2595

Carneiro, P., Galasso, E., López Garcia, I., Bedregal, P., \& Cordero, M. (2019). Parental Beliefs, Investments, and Child Development: Evidence from a Large-Scale Experiment. (12506).

Carranza, E. (2014). Soil Endowments, Female Labor Force Participation, and the Demographic Deficit of Women in India. American Economic Journal: Applied Economics, 6(4), $197-225$. 
Cason, T. N., Masters, W. A., \& Sheremeta, R. M. (2010). Entry into winner-take-all and proportional-prize contests: An experimental study. Journal of Public Economics, 94(9), 604-611. doi: 10.1016/j.jpubeco.2010.05.006

Caucutt, E. M., \& Lochner, L. (2012). Early and Late Human Capital Investments, Borrowing Constraints, and the Family (Working Paper No. 18493). National Bureau of Economic Research. doi: 10.3386/w18493

Cettolin, E., Riedl, A., \& Tran, G. (2017). Giving in the face of risk. Journal of Risk and Uncertainty, 55(2), 95-118. doi: 10.1007/s11166-017-9270-2

Checchi, D., Fiorio, C. V., \& Leonardi, M. (2014). Parents' risk aversion and children's educational attainment. Labour Economics, 30, 164-175. doi: 10.1016/j.labeco.2014.04.001

Chhabra, E., Najeeb, F., \& Raju, D. (2019). Effects over the Life of a Program: Evidence from an Education Conditional Cash Transfer Program for Girls (SSRN Scholarly Paper No. ID 3507842). Rochester, NY: Social Science Research Network.

Choudhary, A., Moses, P. D., Mony, P., \& Mathai, M. (2006). Prevalence of anaemia among adolescent girls in the urban slums of Vellore, south India. Tropical Doctor, 36(3), 167-169. doi: $10.1258 / 004947506777978253$

Clark, S. (2000). Son Preference and Sex Composition of Children: Evidence from India. Demography, 37(1), 95-108. doi: 10.2307/2648099

Clasen, T., Boisson, S., Routray, P., Torondel, B., Bell, M., Cumming, O., ... Schmidt, W.-P. (2014). Effectiveness of a rural sanitation programme on diarrhoea, soil-transmitted helminth infection, and child malnutrition in Odisha, India: A cluster-randomised trial. The Lancet Global Health, 2(11), e645-e653. doi: 10.1016/S2214-109X(14)70307-9

Coffey, D., \& Spears, D. (2019). Neonatal death in India: The effect of birth order in a context of maternal undernutrition.

Cunha, F., Elo, I., \& Culhane, J. (2013). Eliciting Maternal Expectations about the Technology of Cognitive Skill Formation (Working Paper No. 19144). National Bureau of Economic Research. doi: 10.3386/w19144

Cunha, F., \& Heckman, J. (2007). The Technology of Skill Formation. American Economic Review, 97(2), 31-47. doi: 10.1257/aer.97.2.31 
Currie, J., \& Almond, D. (2011). Chapter 15 - Human capital development before age five**We thank Maya Rossin and David Munroe for excellent research assistance, participants in the Berkeley Handbook of Labor Economics Conference in November 2009 for helpful comments, and Christine Pal and Hongyan Zhao for proofreading the equations. In D. Card \& O. Ashenfelter (Eds.), Handbook of Labor Economics (Vol. 4, pp. 1315-1486). Elsevier. doi: 10.1016/S0169-7218(11)02413-0

Datar, A., Kilburn, M. R., \& Loughran, D. S. (2010). Endowments and Parental Investments in Infancy and Early Childhood. Demography, 47(1), 145-162. (WOS:000275218900008)

Datta Gupta, N., Lausten, M., \& Pozzoli, D. (2016). Does mother know best? Parental discrepancies in assessing child behavioral and educational outcomes. Review of Economics of the Household. doi: 10.1007/s11150-016-9341-1

de Haen, H., Klasen, S., \& Qaim, M. (2011). What do we really know? Metrics for food insecurity and undernutrition. Food Policy, 36(6), 760-769. doi: 10.1016/j.foodpol.2011.08 .003

Deaton, A. (2003). Health, Inequality, and Economic Development. Journal of Economic Literature, 41(1), 113-158. doi: 10.1257/jel.41.1.113

Dechenaux, E., Kovenock, D., \& Sheremeta, R. M. (2015). A survey of experimental research on contests, all-pay auctions and tournaments. Experimental Economics, 18(4), 609-669. doi: 10.1007/s10683-014-9421-0

Delavande, A., Giné, X., \& McKenzie, D. (2011). Measuring subjective expectations in developing countries: A critical review and new evidence. Journal of Development Economics, 94(2), 151-163. doi: 10.1016/j.jdeveco.2010.01.008

Delavande, A., \& Kohler, H.-P. (2009). Subjective expectations in the context of HIV/AIDS in Malawi. Demographic research, 20, 817-874. doi: 10.4054/DemRes.2009.20.31

Del Bono, E., Ermisch, J., \& Francesconi, M. (2012). Intrafamily Resource Allocations: A Dynamic Structural Model of Birth Weight. Journal of Labor Economics, 30(3), 657-706. (WOS:000306105000006) doi: 10.1086/664831

De Paola, M., \& Gioia, F. (2016). Who performs better under time pressure? Results from a field experiment. Journal of Economic Psychology, 53, 37-53. doi: 10.1016/j.joep.2015.12.002 
Department of School Education and Literacy, \& Ministry of Human Resource and Development. (2015). Best Practices followed by the State/UTs (Tech. Rep.). New Delhi.

Dercon, S., \& Singh, A. (2013). From Nutrition to Aspirations and Self-Efficacy: Gender Bias over Time among Children in Four Countries. World Development, 45, 31-50. doi: 10.1016/j.worlddev.2012.12.001

Deshmukh, P. R., Garg, B. S., \& Bharambe, M. S. (2008). Effectiveness of weekly supplementation of iron to control anaemia among adolescent girls of Nashik, Maharashtra, India. Journal of Health Population and Nutrition, 26(1), 74-78.

Di Cagno, D., Galliera, A., Güth, W., \& Panaccione, L. (2016). A hybrid public good experiment eliciting multi-dimensional choice data. Journal of Economic Psychology, 56, 20-38. doi: $10.1016 /$ j.joep.2016.05.001

Dizon-Ross, R. (2019). Parents' Beliefs about Their Children's Academic Ability: Implications for Educational Investments. American Economic Review, 109(8), 2728-2765. doi: 10.1257/ aer.20171172

Dreber, A., von Essen, E., \& Ranehill, E. (2014). Gender and competition in adolescence: Task matters. Experimental Economics, 17(1), 154-172. doi: 10.1007/s10683-013-9361-0

Dror, D. K., \& Allen, L. H. (2011). The Importance of Milk and other Animal-Source Foods for Children in Low-Income Countries:. Food and Nutrition Bulletin. doi: 10.1177/ 156482651103200307

Durante, K. M., Griskevicius, V., Redden, J. P., \& White, A. E. (2015). Spending on Daughters versus Sons in Economic Recessions. Journal of Consumer Research, 42(3), 435-457. (WOS:000363253600005) doi: 10.1093/jcr/ucv023

Eisenberger, R., \& Weber, M. (1995). Willingness-to-pay and willingness-to-accept for risky and ambiguous lotteries. Journal of Risk and Uncertainty, 10(3), 223-233. doi: 10.1007/ BF01207552

Ejrnaes, M., \& Portner, C. C. (2004). Birth order and the intrahousehold allocation of time and education. Review of Economics and Statistics, 86(4), 1008-1019. (WOS:000226002900013) doi: 10.1162/0034653043125176 
Emran, M. S., Jiang, H., \& Shilpi, F. (2020). Gender Bias and Intergenerational Educational Mobility: Theory and Evidence from China and India [MPRA Paper]. https://mpra.ub.unimuenchen.de/99131/.

Eriksson, T., Teyssier, S., \& Villeval, M.-C. (2009). Self-Selection and The Efficiency of Tournaments. Economic Inquiry, 47(3), 530-548. doi: 10.1111/j.1465-7295.2007.00094.x

Eswaran, M., \& Kotwal, A. (2004). A theory of gender differences in parental altruism. Canadian Journal of Economics/Revue Canadienne d'Economique, 37(4), 918-950. doi: 10.1111/j.0008-4085.2004.00254.x

Falk, A., \& Zehnder, C. (2013). A city-wide experiment on trust discrimination. Journal of Public Economics, 100, 15-27. doi: 10.1016/j.jpubeco.2013.01.005

Falkingham, M., Abdelhamid, A., Curtis, P., Fairweather-Tait, S., Dye, L., \& Hooper, L. (2010). The effects of oral iron supplementation on cognition in older children and adults: A systematic review and meta-analysis. Nutrition Journal, 9(1). doi: 10.1186/1475-2891-9-4

Faravelli, M., \& Stanca, L. (2014). Economic incentives and social preferences: Causal evidence of non-separability. Journal of Economic Behavior \& Organization, 108, 273-289. doi: $10.1016 /$ j.jebo.2014.10.018

Favara, M. (2017). Do Dreams Come True? Aspirations and Educational Attainments of Ethiopian Boys and Girls. Journal of African Economies, 26(5), 561-583. doi: 10.1093/jae/ ejx018

Fischbacher, U., \& Gachter, S. (2010). Social Preferences, Beliefs, and the Dynamics of Free Riding in Public Goods Experiments. American Economic Review, 100(1), 541-56. doi: 10.1257/aer.100.1.541

Fischbacher, U., Gächter, S., \& Fehr, E. (2001). Are people conditionally cooperative? Evidence from a public goods experiment. Economics Letters, 71(3), 397-404. doi: $10.1016 / \mathrm{S} 0165-1765(01) 00394-9$

Fischbacher, U., Gächter, S., \& Quercia, S. (2012). The behavioral validity of the strategy method in public good experiments. Journal of Economic Psychology, 33(4), 897-913. doi: 10.1016/j.joep.2012.04.002 
Gambetti, E., \& Giusberti, F. (2019). Personality, decision-making styles and investments. Journal of Behavioral and Experimental Economics, 80, 14-24. doi: 10.1016/j.socec.2019 .03 .002

General Assembly resolution. (2015, September). Transforming our world: The 2030 Agenda for Sustainable Development.

Genicot, G., \& Ray, D. (2017). Aspirations and Inequality. Econometrica, 85(2), 489-519. doi: 10.3982/ECTA13865

George, N., \& Ray, S. (2016). Bihar district nutrition profiles: Jehanabad.

George, N., Vaid, A., Nguyen, P. H., Avula, R., \& Menon, P. (2017). Bihar district nutrition profile: Jehanabad. New Delhi, India: International Food Policy Research Institute (IFPRI).

Gerstadt, C. L., Hong, Y. J., \& Diamond, A. (1994). The relationship between cognition and action: Performance of children 3 1/2-7 years old on a Stroop-like day-night test. Cognition, 53(2), 129-153. doi: 10.1016/0010-0277(94)90068-х

Geruso, M., \& Spears, D. (2018). Neighborhood Sanitation and Infant Mortality. American Economic Journal: Applied Economics, 10(2), 125-162. doi: 10.1257/app.20150431

Giné, X., Townsend, R., \& Vickery, J. (2009). Forecasting when it matters: Evidence from semi-arid India. World Bank Mimeo.

Glewwe, P., \& Muralidharan, K. (2016). Chapter 10 - Improving Education Outcomes in Developing Countries: Evidence, Knowledge Gaps, and Policy Implications. In E. A. Hanushek, S. Machin, \& L. Woessmann (Eds.), Handbook of the Economics of Education (Vol. 5, pp. 653-743). Elsevier. doi: 10.1016/B978-0-444-63459-7.00010-5

Glick, P., \& Sahn, D. E. (2000). Schooling of girls and boys in a West African country: The effects of parental education, income, and household structure. Economics of Education Review, 19(1), 63-87. doi: 10.1016/S0272-7757(99)00029-1

Gneezy, U., Niederle, M., \& Rustichini, A. (2003). Performance in Competitive Environments: Gender Differences. The Quarterly Journal of Economics, 118(3), 1049-1074. doi: 10.1162/ 00335530360698496 
Günther, C., Ekinci, N. A., Schwieren, C., \& Strobel, M. (2010). Women can’t jump?-An experiment on competitive attitudes and stereotype threat. Journal of Economic Behavior \& Organization, 75(3), 395-401. doi: 10.1016/j.jebo.2010.05.003

Gupta, A., Khalid, N., Desphande, D., Hathi, P., Kapur, A., Srivastav, N., .. Coffey, D. (2019). Changes in Open Defecation in Rural North India: 2014-2018. (12065).

Gupta, M. D. (1987a). Selective Discrimination against Female Children in Rural Punjab, India. Population and Development Review, 13(1), 77-100. doi: 10.2307/1972121

Gupta, M. D. (1987b). Selective Discrimination against Female Children in Rural Punjab, India. Population and Development Review, 13(1), 77-100. doi: 10.2307/1972121

Gupta, V., Downs, S. M., Ghosh-Jerath, S., Lock, K., \& Singh, A. (2016). Unhealthy Fat in Street and Snack Foods in Low-Socioeconomic Settings in India: A Case Study of the Food Environments of Rural Villages and an Urban Slum. Journal of Nutrition Education and Behavior, 48(4), 269-+. (WOS:000374234400007) doi: 10.1016/j.jneb.2015.11.006

Güth, W., Mugera, H., Muscau, A., \& Ploner, M. (2014). Deterministic versus probabilistic consequences of trust and trustworthiness: An experimental investigation. Journal of Economic Psychology, 42, 28-40. doi: 10.1016/j.joep.2013.11.003

Hajimoladarvish, N. (2018). How do people reduce compound lotteries? Journal of Behavioral and Experimental Economics, 75, 126-133. doi: 10.1016/j.socec.2018.06.002

Halterman, S. J., Kaczorowski, M. J., Aligne, C., Auinger, P., \& Szilagyi, W. P. (2001). Iron Deficiency and Cognitive Achievement Among School-Aged Children and Adolescents in the United States. Pediatrics, 107, 1381-6. doi: 10.1542/peds.107.6.1381

Hammer, J., \& Spears, D. (2016). Village sanitation and child health: Effects and external validity in a randomized field experiment in rural India. Journal of Health Economics, 48, 135-148. doi: 10.1016/j.jhealeco.2016.03.003

Harris-Fry, H., Shrestha, N., Costello, A., \& Saville, N. M. (2017). Determinants of intrahousehold food allocation between adults in South Asia - a systematic review. International Journal for Equity in Health, 16(1). doi: 10.1186/s12939-017-0603-1 
Hathi, P., Haque, S., Pant, L., Coffey, D., \& Spears, D. (2017). Place and Child Health: The Interaction of Population Density and Sanitation in Developing Countries. Demography, 54(1), 337-360. doi: 10.1007/s13524-016-0538-y

Headey, D., Chiu, A., \& Kadiyala, S. (2011). Agriculture's role in the Indian enigma: Help or hindrance to the undernutrition crisis? (Tech. Rep. No. 1085). International Food Policy Research Institute (IFPRI).

Headey, D., Chiu, A., \& Kadiyala, S. (2012). Agriculture's role in the Indian enigma: Help or hindrance to the crisis of undernutrition? Food Security, 4(1), 87-102. doi: 10.1007/ s12571-011-0161-0

Headey, D., Hirvonen, K., \& Hoddinott, J. (2018). Animal Sourced Foods and Child Stunting. American Journal of Agricultural Economics, 100(5), 1302-1319. doi: 10.1093/ajae/aay053

Headey, D., Hoddinott, J., \& Park, S. (2016). Drivers of nutritional change in four South Asian countries: A dynamic observational analysis: Nutritional change in four South Asian countries. Maternal \& Child Nutrition, 12, 210-218. doi: 10.1111/mcn.12274

Heath, R., \& Mushfiq Mobarak, A. (2012). Does Demand or Supply Constrain Investments in Education? Evidence from Garment Sector Jobs in Bangladesh.

Heger Boyle, E., \& Sobek, M. (2019). IPUMS-Demographic and Health Surveys: Version 7 [dataset]. Minnesota Population Center and ICF International.

Heinz, M., Normann, H.-T., \& Rau, H. A. (2016). How competitiveness may cause a gender wage gap: Experimental evidence. European Economic Review, 90, 336-349. doi: 10.1016/ j.euroecorev.2016.02.011

Hoddinott, J., Behrman, J. R., Maluccio, J. A., Melgar, P., Quisumbing, A. R., Ramirez-Zea, M., ... Martorell, R. (2013). Adult consequences of growth failure in early childhood. American Journal of Clinical Nutrition, 98(5), 1170-1178. doi: 10.3945/ajcn.113.064584

Hopfensitz, A., \& Van Winden, F. (2008). Dynamic Choice, Independence and Emotions. Theory and Decision, 64(2-3), 249-300. doi: 10.1007/s11238-007-9058-y

Hudspeth, W. J., \& Pribram, K. H. (1990). Stages of brain and cognitive maturation. Journal of Educational Psychology, 82(4), 881-884. doi: 10.1037/0022-0663.82.4.881 
Iannotti, L. L., Lutter, C. K., Stewart, C. P., Riofrío, C. A. G., Malo, C., Reinhart, G., .. Waters, W. F. (2017). Eggs in Early Complementary Feeding and Child Growth: A Randomized Controlled Trial. Pediatrics, 140(1). doi: 10.1542/peds.2016-3459

ICF. (2004). Demographic and Health Surveys (various) [Datasets]. Rockville, Maryland, US: ICF.

Jaacks, L. M., Slining, M. M., \& Popkin, B. M. (2015). Recent underweight and overweight trends by rural-urban residence among women in low- and middle-income countries. The Journal of Nutrition, 145(2), 352-357. doi: 10.3945/jn.114.203562

Jayachandran, S. (2015). The Roots of Gender Inequality in Developing Countries. Annual Review of Economics, 7(1), 63-88. doi: 10.1146/annurev-economics-080614-115404

Jayachandran, S., \& National Bureau of Economic Research. (2009). Why Do Mothers Breastfeed Girls Less Than Boys? Evidence and Implications for Child Health in India. Cambridge, Mass: National Bureau of Economic Research.

Jayachandran, S., \& Pande, R. (2017). Why Are Indian Children So Short? The Role of Birth Order and Son Preference. American Economic Review, 107(9), 2600-2629. doi: 10.1257/aer.20151282

Jee, Y. H., Baron, J., Phillip, M., \& Bhutta, Z. A. (2014). Malnutrition and Catch-Up Growth during Childhood and Puberty. World review of nutrition and dietetics, 109, 89-100. doi: $10.1159 / 000356109$

Jensen, R. T. (2003). Equal Treatment, Unequal Outcomes? Generating Sex Inequality Through Fertility Behavior (Tech. Rep.). Mimeo, Harvard University.

Jensen, R. T. (2010). Economic Opportunities and Gender Differences in Human Capital: Experimental Evidence for India (Working Paper No. 16021). National Bureau of Economic Research. doi: 10.3386/w16021

Jensen, R. T., \& Miller, N. (2010). Keepin' em Down on the Farm: Old Age Security and Strategic Underinvestment in Children.

Ji, X., Cui, N., \& Liu, J. (2017). Neurocognitive Function Is Associated With Serum Iron Status in Early Adolescents. Biological Research For Nursing, 19(3), 269-277. doi: 10.1177/ 1099800417690828 
John, J. P. (2017). Gender differences and the effect of facing harder competition. Journal of Economic Behavior \& Organization, 143, 201-222. (WOS:000418970500014) doi: 10.1016/ j.jebo.2017.08.012

Johnson, R. C., \& Schoeni, R. F. (2011). The Influence of Early-Life Events on Human Capital, Health Status, and Labor Market Outcomes Over the Life Course. The B.E. journal of economic analysis \& policy, 11(3). doi: 10.2202/1935-1682.2521

Jones, A. M. (2009). Panel Data Methods and Applications to Health Economics. In T. C. Mills \& K. Patterson (Eds.), Palgrave Handbook of Econometrics: Volume 2: Applied Econometrics (pp. 557-631). London: Palgrave Macmillan UK. doi: 10.1057/9780230244405_12

Jordan, J., McAuliffe, K., \& Rand, D. (2016). The effects of endowment size and strategy method on third party punishment. Experimental Economics, 19(4), 741-763. doi: 10.1007/ s10683-015-9466-8

Jurges, H. (2000). Of rotten kids and Rawlsian parents: The optimal timing of intergenerational transfers. Journal of Population Economics, 13(1), 147-157. (WOS:000089429400011) doi: $10.1007 / \mathrm{s} 001480050128$

Karagiannaki, E. (2017). The effect of parental wealth on children's outcomes in early adulthood. The Journal of Economic Inequality, 15(3), 217-243. doi: 10.1007/s10888-017-9350 $-1$

Kaul, T. (2018). Intra-household allocation of educational expenses: Gender discrimination and investing in the future. World Development, 104, 336-343. doi: 10.1016/j.worlddev.2017.12 .017

Khadjavi, M., \& Nicklisch, A. (2018). Parents' ambitions and children's competitiveness. Journal of Economic Psychology, 67, 87-102. doi: 10.1016/j.joep.2018.05.004

Kim, Y.-J. (2020). Born to be more educated? Birth order and schooling. Review of Economics of the Household, 18(1), 165-180. doi: 10.1007/s11150-019-09462-1

Klasen, S. (2008). Poverty, undernutrition, and child mortality: Some inter-regional puzzles and their implicationsfor research and policy. The Journal of Economic Inequality, 6(1), 89-115. doi: 10.1007/s10888-007-9056-X 
Klasen, S. (2016). Gender, institutions, and economic development: Findings and open research and policy issues (Working Paper No. 211). Courant Research Centre: Poverty, Equity and Growth - Discussion Papers.

Krämer, M., Kumar, S., \& Vollmer, S. (2018). Improving Children Health and Cognition: Evidence from School-Based Nutrition Intervention in India. Courant Research Centre: Poverty, Equity and Growth - Discussion Papers.

Krämer, M., Kumar, S., \& Vollmer, S. (2020). Improving Child Health and Cognition: Evidence from a School-Based Nutrition Intervention in India. The Review of Economics and Statistics, 1-51. doi: 10.1162/rest_a_00950

Krawczyk, M., \& Le Lec, F. (2010). 'Give me a chance!' An experiment in social decision under risk. Experimental Economics, 13(4), 500-511. doi: 10.1007/s10683-010-9253-5

Krebs, N. F., Mazariegos, M., Tshefu, A., Bose, C., Sami, N., Chomba, E., ... Hambidge, K. M. (2011). Meat Consumption is Associated with Less Stunting among Toddlers in Four Diverse Low-Income Settings. Food and Nutrition Bulletin, 32(3), 185-191. doi: 10.1177/ 156482651103200301

Kumar, M. V., \& Rajagopalan, S. (2007). Multiple micronutrient fortification of salt and its effect on cognition in Chennai school children. Asia Pacific Journal of Clinical Nutrition, 16(3), 505-511. (WOS:000248989000016)

Larsen, D. A., Grisham, T., Slawsky, E., \& Narine, L. (2017). An individual-level meta-analysis assessing the impact of community-level sanitation access on child stunting, anemia, and diarrhea: Evidence from DHS and MICS surveys. PLOS Neglected Tropical Diseases, 11(6), e0005591. doi: 10.1371/journal.pntd.0005591

Lee, D. S. (2009). Training, Wages, and Sample Selection: Estimating Sharp Bounds on Treatment Effects. The Review of Economic Studies, 76(3), 1071-1102. doi: 10.1111/j.1467 $-937 X .2009 .00536 . x$

Li, L., Huang, L., Shi, Y., Luo, R., Yang, M., \& Rozelle, S. (2018). Anemia and student's educational performance in rural Central China: Prevalence, correlates and impacts. China Economic Review, 51, 283-293. doi: 10.1016/j.chieco.2017.07.006 
Lundberg, S. (2005). Sons, daughters, and parental behaviour. Oxford Review of Economic Policy, 21(3), 340-356. (WOS:000234779000002) doi: 10.1093/oxrep/gri020

Luo, R., Shi, Y., Zhang, L., Liu, C., Rozelle, S., Sharbono, B., ... Martorell, R. (2012). Nutrition and Educational Performance in Rural China's Elementary Schools: Results of a Randomized Control Trial in Shaanxi Province. Economic Development and Cultural Change, 60(4), 735-772. doi: 10.1086/665606

Maertens, A., \& Chari, A. V. (2020). What's Your Child Worth? An Analysis of Expected Dowry Payments in Rural India. World Development, 130, 104927. doi: 10.1016/j.worlddev .2020 .104927

Majid, H. (2018). Child endowments and parental investments: Intra-household allocation in oportunidades families in Mexico. Review of Development Economics, 22(1), 91-114. doi: $10.1111 /$ rode. 12331

Malhotra, A., \& Passi, S. J. (2007). Diet quality and nutritional status of rural adolescent girl beneficiaries of ICDS in north India. Asia Pacific Journal of Clinical Nutrition, 16(1), 8-16.

Malin, A. J. (1969). Malin's intelligence scale for Indian children. Nagpu (India): Child Guidance Center.

Martinsson, P., Myrseth, K. O. R., \& Wollbrant, C. (2014). Social dilemmas: When selfcontrol benefits cooperation. Journal of Economic Psychology, 45, 213-236. doi: 10.1016/ j.joep.2014.09.004

McKenzie, D. (2012, November). Beyond baseline and follow-up: The case for more $\mathrm{T}$ in experiments. Journal of Development Economics, 99(2), 210-221. doi: 10.1016/j.jdeveco .2012 .01 .002

Meenakshi, J. V. (2016). Trends and patterns in the triple burden of malnutrition in India. Agricultural Economics, 47, 115-134. (WOS:000398396200010) doi: 10.1111/agec.12304

Menon, P., Headey, D., Avula, R., \& Nguyen, P. H. (2018). Understanding the geographical burden of stunting in India: A regression-decomposition analysis of district-level data from 2015-16. Maternal \& Child Nutrition, 14(4), e12620. doi: 10.1111/mcn.12620

Midday Meal Scheme. (2017). Annual Work Plan \& Budget 2017-18 (Tech. Rep. No. Bihar). 
Ministry of Health \& Family Welfare. (2016). Operational Guidelines for Weekly IFA Supplementation Programme for School Based Adolescents: Guidelines for Teachers and Principals.

Ministry of Human Resource Development. (2015). Notification (Vol. Part II -Section 3- Subsection (i)).

Ministry of Human Resource Development. (2017). D.O. No. 14-10/2016/ MDM 1-2 (EE.5) (Tech. Rep.).

Mullett, T. L., McDonald, R. L., \& Brown, G. D. A. (2020). Cooperation in Public Goods Games Predicts Behavior in Incentive-Matched Binary Dilemmas: Evidence for Stable Prosociality. Economic Inquiry, 58(1), 67-85. (WOS:000495964700005) doi: 10.1111/ecin.12796

Munshi, D. K., \& Richard Rosenzweig, M. (2006). Traditional Institutions Meet the Modern World: Caste, Gender, and Schooling Choice in a Globalizing Economy." American Economic Review 96(4. American Economic Review, 96, 1225-1252. doi: 10.2139/ssrn.424620

Murphy, S. P., \& Allen, L. H. (2003). Nutritional Importance of Animal Source Foods. The Journal of Nutrition, 133(11), 3932S-3935S. doi: 10.1093/jn/133.11.3932S

Neumann, C., Harris, D. M., \& Rogers, L. M. (2002). Contribution of animal source foods in improving diet quality and function in children in the developing world. Nutrition Research, 22(1), 193-220. doi: 10.1016/S0271-5317(01)00374-8

Neumann, C. G., Bwibo, N. O., Murphy, S. P., Sigman, M., Whaley, S., Allen, L. H., ... Demment, M. W. (2003). Animal Source Foods Improve Dietary Quality, Micronutrient Status, Growth and Cognitive Function in Kenyan School Children: Background, Study Design and Baseline Findings. The Journal of Nutrition, 133(11), 3941S-3949S. doi: 10.1093/jn/133.11.3941S

NITI Aayog (Ed.). (n.d.). Healthy States, Progressive India Reeport on the Ranks of States and Union Territories.

Osei, A. K., Rosenberg, I. H., Houser, R. F., Bulusu, S., Mathews, M., \& Hamer, D. H. (2010). Community-Level Micronutrient Fortification of School Lunch Meals Improved Vitamin A, 
Folate, and Iron Status of Schoolchildren in Himalayan Villages of India. Journal of Nutrition, 140(6), 1146-1154. (WOS:000277800700014) doi: 10.3945/jn.109.114751

Oster, E. (2009). Does increased access increase equality? Gender and child health investments in India. Journal of Development Economics, 89(1), 62-76. doi: 10.1016/j.jdeveco.2008.07 .003

Pande, R. P. (2003). Selective gender differences in childhood nutrition and immunization in rural India: The role of siblings. Demography, 40(3), 395-418. doi: 10.1353/dem.2003 .0029

Pickering, A. J., Djebbari, H., Lopez, C., Coulibaly, M., \& Alzua, M. L. (2015). Effect of a community-led sanitation intervention on child diarrhoea and child growth in rural Mali: A cluster-randomised controlled trial. The Lancet Global Health, 3(11), e701-e711. doi: 10.1016/S2214-109X(15)00144-8

Pingali, P. (2007). Westernization of Asian diets and the transformation of food systems: Implications for research and policy. Food Policy, 32(3), 281-298. doi: 10.1016/j.foodpol .2006 .08 .001

Pinkaew, S., Winichagoon, P., Hurrell, R. F., \& Wegmuller, R. (2013). Extruded Rice Grains Fortified with Zinc, Iron, and Vitamin A Increase Zinc Status of Thai School Children When Incorporated into a School Lunch Program. Journal of Nutrition, 143(3), 362-368. (WOS:000315173500016) doi: 10.3945/jn.112.166058

Prendergast, A. J., \& Humphrey, J. H. (2014). The stunting syndrome in developing countries. Paediatrics and International Child Health, 34(4), 250-265. doi: 10.1179/2046905514Y .0000000158

Qaim, M. (2017). Globalisation of agrifood systems and sustainable nutrition. Proceedings of the Nutrition Society, 76(1), 12-21. doi: 10.1017/S0029665116000598

Radhika, M. S., Nair, K. M., Kumar, R. H., Rao, M. V., Ravinder, P., Reddy, C. G., \& Brahmam, G. N. (2011). Micronized ferric pyrophosphate supplied through extruded rice kernels improves body iron stores in children: A double-blind, randomized, placebo-controlled midday meal feeding trial in Indian schoolchildren. The American Journal of Clinical Nutrition, 94(5), 1202-1210. doi: 10.3945/ajcn.110.007179 
Ramalingaswami, V., Jonsson, U., \& Rohde, J. (1996). Commentary: The Asian enigma. https://www.unicef.org/pon96/nuenigma.htm\#Professor.

Rao, D. R., Vijayapushpam, T., Rao, G. M. S., Antony, G. M., \& Sarma, K. V. R. (2007). Dietary habits and effect of two different educational tools on nutrition knowledge of school going adolescent girls in Hyderabad, India. European Journal of Clinical Nutrition, 61(9), $1081-1085$.

Reserve Bank of India (Ed.). (2019). Handbook of Statistics on Indian States. Mumbai.

Restrepo, B. J. (2016). Parental investment responses to a low birth weight outcome: Who compensates and who reinforces? Journal of Population Economics, 29(4), 969-989. doi: $10.1007 / \mathrm{s} 00148-016-0590-3$

Robert C. Feenstra, R. I. (2016). Penn World Table 9.0. Groningen Growth and Development Centre. doi: $10.15141 / \mathrm{s} 5 \mathrm{j} 01 \mathrm{t}$

Robert C. Feenstra, R. I. (2019). Penn World Table 9.1. Groningen Growth and Development Centre. doi: 10.15141/s50t0r

Rosenblum, D. (2013). The effect of fertility decisions on excess female mortality in India. Journal of Population Economics, 26(1), 147-180. doi: 10.1007/s00148-012-0427-7

Rosenblum, D. (2017). Estimating the Private Economic Benefits of Sons Versus Daughters in India. Feminist Economics, 23(1), 77-107. doi: 10.1080/13545701.2016.1195004

Rosenzweig, M. R., \& Schultz, T. P. (1982). Market Opportunities, Genetic Endowments, and Intrafamily Resource Distribution: Child Survival in Rural India. The American Economic Review, 72(4), 803-815.

Ross, P. H. (2019). Occupation aspirations, education investment, and cognitive outcomes: Evidence from Indian adolescents. World Development, 123, 104613. doi: 10.1016/ j.worlddev.2019.104613

Röthlisberger, M., Neuenschwander, R., Michel, E., \& Roebers, C. M. (2010). Exekutive Funktionen: Zugrundeliegende kognitive Prozesse und deren Korrelate bei Kindern im späten Vorschulalter. Zeitschrift für Entwicklungspsychologie und Pädagogische Psychologie, 42(2), 99-110. doi: 10.1026/0049-8637/a000010

Rutstein, S. O. (n.d.). Steps to constructing the new DHS Wealth Index. DHS Program. 
Sahoo, S., \& Klasen, S. (2018). Gender Segregation in Education and its Implications for Labour Market Outcomes: Evidence from India (SSRN Scholarly Paper No. ID 3217476). Rochester, NY: Social Science Research Network.

Selten, R. (1967). Die Strategiemethode zur Erforschung des eingeschränkt rationalen Verhaltens im Rahmen eines Oligopolexperiments. In Beiträge zur experimentellen Wirtschaftsforschung (p. 136\&ndash;168). Tübingen: Mohr.

Serneels, P., \& Dercon, S. (2014). Aspirations, Poverty and Education. Evidence from India. www.younglives.org.uk(125).

Shetty, P. S. (2002). Nutrition transition in India. Public Health Nutrition, 5(1A), 175-182. (WOS:000174850400012) doi: 10.1079/PHN2001291

Shurchkov, O. (2012). Under Pressure: Gender Differences in Output Quality and Quantity Under Competition and Time Constraints. Journal of the European Economic Association, 10(5), 1189-1213. (_eprint: https://onlinelibrary.wiley.com/doi/pdf/10.1111/j.15424774.2012.01084.x) doi: 10.1111/j.1542-4774.2012.01084.x

Sivakumar, B., Brahmam, G. N., Madhavan Nair, K., Ranganathan, S., Vishnuvardhan Rao, M., Vijayaraghavan, K., \& Krishnaswamy, K. (2001). Prospects of fortification of salt with iron and iodine. The British Journal of Nutrition, 85 Suppl 2, S167-173.

Sivakumar, B., \& Nair, K. M. (2002). Double fortified salt at crossroads. The Indian Journal of Pediatrics, 69(7), 617. doi: 10.1007/BF02722691

Smith, L. C. (2003). The Asian Enigma. In The Importance of Women's Status for Child Nutrition in Developing Countries (pp. 117-125). Intl Food Policy Res Inst.

Smith, L. C., Ramakrishnan, U., Ndiaye, A., Haddad, L., \& Martorell, R. (2003). The Importance of Women's Status for Child Nutrition in Developing Countries: International Food Policy Research Institute (Ifpri) Research Report Abstract 131. Food and Nutrition Bulletin, 24(3), 287-288. doi: 10.1177/156482650302400309

Sovero, V. (2018). Risk preferences and child investments: Evidence from Mexico. Review of Economics of the Household, 16(4), 1027-1047. doi: 10.1007/s11150-017-9372-2

Spears, D. (2018). Exposure to open defecation can account for the Indian enigma of child height. Journal of Development Economics, 102277. doi: 10.1016/j.jdeveco.2018.08.003 
Spears, D., Coffey, D., \& Behrman, J. R. (2019). Birth Order, Fertility, and Child Height in India and Africa.

Spears, D., Ghosh, A., \& Cumming, O. (2013). Open Defecation and Childhood Stunting in India: An Ecological Analysis of New Data from 112 Districts. PLoS ONE, 8(9), e73784. doi: 10.1371/journal.pone.0073784

Stinebrickner, R., \& Stinebrickner, T. R. (2014). A Major in Science? Initial Beliefs and Final Outcomes for College Major and Dropout. The Review of Economic Studies, 81(1), 426-472. doi: $10.1093 /$ restud/rdt025

Stinebrickner, T., \& Stinebrickner, R. (2012). Learning about Academic Ability and the College Dropout Decision. Journal of Labor Economics, 30(4), 707-748. doi: 10.1086/666525

Tabetando, R. (2019). Parental risk aversion and educational investment: Panel evidence from rural Uganda. Review of Economics of the Household, 17(2), 647-670. doi: 10.1007/s11150 $-018-9437-\mathrm{x}$

Tauchmann, H. (2014). Lee (2009) treatment-effect bounds for nonrandom sample selection. Stata Journal, 14(4), 884-894.

Thatcher, R. W. (1991). Maturation of the human frontal lobes: Physiological evidence for staging. Developmental Neuropsychology, 7(3), 397-419. doi: 10.1080/87565649109540500

UNDP. (2019). Human Development Report 2019 (Tech. Rep.). New York.

UNICEF. (1990). Strategy for Imrpoved Nutrition of Children and Women in Developing Countries (Tech. Rep.). New York: Author.

van den Bold, M., Quisumbing, A. R., \& Gillespie, S. (2013). Women's empowerment and nutrition: An evidence review. (IFPRI Discussion Paper No. 1294). Washington, D.C.: International Food Policy Research Institute (IFPRI).

van Winden, F., Krawczyk, M., \& Hopfensitz, A. (2011). Investment, resolution of risk, and the role of affect. Journal of Economic Psychology, 32(6), 918-939. doi: 10.1016/j.joep.2011 .07 .007

Vandegrift, D., \& Brown, P. (2003). Task difficulty, incentive effects, and the selection of high-variance strategies: An experimental examination of tournament behavior. Labour Economics, 10(4), 481-497. doi: 10.1016/S0927-5371(03)00033-2 
Venkatraman, S., Aloysius, J. A., \& Davis, F. D. (2006). Multiple prospect framing and decision behavior: The mediational roles of perceived riskiness and perceived ambiguity. Organizational Behavior and Human Decision Processes, 101(1), 59-73. doi: 10.1016/ j.obhdp.2006.04.006

Vinodkumar, M., \& Rajagopalan, S. (2009). Efficacy of fortification of school meals with ferrous glycine phosphate and riboflavin against anemia and angular stomatitis in schoolchildren. Food and Nutrition Bulletin, 30(3), 260-264. (WOS:000270929400007)

Vyrastekova, J., Huisman, J., Mosha, I., \& Smits, J. (2014). Mothers More Altruistic than Fathers, but Only When Bearing Responsibility Alone: Evidence from Parental Choice Experiments in Tanzania. Plos One, 9(6), e99952. (WOS:000338709500025) doi: 10.1371/ journal.pone.0099952

Wang, L., Zhang, Z., McArdle, J. J., \& Salthouse, T. A. (2008). Investigating Ceiling Effects in Longitudinal Data Analysis. Multivariate Behavioral Research, 43(3), 476-496. doi: $10.1080 / 00273170802285941$

WHO. (1959). Iron deficiency anaemia : Report of a study group. Geneva: World Health Organization.

WHO. (2011). Haemoglobin concentrations for the diagnosis of anaemia and assessment of severity. Geneva: World Health Organization.

WHO Multicentre Growth Reference Study Group. (2006). Assessment of differences in linear growth among populations in the WHO Multicentre Growth Reference Study. Acta Paediatrica (Oslo, Norway: 1992). Supplement, 450, 56-65.

World Bank. (2016). Bihar. Poverty, Growth, and Inequality (Text/HTML). World Bank Group.

World Bank. (2019). World Development Indicators. Washingtion, D.C.: Author.

Ye, M., \& Yi, J. (2017). Parental preferences, production technologies, and provision for progeny. Journal of Comparative Economics, 45(2), 261-270. doi: 10.1016/j.jce.2016.09 .003

Yi, J., Heckman, J. J., Zhang, J., \& Conti, G. (2015). Early Health Shocks, Intra-household Resource Allocation and Child Outcomes. The Economic Journal, 125(588), F347-F371. doi: 10.1111/ecoj.12291 
Zhao, Q., Wang, X., \& Rozelle, S. (2019). Better cognition, better school performance? Evidence from primary schools in China. China Economic Review, 55, 199-217. doi: 10.1016/j.chieco.2019.04.005 
A Introduction 


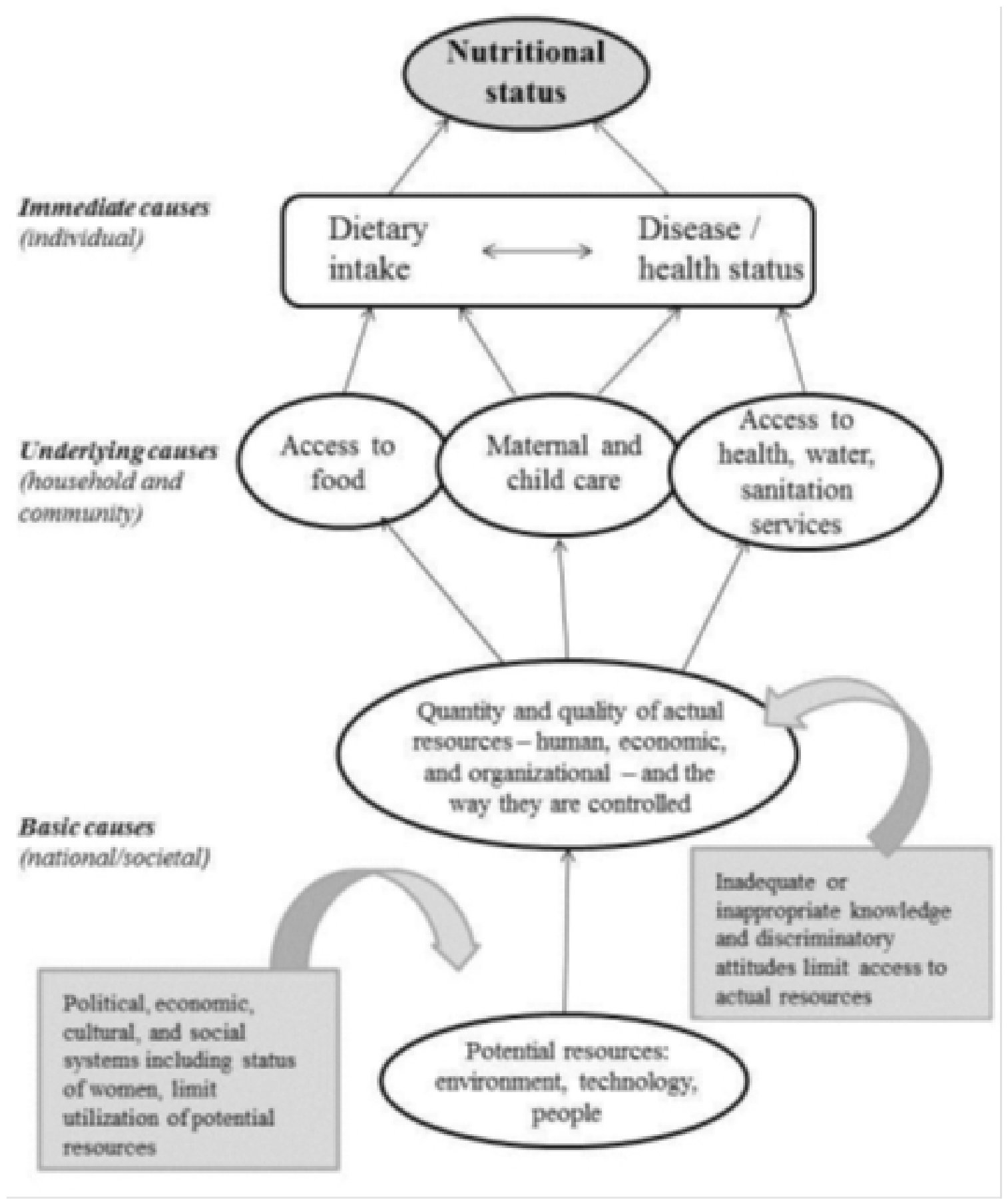

Figure A.1: Conceptual Framework Depicting Causes of Malnutrition and Links between Women's Empowerment and Nutrition

Source: van den Bold et al. (2013) based on adaptation from Smith et al. (2003) and UNICEF (1990) 


\section{B $\mid$ Essay 1}

\section{Results (2004-2010) by J+P and Replicated Results (2004- 2010): Same Methodology and Data from the Same Time Period}

\subsection{Summary Statistics}

Table B.1: Summary Statistics (2004-2010): Original

\begin{tabular}{|c|c|c|c|c|c|}
\hline & $\begin{array}{c}\text { India } \\
\text { subsample }\end{array}$ & $\begin{array}{c}\text { Africa } \\
\text { subsample }\end{array}$ & & $\begin{array}{c}\text { India } \\
\text { subsample }\end{array}$ & $\begin{array}{c}\text { Africa } \\
\text { subsample }\end{array}$ \\
\hline Mother's age at birth (years) & $\begin{array}{l}24.75 \\
{[5.23]}\end{array}$ & $\begin{array}{l}26.96 \\
{[6.86]}\end{array}$ & Child's age (months) & $\begin{array}{c}30.20 \\
{[16.90]}\end{array}$ & $\begin{array}{c}28.27 \\
{[17.06]}\end{array}$ \\
\hline Mother's total children born & $\begin{array}{c}2.74 \\
{[1.82]}\end{array}$ & $\begin{array}{c}3.88 \\
{[2.54]}\end{array}$ & Child is a girl & $\begin{array}{c}0.48 \\
{[0.50]}\end{array}$ & $\begin{array}{c}0.50 \\
{[0.50]}\end{array}$ \\
\hline Mother's desired fertility & $\begin{array}{c}2.47 \\
{[0.96]}\end{array}$ & $\begin{array}{c}4.62 \\
{[1.47]}\end{array}$ & Child's birth order & $\begin{array}{c}2.62 \\
{[1.80]}\end{array}$ & $\begin{array}{c}3.74 \\
{[2.48]}\end{array}$ \\
\hline Mother wants more children & $\begin{array}{c}0.34 \\
{[0.47]}\end{array}$ & $\begin{array}{c}0.67 \\
{[0.46]}\end{array}$ & Child's HFA z-score & $\begin{array}{l}-1.51 \\
{[1.81]}\end{array}$ & $\begin{array}{l}-1.35 \\
{[1.94]}\end{array}$ \\
\hline Mother completed her fertility & $\begin{array}{c}0.67 \\
{[0.47]}\end{array}$ & $\begin{array}{c}0.33 \\
{[0.47]}\end{array}$ & Child is stunted & $\begin{array}{c}0.40 \\
{[0.49]}\end{array}$ & $\begin{array}{c}0.38 \\
{[0.48]}\end{array}$ \\
\hline Mother is literate & $\begin{array}{c}0.58 \\
{[0.49]}\end{array}$ & $\begin{array}{c}0.50 \\
{[0.50]}\end{array}$ & Child's WFA z-score & $\begin{array}{l}-1.53 \\
{[1.33]}\end{array}$ & $\begin{array}{c}-0.88 \\
{[1.42]}\end{array}$ \\
\hline Mother's height (meters) & $\begin{array}{c}1.52 \\
{[0.06]}\end{array}$ & $\begin{array}{c}1.58 \\
{[0.07]}\end{array}$ & Child's hemoglobin level (g/dl) & $\begin{array}{l}10.28 \\
{[1.57]}\end{array}$ & $\begin{array}{l}10.15 \\
{[1.68]}\end{array}$ \\
\hline Mother took iron supplements & $\begin{array}{c}0.69 \\
{[0.46]}\end{array}$ & $\begin{array}{c}0.62 \\
{[0.48]}\end{array}$ & Child is deceased & $\begin{array}{c}0.05 \\
{[0.22]}\end{array}$ & $\begin{array}{c}0.07 \\
{[0.26]}\end{array}$ \\
\hline Mother's total tetanus shots & $\begin{array}{c}1.87 \\
{[0.94]}\end{array}$ & $\begin{array}{c}1.41 \\
{[1.20]}\end{array}$ & Child taking iron pills & $\begin{array}{c}0.06 \\
{[0.23]}\end{array}$ & $\begin{array}{c}0.11 \\
{[0.32]}\end{array}$ \\
\hline Total prenatal visits & $\begin{array}{c}4.04 \\
{[3.48]}\end{array}$ & $\begin{array}{c}3.85 \\
{[3.07]}\end{array}$ & Child's total vaccinations & $\begin{array}{c}6.61 \\
{[2.80]}\end{array}$ & $\begin{array}{c}6.24 \\
{[3.12]}\end{array}$ \\
\hline Delivery at health facility & $\begin{array}{c}0.45 \\
{[0.50]}\end{array}$ & $\begin{array}{c}0.47 \\
{[0.50]}\end{array}$ & Birth spacing (months) & $\begin{array}{c}36.16 \\
{[20.32]}\end{array}$ & $\begin{array}{c}38.69 \\
{[20.63]}\end{array}$ \\
\hline Postnatal check within 2 months & $\begin{array}{c}0.09 \\
{[0.29]}\end{array}$ & $\begin{array}{c}0.30 \\
{[0.46]}\end{array}$ & Diarrhea in last 2 weeks & $\begin{array}{c}0.09 \\
{[0.29]}\end{array}$ & $\begin{array}{c}0.16 \\
{[0.36]}\end{array}$ \\
\hline Average pooled inputs & $\begin{array}{c}0.33 \\
{[0.28]}\end{array}$ & $\begin{array}{c}0.38 \\
{[0.30]}\end{array}$ & Open defecation & $\begin{array}{c}0.46 \\
{[0.50]}\end{array}$ & $\begin{array}{c}0.32 \\
{[0.47]}\end{array}$ \\
\hline Percent non-resident among children & $\begin{array}{c}0.02 \\
{[0.04]}\end{array}$ & $\begin{array}{c}0.10 \\
{[0.08]}\end{array}$ & Number of PSUs & 3,822 & 10,366 \\
\hline Number of adult females in household & $\begin{array}{c}1.85 \\
{[1.09]}\end{array}$ & $\begin{array}{c}1.60 \\
{[1.06]}\end{array}$ & Main sample of children & 42,069 & 126,039 \\
\hline Log GDP per capita (in child's birth year) & $\begin{array}{c}7.78 \\
{[0.10]}\end{array}$ & $\begin{array}{c}7.36 \\
{[0.65]}\end{array}$ & & & \\
\hline
\end{tabular}

Source: J+P 
Table B.2: Summary Statistics (2004-2010): Unweighted

\begin{tabular}{|c|c|c|c|c|c|}
\hline & $\begin{array}{c}\text { India } \\
\text { subsample }\end{array}$ & $\begin{array}{c}\text { Africa } \\
\text { subsample }\end{array}$ & & $\begin{array}{c}\text { India } \\
\text { subsample }\end{array}$ & $\begin{array}{c}\text { Africa } \\
\text { subsample }\end{array}$ \\
\hline Mother's age at birth (years) & $\begin{array}{l}24.75 \\
{[5.23]}\end{array}$ & $\begin{array}{l}26.96 \\
{[6.86]}\end{array}$ & Child's age (months) & $\begin{array}{c}30.20 \\
{[16.90]}\end{array}$ & $\begin{array}{c}28.27 \\
{[17.06]}\end{array}$ \\
\hline Mother's total children born & $\begin{array}{c}2.74 \\
{[1.82]}\end{array}$ & $\begin{array}{c}3.88 \\
{[2.54]}\end{array}$ & Child is a girl & $\begin{array}{c}0.48 \\
{[0.50]}\end{array}$ & $\begin{array}{c}0.50 \\
{[0.50]}\end{array}$ \\
\hline Mother's desired fertility & $\begin{array}{c}2.47 \\
{[0.96]}\end{array}$ & $\begin{array}{c}4.62 \\
{[1.47]}\end{array}$ & Child's birth order & $\begin{array}{c}2.62 \\
{[1.80]}\end{array}$ & $\begin{array}{c}3.74 \\
{[2.48]}\end{array}$ \\
\hline Mother wants more children & $\begin{array}{c}0.34 \\
{[0.47]}\end{array}$ & $\begin{array}{c}0.67 \\
{[0.46]}\end{array}$ & Child's HFA z-score & $\begin{array}{l}-1.51 \\
{[1.81]}\end{array}$ & $\begin{array}{l}-1.35 \\
{[1.94]}\end{array}$ \\
\hline Mother completed her fertility & $\begin{array}{c}0.67 \\
{[0.47]}\end{array}$ & $\begin{array}{c}0.33 \\
{[0.47]}\end{array}$ & Child is stunted & $\begin{array}{c}0.40 \\
{[0.49]}\end{array}$ & $\begin{array}{c}0.38 \\
{[0.48]}\end{array}$ \\
\hline Mother is literate & $\begin{array}{c}0.58 \\
{[0.49]}\end{array}$ & $\begin{array}{c}0.49 \\
{[0.50]}\end{array}$ & Child's WFA z-score & $\begin{array}{l}-1.53 \\
{[1.33]}\end{array}$ & $\begin{array}{c}-0.88 \\
{[1.42]}\end{array}$ \\
\hline Mother's height (meters) & $\begin{array}{c}1.52 \\
{[0.06]}\end{array}$ & $\begin{array}{c}1.58 \\
{[0.07]}\end{array}$ & Child's hemoglobin level (g/dl) & $\begin{array}{l}10.28 \\
{[1.57]}\end{array}$ & $\begin{array}{l}10.15 \\
{[1.68]}\end{array}$ \\
\hline Mother took iron supplements & $\begin{array}{c}0.69 \\
{[0.46]}\end{array}$ & $\begin{array}{c}0.62 \\
{[0.49]}\end{array}$ & Child is deceased & $\begin{array}{c}0.05 \\
{[0.22]}\end{array}$ & $\begin{array}{c}0.07 \\
{[0.26]}\end{array}$ \\
\hline Mother's total tetanus shots & $\begin{array}{c}1.87 \\
{[0.94]}\end{array}$ & $\begin{array}{c}1.41 \\
{[1.20]}\end{array}$ & Child taking iron pills & $\begin{array}{c}0.06 \\
{[0.23]}\end{array}$ & $\begin{array}{c}0.11 \\
{[0.32]}\end{array}$ \\
\hline Total prenatal visits & $\begin{array}{c}4.04 \\
{[3.48]}\end{array}$ & $\begin{array}{c}3.85 \\
{[3.07]}\end{array}$ & Child's total vaccinations & $\begin{array}{c}6.61 \\
{[2.80]}\end{array}$ & $\begin{array}{c}6.24 \\
{[3.12]}\end{array}$ \\
\hline Delivery at health facility & $\begin{array}{c}0.45 \\
{[0.50]}\end{array}$ & $\begin{array}{c}0.47 \\
{[0.50]}\end{array}$ & Birth spacing (months) & $\begin{array}{c}36.16 \\
{[20.32]}\end{array}$ & $\begin{array}{c}38.69 \\
{[20.63]}\end{array}$ \\
\hline Postnatal check within 2 months & $\begin{array}{c}0.09 \\
{[0.29]}\end{array}$ & $\begin{array}{c}0.30 \\
{[0.46]}\end{array}$ & Diarrhea in last 2 weeks & $\begin{array}{c}0.09 \\
{[0.29]}\end{array}$ & $\begin{array}{c}0.16 \\
{[0.36]}\end{array}$ \\
\hline Average pooled inputs & $\begin{array}{c}0.33 \\
{[0.28]}\end{array}$ & $\begin{array}{c}0.38 \\
{[0.30]}\end{array}$ & Open defecation & $\begin{array}{c}0.46 \\
{[0.50]}\end{array}$ & $\begin{array}{c}0.32 \\
{[0.47]}\end{array}$ \\
\hline Percent non-resident among children & $\begin{array}{c}0.02 \\
{[0.04]}\end{array}$ & $\begin{array}{c}0.10 \\
{[0.08]}\end{array}$ & Number of PSUs & 3,822 & 10,366 \\
\hline Number of adult females in household & $\begin{array}{c}1.85 \\
{[1.09]}\end{array}$ & $\begin{array}{c}1.60 \\
{[1.06]}\end{array}$ & Main sample of children & 42,069 & 126,066 \\
\hline Log GDP per capita (in child's birth year) & $\begin{array}{c}7.78 \\
{[0.10]}\end{array}$ & $\begin{array}{c}7.36 \\
{[0.65]}\end{array}$ & & & \\
\hline
\end{tabular}

Notes: The means of the specified variables are calculated separately for the India and Africa subsamples. Standard deviations appear in brackets. Please consider the notes in Table 2.3 for further explanations.

Source: Adapted from J+P using data from DHS (Heger Boyle \& Sobek, 2019) 


\subsection{India's Differential Birth Order Gradient in Child Height and Re- lated Outcomes}

Table B.3: India's Differential Birth Order Gradient in Child Height and Related Outcomes (2004-2010): Original

\begin{tabular}{|c|c|c|c|c|c|c|c|c|c|}
\hline & $\begin{array}{l}\text { HFA } \\
\text { Z- } \\
\text { score } \\
(1)\end{array}$ & $\begin{array}{l}\text { HFA } \\
\text { Z- } \\
\text { score } \\
(2)\end{array}$ & $\begin{array}{l}\text { HFA } \\
\text { z- } \\
\text { score } \\
(3)\end{array}$ & $\begin{array}{l}\text { HFA } \\
\text { Z- } \\
\text { score } \\
(4)\end{array}$ & $\begin{array}{l}\text { HFA } \\
\text { Z- } \\
\text { score } \\
(5)\end{array}$ & $\begin{array}{l}\text { Stunted } \\
\text { (6) }\end{array}$ & $\begin{array}{l}\text { WFA } \\
\text { z- } \\
\text { score } \\
(7)\end{array}$ & $\begin{array}{c}\mathrm{Hb} \\
\text { level } \\
(8)\end{array}$ & $\begin{array}{l}\text { Deceasec } \\
\text { (9) }\end{array}$ \\
\hline India & $\begin{array}{l}-0.082 \\
{[0.011]}\end{array}$ & $\begin{array}{c}0.092 \\
{[0.018]}\end{array}$ & & & & & & & \\
\hline India $\times 2$ nd child & & $\begin{array}{l}-0.144 \\
{[0.025]}\end{array}$ & $\begin{array}{l}-0.161 \\
{[0.027]}\end{array}$ & $\begin{array}{l}-0.110 \\
{[0.063]}\end{array}$ & $\begin{array}{l}-0.243 \\
{[0.048]}\end{array}$ & $\begin{array}{c}0.051 \\
{[0.007]}\end{array}$ & $\begin{array}{l}-0.146 \\
{[0.020]}\end{array}$ & $\begin{array}{l}-0.094 \\
{[0.030]}\end{array}$ & $\begin{array}{c}0.003 \\
{[0.004]}\end{array}$ \\
\hline India $\times 3$ rd + child & & $\begin{array}{l}-0.377 \\
{[0.024]}\end{array}$ & $\begin{array}{l}-0.227 \\
{[0.032]}\end{array}$ & $\begin{array}{l}-0.193 \\
{[0.092]}\end{array}$ & $\begin{array}{l}-0.436 \\
{[0.085]}\end{array}$ & $\begin{array}{c}0.064 \\
{[0.009]}\end{array}$ & $\begin{array}{l}-0.198 \\
{[0.024]}\end{array}$ & $\begin{array}{l}-0.159 \\
{[0.036]}\end{array}$ & $\begin{array}{c}0.002 \\
{[0.004]}\end{array}$ \\
\hline 2nd child & & $\begin{array}{c}0.023 \\
{[0.015]}\end{array}$ & $\begin{array}{l}-0.011 \\
{[0.017]}\end{array}$ & $\begin{array}{l}-0.097 \\
{[0.053]}\end{array}$ & $\begin{array}{l}-0.167 \\
{[0.027]}\end{array}$ & $\begin{array}{c}0.009 \\
{[0.004]}\end{array}$ & $\begin{array}{c}0.009 \\
{[0.012]}\end{array}$ & $\begin{array}{l}-0.011 \\
{[0.022]}\end{array}$ & $\begin{array}{l}-0.014 \\
{[0.002]}\end{array}$ \\
\hline $3 \mathrm{rd}+$ child & & $\begin{array}{l}-0.066 \\
{[0.013]}\end{array}$ & $\begin{array}{l}-0.118 \\
{[0.019]}\end{array}$ & $\begin{array}{l}-0.169 \\
{[0.074]}\end{array}$ & $\begin{array}{l}-0.334 \\
{[0.044]}\end{array}$ & $\begin{array}{c}0.036 \\
{[0.005]}\end{array}$ & $\begin{array}{l}-0.063 \\
{[0.014]}\end{array}$ & $\begin{array}{l}-0.037 \\
{[0.025]}\end{array}$ & $\begin{array}{l}-0.011 \\
{[0.003]}\end{array}$ \\
\hline Africa mean of outcome & -1.351 & -1.351 & -1.351 & -1.351 & -1.351 & 0.375 & -0.877 & 10.150 & 0.071 \\
\hline Child's age dummies $\times$ India & No & No & Yes & Yes & Yes & Yes & Yes & Yes & Yes \\
\hline Mother's literacy $\times$ India & No & No & Yes & Yes & No & Yes & Yes & Yes & Yes \\
\hline Mother's age at birth $\times$ India & No & No & Yes & Yes & No & Yes & Yes & Yes & Yes \\
\hline PSU FEs & No & No & Yes & Yes & No & Yes & Yes & Yes & Yes \\
\hline Mother FEs & No & No & No & No & Yes & No & No & No & No \\
\hline Completed fertility sample & No & No & No & Yes & No & No & No & No & No \\
\hline Observations & 168,108 & 168,108 & 167,737 & 66,566 & 83,228 & 167,737 & 167,737 & 88,838 & 199,514 \\
\hline
\end{tabular}

Source: J+P 
Table B.4: India's Differential Birth Order Gradient in Child Height and Related Outcomes (2004-2010): Unweighted

\begin{tabular}{|c|c|c|c|c|c|c|c|c|c|}
\hline & $\begin{array}{l}\text { HFA } \\
\text { Z- } \\
\text { score } \\
(1)\end{array}$ & $\begin{array}{l}\text { HFA } \\
\text { Z- } \\
\text { score } \\
(2)\end{array}$ & $\begin{array}{l}\text { HFA } \\
\text { z- } \\
\text { score } \\
(3)\end{array}$ & $\begin{array}{l}\text { HFA } \\
\text { Z- } \\
\text { score } \\
(4)\end{array}$ & $\begin{array}{l}\text { HFA } \\
\text { Z- } \\
\text { score } \\
(5)\end{array}$ & $\begin{array}{l}\text { Stunted } \\
\text { (6) }\end{array}$ & $\begin{array}{l}\text { WFA } \\
\text { Z- } \\
\text { score } \\
(7)\end{array}$ & $\begin{array}{c}\mathrm{Hb} \\
\text { level } \\
(8)\end{array}$ & $\begin{array}{l}\text { Deceasec } \\
\text { (9) }\end{array}$ \\
\hline India & $\begin{array}{l}-0.083 \\
{[0.011]}\end{array}$ & $\begin{array}{c}0.092 \\
{[0.018]}\end{array}$ & & & & & & & \\
\hline India $\times 2$ nd child & & $\begin{array}{l}-0.144 \\
{[0.025]}\end{array}$ & $\begin{array}{l}-0.161 \\
{[0.027]}\end{array}$ & $\begin{array}{l}-0.110 \\
{[0.063]}\end{array}$ & $\begin{array}{l}-0.243 \\
{[0.048]}\end{array}$ & $\begin{array}{c}0.051 \\
{[0.007]}\end{array}$ & $\begin{array}{l}-0.147 \\
{[0.020]}\end{array}$ & $\begin{array}{l}-0.094 \\
{[0.030]}\end{array}$ & $\begin{array}{c}0.003 \\
{[0.004]}\end{array}$ \\
\hline India $\times 3$ rd + child & & $\begin{array}{l}-0.377 \\
{[0.024]}\end{array}$ & $\begin{array}{l}-0.228 \\
{[0.032]}\end{array}$ & $\begin{array}{l}-0.194 \\
{[0.092]}\end{array}$ & $\begin{array}{l}-0.436 \\
{[0.085]}\end{array}$ & $\begin{array}{c}0.064 \\
{[0.009]}\end{array}$ & $\begin{array}{l}-0.199 \\
{[0.024]}\end{array}$ & $\begin{array}{l}-0.158 \\
{[0.036]}\end{array}$ & $\begin{array}{c}0.002 \\
{[0.004]}\end{array}$ \\
\hline 2nd child & & $\begin{array}{c}0.024 \\
{[0.015]}\end{array}$ & $\begin{array}{l}-0.011 \\
{[0.017]}\end{array}$ & $\begin{array}{l}-0.096 \\
{[0.053]}\end{array}$ & $\begin{array}{l}-0.167 \\
{[0.027]}\end{array}$ & $\begin{array}{c}0.009 \\
{[0.004]}\end{array}$ & $\begin{array}{c}0.010 \\
{[0.012]}\end{array}$ & $\begin{array}{l}-0.010 \\
{[0.022]}\end{array}$ & $\begin{array}{l}-0.014 \\
{[0.002]}\end{array}$ \\
\hline 3rd + child & & $\begin{array}{l}-0.065 \\
{[0.013]}\end{array}$ & $\begin{array}{l}-0.117 \\
{[0.019]}\end{array}$ & $\begin{array}{l}-0.168 \\
{[0.074]}\end{array}$ & $\begin{array}{l}-0.334 \\
{[0.044]}\end{array}$ & $\begin{array}{c}0.036 \\
{[0.005]}\end{array}$ & $\begin{array}{l}-0.063 \\
{[0.014]}\end{array}$ & $\begin{array}{l}-0.038 \\
{[0.025]}\end{array}$ & $\begin{array}{l}-0.011 \\
{[0.003]}\end{array}$ \\
\hline Africa mean of outcome & -1.351 & -1.351 & -1.351 & -1.351 & -1.351 & 0.375 & -0.877 & 10.149 & 0.072 \\
\hline Child's age dummies $\times$ India & No & No & Yes & Yes & Yes & Yes & Yes & Yes & Yes \\
\hline Mother's literacy $\times$ India & No & No & Yes & Yes & No & Yes & Yes & Yes & Yes \\
\hline Mother's age at birth $\times$ India & No & No & Yes & Yes & No & Yes & Yes & Yes & Yes \\
\hline PSU FEs & No & No & Yes & Yes & No & Yes & Yes & Yes & Yes \\
\hline Mother FEs & No & No & No & No & Yes & No & No & No & No \\
\hline Completed fertility sample & No & No & No & Yes & No & No & No & No & No \\
\hline Observations & 168,135 & 168,135 & 167,765 & 66,574 & 83,243 & 167,765 & 167,765 & 88,893 & 199,514 \\
\hline
\end{tabular}

Notes: Standard errors are clustered by mother and appear in brackets. Please consider the notes in Table 2.6 for further explanations. Source: Adapted from J+P using data from DHS (Heger Boyle \& Sobek, 2019) 


\subsection{Child Health Inputs}

Table B.5: Child Health Inputs (2004-2010): Original

\begin{tabular}{|c|c|c|c|c|c|c|c|c|}
\hline & \multicolumn{4}{|c|}{ Prenatal inputs } & \multicolumn{3}{|c|}{ Postnatal inputs } & \multirow[b]{2}{*}{$\begin{array}{c}\text { Average } \\
\text { pooled } \\
\text { inputs } \\
(8)\end{array}$} \\
\hline & $\begin{array}{c}\text { Total } \\
\text { prenatal } \\
\text { visits } \\
\text { (1) }\end{array}$ & $\begin{array}{l}\text { Mother } \\
\text { took iron } \\
\text { supple- } \\
\text { ments } \\
\text { (2) }\end{array}$ & $\begin{array}{c}\text { Mother's } \\
\text { total } \\
\text { tetanus } \\
\text { shots } \\
\text { (3) }\end{array}$ & $\begin{array}{c}\text { Delivery } \\
\text { at health } \\
\text { facility } \\
\text { (4) }\end{array}$ & $\begin{array}{l}\text { Postnatal } \\
\text { check } \\
\text { within } 2 \\
\text { months } \\
\quad(5)\end{array}$ & $\begin{array}{c}\text { Child } \\
\text { taking } \\
\text { iron pills } \\
(6)\end{array}$ & $\begin{array}{c}\text { Child's } \\
\text { total vac- } \\
\text { cinations } \\
\text { (7) }\end{array}$ & \\
\hline India $\times 2$ nd child & $\begin{array}{l}-0.525 \\
{[0.052]}\end{array}$ & $\begin{array}{c}-0.031 \\
{[0.008]}\end{array}$ & $\begin{array}{c}-0.019 \\
{[0.018]}\end{array}$ & $\begin{array}{c}-0.040 \\
{[0.006]}\end{array}$ & $\begin{array}{c}-0.009 \\
{[0.013]}\end{array}$ & $\begin{array}{c}-0.008 \\
{[0.005]}\end{array}$ & $\begin{array}{l}-0.203 \\
{[0.039]}\end{array}$ & $\begin{array}{c}-0.011 \\
{[0.003]}\end{array}$ \\
\hline India $\times 3$ rd + child & $\begin{array}{c}-1.012 \\
{[0.060]}\end{array}$ & $\begin{array}{c}-0.071 \\
{[0.009]}\end{array}$ & $\begin{array}{c}-0.036 \\
{[0.021]}\end{array}$ & $\begin{array}{c}-0.092 \\
{[0.008]}\end{array}$ & $\begin{array}{c}0.014 \\
{[0.014]}\end{array}$ & $\begin{array}{c}-0.010 \\
{[0.006]}\end{array}$ & $\begin{array}{c}-0.462 \\
{[0.051]}\end{array}$ & $\begin{array}{c}-0.033 \\
{[0.004]}\end{array}$ \\
\hline 2nd child & $\begin{array}{c}-0.181 \\
{[0.029]}\end{array}$ & $\begin{array}{c}-0.014 \\
{[0.005]}\end{array}$ & $\begin{array}{c}-0.112 \\
{[0.013]}\end{array}$ & $\begin{array}{c}-0.088 \\
{[0.004]}\end{array}$ & $\begin{array}{c}0.005 \\
{[0.010]}\end{array}$ & $\begin{array}{c}-0.004 \\
{[0.004]}\end{array}$ & $\begin{array}{c}-0.098 \\
{[0.025]}\end{array}$ & $\begin{array}{c}-0.044 \\
{[0.002]}\end{array}$ \\
\hline 3rd+ child & $\begin{array}{c}-0.431 \\
{[0.033]}\end{array}$ & $\begin{array}{c}-0.031 \\
{[0.005]}\end{array}$ & $\begin{array}{c}-0.206 \\
{[0.014]}\end{array}$ & $\begin{array}{c}-0.133 \\
{[0.004]}\end{array}$ & $\begin{array}{c}-0.022 \\
{[0.011]}\end{array}$ & $\begin{array}{c}-0.013 \\
{[0.005]}\end{array}$ & $\begin{array}{c}-0.207 \\
{[0.030]}\end{array}$ & $\begin{array}{c}-0.071 \\
{[0.003]}\end{array}$ \\
\hline Africa mean of outcome & 3.846 & 0.622 & 1.415 & 0.472 & 0.302 & 0.113 & 6.245 & 0.380 \\
\hline India mean of outcome & 4.041 & 0.689 & 1.872 & 0.450 & 0.090 & 0.055 & 6.607 & 0.334 \\
\hline Age \& other controls & Yes & Yes & Yes & Yes & Yes & Yes & Yes & Yes \\
\hline Observations & 115,343 & 117,686 & 117,199 & 167,377 & 35,888 & 91,936 & 122,898 & 167,724 \\
\hline
\end{tabular}

Source: J+P

Table B.6: Child Health Inputs (2004-2010): Unweighted

\begin{tabular}{|c|c|c|c|c|c|c|c|c|}
\hline & \multicolumn{4}{|c|}{ Prenatal inputs } & \multicolumn{3}{|c|}{ Postnatal inputs } & \multirow[b]{2}{*}{$\begin{array}{c}\text { Average } \\
\text { pooled } \\
\text { inputs } \\
(8)\end{array}$} \\
\hline & $\begin{array}{c}\text { Total } \\
\text { prenatal } \\
\text { visits } \\
\text { (1) }\end{array}$ & $\begin{array}{l}\text { Mother } \\
\text { took iron } \\
\text { supple- } \\
\text { ments } \\
\text { (2) }\end{array}$ & $\begin{array}{l}\text { Mother's } \\
\text { total } \\
\text { tetanus } \\
\text { shots } \\
\text { (3) }\end{array}$ & $\begin{array}{c}\text { Delivery } \\
\text { at health } \\
\text { facility } \\
\text { (4) }\end{array}$ & $\begin{array}{l}\text { Postnatal } \\
\text { check } \\
\text { within } 2 \\
\text { months } \\
\text { (5) }\end{array}$ & $\begin{array}{c}\text { Child } \\
\text { taking } \\
\text { iron pills } \\
(6)\end{array}$ & $\begin{array}{c}\text { Child's } \\
\text { total vac- } \\
\text { cinations } \\
\text { (7) }\end{array}$ & \\
\hline India $\times 2$ nd child & $\begin{array}{c}-0.525 \\
{[0.052]}\end{array}$ & $\begin{array}{c}-0.031 \\
{[0.008]}\end{array}$ & $\begin{array}{c}-0.019 \\
{[0.018]}\end{array}$ & $\begin{array}{c}-0.040 \\
{[0.006]}\end{array}$ & $\begin{array}{c}-0.008 \\
{[0.013]}\end{array}$ & $\begin{array}{c}-0.008 \\
{[0.005]}\end{array}$ & $\begin{array}{c}-0.204 \\
{[0.039]}\end{array}$ & $\begin{array}{c}-0.011 \\
{[0.003]}\end{array}$ \\
\hline India $\times 3$ rd + child & $\begin{array}{c}-1.011 \\
{[0.060]}\end{array}$ & $\begin{array}{c}-0.072 \\
{[0.009]}\end{array}$ & $\begin{array}{c}-0.036 \\
{[0.021]}\end{array}$ & $\begin{array}{c}-0.092 \\
{[0.008]}\end{array}$ & $\begin{array}{c}0.015 \\
{[0.014]}\end{array}$ & $\begin{array}{c}-0.010 \\
{[0.006]}\end{array}$ & $\begin{array}{c}-0.462 \\
{[0.051]}\end{array}$ & $\begin{array}{c}-0.033 \\
{[0.004]}\end{array}$ \\
\hline 2nd child & $\begin{array}{c}-0.182 \\
{[0.029]}\end{array}$ & $\begin{array}{c}-0.014 \\
{[0.005]}\end{array}$ & $\begin{array}{c}-0.111 \\
{[0.013]}\end{array}$ & $\begin{array}{c}-0.088 \\
{[0.004]}\end{array}$ & $\begin{array}{c}0.004 \\
{[0.010]}\end{array}$ & $\begin{array}{c}-0.004 \\
{[0.004]}\end{array}$ & $\begin{array}{c}-0.097 \\
{[0.025]}\end{array}$ & $\begin{array}{c}-0.044 \\
{[0.002]}\end{array}$ \\
\hline $3 \mathrm{rd}+$ child & $\begin{array}{c}-0.432 \\
{[0.033]}\end{array}$ & $\begin{array}{c}-0.031 \\
{[0.005]}\end{array}$ & $\begin{array}{c}-0.207 \\
{[0.014]}\end{array}$ & $\begin{array}{c}-0.133 \\
{[0.004]}\end{array}$ & $\begin{array}{c}-0.023 \\
{[0.011]}\end{array}$ & $\begin{array}{c}-0.014 \\
{[0.005]}\end{array}$ & $\begin{array}{c}-0.207 \\
{[0.030]}\end{array}$ & $\begin{array}{c}-0.071 \\
{[0.003]}\end{array}$ \\
\hline Africa mean of outcome & 3.847 & 0.622 & 1.415 & 0.472 & 0.302 & 0.113 & 6.245 & 0.380 \\
\hline India mean of outcome & 4.041 & 0.689 & 1.872 & 0.450 & 0.090 & 0.055 & 6.607 & 0.334 \\
\hline Age \& other controls & Yes & Yes & Yes & Yes & Yes & Yes & Yes & Yes \\
\hline Observations & 115,364 & 117,707 & 117,219 & 167,405 & 35,902 & 91,964 & 122,922 & 167,752 \\
\hline
\end{tabular}

Notes: Standard errors are clustered by mother and appear in brackets. Please consider the notes in Table 2.8 for further explanations.

Source: Adapted from J+P using data from DHS (Heger Boyle \& Sobek, 2019) 


\subsection{Cultural Norms and Child Height: Within-India Evidence}

Table B.7: Cultural Norms and Child Height: Within-India Evidence (2004-2010): Original

\begin{tabular}{|c|c|c|c|c|c|c|}
\hline \multirow[t]{2}{*}{ Low son preference proxy: } & \multicolumn{2}{|c|}{ Kerala \& Northeast } & \multicolumn{2}{|c|}{$\begin{array}{l}\text { Below-median } \\
\text { child sex ratio }\end{array}$} & \multicolumn{2}{|c|}{ Muslims } \\
\hline & $\begin{array}{c}\text { HFA } \\
\text { z-score } \\
(1)\end{array}$ & $\begin{array}{c}\text { WFA } \\
\text { z-score } \\
(2)\end{array}$ & $\begin{array}{c}\text { HFA } \\
\text { z-score } \\
(3)\end{array}$ & $\begin{array}{c}\text { WFA } \\
\text { z-score } \\
(4)\end{array}$ & $\begin{array}{c}\text { HFA } \\
\text { z-score } \\
(5)\end{array}$ & $\begin{array}{c}\text { WFA } \\
\text { z-score } \\
(6)\end{array}$ \\
\hline Low son pref proxy $\times 2$ nd child & $\begin{array}{c}0.078 \\
{[0.039]}\end{array}$ & $\begin{array}{c}0.008 \\
{[0.029]}\end{array}$ & $\begin{array}{c}0.078 \\
{[0.030]}\end{array}$ & $\begin{array}{c}0.039 \\
{[0.023]}\end{array}$ & $\begin{array}{l}-0.027 \\
{[0.047]}\end{array}$ & $\begin{array}{c}0.034 \\
{[0.035]}\end{array}$ \\
\hline Low son pref proxy $\times 3$ rd + child & $\begin{array}{c}0.108 \\
{[0.045]}\end{array}$ & $\begin{array}{c}0.069 \\
{[0.033]}\end{array}$ & $\begin{array}{c}0.081 \\
{[0.036]}\end{array}$ & $\begin{array}{c}0.039 \\
{[0.027]}\end{array}$ & $\begin{array}{c}0.184 \\
{[0.055]}\end{array}$ & $\begin{array}{c}0.156 \\
{[0.041]}\end{array}$ \\
\hline 2nd child & $\begin{array}{l}-0.185 \\
{[0.017]}\end{array}$ & $\begin{array}{c}-0.154 \\
{[0.013]}\end{array}$ & $\begin{array}{l}-0.207 \\
{[0.020]}\end{array}$ & $\begin{array}{l}-0.173 \\
{[0.015]}\end{array}$ & $\begin{array}{l}-0.159 \\
{[0.017]}\end{array}$ & $\begin{array}{c}-0.153 \\
{[0.013]}\end{array}$ \\
\hline 3rd + child & $\begin{array}{c}-0.422 \\
{[0.020]}\end{array}$ & $\begin{array}{l}-0.350 \\
{[0.015]}\end{array}$ & $\begin{array}{l}-0.437 \\
{[0.024]}\end{array}$ & $\begin{array}{c}-0.363 \\
{[0.019]}\end{array}$ & $\begin{array}{l}-0.412 \\
{[0.021]}\end{array}$ & $\begin{array}{l}-0.354 \\
{[0.016]}\end{array}$ \\
\hline Low son pref group mean of outcome & -1.388 & -1.198 & -1.561 & -1.491 & -1.732 & -1.602 \\
\hline High son pref group mean of outcome & -1.710 & -1.648 & -1.721 & -1.622 & -1.691 & -1.628 \\
\hline Age \& other controls & $\begin{array}{c}\text { NFHS } \\
1-3\end{array}$ & $\begin{array}{c}\text { NFHS } \\
1-3\end{array}$ & $\begin{array}{c}\text { NFHS } \\
1-3\end{array}$ & $\begin{array}{c}\text { NFHS } \\
1-3\end{array}$ & $\begin{array}{c}\text { NFHS } \\
1-3\end{array}$ & $\begin{array}{c}\text { NFHS } \\
1-3\end{array}$ \\
\hline Observations & Yes & Yes & Yes & Yes & Yes & Yes \\
\hline $\mathrm{N}$ & 95,125 & 95,125 & 95,125 & 95,125 & 82,084 & 82,084 \\
\hline
\end{tabular}

Source: J+P 
Table B.8: Cultural Norms and Child Height: Within-India Evidence (2004-2010): Unweighted

\begin{tabular}{|c|c|c|c|c|c|c|}
\hline \multirow[t]{2}{*}{ Low son preference proxy: } & \multicolumn{2}{|c|}{ Kerala \& Northeast } & \multicolumn{2}{|c|}{$\begin{array}{l}\text { Below-median } \\
\text { child sex ratio }\end{array}$} & \multicolumn{2}{|c|}{ Muslims } \\
\hline & $\begin{array}{c}\text { HFA } \\
\text { z-score } \\
\text { (1) }\end{array}$ & $\begin{array}{c}\text { WFA } \\
\text { z-score } \\
\text { (2) }\end{array}$ & $\begin{array}{c}\text { HFA } \\
\text { z-score } \\
\text { (3) }\end{array}$ & $\begin{array}{c}\text { WFA } \\
\text { z-score } \\
\text { (4) }\end{array}$ & $\begin{array}{c}\text { HFA } \\
\text { z-score } \\
\text { (5) }\end{array}$ & $\begin{array}{c}\text { WFA } \\
\text { z-score } \\
(6)\end{array}$ \\
\hline Low son pref proxy $\times 2$ nd child & $\begin{array}{c}0.078 \\
{[0.039]}\end{array}$ & $\begin{array}{c}0.008 \\
{[0.029]}\end{array}$ & $\begin{array}{c}0.077 \\
{[0.030]}\end{array}$ & $\begin{array}{c}0.038 \\
{[0.023]}\end{array}$ & $\begin{array}{l}-0.027 \\
{[0.047]}\end{array}$ & $\begin{array}{r}0.034 \\
{[0.035]}\end{array}$ \\
\hline Low son pref proxy $\times 3$ rd + child & $\begin{array}{c}0.108 \\
{[0.045]}\end{array}$ & $\begin{array}{c}0.069 \\
{[0.033]}\end{array}$ & $\begin{array}{c}0.084 \\
{[0.036]}\end{array}$ & $\begin{array}{c}0.047 \\
{[0.027]}\end{array}$ & $\begin{array}{c}0.184 \\
{[0.055]}\end{array}$ & $\begin{array}{c}0.156 \\
{[0.041]}\end{array}$ \\
\hline 2nd child & $\begin{array}{c}-0.185 \\
{[0.017]}\end{array}$ & $\begin{array}{c}-0.154 \\
{[0.013]}\end{array}$ & $\begin{array}{l}-0.205 \\
{[0.020]}\end{array}$ & $\begin{array}{c}-0.172 \\
{[0.015]}\end{array}$ & $\begin{array}{l}-0.159 \\
{[0.017]}\end{array}$ & $\begin{array}{l}-0.153 \\
{[0.013]}\end{array}$ \\
\hline 3rd+ child & $\begin{array}{l}-0.422 \\
{[0.020]}\end{array}$ & $\begin{array}{l}-0.350 \\
{[0.015]}\end{array}$ & $\begin{array}{l}-0.438 \\
{[0.024]}\end{array}$ & $\begin{array}{c}-0.364 \\
{[0.018]}\end{array}$ & $\begin{array}{l}-0.412 \\
{[0.021]}\end{array}$ & $\begin{array}{l}-0.354 \\
{[0.016}\end{array}$ \\
\hline Low son pref group mean of outcome & -1.388 & -1.198 & -1.568 & -1.491 & -1.732 & -1.602 \\
\hline High son pref group mean of outcome & -1.710 & -1.648 & -1.712 & -1.618 & -1.691 & -1.628 \\
\hline Age \& other controls & $\begin{array}{c}\text { NFHS } \\
1-3\end{array}$ & $\begin{array}{c}\text { NFHS } \\
1-3\end{array}$ & $\begin{array}{c}\text { NFHS } \\
1-3\end{array}$ & $\begin{array}{c}\text { NFHS } \\
1-3\end{array}$ & $\begin{array}{c}\text { NFHS } \\
1-3\end{array}$ & $\begin{array}{c}\text { NFHS } \\
1-3\end{array}$ \\
\hline $\begin{array}{l}\text { Observations } \\
\mathrm{N}\end{array}$ & $\begin{array}{c}\text { Yes } \\
95,125\end{array}$ & $\begin{array}{c}\text { Yes } \\
95,125\end{array}$ & $\begin{array}{c}\text { Yes } \\
95,125\end{array}$ & $\begin{array}{c}\text { Yes } \\
95,125\end{array}$ & $\begin{array}{c}\text { Yes } \\
82,084\end{array}$ & $\begin{array}{c}\text { Yes } \\
82,084\end{array}$ \\
\hline
\end{tabular}

Notes: Standard errors are clustered by mother and appear in brackets. In all columns the sample uses NFHS 1-3. NFHS-1 only has data for children aged four years and younger, and NFHS-2 only has data for children aged 3 years and younger. All columns include child age dummies, maternal age, mother's literacy, and child age dummies, maternal age, and mother's literacy interacted with Low son pref proxy. All columns include survey and PSU fixed effects, and survey and PSU fixed effects interacted with Low son pref proxy. In columns 1-4, the main effect Low son pref proxy is absorbed by PSU fixed effects. Kerala and Northeast include Arunachal Pradesh, Assam, Kerala, Manipur,

Meghalaya, Mizoram, Nagaland, Sikkim, and Tripura. Child sex ratio is defined as the number of boys aged 0-6 years over the number of girls aged 0-6 years in the respondent's state-by-rural cell. In columns 5 and 6, the sample is restricted to Muslims and Hindus.

Source: Adapted from J+P using data from DHS (Heger Boyle \& Sobek, 2019) 


\subsection{Child Gender and the Birth Order Gradient in Height}

Table B.9: Child Gender and the Birth Order Gradient in Height (2004-2010): Original

\begin{tabular}{|c|c|c|c|c|c|c|c|c|}
\hline & $\begin{array}{c}\text { HFA } \\
\text { z-score } \\
\text { (1) }\end{array}$ & $\begin{array}{l}\text { HFA } \\
\text { z-score } \\
\text { (2) }\end{array}$ & $\begin{array}{l}\text { HFA } \\
\text { z-score } \\
\text { (3) }\end{array}$ & $\begin{array}{c}\text { WFA } \\
\text { z-score } \\
\text { (4) }\end{array}$ & $\begin{array}{c}\text { HFA } \\
\text { z-score } \\
\text { (5) }\end{array}$ & $\begin{array}{l}\text { HFA } \\
\text { z-score } \\
(6)\end{array}$ & $\begin{array}{l}\text { HFA } \\
\text { z-score } \\
\text { (7) }\end{array}$ & $\begin{array}{c}\text { WFA } \\
\text { z-score } \\
(8)\end{array}$ \\
\hline India & $\begin{array}{c}0.148 \\
{[0.026]}\end{array}$ & & & & $\begin{array}{c}-0.011 \\
{[0.014]}\end{array}$ & & & \\
\hline India $\times$ Girl & $\begin{array}{c}-0.111 \\
{[0.036]}\end{array}$ & & & & $\begin{array}{c}-0.143 \\
{[0.020]}\end{array}$ & $\begin{array}{l}-0.147 \\
{[0.019]}\end{array}$ & $\begin{array}{c}-0.098 \\
{[0.032]}\end{array}$ & $\begin{array}{c}-0.116 \\
{[0.014]}\end{array}$ \\
\hline India $\times 2$ nd child & $\begin{array}{c}-0.107 \\
{[0.036]}\end{array}$ & $\begin{array}{c}-0.152 \\
{[0.040]}\end{array}$ & $\begin{array}{c}-0.228 \\
{[0.069]}\end{array}$ & $\begin{array}{c}-0.122 \\
{[0.030]}\end{array}$ & & & & \\
\hline India $\times 3 r d+$ child & $\begin{array}{c}-0.352 \\
{[0.033]}\end{array}$ & $\begin{array}{c}-0.221 \\
{[0.047]}\end{array}$ & $\begin{array}{c}-0.414 \\
{[0.097]}\end{array}$ & $\begin{array}{c}-0.175 \\
{[0.035]}\end{array}$ & & & & \\
\hline India $\times 2$ nd child $\times$ Girl & $\begin{array}{c}-0.076 \\
{[0.053]}\end{array}$ & $\begin{array}{c}-0.045 \\
{[0.057]}\end{array}$ & $\begin{array}{c}-0.024 \\
{[0.101]}\end{array}$ & $\begin{array}{c}-0.047 \\
{[0.043]}\end{array}$ & & & & \\
\hline India $\times 3$ rd + child $\times$ Girl & $\begin{array}{c}-0.051 \\
{[0.047]}\end{array}$ & $\begin{array}{l}-0.048 \\
{[0.067]}\end{array}$ & $\begin{array}{c}-0.030 \\
{[0.092]}\end{array}$ & $\begin{array}{c}-0.064 \\
{[0.049]}\end{array}$ & & & & \\
\hline Africa mean of outcome & -1.575 & -1.575 & -1.575 & -1.575 & -1.351 & -1.351 & -1.351 & -1.351 \\
\hline Age \& other controls & No & Yes & No & Yes & No & Yes & No & Yes \\
\hline Mother FEs & No & No & Yes & No & No & No & Yes & No \\
\hline Observations & 168,108 & 165,596 & 83,228 & 165,596 & 168,108 & 167,737 & 83,228 & 167,737 \\
\hline
\end{tabular}

Source: $\mathrm{J}+\mathrm{P}$

Table B.10: Child Gender and the Birth Order Gradient in Height (2004-2010): Unweighted

\begin{tabular}{|c|c|c|c|c|c|c|c|c|}
\hline & $\begin{array}{l}\text { HFA } \\
\text { Z-score } \\
\text { (1) }\end{array}$ & $\begin{array}{c}\text { HFA } \\
\text { z-score } \\
\text { (2) }\end{array}$ & $\begin{array}{c}\text { HFA } \\
\text { z-score } \\
\text { (3) }\end{array}$ & $\begin{array}{c}\text { WFA } \\
\text { z-score } \\
\text { (4) }\end{array}$ & $\begin{array}{l}\text { HFA } \\
\text { z-score } \\
\text { (5) }\end{array}$ & $\begin{array}{l}\text { HFA } \\
\text { z-score } \\
(6)\end{array}$ & $\begin{array}{l}\text { HFA } \\
\text { Z-score } \\
\text { (7) }\end{array}$ & $\begin{array}{c}\text { WFA } \\
\text { z-score } \\
(8)\end{array}$ \\
\hline India & $\begin{array}{c}0.148 \\
{[0.026]}\end{array}$ & & & & $\begin{array}{c}-0.011 \\
{[0.014]}\end{array}$ & & & \\
\hline India $\times$ Girl & $\begin{array}{c}-0.112 \\
{[0.036]}\end{array}$ & & & & $\begin{array}{c}-0.143 \\
{[0.020]}\end{array}$ & $\begin{array}{l}-0.147 \\
{[0.019]}\end{array}$ & $\begin{array}{c}-0.098 \\
{[0.032]}\end{array}$ & $\begin{array}{c}-0.116 \\
{[0.014]}\end{array}$ \\
\hline India $\times 2$ nd child & $\begin{array}{l}-0.107 \\
{[0.036]}\end{array}$ & $\begin{array}{c}-0.153 \\
{[0.040]}\end{array}$ & $\begin{array}{c}-0.228 \\
{[0.069]}\end{array}$ & $\begin{array}{c}-0.122 \\
{[0.030]}\end{array}$ & & & & \\
\hline India $\times 3$ rd + child & $\begin{array}{c}-0.352 \\
{[0.033]}\end{array}$ & $\begin{array}{c}-0.222 \\
{[0.047]}\end{array}$ & $\begin{array}{c}-0.414 \\
{[0.097]}\end{array}$ & $\begin{array}{l}-0.176 \\
{[0.035]}\end{array}$ & & & & \\
\hline India $\times 2$ nd child $\times$ Girl & $\begin{array}{c}-0.077 \\
{[0.053]}\end{array}$ & $\begin{array}{c}-0.045 \\
{[0.057]}\end{array}$ & $\begin{array}{c}-0.024 \\
{[0.101]}\end{array}$ & $\begin{array}{l}-0.047 \\
{[0.042]}\end{array}$ & & & & \\
\hline India $\times$ 3rd + child $\times$ Girl & $\begin{array}{c}-0.051 \\
{[0.047]}\end{array}$ & $\begin{array}{c}-0.048 \\
{[0.067]}\end{array}$ & $\begin{array}{c}-0.030 \\
{[0.092]}\end{array}$ & $\begin{array}{c}-0.063 \\
{[0.049]}\end{array}$ & & & & \\
\hline Africa mean of outcome & -1.351 & -1.351 & -1.351 & -0.877 & -1.351 & -1.351 & -1.351 & -0.877 \\
\hline Age \& other controls & No & Yes & No & Yes & No & Yes & No & Yes \\
\hline Mother FEs & No & No & Yes & No & No & No & Yes & No \\
\hline Observations & 168,135 & 165,623 & 83,243 & 165,623 & 168,135 & 167,765 & 83,243 & 167,765 \\
\hline
\end{tabular}

Notes: Standard errors are clustered by mother and appear in brackets. Please consider the notes in Table 2.10 for further explanations.

Source: Adapted from J+P using data DHS (Heger Boyle \& Sobek, 2019) 


\subsection{Impact on Average Height - Accounting exercise}

Table B.11: Accounting Exercise Part 1: Sample Comparison (2004-2010): Original

\begin{tabular}{|c|c|c|c|}
\hline & & $\begin{array}{l}\text { Accounting } \\
\text { Exercise } 1\end{array}$ & $\begin{array}{c}\text { Accounting } \\
\text { Exercise } 2\end{array}$ \\
\hline & $\begin{array}{c}\text { HFA z-score } \\
\text { (1) }\end{array}$ & $\begin{array}{c}\text { HFA z-score } \\
\text { (2) }\end{array}$ & $\begin{array}{c}\text { HFA z-score } \\
\text { (3) }\end{array}$ \\
\hline India & $\begin{array}{c}-0.162 \\
{[0.017]}\end{array}$ & & \\
\hline Gradient proxy & & $\begin{array}{c}0.400 \\
{[0.070]}\end{array}$ & $\begin{array}{c}0.688 \\
{[0.132]}\end{array}$ \\
\hline \multicolumn{4}{|l|}{ Mean of gradient proxy } \\
\hline India & & -0.331 & -0.234 \\
\hline Africa & & -0.066 & -0.037 \\
\hline Kerala \& Northeast & & -0.229 & -0.155 \\
\hline Rest of India & & -0.358 & -0.257 \\
\hline Log GDP per capita & Yes & Yes & Yes \\
\hline Sample & Full & Africa & Africa \\
\hline Observations & 168,108 & 126,039 & 126,039 \\
\hline
\end{tabular}

Table B.12: Accounting Exercise Part 1: Sample Comparison (2004-2010): Unweighted

\begin{tabular}{|c|c|c|c|}
\hline & & $\begin{array}{l}\text { Accounting } \\
\text { Exercise } 1\end{array}$ & $\begin{array}{c}\text { Accounting } \\
\text { Exercise } 2\end{array}$ \\
\hline & $\begin{array}{c}\text { HFA z-score } \\
\text { (1) }\end{array}$ & $\begin{array}{c}\text { HFA z-score } \\
\text { (2) }\end{array}$ & $\begin{array}{c}\text { HFA z-score } \\
\text { (3) }\end{array}$ \\
\hline India & $\begin{array}{c}-0.162 \\
{[0.017]}\end{array}$ & & \\
\hline Gradient proxy & & $\begin{array}{c}0.412 \\
{[0.069]}\end{array}$ & $\begin{array}{c}0.704 \\
{[0.131]}\end{array}$ \\
\hline \multicolumn{4}{|l|}{ Mean of gradient proxy } \\
\hline India & & -0.331 & -0.234 \\
\hline Africa & & -0.066 & -0.037 \\
\hline Kerala \& Northeast & & -0.229 & -0.155 \\
\hline Rest of India & & -0.358 & -0.257 \\
\hline Log GDP per capita & Yes & Yes & Yes \\
\hline Sample & Full & Africa & Africa \\
\hline Observations & 168,135 & 126,066 & 126,066 \\
\hline
\end{tabular}

Notes: Standard errors are clustered by PSU and appear in brackets. Please consider the notes in table 2.12 for further explanations. Source: Adapted from J+P using data from IPUMS DHS (ICF, 2004) and DHS (Heger Boyle \& Sobek, 2019) 
Table B.13: Accounting Exercise Part 2: Sample Comparison (2004-2010): Original

Accounting Accounting

Exercise $1 \quad$ Exercise 2

Calculation 1: Share explained by birth order gradient

- India-Africa gap in birth order gradient

$\begin{array}{ll}-0.265 & -0.197\end{array}$

- India-Africa gap in birth order gradient $\times$ Gradient coeff

$-0.106 \quad-0.136$

- Explained share of India-Africa level gap in height (shown in column 1)

$65 \%$

$84 \%$

Calculation 2: Share explained by birth order gradient rooted in eldest son preference

- Rest of India - Kerala \& NE gap in birth order gradient

$-0.129$

$-0.102$

- Rest of India - Kerala \& NE gap in birth order gradient $\times$ Gradient coff

$-0.052$

$-0.070$

- Explained share of India-Africa level gap in height (shown in column 1)

$32 \%$

$43 \%$ Source: J+P

Table B.14: Accounting Exercise Part 2: Sample Comparison (2004-2010): Unweighted

Accounting Accounting

Exercise 1

Exercise 2

Calculation 1: Share explained by birth order gradient

- India-Africa gap in birth order gradient

$-0.265$

$-0.197$

- India-Africa gap in birth order gradient $\times$ Gradient coeff

$-0.109$

$-0.139$

- Explained share of India-Africa level gap in height (shown in column 1)

$67 \%$

$86 \%$

Calculation 2: Share explained by birth order gradient rooted in eldest son preference

- Rest of India - Kerala \& NE gap in birth order gradient

$-0.129$

$-0.102$

- Rest of India - Kerala \& NE gap in birth order gradient $\times$ Gradient coff

$-0.053$

$-0.072$

- Explained share of India-Africa level gap in height (shown in column 1)

$33 \%$

$44 \%$

Source: Adapted from J+Pusing data from DHS (Heger Boyle \& Sobek, 2019) 


\section{Replicated Results (2004-2010) and Replicated Results (2011- 2017): Same Methodology and Data from the More Recent Time Period}

\subsection{Summary Statistics}

Table B.15: Summary Statistics (2004-2010)

\begin{tabular}{|c|c|c|c|c|c|}
\hline & $\begin{array}{c}\text { India } \\
\text { subsample }\end{array}$ & $\begin{array}{c}\text { Africa } \\
\text { subsample }\end{array}$ & & $\begin{array}{c}\text { India } \\
\text { subsample }\end{array}$ & $\begin{array}{c}\text { Africa } \\
\text { subsample }\end{array}$ \\
\hline Mother's age at birth (years) & $\begin{array}{l}24.75 \\
{[5.23]}\end{array}$ & $\begin{array}{l}26.96 \\
{[6.86]}\end{array}$ & Child's age (months) & $\begin{array}{c}30.20 \\
{[16.90]}\end{array}$ & $\begin{array}{c}28.27 \\
{[17.06]}\end{array}$ \\
\hline Mother's total children born & $\begin{array}{c}2.74 \\
{[1.82]}\end{array}$ & $\begin{array}{c}3.88 \\
{[2.54]}\end{array}$ & Child is a girl & $\begin{array}{c}0.48 \\
{[0.50]}\end{array}$ & $\begin{array}{c}0.50 \\
{[0.50]}\end{array}$ \\
\hline Mother's desired fertility & $\begin{array}{c}2.47 \\
{[0.96]}\end{array}$ & $\begin{array}{c}4.62 \\
{[1.47]}\end{array}$ & Child's birth order & $\begin{array}{c}2.62 \\
{[1.80]}\end{array}$ & $\begin{array}{c}3.74 \\
{[2.48]}\end{array}$ \\
\hline Mother wants more children & $\begin{array}{c}0.34 \\
{[0.47]}\end{array}$ & $\begin{array}{c}0.67 \\
{[0.46]}\end{array}$ & Child's HFA z-score & $\begin{array}{l}-1.51 \\
{[1.81]}\end{array}$ & $\begin{array}{l}-1.35 \\
{[1.94]}\end{array}$ \\
\hline Mother completed her fertility & $\begin{array}{c}0.67 \\
{[0.47]}\end{array}$ & $\begin{array}{c}0.33 \\
{[0.47]}\end{array}$ & Child is stunted & $\begin{array}{c}0.40 \\
{[0.49]}\end{array}$ & $\begin{array}{c}0.38 \\
{[0.48]}\end{array}$ \\
\hline Mother is literate & $\begin{array}{c}0.58 \\
{[0.49]}\end{array}$ & $\begin{array}{c}0.49 \\
{[0.50]}\end{array}$ & Child's WFA z-score & $\begin{array}{l}-1.53 \\
{[1.33]}\end{array}$ & $\begin{array}{l}-0.88 \\
{[1.42]}\end{array}$ \\
\hline Mother's height (meters) & $\begin{array}{c}1.52 \\
{[0.06]}\end{array}$ & $\begin{array}{c}1.58 \\
{[0.07]}\end{array}$ & Child's hemoglobin level (g/dl) & $\begin{array}{l}10.28 \\
{[1.57]}\end{array}$ & $\begin{array}{l}10.15 \\
{[1.68]}\end{array}$ \\
\hline Mother took iron supplements & $\begin{array}{c}0.69 \\
{[0.46]}\end{array}$ & $\begin{array}{c}0.62 \\
{[0.49]}\end{array}$ & Child is deceased & $\begin{array}{c}0.05 \\
{[0.22]}\end{array}$ & $\begin{array}{c}0.07 \\
{[0.26]}\end{array}$ \\
\hline Mother's total tetanus shots & $\begin{array}{c}1.87 \\
{[0.94]}\end{array}$ & $\begin{array}{c}1.41 \\
{[1.20]}\end{array}$ & Child taking iron pills & $\begin{array}{c}0.06 \\
{[0.23]}\end{array}$ & $\begin{array}{c}0.11 \\
{[0.32]}\end{array}$ \\
\hline Total prenatal visits & $\begin{array}{c}4.04 \\
{[3.48]}\end{array}$ & $\begin{array}{c}3.85 \\
{[3.07]}\end{array}$ & Child's total vaccinations & $\begin{array}{c}6.61 \\
{[2.80]}\end{array}$ & $\begin{array}{c}6.24 \\
{[3.12]}\end{array}$ \\
\hline Delivery at health facility & $\begin{array}{c}0.45 \\
{[0.50]}\end{array}$ & $\begin{array}{c}0.47 \\
{[0.50]}\end{array}$ & Birth spacing (months) & $\begin{array}{c}36.16 \\
{[20.32]}\end{array}$ & $\begin{array}{c}38.69 \\
{[20.63]}\end{array}$ \\
\hline Postnatal check within 2 months & $\begin{array}{c}0.09 \\
{[0.29]}\end{array}$ & $\begin{array}{c}0.30 \\
{[0.46]}\end{array}$ & Diarrhea in last 2 weeks & $\begin{array}{c}0.09 \\
{[0.29]}\end{array}$ & $\begin{array}{c}0.16 \\
{[0.36]}\end{array}$ \\
\hline Average pooled inputs & $\begin{array}{c}0.33 \\
{[0.28]}\end{array}$ & $\begin{array}{c}0.38 \\
{[0.30]}\end{array}$ & Open defecation & $\begin{array}{c}0.46 \\
{[0.50]}\end{array}$ & $\begin{array}{c}0.32 \\
{[0.47]}\end{array}$ \\
\hline Percent non-resident among children & $\begin{array}{c}0.02 \\
{[0.04]}\end{array}$ & $\begin{array}{c}0.10 \\
{[0.08]}\end{array}$ & Number of PSUs & 3,822 & 10,366 \\
\hline Number of adult females in household & $\begin{array}{c}1.85 \\
{[1.09]}\end{array}$ & $\begin{array}{c}1.60 \\
{[1.06]}\end{array}$ & Main sample of children & 42,069 & 126,066 \\
\hline Log GDP per capita (in child's birth year) & $\begin{array}{c}7.78 \\
{[0.10]}\end{array}$ & $\begin{array}{c}7.36 \\
{[0.65]}\end{array}$ & & & \\
\hline
\end{tabular}

Notes: The means of the specified variables are calculated separately for the India and Africa subsamples. Standard deviations appear in brackets. Please consider the notes in Table 2.3 for further explanations.

Source: Adapted from J+P using data from DHS (Heger Boyle \& Sobek, 2019) 
Table B.16: Summary Statistics (2011-2017)

\begin{tabular}{|c|c|c|c|c|c|}
\hline & $\begin{array}{c}\text { India } \\
\text { subsample }\end{array}$ & $\begin{array}{c}\text { Africa } \\
\text { subsample }\end{array}$ & & $\begin{array}{c}\text { India } \\
\text { subsample }\end{array}$ & $\begin{array}{c}\text { Africa } \\
\text { subsample }\end{array}$ \\
\hline Mother's age at birth (years) & $\begin{array}{l}25.12 \\
{[4.96]}\end{array}$ & $\begin{array}{l}27.23 \\
{[6.71]}\end{array}$ & Child's age (months) & $\begin{array}{c}30.14 \\
{[16.92]}\end{array}$ & $\begin{array}{c}28.90 \\
{[17.02]}\end{array}$ \\
\hline Mother's total children born & $\begin{array}{c}2.38 \\
{[1.49]}\end{array}$ & $\begin{array}{c}3.81 \\
{[2.48]}\end{array}$ & Child is a girl & $\begin{array}{c}0.48 \\
{[0.50]}\end{array}$ & $\begin{array}{c}0.50 \\
{[0.50]}\end{array}$ \\
\hline Mother's desired fertility & $\begin{array}{c}2.42 \\
{[0.99]}\end{array}$ & $\begin{array}{c}4.73 \\
{[1.41]}\end{array}$ & Child's birth order & $\begin{array}{c}2.26 \\
{[1.47]}\end{array}$ & $\begin{array}{c}3.70 \\
{[2.42]}\end{array}$ \\
\hline Mother wants more children & $\begin{array}{c}0.41 \\
{[0.47]}\end{array}$ & $\begin{array}{c}0.71 \\
{[0.44]}\end{array}$ & Child's HFA z-score & $\begin{array}{l}-1.26 \\
{[1.82]}\end{array}$ & $\begin{array}{l}-1.11 \\
{[1.73]}\end{array}$ \\
\hline Mother completed her fertility & $\begin{array}{c}0.61 \\
{[0.49]}\end{array}$ & $\begin{array}{c}0.28 \\
{[0.45]}\end{array}$ & Child is stunted & $\begin{array}{c}0.35 \\
{[0.48]}\end{array}$ & $\begin{array}{c}0.29 \\
{[0.45]}\end{array}$ \\
\hline Mother is literate & $\begin{array}{c}0.67 \\
{[0.47]}\end{array}$ & $\begin{array}{c}0.48 \\
{[0.50]}\end{array}$ & Child's WFA z-score & $\begin{array}{l}-1.43 \\
{[1.30]}\end{array}$ & $\begin{array}{l}-0.86 \\
{[1.31]}\end{array}$ \\
\hline Mother's height (meters) & $\begin{array}{c}1.52 \\
{[0.06]}\end{array}$ & $\begin{array}{c}1.58 \\
{[0.06]}\end{array}$ & Child's hemoglobin level (g/dl) & $\begin{array}{l}10.60 \\
{[1.51]}\end{array}$ & $\begin{array}{l}10.33 \\
{[1.63]}\end{array}$ \\
\hline Mother took iron supplements & $\begin{array}{c}0.77 \\
{[0.42]}\end{array}$ & $\begin{array}{c}0.76 \\
{[0.43]}\end{array}$ & Child is deceased & $\begin{array}{c}0.04 \\
{[0.20]}\end{array}$ & $\begin{array}{c}0.05 \\
{[0.22]}\end{array}$ \\
\hline Mother's total tetanus shots & $\begin{array}{c}1.91 \\
{[0.78]}\end{array}$ & $\begin{array}{c}1.42 \\
{[1.09]}\end{array}$ & Child taking iron pills & $\begin{array}{c}0.23 \\
{[0.42]}\end{array}$ & $\begin{array}{c}0.07 \\
{[0.25]}\end{array}$ \\
\hline Total prenatal visits & $\begin{array}{c}4.19 \\
{[3.86]}\end{array}$ & $\begin{array}{c}3.77 \\
{[2.92]}\end{array}$ & Child's total vaccinations & $\begin{array}{c}7.30 \\
{[2.70]}\end{array}$ & $\begin{array}{c}4.92 \\
{[3.55]}\end{array}$ \\
\hline Delivery at health facility & $\begin{array}{c}0.76 \\
{[0.43]}\end{array}$ & $\begin{array}{c}0.58 \\
{[0.49]}\end{array}$ & Birth spacing (months) & $\begin{array}{c}37.26 \\
{[21.45]}\end{array}$ & $\begin{array}{c}38.83 \\
{[20.79]}\end{array}$ \\
\hline Postnatal check within 2 months & $\begin{array}{c}0.36 \\
{[0.48]}\end{array}$ & $\begin{array}{c}0.49 \\
{[0.50]}\end{array}$ & Diarrhea in last 2 weeks & $\begin{array}{c}0.09 \\
{[0.29]}\end{array}$ & $\begin{array}{c}0.16 \\
{[0.36]}\end{array}$ \\
\hline Average pooled inputs & $\begin{array}{c}0.46 \\
{[0.25]}\end{array}$ & $\begin{array}{c}0.40 \\
{[0.29]}\end{array}$ & Open defecation & $\begin{array}{c}0.44 \\
{[0.50]}\end{array}$ & $\begin{array}{c}0.25 \\
{[0.43]}\end{array}$ \\
\hline Percent non-resident among children & $\begin{array}{c}0.02 \\
{[0.04]}\end{array}$ & $\begin{array}{c}0.09 \\
{[0.00]}\end{array}$ & Number of PSUs & 28,215 & 12,684 \\
\hline Number of adult females in household & $\begin{array}{c}1.91 \\
{[1.03]}\end{array}$ & $\begin{array}{c}1.94 \\
{[1.66]}\end{array}$ & Main sample of children & 230,220 & 168,490 \\
\hline Log GDP per capita (in child's birth year) & $\begin{array}{c}8.51 \\
{[0.08]}\end{array}$ & $\begin{array}{c}7.75 \\
{[0.68]}\end{array}$ & & & \\
\hline
\end{tabular}

Notes: The means of the specified variables are calculated separately for the India and Africa subsamples. Standard deviations appear in brackets. Please consider the notes in Table 2.4 for further explanations.

Source: Adapted from J+P using data from IPUMS DHS (ICF, 2004) and DHS (Heger Boyle \& Sobek, 2019) 
Figure B.1: Child Height versus National GDP (2004-2010) vs (2011-2017): Unweighted

Replication (2004-2010)

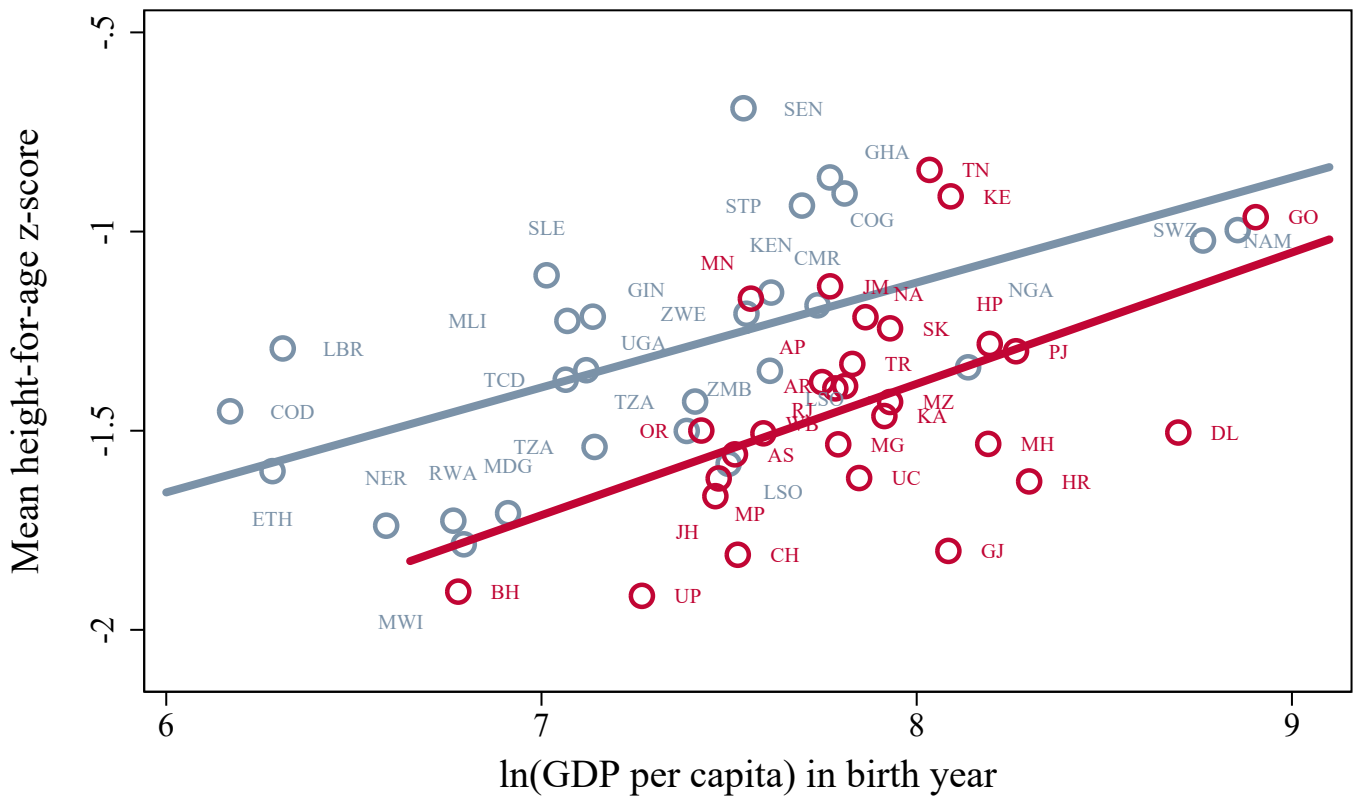

\begin{tabular}{|lll}
\hline African countries & Africa fitted values \\
Indian states & India fitted values
\end{tabular}

Replication (2011-2017)

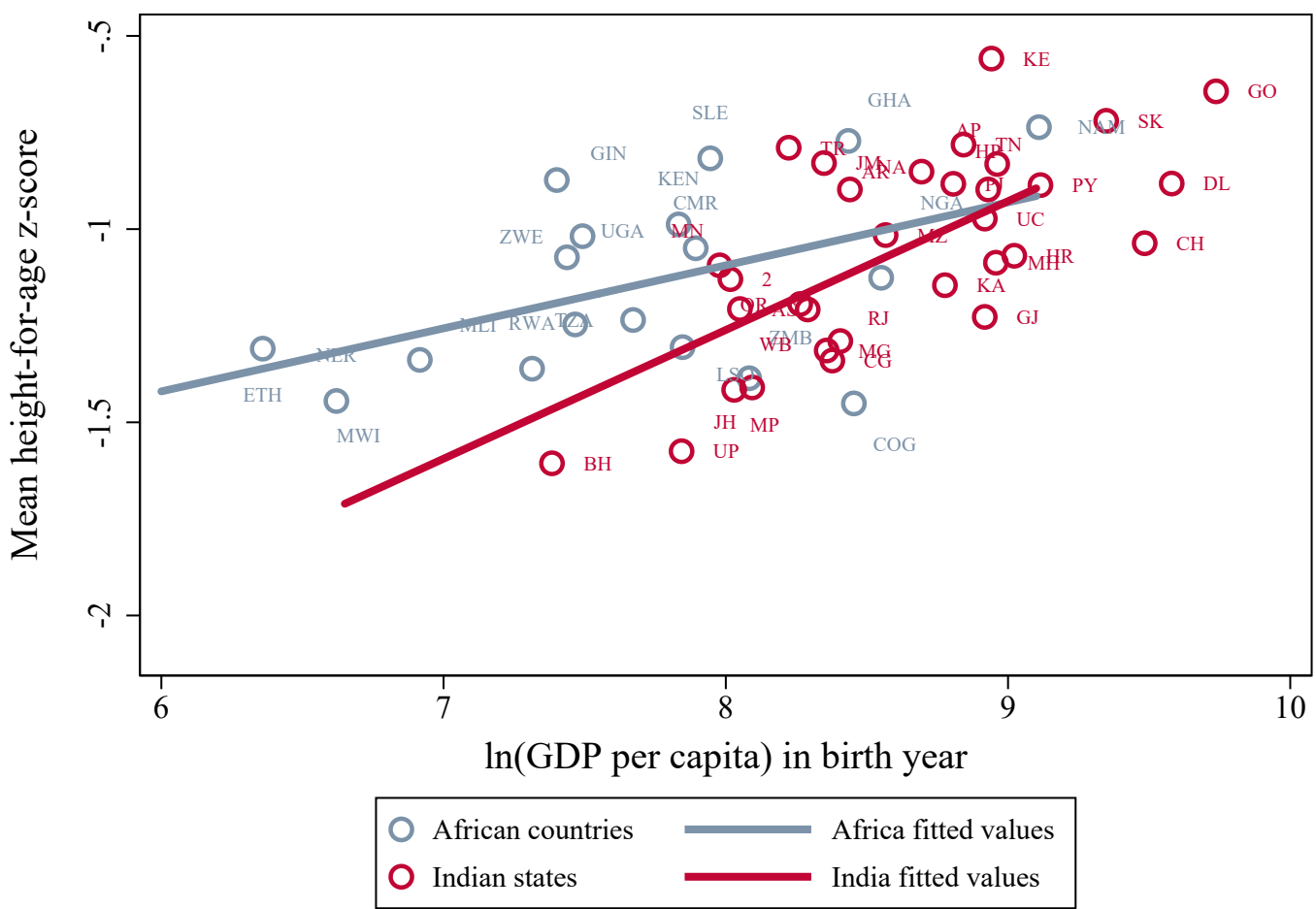

Notes: The light and dark circles represent sub-Saharan African countries and Indian states, respectively. The averages are calculated over all children less than 60 months old. The lines represent the best linear fit for each sample.

Source: Adapted from J+P using data from Penn World Table 9.0, Penn World Table 9.1, and the Handbook of Statistics on Indian States (Robert C. Feenstra, 2016, 2019; Reserve Bank of India, 2019) 


\subsection{India's Differential Birth Order Gradient in Child Height and Re- lated Outcomes}

Table B.17: India's Differential Birth Order Gradient in Child Height and Related Outcomes (2004-2010)

\begin{tabular}{|c|c|c|c|c|c|c|c|c|c|}
\hline & $\begin{array}{l}\text { HFA } \\
\text { Z- } \\
\text { score } \\
(1)\end{array}$ & $\begin{array}{l}\text { HFA } \\
\text { Z- } \\
\text { score } \\
(2)\end{array}$ & $\begin{array}{l}\text { HFA } \\
\text { z- } \\
\text { score } \\
(3)\end{array}$ & $\begin{array}{l}\text { HFA } \\
\text { Z- } \\
\text { score } \\
(4)\end{array}$ & $\begin{array}{l}\text { HFA } \\
\text { Z- } \\
\text { score } \\
(5)\end{array}$ & $\begin{array}{l}\text { Stunted } \\
\text { (6) }\end{array}$ & $\begin{array}{l}\text { WFA } \\
\text { z- } \\
\text { score } \\
(7)\end{array}$ & $\begin{array}{c}\mathrm{Hb} \\
\text { level } \\
(8)\end{array}$ & $\begin{array}{l}\text { Deceasec } \\
\text { (9) }\end{array}$ \\
\hline India & $\begin{array}{l}-0.083 \\
{[0.011]}\end{array}$ & $\begin{array}{c}0.092 \\
{[0.018]}\end{array}$ & & & & & & & \\
\hline India $\times 2$ nd child & & $\begin{array}{l}-0.144 \\
{[0.025]}\end{array}$ & $\begin{array}{l}-0.161 \\
{[0.027]}\end{array}$ & $\begin{array}{l}-0.110 \\
{[0.063]}\end{array}$ & $\begin{array}{l}-0.243 \\
{[0.048]}\end{array}$ & $\begin{array}{c}0.051 \\
{[0.007]}\end{array}$ & $\begin{array}{l}-0.147 \\
{[0.020]}\end{array}$ & $\begin{array}{l}-0.094 \\
{[0.030]}\end{array}$ & $\begin{array}{c}0.003 \\
{[0.004]}\end{array}$ \\
\hline India $\times 3$ rd + child & & $\begin{array}{l}-0.377 \\
{[0.024]}\end{array}$ & $\begin{array}{l}-0.228 \\
{[0.032]}\end{array}$ & $\begin{array}{l}-0.194 \\
{[0.092]}\end{array}$ & $\begin{array}{l}-0.436 \\
{[0.085]}\end{array}$ & $\begin{array}{c}0.064 \\
{[0.009]}\end{array}$ & $\begin{array}{l}-0.199 \\
{[0.024]}\end{array}$ & $\begin{array}{l}-0.158 \\
{[0.036]}\end{array}$ & $\begin{array}{c}0.002 \\
{[0.004]}\end{array}$ \\
\hline 2nd child & & $\begin{array}{c}0.024 \\
{[0.015]}\end{array}$ & $\begin{array}{l}-0.011 \\
{[0.017]}\end{array}$ & $\begin{array}{l}-0.096 \\
{[0.053]}\end{array}$ & $\begin{array}{l}-0.167 \\
{[0.027]}\end{array}$ & $\begin{array}{c}0.009 \\
{[0.004]}\end{array}$ & $\begin{array}{c}0.010 \\
{[0.012]}\end{array}$ & $\begin{array}{l}-0.010 \\
{[0.022]}\end{array}$ & $\begin{array}{l}-0.014 \\
{[0.002]}\end{array}$ \\
\hline $3 \mathrm{rd}+$ child & & $\begin{array}{l}-0.065 \\
{[0.013]}\end{array}$ & $\begin{array}{l}-0.117 \\
{[0.019]}\end{array}$ & $\begin{array}{l}-0.168 \\
{[0.074]}\end{array}$ & $\begin{array}{l}-0.334 \\
{[0.044]}\end{array}$ & $\begin{array}{c}0.036 \\
{[0.005]}\end{array}$ & $\begin{array}{l}-0.063 \\
{[0.014]}\end{array}$ & $\begin{array}{l}-0.038 \\
{[0.025]}\end{array}$ & $\begin{array}{l}-0.011 \\
{[0.003]}\end{array}$ \\
\hline Africa mean of outcome & -1.351 & -1.351 & -1.351 & -1.351 & -1.351 & 0.375 & -0.877 & 10.149 & 0.072 \\
\hline Child's age dummies $\times$ India & No & No & Yes & Yes & Yes & Yes & Yes & Yes & Yes \\
\hline Mother's literacy $\times$ India & No & No & Yes & Yes & No & Yes & Yes & Yes & Yes \\
\hline Mother's age at birth $\times$ India & No & No & Yes & Yes & No & Yes & Yes & Yes & Yes \\
\hline PSU FEs & No & No & Yes & Yes & No & Yes & Yes & Yes & Yes \\
\hline Mother FEs & No & No & No & No & Yes & No & No & No & No \\
\hline Completed fertility sample & No & No & No & Yes & No & No & No & No & No \\
\hline Observations & 168,135 & 168,135 & 167,765 & 66,574 & 83,243 & 167,765 & 167,765 & 88,893 & 199,514 \\
\hline
\end{tabular}

Notes: Standard errors are clustered by mother and appear in brackets. Please consider the notes in Table 2.6 for further explanations.

Source: Adapted from Jayachandran \& Pande (2017) using data from DHS (Heger Boyle \& Sobek, 2019) 
Table B.18: India's Differential Birth Order Gradient in Child Height and Related Outcomes (2011-2017)

\begin{tabular}{|c|c|c|c|c|c|c|c|c|c|}
\hline & $\begin{array}{l}\text { HFA } \\
\text { Z- } \\
\text { score } \\
(1)\end{array}$ & $\begin{array}{l}\text { HFA } \\
\text { Z- } \\
\text { score } \\
(2)\end{array}$ & $\begin{array}{l}\text { HFA } \\
\text { z- } \\
\text { score } \\
(3)\end{array}$ & $\begin{array}{l}\text { HFA } \\
\text { Z- } \\
\text { score } \\
(4)\end{array}$ & $\begin{array}{l}\text { HFA } \\
\text { Z- } \\
\text { score } \\
(5)\end{array}$ & $\begin{array}{l}\text { Stunted } \\
\text { (6) }\end{array}$ & $\begin{array}{l}\text { WFA } \\
\text { Z- } \\
\text { score } \\
(7)\end{array}$ & $\begin{array}{c}\mathrm{Hb} \\
\text { level } \\
(8)\end{array}$ & $\begin{array}{l}\text { Deceasec } \\
\text { (9) }\end{array}$ \\
\hline India & $\begin{array}{l}-0.107 \\
{[0.006]}\end{array}$ & $\begin{array}{l}-0.019 \\
{[0.010]}\end{array}$ & & & & & & & \\
\hline India $\times 2$ nd child & & $\begin{array}{l}-0.105 \\
{[0.014]}\end{array}$ & $\begin{array}{l}-0.073 \\
{[0.015]}\end{array}$ & $\begin{array}{l}-0.059 \\
{[0.055]}\end{array}$ & $\begin{array}{l}-0.168 \\
{[0.028]}\end{array}$ & $\begin{array}{c}0.024 \\
{[0.004]}\end{array}$ & $\begin{array}{l}-0.087 \\
{[0.011]}\end{array}$ & $\begin{array}{l}-0.039 \\
{[0.018]}\end{array}$ & $\begin{array}{l}-0.002 \\
{[0.002]}\end{array}$ \\
\hline India $\times 3$ rd + child & & $\begin{array}{l}-0.271 \\
{[0.013]}\end{array}$ & $\begin{array}{l}-0.112 \\
{[0.018]}\end{array}$ & $\begin{array}{l}-0.082 \\
{[0.076]}\end{array}$ & $\begin{array}{l}-0.326 \\
{[0.049]}\end{array}$ & $\begin{array}{c}0.028 \\
{[0.005]}\end{array}$ & $\begin{array}{l}-0.129 \\
{[0.014]}\end{array}$ & $\begin{array}{l}-0.013 \\
{[0.020]}\end{array}$ & $\begin{array}{l}-0.000 \\
{[0.002]}\end{array}$ \\
\hline 2nd child & & $\begin{array}{c}0.007 \\
{[0.012]}\end{array}$ & $\begin{array}{l}-0.049 \\
{[0.013]}\end{array}$ & $\begin{array}{l}-0.092 \\
{[0.053]}\end{array}$ & $\begin{array}{l}-0.178 \\
{[0.021]}\end{array}$ & $\begin{array}{c}0.011 \\
{[0.004]}\end{array}$ & $\begin{array}{l}-0.014 \\
{[0.010]}\end{array}$ & $\begin{array}{l}-0.026 \\
{[0.016]}\end{array}$ & $\begin{array}{l}-0.009 \\
{[0.002]}\end{array}$ \\
\hline 3rd + child & & $\begin{array}{l}-0.104 \\
{[0.010]}\end{array}$ & $\begin{array}{l}-0.155 \\
{[0.014]}\end{array}$ & $\begin{array}{l}-0.129 \\
{[0.072]}\end{array}$ & $\begin{array}{l}-0.314 \\
{[0.033]}\end{array}$ & $\begin{array}{c}0.043 \\
{[0.004]}\end{array}$ & $\begin{array}{l}-0.082 \\
{[0.011]}\end{array}$ & $\begin{array}{l}-0.114 \\
{[0.018]}\end{array}$ & $\begin{array}{l}-0.009 \\
{[0.002]}\end{array}$ \\
\hline Africa mean of outcome & -1.110 & -1.110 & -1.110 & -1.110 & -1.110 & 0.289 & -0.858 & 10.332 & 0.049 \\
\hline Child's age dummies $\times$ India & No & No & Yes & Yes & Yes & Yes & Yes & Yes & Yes \\
\hline Mother's literacy $\times$ India & No & No & Yes & Yes & No & Yes & Yes & Yes & Yes \\
\hline Mother's age at birth $\times$ India & No & No & Yes & Yes & No & Yes & Yes & Yes & Yes \\
\hline PSU FEs & No & No & Yes & Yes & No & Yes & Yes & Yes & Yes \\
\hline Mother FEs & No & No & No & No & Yes & No & No & No & No \\
\hline Completed fertility sample & No & No & No & Yes & No & No & No & No & No \\
\hline Observations & 398,710 & 398,710 & 397,702 & 176,665 & 189,520 & 397,702 & 397,702 & 300,933 & 410,460 \\
\hline
\end{tabular}

Notes: Standard errors are clustered by mother and appear in brackets. Please consider the notes in Table 2.6 for further explanations. Source: Adapted from J+P using data from IPUMS DHS (ICF, 2004) and DHS (Heger Boyle \& Sobek, 2019) 
Figure B.2: Child Height in India and Africa, by Child's Birth Order (2004-2010) vs (20112017): Unweighted

Replication (2004-2010)

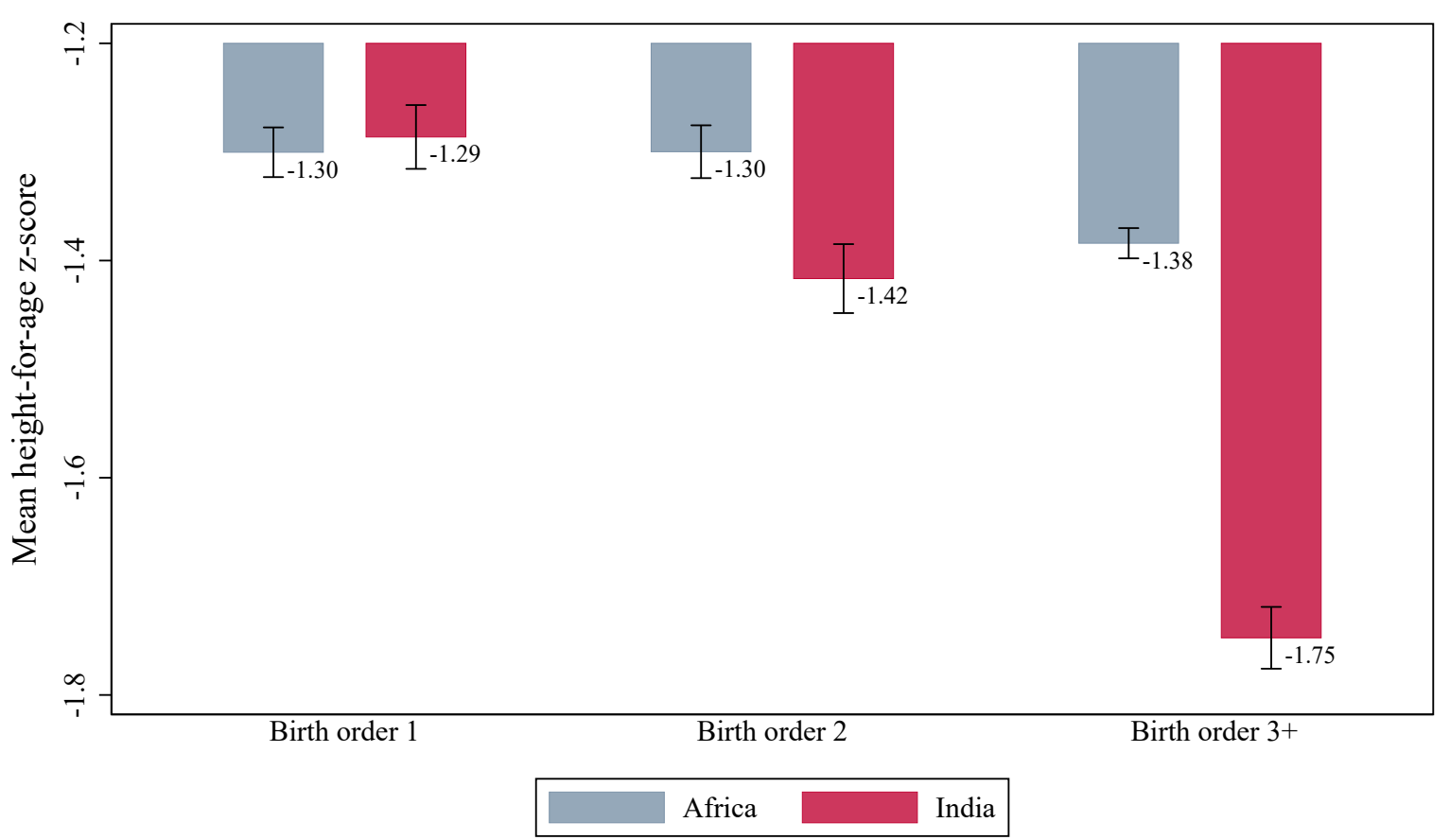

Replication (2011-2017)

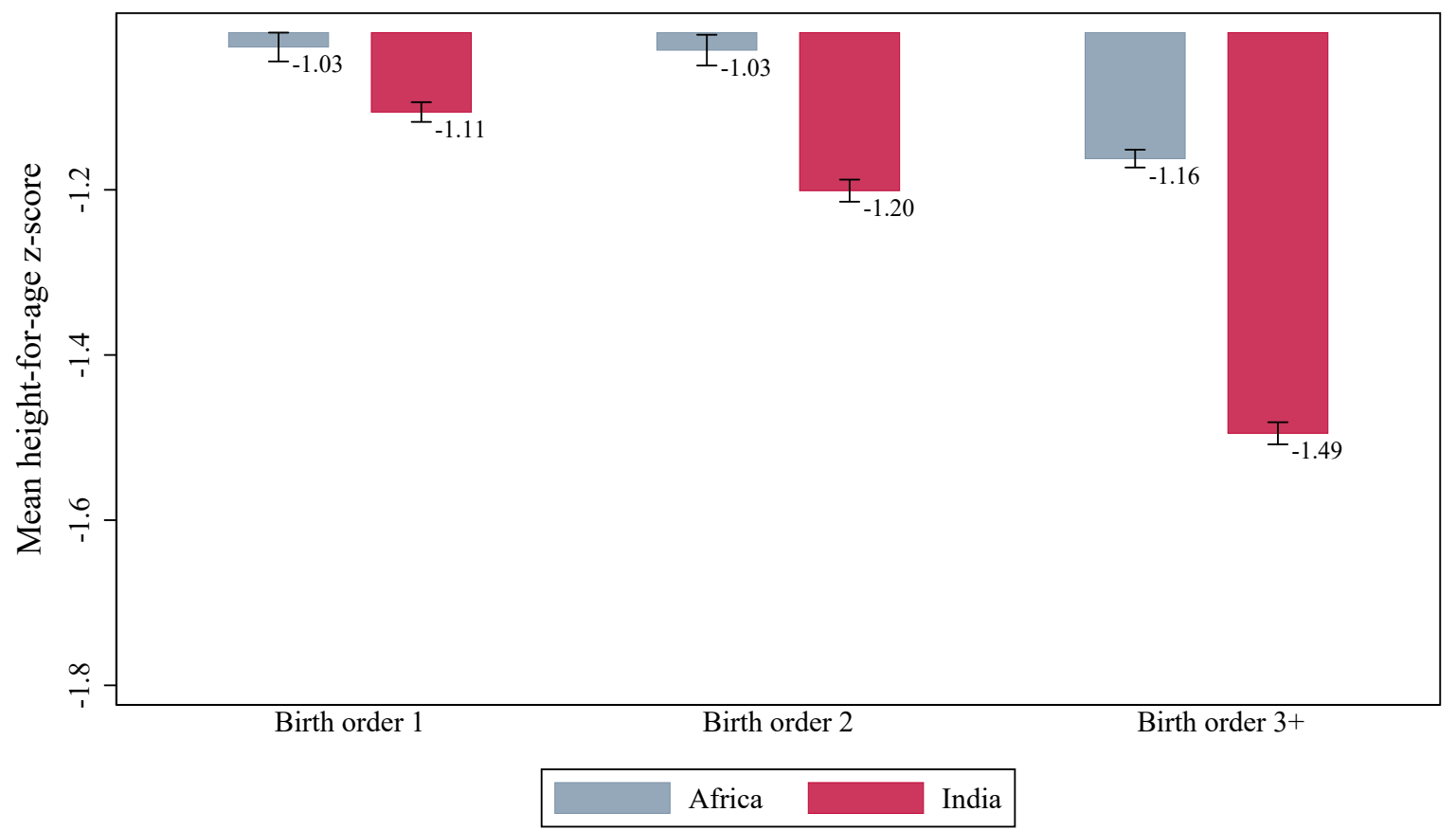

Notes: The figure depicts the mean child height-for-age z-scores for sub-Saharan Africa and India, by the birth order of the child. The mean is calculated over all children less than 60 months old.

Source: Adapted from J+P using data from DHS (ICF, 2004) and IPUMS DHS (Heger Boyle \& Sobek, 2019) 


\subsection{Child Health Inputs}

Table B.19: Child Health Inputs (2004-2010)

\begin{tabular}{|c|c|c|c|c|c|c|c|c|}
\hline & \multicolumn{4}{|c|}{ Prenatal inputs } & \multicolumn{3}{|c|}{ Postnatal inputs } & \multirow[b]{2}{*}{$\begin{array}{c}\text { Average } \\
\text { pooled } \\
\text { inputs } \\
(8)\end{array}$} \\
\hline & $\begin{array}{c}\text { Total } \\
\text { prenatal } \\
\text { visits } \\
(1)\end{array}$ & $\begin{array}{l}\text { Mother } \\
\text { took iron } \\
\text { supple- } \\
\text { ments } \\
\text { (2) }\end{array}$ & $\begin{array}{c}\text { Mother's } \\
\text { total } \\
\text { tetanus } \\
\text { shots } \\
\text { (3) }\end{array}$ & $\begin{array}{c}\text { Delivery } \\
\text { at health } \\
\text { facility } \\
\text { (4) }\end{array}$ & $\begin{array}{c}\text { Postnatal } \\
\text { check } \\
\text { within } 2 \\
\text { months } \\
\text { (5) }\end{array}$ & $\begin{array}{c}\text { Child } \\
\text { taking } \\
\text { iron pills } \\
(6)\end{array}$ & $\begin{array}{c}\text { Child's } \\
\text { total vac- } \\
\text { cinations } \\
\text { (7) }\end{array}$ & \\
\hline India $\times 2$ nd child & $\begin{array}{c}-0.525 \\
{[0.052]}\end{array}$ & $\begin{array}{c}-0.031 \\
{[0.008]}\end{array}$ & $\begin{array}{c}-0.019 \\
{[0.018]}\end{array}$ & $\begin{array}{c}-0.040 \\
{[0.006]}\end{array}$ & $\begin{array}{c}-0.008 \\
{[0.013]}\end{array}$ & $\begin{array}{c}-0.008 \\
{[0.005]}\end{array}$ & $\begin{array}{c}-0.204 \\
{[0.039]}\end{array}$ & $\begin{array}{c}-0.011 \\
{[0.003]}\end{array}$ \\
\hline India $\times 3$ rd + child & $\begin{array}{l}-1.011 \\
{[0.060]}\end{array}$ & $\begin{array}{c}-0.072 \\
{[0.009]}\end{array}$ & $\begin{array}{c}-0.036 \\
{[0.021]}\end{array}$ & $\begin{array}{c}-0.092 \\
{[0.008]}\end{array}$ & $\begin{array}{c}0.015 \\
{[0.014]}\end{array}$ & $\begin{array}{c}-0.010 \\
{[0.006]}\end{array}$ & $\begin{array}{c}-0.462 \\
{[0.051]}\end{array}$ & $\begin{array}{l}-0.033 \\
{[0.004]}\end{array}$ \\
\hline 2nd child & $\begin{array}{c}-0.182 \\
{[0.029]}\end{array}$ & $\begin{array}{c}-0.014 \\
{[0.005]}\end{array}$ & $\begin{array}{l}-0.111 \\
{[0.013]}\end{array}$ & $\begin{array}{c}-0.088 \\
{[0.004]}\end{array}$ & $\begin{array}{c}0.004 \\
{[0.010]}\end{array}$ & $\begin{array}{c}-0.004 \\
{[0.004]}\end{array}$ & $\begin{array}{c}-0.097 \\
{[0.025]}\end{array}$ & $\begin{array}{c}-0.044 \\
{[0.002]}\end{array}$ \\
\hline $3 \mathrm{rd}+$ child & $\begin{array}{c}-0.432 \\
{[0.033]}\end{array}$ & $\begin{array}{c}-0.031 \\
{[0.005]}\end{array}$ & $\begin{array}{c}-0.207 \\
{[0.014]}\end{array}$ & $\begin{array}{c}-0.133 \\
{[0.004]}\end{array}$ & $\begin{array}{c}-0.023 \\
{[0.011]}\end{array}$ & $\begin{array}{c}-0.014 \\
{[0.005]}\end{array}$ & $\begin{array}{c}-0.207 \\
{[0.030]}\end{array}$ & $\begin{array}{c}-0.071 \\
{[0.003]}\end{array}$ \\
\hline Africa mean of outcome & 3.847 & 0.622 & 1.415 & 0.472 & 0.302 & 0.113 & 6.245 & 0.380 \\
\hline India mean of outcome & 4.041 & 0.689 & 1.872 & 0.450 & 0.090 & 0.055 & 6.607 & 0.334 \\
\hline Age \& other controls & Yes & Yes & Yes & Yes & Yes & Yes & Yes & Yes \\
\hline Observations & 115,364 & 117,707 & 117,219 & 167,405 & 35,902 & 91,964 & 122,922 & 167,752 \\
\hline
\end{tabular}

Notes: Standard errors are clustered by mother and appear in brackets. Please consider the notes in Table 2.8 for further explanations.

Source: Adapted from J+P using data from DHS (Heger Boyle \& Sobek, 2019)

Table B.20: Child Health Inputs (2011-2017)

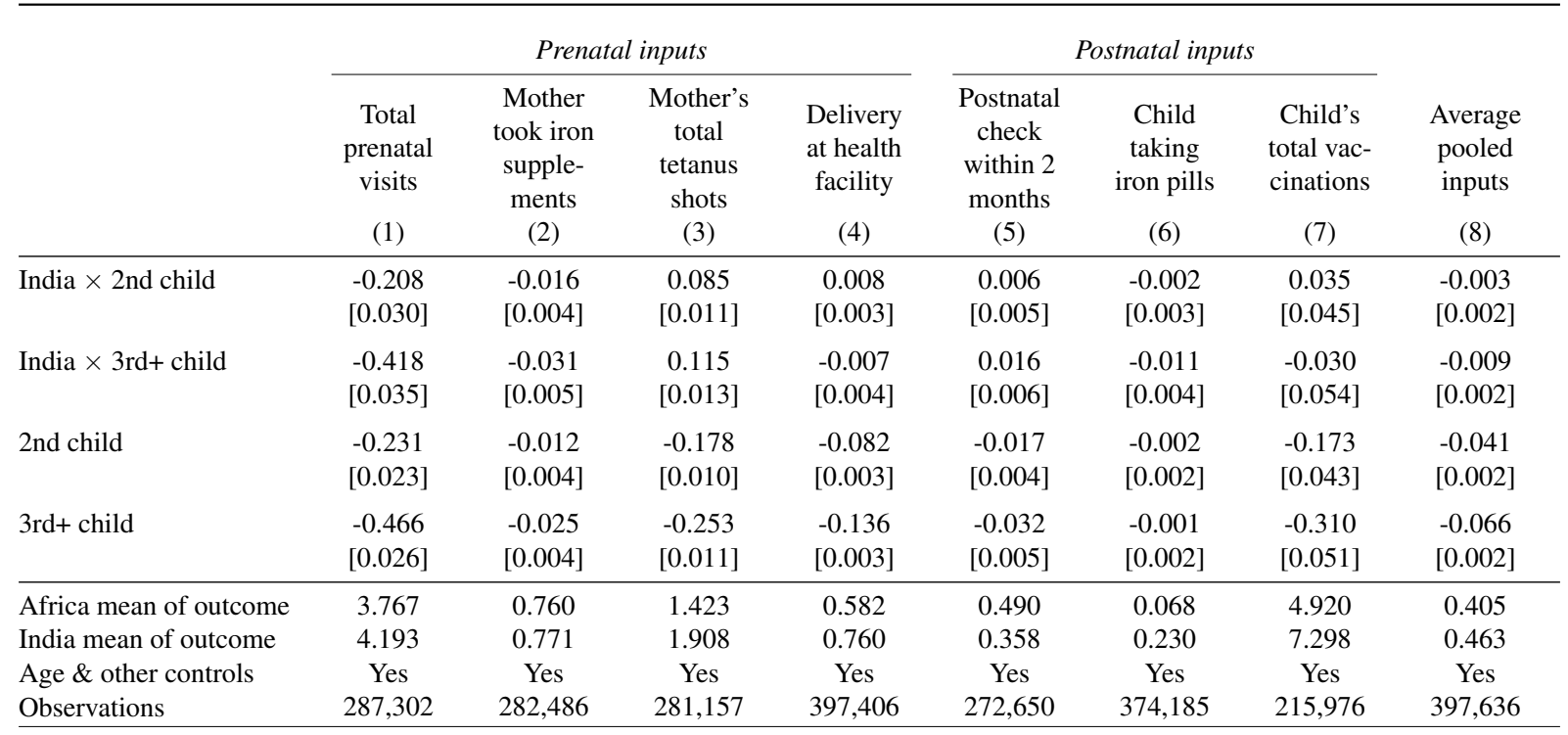

Notes: Standard errors are clustered by mother and appear in brackets. Please consider the notes in Table 2.8 for further explanations. Source: Adapted from J+P using data from IPUMS DHS (ICF, 2004) and DHS (Heger Boyle \& Sobek, 2019) 


\subsection{Cultural Norms and Child Height: Within-India Evidence}

Table B.21: Cultural Norms and Child Height: Within-India Evidence (2004-2010)

\begin{tabular}{|c|c|c|c|c|c|c|}
\hline \multirow[t]{2}{*}{ Low son preference proxy: } & \multicolumn{2}{|c|}{ Kerala \& Northeast } & \multicolumn{2}{|c|}{$\begin{array}{l}\text { Below-median } \\
\text { child sex ratio }\end{array}$} & \multicolumn{2}{|c|}{ Muslims } \\
\hline & $\begin{array}{c}\text { HFA } \\
\text { z-score } \\
\text { (1) }\end{array}$ & $\begin{array}{c}\text { WFA } \\
\text { z-score } \\
\text { (2) }\end{array}$ & $\begin{array}{c}\text { HFA } \\
\text { z-score } \\
\text { (3) }\end{array}$ & $\begin{array}{c}\text { WFA } \\
\text { z-score } \\
\text { (4) }\end{array}$ & $\begin{array}{c}\text { HFA } \\
\text { z-score } \\
\text { (5) }\end{array}$ & $\begin{array}{c}\text { WFA } \\
\text { z-score } \\
(6)\end{array}$ \\
\hline Low son pref proxy $\times 2$ nd child & $\begin{array}{c}0.078 \\
{[0.039]}\end{array}$ & $\begin{array}{c}0.008 \\
{[0.029]}\end{array}$ & $\begin{array}{c}0.077 \\
{[0.030]}\end{array}$ & $\begin{array}{c}0.038 \\
{[0.023]}\end{array}$ & $\begin{array}{l}-0.027 \\
{[0.047]}\end{array}$ & $\begin{array}{c}0.034 \\
{[0.035]}\end{array}$ \\
\hline Low son pref proxy $\times 3$ rd + child & $\begin{array}{c}0.108 \\
{[0.045]}\end{array}$ & $\begin{array}{c}0.069 \\
{[0.033]}\end{array}$ & $\begin{array}{c}0.084 \\
{[0.036]}\end{array}$ & $\begin{array}{c}0.047 \\
{[0.027]}\end{array}$ & $\begin{array}{c}0.184 \\
{[0.055]}\end{array}$ & $\begin{array}{c}0.156 \\
{[0.041]}\end{array}$ \\
\hline 2nd child & $\begin{array}{l}-0.185 \\
{[0.017]}\end{array}$ & $\begin{array}{l}-0.154 \\
{[0.013]}\end{array}$ & $\begin{array}{l}-0.205 \\
{[0.020]}\end{array}$ & $\begin{array}{l}-0.172 \\
{[0.015]}\end{array}$ & $\begin{array}{l}-0.159 \\
{[0.017]}\end{array}$ & $\begin{array}{c}-0.153 \\
{[0.013]}\end{array}$ \\
\hline 3rd+ child & $\begin{array}{c}-0.422 \\
{[0.020]}\end{array}$ & $\begin{array}{c}-0.350 \\
{[0.015]}\end{array}$ & $\begin{array}{l}-0.438 \\
{[0.024]}\end{array}$ & $\begin{array}{l}-0.364 \\
{[0.018]}\end{array}$ & $\begin{array}{c}-0.412 \\
{[0.021]}\end{array}$ & $\begin{array}{c}-0.354 \\
{[0.016]}\end{array}$ \\
\hline Low son pref group mean of outcome & -1.388 & -1.198 & -1.568 & -1.491 & -1.732 & -1.602 \\
\hline High son pref group mean of outcome & -1.710 & -1.648 & -1.712 & -1.618 & -1.691 & -1.628 \\
\hline Age \& other controls & $\begin{array}{c}\text { NFHS } \\
1-3\end{array}$ & $\begin{array}{c}\text { NFHS } \\
1-3\end{array}$ & $\begin{array}{c}\text { NFHS } \\
1-3\end{array}$ & $\begin{array}{c}\text { NFHS } \\
1-3\end{array}$ & $\begin{array}{c}\text { NFHS } \\
1-3\end{array}$ & $\begin{array}{c}\text { NFHS } \\
1-3\end{array}$ \\
\hline $\begin{array}{l}\text { Observations } \\
\mathrm{N}\end{array}$ & $\begin{array}{c}\text { Yes } \\
95,125\end{array}$ & $\begin{array}{c}\text { Yes } \\
95,125\end{array}$ & $\begin{array}{c}\text { Yes } \\
95,125\end{array}$ & $\begin{array}{c}\text { Yes } \\
95,125\end{array}$ & $\begin{array}{c}\text { Yes } \\
82,084\end{array}$ & $\begin{array}{c}\text { Yes } \\
82,084\end{array}$ \\
\hline
\end{tabular}

Notes: Standard errors are clustered by mother and appear in brackets. In all columns the sample uses NFHS 1-3. NFHS-1 only has data for children aged four years and younger, and NFHS-2 only has data for children aged 3 years and younger. All columns include child age dummies, maternal age, mother's literacy, and child age dummies, maternal age, and mother's literacy interacted with Low son pref proxy. All columns include survey and PSU fixed effects, and survey and PSU fixed effects interacted with Low son pref proxy. In columns 1-4, the main effect Low son pref proxy is absorbed by PSU fixed effects. Kerala and Northeast include Arunachal Pradesh, Assam, Kerala, Manipur,

Meghalaya, Mizoram, Nagaland, Sikkim, and Tripura. Child sex ratio is defined as the number of boys aged 0-6 years over the number of girls aged 0-6 years in the respondent's state-by-rural cell. In columns 5 and 6, the sample is restricted to Muslims and Hindus.

Source: Adapted from J+P using data from DHS (Heger Boyle \& Sobek, 2019) 
Table B.22: Cultural Norms and Child Height: Within-India Evidence (2004-2017)

\begin{tabular}{|c|c|c|c|c|c|c|}
\hline \multirow[t]{2}{*}{ Low son preference proxy: } & \multicolumn{2}{|c|}{ Kerala \& Northeast } & \multicolumn{2}{|c|}{$\begin{array}{l}\text { Below-median } \\
\text { child sex ratio }\end{array}$} & \multicolumn{2}{|c|}{ Muslims } \\
\hline & $\begin{array}{c}\text { HFA } \\
\text { z-score } \\
(1)\end{array}$ & $\begin{array}{c}\text { WFA } \\
\text { Z-score } \\
(2)\end{array}$ & $\begin{array}{c}\text { HFA } \\
\text { z-score } \\
\text { (3) }\end{array}$ & $\begin{array}{c}\text { WFA } \\
\text { z-score } \\
(4)\end{array}$ & $\begin{array}{c}\text { HFA } \\
\text { z-score } \\
\text { (5) }\end{array}$ & $\begin{array}{c}\text { WFA } \\
\text { z-score } \\
(6)\end{array}$ \\
\hline Low son pref proxy $\times 2$ nd child & $\begin{array}{c}0.044 \\
{[0.021]}\end{array}$ & $\begin{array}{c}0.033 \\
{[0.015]}\end{array}$ & $\begin{array}{c}0.032 \\
{[0.016]}\end{array}$ & $\begin{array}{c}0.035 \\
{[0.011]}\end{array}$ & $\begin{array}{c}0.034 \\
{[0.024]}\end{array}$ & $\begin{array}{r}0.043 \\
{[0.017]}\end{array}$ \\
\hline Low son pref proxy $\times 3$ rd + child & $\begin{array}{c}0.076 \\
{[0.026]}\end{array}$ & $\begin{array}{c}0.057 \\
{[0.019]}\end{array}$ & $\begin{array}{c}0.083 \\
{[0.020]}\end{array}$ & $\begin{array}{c}0.050 \\
{[0.014]}\end{array}$ & $\begin{array}{c}0.127 \\
{[0.029]}\end{array}$ & $\begin{array}{c}0.104 \\
{[0.021]}\end{array}$ \\
\hline 2nd child & $\begin{array}{l}-0.146 \\
{[0.008]}\end{array}$ & $\begin{array}{l}-0.123 \\
{[0.006]}\end{array}$ & $\begin{array}{l}-0.153 \\
{[0.010]}\end{array}$ & $\begin{array}{l}-0.135 \\
{[0.007]}\end{array}$ & $\begin{array}{l}-0.142 \\
{[0.009]}\end{array}$ & $\begin{array}{l}-0.124 \\
{[0.007]}\end{array}$ \\
\hline $3 r d+$ child & $\begin{array}{c}-0.331 \\
{[0.011]}\end{array}$ & $\begin{array}{l}-0.267 \\
{[0.008]}\end{array}$ & $\begin{array}{l}-0.356 \\
{[0.013]}\end{array}$ & $\begin{array}{l}-0.283 \\
{[0.010]}\end{array}$ & $\begin{array}{l}-0.335 \\
{[0.012]}\end{array}$ & $\begin{array}{r}-0.274 \\
{[0.009]}\end{array}$ \\
\hline Low son pref group mean of ot & -1.153 & -1.056 & -1.334 & -1.388 & -1.426 & -1.451 \\
\hline High son pref group mean of outcome & -1.416 & -1.548 & -1.408 & -1.532 & -1.405 & -1.539 \\
\hline Age \& other controls & Yes & Yes & Yes & Yes & Yes & Yes \\
\hline Observations & 322974 & 322974 & 320963 & 320963 & 280068 & 280068 \\
\hline
\end{tabular}

Notes: Standard errors are clustered by mother and appear in brackets. In all columns the sample uses NFHS 1-3 in Table 8 and NFHS 1-4 in Table 9. NFHS-1 only has data for children aged four years and younger, and NFHS-2 only has data for children aged 3 years and younger. All columns include child age dummies, maternal age, mother's literacy, and child age dummies, maternal age, and mother's literacy interacted with Low son pref proxy. All columns include survey and PSU fixed effects, and survey and PSU fixed effects interacted with Low son pref proxy. In columns 1-4, the main effect Low son pref proxy is absorbed by PSU fixed effects. Kerala and Northeast include Arunachal Pradesh, Assam, Kerala, Manipur, Meghalaya, Mizoram, Nagaland, Sikkim, and Tripura. Child sex ratio is defined as the number of boys aged 0-6 years over the number of girls aged 0-6 years in the respondent's state-by-rural cell. In columns 5 and 6 , the sample is restricted to Muslims and Hindus.

Source: Adapted from J+P using data from DHS (Heger Boyle \& Sobek, 2019) 
Table B.23: Cultural Norms and Child Height: Within-India Evidence (2015/6)

\begin{tabular}{|c|c|c|c|c|c|c|}
\hline \multirow[t]{2}{*}{ Low son preference proxy: } & \multicolumn{2}{|c|}{ Kerala \& Northeast } & \multicolumn{2}{|c|}{$\begin{array}{l}\text { Below-median } \\
\text { child sex ratio }\end{array}$} & \multicolumn{2}{|c|}{ Muslims } \\
\hline & $\begin{array}{c}\text { HFA } \\
\text { z-score } \\
(1)\end{array}$ & $\begin{array}{c}\text { WFA } \\
\text { z-score } \\
(2)\end{array}$ & $\begin{array}{c}\text { HFA } \\
\text { z-score } \\
(3)\end{array}$ & $\begin{array}{c}\text { WFA } \\
\text { z-score } \\
(4)\end{array}$ & $\begin{array}{c}\text { HFA } \\
\text { z-score } \\
(5)\end{array}$ & $\begin{array}{c}\text { WFA } \\
\text { z-score } \\
(6)\end{array}$ \\
\hline Low son pref proxy $\times 2$ nd child & $\begin{array}{c}0.030 \\
{[0.025]}\end{array}$ & $\begin{array}{c}0.047 \\
{[0.018]}\end{array}$ & $\begin{array}{c}0.020 \\
{[0.018]}\end{array}$ & $\begin{array}{c}0.037 \\
{[0.013]}\end{array}$ & $\begin{array}{c}0.044 \\
{[0.027]}\end{array}$ & $\begin{array}{c}0.039 \\
{[0.019]}\end{array}$ \\
\hline Low son pref proxy $\times 3$ rd + child & $\begin{array}{c}0.066 \\
{[0.031]}\end{array}$ & $\begin{array}{c}0.055 \\
{[0.022]}\end{array}$ & $\begin{array}{c}0.088 \\
{[0.024]}\end{array}$ & $\begin{array}{c}0.056 \\
{[0.017]}\end{array}$ & $\begin{array}{c}0.080 \\
{[0.034]}\end{array}$ & $\begin{array}{c}0.065 \\
{[0.024]}\end{array}$ \\
\hline 2nd child & $\begin{array}{c}-0.127 \\
{[0.010]}\end{array}$ & $\begin{array}{c}-0.110 \\
{[0.007]}\end{array}$ & $\begin{array}{c}-0.130 \\
{[0.012]}\end{array}$ & $\begin{array}{c}-0.118 \\
{[0.009]}\end{array}$ & $\begin{array}{c}-0.128 \\
{[0.011]}\end{array}$ & $\begin{array}{c}-0.109 \\
{[0.008]}\end{array}$ \\
\hline 3rd + child & $\begin{array}{c}-0.280 \\
{[0.013]}\end{array}$ & $\begin{array}{c}-0.222 \\
{[0.009]}\end{array}$ & $\begin{array}{c}-0.309 \\
{[0.015]}\end{array}$ & $\begin{array}{l}-0.239 \\
{[0.011]}\end{array}$ & $\begin{array}{c}-0.284 \\
{[0.014]}\end{array}$ & $\begin{array}{c}-0.225 \\
{[0.010]}\end{array}$ \\
\hline Low son pref group mean of outcome & -1.033 & -0.984 & -1.239 & -1.346 & -1.307 & -1.393 \\
\hline High son pref group mean of outcome & -1.300 & -1.508 & -1.279 & -1.495 & -1.288 & -1.503 \\
\hline Age \& other controls & Yes & Yes & Yes & Yes & Yes & Yes \\
\hline Observations & 227849 & 227849 & 225838 & 225838 & 197984 & 197984 \\
\hline
\end{tabular}

Notes: Standard errors are clustered by mother and appear in brackets. In all columns the sample uses NFHS 4 . All columns include child age dummies, maternal age, mother's literacy, and child age dummies, maternal age, and mother's literacy interacted with Low son pref proxy. All columns include survey and PSU fixed effects, and survey and PSU fixed effects interacted with Low son pref proxy. In columns 1-4, the main effect Low son pref proxy is absorbed by PSU fixed effects. Kerala and Northeast include Arunachal Pradesh, Assam, Kerala, Manipur,

Meghalaya, Mizoram, Nagaland, Sikkim, and Tripura. Child sex ratio is defined as the number of boys aged 0-6 years over the number of girls aged 0-6 years in the respondent's state-by-rural cell. In columns 5 and 6, the sample is restricted to Muslims and Hindus.

Source: Adapted from J+P using data from DHS (Heger Boyle \& Sobek, 2019) 


\subsection{Child Gender and the Birth Order Gradient in Height}

Table B.24: Child Gender and the Birth Order Gradient in Height (2004-2010)

\begin{tabular}{|c|c|c|c|c|c|c|c|c|}
\hline & $\begin{array}{c}\text { HFA } \\
\text { z-score } \\
\text { (1) }\end{array}$ & $\begin{array}{l}\text { HFA } \\
\text { z-score } \\
\text { (2) }\end{array}$ & $\begin{array}{l}\text { HFA } \\
\text { z-score } \\
\text { (3) }\end{array}$ & $\begin{array}{c}\text { WFA } \\
\text { z-score } \\
\text { (4) }\end{array}$ & $\begin{array}{c}\text { HFA } \\
\text { z-score } \\
\text { (5) }\end{array}$ & $\begin{array}{l}\text { HFA } \\
\text { z-score } \\
(6)\end{array}$ & $\begin{array}{l}\text { HFA } \\
\text { z-score } \\
\text { (7) }\end{array}$ & $\begin{array}{c}\text { WFA } \\
\text { z-score } \\
(8)\end{array}$ \\
\hline India & $\begin{array}{c}0.148 \\
{[0.026]}\end{array}$ & & & & $\begin{array}{c}-0.011 \\
{[0.014]}\end{array}$ & & & \\
\hline India $\times$ Girl & $\begin{array}{c}-0.112 \\
{[0.036]}\end{array}$ & & & & $\begin{array}{c}-0.143 \\
{[0.020]}\end{array}$ & $\begin{array}{l}-0.147 \\
{[0.019]}\end{array}$ & $\begin{array}{l}-0.098 \\
{[0.032]}\end{array}$ & $\begin{array}{l}-0.116 \\
{[0.014]}\end{array}$ \\
\hline India $\times 2$ nd child & $\begin{array}{l}-0.107 \\
{[0.036]}\end{array}$ & $\begin{array}{l}-0.153 \\
{[0.040]}\end{array}$ & $\begin{array}{l}-0.228 \\
{[0.069]}\end{array}$ & $\begin{array}{l}-0.122 \\
{[0.030]}\end{array}$ & & & & \\
\hline India $\times 3$ rd + child & $\begin{array}{c}-0.352 \\
{[0.033]}\end{array}$ & $\begin{array}{l}-0.222 \\
{[0.047]}\end{array}$ & $\begin{array}{c}-0.414 \\
{[0.097]}\end{array}$ & $\begin{array}{l}-0.176 \\
{[0.035]}\end{array}$ & & & & \\
\hline India $\times 2$ nd child $\times$ Girl & $\begin{array}{c}-0.077 \\
{[0.053]}\end{array}$ & $\begin{array}{l}-0.045 \\
{[0.057]}\end{array}$ & $\begin{array}{c}-0.024 \\
{[0.101]}\end{array}$ & $\begin{array}{l}-0.047 \\
{[0.042]}\end{array}$ & & & & \\
\hline India $\times 3$ rd + child $\times$ Girl & $\begin{array}{l}-0.051 \\
{[0.047]}\end{array}$ & $\begin{array}{l}-0.048 \\
{[0.067]}\end{array}$ & $\begin{array}{l}-0.030 \\
{[0.092]}\end{array}$ & $\begin{array}{l}-0.063 \\
{[0.049]}\end{array}$ & & & & \\
\hline 2nd child & $\begin{array}{c}0.023 \\
{[0.022]}\end{array}$ & $\begin{array}{l}-0.005 \\
{[0.026]}\end{array}$ & $\begin{array}{c}-0.202 \\
{[0.041]}\end{array}$ & $\begin{array}{c}0.006 \\
{[0.019]}\end{array}$ & & & & \\
\hline $3 \mathrm{rd}+$ child & $\begin{array}{c}-0.057 \\
{[0.019]}\end{array}$ & $\begin{array}{l}-0.113 \\
{[0.029]}\end{array}$ & $\begin{array}{c}-0.355 \\
{[0.052]}\end{array}$ & $\begin{array}{l}-0.069 \\
{[0.021]}\end{array}$ & & & & \\
\hline Africa mean of outcome & -1.351 & -1.351 & -1.351 & -0.877 & -1.351 & -1.351 & -1.351 & -0.877 \\
\hline Age \& other controls & No & Yes & No & Yes & No & Yes & No & Yes \\
\hline Mother FEs & No & No & Yes & No & No & No & Yes & No \\
\hline Observations & 168,135 & 165,623 & 83,243 & 165,623 & 168,135 & 167,765 & 83,243 & 167,765 \\
\hline
\end{tabular}

Notes: Standard errors are clustered by mother and appear in brackets. Please consider the notes in Table 2.10 for further explanations. Source: Adapted from J+P using data from DHS (Heger Boyle \& Sobek, 2019)

Table B.25: Child Gender and the Birth Order Gradient in Height (2011-2017)

\begin{tabular}{|c|c|c|c|c|c|c|c|c|}
\hline & $\begin{array}{c}\text { HFA } \\
\text { z-score } \\
(1)\end{array}$ & $\begin{array}{l}\text { HFA } \\
\text { z-score } \\
\text { (2) }\end{array}$ & $\begin{array}{c}\text { HFA } \\
\text { z-score } \\
\text { (3) }\end{array}$ & $\begin{array}{c}\text { WFA } \\
\text { z-score } \\
\text { (4) }\end{array}$ & $\begin{array}{c}\text { HFA } \\
\text { z-score } \\
\text { (5) }\end{array}$ & $\begin{array}{l}\text { HFA } \\
\text { z-score } \\
(6)\end{array}$ & $\begin{array}{c}\text { HFA } \\
\text { z-score } \\
(7)\end{array}$ & $\begin{array}{c}\text { WFA } \\
\text { z-score } \\
(8)\end{array}$ \\
\hline India & $\begin{array}{c}0.028 \\
{[0.014]}\end{array}$ & & & & $\begin{array}{l}-0.068 \\
{[0.008]}\end{array}$ & & & \\
\hline India $\times$ Girl & $\begin{array}{l}-0.091 \\
{[0.020]}\end{array}$ & & & & $\begin{array}{l}-0.076 \\
{[0.011]}\end{array}$ & $\begin{array}{l}-0.072 \\
{[0.010]}\end{array}$ & $\begin{array}{l}-0.055 \\
{[0.018]}\end{array}$ & $\begin{array}{l}-0.044 \\
{[0.008]}\end{array}$ \\
\hline India $\times$ 2nd child & $\begin{array}{l}-0.100 \\
{[0.021]}\end{array}$ & $\begin{array}{l}-0.043 \\
{[0.023]}\end{array}$ & $\begin{array}{l}-0.181 \\
{[0.040]}\end{array}$ & $\begin{array}{c}-0.062 \\
{[0.017]}\end{array}$ & & & & \\
\hline India $\times 3$ rd + child & $\begin{array}{c}-0.271 \\
{[0.019]}\end{array}$ & $\begin{array}{l}-0.066 \\
{[0.027]}\end{array}$ & $\begin{array}{c}-0.349 \\
{[0.056]}\end{array}$ & $\begin{array}{l}-0.090 \\
{[0.020]}\end{array}$ & & & & \\
\hline India $\times 2$ nd child $\times$ Girl & $\begin{array}{l}-0.011 \\
{[0.030]}\end{array}$ & $\begin{array}{l}-0.057 \\
{[0.033]}\end{array}$ & $\begin{array}{c}0.029 \\
{[0.057]}\end{array}$ & $\begin{array}{l}-0.048 \\
{[0.025]}\end{array}$ & & & & \\
\hline India $\times$ 3rd + child $\times$ Girl & $\begin{array}{l}-0.002 \\
{[0.026]}\end{array}$ & $\begin{array}{l}-0.094 \\
{[0.038]}\end{array}$ & $\begin{array}{c}0.054 \\
{[0.053]}\end{array}$ & $\begin{array}{l}-0.074 \\
{[0.028]}\end{array}$ & & & & \\
\hline 2nd child & $\begin{array}{c}0.023 \\
{[0.017]}\end{array}$ & $\begin{array}{l}-0.049 \\
{[0.019]}\end{array}$ & $\begin{array}{c}-0.156 \\
{[0.031]}\end{array}$ & $\begin{array}{l}-0.010 \\
{[0.015]}\end{array}$ & & & & \\
\hline $3 \mathrm{rd}+$ child & $\begin{array}{l}-0.067 \\
{[0.014]}\end{array}$ & $\begin{array}{l}-0.144 \\
{[0.021]}\end{array}$ & $\begin{array}{c}-0.286 \\
{[0.039]}\end{array}$ & $\begin{array}{l}-0.074 \\
{[0.016]}\end{array}$ & & & & \\
\hline Africa mean of outcome & -1.110 & -1.110 & -1.110 & -0.858 & -1.110 & -1.110 & -1.110 & -0.858 \\
\hline Age \& other controls & No & Yes & No & Yes & No & Yes & No & Yes \\
\hline Mother FEs & No & No & Yes & No & No & No & Yes & No \\
\hline Observations & 398,710 & 390,071 & 189,520 & 390,071 & 398,710 & 397,702 & 189,520 & 397,702 \\
\hline
\end{tabular}

Notes: Standard errors are clustered by mother and appear in brackets. Please consider the notes in Table 2.10 for further explanations. Source: Adapted from J+P using data from IPUMS DHS (ICF, 2004) and DHS (Heger Boyle \& Sobek, 2019) 


\subsection{Impact on Average Height - Accounting exercise}

Table B.26: Accounting Exercise Part 1: Sample Comparison (2004-2010)

\begin{tabular}{|c|c|c|c|}
\hline & & Accounting Exercise 1 & Accounting Exercise 2 \\
\hline & $\begin{array}{c}\text { HFA z-score } \\
\text { (1) }\end{array}$ & $\begin{array}{l}\text { HFA z-score } \\
\text { (2) }\end{array}$ & $\begin{array}{c}\text { HFA z-score } \\
\text { (3) }\end{array}$ \\
\hline India & $\begin{array}{c}-0.162 \\
{[0.017]}\end{array}$ & & \\
\hline Gradient proxy & & $\begin{array}{c}0.412 \\
{[0.069]}\end{array}$ & $\begin{array}{c}0.704 \\
{[0.131]}\end{array}$ \\
\hline \multicolumn{4}{|l|}{ Mean of gradient proxy } \\
\hline India & & -0.331 & -0.234 \\
\hline Africa & & -0.066 & -0.037 \\
\hline Kerala \& Northeast & & -0.229 & -0.155 \\
\hline Rest of India & & -0.358 & -0.257 \\
\hline Log GDP per capita & Yes & Yes & Yes \\
\hline Sample & Full & Africa & Africa \\
\hline Observations & 168,135 & 126,066 & 126,066 \\
\hline
\end{tabular}

Table B.27: Accounting Exercise Part 1: Sample Comparison (2011-2017)

\begin{tabular}{|c|c|c|c|}
\hline & & $\begin{array}{c}\text { Accounting } \\
\text { Exercise } 1\end{array}$ & $\begin{array}{c}\text { Accounting } \\
\text { Exercise } 2\end{array}$ \\
\hline & $\begin{array}{c}\text { HFA z-score } \\
\text { (1) }\end{array}$ & $\begin{array}{c}\text { HFA z-score } \\
\text { (2) }\end{array}$ & $\begin{array}{c}\text { HFA z-score } \\
\text { (3) }\end{array}$ \\
\hline India & $\begin{array}{c}-0.186 \\
{[0.015]}\end{array}$ & & \\
\hline Gradient proxy & & $\begin{array}{c}0.431 \\
{[0.123]}\end{array}$ & $\begin{array}{c}0.375 \\
{[0.187]}\end{array}$ \\
\hline \multicolumn{4}{|l|}{ Mean of gradient proxy } \\
\hline India & & -0.251 & -0.192 \\
\hline Africa & & -0.107 & -0.070 \\
\hline Kerala \& Northeast & & -0.182 & -0.142 \\
\hline Rest of India & & -0.264 & -0.203 \\
\hline Log GDP per capita & Yes & Yes & Yes \\
\hline Sample & Full & Africa & Africa \\
\hline Observations & 398,710 & 168,490 & 168,490 \\
\hline
\end{tabular}

Notes: Standard errors are clustered by PSU and appear in brackets. Please consider the notes in Table 2.12 for further explanations. Source: Adapted from J+P using data from IPUMS DHS (ICF, 2004) and DHS (Heger Boyle \& Sobek, 2019) 
Table B.28: Accounting Exercise Part 2: Sample Comparison (2004-2010)

Accounting Accounting

Exercise $1 \quad$ Exercise 2

Calculation 1: Share explained by birth order gradient

- India-Africa gap in birth order gradient $\quad-0.265$

$-0.197$

- India-Africa gap in birth order gradient $\times$ Gradient coeff

$-0.109 \quad-0.139$

- Explained share of India-Africa level gap in height (shown in column 1)

$67 \%$

$86 \%$

Calculation 2: Share explained by birth order gradient rooted in eldest son preference

- Rest of India - Kerala \& NE gap in birth order gradient

$-0.129$

$-0.102$

- Rest of India - Kerala \& NE gap in birth order gradient $\times$ Gradient coff

$-0.053$

$-0.072$

- Explained share of India-Africa level gap in height (shown in column 1)

$33 \%$

$44 \%$

Source: Adapted from J+P using data from DHS (Heger Boyle \& Sobek, 2019)

Table B.29: Accounting Exercise Part 2: Sample Comparison (2010-2017)

Accounting Accounting

Exercise 1

Exercise 2

Calculation 1: Share explained by birth order gradient

- India-Africa gap in birth order gradient

$-0.144 \quad-0.122$

- India-Africa gap in birth order gradient $\times$ Gradient coeff

$-0.062$

$-0.046$

- Explained share of India-Africa level gap in height (shown in column 1)

$33 \%$

$25 \%$

Calculation 2: Share explained by birth order gradient rooted in eldest son preference

- Rest of India - Kerala \& NE gap in birth order gradient

$-0.082$

$-0.061$

- Rest of India - Kerala \& NE gap in birth order gradient $\times$ Gradient coff

$-0.035$

$-0.023$

- Explained share of India-Africa level gap in height (shown in column 1)

$19 \%$

$12 \%$

Source: Adapted from J+P using data from IPUMS DHS (ICF, 2004) and DHS (Heger Boyle \& Sobek, 2019) 


\section{Replicated Results (2004-2010): Adjusted Methodology and Data from the Same Time Period}

\subsection{Summary Statistics}

Table B.30: Summary Statistics (2004-2010): Unweighted

\begin{tabular}{|c|c|c|c|c|c|}
\hline & $\begin{array}{c}\text { India } \\
\text { subsample }\end{array}$ & $\begin{array}{c}\text { Africa } \\
\text { subsample }\end{array}$ & & $\begin{array}{c}\text { India } \\
\text { subsample }\end{array}$ & $\begin{array}{c}\text { Africa } \\
\text { subsample }\end{array}$ \\
\hline Mother's age at birth (years) & $\begin{array}{l}24.75 \\
{[5.23]}\end{array}$ & $\begin{array}{l}26.96 \\
{[6.86]}\end{array}$ & Child's age (months) & $\begin{array}{c}30.20 \\
{[16.90]}\end{array}$ & $\begin{array}{c}28.27 \\
{[17.06]}\end{array}$ \\
\hline Mother's total children born & $\begin{array}{c}2.74 \\
{[1.82]}\end{array}$ & $\begin{array}{c}3.88 \\
{[2.54]}\end{array}$ & Child is a girl & $\begin{array}{c}0.48 \\
{[0.50]}\end{array}$ & $\begin{array}{c}0.50 \\
{[0.50]}\end{array}$ \\
\hline Mother's desired fertility & $\begin{array}{c}2.47 \\
{[0.96]}\end{array}$ & $\begin{array}{c}4.62 \\
{[1.47]}\end{array}$ & Child's birth order & $\begin{array}{c}2.62 \\
{[1.80]}\end{array}$ & $\begin{array}{c}3.74 \\
{[2.48]}\end{array}$ \\
\hline Mother wants more children & $\begin{array}{c}0.34 \\
{[0.47]}\end{array}$ & $\begin{array}{c}0.67 \\
{[0.46]}\end{array}$ & Child's HFA z-score & $\begin{array}{l}-1.51 \\
{[1.81]}\end{array}$ & $\begin{array}{l}-1.35 \\
{[1.94]}\end{array}$ \\
\hline Mother completed her fertility & $\begin{array}{c}0.67 \\
{[0.47]}\end{array}$ & $\begin{array}{c}0.33 \\
{[0.47]}\end{array}$ & Child is stunted & $\begin{array}{c}0.40 \\
{[0.49]}\end{array}$ & $\begin{array}{c}0.38 \\
{[0.48]}\end{array}$ \\
\hline Mother is literate & $\begin{array}{c}0.58 \\
{[0.49]}\end{array}$ & $\begin{array}{c}0.49 \\
{[0.50]}\end{array}$ & Child's WFA z-score & $\begin{array}{l}-1.53 \\
{[1.33]}\end{array}$ & $\begin{array}{l}-0.88 \\
{[1.42]}\end{array}$ \\
\hline Mother's height (meters) & $\begin{array}{c}1.52 \\
{[0.06]}\end{array}$ & $\begin{array}{c}1.58 \\
{[0.07]}\end{array}$ & Child's hemoglobin level (g/dl) & $\begin{array}{l}10.28 \\
{[1.57]}\end{array}$ & $\begin{array}{l}10.15 \\
{[1.68]}\end{array}$ \\
\hline Mother took iron supplements & $\begin{array}{c}0.69 \\
{[0.46]}\end{array}$ & $\begin{array}{c}0.62 \\
{[0.49]}\end{array}$ & Child is deceased & $\begin{array}{c}0.05 \\
{[0.22]}\end{array}$ & $\begin{array}{c}0.07 \\
{[0.26]}\end{array}$ \\
\hline Mother's total tetanus shots & $\begin{array}{c}1.87 \\
{[0.94]}\end{array}$ & $\begin{array}{c}1.41 \\
{[1.20]}\end{array}$ & Child taking iron pills & $\begin{array}{c}0.06 \\
{[0.23]}\end{array}$ & $\begin{array}{c}0.11 \\
{[0.32]}\end{array}$ \\
\hline Total prenatal visits & $\begin{array}{c}4.04 \\
{[3.48]}\end{array}$ & $\begin{array}{c}3.85 \\
{[3.07]}\end{array}$ & Child's total vaccinations & $\begin{array}{c}6.61 \\
{[2.80]}\end{array}$ & $\begin{array}{c}6.24 \\
{[3.12]}\end{array}$ \\
\hline Delivery at health facility & $\begin{array}{c}0.45 \\
{[0.50]}\end{array}$ & $\begin{array}{c}0.47 \\
{[0.50]}\end{array}$ & Birth spacing (months) & $\begin{array}{c}36.16 \\
{[20.32]}\end{array}$ & $\begin{array}{c}38.69 \\
{[20.63]}\end{array}$ \\
\hline Postnatal check within 2 months & $\begin{array}{c}0.09 \\
{[0.29]}\end{array}$ & $\begin{array}{c}0.30 \\
{[0.46]}\end{array}$ & Diarrhea in last 2 weeks & $\begin{array}{c}0.09 \\
{[0.29]}\end{array}$ & $\begin{array}{c}0.16 \\
{[0.36]}\end{array}$ \\
\hline Average pooled inputs & $\begin{array}{c}0.33 \\
{[0.28]}\end{array}$ & $\begin{array}{c}0.38 \\
{[0.30]}\end{array}$ & Open defecation & $\begin{array}{c}0.46 \\
{[0.50]}\end{array}$ & $\begin{array}{c}0.32 \\
{[0.47]}\end{array}$ \\
\hline Percent non-resident among children & $\begin{array}{c}0.02 \\
{[0.04]}\end{array}$ & $\begin{array}{c}0.10 \\
{[0.08]}\end{array}$ & Number of PSUs & 3,822 & 10,366 \\
\hline Number of adult females in household & $\begin{array}{c}1.85 \\
{[1.09]}\end{array}$ & $\begin{array}{c}1.60 \\
{[1.06]}\end{array}$ & Main sample of children & 42,069 & 126,066 \\
\hline Log GDP per capita (in child's birth year) & $\begin{array}{c}7.78 \\
{[0.10]}\end{array}$ & $\begin{array}{c}7.36 \\
{[0.65]}\end{array}$ & & & \\
\hline
\end{tabular}

Notes: The means of the specified variables are calculated separately for the India and Africa subsamples. Standard deviations appear in brackets. Please consider the notes in Table 2.3 for further explanations.

Source: Adapted from J+P using data from DHS (Heger Boyle \& Sobek, 2019) 
Table B.31: Summary Statistics (2004-2010): Weighted India

\begin{tabular}{|c|c|c|c|c|c|}
\hline & $\begin{array}{c}\text { India } \\
\text { subsample }\end{array}$ & $\begin{array}{c}\text { Africa } \\
\text { subsample }\end{array}$ & & $\begin{array}{c}\text { India } \\
\text { subsample }\end{array}$ & $\begin{array}{c}\text { Africa } \\
\text { subsample }\end{array}$ \\
\hline Mother's age at birth (years) & $\begin{array}{l}24.25 \\
{[5.19]}\end{array}$ & $\begin{array}{l}26.96 \\
{[6.86]}\end{array}$ & Child's age (months) & $\begin{array}{c}30.18 \\
{[17.01]}\end{array}$ & $\begin{array}{c}28.27 \\
{[17.06]}\end{array}$ \\
\hline Mother's total children born & $\begin{array}{c}2.87 \\
{[1.91]}\end{array}$ & $\begin{array}{c}3.88 \\
{[2.54]}\end{array}$ & Child is a girl & $\begin{array}{c}0.48 \\
{[0.50]}\end{array}$ & $\begin{array}{c}0.50 \\
{[0.50]}\end{array}$ \\
\hline Mother's desired fertility & $\begin{array}{c}2.45 \\
{[0.89]}\end{array}$ & $\begin{array}{c}4.62 \\
{[1.47]}\end{array}$ & Child's birth order & $\begin{array}{c}2.74 \\
{[1.88]}\end{array}$ & $\begin{array}{c}3.74 \\
{[2.48]}\end{array}$ \\
\hline Mother wants more children & $\begin{array}{c}0.34 \\
{[0.47]}\end{array}$ & $\begin{array}{c}0.67 \\
{[0.46]}\end{array}$ & Child's HFA z-score & $\begin{array}{l}-1.67 \\
{[1.80]}\end{array}$ & $\begin{array}{l}-1.35 \\
{[1.94]}\end{array}$ \\
\hline Mother completed her fertility & $\begin{array}{c}0.67 \\
{[0.47]}\end{array}$ & $\begin{array}{c}0.33 \\
{[0.47]}\end{array}$ & Child is stunted & $\begin{array}{c}0.45 \\
{[0.50]}\end{array}$ & $\begin{array}{c}0.38 \\
{[0.48]}\end{array}$ \\
\hline Mother is literate & $\begin{array}{c}0.49 \\
{[0.50]}\end{array}$ & $\begin{array}{c}0.49 \\
{[0.50]}\end{array}$ & Child's WFA z-score & $\begin{array}{l}-1.70 \\
{[1.30]}\end{array}$ & $\begin{array}{c}-0.88 \\
{[1.42]}\end{array}$ \\
\hline Mother's height (meters) & $\begin{array}{c}1.52 \\
{[0.06]}\end{array}$ & $\begin{array}{c}1.58 \\
{[0.07]}\end{array}$ & Child's hemoglobin level (g/dl) & $\begin{array}{l}10.10 \\
{[1.56]}\end{array}$ & $\begin{array}{l}10.15 \\
{[1.68]}\end{array}$ \\
\hline Mother took iron supplements & $\begin{array}{c}0.66 \\
{[0.47]}\end{array}$ & $\begin{array}{c}0.62 \\
{[0.49]}\end{array}$ & Child is deceased & $\begin{array}{c}0.06 \\
{[0.23]}\end{array}$ & $\begin{array}{c}0.07 \\
{[0.26]}\end{array}$ \\
\hline Mother's total tetanus shots & $\begin{array}{c}1.86 \\
{[0.95]}\end{array}$ & $\begin{array}{c}1.41 \\
{[1.20]}\end{array}$ & Child taking iron pills & $\begin{array}{c}0.05 \\
{[0.21]}\end{array}$ & $\begin{array}{c}0.11 \\
{[0.32]}\end{array}$ \\
\hline Total prenatal visits & $\begin{array}{c}3.49 \\
{[3.32]}\end{array}$ & $\begin{array}{c}3.85 \\
{[3.07]}\end{array}$ & Child's total vaccinations & $\begin{array}{c}6.42 \\
{[2.75]}\end{array}$ & $\begin{array}{c}6.24 \\
{[3.12]}\end{array}$ \\
\hline Delivery at health facility & $\begin{array}{c}0.39 \\
{[0.49]}\end{array}$ & $\begin{array}{c}0.47 \\
{[0.50]}\end{array}$ & Birth spacing (months) & $\begin{array}{c}35.43 \\
{[19.42]}\end{array}$ & $\begin{array}{c}38.69 \\
{[20.63]}\end{array}$ \\
\hline Postnatal check within 2 months & $\begin{array}{c}0.08 \\
{[0.28]}\end{array}$ & $\begin{array}{c}0.30 \\
{[0.46]}\end{array}$ & Diarrhea in last 2 weeks & $\begin{array}{c}0.09 \\
{[0.29]}\end{array}$ & $\begin{array}{c}0.16 \\
{[0.36]}\end{array}$ \\
\hline Average pooled inputs & $\begin{array}{c}0.30 \\
{[0.27]}\end{array}$ & $\begin{array}{c}0.38 \\
{[0.30]}\end{array}$ & Open defecation & $\begin{array}{c}0.63 \\
{[0.48]}\end{array}$ & $\begin{array}{c}0.32 \\
{[0.47]}\end{array}$ \\
\hline Percent non-resident among children & $\begin{array}{c}0.02 \\
{[0.03]}\end{array}$ & $\begin{array}{c}0.10 \\
{[0.08]}\end{array}$ & Number of PSUs & 3,822 & 10,366 \\
\hline Number of adult females in household & $\begin{array}{c}1.89 \\
{[1.11]}\end{array}$ & $\begin{array}{c}1.60 \\
{[1.06]}\end{array}$ & Main sample of children & 42,069 & 126,066 \\
\hline Log GDP per capita (in child's birth year) & $\begin{array}{c}7.77 \\
{[0.10]}\end{array}$ & $\begin{array}{c}7.36 \\
{[0.65]}\end{array}$ & & & \\
\hline
\end{tabular}

Notes: The means of the specified variables are calculated separately for the India and Africa subsamples. Standard deviations appear in brackets. Please consider the notes in Table 2.3 for further explanations.

Source: Adapted from J+P using data from DHS (Heger Boyle \& Sobek, 2019) 
Table B.32: Summary Statistics (2004-2010): Weighted

\begin{tabular}{|c|c|c|c|c|c|}
\hline & $\begin{array}{c}\text { India } \\
\text { subsample }\end{array}$ & $\begin{array}{c}\text { Africa } \\
\text { subsample }\end{array}$ & & $\begin{array}{c}\text { India } \\
\text { subsample }\end{array}$ & $\begin{array}{c}\text { Africa } \\
\text { subsample }\end{array}$ \\
\hline Mother's age at birth (years) & $\begin{array}{l}24.25 \\
{[5.19]}\end{array}$ & $\begin{array}{l}26.95 \\
{[6.85]}\end{array}$ & Child's age (months) & $\begin{array}{c}30.18 \\
{[17.01]}\end{array}$ & $\begin{array}{c}28.26 \\
{[17.05]}\end{array}$ \\
\hline Mother's total children born & $\begin{array}{c}2.87 \\
{[1.91]}\end{array}$ & $\begin{array}{c}3.90 \\
{[2.55]}\end{array}$ & Child is a girl & $\begin{array}{c}0.48 \\
{[0.50]}\end{array}$ & $\begin{array}{c}0.50 \\
{[0.50]}\end{array}$ \\
\hline Mother's desired fertility & $\begin{array}{c}2.45 \\
{[0.89]}\end{array}$ & $\begin{array}{c}4.62 \\
{[1.46]}\end{array}$ & Child's birth order & $\begin{array}{c}2.74 \\
{[1.88]}\end{array}$ & $\begin{array}{c}3.75 \\
{[2.48]}\end{array}$ \\
\hline Mother wants more children & $\begin{array}{c}0.34 \\
{[0.47]}\end{array}$ & $\begin{array}{c}0.67 \\
{[0.46]}\end{array}$ & Child's HFA z-score & $\begin{array}{l}-1.67 \\
{[1.80]}\end{array}$ & $\begin{array}{l}-1.36 \\
{[1.96]}\end{array}$ \\
\hline Mother completed her fertility & $\begin{array}{c}0.67 \\
{[0.47]}\end{array}$ & $\begin{array}{c}0.33 \\
{[0.47]}\end{array}$ & Child is stunted & $\begin{array}{c}0.45 \\
{[0.50]}\end{array}$ & $\begin{array}{c}0.38 \\
{[0.49]}\end{array}$ \\
\hline Mother is literate & $\begin{array}{c}0.49 \\
{[0.50]}\end{array}$ & $\begin{array}{c}0.48 \\
{[0.50]}\end{array}$ & Child's WFA z-score & $\begin{array}{l}-1.70 \\
{[1.30]}\end{array}$ & $\begin{array}{l}-0.89 \\
{[1.44]}\end{array}$ \\
\hline Mother's height (meters) & $\begin{array}{c}1.52 \\
{[0.06]}\end{array}$ & $\begin{array}{c}1.58 \\
{[0.07]}\end{array}$ & Child's hemoglobin level (g/dl) & $\begin{array}{l}10.10 \\
{[1.56]}\end{array}$ & $\begin{array}{l}10.11 \\
{[1.70]}\end{array}$ \\
\hline Mother took iron supplements & $\begin{array}{c}0.66 \\
{[0.47]}\end{array}$ & $\begin{array}{c}0.62 \\
{[0.49]}\end{array}$ & Child is deceased & $\begin{array}{c}0.06 \\
{[0.23]}\end{array}$ & $\begin{array}{c}0.07 \\
{[0.26]}\end{array}$ \\
\hline Mother's total tetanus shots & $\begin{array}{c}1.86 \\
{[0.95]}\end{array}$ & $\begin{array}{c}1.41 \\
{[1.21]}\end{array}$ & Child taking iron pills & $\begin{array}{c}0.05 \\
{[0.21]}\end{array}$ & $\begin{array}{c}0.13 \\
{[0.34]}\end{array}$ \\
\hline Total prenatal visits & $\begin{array}{c}3.49 \\
{[3.32]}\end{array}$ & $\begin{array}{c}3.87 \\
{[3.28]}\end{array}$ & Child's total vaccinations & $\begin{array}{c}6.42 \\
{[2.75]}\end{array}$ & $\begin{array}{c}6.14 \\
{[3.17]}\end{array}$ \\
\hline Delivery at health facility & $\begin{array}{c}0.39 \\
{[0.49]}\end{array}$ & $\begin{array}{c}0.47 \\
{[0.50]}\end{array}$ & Birth spacing (months) & $\begin{array}{c}35.43 \\
{[19.42]}\end{array}$ & $\begin{array}{c}38.43 \\
{[20.43]}\end{array}$ \\
\hline Postnatal check within 2 months & $\begin{array}{c}0.08 \\
{[0.28]}\end{array}$ & $\begin{array}{c}0.32 \\
{[0.47]}\end{array}$ & Diarrhea in last 2 weeks & $\begin{array}{c}0.09 \\
{[0.29]}\end{array}$ & $\begin{array}{c}0.16 \\
{[0.37]}\end{array}$ \\
\hline Average pooled inputs & $\begin{array}{c}0.30 \\
{[0.27]}\end{array}$ & $\begin{array}{c}0.38 \\
{[0.31]}\end{array}$ & Open defecation & $\begin{array}{c}0.63 \\
{[0.48]}\end{array}$ & $\begin{array}{c}0.32 \\
{[0.47]}\end{array}$ \\
\hline Percent non-resident among children & $\begin{array}{c}0.02 \\
{[0.03]}\end{array}$ & $\begin{array}{c}0.09 \\
{[0.08]}\end{array}$ & Number of PSUs & 3,822 & 10,366 \\
\hline Number of adult females in household & $\begin{array}{c}1.89 \\
{[1.11]}\end{array}$ & $\begin{array}{c}1.59 \\
{[1.05]}\end{array}$ & Main sample of children & 42,069 & 126,066 \\
\hline Log GDP per capita (in child's birth year) & $\begin{array}{c}7.77 \\
{[0.10]}\end{array}$ & $\begin{array}{c}7.35 \\
{[0.67]}\end{array}$ & & & \\
\hline
\end{tabular}

Notes: The means of the specified variables are calculated separately for the India and Africa subsamples. Standard deviations appear in brackets. Please consider the notes in Table 2.3 for further explanations.

Source: Adapted from J+P using data from DHS (Heger Boyle \& Sobek, 2019) 
Figure B.3: Child Height versus National GDP (2004-2010): Unweighted vs Weighted Replication (2004-2010): Unweighted

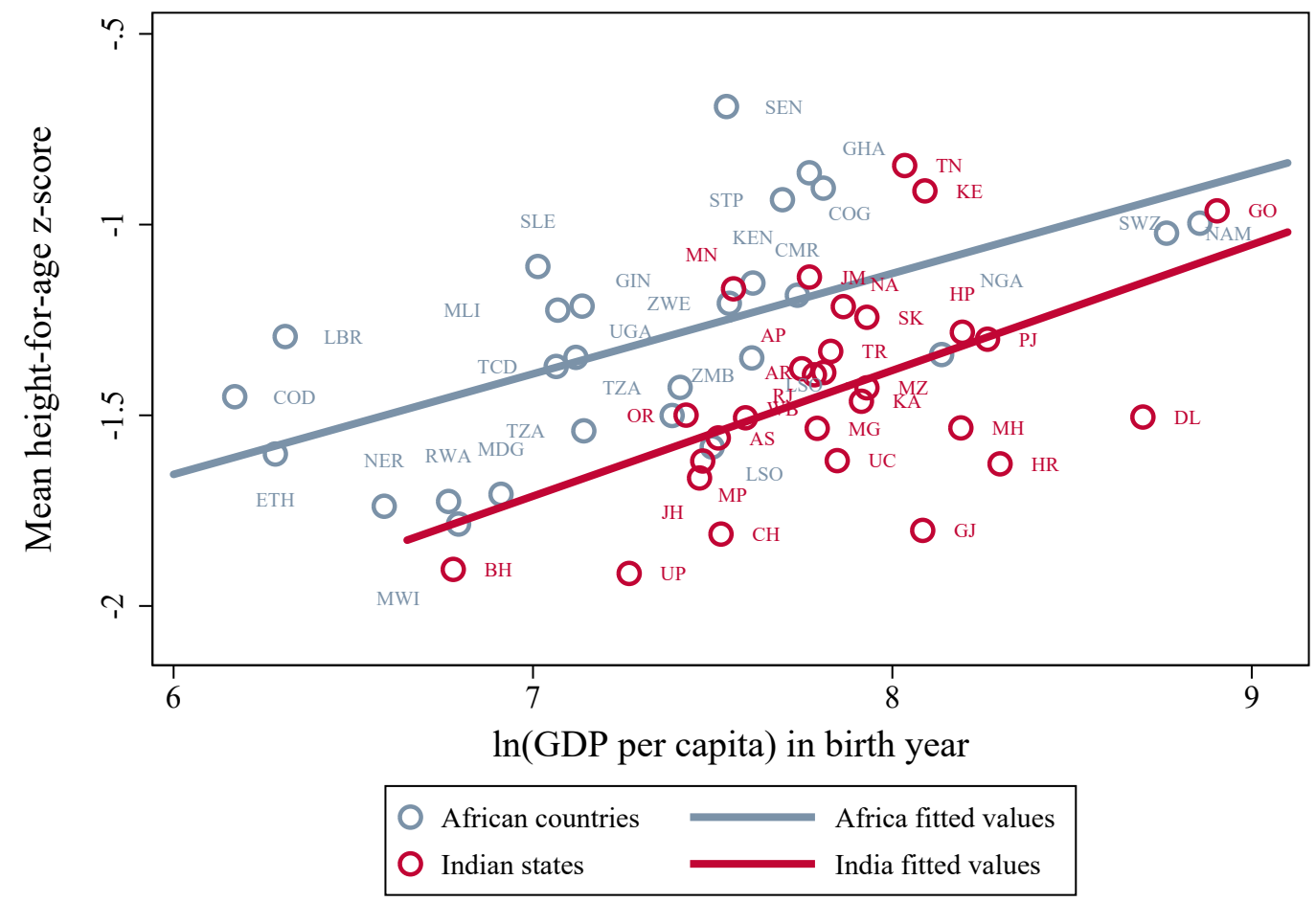

Replication (2004-2010): Weighted India

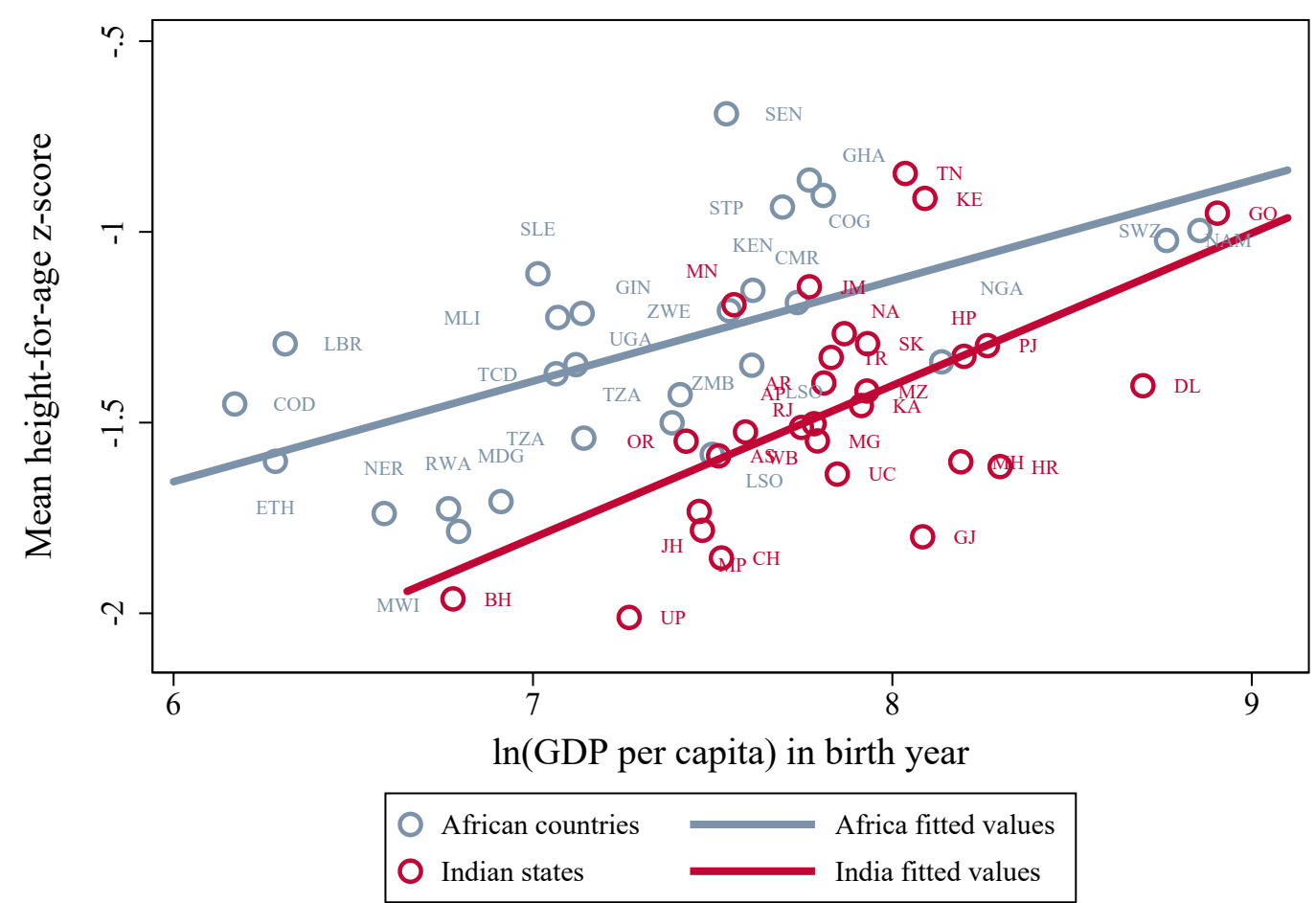

Notes: The light and dark circles represent sub-Saharan African countries and Indian states, respectively. The averages are calculated over all children less than 60 months old. The lines represent the best linear fit for each sample.

Source: Adapted from J+P using data from Penn World Table 9.0, Penn World Table 9.1, and the Handbook of Statistics on Indian States (Robert C. Feenstra, 2016, 2019; Reserve Bank of India, 2019) 
Figure B.4: Child Height versus National GDP (2004-2010): Weighted

Replication (2004-2010): Weighted

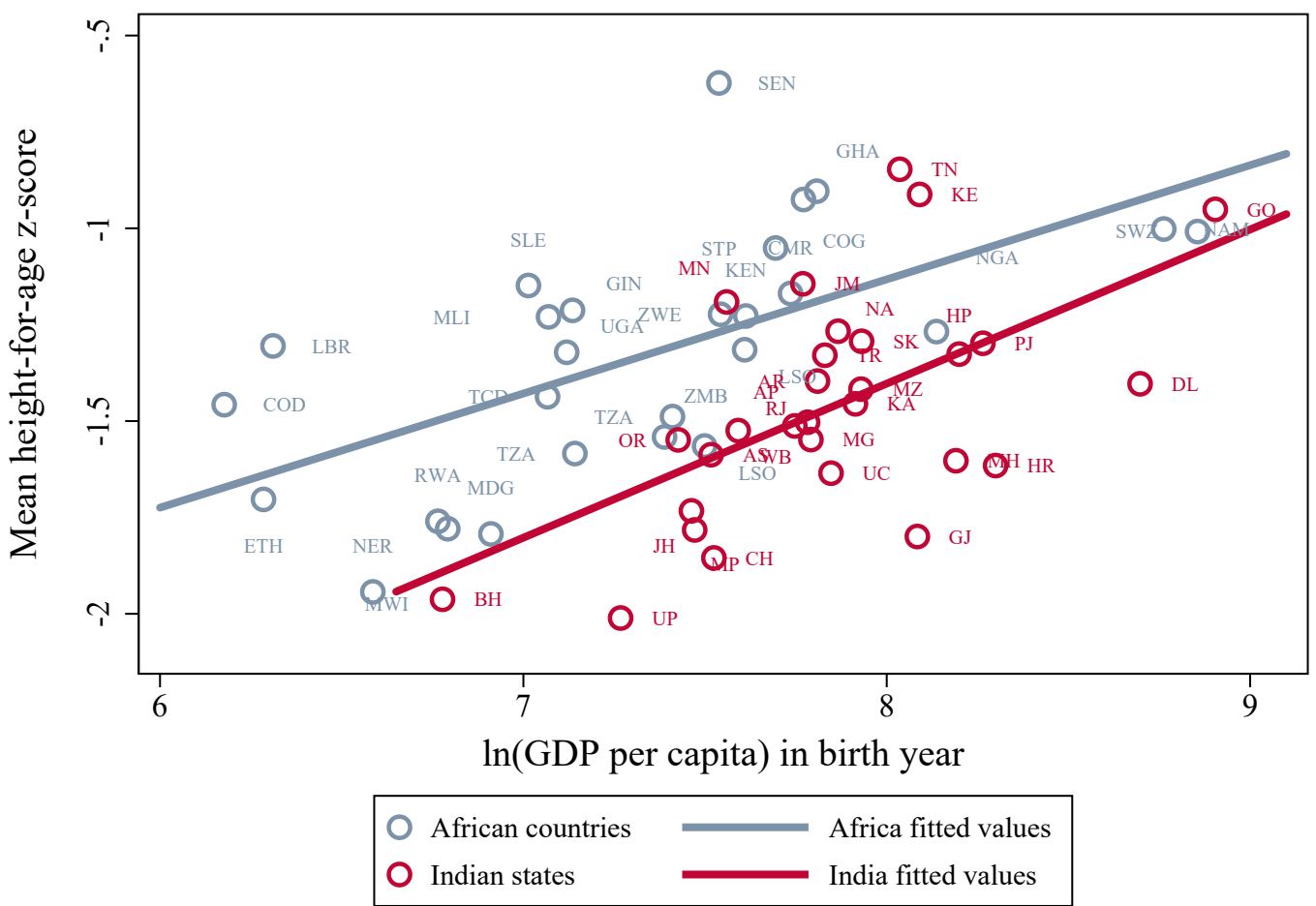

Notes: The light and dark circles represent sub-Saharan African countries and Indian states, respectively. The averages are calculated over all children less than 60 months old. The lines represent the best linear fit for each sample.

Source: Adapted from J+P using data from Penn World Table 9.0, Penn World Table 9.1, and the Handbook of Statistics on Indian States (Robert C. Feenstra, 2016, 2019; Reserve Bank of India, 2019) 


\subsection{India's Differential Birth Order Gradient in Child Height and Re- lated Outcomes}

Table B.33: India's Differential Birth Order Gradient in Child Height and Related Outcomes (2004-2010): Unweighted

\begin{tabular}{|c|c|c|c|c|c|c|c|c|c|}
\hline & $\begin{array}{l}\text { HFA } \\
\text { Z- } \\
\text { score } \\
(1)\end{array}$ & $\begin{array}{l}\text { HFA } \\
\text { Z- } \\
\text { score } \\
(2)\end{array}$ & $\begin{array}{l}\text { HFA } \\
\text { z- } \\
\text { score } \\
(3)\end{array}$ & $\begin{array}{l}\text { HFA } \\
\text { Z- } \\
\text { score } \\
(4)\end{array}$ & $\begin{array}{l}\text { HFA } \\
\text { Z- } \\
\text { score } \\
(5)\end{array}$ & $\begin{array}{l}\text { Stunted } \\
\text { (6) }\end{array}$ & $\begin{array}{l}\text { WFA } \\
\text { z- } \\
\text { score } \\
(7)\end{array}$ & $\begin{array}{c}\mathrm{Hb} \\
\text { level } \\
(8)\end{array}$ & $\begin{array}{l}\text { Deceasec } \\
\text { (9) }\end{array}$ \\
\hline India & $\begin{array}{l}-0.083 \\
{[0.011]}\end{array}$ & $\begin{array}{c}0.092 \\
{[0.018]}\end{array}$ & & & & & & & \\
\hline India $\times 2$ nd child & & $\begin{array}{l}-0.144 \\
{[0.025]}\end{array}$ & $\begin{array}{l}-0.161 \\
{[0.027]}\end{array}$ & $\begin{array}{l}-0.110 \\
{[0.063]}\end{array}$ & $\begin{array}{l}-0.243 \\
{[0.048]}\end{array}$ & $\begin{array}{c}0.051 \\
{[0.007]}\end{array}$ & $\begin{array}{l}-0.147 \\
{[0.020]}\end{array}$ & $\begin{array}{l}-0.094 \\
{[0.030]}\end{array}$ & $\begin{array}{c}0.003 \\
{[0.004]}\end{array}$ \\
\hline India $\times 3$ rd + child & & $\begin{array}{l}-0.377 \\
{[0.024]}\end{array}$ & $\begin{array}{l}-0.228 \\
{[0.032]}\end{array}$ & $\begin{array}{l}-0.194 \\
{[0.092]}\end{array}$ & $\begin{array}{l}-0.436 \\
{[0.085]}\end{array}$ & $\begin{array}{c}0.064 \\
{[0.009]}\end{array}$ & $\begin{array}{l}-0.199 \\
{[0.024]}\end{array}$ & $\begin{array}{l}-0.158 \\
{[0.036]}\end{array}$ & $\begin{array}{c}0.002 \\
{[0.004]}\end{array}$ \\
\hline 2nd child & & $\begin{array}{c}0.024 \\
{[0.015]}\end{array}$ & $\begin{array}{l}-0.011 \\
{[0.017]}\end{array}$ & $\begin{array}{l}-0.096 \\
{[0.053]}\end{array}$ & $\begin{array}{l}-0.167 \\
{[0.027]}\end{array}$ & $\begin{array}{c}0.009 \\
{[0.004]}\end{array}$ & $\begin{array}{c}0.010 \\
{[0.012]}\end{array}$ & $\begin{array}{l}-0.010 \\
{[0.022]}\end{array}$ & $\begin{array}{l}-0.014 \\
{[0.002]}\end{array}$ \\
\hline $3 \mathrm{rd}+$ child & & $\begin{array}{l}-0.065 \\
{[0.013]}\end{array}$ & $\begin{array}{l}-0.117 \\
{[0.019]}\end{array}$ & $\begin{array}{l}-0.168 \\
{[0.074]}\end{array}$ & $\begin{array}{l}-0.334 \\
{[0.044]}\end{array}$ & $\begin{array}{c}0.036 \\
{[0.005]}\end{array}$ & $\begin{array}{l}-0.063 \\
{[0.014]}\end{array}$ & $\begin{array}{l}-0.038 \\
{[0.025]}\end{array}$ & $\begin{array}{l}-0.011 \\
{[0.003]}\end{array}$ \\
\hline Africa mean of outcome & -1.351 & -1.351 & -1.351 & -1.351 & -1.351 & 0.375 & -0.877 & 10.149 & 0.072 \\
\hline Child's age dummies $\times$ India & No & No & Yes & Yes & Yes & Yes & Yes & Yes & Yes \\
\hline Mother's literacy $\times$ India & No & No & Yes & Yes & No & Yes & Yes & Yes & Yes \\
\hline Mother's age at birth $\times$ India & No & No & Yes & Yes & No & Yes & Yes & Yes & Yes \\
\hline PSU FEs & No & No & Yes & Yes & No & Yes & Yes & Yes & Yes \\
\hline Mother FEs & No & No & No & No & Yes & No & No & No & No \\
\hline Completed fertility sample & No & No & No & Yes & No & No & No & No & No \\
\hline Observations & 168,135 & 168,135 & 167,765 & 66,574 & 83,243 & 167,765 & 167,765 & 88,893 & 199,514 \\
\hline
\end{tabular}

Notes: Standard errors are clustered by mother and appear in brackets. Please consider the notes in Table 2.8 for further explanations.

Source: Adapted from J+P using data from DHS (Heger Boyle \& Sobek, 2019) 
Table B.34: India's Differential Birth Order Gradient in Child Height and Related Outcomes (2004-2010): Weighted India

\begin{tabular}{|c|c|c|c|c|c|c|c|c|c|}
\hline & $\begin{array}{l}\text { HFA } \\
\text { Z- } \\
\text { score } \\
(1)\end{array}$ & $\begin{array}{l}\text { HFA } \\
\text { Z- } \\
\text { score } \\
(2)\end{array}$ & $\begin{array}{l}\text { HFA } \\
\text { Z- } \\
\text { score } \\
(3)\end{array}$ & $\begin{array}{l}\text { HFA } \\
\text { Z- } \\
\text { score } \\
(4)\end{array}$ & $\begin{array}{l}\text { HFA } \\
\text { Z- } \\
\text { score } \\
(5)\end{array}$ & $\begin{array}{l}\text { Stunted } \\
\text { (6) }\end{array}$ & $\begin{array}{l}\text { WFA } \\
\text { Z- } \\
\text { score } \\
(7)\end{array}$ & $\begin{array}{c}\mathrm{Hb} \\
\text { level } \\
(8)\end{array}$ & $\begin{array}{l}\text { Deceasec } \\
\text { (9) }\end{array}$ \\
\hline India & $\begin{array}{l}-0.083 \\
{[0.011]}\end{array}$ & $\begin{array}{l}-0.086 \\
{[0.021]}\end{array}$ & & & & & & & \\
\hline India $\times 2$ nd child & & $\begin{array}{l}-0.108 \\
{[0.029]}\end{array}$ & $\begin{array}{l}-0.138 \\
{[0.032]}\end{array}$ & $\begin{array}{l}-0.110 \\
{[0.068]}\end{array}$ & $\begin{array}{l}-0.275 \\
{[0.057]}\end{array}$ & $\begin{array}{c}0.047 \\
{[0.009]}\end{array}$ & $\begin{array}{l}-0.136 \\
{[0.024]}\end{array}$ & $\begin{array}{l}-0.094 \\
{[0.035]}\end{array}$ & $\begin{array}{l}-0.005 \\
{[0.005]}\end{array}$ \\
\hline India $\times 3$ rd + child & & $\begin{array}{l}-0.360 \\
{[0.029]}\end{array}$ & $\begin{array}{l}-0.203 \\
{[0.039]}\end{array}$ & $\begin{array}{l}-0.197 \\
{[0.102]}\end{array}$ & $\begin{array}{l}-0.471 \\
{[0.102]}\end{array}$ & $\begin{array}{c}0.059 \\
{[0.011]}\end{array}$ & $\begin{array}{l}-0.190 \\
{[0.029]}\end{array}$ & $\begin{array}{l}-0.163 \\
{[0.042]}\end{array}$ & $\begin{array}{l}-0.005 \\
{[0.006]}\end{array}$ \\
\hline 2nd child & & $\begin{array}{c}0.024 \\
{[0.015]}\end{array}$ & $\begin{array}{l}-0.011 \\
{[0.017]}\end{array}$ & $\begin{array}{l}-0.096 \\
{[0.053]}\end{array}$ & $\begin{array}{l}-0.167 \\
{[0.027]}\end{array}$ & $\begin{array}{c}0.009 \\
{[0.004]}\end{array}$ & $\begin{array}{c}0.010 \\
{[0.012]}\end{array}$ & $\begin{array}{l}-0.010 \\
{[0.022]}\end{array}$ & $\begin{array}{l}-0.014 \\
{[0.002]}\end{array}$ \\
\hline 3rd+ child & & $\begin{array}{l}-0.065 \\
{[0.013]}\end{array}$ & $\begin{array}{l}-0.117 \\
{[0.019]}\end{array}$ & $\begin{array}{l}-0.168 \\
{[0.074]}\end{array}$ & $\begin{array}{l}-0.334 \\
{[0.044]}\end{array}$ & $\begin{array}{c}0.036 \\
{[0.005]}\end{array}$ & $\begin{array}{l}-0.063 \\
{[0.014]}\end{array}$ & $\begin{array}{l}-0.038 \\
{[0.025]}\end{array}$ & $\begin{array}{l}-0.011 \\
{[0.003]}\end{array}$ \\
\hline Africa mean of outcome & -1.351 & -1.351 & -1.351 & -1.351 & -1.351 & 0.375 & -0.877 & 10.149 & 0.072 \\
\hline Child's age dummies $\times$ India & No & No & Yes & Yes & Yes & Yes & Yes & Yes & Yes \\
\hline Mother's literacy $\times$ India & No & No & Yes & Yes & No & Yes & Yes & Yes & Yes \\
\hline Mother's age at birth $\times$ India & No & No & Yes & Yes & No & Yes & Yes & Yes & Yes \\
\hline PSU FEs & No & No & Yes & Yes & No & Yes & Yes & Yes & Yes \\
\hline Mother FEs & No & No & No & No & Yes & No & No & No & No \\
\hline Completed fertility sample & No & No & No & Yes & No & No & No & No & No \\
\hline Observations & 168,135 & 168,135 & 167,765 & 66,574 & 83,243 & 167,765 & 167,765 & 88,893 & 199,514 \\
\hline
\end{tabular}

Notes: Standard errors are clustered by mother and appear in brackets. Please consider the notes in Table 2.6 for further explanations. Source: Adapted from J+P using data from DHS (Heger Boyle \& Sobek, 2019) 
Table B.35: India's Differential Birth Order Gradient in Child Height and Related Outcomes (2004-2010): Weighted

\begin{tabular}{|c|c|c|c|c|c|c|c|c|c|}
\hline & $\begin{array}{l}\text { HFA } \\
\text { Z- } \\
\text { score } \\
(1)\end{array}$ & $\begin{array}{l}\text { HFA } \\
\text { Z- } \\
\text { score } \\
(2)\end{array}$ & $\begin{array}{l}\text { HFA } \\
\text { z- } \\
\text { score } \\
(3)\end{array}$ & $\begin{array}{l}\text { HFA } \\
\text { Z- } \\
\text { score } \\
(4)\end{array}$ & $\begin{array}{l}\text { HFA } \\
\text { Z- } \\
\text { score } \\
(5)\end{array}$ & $\begin{array}{l}\text { Stunted } \\
\text { (6) }\end{array}$ & $\begin{array}{l}\text { WFA } \\
\text { Z- } \\
\text { score } \\
(7)\end{array}$ & $\begin{array}{c}\mathrm{Hb} \\
\text { level } \\
(8)\end{array}$ & $\begin{array}{l}\text { Deceasec } \\
\text { (9) }\end{array}$ \\
\hline India & $\begin{array}{l}-0.083 \\
{[0.011]}\end{array}$ & $\begin{array}{l}-0.073 \\
{[0.023]}\end{array}$ & & & & & & & \\
\hline India $\times 2$ nd child & & $\begin{array}{l}-0.119 \\
{[0.032]}\end{array}$ & $\begin{array}{l}-0.152 \\
{[0.034]}\end{array}$ & $\begin{array}{l}-0.064 \\
{[0.081]}\end{array}$ & $\begin{array}{l}-0.274 \\
{[0.061]}\end{array}$ & $\begin{array}{c}0.047 \\
{[0.010]}\end{array}$ & $\begin{array}{l}-0.147 \\
{[0.025]}\end{array}$ & $\begin{array}{l}-0.089 \\
{[0.039]}\end{array}$ & $\begin{array}{l}-0.002 \\
{[0.005]}\end{array}$ \\
\hline India $\times 3$ rd + child & & $\begin{array}{l}-0.356 \\
{[0.030]}\end{array}$ & $\begin{array}{l}-0.199 \\
{[0.041]}\end{array}$ & $\begin{array}{l}-0.088 \\
{[0.117]}\end{array}$ & $\begin{array}{l}-0.442 \\
{[0.107]}\end{array}$ & $\begin{array}{c}0.056 \\
{[0.012]}\end{array}$ & $\begin{array}{l}-0.192 \\
{[0.030]}\end{array}$ & $\begin{array}{l}-0.174 \\
{[0.046]}\end{array}$ & $\begin{array}{l}-0.001 \\
{[0.006]}\end{array}$ \\
\hline 2nd child & & $\begin{array}{c}0.035 \\
{[0.019]}\end{array}$ & $\begin{array}{c}0.003 \\
{[0.021]}\end{array}$ & $\begin{array}{l}-0.142 \\
{[0.069]}\end{array}$ & $\begin{array}{l}-0.168 \\
{[0.034]}\end{array}$ & $\begin{array}{c}0.009 \\
{[0.005]}\end{array}$ & $\begin{array}{c}0.020 \\
{[0.015]}\end{array}$ & $\begin{array}{l}-0.015 \\
{[0.027]}\end{array}$ & $\begin{array}{l}-0.016 \\
{[0.003]}\end{array}$ \\
\hline 3rd + child & & $\begin{array}{l}-0.070 \\
{[0.016]}\end{array}$ & $\begin{array}{l}-0.121 \\
{[0.024]}\end{array}$ & $\begin{array}{l}-0.277 \\
{[0.094]}\end{array}$ & $\begin{array}{l}-0.363 \\
{[0.054]}\end{array}$ & $\begin{array}{c}0.038 \\
{[0.006]}\end{array}$ & $\begin{array}{l}-0.061 \\
{[0.017]}\end{array}$ & $\begin{array}{l}-0.026 \\
{[0.031]}\end{array}$ & $\begin{array}{l}-0.015 \\
{[0.003]}\end{array}$ \\
\hline Africa mean of outcome & -1.363 & -1.363 & -1.363 & -1.363 & -1.363 & 0.381 & -0.889 & 10.107 & 0.074 \\
\hline Child's age dummies $\times$ India & No & No & Yes & Yes & Yes & Yes & Yes & Yes & Yes \\
\hline Mother's literacy $\times$ India & No & No & Yes & Yes & No & Yes & Yes & Yes & Yes \\
\hline Mother's age at birth $\times$ India & No & No & Yes & Yes & No & Yes & Yes & Yes & Yes \\
\hline PSU FEs & No & No & Yes & Yes & No & Yes & Yes & Yes & Yes \\
\hline Mother FEs & No & No & No & No & Yes & No & No & No & No \\
\hline Completed fertility sample & No & No & No & Yes & No & No & No & No & No \\
\hline Observations & 168,135 & 168,135 & 167,765 & 66,574 & 83,243 & 167,765 & 167,765 & 88,893 & 199,514 \\
\hline
\end{tabular}

Notes: Standard errors are clustered by mother and appear in brackets. Please consider the notes in Table 2.6 for further explanations. Source: Adapted from J+P using data from DHS (Heger Boyle \& Sobek, 2019) 
Figure B.5: Child Height in India and Africa, by Child's Birth Order (2004-2010): Unweighted vs Weighted

Replication (2004-2010): Unweighted

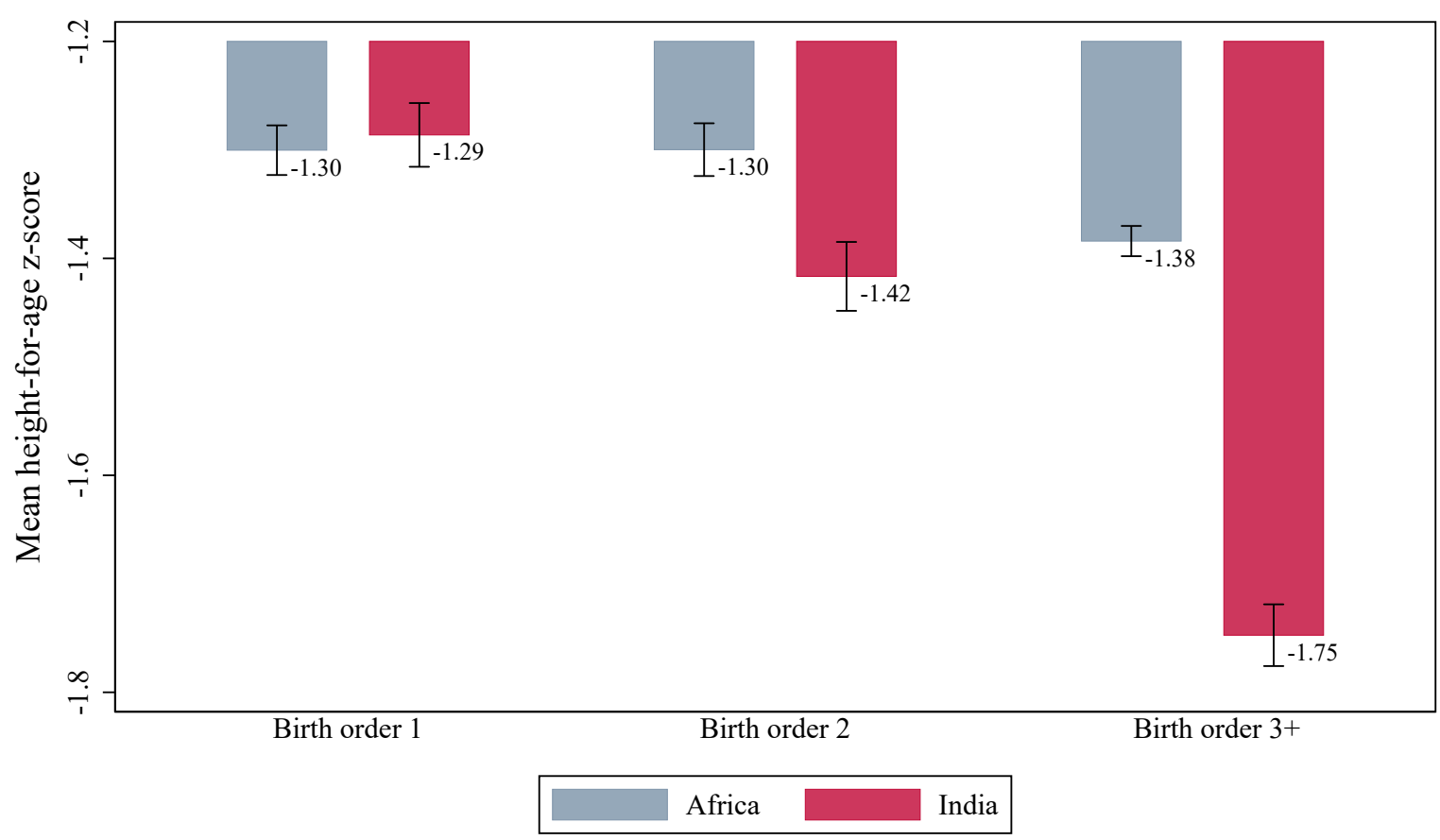

Replication (2004-2010): Weighted India

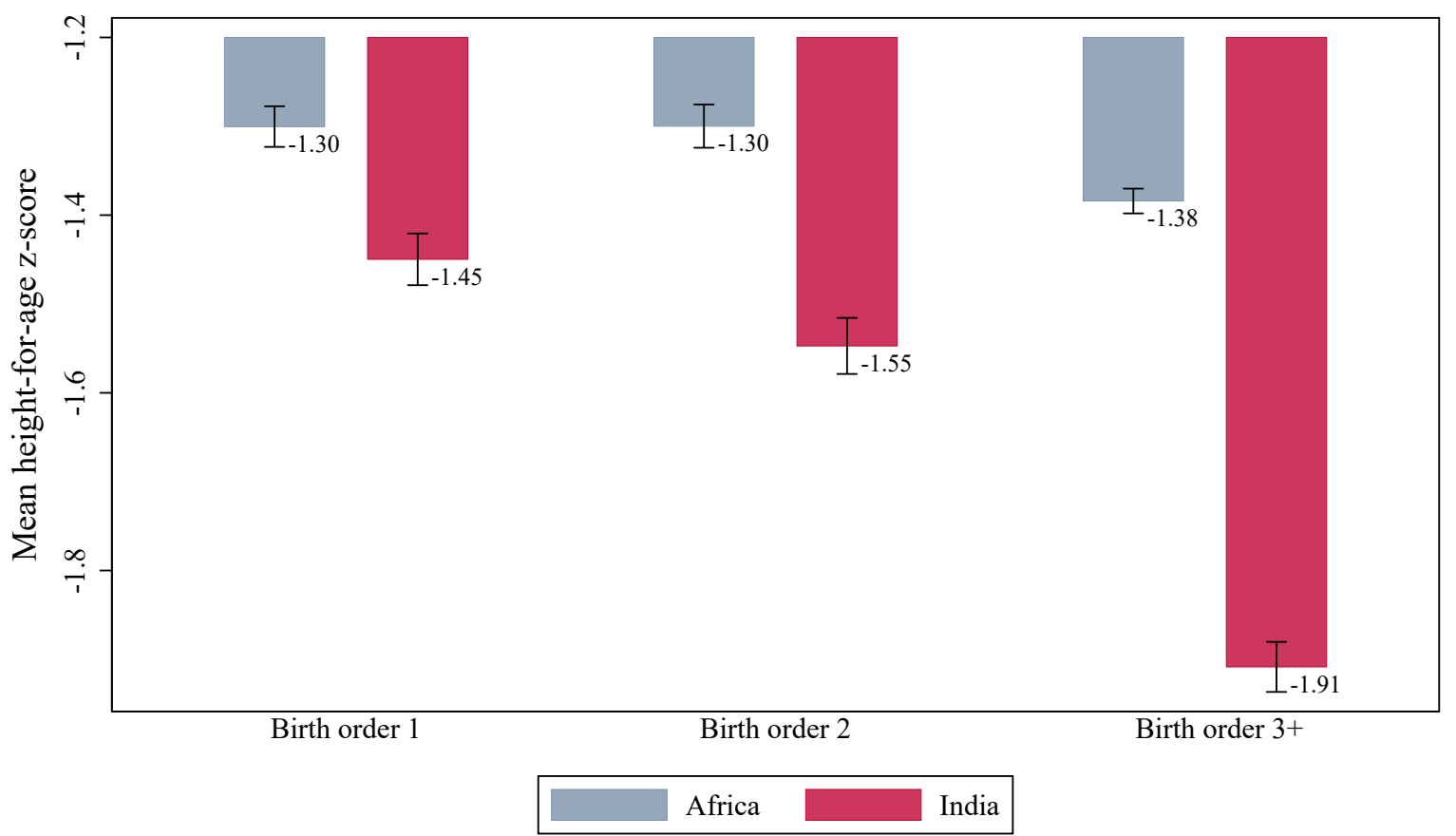

Notes: The figure depicts the mean child height-for-age z-scores for sub-Saharan Africa and India, by the birth order of the child. The mean is calculated over all children less than 60 months old.

Source: Adapted from J+P using data from DHS (ICF, 2004) 
Figure B.6: Child Height in India and Africa, by Child's Birth Order (2004-2010): Weighted Replication (2004-2010): Weighted

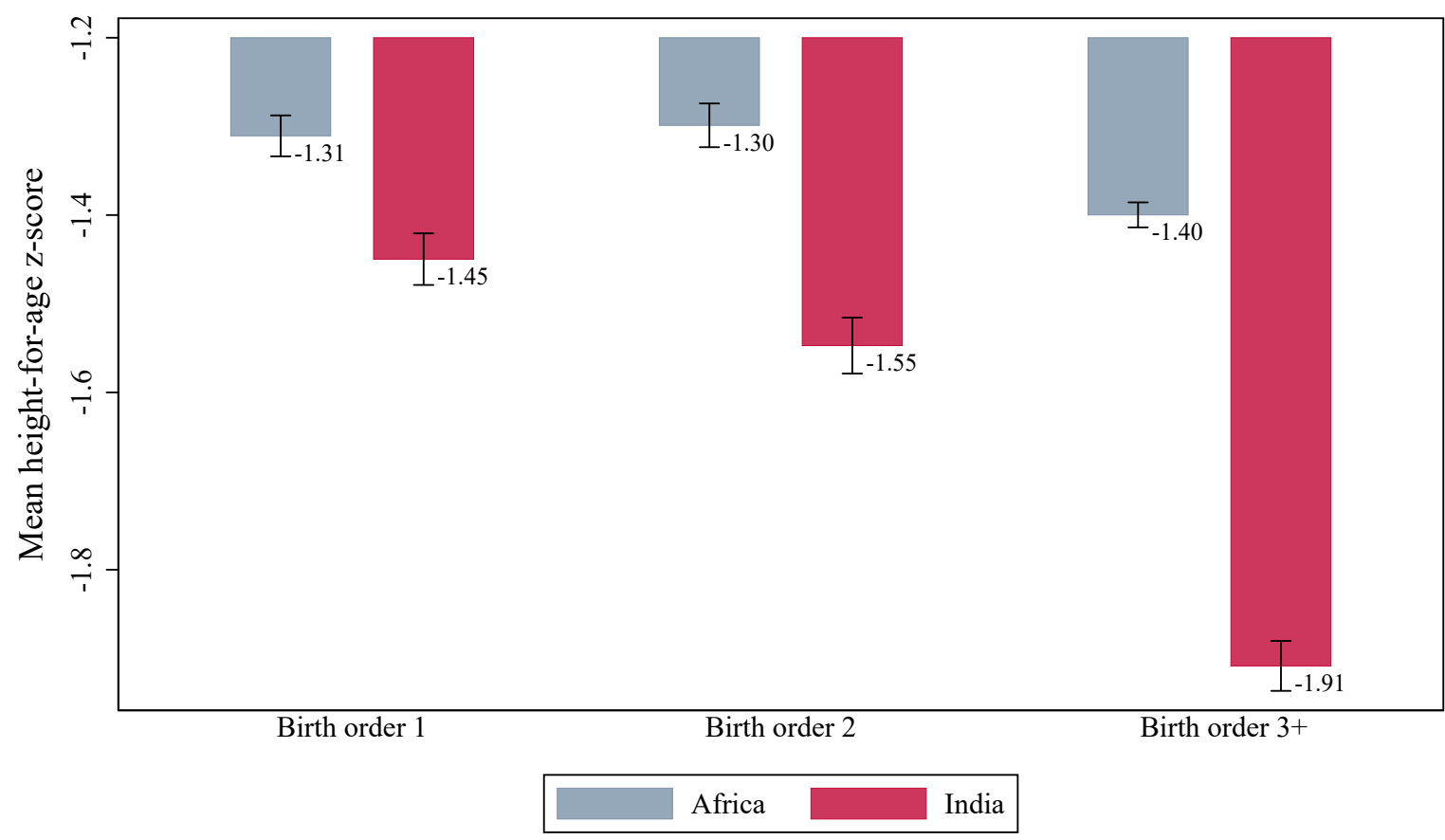

Notes: The figure depicts the mean child height-for-age z-scores for sub-Saharan Africa and India, by the birth order of the child. The mean is calculated over all children less than 60 months old.

Source: Adapted from J+P using data from DHS (ICF, 2004)

\subsection{Child Health Inputs}

Table B.36: Child Health Inputs (2004-2010): Unweighted

\begin{tabular}{|c|c|c|c|c|c|c|c|c|}
\hline & \multicolumn{4}{|c|}{ Prenatal inputs } & \multicolumn{3}{|c|}{ Postnatal inputs } & \multirow[b]{2}{*}{$\begin{array}{c}\text { Average } \\
\text { pooled } \\
\text { inputs } \\
(8)\end{array}$} \\
\hline & $\begin{array}{c}\text { Total } \\
\text { prenatal } \\
\text { visits } \\
(1)\end{array}$ & $\begin{array}{l}\text { Mother } \\
\text { took iron } \\
\text { supple- } \\
\text { ments } \\
\text { (2) }\end{array}$ & $\begin{array}{l}\text { Mother's } \\
\text { total } \\
\text { tetanus } \\
\text { shots } \\
\text { (3) }\end{array}$ & $\begin{array}{c}\text { Delivery } \\
\text { at health } \\
\text { facility } \\
\text { (4) }\end{array}$ & $\begin{array}{l}\text { Postnatal } \\
\text { check } \\
\text { within } 2 \\
\text { months } \\
\text { (5) }\end{array}$ & $\begin{array}{c}\text { Child } \\
\text { taking } \\
\text { iron pills } \\
(6)\end{array}$ & $\begin{array}{c}\text { Child's } \\
\text { total vac- } \\
\text { cinations } \\
\text { (7) }\end{array}$ & \\
\hline India $\times 2$ nd child & $\begin{array}{c}-0.525 \\
{[0.052]}\end{array}$ & $\begin{array}{c}-0.031 \\
{[0.008]}\end{array}$ & $\begin{array}{c}-0.019 \\
{[0.018]}\end{array}$ & $\begin{array}{c}-0.040 \\
{[0.006]}\end{array}$ & $\begin{array}{c}-0.008 \\
{[0.013]}\end{array}$ & $\begin{array}{c}-0.008 \\
{[0.005]}\end{array}$ & $\begin{array}{c}-0.204 \\
{[0.039]}\end{array}$ & $\begin{array}{l}-0.011 \\
{[0.003]}\end{array}$ \\
\hline India $\times 3$ rd + child & $\begin{array}{l}-1.011 \\
{[0.060]}\end{array}$ & $\begin{array}{c}-0.072 \\
{[0.009]}\end{array}$ & $\begin{array}{c}-0.036 \\
{[0.021]}\end{array}$ & $\begin{array}{c}-0.092 \\
{[0.008]}\end{array}$ & $\begin{array}{c}0.015 \\
{[0.014]}\end{array}$ & $\begin{array}{c}-0.010 \\
{[0.006]}\end{array}$ & $\begin{array}{c}-0.462 \\
{[0.051]}\end{array}$ & $\begin{array}{l}-0.033 \\
{[0.004]}\end{array}$ \\
\hline 2nd child & $\begin{array}{c}-0.182 \\
{[0.029]}\end{array}$ & $\begin{array}{c}-0.014 \\
{[0.005]}\end{array}$ & $\begin{array}{l}-0.111 \\
{[0.013]}\end{array}$ & $\begin{array}{c}-0.088 \\
{[0.004]}\end{array}$ & $\begin{array}{c}0.004 \\
{[0.010]}\end{array}$ & $\begin{array}{c}-0.004 \\
{[0.004]}\end{array}$ & $\begin{array}{c}-0.097 \\
{[0.025]}\end{array}$ & $\begin{array}{l}-0.044 \\
{[0.002]}\end{array}$ \\
\hline $3 r d+$ child & $\begin{array}{c}-0.432 \\
{[0.033]}\end{array}$ & $\begin{array}{c}-0.031 \\
{[0.005]}\end{array}$ & $\begin{array}{c}-0.207 \\
{[0.014]}\end{array}$ & $\begin{array}{c}-0.133 \\
{[0.004]}\end{array}$ & $\begin{array}{c}-0.023 \\
{[0.011]}\end{array}$ & $\begin{array}{c}-0.014 \\
{[0.005]}\end{array}$ & $\begin{array}{c}-0.207 \\
{[0.030]}\end{array}$ & $\begin{array}{l}-0.071 \\
{[0.003]}\end{array}$ \\
\hline Africa mean of outcome & 3.847 & 0.622 & 1.415 & 0.472 & 0.302 & 0.113 & 6.245 & 0.380 \\
\hline India mean of outcome & 4.041 & 0.689 & 1.872 & 0.450 & 0.090 & 0.055 & 6.607 & 0.334 \\
\hline Age \& other controls & Yes & Yes & Yes & Yes & Yes & Yes & Yes & Yes \\
\hline Observations & 115,364 & 117,707 & 117,219 & 167,405 & 35,902 & 91,964 & 122,922 & 167,752 \\
\hline
\end{tabular}

Notes: Standard errors are clustered by mother and appear in brackets. Please consider the notes in Table 2.8 for further explanations.

Source: Adapted from J+P using data from DHS (Heger Boyle \& Sobek, 2019) 
Table B.37: Child Health Inputs (2004-2010): Weighted India

\begin{tabular}{|c|c|c|c|c|c|c|c|c|}
\hline & \multicolumn{4}{|c|}{ Prenatal inputs } & \multicolumn{3}{|c|}{ Postnatal inputs } & \multirow[b]{2}{*}{$\begin{array}{c}\text { Average } \\
\text { pooled } \\
\text { inputs } \\
(8) \\
\end{array}$} \\
\hline & $\begin{array}{c}\text { Total } \\
\text { prenatal } \\
\text { visits } \\
(1)\end{array}$ & $\begin{array}{l}\text { Mother } \\
\text { took iron } \\
\text { supple- } \\
\text { ments } \\
\text { (2) }\end{array}$ & $\begin{array}{l}\text { Mother's } \\
\text { total } \\
\text { tetanus } \\
\text { shots } \\
\text { (3) }\end{array}$ & $\begin{array}{c}\text { Delivery } \\
\text { at health } \\
\text { facility } \\
\text { (4) }\end{array}$ & $\begin{array}{l}\text { Postnatal } \\
\text { check } \\
\text { within } 2 \\
\text { months } \\
\text { (5) }\end{array}$ & $\begin{array}{c}\text { Child } \\
\text { taking } \\
\text { iron pills } \\
(6)\end{array}$ & $\begin{array}{c}\text { Child's } \\
\text { total vac- } \\
\text { cinations } \\
\text { (7) }\end{array}$ & \\
\hline India $\times 2$ nd child & $\begin{array}{c}-0.536 \\
{[0.060]}\end{array}$ & $\begin{array}{c}-0.036 \\
{[0.010]}\end{array}$ & $\begin{array}{c}-0.012 \\
{[0.021]}\end{array}$ & $\begin{array}{c}-0.049 \\
{[0.007]}\end{array}$ & $\begin{array}{l}-0.003 \\
{[0.014]}\end{array}$ & $\begin{array}{c}-0.008 \\
{[0.006]}\end{array}$ & $\begin{array}{c}-0.213 \\
{[0.047]}\end{array}$ & $\begin{array}{c}-0.012 \\
{[0.004]}\end{array}$ \\
\hline India $\times 3$ rd + child & $\begin{array}{c}-0.946 \\
{[0.068]}\end{array}$ & $\begin{array}{l}-0.075 \\
{[0.012]}\end{array}$ & $\begin{array}{c}-0.032 \\
{[0.025]}\end{array}$ & $\begin{array}{c}-0.097 \\
{[0.009]}\end{array}$ & $\begin{array}{c}0.018 \\
{[0.015]}\end{array}$ & $\begin{array}{c}-0.003 \\
{[0.007]}\end{array}$ & $\begin{array}{l}-0.487 \\
{[0.062]}\end{array}$ & $\begin{array}{c}-0.030 \\
{[0.005]}\end{array}$ \\
\hline 2nd child & $\begin{array}{c}-0.182 \\
{[0.029]}\end{array}$ & $\begin{array}{c}-0.014 \\
{[0.005]}\end{array}$ & $\begin{array}{c}-0.111 \\
{[0.013]}\end{array}$ & $\begin{array}{c}-0.088 \\
{[0.004]}\end{array}$ & $\begin{array}{c}0.004 \\
{[0.010]}\end{array}$ & $\begin{array}{c}-0.004 \\
{[0.004]}\end{array}$ & $\begin{array}{c}-0.097 \\
{[0.025]}\end{array}$ & $\begin{array}{c}-0.044 \\
{[0.002]}\end{array}$ \\
\hline 3rd+ child & $\begin{array}{c}-0.432 \\
{[0.033]}\end{array}$ & $\begin{array}{c}-0.031 \\
{[0.005]}\end{array}$ & $\begin{array}{c}-0.207 \\
{[0.014]}\end{array}$ & $\begin{array}{c}-0.133 \\
{[0.004]}\end{array}$ & $\begin{array}{c}-0.023 \\
{[0.011]}\end{array}$ & $\begin{array}{c}-0.014 \\
{[0.005]}\end{array}$ & $\begin{array}{c}-0.207 \\
{[0.030]}\end{array}$ & $\begin{array}{c}-0.071 \\
{[0.003]}\end{array}$ \\
\hline Africa mean of outcome & 3.847 & 0.622 & 1.415 & 0.472 & 0.302 & 0.113 & 6.245 & 0.380 \\
\hline India mean of outcome & 3.494 & 0.661 & 1.863 & 0.389 & 0.083 & 0.046 & 6.419 & 0.297 \\
\hline Age \& other controls & Yes & Yes & Yes & Yes & Yes & Yes & Yes & Yes \\
\hline Observations & 115,364 & 117,707 & 117,219 & 167,405 & 35,902 & 91,964 & 122,922 & 167,752 \\
\hline
\end{tabular}

Notes: Standard errors are clustered by mother and appear in brackets. Please consider the notes in Table 2.8 for further explanations. Source: Adapted from J+P using data from DHS (Heger Boyle \& Sobek, 2019)

Table B.38: Child Health Inputs (2004-2010): Weighted

\begin{tabular}{|c|c|c|c|c|c|c|c|c|}
\hline & \multicolumn{4}{|c|}{ Prenatal inputs } & \multicolumn{3}{|c|}{ Postnatal inputs } & \multirow[b]{2}{*}{$\begin{array}{c}\text { Average } \\
\text { pooled } \\
\text { inputs } \\
(8) \\
\end{array}$} \\
\hline & $\begin{array}{c}\text { Total } \\
\text { prenatal } \\
\text { visits } \\
(1)\end{array}$ & $\begin{array}{l}\text { Mother } \\
\text { took iron } \\
\text { supple- } \\
\text { ments } \\
\text { (2) }\end{array}$ & $\begin{array}{l}\text { Mother's } \\
\text { total } \\
\text { tetanus } \\
\text { shots } \\
\text { (3) }\end{array}$ & $\begin{array}{c}\text { Delivery } \\
\text { at health } \\
\text { facility } \\
\text { (4) }\end{array}$ & $\begin{array}{l}\text { Postnatal } \\
\text { check } \\
\text { within } 2 \\
\text { months } \\
\text { (5) }\end{array}$ & $\begin{array}{c}\text { Child } \\
\text { taking } \\
\text { iron pills } \\
(6)\end{array}$ & $\begin{array}{c}\text { Child's } \\
\text { total vac- } \\
\text { cinations } \\
\text { (7) }\end{array}$ & \\
\hline India $\times 2$ nd child & $\begin{array}{c}-0.518 \\
{[0.064]}\end{array}$ & $\begin{array}{c}-0.036 \\
{[0.010]}\end{array}$ & $\begin{array}{c}-0.029 \\
{[0.023]}\end{array}$ & $\begin{array}{c}-0.057 \\
{[0.008]}\end{array}$ & $\begin{array}{c}-0.001 \\
{[0.016]}\end{array}$ & $\begin{array}{c}-0.007 \\
{[0.007]}\end{array}$ & $\begin{array}{c}-0.208 \\
{[0.051]}\end{array}$ & $\begin{array}{c}-0.016 \\
{[0.004]}\end{array}$ \\
\hline India $\times 3 r d+$ child & $\begin{array}{c}-0.940 \\
{[0.073]}\end{array}$ & $\begin{array}{c}-0.080 \\
{[0.012]}\end{array}$ & $\begin{array}{c}-0.048 \\
{[0.027]}\end{array}$ & $\begin{array}{c}-0.109 \\
{[0.010]}\end{array}$ & $\begin{array}{c}0.021 \\
{[0.017]}\end{array}$ & $\begin{array}{c}-0.001 \\
{[0.008]}\end{array}$ & $\begin{array}{c}-0.488 \\
{[0.066]}\end{array}$ & $\begin{array}{c}-0.035 \\
{[0.005]}\end{array}$ \\
\hline 2nd child & $\begin{array}{c}-0.200 \\
{[0.037]}\end{array}$ & $\begin{array}{c}-0.013 \\
{[0.006]}\end{array}$ & $\begin{array}{c}-0.095 \\
{[0.016]}\end{array}$ & $\begin{array}{c}-0.079 \\
{[0.004]}\end{array}$ & $\begin{array}{c}0.001 \\
{[0.012]}\end{array}$ & $\begin{array}{c}-0.004 \\
{[0.005]}\end{array}$ & $\begin{array}{c}-0.102 \\
{[0.031]}\end{array}$ & $\begin{array}{c}-0.041 \\
{[0.003]}\end{array}$ \\
\hline 3rd+ child & $\begin{array}{c}-0.438 \\
{[0.042]}\end{array}$ & $\begin{array}{c}-0.026 \\
{[0.006]}\end{array}$ & $\begin{array}{c}-0.191 \\
{[0.017]}\end{array}$ & $\begin{array}{c}-0.121 \\
{[0.005]}\end{array}$ & $\begin{array}{c}-0.026 \\
{[0.013]}\end{array}$ & $\begin{array}{c}-0.016 \\
{[0.007]}\end{array}$ & $\begin{array}{c}-0.205 \\
{[0.037]}\end{array}$ & $\begin{array}{c}-0.067 \\
{[0.003]}\end{array}$ \\
\hline Africa mean of outcome & 3.871 & 0.616 & 1.407 & 0.466 & 0.323 & 0.134 & 6.142 & 0.377 \\
\hline India mean of outcome & 3.494 & 0.661 & 1.863 & 0.389 & 0.083 & 0.046 & 6.419 & 0.297 \\
\hline Age \& other controls & Yes & Yes & Yes & Yes & Yes & Yes & Yes & Yes \\
\hline Observations & 115,364 & 117,707 & 117,219 & 167,405 & 35,902 & 91,964 & 122,922 & 167,752 \\
\hline
\end{tabular}

Notes: Standard errors are clustered by mother and appear in brackets. Please consider the notes in Table 2.8 for further explanations. Source: Adapted from J+P using data from DHS (Heger Boyle \& Sobek, 2019) 


\subsection{Cultural Norms and Child Height: Within-India Evidence}

Table B.39: Cultural Norms and Child Height: Within-India Evidence (2004-2010): Unweighted

\begin{tabular}{|c|c|c|c|c|c|c|}
\hline \multirow[t]{2}{*}{ Low son preference proxy: } & \multicolumn{2}{|c|}{ Kerala \& Northeast } & \multicolumn{2}{|c|}{ Below-median child sex ratio } & \multicolumn{2}{|c|}{ Muslims } \\
\hline & $\begin{array}{c}\text { HFA } \\
\text { z-score } \\
(1)\end{array}$ & $\begin{array}{c}\text { WFA } \\
\text { z-score } \\
(2)\end{array}$ & $\begin{array}{c}\text { HFA } \\
\text { z-score } \\
\text { (3) }\end{array}$ & $\begin{array}{l}\text { WFA } \\
\text { z-score } \\
(4)\end{array}$ & $\begin{array}{c}\text { HFA } \\
\text { z-score } \\
(5)\end{array}$ & $\begin{array}{c}\text { WFA } \\
\text { z-score } \\
(6)\end{array}$ \\
\hline Low son pref proxy $\times 2$ nd child & $\begin{array}{c}0.078 \\
{[0.039]}\end{array}$ & $\begin{array}{c}0.008 \\
{[0.029]}\end{array}$ & $\begin{array}{c}0.077 \\
{[0.030]}\end{array}$ & $\begin{array}{c}0.038 \\
{[0.023]}\end{array}$ & $\begin{array}{c}-0.027 \\
{[0.047]}\end{array}$ & $\begin{array}{c}0.034 \\
{[0.035]}\end{array}$ \\
\hline Low son pref proxy $\times 3$ rd + child & $\begin{array}{c}0.108 \\
{[0.045]}\end{array}$ & $\begin{array}{c}0.069 \\
{[0.033]}\end{array}$ & $\begin{array}{c}0.084 \\
{[0.036]}\end{array}$ & $\begin{array}{c}0.047 \\
{[0.027]}\end{array}$ & $\begin{array}{c}0.184 \\
{[0.055]}\end{array}$ & $\begin{array}{c}0.156 \\
{[0.041]}\end{array}$ \\
\hline 2nd child & $\begin{array}{c}-0.185 \\
{[0.017]}\end{array}$ & $\begin{array}{c}-0.154 \\
{[0.013]}\end{array}$ & $\begin{array}{c}-0.205 \\
{[0.020]}\end{array}$ & $\begin{array}{c}-0.172 \\
{[0.015]}\end{array}$ & $\begin{array}{l}-0.159 \\
{[0.017]}\end{array}$ & $\begin{array}{c}-0.153 \\
{[0.013]}\end{array}$ \\
\hline 3rd+ child & $\begin{array}{c}-0.422 \\
{[0.020]}\end{array}$ & $\begin{array}{c}-0.350 \\
{[0.015]}\end{array}$ & $\begin{array}{c}-0.438 \\
{[0.024]}\end{array}$ & $\begin{array}{c}-0.364 \\
{[0.018]}\end{array}$ & $\begin{array}{c}-0.412 \\
{[0.021]}\end{array}$ & $\begin{array}{c}-0.354 \\
{[0.016]}\end{array}$ \\
\hline $\begin{array}{l}\text { Low son pref group mean of outcome } \\
\text { High son pref group mean of outcome }\end{array}$ & $\begin{array}{l}-1.388 \\
-1.710\end{array}$ & $\begin{array}{l}-1.198 \\
-1.648\end{array}$ & $\begin{array}{l}-1.568 \\
-1.712\end{array}$ & $\begin{array}{l}-1.491 \\
-1.618\end{array}$ & $\begin{array}{l}-1.732 \\
-1.691\end{array}$ & $\begin{array}{l}-1.602 \\
-1.628\end{array}$ \\
\hline Age \& other controls & $\begin{array}{c}\text { NFHS } \\
1-3\end{array}$ & $\begin{array}{c}\text { NFHS } \\
1-3\end{array}$ & $\begin{array}{c}\text { NFHS } \\
1-3\end{array}$ & $\begin{array}{c}\text { NFHS } \\
1-3\end{array}$ & $\begin{array}{c}\text { NFHS } \\
1-3\end{array}$ & $\begin{array}{c}\text { NFHS } \\
1-3\end{array}$ \\
\hline Observations & Yes & Yes & Yes & Yes & Yes & Yes \\
\hline $\mathrm{N}$ & 95,125 & 95,125 & 95,125 & 95,125 & 82,084 & 82,084 \\
\hline
\end{tabular}

Notes: Standard errors are clustered by mother and appear in brackets. In all columns the sample uses NFHS 1-3. NFHS-1 only has data for children aged four years and younger, and NFHS-2 only has data for children aged 3 years and younger. All columns include child age dummies, maternal age, mother's literacy, and child age dummies, maternal age, and mother's literacy interacted with Low son pref proxy. All columns include survey and PSU fixed effects, and survey and PSU fixed effects interacted with Low son pref proxy. In columns 1-4, the main effect Low son pref proxy is absorbed by PSU fixed effects. Kerala and Northeast include Arunachal Pradesh, Assam, Kerala, Manipur,

Meghalaya, Mizoram, Nagaland, Sikkim, and Tripura. Child sex ratio is defined as the number of boys aged 0-6 years over the number of girls aged 0-6 years in the respondent's state-by-rural cell. In columns 5 and 6, the sample is restricted to Muslims and Hindus.

Source: Adapted from J+P using data from DHS (Heger Boyle \& Sobek, 2019) 
Table B.40: Cultural Norms and Child Height: Within-India Evidence (2004-2010): Weighted India

\begin{tabular}{|c|c|c|c|c|c|c|}
\hline \multirow[t]{2}{*}{ Low son preference proxy: } & \multicolumn{2}{|c|}{ Kerala \& Northeast } & \multicolumn{2}{|c|}{$\begin{array}{l}\text { Below-median } \\
\text { child sex ratio }\end{array}$} & \multicolumn{2}{|c|}{ Muslims } \\
\hline & $\begin{array}{c}\text { HFA } \\
\text { z-score } \\
\text { (1) }\end{array}$ & $\begin{array}{c}\text { WFA } \\
\text { Z-score } \\
\text { (2) }\end{array}$ & $\begin{array}{c}\text { HFA } \\
\text { z-score } \\
\text { (3) }\end{array}$ & $\begin{array}{c}\text { WFA } \\
\text { z-score } \\
(4)\end{array}$ & $\begin{array}{c}\text { HFA } \\
\text { z-score } \\
(5)\end{array}$ & $\begin{array}{c}\text { WFA } \\
\text { z-score } \\
(6)\end{array}$ \\
\hline Low son pref proxy $\times 2$ nd child & $\begin{array}{c}0.058 \\
{[0.053]}\end{array}$ & $\begin{array}{c}-0.003 \\
{[0.039]}\end{array}$ & $\begin{array}{c}0.082 \\
{[0.037]}\end{array}$ & $\begin{array}{c}0.049 \\
{[0.029]}\end{array}$ & $\begin{array}{c}-0.052 \\
{[0.055]}\end{array}$ & $\begin{array}{c}0.033 \\
{[0.043]}\end{array}$ \\
\hline Low son pref proxy $\times 3$ rd + child & $\begin{array}{c}-0.025 \\
{[0.061]}\end{array}$ & $\begin{array}{c}-0.002 \\
{[0.046]}\end{array}$ & $\begin{array}{c}0.003 \\
{[0.045]}\end{array}$ & $\begin{array}{c}-0.015 \\
{[0.035]}\end{array}$ & $\begin{array}{c}0.163 \\
{[0.065]}\end{array}$ & $\begin{array}{c}0.141 \\
{[0.049]}\end{array}$ \\
\hline 2nd child & $\begin{array}{c}-0.164 \\
{[0.019]}\end{array}$ & $\begin{array}{c}-0.135 \\
{[0.015]}\end{array}$ & $\begin{array}{c}-0.194 \\
{[0.023]}\end{array}$ & $\begin{array}{c}-0.157 \\
{[0.018]}\end{array}$ & $\begin{array}{c}-0.147 \\
{[0.021]}\end{array}$ & $\begin{array}{c}-0.136 \\
{[0.016]}\end{array}$ \\
\hline 3rd+ child & $\begin{array}{c}-0.368 \\
{[0.023]}\end{array}$ & $\begin{array}{c}-0.305 \\
{[0.018]}\end{array}$ & $\begin{array}{c}-0.375 \\
{[0.028]}\end{array}$ & $\begin{array}{c}-0.309 \\
{[0.021]}\end{array}$ & $\begin{array}{c}-0.390 \\
{[0.025]}\end{array}$ & $\begin{array}{c}-0.322 \\
{[0.019]}\end{array}$ \\
\hline Low son pref group mean of outcome & -1.462 & -1.299 & -1.723 & -1.700 & -1.857 & -1.727 \\
\hline High son pref group mean of outcome & -1.799 & -1.743 & -1.810 & -1.721 & -1.783 & -1.734 \\
\hline Age \& other controls & $\begin{array}{c}\text { NFHS } \\
1-3\end{array}$ & $\begin{array}{c}\text { NFHS } \\
1-3\end{array}$ & $\begin{array}{c}\text { NFHS } \\
1-3\end{array}$ & $\begin{array}{c}\text { NFHS } \\
1-3\end{array}$ & $\begin{array}{c}\text { NFHS } \\
1-3\end{array}$ & $\begin{array}{c}\text { NFHS } \\
1-3\end{array}$ \\
\hline Observations & Yes & Yes & Yes & Yes & Yes & Yes \\
\hline $\mathrm{N}$ & 95,125 & 95,125 & 95,125 & 95,125 & 82,084 & 82,084 \\
\hline
\end{tabular}

Notes: Standard errors are clustered by mother and appear in brackets. In all columns the sample uses NFHS 1-3. NFHS-1 only has data for children aged four years and younger, and NFHS-2 only has data for children aged 3 years and younger. All columns include child age dummies, maternal age, mother's literacy, and child age dummies, maternal age, and mother's literacy interacted with Low son pref proxy. All columns include survey and PSU fixed effects, and survey and PSU fixed effects interacted with Low son pref proxy. In columns 1-4, the main effect Low son pref proxy is absorbed by PSU fixed effects. Kerala and Northeast include Arunachal Pradesh, Assam, Kerala, Manipur,

Meghalaya, Mizoram, Nagaland, Sikkim, and Tripura. Child sex ratio is defined as the number of boys aged 0-6 years over the number of girls aged 0-6 years in the respondent's state-by-rural cell. In columns 5 and 6, the sample is restricted to Muslims and Hindus.

Source: Adapted from J+P using data from DHS (Heger Boyle \& Sobek, 2019) 


\subsection{Child Gender and the Birth Order Gradient in Height}

Table B.41: Child Gender and the Birth Order Gradient in Height (2004-2010): Unweighted

\begin{tabular}{|c|c|c|c|c|c|c|c|c|}
\hline & $\begin{array}{l}\text { HFA } \\
\text { Z-score } \\
\text { (1) }\end{array}$ & $\begin{array}{l}\text { HFA } \\
\text { z-score } \\
\text { (2) }\end{array}$ & $\begin{array}{l}\text { HFA } \\
\text { z-score } \\
\text { (3) }\end{array}$ & $\begin{array}{c}\text { WFA } \\
\text { z-score } \\
\text { (4) }\end{array}$ & $\begin{array}{c}\text { HFA } \\
\text { z-score } \\
\text { (5) }\end{array}$ & $\begin{array}{l}\text { HFA } \\
\text { z-score } \\
(6)\end{array}$ & $\begin{array}{l}\text { HFA } \\
\text { z-score } \\
\text { (7) }\end{array}$ & $\begin{array}{c}\text { WFA } \\
\text { z-score } \\
(8)\end{array}$ \\
\hline India & $\begin{array}{c}0.148 \\
{[0.026]}\end{array}$ & & & & $\begin{array}{l}-0.011 \\
{[0.014]}\end{array}$ & & & \\
\hline India $\times$ Girl & $\begin{array}{l}-0.112 \\
{[0.036]}\end{array}$ & & & & $\begin{array}{l}-0.143 \\
{[0.020]}\end{array}$ & $\begin{array}{l}-0.147 \\
{[0.019]}\end{array}$ & $\begin{array}{l}-0.098 \\
{[0.032]}\end{array}$ & $\begin{array}{l}-0.116 \\
{[0.014]}\end{array}$ \\
\hline India $\times 2$ nd child & $\begin{array}{l}-0.107 \\
{[0.036]}\end{array}$ & $\begin{array}{l}-0.153 \\
{[0.040]}\end{array}$ & $\begin{array}{l}-0.228 \\
{[0.069]}\end{array}$ & $\begin{array}{l}-0.122 \\
{[0.030]}\end{array}$ & & & & \\
\hline India $\times 3 r d+$ child & $\begin{array}{c}-0.352 \\
{[0.033]}\end{array}$ & $\begin{array}{l}-0.222 \\
{[0.047]}\end{array}$ & $\begin{array}{c}-0.414 \\
{[0.097]}\end{array}$ & $\begin{array}{l}-0.176 \\
{[0.035]}\end{array}$ & & & & \\
\hline India $\times 2$ nd child $\times$ Girl & $\begin{array}{c}-0.077 \\
{[0.053]}\end{array}$ & $\begin{array}{l}-0.045 \\
{[0.057]}\end{array}$ & $\begin{array}{c}-0.024 \\
{[0.101]}\end{array}$ & $\begin{array}{l}-0.047 \\
{[0.042]}\end{array}$ & & & & \\
\hline India $\times$ 3rd + child $\times$ Girl & $\begin{array}{l}-0.051 \\
{[0.047]}\end{array}$ & $\begin{array}{l}-0.048 \\
{[0.067]}\end{array}$ & $\begin{array}{l}-0.030 \\
{[0.092]}\end{array}$ & $\begin{array}{l}-0.063 \\
{[0.049]}\end{array}$ & & & & \\
\hline 2nd child & $\begin{array}{c}0.023 \\
{[0.022]}\end{array}$ & $\begin{array}{l}-0.005 \\
{[0.026]}\end{array}$ & $\begin{array}{c}-0.202 \\
{[0.041]}\end{array}$ & $\begin{array}{c}0.006 \\
{[0.019]}\end{array}$ & & & & \\
\hline 3rd+ child & $\begin{array}{l}-0.057 \\
{[0.019]}\end{array}$ & $\begin{array}{l}-0.113 \\
{[0.029]}\end{array}$ & $\begin{array}{l}-0.355 \\
{[0.052]}\end{array}$ & $\begin{array}{l}-0.069 \\
{[0.021]}\end{array}$ & & & & \\
\hline Africa mean of outcome & -1.351 & -1.351 & -1.351 & -0.877 & -1.351 & -1.351 & -1.351 & -0.877 \\
\hline Age \& other controls & No & Yes & No & Yes & No & Yes & No & Yes \\
\hline Mother FEs & No & No & Yes & No & No & No & Yes & No \\
\hline Observations & 168,135 & 165,623 & 83,243 & 165,623 & 168,135 & 167,765 & 83,243 & 167,765 \\
\hline
\end{tabular}

Notes: Standard errors are clustered by mother and appear in brackets. Please consider the notes in Table 2.10 for further explanations. Source: Adapted from J+P using data from DHS (Heger Boyle \& Sobek, 2019)

Table B.42: Child Gender and the Birth Order Gradient in Height (2004-2010): Weighted India

\begin{tabular}{|c|c|c|c|c|c|c|c|c|}
\hline & $\begin{array}{c}\text { HFA } \\
\text { z-score } \\
\text { (1) }\end{array}$ & $\begin{array}{l}\text { HFA } \\
\text { z-score } \\
\text { (2) }\end{array}$ & $\begin{array}{c}\text { HFA } \\
\text { z-score } \\
\text { (3) }\end{array}$ & $\begin{array}{l}\text { WFA } \\
\text { z-score } \\
\text { (4) }\end{array}$ & $\begin{array}{c}\text { HFA } \\
\text { z-score } \\
\text { (5) }\end{array}$ & $\begin{array}{l}\text { HFA } \\
\text { z-score } \\
\text { (6) }\end{array}$ & $\begin{array}{c}\text { HFA } \\
\text { z-score } \\
\text { (7) }\end{array}$ & $\begin{array}{c}\text { WFA } \\
\text { z-score } \\
(8)\end{array}$ \\
\hline India & $\begin{array}{l}-0.005 \\
{[0.031]}\end{array}$ & & & & $\begin{array}{c}-0.169 \\
{[0.017]}\end{array}$ & & & \\
\hline India $\times$ Girl & $\begin{array}{c}-0.160 \\
{[0.043]}\end{array}$ & & & & $\begin{array}{c}-0.171 \\
{[0.024]}\end{array}$ & $\begin{array}{l}-0.176 \\
{[0.023]}\end{array}$ & $\begin{array}{l}-0.126 \\
{[0.039]}\end{array}$ & $\begin{array}{l}-0.139 \\
{[0.017]}\end{array}$ \\
\hline India $\times 2$ nd child & $\begin{array}{l}-0.080 \\
{[0.043]}\end{array}$ & $\begin{array}{l}-0.140 \\
{[0.048]}\end{array}$ & $\begin{array}{l}-0.264 \\
{[0.081]}\end{array}$ & $\begin{array}{l}-0.105 \\
{[0.035]}\end{array}$ & & & & \\
\hline India $\times 3$ rd + child & $\begin{array}{l}-0.356 \\
{[0.040]}\end{array}$ & $\begin{array}{l}-0.247 \\
{[0.057]}\end{array}$ & $\begin{array}{l}-0.481 \\
{[0.115]}\end{array}$ & $\begin{array}{l}-0.191 \\
{[0.041]}\end{array}$ & & & & \\
\hline India $\times 2$ nd child $\times$ Girl & $\begin{array}{c}-0.060 \\
{[0.062]}\end{array}$ & $\begin{array}{l}-0.006 \\
{[0.068]}\end{array}$ & $\begin{array}{c}-0.024 \\
{[0.118]}\end{array}$ & $\begin{array}{l}-0.057 \\
{[0.051]}\end{array}$ & & & & \\
\hline India $\times$ 3rd + child $\times$ Girl & $\begin{array}{l}-0.009 \\
{[0.056]}\end{array}$ & $\begin{array}{c}0.067 \\
{[0.081]}\end{array}$ & $\begin{array}{c}0.018 \\
{[0.108]}\end{array}$ & $\begin{array}{l}-0.023 \\
{[0.058]}\end{array}$ & & & & \\
\hline 2nd child & $\begin{array}{c}0.023 \\
{[0.022]}\end{array}$ & $\begin{array}{l}-0.005 \\
{[0.026]}\end{array}$ & $\begin{array}{l}-0.202 \\
{[0.041]}\end{array}$ & $\begin{array}{c}0.006 \\
{[0.019]}\end{array}$ & & & & \\
\hline $3 \mathrm{rd}+$ child & $\begin{array}{l}-0.057 \\
{[0.019]}\end{array}$ & $\begin{array}{l}-0.113 \\
{[0.029]}\end{array}$ & $\begin{array}{l}-0.355 \\
{[0.052]}\end{array}$ & $\begin{array}{l}-0.069 \\
{[0.021]}\end{array}$ & & & & \\
\hline Africa mean of outcome & -1.351 & -1.351 & -1.351 & -0.877 & -1.351 & -1.351 & -1.351 & -0.877 \\
\hline Age \& other controls & No & Yes & No & Yes & No & Yes & No & Yes \\
\hline Mother FEs & No & No & Yes & No & No & No & Yes & No \\
\hline Observations & 168,135 & 165,623 & 83,243 & 165,623 & 168,135 & 167,765 & 83,243 & 167,765 \\
\hline
\end{tabular}

Notes: Standard errors are clustered by mother and appear in brackets. Please consider the notes in Table 2.10 for further explanations.

Source: Adapted from J+P using data from DHS (Heger Boyle \& Sobek, 2019) 
Table B.43: Child Gender and the Birth Order Gradient in Height (2004-2010): Weighted

\begin{tabular}{|c|c|c|c|c|c|c|c|c|}
\hline & $\begin{array}{c}\text { HFA } \\
\text { Z-score } \\
(1)\end{array}$ & $\begin{array}{c}\text { HFA } \\
\text { z-score } \\
(2)\end{array}$ & $\begin{array}{c}\text { HFA } \\
\text { z-score } \\
(3)\end{array}$ & $\begin{array}{c}\text { WFA } \\
\text { Z-score } \\
(4)\end{array}$ & $\begin{array}{c}\text { HFA } \\
\text { Z-score } \\
(5)\end{array}$ & $\begin{array}{c}\text { HFA } \\
\text { z-score } \\
(6)\end{array}$ & $\begin{array}{c}\text { HFA } \\
\text { z-score } \\
(7)\end{array}$ & $\begin{array}{c}\text { WFA } \\
\text { z-score } \\
(8)\end{array}$ \\
\hline India & $\begin{array}{c}-0.003 \\
{[0.033]}\end{array}$ & & & & $\begin{array}{c}-0.157 \\
{[0.018]}\end{array}$ & & & \\
\hline India $\times$ Girl & $\begin{array}{c}-0.140 \\
{[0.046]}\end{array}$ & & & & $\begin{array}{c}-0.167 \\
{[0.025]}\end{array}$ & $\begin{array}{c}-0.172 \\
{[0.024]}\end{array}$ & $\begin{array}{c}-0.110 \\
{[0.040]}\end{array}$ & $\begin{array}{c}-0.143 \\
{[0.018]}\end{array}$ \\
\hline India $\times 2$ nd child & $\begin{array}{c}-0.077 \\
{[0.046]}\end{array}$ & $\begin{array}{c}-0.157 \\
{[0.051]}\end{array}$ & $\begin{array}{c}-0.289 \\
{[0.086]}\end{array}$ & $\begin{array}{c}-0.116 \\
{[0.037]}\end{array}$ & & & & \\
\hline India $\times 3$ rd + child & $\begin{array}{c}-0.342 \\
{[0.042]}\end{array}$ & $\begin{array}{c}-0.246 \\
{[0.061]}\end{array}$ & $\begin{array}{c}-0.459 \\
{[0.121]}\end{array}$ & $\begin{array}{c}-0.196 \\
{[0.044]}\end{array}$ & & & & \\
\hline India $\times 2$ nd child $\times$ Girl & $\begin{array}{c}-0.089 \\
{[0.066]}\end{array}$ & $\begin{array}{c}-0.004 \\
{[0.073]}\end{array}$ & $\begin{array}{c}0.030 \\
{[0.126]}\end{array}$ & $\begin{array}{c}-0.059 \\
{[0.054]}\end{array}$ & & & & \\
\hline India $\times$ 3rd + child $\times$ Girl & $\begin{array}{c}-0.028 \\
{[0.059]}\end{array}$ & $\begin{array}{c}0.075 \\
{[0.086]}\end{array}$ & $\begin{array}{c}0.040 \\
{[0.115]}\end{array}$ & $\begin{array}{c}-0.016 \\
{[0.062]}\end{array}$ & & & & \\
\hline 2nd child & $\begin{array}{c}0.021 \\
{[0.028]}\end{array}$ & $\begin{array}{c}0.011 \\
{[0.031]}\end{array}$ & $\begin{array}{c}-0.178 \\
{[0.051]}\end{array}$ & $\begin{array}{c}0.016 \\
{[0.022]}\end{array}$ & & & & \\
\hline 3rd + child & $\begin{array}{c}-0.070 \\
{[0.023]}\end{array}$ & $\begin{array}{c}-0.113 \\
{[0.035]}\end{array}$ & $\begin{array}{c}-0.377 \\
{[0.064]}\end{array}$ & $\begin{array}{c}-0.064 \\
{[0.025]}\end{array}$ & & & & \\
\hline Africa mean of outcome & -1.363 & -1.363 & -1.363 & -0.889 & -1.363 & -1.363 & -1.363 & -0.889 \\
\hline Age \& other controls & No & Yes & No & Yes & No & Yes & No & Yes \\
\hline Mother FEs & No & No & Yes & No & No & No & Yes & No \\
\hline Observations & 168,135 & 165,623 & 83,243 & 165,623 & 168,135 & 167,765 & 83,243 & 167,765 \\
\hline
\end{tabular}

Notes: Standard errors are clustered by mother and appear in brackets. Please consider the notes in Table 2.10 for further explanations. Source: Adapted from J+P using data from DHS (Heger Boyle \& Sobek, 2019) 


\subsection{Impact on Average Height - Accounting exercise}

Table B.44: Accounting Exercise Part 1: Sample Comparison (2004-2010): Unweighted

\begin{tabular}{|c|c|c|c|}
\hline & & $\begin{array}{l}\text { Accounting } \\
\text { Exercise } 1\end{array}$ & $\begin{array}{l}\text { Accounting } \\
\text { Exercise } 2\end{array}$ \\
\hline & $\begin{array}{c}\text { HFA z-score } \\
\text { (1) }\end{array}$ & $\begin{array}{c}\text { HFA z-score } \\
\text { (2) }\end{array}$ & $\begin{array}{c}\text { HFA z-score } \\
\text { (3) }\end{array}$ \\
\hline India & $\begin{array}{c}-0.162 \\
{[0.017]}\end{array}$ & & \\
\hline Gradient proxy & & $\begin{array}{c}0.412 \\
{[0.069]}\end{array}$ & $\begin{array}{c}0.704 \\
{[0.131]}\end{array}$ \\
\hline \multicolumn{4}{|l|}{ Mean of gradient proxy } \\
\hline India & & -0.331 & -0.234 \\
\hline Africa & & -0.066 & -0.037 \\
\hline Kerala \& Northeast & & -0.229 & -0.155 \\
\hline Rest of India & & -0.358 & -0.257 \\
\hline Log GDP per capita & Yes & Yes & Yes \\
\hline Sample & Full & Africa & Africa \\
\hline Observations & 168,135 & 126,066 & 126,066 \\
\hline
\end{tabular}

Table B.45: Accounting Exercise Part 1: Sample Comparison (2004-2010): Weighted India

\begin{tabular}{|c|c|c|c|}
\hline & & $\begin{array}{l}\text { Accounting } \\
\text { Exercise } 1\end{array}$ & $\begin{array}{c}\text { Accounting } \\
\text { Exercise } 2\end{array}$ \\
\hline & $\begin{array}{c}\text { HFA z-score } \\
\text { (1) }\end{array}$ & $\begin{array}{c}\text { HFA z-score } \\
\text { (2) }\end{array}$ & $\begin{array}{c}\text { HFA z-score } \\
\text { (3) }\end{array}$ \\
\hline India & $\begin{array}{c}-0.332 \\
{[0.020]}\end{array}$ & & \\
\hline Gradient proxy & & $\begin{array}{c}0.412 \\
{[0.069]}\end{array}$ & $\begin{array}{c}0.704 \\
{[0.131]} \\
\end{array}$ \\
\hline \multicolumn{4}{|l|}{ Mean of gradient proxy } \\
\hline India & & -0.324 & -0.236 \\
\hline Africa & & -0.066 & -0.038 \\
\hline Kerala \& Northeast & & -0.214 & -0.184 \\
\hline Rest of India & & -0.324 & -0.234 \\
\hline Log GDP per capita & Yes & Yes & Yes \\
\hline Sample & Full & Africa & Africa \\
\hline Observations & 168,135 & 126,066 & 126,066 \\
\hline
\end{tabular}

Notes: Standard errors are clustered by PSU and appear in brackets. Please consider the notes in Table 2.12 for further explanations. Source: Adapted from J+P using data from DHS (Heger Boyle \& Sobek, 2019) 
Table B.46: Sample Comparison (2004-2010): Weighted

\begin{tabular}{|c|c|c|c|}
\hline & & $\begin{array}{l}\text { Accounting } \\
\text { Exercise } 1\end{array}$ & $\begin{array}{c}\text { Accounting } \\
\text { Exercise } 2\end{array}$ \\
\hline & $\begin{array}{c}\text { HFA z-score } \\
\text { (1) }\end{array}$ & $\begin{array}{c}\text { HFA z-score } \\
\text { (2) }\end{array}$ & $\begin{array}{c}\text { HFA z-score } \\
\text { (3) }\end{array}$ \\
\hline India & $\begin{array}{c}-0.342 \\
{[0.020]}\end{array}$ & & \\
\hline Gradient proxy & & $\begin{array}{c}0.335 \\
{[0.073]}\end{array}$ & $\begin{array}{c}0.703 \\
{[0.139]}\end{array}$ \\
\hline \multicolumn{4}{|l|}{ Mean of gradient proxy } \\
\hline India & & -0.324 & -0.236 \\
\hline Africa & & -0.068 & -0.040 \\
\hline Kerala \& Northeast & & -0.214 & -0.184 \\
\hline Rest of India & & -0.324 & -0.234 \\
\hline Log GDP per capita & Yes & Yes & Yes \\
\hline Sample & Full & Africa & Africa \\
\hline Observations & 168,135 & 126,066 & 126,066 \\
\hline
\end{tabular}

Notes: Standard errors are clustered by PSU and appear in brackets. Please consider the notes in Table 2.12 for further explanations. Source: Adapted from J+P using data from DHS (Heger Boyle \& Sobek, 2019) 
Table B.47: Accounting Exercise Part 2: Sample Comparison (2004-2010): Unweighted

Accounting Accounting

Exercise $1 \quad$ Exercise 2

Calculation 1: Share explained by birth order gradient

- India-Africa gap in birth order gradient

$-0.265 \quad-0.197$

- India-Africa gap in birth order gradient $\times$ Gradient coeff

$-0.109-0.139$

- Explained share of India-Africa level gap in height (shown in column 1)

$67 \% \quad 86 \%$

Calculation 2: Share explained by birth order gradient rooted in eldest son preference

- Rest of India - Kerala \& NE gap in birth order gradient

$-0.129-0.102$

- Rest of India - Kerala \& NE gap in birth order gradient $\times$ Gradient coff

$-0.053-0.072$

- Explained share of India-Africa level gap in height (shown in column 1)

$33 \%$

$44 \%$

Source: Adapted from J+P using data from DHS (Heger Boyle \& Sobek, 2019)

Table B.48: Accounting Exercise Part 2: Sample Comparison (2004-2010): Weighted India

Accounting Accounting

Exercise $1 \quad$ Exercise 2

Calculation 1: Share explained by birth order gradient

- India-Africa gap in birth order gradient

$\begin{array}{ll}-0.258 & -0.198 \\ -0.106 & -0.139 \\ 32 \% & 42 \%\end{array}$

- Explained share of India-Africa level gap in height (shown in column 1)

$-0.106$

$42 \%$

Calculation 2: Share explained by birth order gradient rooted in eldest son preference

- Rest of India - Kerala \& NE gap in birth order gradient

$-0.110 \quad-0.050$

- Rest of India - Kerala \& NE gap in birth order gradient $\times$ Gradient coff

$-0.045-0.035$

- Explained share of India-Africa level gap in height (shown in column 1)

$14 \%$

$11 \%$

Source: Adapted from J+P using data from DHS (Heger Boyle \& Sobek, 2019)

Table B.49: Accounting Exercise Part 2: Sample Comparison (2004-2010): Weighted

Accounting Accounting

Exercise $1 \quad$ Exercise 2

Calculation 1: Share explained by birth order gradient

- India-Africa gap in birth order gradient

$-0.256 \quad-0.196$

- India-Africa gap in birth order gradient $\times$ Gradient coeff

$-0.086$

$-0.138$

- Explained share of India-Africa level gap in height (shown in column 1)

$25 \%$

$40 \%$

Calculation 2: Share explained by birth order gradient rooted in eldest son preference

- Rest of India - Kerala \& NE gap in birth order gradient

$-0.110$

$-0.050$

- Rest of India - Kerala \& NE gap in birth order gradient $\times$ Gradient coff

$-0.037$

$-0.035$

- Explained share of India-Africa level gap in height (shown in column 1)

$11 \%$

$10 \%$

Source: Adapted from J+P using data from DHS (Heger Boyle \& Sobek, 2019) 


\section{Replicated Results (2004-2010) and Replicated Results (2011- 2017): Adjusted Methodology and Data from the More Re- cent Time Period}

\subsection{Summary Statistics}

Table B.50: Summary Statistics (2004-2010): Weighted

\begin{tabular}{|c|c|c|c|c|c|}
\hline & $\begin{array}{c}\text { India } \\
\text { subsample }\end{array}$ & $\begin{array}{c}\text { Africa } \\
\text { subsample }\end{array}$ & & $\begin{array}{c}\text { India } \\
\text { subsample }\end{array}$ & $\begin{array}{c}\text { Africa } \\
\text { subsample }\end{array}$ \\
\hline Mother's age at birth (years) & $\begin{array}{l}24.25 \\
{[5.19]}\end{array}$ & $\begin{array}{l}26.95 \\
{[6.85]}\end{array}$ & Child's age (months) & $\begin{array}{c}30.18 \\
{[17.01]}\end{array}$ & $\begin{array}{c}28.26 \\
{[17.05]}\end{array}$ \\
\hline Mother's total children born & $\begin{array}{c}2.87 \\
{[1.91]}\end{array}$ & $\begin{array}{c}3.90 \\
{[2.55]}\end{array}$ & Child is a girl & $\begin{array}{c}0.48 \\
{[0.50]}\end{array}$ & $\begin{array}{c}0.50 \\
{[0.50]}\end{array}$ \\
\hline Mother's desired fertility & $\begin{array}{c}2.45 \\
{[0.89]}\end{array}$ & $\begin{array}{c}4.62 \\
{[1.46]}\end{array}$ & Child's birth order & $\begin{array}{c}2.74 \\
{[1.88]}\end{array}$ & $\begin{array}{c}3.75 \\
{[2.48]}\end{array}$ \\
\hline Mother wants more children & $\begin{array}{c}0.34 \\
{[0.47]}\end{array}$ & $\begin{array}{c}0.67 \\
{[0.46]}\end{array}$ & Child's HFA z-score & $\begin{array}{l}-1.67 \\
{[1.80]}\end{array}$ & $\begin{array}{l}-1.36 \\
{[1.96]}\end{array}$ \\
\hline Mother completed her fertility & $\begin{array}{c}0.67 \\
{[0.47]}\end{array}$ & $\begin{array}{c}0.33 \\
{[0.47]}\end{array}$ & Child is stunted & $\begin{array}{c}0.45 \\
{[0.50]}\end{array}$ & $\begin{array}{c}0.38 \\
{[0.49]}\end{array}$ \\
\hline Mother is literate & $\begin{array}{c}0.49 \\
{[0.50]}\end{array}$ & $\begin{array}{c}0.48 \\
{[0.50]}\end{array}$ & Child's WFA z-score & $\begin{array}{l}-1.70 \\
{[1.30]}\end{array}$ & $\begin{array}{l}-0.89 \\
{[1.44]}\end{array}$ \\
\hline Mother's height (meters) & $\begin{array}{c}1.52 \\
{[0.06]}\end{array}$ & $\begin{array}{c}1.58 \\
{[0.07]}\end{array}$ & Child's hemoglobin level $(\mathrm{g} / \mathrm{dl})$ & $\begin{array}{l}10.10 \\
{[1.56]}\end{array}$ & $\begin{array}{l}10.11 \\
{[1.70]}\end{array}$ \\
\hline Mother took iron supplements & $\begin{array}{c}0.66 \\
{[0.47]}\end{array}$ & $\begin{array}{c}0.62 \\
{[0.49]}\end{array}$ & Child is deceased & $\begin{array}{c}0.06 \\
{[0.23]}\end{array}$ & $\begin{array}{c}0.07 \\
{[0.26]}\end{array}$ \\
\hline Mother's total tetanus shots & $\begin{array}{c}1.86 \\
{[0.95]}\end{array}$ & $\begin{array}{c}1.41 \\
{[1.21]}\end{array}$ & Child taking iron pills & $\begin{array}{c}0.05 \\
{[0.21]}\end{array}$ & $\begin{array}{c}0.13 \\
{[0.34]}\end{array}$ \\
\hline Total prenatal visits & $\begin{array}{c}3.49 \\
{[3.32]}\end{array}$ & $\begin{array}{c}3.87 \\
{[3.28]}\end{array}$ & Child's total vaccinations & $\begin{array}{c}6.42 \\
{[2.75]}\end{array}$ & $\begin{array}{c}6.14 \\
{[3.17]}\end{array}$ \\
\hline Delivery at health facility & $\begin{array}{c}0.39 \\
{[0.49]}\end{array}$ & $\begin{array}{c}0.47 \\
{[0.50]}\end{array}$ & Birth spacing (months) & $\begin{array}{c}35.43 \\
{[19.42]}\end{array}$ & $\begin{array}{c}38.43 \\
{[20.43]}\end{array}$ \\
\hline Postnatal check within 2 months & $\begin{array}{c}0.08 \\
{[0.28]}\end{array}$ & $\begin{array}{c}0.32 \\
{[0.47]}\end{array}$ & Diarrhea in last 2 weeks & $\begin{array}{c}0.09 \\
{[0.29]}\end{array}$ & $\begin{array}{c}0.16 \\
{[0.37]}\end{array}$ \\
\hline Average pooled inputs & $\begin{array}{c}0.30 \\
{[0.27]}\end{array}$ & $\begin{array}{c}0.38 \\
{[0.31]}\end{array}$ & Open defecation & $\begin{array}{c}0.63 \\
{[0.48]}\end{array}$ & $\begin{array}{c}0.32 \\
{[0.47]}\end{array}$ \\
\hline Percent non-resident among children & $\begin{array}{c}0.02 \\
{[0.03]}\end{array}$ & $\begin{array}{c}0.09 \\
{[0.08]}\end{array}$ & Number of PSUs & 3,822 & 10,366 \\
\hline Number of adult females in household & $\begin{array}{c}1.89 \\
{[1.11]}\end{array}$ & $\begin{array}{c}1.59 \\
{[1.05]}\end{array}$ & Main sample of children & 42,069 & 126,066 \\
\hline Log GDP per capita (in child's birth year) & $\begin{array}{c}7.77 \\
{[0.10]}\end{array}$ & $\begin{array}{c}7.35 \\
{[0.67]}\end{array}$ & & & \\
\hline
\end{tabular}

Notes: The means of the specified variables are calculated separately for the India and Africa subsamples. Standard deviations appear in brackets. Please consider the notes in Table 2.4 for further explanations.

Source: Adapted from J+P using data from DHS (Heger Boyle \& Sobek, 2019) 
Table B.51: Summary Statistics (2011-2017): Weighted

\begin{tabular}{|c|c|c|c|c|c|}
\hline & $\begin{array}{c}\text { India } \\
\text { subsample }\end{array}$ & $\begin{array}{c}\text { Africa } \\
\text { subsample }\end{array}$ & & $\begin{array}{c}\text { India } \\
\text { subsample }\end{array}$ & $\begin{array}{c}\text { Africa } \\
\text { subsample }\end{array}$ \\
\hline Mother's age at birth (years) & $\begin{array}{l}24.72 \\
{[4.76]}\end{array}$ & $\begin{array}{l}27.13 \\
{[6.68]}\end{array}$ & Child's age (months) & $\begin{array}{c}30.18 \\
{[16.88]}\end{array}$ & $\begin{array}{c}28.92 \\
{[17.06]}\end{array}$ \\
\hline Mother's total children born & $\begin{array}{c}2.30 \\
{[1.42]}\end{array}$ & $\begin{array}{c}3.75 \\
{[2.46]}\end{array}$ & Child is a girl & $\begin{array}{c}0.48 \\
{[0.50]}\end{array}$ & $\begin{array}{c}0.50 \\
{[0.50]}\end{array}$ \\
\hline Mother's desired fertility & $\begin{array}{c}2.28 \\
{[0.88]}\end{array}$ & $\begin{array}{c}4.62 \\
{[1.44]}\end{array}$ & Child's birth order & $\begin{array}{c}2.18 \\
{[1.40]}\end{array}$ & $\begin{array}{c}3.64 \\
{[2.41]}\end{array}$ \\
\hline Mother wants more children & $\begin{array}{c}0.39 \\
{[0.48]}\end{array}$ & $\begin{array}{c}0.69 \\
{[0.45]}\end{array}$ & Child's HFA z-score & $\begin{array}{l}-1.26 \\
{[1.82]}\end{array}$ & $\begin{array}{l}-1.16 \\
{[1.79]}\end{array}$ \\
\hline Mother completed her fertility & $\begin{array}{c}0.63 \\
{[0.48]}\end{array}$ & $\begin{array}{c}0.31 \\
{[0.46]}\end{array}$ & Child is stunted & $\begin{array}{c}0.35 \\
{[0.48]}\end{array}$ & $\begin{array}{c}0.31 \\
{[0.46]}\end{array}$ \\
\hline Mother is literate & $\begin{array}{c}0.68 \\
{[0.47]}\end{array}$ & $\begin{array}{c}0.55 \\
{[0.50]}\end{array}$ & Child's WFA z-score & $\begin{array}{l}-1.47 \\
{[1.28]}\end{array}$ & $\begin{array}{l}-0.84 \\
{[1.35]}\end{array}$ \\
\hline Mother's height (meters) & $\begin{array}{c}1.52 \\
{[0.06]}\end{array}$ & $\begin{array}{c}1.58 \\
{[0.06]}\end{array}$ & Child's hemoglobin level (g/dl) & $\begin{array}{l}10.55 \\
{[1.48]}\end{array}$ & $\begin{array}{l}10.44 \\
{[1.63]}\end{array}$ \\
\hline Mother took iron supplements & $\begin{array}{c}0.78 \\
{[0.41]}\end{array}$ & $\begin{array}{c}0.74 \\
{[0.44]}\end{array}$ & Child is deceased & $\begin{array}{c}0.04 \\
{[0.19]}\end{array}$ & $\begin{array}{c}0.05 \\
{[0.22]}\end{array}$ \\
\hline Mother's total tetanus shots & $\begin{array}{c}1.93 \\
{[0.78]}\end{array}$ & $\begin{array}{c}1.41 \\
{[1.11]}\end{array}$ & Child taking iron pills & $\begin{array}{c}0.25 \\
{[0.43]}\end{array}$ & $\begin{array}{c}0.08 \\
{[0.27]}\end{array}$ \\
\hline Total prenatal visits & $\begin{array}{c}4.63 \\
{[4.20]}\end{array}$ & $\begin{array}{c}3.99 \\
{[3.17]}\end{array}$ & Child's total vaccinations & $\begin{array}{c}7.43 \\
{[2.60]}\end{array}$ & $\begin{array}{c}4.98 \\
{[3.50]}\end{array}$ \\
\hline Delivery at health facility & $\begin{array}{c}0.80 \\
{[0.40]}\end{array}$ & $\begin{array}{c}0.58 \\
{[0.49]}\end{array}$ & Birth spacing (months) & $\begin{array}{c}37.16 \\
{[21.61]}\end{array}$ & $\begin{array}{c}39.46 \\
{[21.44]}\end{array}$ \\
\hline Postnatal check within 2 months & $\begin{array}{c}0.38 \\
{[0.48]}\end{array}$ & $\begin{array}{c}0.45 \\
{[0.50]}\end{array}$ & Diarrhea in last 2 weeks & $\begin{array}{c}0.09 \\
{[0.29]}\end{array}$ & $\begin{array}{c}0.15 \\
{[0.36]}\end{array}$ \\
\hline Average pooled inputs & $\begin{array}{c}0.47 \\
{[0.24]}\end{array}$ & $\begin{array}{c}0.38 \\
{[0.28]}\end{array}$ & Open defecation & $\begin{array}{c}0.47 \\
{[0.50]}\end{array}$ & $\begin{array}{c}0.23 \\
{[0.42]}\end{array}$ \\
\hline Percent non-resident among children & $\begin{array}{c}0.02 \\
{[0.03]}\end{array}$ & $\begin{array}{c}0.09 \\
{[0.00]}\end{array}$ & Number of PSUs & 28,215 & 12,684 \\
\hline Number of adult females in household & $\begin{array}{c}1.94 \\
{[1.04]}\end{array}$ & $\begin{array}{c}1.59 \\
{[1.12]}\end{array}$ & Main sample of children & 230,220 & 168,490 \\
\hline Log GDP per capita (in child's birth year) & $\begin{array}{c}8.50 \\
{[0.08]}\end{array}$ & $\begin{array}{c}7.80 \\
{[0.68]}\end{array}$ & & & \\
\hline
\end{tabular}

Notes: The means of the specified variables are calculated separately for the India and Africa subsamples. Standard deviations appear in brackets. Please consider the notes in Table 2.4 for further explanations.

Source: Adapted from J+P using data from IPUMS DHS (ICF, 2004) and DHS (Heger Boyle \& Sobek, 2019) 
Figure B.7: Child Height versus National GDP (2004-2010) vs (2011-2017): Weighted

Replication (2004-2010): Weighted

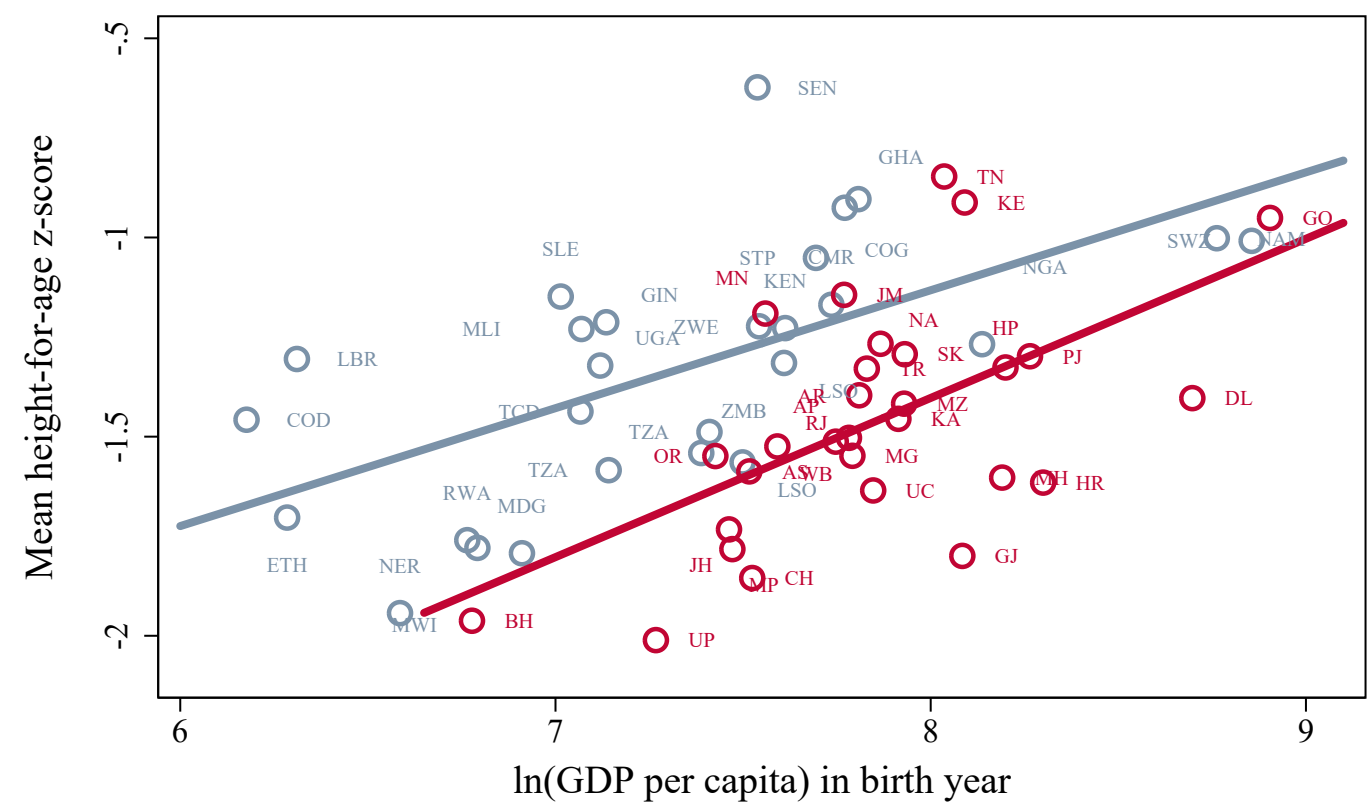

$\begin{array}{lll} & \text { African countries } & \text { Africa fitted values } \\ \text { Indian states } & \text { India fitted values }\end{array}$

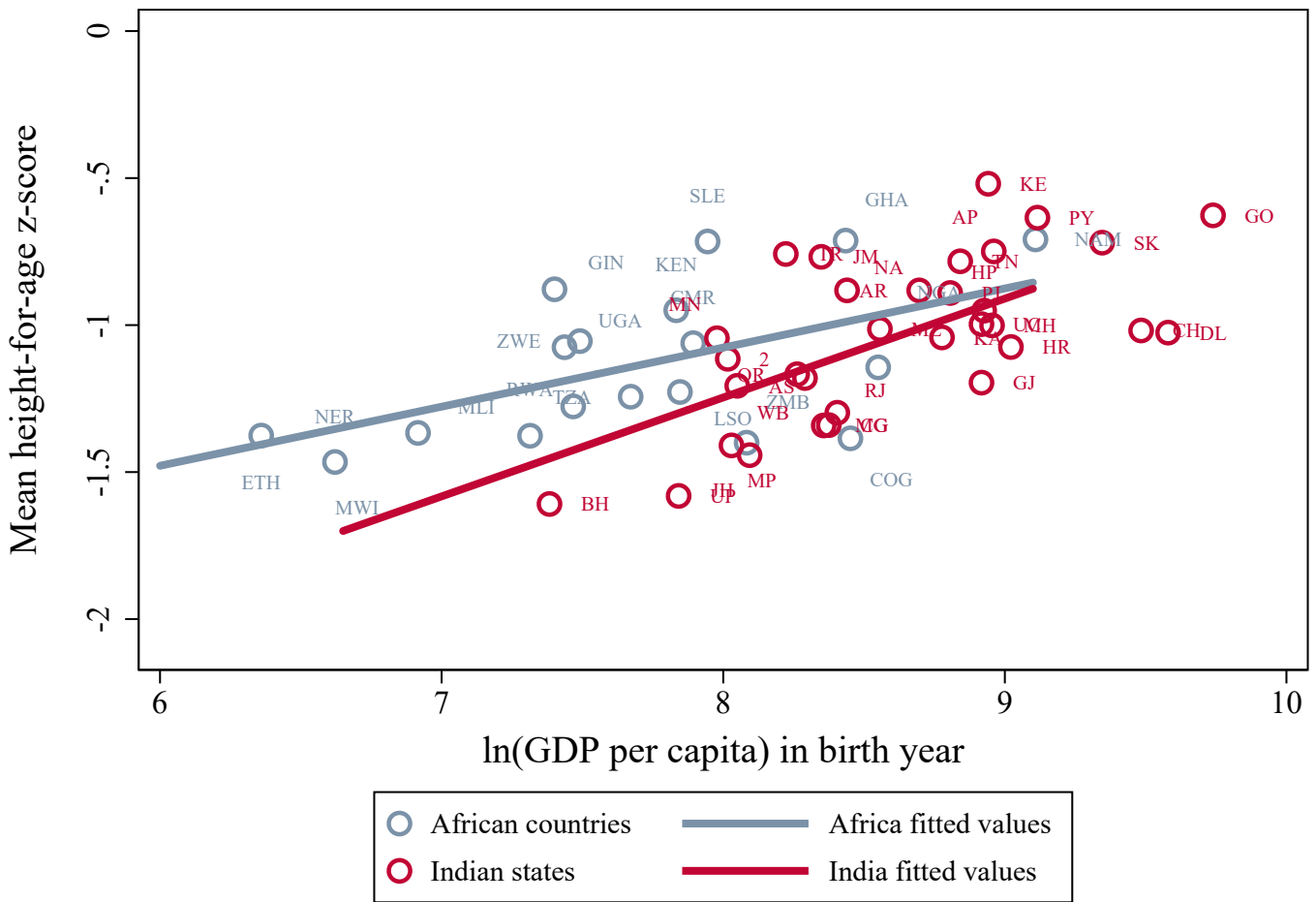

Notes: The light and dark circles represent sub-Saharan African countries and Indian states, respectively. The averages are calculated over all children less than 60 months old. The lines represent the best linear fit for each sample.

Source: Adapted from J+P using data from Penn World Table 9.0, Penn World Table 9.1, and the Handbook of Statistics on Indian States (Robert C. Feenstra, 2016, 2019; Reserve Bank of India, 2019) 


\subsection{India's Differential Birth Order Gradient in Child Height and Re- lated Outcomes}

Table B.52: India's Differential Birth Order Gradient in Child Height and Related Outcomes (2004-2010): Weighted

\begin{tabular}{|c|c|c|c|c|c|c|c|c|c|}
\hline & $\begin{array}{l}\text { HFA } \\
\text { Z- } \\
\text { score } \\
(1)\end{array}$ & $\begin{array}{l}\text { HFA } \\
\text { Z- } \\
\text { score } \\
(2)\end{array}$ & $\begin{array}{l}\text { HFA } \\
\text { z- } \\
\text { score } \\
(3)\end{array}$ & $\begin{array}{l}\text { HFA } \\
\text { Z- } \\
\text { score } \\
(4)\end{array}$ & $\begin{array}{l}\text { HFA } \\
\text { Z- } \\
\text { score } \\
(5)\end{array}$ & $\begin{array}{l}\text { Stunted } \\
\text { (6) }\end{array}$ & $\begin{array}{l}\text { WFA } \\
\text { z- } \\
\text { score } \\
(7)\end{array}$ & $\begin{array}{c}\mathrm{Hb} \\
\text { level } \\
(8)\end{array}$ & $\begin{array}{l}\text { Deceasec } \\
\text { (9) }\end{array}$ \\
\hline India & $\begin{array}{l}-0.083 \\
{[0.011]}\end{array}$ & $\begin{array}{l}-0.073 \\
{[0.023]}\end{array}$ & & & & & & & \\
\hline India $\times 2$ nd child & & $\begin{array}{l}-0.119 \\
{[0.032]}\end{array}$ & $\begin{array}{l}-0.152 \\
{[0.034]}\end{array}$ & $\begin{array}{l}-0.064 \\
{[0.081]}\end{array}$ & $\begin{array}{l}-0.274 \\
{[0.061]}\end{array}$ & $\begin{array}{c}0.047 \\
{[0.010]}\end{array}$ & $\begin{array}{l}-0.147 \\
{[0.025]}\end{array}$ & $\begin{array}{l}-0.089 \\
{[0.039]}\end{array}$ & $\begin{array}{l}-0.002 \\
{[0.005]}\end{array}$ \\
\hline India $\times 3$ rd + child & & $\begin{array}{l}-0.356 \\
{[0.030]}\end{array}$ & $\begin{array}{l}-0.199 \\
{[0.041]}\end{array}$ & $\begin{array}{l}-0.088 \\
{[0.117]}\end{array}$ & $\begin{array}{l}-0.442 \\
{[0.107]}\end{array}$ & $\begin{array}{c}0.056 \\
{[0.012]}\end{array}$ & $\begin{array}{l}-0.192 \\
{[0.030]}\end{array}$ & $\begin{array}{l}-0.174 \\
{[0.046]}\end{array}$ & $\begin{array}{l}-0.001 \\
{[0.006]}\end{array}$ \\
\hline 2nd child & & $\begin{array}{c}0.035 \\
{[0.019]}\end{array}$ & $\begin{array}{c}0.003 \\
{[0.021]}\end{array}$ & $\begin{array}{l}-0.142 \\
{[0.069]}\end{array}$ & $\begin{array}{l}-0.168 \\
{[0.034]}\end{array}$ & $\begin{array}{c}0.009 \\
{[0.005]}\end{array}$ & $\begin{array}{c}0.020 \\
{[0.015]}\end{array}$ & $\begin{array}{l}-0.015 \\
{[0.027]}\end{array}$ & $\begin{array}{l}-0.016 \\
{[0.003]}\end{array}$ \\
\hline $3 \mathrm{rd}+$ child & & $\begin{array}{l}-0.070 \\
{[0.016]}\end{array}$ & $\begin{array}{l}-0.121 \\
{[0.024]}\end{array}$ & $\begin{array}{l}-0.277 \\
{[0.094]}\end{array}$ & $\begin{array}{l}-0.363 \\
{[0.054]}\end{array}$ & $\begin{array}{c}0.038 \\
{[0.006]}\end{array}$ & $\begin{array}{l}-0.061 \\
{[0.017]}\end{array}$ & $\begin{array}{l}-0.026 \\
{[0.031]}\end{array}$ & $\begin{array}{l}-0.015 \\
{[0.003]}\end{array}$ \\
\hline Africa mean of outcome & -1.363 & -1.363 & -1.363 & -1.363 & -1.363 & 0.381 & -0.889 & 10.107 & 0.074 \\
\hline Child's age dummies $\times$ India & No & No & Yes & Yes & Yes & Yes & Yes & Yes & Yes \\
\hline Mother's literacy $\times$ India & No & No & Yes & Yes & No & Yes & Yes & Yes & Yes \\
\hline Mother's age at birth $\times$ India & No & No & Yes & Yes & No & Yes & Yes & Yes & Yes \\
\hline PSU FEs & No & No & Yes & Yes & No & Yes & Yes & Yes & Yes \\
\hline Mother FEs & No & No & No & No & Yes & No & No & No & No \\
\hline Completed fertility sample & No & No & No & Yes & No & No & No & No & No \\
\hline Observations & 168,135 & 168,135 & 167,765 & 66,574 & 83,243 & 167,765 & 167,765 & 88,893 & 199,514 \\
\hline
\end{tabular}

Notes: Standard errors are clustered by mother and appear in brackets. Please consider the notes in Table 2.6 for further explanations.

Source: Adapted from J+P using data from DHS (Heger Boyle \& Sobek, 2019) 
Table B.53: India's Differential Birth Order Gradient in Child Height and Related Outcomes (2011-2017): Weighted

\begin{tabular}{|c|c|c|c|c|c|c|c|c|c|}
\hline & $\begin{array}{l}\text { HFA } \\
\text { Z- } \\
\text { score } \\
(1)\end{array}$ & $\begin{array}{l}\text { HFA } \\
\text { Z- } \\
\text { score } \\
(2)\end{array}$ & $\begin{array}{l}\text { HFA } \\
\text { z- } \\
\text { score } \\
(3)\end{array}$ & $\begin{array}{l}\text { HFA } \\
\text { Z- } \\
\text { score } \\
(4)\end{array}$ & $\begin{array}{l}\text { HFA } \\
\text { Z- } \\
\text { score } \\
(5)\end{array}$ & $\begin{array}{l}\text { Stunted } \\
\text { (6) }\end{array}$ & $\begin{array}{l}\text { WFA } \\
\text { Z- } \\
\text { score } \\
(7)\end{array}$ & $\begin{array}{c}\mathrm{Hb} \\
\text { level } \\
(8)\end{array}$ & $\begin{array}{l}\text { Deceasec } \\
\text { (9) }\end{array}$ \\
\hline India & $\begin{array}{l}-0.107 \\
{[0.006]}\end{array}$ & $\begin{array}{c}0.036 \\
{[0.015]}\end{array}$ & & & & & & & \\
\hline India $\times 2$ nd child & & $\begin{array}{l}-0.113 \\
{[0.020]}\end{array}$ & $\begin{array}{l}-0.077 \\
{[0.022]}\end{array}$ & $\begin{array}{l}-0.099 \\
{[0.070]}\end{array}$ & $\begin{array}{l}-0.179 \\
{[0.038]}\end{array}$ & $\begin{array}{c}0.026 \\
{[0.006]}\end{array}$ & $\begin{array}{l}-0.093 \\
{[0.016]}\end{array}$ & $\begin{array}{l}-0.045 \\
{[0.025]}\end{array}$ & $\begin{array}{l}-0.002 \\
{[0.003]}\end{array}$ \\
\hline India $\times 3$ rd + child & & $\begin{array}{l}-0.309 \\
{[0.019]}\end{array}$ & $\begin{array}{l}-0.114 \\
{[0.026]}\end{array}$ & $\begin{array}{l}-0.081 \\
{[0.097]}\end{array}$ & $\begin{array}{l}-0.413 \\
{[0.067]}\end{array}$ & $\begin{array}{c}0.027 \\
{[0.007]}\end{array}$ & $\begin{array}{l}-0.135 \\
{[0.019]}\end{array}$ & $\begin{array}{l}-0.008 \\
{[0.028]}\end{array}$ & $\begin{array}{c}0.001 \\
{[0.003]}\end{array}$ \\
\hline 2nd child & & $\begin{array}{c}0.003 \\
{[0.016]}\end{array}$ & $\begin{array}{l}-0.056 \\
{[0.018]}\end{array}$ & $\begin{array}{l}-0.077 \\
{[0.067]}\end{array}$ & $\begin{array}{l}-0.208 \\
{[0.029]}\end{array}$ & $\begin{array}{c}0.014 \\
{[0.005]}\end{array}$ & $\begin{array}{l}-0.014 \\
{[0.013]}\end{array}$ & $\begin{array}{l}-0.033 \\
{[0.022]}\end{array}$ & $\begin{array}{l}-0.009 \\
{[0.002]}\end{array}$ \\
\hline 3rd + child & & $\begin{array}{l}-0.136 \\
{[0.014]}\end{array}$ & $\begin{array}{l}-0.167 \\
{[0.020]}\end{array}$ & $\begin{array}{l}-0.150 \\
{[0.091]}\end{array}$ & $\begin{array}{l}-0.315 \\
{[0.047]}\end{array}$ & $\begin{array}{c}0.047 \\
{[0.005]}\end{array}$ & $\begin{array}{l}-0.083 \\
{[0.015]}\end{array}$ & $\begin{array}{l}-0.127 \\
{[0.025]}\end{array}$ & $\begin{array}{l}-0.011 \\
{[0.002]}\end{array}$ \\
\hline Africa mean of outcome & -1.163 & -1.163 & -1.163 & -1.163 & -1.163 & 0.311 & -0.838 & 10.439 & 0.050 \\
\hline Child's age dummies $\times$ India & No & No & Yes & Yes & Yes & Yes & Yes & Yes & Yes \\
\hline Mother's literacy $\times$ India & No & No & Yes & Yes & No & Yes & Yes & Yes & Yes \\
\hline Mother's age at birth $\times$ India & No & No & Yes & Yes & No & Yes & Yes & Yes & Yes \\
\hline PSU FEs & No & No & Yes & Yes & No & Yes & Yes & Yes & Yes \\
\hline Mother FEs & No & No & No & No & Yes & No & No & No & No \\
\hline Completed fertility sample & No & No & No & Yes & No & No & No & No & No \\
\hline Observations & 398,710 & 398,710 & 397,702 & 176,665 & 189,520 & 397,702 & 397,702 & 300,933 & 410,460 \\
\hline
\end{tabular}

Notes: Standard errors are clustered by mother and appear in brackets. Please consider the notes in Table 2.6 for further explanations. Source: Adapted from J+P using data from IPUMS DHS (ICF, 2004) and DHS (Heger Boyle \& Sobek, 2019) 
Figure B.8: Child Height in India and Africa, by Child's Birth Order (2004-2010) vs (20112017): Weighted

Replication (2004-2010): Weighted

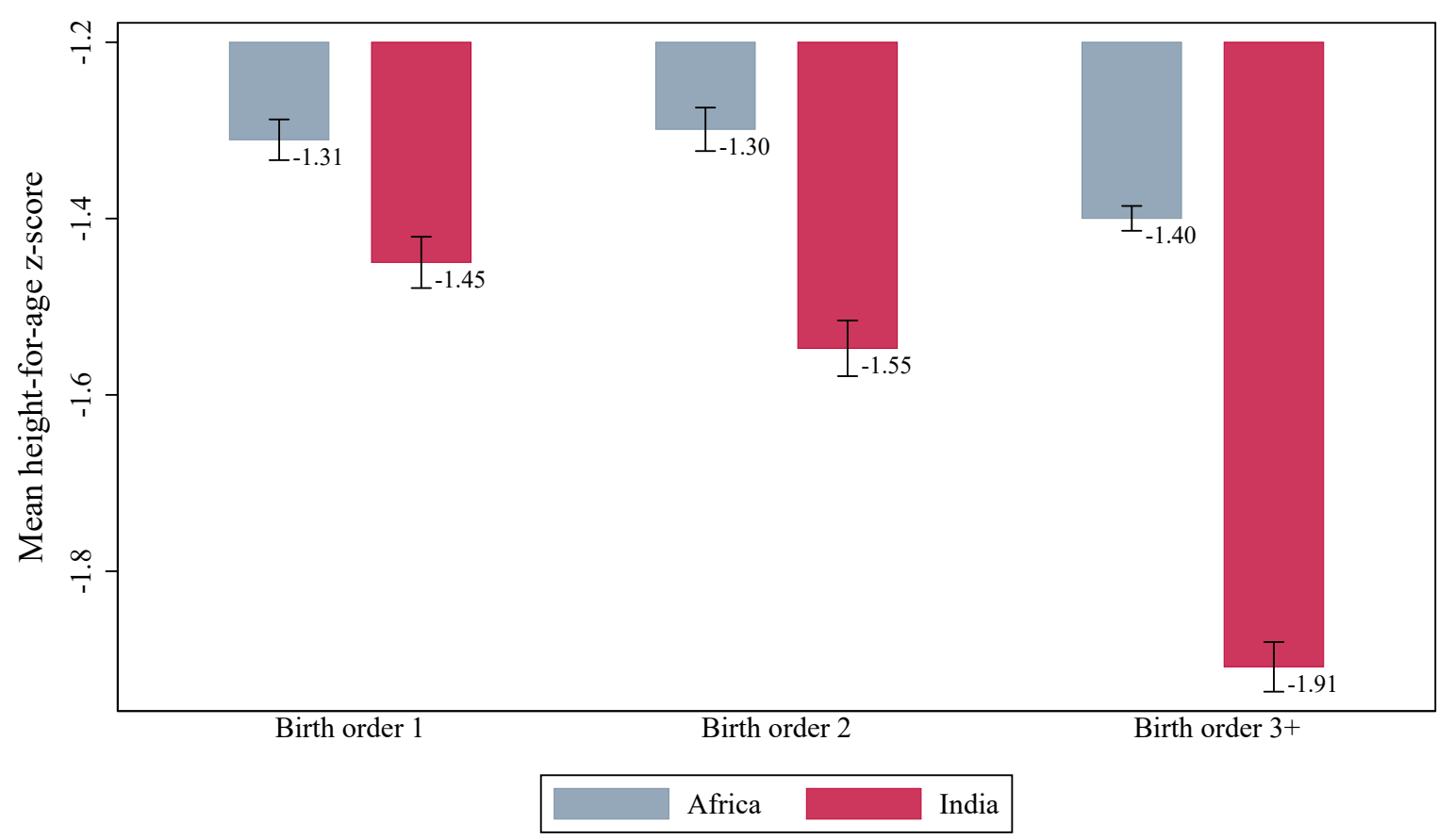

Replication (2011-2017): Weighted

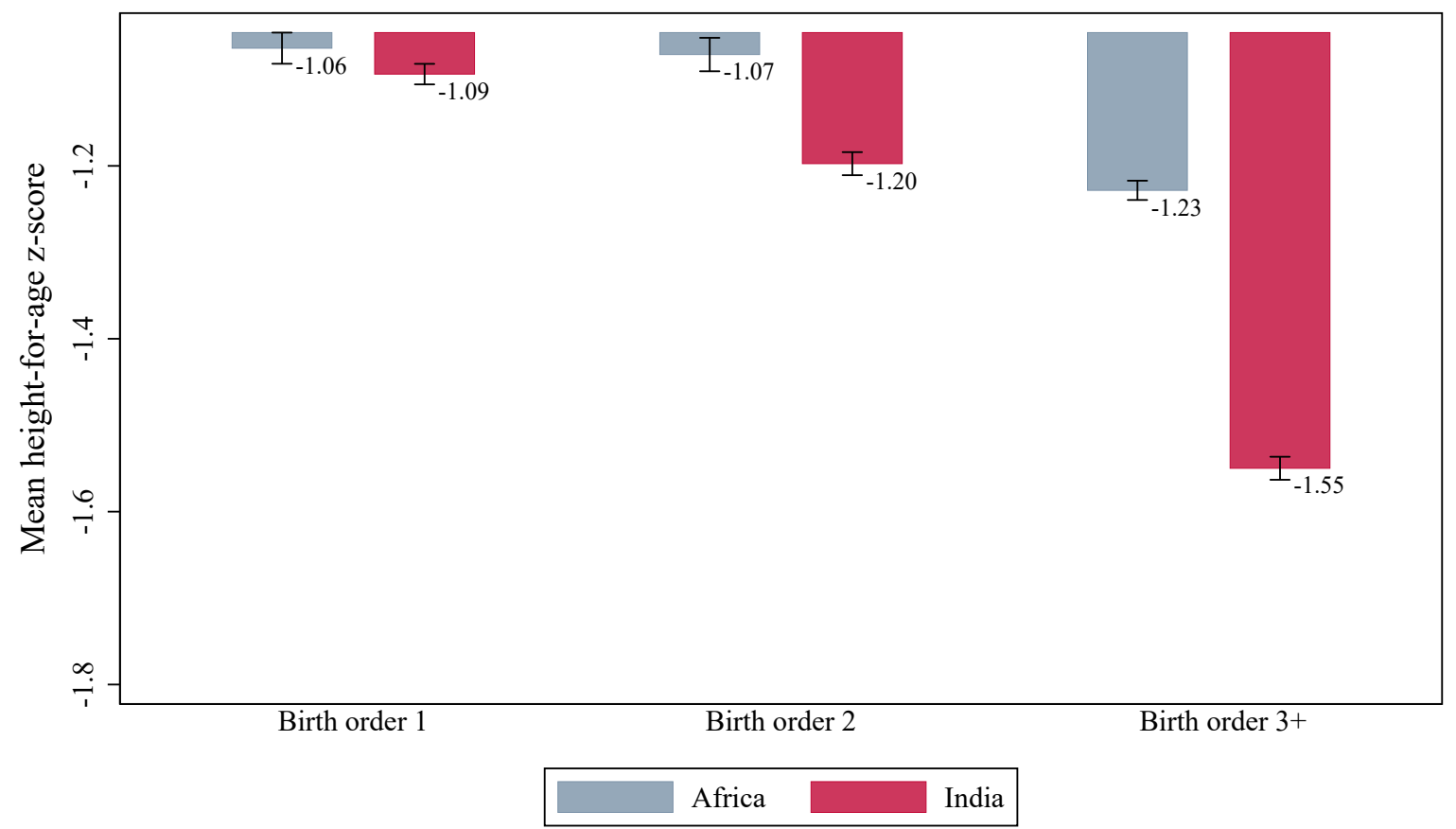

Notes: The figure depicts the mean child height-for-age z-scores for sub-Saharan Africa and India, by the birth order of the child. The mean is calculated over all children less than 60 months old.

Source: Adapted from J+P using data from DHS (ICF, 2004) and IPUMS DHS (Heger Boyle \& Sobek, 2019) 


\subsection{Child Health Inputs}

Table B.54: Child Health Inputs (2004-2010): Weighted

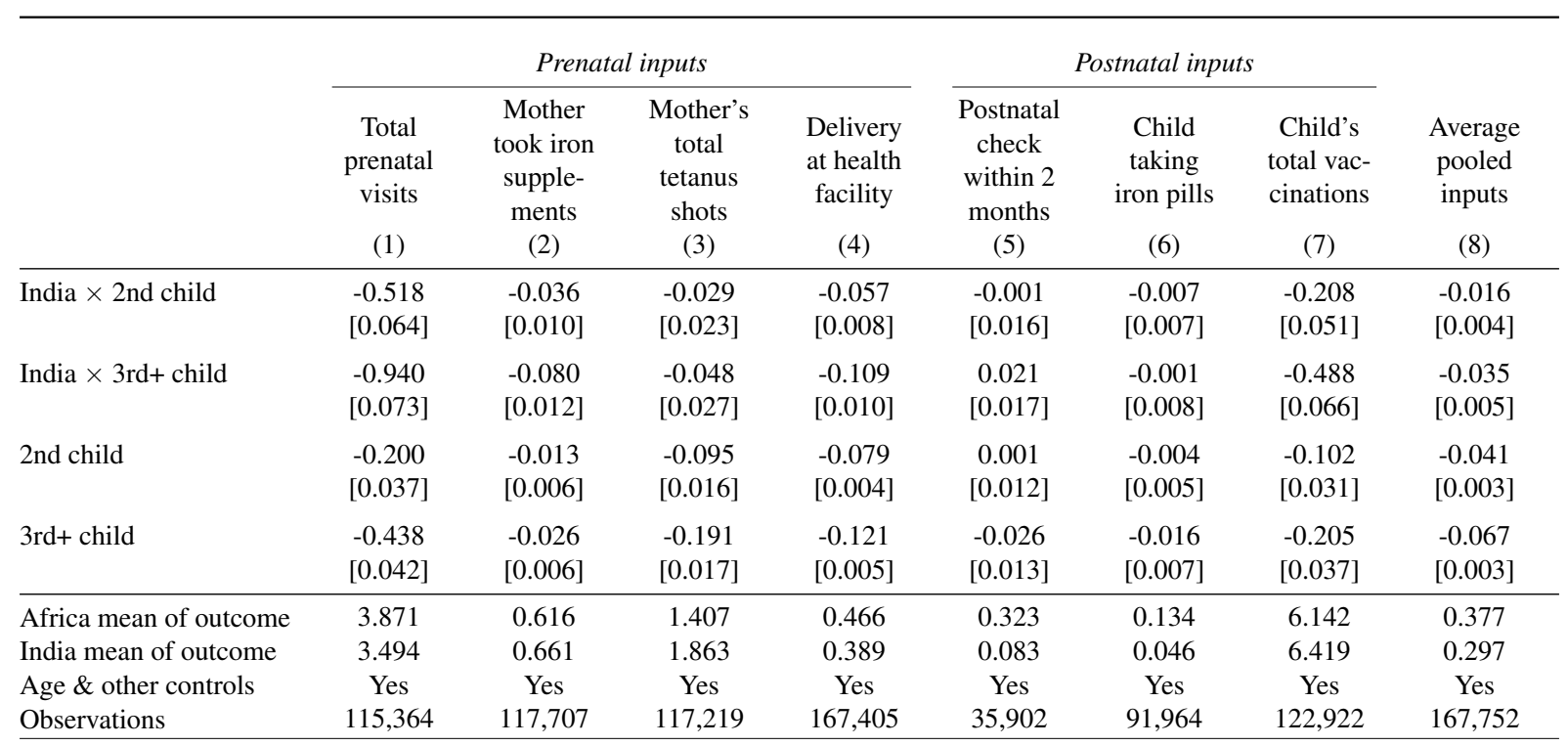

Notes: Standard errors are clustered by mother and appear in brackets. Please consider the notes in Table 2.8 for further explanations.

Source: Adapted from J+P using data from DHS (Heger Boyle \& Sobek, 2019)

Table B.55: Child Health Inputs (2011-2017): Weighted

\begin{tabular}{|c|c|c|c|c|c|c|c|c|}
\hline & \multicolumn{4}{|c|}{ Prenatal inputs } & \multicolumn{3}{|c|}{ Postnatal inputs } & \multirow[b]{2}{*}{$\begin{array}{l}\text { Average } \\
\text { pooled } \\
\text { inputs } \\
\text { (8) }\end{array}$} \\
\hline & $\begin{array}{c}\text { Total } \\
\text { prenatal } \\
\text { visits } \\
(1)\end{array}$ & $\begin{array}{l}\text { Mother } \\
\text { took iron } \\
\text { supple- } \\
\text { ments } \\
\text { (2) }\end{array}$ & $\begin{array}{c}\text { Mother's } \\
\text { total } \\
\text { tetanus } \\
\text { shots } \\
\text { (3) }\end{array}$ & $\begin{array}{c}\text { Delivery } \\
\text { at health } \\
\text { facility } \\
\text { (4) }\end{array}$ & $\begin{array}{l}\text { Postnatal } \\
\text { check } \\
\text { within } 2 \\
\text { months } \\
\quad(5)\end{array}$ & $\begin{array}{c}\text { Child } \\
\text { taking } \\
\text { iron pills } \\
(6)\end{array}$ & $\begin{array}{c}\text { Child's } \\
\text { total vac- } \\
\text { cinations } \\
\text { (7) }\end{array}$ & \\
\hline India $\times 2$ nd child & $\begin{array}{c}-0.162 \\
{[0.048]}\end{array}$ & $\begin{array}{c}-0.006 \\
{[0.006]}\end{array}$ & $\begin{array}{c}0.047 \\
{[0.016]}\end{array}$ & $\begin{array}{c}0.010 \\
{[0.004]}\end{array}$ & $\begin{array}{c}0.006 \\
{[0.007]}\end{array}$ & $\begin{array}{c}-0.003 \\
{[0.004]}\end{array}$ & $\begin{array}{c}0.113 \\
{[0.058]}\end{array}$ & $\begin{array}{c}-0.000 \\
{[0.003]}\end{array}$ \\
\hline India $\times 3$ rd + child & $\begin{array}{c}-0.353 \\
{[0.055]}\end{array}$ & $\begin{array}{c}-0.022 \\
{[0.007]}\end{array}$ & $\begin{array}{c}0.088 \\
{[0.018]}\end{array}$ & $\begin{array}{c}0.003 \\
{[0.006]}\end{array}$ & $\begin{array}{c}0.016 \\
{[0.008]}\end{array}$ & $\begin{array}{c}-0.016 \\
{[0.005]}\end{array}$ & $\begin{array}{c}0.052 \\
{[0.070]}\end{array}$ & $\begin{array}{c}-0.005 \\
{[0.003]}\end{array}$ \\
\hline 2nd child & $\begin{array}{c}-0.279 \\
{[0.034]}\end{array}$ & $\begin{array}{c}-0.016 \\
{[0.005]}\end{array}$ & $\begin{array}{c}-0.127 \\
{[0.014]}\end{array}$ & $\begin{array}{c}-0.078 \\
{[0.004]}\end{array}$ & $\begin{array}{c}-0.014 \\
{[0.006]}\end{array}$ & $\begin{array}{c}-0.002 \\
{[0.003]}\end{array}$ & $\begin{array}{c}-0.232 \\
{[0.055]}\end{array}$ & $\begin{array}{c}-0.043 \\
{[0.002]}\end{array}$ \\
\hline 3rd+ child & $\begin{array}{c}-0.565 \\
{[0.038]}\end{array}$ & $\begin{array}{c}-0.027 \\
{[0.006]}\end{array}$ & $\begin{array}{c}-0.207 \\
{[0.016]}\end{array}$ & $\begin{array}{c}-0.135 \\
{[0.005]}\end{array}$ & $\begin{array}{c}-0.028 \\
{[0.007]}\end{array}$ & $\begin{array}{c}-0.002 \\
{[0.004]}\end{array}$ & $\begin{array}{c}-0.380 \\
{[0.065]}\end{array}$ & $\begin{array}{c}-0.071 \\
{[0.003]}\end{array}$ \\
\hline Africa mean of outcome & 3.993 & 0.742 & 1.410 & 0.582 & 0.448 & 0.078 & 4.982 & 0.382 \\
\hline India mean of outcome & 4.631 & 0.783 & 1.933 & 0.795 & 0.376 & 0.251 & 7.431 & 0.475 \\
\hline Age \& other controls & Yes & Yes & Yes & Yes & Yes & Yes & Yes & Yes \\
\hline Observations & 287,302 & 282,486 & 281,157 & 397,406 & 272,650 & 374,185 & 215,976 & 397,636 \\
\hline
\end{tabular}

Notes: Standard errors are clustered by mother and appear in brackets. Please consider the notes in Table 2.8 for further explanations. Source: Adapted from J+P using data from IPUMS DHS (ICF, 2004) and DHS (Heger Boyle \& Sobek, 2019) 


\subsection{Cultural Norms and Child Height: Within-India Evidence}

Table B.56: Cultural Norms and Child Height: Within-India Evidence (2004-2010): Weighted

\begin{tabular}{|c|c|c|c|c|c|c|}
\hline \multirow[t]{2}{*}{ Low son preference proxy: } & \multicolumn{2}{|c|}{ Kerala \& Northeast } & \multicolumn{2}{|c|}{$\begin{array}{l}\text { Below-median } \\
\text { child sex ratio }\end{array}$} & \multicolumn{2}{|c|}{ Muslims } \\
\hline & $\begin{array}{c}\text { HFA } \\
\text { z-score } \\
(1)\end{array}$ & $\begin{array}{c}\text { WFA } \\
\text { z-score } \\
(2)\end{array}$ & $\begin{array}{c}\text { HFA } \\
\text { z-score } \\
\text { (3) }\end{array}$ & $\begin{array}{c}\text { WFA } \\
\text { z-score } \\
\text { (4) }\end{array}$ & $\begin{array}{c}\text { HFA } \\
\text { z-score } \\
\text { (5) }\end{array}$ & $\begin{array}{c}\text { WFA } \\
\text { z-score } \\
(6)\end{array}$ \\
\hline Low son pref proxy $\times 2$ nd child & $\begin{array}{c}0.058 \\
{[0.053]}\end{array}$ & $\begin{array}{l}-0.003 \\
{[0.039]}\end{array}$ & $\begin{array}{c}0.082 \\
{[0.037]}\end{array}$ & $\begin{array}{c}0.049 \\
{[0.029]}\end{array}$ & $\begin{array}{l}-0.052 \\
{[0.055]}\end{array}$ & $\begin{array}{c}0.033 \\
{[0.043]}\end{array}$ \\
\hline Low son pref proxy $\times 3$ rd + child & $\begin{array}{l}-0.025 \\
{[0.061]}\end{array}$ & $\begin{array}{c}-0.002 \\
{[0.046]}\end{array}$ & $\begin{array}{c}0.003 \\
{[0.045]}\end{array}$ & $\begin{array}{l}-0.015 \\
{[0.035]}\end{array}$ & $\begin{array}{c}0.163 \\
{[0.065]}\end{array}$ & $\begin{array}{c}0.141 \\
{[0.049]}\end{array}$ \\
\hline 2nd child & $\begin{array}{c}-0.164 \\
{[0.019]}\end{array}$ & $\begin{array}{l}-0.135 \\
{[0.015]}\end{array}$ & $\begin{array}{l}-0.194 \\
{[0.023]}\end{array}$ & $\begin{array}{c}-0.157 \\
{[0.018]}\end{array}$ & $\begin{array}{l}-0.147 \\
{[0.021]}\end{array}$ & $\begin{array}{l}-0.136 \\
{[0.016]}\end{array}$ \\
\hline 3rd+ child & $\begin{array}{c}-0.368 \\
{[0.023]}\end{array}$ & $\begin{array}{l}-0.305 \\
{[0.018]}\end{array}$ & $\begin{array}{l}-0.375 \\
{[0.028]}\end{array}$ & $\begin{array}{c}-0.309 \\
{[0.021]}\end{array}$ & $\begin{array}{l}-0.390 \\
{[0.025]}\end{array}$ & $\begin{array}{c}-0.322 \\
{[0.019]}\end{array}$ \\
\hline Low son pref group mean of outcome & -1.462 & -1.299 & -1.723 & -1.700 & -1.857 & -1.727 \\
\hline High son pref group mean of outcome & -1.799 & -1.743 & -1.810 & -1.721 & -1.783 & -1.734 \\
\hline Age \& other controls & $\begin{array}{c}\text { NFHS } \\
1-3\end{array}$ & $\begin{array}{c}\text { NFHS } \\
1-3\end{array}$ & $\begin{array}{c}\text { NFHS } \\
1-3\end{array}$ & $\begin{array}{c}\text { NFHS } \\
1-3\end{array}$ & $\begin{array}{c}\text { NFHS } \\
1-3\end{array}$ & $\begin{array}{c}\text { NFHS } \\
1-3\end{array}$ \\
\hline $\begin{array}{l}\text { Observations } \\
\mathrm{N}\end{array}$ & $\begin{array}{c}\text { Yes } \\
95,125\end{array}$ & $\begin{array}{c}\text { Yes } \\
95,125\end{array}$ & $\begin{array}{c}\text { Yes } \\
95,125\end{array}$ & $\begin{array}{c}\text { Yes } \\
95,125\end{array}$ & $\begin{array}{c}\text { Yes } \\
82,084\end{array}$ & $\begin{array}{c}\text { Yes } \\
82,084\end{array}$ \\
\hline
\end{tabular}

Notes: Standard errors are clustered by mother and appear in brackets. In all columns the sample uses NFHS 1-3. NFHS-1 only has data for children aged four years and younger, and NFHS-2 only has data for children aged 3 years and younger. All columns include child age dummies, maternal age, mother's literacy, and child age dummies, maternal age, and mother's literacy interacted with Low son pref proxy. All columns include survey and PSU fixed effects, and survey and PSU fixed effects interacted with Low son pref proxy. In columns 1-4, the main effect Low son pref proxy is absorbed by PSU fixed effects. Kerala and Northeast include Arunachal Pradesh, Assam, Kerala, Manipur,

Meghalaya, Mizoram, Nagaland, Sikkim, and Tripura. Child sex ratio is defined as the number of boys aged 0-6 years over the number of girls aged 0-6 years in the respondent's state-by-rural cell. In columns 5 and 6, the sample is restricted to Muslims and Hindus.

Source: Adapted from J+P using data from DHS (Heger Boyle \& Sobek, 2019) 
Table B.57: Cultural Norms and Child Height: Within-India Evidence (2004-2017): Weighted

\begin{tabular}{|c|c|c|c|c|c|c|}
\hline \multirow[t]{2}{*}{ Low son preference proxy: } & \multicolumn{2}{|c|}{ Kerala \& Northeast } & \multicolumn{2}{|c|}{$\begin{array}{l}\text { Below-median } \\
\text { child sex ratio }\end{array}$} & \multicolumn{2}{|c|}{ Muslims } \\
\hline & $\begin{array}{c}\text { HFA } \\
\text { z-score } \\
\text { (1) }\end{array}$ & $\begin{array}{c}\text { WFA } \\
\text { z-score } \\
\text { (2) }\end{array}$ & $\begin{array}{c}\text { HFA } \\
\text { z-score } \\
\text { (3) }\end{array}$ & $\begin{array}{c}\text { WFA } \\
\text { z-score } \\
\text { (4) }\end{array}$ & $\begin{array}{c}\text { HFA } \\
\text { z-score } \\
\text { (5) }\end{array}$ & $\begin{array}{c}\text { WFA } \\
\text { z-score } \\
(6)\end{array}$ \\
\hline Low son pref proxy $\times 2$ nd child & $\begin{array}{c}0.031 \\
{[0.034]}\end{array}$ & $\begin{array}{c}0.003 \\
{[0.026]}\end{array}$ & $\begin{array}{c}0.007 \\
{[0.021]}\end{array}$ & $\begin{array}{c}0.017 \\
{[0.016]}\end{array}$ & $\begin{array}{c}0.028 \\
{[0.032]}\end{array}$ & $\begin{array}{c}0.042 \\
{[0.024]}\end{array}$ \\
\hline Low son pref proxy $\times 3$ rd + child & $\begin{array}{c}0.038 \\
{[0.042]}\end{array}$ & $\begin{array}{c}0.003 \\
{[0.031]}\end{array}$ & $\begin{array}{c}0.050 \\
{[0.027]}\end{array}$ & $\begin{array}{c}0.012 \\
{[0.020]}\end{array}$ & $\begin{array}{c}0.089 \\
{[0.040]}\end{array}$ & $\begin{array}{c}0.092 \\
{[0.029]}\end{array}$ \\
\hline 2nd child & $\begin{array}{l}-0.145 \\
{[0.011]}\end{array}$ & $\begin{array}{l}-0.115 \\
{[0.008]}\end{array}$ & $\begin{array}{l}-0.146 \\
{[0.014]}\end{array}$ & $\begin{array}{l}-0.125 \\
{[0.010]}\end{array}$ & $\begin{array}{l}-0.148 \\
{[0.012]}\end{array}$ & $\begin{array}{c}-0.122 \\
{[0.009]}\end{array}$ \\
\hline 3rd + child & $\begin{array}{c}-0.320 \\
{[0.014]}\end{array}$ & $\begin{array}{c}-0.250 \\
{[0.010]}\end{array}$ & $\begin{array}{c}-0.341 \\
{[0.017]}\end{array}$ & $\begin{array}{c}-0.262 \\
{[0.013]}\end{array}$ & $\begin{array}{l}-0.335 \\
{[0.015]}\end{array}$ & $\begin{array}{l}-0.268 \\
{[0.011]}\end{array}$ \\
\hline Low son pref group mean of outcome & -1.153 & -1.056 & -1.334 & -1.388 & -1.426 & -1.451 \\
\hline High son pref group mean of outcome & -1.416 & -1.548 & -1.408 & -1.532 & -1.405 & -1.539 \\
\hline Age \& other controls & Yes & Yes & Yes & Yes & Yes & Yes \\
\hline Observations & 322974 & 322974 & 320963 & 320963 & 280068 & 280068 \\
\hline
\end{tabular}

Notes: Standard errors are clustered by mother and appear in brackets. In all columns the sample uses NFHS 1-4. NFHS-1 only has data for children aged four years and younger, and NFHS-2 only has data for children aged 3 years and younger. All columns include child age dummies, maternal age, mother's literacy, and child age dummies, maternal age, and mother's literacy interacted with Low son pref proxy. All columns include survey and PSU fixed effects, and survey and PSU fixed effects interacted with Low son pref proxy. In columns 1-4, the main effect Low son pref proxy is absorbed by PSU fixed effects. Kerala and Northeast include Arunachal Pradesh, Assam, Kerala, Manipur,

Meghalaya, Mizoram, Nagaland, Sikkim, and Tripura. Child sex ratio is defined as the number of boys aged 0-6 years over the number of girls aged 0-6 years in the respondent's state-by-rural cell. In columns 5 and 6, the sample is restricted to Muslims and Hindus.

Source: Adapted from J+P using data from DHS (Heger Boyle \& Sobek, 2019) 
Table B.58: Cultural Norms and Child Height: Within-India Evidence (2015/6): Weighted

\begin{tabular}{|c|c|c|c|c|c|c|}
\hline \multirow[t]{2}{*}{ Low son preference proxy: } & \multicolumn{2}{|c|}{ Kerala \& Northeast } & \multicolumn{2}{|c|}{$\begin{array}{l}\text { Below-median } \\
\text { child sex ratio }\end{array}$} & \multicolumn{2}{|c|}{ Muslims } \\
\hline & $\begin{array}{c}\text { HFA } \\
\text { z-score } \\
\text { (1) }\end{array}$ & $\begin{array}{c}\text { WFA } \\
\text { z-score } \\
(2)\end{array}$ & $\begin{array}{c}\text { HFA } \\
\text { z-score } \\
(3)\end{array}$ & $\begin{array}{c}\text { WFA } \\
\text { z-score } \\
(4)\end{array}$ & $\begin{array}{c}\text { HFA } \\
\text { z-score } \\
(5)\end{array}$ & $\begin{array}{c}\text { WFA } \\
\text { z-score } \\
(6)\end{array}$ \\
\hline Low son pref proxy $\times 2$ nd child & $\begin{array}{c}0.033 \\
{[0.044]}\end{array}$ & $\begin{array}{c}0.022 \\
{[0.033]}\end{array}$ & $\begin{array}{c}-0.021 \\
{[0.026]}\end{array}$ & $\begin{array}{c}0.006 \\
{[0.019]}\end{array}$ & $\begin{array}{c}0.046 \\
{[0.039]}\end{array}$ & $\begin{array}{c}0.039 \\
{[0.028]}\end{array}$ \\
\hline Low son pref proxy $\times 3$ rd + child & $\begin{array}{c}0.111 \\
{[0.058]}\end{array}$ & $\begin{array}{c}0.031 \\
{[0.042]}\end{array}$ & $\begin{array}{c}0.081 \\
{[0.034]}\end{array}$ & $\begin{array}{c}0.036 \\
{[0.025]}\end{array}$ & $\begin{array}{c}0.033 \\
{[0.050]}\end{array}$ & $\begin{array}{c}0.057 \\
{[0.035]}\end{array}$ \\
\hline 2nd child & $\begin{array}{c}-0.135 \\
{[0.013]}\end{array}$ & $\begin{array}{c}-0.110 \\
{[0.010]}\end{array}$ & $\begin{array}{c}-0.124 \\
{[0.017]}\end{array}$ & $\begin{array}{c}-0.113 \\
{[0.012]}\end{array}$ & $\begin{array}{c}-0.143 \\
{[0.014]}\end{array}$ & $\begin{array}{c}-0.119 \\
{[0.010]}\end{array}$ \\
\hline $3 \mathrm{rd}+$ child & $\begin{array}{c}-0.289 \\
{[0.017]}\end{array}$ & $\begin{array}{c}-0.220 \\
{[0.013]}\end{array}$ & $\begin{array}{c}-0.318 \\
{[0.022]}\end{array}$ & $\begin{array}{c}-0.237 \\
{[0.016]}\end{array}$ & $\begin{array}{c}-0.295 \\
{[0.018]}\end{array}$ & $\begin{array}{c}-0.233 \\
{[0.014]}\end{array}$ \\
\hline Low son pref group mean of outcome & -1.033 & -0.984 & -1.239 & -1.346 & -1.307 & -1.393 \\
\hline High son pref group mean of outcome & -1.300 & -1.508 & -1.279 & -1.495 & -1.288 & -1.503 \\
\hline Age \& other controls & Yes & Yes & Yes & Yes & Yes & Yes \\
\hline Observations & 227849 & 227849 & 225838 & 225838 & 197984 & 197984 \\
\hline
\end{tabular}

Notes: Standard errors are clustered by mother and appear in brackets. In all columns the sample uses NFHS 4 . All columns include child age dummies, maternal age, mother's literacy, and child age dummies, maternal age, and mother's literacy interacted with Low son pref proxy. All columns include survey and PSU fixed effects, and survey and PSU fixed effects interacted with Low son pref proxy. In columns 1-4, the main effect Low son pref proxy is absorbed by PSU fixed effects. Kerala and Northeast include Arunachal Pradesh, Assam, Kerala, Manipur,

Meghalaya, Mizoram, Nagaland, Sikkim, and Tripura. Child sex ratio is defined as the number of boys aged 0-6 years over the number of girls aged 0-6 years in the respondent's state-by-rural cell. In columns 5 and 6, the sample is restricted to Muslims and Hindus.

Source: Adapted from J+P using data from DHS (Heger Boyle \& Sobek, 2019) 


\subsection{Child Gender and the Birth Order Gradient in Height}

Table B.59: Child Gender and the Birth Order Gradient in Height (2004-2010): Weighted

\begin{tabular}{|c|c|c|c|c|c|c|c|c|}
\hline & $\begin{array}{l}\text { HFA } \\
\text { Z-score } \\
\text { (1) }\end{array}$ & $\begin{array}{l}\text { HFA } \\
\text { z-score } \\
\text { (2) }\end{array}$ & $\begin{array}{l}\text { HFA } \\
\text { z-score } \\
\text { (3) }\end{array}$ & $\begin{array}{c}\text { WFA } \\
\text { z-score } \\
\text { (4) }\end{array}$ & $\begin{array}{c}\text { HFA } \\
\text { z-score } \\
\text { (5) }\end{array}$ & $\begin{array}{l}\text { HFA } \\
\text { z-score } \\
(6)\end{array}$ & $\begin{array}{l}\text { HFA } \\
\text { z-score } \\
\text { (7) }\end{array}$ & $\begin{array}{c}\text { WFA } \\
\text { z-score } \\
(8)\end{array}$ \\
\hline India & $\begin{array}{l}-0.003 \\
{[0.033]}\end{array}$ & & & & $\begin{array}{l}-0.157 \\
{[0.018]}\end{array}$ & & & \\
\hline India $\times$ Girl & $\begin{array}{l}-0.140 \\
{[0.046]}\end{array}$ & & & & $\begin{array}{l}-0.167 \\
{[0.025]}\end{array}$ & $\begin{array}{l}-0.172 \\
{[0.024]}\end{array}$ & $\begin{array}{l}-0.110 \\
{[0.040]}\end{array}$ & $\begin{array}{l}-0.143 \\
{[0.018]}\end{array}$ \\
\hline India $\times 2$ nd child & $\begin{array}{l}-0.077 \\
{[0.046]}\end{array}$ & $\begin{array}{l}-0.157 \\
{[0.051]}\end{array}$ & $\begin{array}{c}-0.289 \\
{[0.086]}\end{array}$ & $\begin{array}{l}-0.116 \\
{[0.037]}\end{array}$ & & & & \\
\hline India $\times 3 r d+$ child & $\begin{array}{c}-0.342 \\
{[0.042]}\end{array}$ & $\begin{array}{l}-0.246 \\
{[0.061]}\end{array}$ & $\begin{array}{c}-0.459 \\
{[0.121]}\end{array}$ & $\begin{array}{l}-0.196 \\
{[0.044]}\end{array}$ & & & & \\
\hline India $\times 2$ nd child $\times$ Girl & $\begin{array}{c}-0.089 \\
{[0.066]}\end{array}$ & $\begin{array}{l}-0.004 \\
{[0.073]}\end{array}$ & $\begin{array}{c}0.030 \\
{[0.126]}\end{array}$ & $\begin{array}{l}-0.059 \\
{[0.054]}\end{array}$ & & & & \\
\hline India $\times 3$ rd + child $\times$ Girl & $\begin{array}{l}-0.028 \\
{[0.059]}\end{array}$ & $\begin{array}{c}0.075 \\
{[0.086]}\end{array}$ & $\begin{array}{c}0.040 \\
{[0.115]}\end{array}$ & $\begin{array}{l}-0.016 \\
{[0.062]}\end{array}$ & & & & \\
\hline 2nd child & $\begin{array}{c}0.021 \\
{[0.028]}\end{array}$ & $\begin{array}{c}0.011 \\
{[0.031]}\end{array}$ & $\begin{array}{l}-0.178 \\
{[0.051]}\end{array}$ & $\begin{array}{c}0.016 \\
{[0.022]}\end{array}$ & & & & \\
\hline 3rd+ child & $\begin{array}{l}-0.070 \\
{[0.023]}\end{array}$ & $\begin{array}{l}-0.113 \\
{[0.035]}\end{array}$ & $\begin{array}{c}-0.377 \\
{[0.064]}\end{array}$ & $\begin{array}{l}-0.064 \\
{[0.025]}\end{array}$ & & & & \\
\hline Africa mean of outcome & -1.363 & -1.363 & -1.363 & -0.889 & -1.363 & -1.363 & -1.363 & -0.889 \\
\hline Age \& other controls & No & Yes & No & Yes & No & Yes & No & Yes \\
\hline Mother FEs & No & No & Yes & No & No & No & Yes & No \\
\hline Observations & 168,135 & 165,623 & 83,243 & 165,623 & 168,135 & 167,765 & 83,243 & 167,765 \\
\hline
\end{tabular}

Notes: Standard errors are clustered by mother and appear in brackets. Please consider the notes in Table 2.10 for further explanations. Source: Adapted from J+P using data from DHS (Heger Boyle \& Sobek, 2019)

Table B.60: Child Gender and the Birth Order Gradient in Height (2010-2017): Weighted

\begin{tabular}{|c|c|c|c|c|c|c|c|c|}
\hline & $\begin{array}{l}\text { HFA } \\
\text { z-score } \\
\text { (1) }\end{array}$ & $\begin{array}{l}\text { HFA } \\
\text { z-score } \\
\text { (2) }\end{array}$ & $\begin{array}{c}\text { HFA } \\
\text { z-score } \\
\text { (3) }\end{array}$ & $\begin{array}{l}\text { WFA } \\
\text { z-score } \\
\text { (4) }\end{array}$ & $\begin{array}{c}\text { HFA } \\
\text { z-score } \\
\text { (5) }\end{array}$ & $\begin{array}{c}\text { HFA } \\
\text { z-score } \\
(6)\end{array}$ & $\begin{array}{l}\text { HFA } \\
\text { z-score } \\
\text { (7) }\end{array}$ & $\begin{array}{c}\text { WFA } \\
\text { z-score } \\
(8)\end{array}$ \\
\hline India & $\begin{array}{c}0.084 \\
{[0.021]}\end{array}$ & & & & $\begin{array}{c}0.004 \\
{[0.011]}\end{array}$ & & & \\
\hline India $\times$ Girl & $\begin{array}{c}-0.094 \\
{[0.029]}\end{array}$ & & & & $\begin{array}{l}-0.104 \\
{[0.015]}\end{array}$ & $\begin{array}{l}-0.097 \\
{[0.015]}\end{array}$ & $\begin{array}{l}-0.091 \\
{[0.024]}\end{array}$ & $\begin{array}{l}-0.066 \\
{[0.011]}\end{array}$ \\
\hline India $\times 2$ nd child & $\begin{array}{l}-0.088 \\
{[0.029]}\end{array}$ & $\begin{array}{l}-0.016 \\
{[0.033]}\end{array}$ & $\begin{array}{c}-0.171 \\
{[0.054]}\end{array}$ & $\begin{array}{c}-0.045 \\
{[0.024]}\end{array}$ & & & & \\
\hline India $\times 3 r d+$ child & $\begin{array}{c}-0.278 \\
{[0.027]}\end{array}$ & $\begin{array}{l}-0.029 \\
{[0.039]}\end{array}$ & $\begin{array}{l}-0.408 \\
{[0.077]}\end{array}$ & $\begin{array}{l}-0.065 \\
{[0.028]}\end{array}$ & & & & \\
\hline India $\times$ 2nd child $\times$ Girl & $\begin{array}{l}-0.049 \\
{[0.043]}\end{array}$ & $\begin{array}{l}-0.108 \\
{[0.047]}\end{array}$ & $\begin{array}{l}-0.007 \\
{[0.076]}\end{array}$ & $\begin{array}{l}-0.088 \\
{[0.034]}\end{array}$ & & & & \\
\hline India $\times$ 3rd + child $\times$ Girl & $\begin{array}{l}-0.066 \\
{[0.037]}\end{array}$ & $\begin{array}{l}-0.172 \\
{[0.054]}\end{array}$ & $\begin{array}{c}0.015 \\
{[0.072]}\end{array}$ & $\begin{array}{c}-0.134 \\
{[0.040]}\end{array}$ & & & & \\
\hline 2nd child & $\begin{array}{l}-0.010 \\
{[0.024]}\end{array}$ & $\begin{array}{l}-0.087 \\
{[0.027]}\end{array}$ & $\begin{array}{l}-0.213 \\
{[0.042]}\end{array}$ & $\begin{array}{l}-0.017 \\
{[0.020]}\end{array}$ & & & & \\
\hline $3 r d+$ child & $\begin{array}{l}-0.109 \\
{[0.020]}\end{array}$ & $\begin{array}{l}-0.174 \\
{[0.030]}\end{array}$ & $\begin{array}{l}-0.292 \\
{[0.055]}\end{array}$ & $\begin{array}{l}-0.079 \\
{[0.022]}\end{array}$ & & & & \\
\hline Africa mean of outcome & -1.163 & -1.163 & -1.163 & -0.838 & -1.163 & -1.163 & -1.163 & -0.838 \\
\hline Age \& other controls & No & Yes & No & Yes & No & Yes & No & Yes \\
\hline Mother FEs & No & No & Yes & No & No & No & Yes & No \\
\hline Observations & 398,710 & 390,071 & 189,520 & 390,071 & 398,710 & 397,702 & 189,520 & 397,702 \\
\hline
\end{tabular}

Notes: Standard errors are clustered by mother and appear in brackets. Please consider the notes in Table 2.10 for further explanations.

Source: Adapted from J+P using data from IPUMS DHS (ICF, 2004) and DHS (Heger Boyle \& Sobek, 2019) 


\subsection{Impact on Average Height - Accounting exercise}

Table B.61: Accounting Exercise Part 1: Sample Comparison (2004-2010): Weighted

\begin{tabular}{|c|c|c|c|}
\hline & & $\begin{array}{l}\text { Accounting } \\
\text { Exercise } 1\end{array}$ & $\begin{array}{c}\text { Accounting } \\
\text { Exercise } 2\end{array}$ \\
\hline & $\begin{array}{c}\text { HFA z-score } \\
\text { (1) }\end{array}$ & $\begin{array}{c}\text { HFA z-score } \\
\text { (2) }\end{array}$ & $\begin{array}{c}\text { HFA z-score } \\
\text { (3) }\end{array}$ \\
\hline India & $\begin{array}{c}-0.342 \\
{[0.020]}\end{array}$ & & \\
\hline Gradient proxy & & $\begin{array}{c}0.335 \\
{[0.073]}\end{array}$ & $\begin{array}{c}0.703 \\
{[0.139]}\end{array}$ \\
\hline \multicolumn{4}{|l|}{ Mean of gradient proxy } \\
\hline India & & -0.324 & -0.236 \\
\hline Africa & & -0.068 & -0.040 \\
\hline Kerala \& Northeast & & -0.214 & -0.184 \\
\hline Rest of India & & -0.324 & -0.234 \\
\hline Log GDP per capita & Yes & Yes & Yes \\
\hline Sample & Full & Africa & Africa \\
\hline Observations & 168,135 & 126,066 & 126,066 \\
\hline
\end{tabular}

Table B.62: Accounting Exercise Part 1: Sample Comparison (2011-2017): Weighted

\begin{tabular}{|c|c|c|c|}
\hline & & $\begin{array}{c}\text { Accounting } \\
\text { Exercise } 1\end{array}$ & $\begin{array}{c}\text { Accounting } \\
\text { Exercise } 2\end{array}$ \\
\hline & $\begin{array}{c}\text { HFA z-score } \\
\text { (1) }\end{array}$ & $\begin{array}{c}\text { HFA z-score } \\
\text { (2) }\end{array}$ & $\begin{array}{c}\text { HFA z-score } \\
\text { (3) }\end{array}$ \\
\hline India & $\begin{array}{c}-0.119 \\
{[0.021]}\end{array}$ & & \\
\hline Gradient proxy & & $\begin{array}{c}-0.784 \\
{[0.149]}\end{array}$ & $\begin{array}{l}-1.701 \\
{[0.259]}\end{array}$ \\
\hline \multicolumn{4}{|l|}{ Mean of gradient proxy } \\
\hline India & & -0.281 & -0.222 \\
\hline Africa & & -0.130 & -0.077 \\
\hline Kerala \& Northeast & & -0.215 & -0.182 \\
\hline Rest of India & & -0.281 & -0.222 \\
\hline Log GDP per capita & Yes & Yes & Yes \\
\hline Sample & Full & Africa & Africa \\
\hline Observations & 398,710 & 168,490 & 168,490 \\
\hline
\end{tabular}

Notes: Standard errors are clustered by PSU and appear in brackets. Please consider the notes in Table 2.12 for further explanations. Source: Adapted from J+P using data from IPUMS DHS (ICF, 2004) and DHS (Heger Boyle \& Sobek, 2019) 
Table B.63: Accounting Exercise Part 2: Sample Comparison (2004-2010): Weighted

Accounting Accounting

Exercise $1 \quad$ Exercise 2

Calculation 1: Share explained by birth order gradient

- India-Africa gap in birth order gradient

$-0.256-0.196$

- India-Africa gap in birth order gradient $\times$ Gradient coeff

$-0.086 \quad-0.138$

- Explained share of India-Africa level gap in height (shown in column 1)

$25 \%$

$40 \%$

Calculation 2: Share explained by birth order gradient rooted in eldest son preference

- Rest of India - Kerala \& NE gap in birth order gradient

$-0.110 \quad-0.050$

- Rest of India - Kerala \& NE gap in birth order gradient $\times$ Gradient coff

$-0.037-0.035$

- Explained share of India-Africa level gap in height (shown in column 1)

$11 \%$

$10 \%$

Source: Adapted from J+P using data from DHS (Heger Boyle \& Sobek, 2019)

Table B.64: Accounting Exercise Part 2: Sample Comparison (2010-2017): Weighted

Accounting Accounting

Exercise 1

Exercise 2

Calculation 1: Share explained by birth order gradient

- India-Africa gap in birth order gradient

$-0.151 \quad-0.145$

- India-Africa gap in birth order gradient $\times$ Gradient coeff

0.118

0.247

- Explained share of India-Africa level gap in height (shown in column 1)

$-99 \%$

$-207 \%$

Calculation 2: Share explained by birth order gradient rooted in eldest son preference

- Rest of India - Kerala \& NE gap in birth order gradient

$-0.066 \quad-0.040$

- Rest of India - Kerala \& NE gap in birth order gradient $\times$ Gradient coff

- Explained share of India-Africa level gap in height (shown in column 1) 


\section{Replicated Results (2004-2010) and Replicated Results (2011- 2017): Adjusted Methodology and Three Macro-Determinants with Data from the More Recent Time Period}

\subsection{Summary Statistics}

Table B.65: Summary Statistics (2004-2010): Weighted Macro-Determinants

\begin{tabular}{|c|c|c|c|c|c|}
\hline & $\begin{array}{c}\text { India } \\
\text { subsample }\end{array}$ & $\begin{array}{c}\text { Africa } \\
\text { subsample }\end{array}$ & & $\begin{array}{c}\text { India } \\
\text { subsample }\end{array}$ & $\begin{array}{c}\text { Africa } \\
\text { subsample }\end{array}$ \\
\hline Mother's age at birth (years) & $\begin{array}{l}24.25 \\
{[5.19]}\end{array}$ & $\begin{array}{l}26.95 \\
{[6.85]}\end{array}$ & 4th poorest wealth quantile & $\begin{array}{c}0.21 \\
{[0.41]}\end{array}$ & $\begin{array}{c}0.18 \\
{[0.38]}\end{array}$ \\
\hline Mother's total children born & $\begin{array}{c}2.87 \\
{[1.91]}\end{array}$ & $\begin{array}{c}3.90 \\
{[2.55]}\end{array}$ & Richest wealth quantile & $\begin{array}{c}0.27 \\
{[0.45]}\end{array}$ & $\begin{array}{c}0.16 \\
{[0.36]}\end{array}$ \\
\hline Mother's desired fertility & $\begin{array}{c}2.45 \\
{[0.89]}\end{array}$ & $\begin{array}{c}4.62 \\
{[1.46]}\end{array}$ & Child's age (months) & $\begin{array}{c}30.18 \\
{[17.01]}\end{array}$ & $\begin{array}{c}28.26 \\
{[17.05]}\end{array}$ \\
\hline Mother wants more children & $\begin{array}{c}0.34 \\
{[0.47]}\end{array}$ & $\begin{array}{c}0.67 \\
{[0.46]}\end{array}$ & Child is a girl & $\begin{array}{c}0.48 \\
{[0.50]}\end{array}$ & $\begin{array}{c}0.50 \\
{[0.50]}\end{array}$ \\
\hline Mother completed her fertility & $\begin{array}{c}0.67 \\
{[0.47]}\end{array}$ & $\begin{array}{c}0.33 \\
{[0.47]}\end{array}$ & Child's birth order & $\begin{array}{c}2.74 \\
{[1.88]}\end{array}$ & $\begin{array}{c}3.75 \\
{[2.48]}\end{array}$ \\
\hline Mother is literate & $\begin{array}{c}0.49 \\
{[0.50]}\end{array}$ & $\begin{array}{c}0.48 \\
{[0.50]}\end{array}$ & Child's HFA z-score & $\begin{array}{l}-1.67 \\
{[1.80]}\end{array}$ & $\begin{array}{l}-1.36 \\
{[1.96]}\end{array}$ \\
\hline Mother's height (meters) & $\begin{array}{c}1.52 \\
{[0.06]}\end{array}$ & $\begin{array}{c}1.58 \\
{[0.07]}\end{array}$ & Child is stunted & $\begin{array}{c}0.45 \\
{[0.50]}\end{array}$ & $\begin{array}{c}0.38 \\
{[0.49]}\end{array}$ \\
\hline Mother took iron supplements & $\begin{array}{c}0.66 \\
{[0.47]}\end{array}$ & $\begin{array}{c}0.62 \\
{[0.49]}\end{array}$ & Child's WFA z-score & $\begin{array}{l}-1.70 \\
{[1.30]}\end{array}$ & $\begin{array}{c}-0.89 \\
{[1.44]}\end{array}$ \\
\hline Mother's total tetanus shots & $\begin{array}{c}1.86 \\
{[0.95]}\end{array}$ & $\begin{array}{c}1.41 \\
{[1.21]}\end{array}$ & Child's hemoglobin level (g/dl) & $\begin{array}{l}10.10 \\
{[1.56]}\end{array}$ & $\begin{array}{l}10.11 \\
{[1.70]}\end{array}$ \\
\hline Total prenatal visits & $\begin{array}{c}3.49 \\
{[3.32]}\end{array}$ & $\begin{array}{c}3.87 \\
{[3.28]}\end{array}$ & Child is deceased & $\begin{array}{c}0.06 \\
{[0.23]}\end{array}$ & $\begin{array}{c}0.07 \\
{[0.26]}\end{array}$ \\
\hline Delivery at health facility & $\begin{array}{c}0.39 \\
{[0.49]}\end{array}$ & $\begin{array}{c}0.47 \\
{[0.50]}\end{array}$ & Child taking iron pills & $\begin{array}{c}0.05 \\
{[0.21]}\end{array}$ & $\begin{array}{c}0.13 \\
{[0.34]}\end{array}$ \\
\hline Postnatal check within 2 months & $\begin{array}{c}0.08 \\
{[0.28]}\end{array}$ & $\begin{array}{c}0.32 \\
{[0.47]}\end{array}$ & Child's total vaccinations & $\begin{array}{c}6.42 \\
{[2.75]}\end{array}$ & $\begin{array}{c}6.14 \\
{[3.17]}\end{array}$ \\
\hline Average pooled inputs & $\begin{array}{c}0.30 \\
{[0.27]}\end{array}$ & $\begin{array}{c}0.38 \\
{[0.31]}\end{array}$ & Birth spacing (months) & $\begin{array}{c}35.43 \\
{[19.42]}\end{array}$ & $\begin{array}{c}38.43 \\
{[20.43]}\end{array}$ \\
\hline Percent non-resident among children & $\begin{array}{c}0.02 \\
{[0.03]}\end{array}$ & $\begin{array}{c}0.09 \\
{[0.08]}\end{array}$ & Diarrhea in last 2 weeks & $\begin{array}{c}0.09 \\
{[0.29]}\end{array}$ & $\begin{array}{c}0.16 \\
{[0.37]}\end{array}$ \\
\hline Number of adult females in household & $\begin{array}{c}1.89 \\
{[1.11]}\end{array}$ & $\begin{array}{c}1.59 \\
{[1.05]}\end{array}$ & Open defecation & $\begin{array}{c}0.63 \\
{[0.48]}\end{array}$ & $\begin{array}{c}0.32 \\
{[0.47]}\end{array}$ \\
\hline Log GDP per capita (in child's birth year) & $\begin{array}{c}7.77 \\
{[0.10]}\end{array}$ & $\begin{array}{c}7.35 \\
{[0.67]}\end{array}$ & Meat or eggs consumed & $\begin{array}{c}0.12 \\
{[0.33]}\end{array}$ & $\begin{array}{c}0.43 \\
{[0.50]}\end{array}$ \\
\hline Poorest wealth quantile & $\begin{array}{c}0.23 \\
{[0.42]}\end{array}$ & $\begin{array}{c}0.23 \\
{[0.42]}\end{array}$ & Dairy products consumed & $\begin{array}{c}0.11 \\
{[0.31]}\end{array}$ & $\begin{array}{c}0.16 \\
{[0.37]}\end{array}$ \\
\hline 2nd poorest wealth quantile & $\begin{array}{c}0.09 \\
{[0.28]}\end{array}$ & $\begin{array}{c}0.24 \\
{[0.43]}\end{array}$ & Number of PSUs & 3,822 & 10,366 \\
\hline 3rd poorest wealth quantile & $\begin{array}{c}0.20 \\
{[0.40]}\end{array}$ & $\begin{array}{c}0.20 \\
{[0.40]}\end{array}$ & Main sample of children & 42,069 & 126,066 \\
\hline
\end{tabular}

Notes: The means of the specified variables are calculated separately for the India and Africa subsamples. Standard deviations appear in brackets. Please consider the notes in Table 2.4 for further explanations.

Source: Adapted from J+P using data from DHS (Heger Boyle \& Sobek, 2019) 
Table B.66: Summary Statistics (2011-2017): Weighted Macro-Determinants

\begin{tabular}{|c|c|c|c|c|c|}
\hline & $\begin{array}{c}\text { India } \\
\text { subsample }\end{array}$ & $\begin{array}{c}\text { Africa } \\
\text { subsample }\end{array}$ & & $\begin{array}{c}\text { India } \\
\text { subsample }\end{array}$ & $\begin{array}{c}\text { Africa } \\
\text { subsample }\end{array}$ \\
\hline Mother's age at birth (years) & $\begin{array}{l}24.72 \\
{[4.76]}\end{array}$ & $\begin{array}{l}27.13 \\
{[6.68]}\end{array}$ & 4th poorest wealth quantile & $\begin{array}{c}0.22 \\
{[0.41]}\end{array}$ & $\begin{array}{c}0.14 \\
{[0.35]}\end{array}$ \\
\hline Mother's total children born & $\begin{array}{c}2.30 \\
{[1.42]}\end{array}$ & $\begin{array}{c}3.75 \\
{[2.46]}\end{array}$ & Richest wealth quantile & $\begin{array}{c}0.29 \\
{[0.45]}\end{array}$ & $\begin{array}{c}0.04 \\
{[0.21]}\end{array}$ \\
\hline Mother's desired fertility & $\begin{array}{c}2.28 \\
{[0.88]}\end{array}$ & $\begin{array}{c}4.62 \\
{[1.44]}\end{array}$ & Child's age (months) & $\begin{array}{c}30.18 \\
{[16.88]}\end{array}$ & $\begin{array}{c}28.92 \\
{[17.06]}\end{array}$ \\
\hline Mother wants more children & $\begin{array}{c}0.39 \\
{[0.48]}\end{array}$ & $\begin{array}{c}0.69 \\
{[0.45]}\end{array}$ & Child is a girl & $\begin{array}{c}0.48 \\
{[0.50]}\end{array}$ & $\begin{array}{c}0.50 \\
{[0.50]}\end{array}$ \\
\hline Mother completed her fertility & $\begin{array}{c}0.63 \\
{[0.48]}\end{array}$ & $\begin{array}{c}0.31 \\
{[0.46]}\end{array}$ & Child's birth order & $\begin{array}{c}2.18 \\
{[1.40]}\end{array}$ & $\begin{array}{c}3.64 \\
{[2.41]}\end{array}$ \\
\hline Mother is literate & $\begin{array}{c}0.68 \\
{[0.47]}\end{array}$ & $\begin{array}{c}0.55 \\
{[0.50]}\end{array}$ & Child's HFA z-score & $\begin{array}{l}-1.26 \\
{[1.82]}\end{array}$ & $\begin{array}{l}-1.16 \\
{[1.79]}\end{array}$ \\
\hline Mother's height (meters) & $\begin{array}{c}1.52 \\
{[0.06]}\end{array}$ & $\begin{array}{c}1.58 \\
{[0.06]}\end{array}$ & Child is stunted & $\begin{array}{c}0.35 \\
{[0.48]}\end{array}$ & $\begin{array}{c}0.31 \\
{[0.46]}\end{array}$ \\
\hline Mother took iron supplements & $\begin{array}{c}0.78 \\
{[0.41]}\end{array}$ & $\begin{array}{c}0.74 \\
{[0.44]}\end{array}$ & Child's WFA z-score & $\begin{array}{l}-1.47 \\
{[1.28]}\end{array}$ & $\begin{array}{c}-0.84 \\
{[1.35]}\end{array}$ \\
\hline Mother's total tetanus shots & $\begin{array}{c}1.93 \\
{[0.78]}\end{array}$ & $\begin{array}{c}1.41 \\
{[1.11]}\end{array}$ & Child's hemoglobin level (g/dl) & $\begin{array}{l}10.55 \\
{[1.48]}\end{array}$ & $\begin{array}{l}10.44 \\
{[1.63]}\end{array}$ \\
\hline Total prenatal visits & $\begin{array}{c}4.63 \\
{[4.20]}\end{array}$ & $\begin{array}{c}3.99 \\
{[3.17]}\end{array}$ & Child is deceased & $\begin{array}{c}0.04 \\
{[0.19]}\end{array}$ & $\begin{array}{c}0.05 \\
{[0.22]}\end{array}$ \\
\hline Delivery at health facility & $\begin{array}{c}0.80 \\
{[0.40]}\end{array}$ & $\begin{array}{c}0.58 \\
{[0.49]}\end{array}$ & Child taking iron pills & $\begin{array}{c}0.25 \\
{[0.43]}\end{array}$ & $\begin{array}{c}0.08 \\
{[0.27]}\end{array}$ \\
\hline Postnatal check within 2 months & $\begin{array}{c}0.38 \\
{[0.48]}\end{array}$ & $\begin{array}{c}0.45 \\
{[0.50]}\end{array}$ & Child's total vaccinations & $\begin{array}{c}7.43 \\
{[2.60]}\end{array}$ & $\begin{array}{c}4.98 \\
{[3.50]}\end{array}$ \\
\hline Average pooled inputs & $\begin{array}{c}0.47 \\
{[0.24]}\end{array}$ & $\begin{array}{c}0.38 \\
{[0.28]}\end{array}$ & Birth spacing (months) & $\begin{array}{c}37.16 \\
{[21.61]}\end{array}$ & $\begin{array}{c}39.46 \\
{[21.44]}\end{array}$ \\
\hline Percent non-resident among children & $\begin{array}{c}0.02 \\
{[0.03]}\end{array}$ & $\begin{array}{c}0.09 \\
{[0.00]}\end{array}$ & Diarrhea in last 2 weeks & $\begin{array}{c}0.09 \\
{[0.29]}\end{array}$ & $\begin{array}{c}0.15 \\
{[0.36]}\end{array}$ \\
\hline Number of adult females in household & $\begin{array}{c}1.94 \\
{[1.04]}\end{array}$ & $\begin{array}{c}1.59 \\
{[1.12]}\end{array}$ & Open defecation & $\begin{array}{c}0.47 \\
{[0.50]}\end{array}$ & $\begin{array}{c}0.23 \\
{[0.42]}\end{array}$ \\
\hline Log GDP per capita (in child's birth year) & $\begin{array}{c}8.50 \\
{[0.08]}\end{array}$ & $\begin{array}{c}7.80 \\
{[0.68]}\end{array}$ & Meat or eggs consumed & $\begin{array}{c}0.14 \\
{[0.35]}\end{array}$ & $\begin{array}{c}0.30 \\
{[0.46]}\end{array}$ \\
\hline Poorest wealth quantile & $\begin{array}{c}0.12 \\
{[0.32]}\end{array}$ & $\begin{array}{c}0.43 \\
{[0.49]}\end{array}$ & Dairy products consumed & $\begin{array}{c}0.13 \\
{[0.34]}\end{array}$ & $\begin{array}{c}0.20 \\
{[0.40]}\end{array}$ \\
\hline 2nd poorest wealth quantile & $\begin{array}{c}0.19 \\
{[0.39]}\end{array}$ & $\begin{array}{c}0.23 \\
{[0.42]}\end{array}$ & Number of PSUs & 28,215 & 12,684 \\
\hline 3 rd poorest wealth quantile & $\begin{array}{c}0.19 \\
{[0.39]}\end{array}$ & $\begin{array}{c}0.15 \\
{[0.36]}\end{array}$ & Main sample of children & 230,220 & 168,490 \\
\hline
\end{tabular}

Notes: The means of the specified variables are calculated separately for the India and Africa subsamples. Standard deviations appear in brackets. Please consider the notes in Table 2.4 for further explanations.

Source: Adapted from J+P using data from IPUMS DHS (ICF, 2004) and DHS (Heger Boyle \& Sobek, 2019) 


\subsection{India's Differential Birth Order Gradient in Child Height and Re- lated Outcomes}

Table B.67: India's Differential Birth Order Gradient in Child Height and Related Outcomes (2004-2010): Weighted 3 Macro-Determinants

\begin{tabular}{|c|c|c|c|c|c|c|c|c|c|}
\hline & $\begin{array}{l}\text { HFA } \\
\text { Z- } \\
\text { score } \\
(1)\end{array}$ & $\begin{array}{l}\text { HFA } \\
\text { Z- } \\
\text { score } \\
(2)\end{array}$ & $\begin{array}{l}\text { HFA } \\
\text { z- } \\
\text { score } \\
(3)\end{array}$ & $\begin{array}{l}\text { HFA } \\
\text { Z- } \\
\text { score } \\
(4)\end{array}$ & $\begin{array}{l}\text { HFA } \\
\text { Z- } \\
\text { score } \\
(5)\end{array}$ & $\begin{array}{l}\text { Stunted } \\
\text { (6) }\end{array}$ & $\begin{array}{l}\text { WFA } \\
\text { Z- } \\
\text { score } \\
(7)\end{array}$ & $\begin{array}{l}\mathrm{Hb} \\
\text { level } \\
(8)\end{array}$ & $\begin{array}{l}\text { Deceased } \\
\text { (9) }\end{array}$ \\
\hline ndia & $\begin{array}{l}-0.352 \\
{[0.023]}\end{array}$ & $\begin{array}{l}-0.329 \\
{[0.036]}\end{array}$ & & & & & & & \\
\hline India $\times 2$ nd child & & $\begin{array}{l}-0.112 \\
{[0.032]}\end{array}$ & $\begin{array}{l}-0.167 \\
{[0.035]}\end{array}$ & $\begin{array}{l}-0.079 \\
{[0.084]}\end{array}$ & $\begin{array}{l}-0.269 \\
{[0.062]}\end{array}$ & $\begin{array}{c}0.053 \\
{[0.010]}\end{array}$ & $\begin{array}{l}-0.146 \\
{[0.026]}\end{array}$ & $\begin{array}{l}-0.090 \\
{[0.040]}\end{array}$ & $\begin{array}{l}-0.002 \\
{[0.005]}\end{array}$ \\
\hline India $\times 3$ rd + child & & $\begin{array}{l}-0.181 \\
{[0.032]}\end{array}$ & $\begin{array}{l}-0.190 \\
{[0.043]}\end{array}$ & $\begin{array}{l}-0.121 \\
{[0.120]}\end{array}$ & $\begin{array}{l}-0.445 \\
{[0.109]}\end{array}$ & $\begin{array}{c}0.056 \\
{[0.012]}\end{array}$ & $\begin{array}{l}-0.168 \\
{[0.031]}\end{array}$ & $\begin{array}{l}-0.165 \\
{[0.048]}\end{array}$ & $\begin{array}{c}0.002 \\
{[0.006]}\end{array}$ \\
\hline 2nd child & & $\begin{array}{c}0.064 \\
{[0.019]}\end{array}$ & $\begin{array}{c}0.013 \\
{[0.021]}\end{array}$ & $\begin{array}{l}-0.124 \\
{[0.071]}\end{array}$ & $\begin{array}{l}-0.157 \\
{[0.034]}\end{array}$ & $\begin{array}{c}0.005 \\
{[0.005]}\end{array}$ & $\begin{array}{c}0.031 \\
{[0.015]}\end{array}$ & $\begin{array}{l}-0.004 \\
{[0.028]}\end{array}$ & $\begin{array}{l}-0.016 \\
{[0.003]}\end{array}$ \\
\hline $3 r d+$ child & & $\begin{array}{l}0.040 \\
{[0.016]}\end{array}$ & $\begin{array}{l}-0.108 \\
{[0.024]}\end{array}$ & $\begin{array}{l}-0.251 \\
{[0.096]}\end{array}$ & $\begin{array}{l}-0.349 \\
{[0.054]}\end{array}$ & $\begin{array}{c}0.032 \\
{[0.006]}\end{array}$ & $\begin{array}{l}-0.046 \\
{[0.017]}\end{array}$ & $\begin{array}{l}-0.012 \\
{[0.031]}\end{array}$ & $\begin{array}{l}-0.015 \\
{[0.003]}\end{array}$ \\
\hline India $\times$ Mother's literacy $=1$ & $\begin{array}{c}0.184 \\
{[0.023]}\end{array}$ & $\begin{array}{c}0.166 \\
{[0.029]}\end{array}$ & $\begin{array}{c}0.091 \\
{[0.034]}\end{array}$ & $\begin{array}{c}0.057 \\
{[0.050]}\end{array}$ & $\begin{array}{c}0.000 \\
{[.]}\end{array}$ & $\begin{array}{l}-0.027 \\
{[0.010]}\end{array}$ & $\begin{array}{c}0.084 \\
{[0.025]}\end{array}$ & $\begin{array}{c}0.057 \\
{[0.037]}\end{array}$ & $\begin{array}{l}-0.004 \\
{[0.005]}\end{array}$ \\
\hline Mother's literacy=1 & $\begin{array}{c}0.089 \\
{[0.011]}\end{array}$ & $\begin{array}{c}0.090 \\
{[0.014]}\end{array}$ & $\begin{array}{c}0.101 \\
{[0.018]}\end{array}$ & $\begin{array}{c}0.106 \\
{[0.034]}\end{array}$ & $\begin{array}{c}0.000 \\
{[.]}\end{array}$ & $\begin{array}{l}-0.030 \\
{[0.005]}\end{array}$ & $\begin{array}{c}0.116 \\
{[0.013]}\end{array}$ & $\begin{array}{c}0.065 \\
{[0.024]}\end{array}$ & $\begin{array}{l}-0.013 \\
{[0.002]}\end{array}$ \\
\hline 2 nd poorest wealth quantile & $\begin{array}{c}0.093 \\
{[0.015]}\end{array}$ & $\begin{array}{c}0.054 \\
{[0.018]}\end{array}$ & $\begin{array}{c}0.044 \\
{[0.021]}\end{array}$ & $\begin{array}{c}0.026 \\
{[0.037]}\end{array}$ & $\begin{array}{c}0.000 \\
{[.]}\end{array}$ & $\begin{array}{l}-0.015 \\
{[0.006]}\end{array}$ & $\begin{array}{c}0.069 \\
{[0.016]}\end{array}$ & $\begin{array}{c}0.029 \\
{[0.026]}\end{array}$ & $\begin{array}{l}-0.001 \\
{[0.003]}\end{array}$ \\
\hline 3 rd poorest wealth quantile & $\begin{array}{c}0.278 \\
{[0.015]}\end{array}$ & $\begin{array}{c}0.242 \\
{[0.018]}\end{array}$ & $\begin{array}{c}0.141 \\
{[0.022]}\end{array}$ & $\begin{array}{c}0.171 \\
{[0.037]}\end{array}$ & $\begin{array}{c}0.000 \\
{[.]}\end{array}$ & $\begin{array}{l}-0.035 \\
{[0.006]}\end{array}$ & $\begin{array}{c}0.115 \\
{[0.016]}\end{array}$ & $\begin{array}{c}0.038 \\
{[0.027]}\end{array}$ & $\begin{array}{l}-0.005 \\
{[0.003]}\end{array}$ \\
\hline 4 th poorest wealth quantile & $\begin{array}{c}0.491 \\
{[0.016]}\end{array}$ & $\begin{array}{c}0.451 \\
{[0.019]}\end{array}$ & $\begin{array}{c}0.246 \\
{[0.026]}\end{array}$ & $\begin{array}{c}0.304 \\
{[0.042]}\end{array}$ & $\begin{array}{c}0.000 \\
{[.]}\end{array}$ & $\begin{array}{l}-0.080 \\
{[0.007]}\end{array}$ & $\begin{array}{c}0.235 \\
{[0.019]}\end{array}$ & $\begin{array}{c}0.101 \\
{[0.031]}\end{array}$ & $\begin{array}{l}-0.006 \\
{[0.004]}\end{array}$ \\
\hline Richest wealth quantile & $\begin{array}{c}0.861 \\
{[0.017]}\end{array}$ & $\begin{array}{c}0.857 \\
{[0.022]}\end{array}$ & $\begin{array}{c}0.449 \\
{[0.033]}\end{array}$ & $\begin{array}{c}0.536 \\
{[0.054]}\end{array}$ & $\begin{array}{c}0.000 \\
{[.]}\end{array}$ & $\begin{array}{l}-0.128 \\
{[0.009]}\end{array}$ & $\begin{array}{c}0.427 \\
{[0.025]}\end{array}$ & $\begin{array}{c}0.240 \\
{[0.041]}\end{array}$ & $\begin{array}{l}-0.016 \\
{[0.004]}\end{array}$ \\
\hline India $\times$ Open defecation $=1$ & $\begin{array}{l}-0.089 \\
{[0.024]}\end{array}$ & $\begin{array}{c}0.040 \\
{[0.030]}\end{array}$ & $\begin{array}{l}-0.062 \\
{[0.045]}\end{array}$ & $\begin{array}{l}-0.014 \\
{[0.063]}\end{array}$ & $\begin{array}{c}0.000 \\
{[.]}\end{array}$ & $\begin{array}{c}0.026 \\
{[0.013]}\end{array}$ & $\begin{array}{l}-0.055 \\
{[0.033]}\end{array}$ & $\begin{array}{l}-0.058 \\
{[0.048]}\end{array}$ & $\begin{array}{l}-0.008 \\
{[0.006]}\end{array}$ \\
\hline Open defecation $=1$ & $\begin{array}{c}0.015 \\
{[0.013]}\end{array}$ & $\begin{array}{l}-0.034 \\
{[0.016]}\end{array}$ & $\begin{array}{l}-0.070 \\
{[0.023]}\end{array}$ & $\begin{array}{l}-0.042 \\
{[0.042]}\end{array}$ & $\begin{array}{c}0.000 \\
{[.]}\end{array}$ & $\begin{array}{c}0.013 \\
{[0.006]}\end{array}$ & $\begin{array}{l}-0.055 \\
{[0.017]}\end{array}$ & $\begin{array}{l}-0.063 \\
{[0.029]}\end{array}$ & $\begin{array}{c}0.005 \\
{[0.003]}\end{array}$ \\
\hline Africa mean of outcome & -1.363 & -1.363 & -1.363 & -1.363 & -1.363 & 0.381 & -0.889 & 10.107 & 0.074 \\
\hline Child's age dummies $\times$ India & No & No & Yes & Yes & Yes & Yes & Yes & Yes & Yes \\
\hline Mother's age at birth $\times$ India & No & No & Yes & Yes & No & Yes & Yes & Yes & Yes \\
\hline PSU FEs & No & No & Yes & Yes & No & Yes & Yes & Yes & Yes \\
\hline Mother FEs & No & No & No & No & Yes & No & No & No & No \\
\hline $\begin{array}{l}\text { Completed fertility sample } \\
\text { p-Value of joint }\end{array}$ & No & No & No & Yes & No & No & No & No & No \\
\hline significance test & 0.000 & 0.000 & 0.000 & 0.000 & & 0.000 & 0.000 & 0.000 & 0.000 \\
\hline Observations & 161,688 & 161,688 & 161,267 & 63,822 & 80,571 & 161,267 & 161,267 & 84,993 & 191,664 \\
\hline
\end{tabular}

Notes: Standard errors are clustered by mother and appear in brackets. Please consider the notes in Table 2.6 for further explanations. Source: Adapted from Jayachandran \& Pande (2017) using data from DHS (Heger Boyle \& Sobek, 2019) 
Table B.68: India's Differential Birth Order Gradient in Child Height and Related Outcomes (2011-2017): Weighted 3 Macro-Determinants

\begin{tabular}{|c|c|c|c|c|c|c|c|c|c|}
\hline & $\begin{array}{l}\text { HFA } \\
\mathrm{Z}^{-} \\
\text {score } \\
(1)\end{array}$ & $\begin{array}{l}\text { HFA } \\
\text { z- } \\
\text { score } \\
(2)\end{array}$ & $\begin{array}{l}\text { HFA } \\
\text { Z- } \\
\text { score } \\
(3)\end{array}$ & $\begin{array}{l}\text { HFA } \\
\text { z- } \\
\text { score } \\
(4)\end{array}$ & $\begin{array}{l}\text { HFA } \\
\text { Z- } \\
\text { score } \\
(5)\end{array}$ & $\begin{array}{l}\text { Stunted } \\
\text { (6) }\end{array}$ & $\begin{array}{l}\text { WFA } \\
\text { z- } \\
\text { score } \\
(7)\end{array}$ & $\begin{array}{c}\mathrm{Hb} \\
\text { level } \\
(8)\end{array}$ & $\begin{array}{l}\text { Decease } \\
\text { (9) }\end{array}$ \\
\hline India & $\begin{array}{l}-0.381 \\
{[0.012]}\end{array}$ & $\begin{array}{l}-0.225 \\
{[0.022]}\end{array}$ & & & & & & & \\
\hline India $\times 2$ nd child & & $\begin{array}{l}-0.089 \\
{[0.020]}\end{array}$ & $\begin{array}{l}-0.074 \\
{[0.022]}\end{array}$ & $\begin{array}{l}-0.117 \\
{[0.070]}\end{array}$ & $\begin{array}{l}-0.166 \\
{[0.038]}\end{array}$ & $\begin{array}{c}0.024 \\
{[0.006]}\end{array}$ & $\begin{array}{l}-0.091 \\
{[0.016]}\end{array}$ & $\begin{array}{l}-0.038 \\
{[0.025]}\end{array}$ & $\begin{array}{l}-0.003 \\
{[0.003]}\end{array}$ \\
\hline India $\times 3$ rd + child & & $\begin{array}{l}-0.188 \\
{[0.019]}\end{array}$ & $\begin{array}{l}-0.103 \\
{[0.026]}\end{array}$ & $\begin{array}{l}-0.108 \\
{[0.099]}\end{array}$ & $\begin{array}{l}-0.389 \\
{[0.068]}\end{array}$ & $\begin{array}{c}0.024 \\
{[0.007]}\end{array}$ & $\begin{array}{l}-0.125 \\
{[0.020]}\end{array}$ & $\begin{array}{c}0.005 \\
{[0.029]}\end{array}$ & $\begin{array}{c}0.000 \\
{[0.003]}\end{array}$ \\
\hline 2nd child & & $\begin{array}{c}0.027 \\
{[0.016]}\end{array}$ & $\begin{array}{l}-0.050 \\
{[0.018]}\end{array}$ & $\begin{array}{l}-0.066 \\
{[0.067]}\end{array}$ & $\begin{array}{l}-0.208 \\
{[0.029]}\end{array}$ & $\begin{array}{c}0.013 \\
{[0.005]}\end{array}$ & $\begin{array}{l}-0.008 \\
{[0.013]}\end{array}$ & $\begin{array}{l}-0.031 \\
{[0.022]}\end{array}$ & $\begin{array}{l}-0.009 \\
{[0.002]}\end{array}$ \\
\hline 3rd + child & & $\begin{array}{c}0.016 \\
{[0.014]}\end{array}$ & $\begin{array}{l}-0.146 \\
{[0.020]}\end{array}$ & $\begin{array}{l}-0.138 \\
{[0.092]}\end{array}$ & $\begin{array}{l}-0.316 \\
{[0.047]}\end{array}$ & $\begin{array}{c}0.042 \\
{[0.005]}\end{array}$ & $\begin{array}{l}-0.064 \\
{[0.015]}\end{array}$ & $\begin{array}{l}-0.121 \\
{[0.025]}\end{array}$ & $\begin{array}{l}-0.011 \\
{[0.003]}\end{array}$ \\
\hline India $\times$ Mother's literacy $=1$ & $\begin{array}{c}0.064 \\
{[0.012]}\end{array}$ & $\begin{array}{l}-0.002 \\
{[0.017]}\end{array}$ & $\begin{array}{c}0.063 \\
{[0.021]}\end{array}$ & $\begin{array}{c}0.033 \\
{[0.037]}\end{array}$ & $\begin{array}{c}0.000 \\
{[.]}\end{array}$ & $\begin{array}{l}-0.027 \\
{[0.006]}\end{array}$ & $\begin{array}{c}0.075 \\
{[0.015]}\end{array}$ & $\begin{array}{c}0.003 \\
{[0.022]}\end{array}$ & $\begin{array}{l}-0.002 \\
{[0.002]}\end{array}$ \\
\hline Mother's literacy $=1$ & $\begin{array}{c}0.176 \\
{[0.009]}\end{array}$ & $\begin{array}{c}0.246 \\
{[0.012]}\end{array}$ & $\begin{array}{c}0.116 \\
{[0.016]}\end{array}$ & $\begin{array}{c}0.147 \\
{[0.033]}\end{array}$ & $\begin{array}{c}0.000 \\
{[.]}\end{array}$ & $\begin{array}{l}-0.031 \\
{[0.004]}\end{array}$ & $\begin{array}{c}0.091 \\
{[0.012]}\end{array}$ & $\begin{array}{c}0.109 \\
{[0.019]}\end{array}$ & $\begin{array}{l}-0.004 \\
{[0.002]}\end{array}$ \\
\hline 2 nd poorest wealth quantile & $\begin{array}{c}0.162 \\
{[0.010]}\end{array}$ & $\begin{array}{c}0.126 \\
{[0.013]}\end{array}$ & $\begin{array}{c}0.090 \\
{[0.014]}\end{array}$ & $\begin{array}{c}0.117 \\
{[0.024]}\end{array}$ & $\begin{array}{c}0.000 \\
{[.]}\end{array}$ & $\begin{array}{l}-0.027 \\
{[0.004]}\end{array}$ & $\begin{array}{l}0.077 \\
{[0.011]}\end{array}$ & $\begin{array}{c}0.081 \\
{[0.015]}\end{array}$ & $\begin{array}{c}0.003 \\
{[0.002]}\end{array}$ \\
\hline 3rd poorest wealth quantile & $\begin{array}{c}0.329 \\
{[0.010]}\end{array}$ & $\begin{array}{c}0.284 \\
{[0.013]}\end{array}$ & $\begin{array}{c}0.180 \\
{[0.017]}\end{array}$ & $\begin{array}{c}0.179 \\
{[0.027]}\end{array}$ & $\begin{array}{c}0.000 \\
{[.]}\end{array}$ & $\begin{array}{l}-0.052 \\
{[0.005]}\end{array}$ & $\begin{array}{c}0.155 \\
{[0.012]}\end{array}$ & $\begin{array}{c}0.116 \\
{[0.017]}\end{array}$ & $\begin{array}{l}-0.000 \\
{[0.002]}\end{array}$ \\
\hline 4th poorest wealth quantile & $\begin{array}{c}0.551 \\
{[0.010]}\end{array}$ & $\begin{array}{c}0.507 \\
{[0.014]}\end{array}$ & $\begin{array}{c}0.334 \\
{[0.019]}\end{array}$ & $\begin{array}{c}0.332 \\
{[0.031]}\end{array}$ & $\begin{array}{c}0.000 \\
{[.]}\end{array}$ & $\begin{array}{l}-0.096 \\
{[0.005]}\end{array}$ & $\begin{array}{c}0.268 \\
{[0.014]}\end{array}$ & $\begin{array}{c}0.172 \\
{[0.020]}\end{array}$ & $\begin{array}{l}-0.004 \\
{[0.002]}\end{array}$ \\
\hline Richest wealth quantile & $\begin{array}{c}0.835 \\
{[0.011]}\end{array}$ & $\begin{array}{c}0.830 \\
{[0.016]}\end{array}$ & $\begin{array}{c}0.525 \\
{[0.024]}\end{array}$ & $\begin{array}{c}0.511 \\
{[0.037]}\end{array}$ & $\begin{array}{c}0.000 \\
{[.]}\end{array}$ & $\begin{array}{l}-0.144 \\
{[0.007]}\end{array}$ & $\begin{array}{c}0.453 \\
{[0.018]}\end{array}$ & $\begin{array}{c}0.267 \\
{[0.024]}\end{array}$ & $\begin{array}{l}-0.006 \\
{[0.003]}\end{array}$ \\
\hline India $\times$ Open defecation $=1$ & $\begin{array}{l}-0.095 \\
{[0.014]}\end{array}$ & $\begin{array}{l}-0.083 \\
{[0.019]}\end{array}$ & $\begin{array}{l}-0.008 \\
{[0.027]}\end{array}$ & $\begin{array}{l}-0.011 \\
{[0.049]}\end{array}$ & $\begin{array}{c}0.000 \\
{[.]}\end{array}$ & $\begin{array}{c}0.007 \\
{[0.007]}\end{array}$ & $\begin{array}{l}-0.035 \\
{[0.020]}\end{array}$ & $\begin{array}{l}-0.000 \\
{[0.028]}\end{array}$ & $\begin{array}{l}-0.003 \\
{[0.003]}\end{array}$ \\
\hline Open defecation $=1$ & $\begin{array}{c}0.018 \\
{[0.011]}\end{array}$ & $\begin{array}{c}0.040 \\
{[0.014]}\end{array}$ & $\begin{array}{l}-0.067 \\
{[0.020]}\end{array}$ & $\begin{array}{l}-0.084 \\
{[0.043]}\end{array}$ & $\begin{array}{c}0.000 \\
{[.]} \\
\end{array}$ & $\begin{array}{c}0.019 \\
{[0.006]}\end{array}$ & $\begin{array}{l}-0.050 \\
{[0.015]}\end{array}$ & $\begin{array}{l}-0.074 \\
{[0.024]}\end{array}$ & $\begin{array}{c}0.006 \\
{[0.003]}\end{array}$ \\
\hline Africa mean of outcome & -1.163 & -1.163 & -1.163 & -1.163 & -1.163 & 0.311 & -0.838 & 10.439 & 0.050 \\
\hline Child's age dummies $\times$ India & No & No & Yes & Yes & Yes & Yes & Yes & Yes & Yes \\
\hline Mother's age at birth $\times$ India & No & No & Yes & Yes & No & Yes & Yes & Yes & Yes \\
\hline PSU FEs & No & No & Yes & Yes & No & Yes & Yes & Yes & Yes \\
\hline Mother FEs & No & No & No & No & Yes & No & No & No & No \\
\hline $\begin{array}{l}\text { Completed fertility sample } \\
\text { p-Value of joint }\end{array}$ & No & No & No & Yes & No & No & No & No & No \\
\hline significance test & 0.000 & 0.000 & 0.000 & 0.000 & & 0.000 & 0.000 & 0.000 & 0.000 \\
\hline Observations & 384,190 & 384,190 & 383,034 & 168,981 & 183,299 & 383,034 & 383,034 & 289,410 & 399,467 \\
\hline
\end{tabular}

Notes: Standard errors are clustered by mother and appear in brackets. Please consider the notes in Table 2.6 for further explanations. Source: Adapted from J+P using data from IPUMS DHS (ICF, 2004) and DHS (Heger Boyle \& Sobek, 2019) 


\subsection{Child Health Inputs}

Table B.69: Child Health Inputs (2004-2010): Weighted Macro-Determinants

\begin{tabular}{|c|c|c|c|c|c|c|c|c|c|c|}
\hline & \multicolumn{4}{|c|}{ Prenatal inputs } & \multicolumn{3}{|c|}{ Postnatal inputs } & \multirow[b]{2}{*}{$\begin{array}{c}\text { Average } \\
\text { pooled } \\
\text { inputs } \\
(8)\end{array}$} & \multicolumn{2}{|c|}{ Animal sourced foods } \\
\hline & $\begin{array}{c}\text { Total } \\
\text { prenatal } \\
\text { visits } \\
(1)\end{array}$ & $\begin{array}{l}\text { Mother } \\
\text { took iron } \\
\text { supple- } \\
\text { ments } \\
(2)\end{array}$ & $\begin{array}{l}\text { Mother's } \\
\text { total } \\
\text { tetanus } \\
\text { shots } \\
\text { (3) }\end{array}$ & $\begin{array}{c}\text { Delivery } \\
\text { at health } \\
\text { facility } \\
\text { (4) }\end{array}$ & $\begin{array}{l}\text { Postnatal } \\
\text { check } \\
\text { within } 2 \\
\text { months } \\
\text { (5) }\end{array}$ & $\begin{array}{c}\text { Child } \\
\text { taking } \\
\text { iron pills } \\
(6)\end{array}$ & $\begin{array}{c}\text { Child's } \\
\text { total vac- } \\
\text { cinations } \\
\text { (7) }\end{array}$ & & $\begin{array}{l}\text { Meat or } \\
\text { eggs } \\
\text { consumed } \\
\text { (9) }\end{array}$ & $\begin{array}{c}\text { Dairy } \\
\text { products } \\
\text { consumed } \\
(10)\end{array}$ \\
\hline India $\times 2$ nd child & $\begin{array}{c}-0.518 \\
{[0.064]}\end{array}$ & $\begin{array}{c}-0.036 \\
{[0.010]}\end{array}$ & $\begin{array}{c}-0.029 \\
{[0.023]}\end{array}$ & $\begin{array}{c}-0.057 \\
{[0.008]}\end{array}$ & $\begin{array}{c}-0.001 \\
{[0.016]}\end{array}$ & $\begin{array}{c}-0.007 \\
{[0.007]}\end{array}$ & $\begin{array}{c}-0.208 \\
{[0.051]}\end{array}$ & $\begin{array}{c}-0.000 \\
{[0.011]}\end{array}$ & $\begin{array}{c}0.027 \\
{[0.009]}\end{array}$ & $\begin{array}{c}-0.016 \\
{[0.004]}\end{array}$ \\
\hline India $\times 3$ rd + child & $\begin{array}{c}-0.940 \\
{[0.073]}\end{array}$ & $\begin{array}{c}-0.080 \\
{[0.012]}\end{array}$ & $\begin{array}{c}-0.048 \\
{[0.027]}\end{array}$ & $\begin{array}{c}-0.109 \\
{[0.010]}\end{array}$ & $\begin{array}{c}0.021 \\
{[0.017]}\end{array}$ & $\begin{array}{c}-0.001 \\
{[0.008]}\end{array}$ & $\begin{array}{c}-0.488 \\
{[0.066]}\end{array}$ & $\begin{array}{c}0.008 \\
{[0.012]}\end{array}$ & $\begin{array}{c}0.029 \\
{[0.011]}\end{array}$ & $\begin{array}{l}-0.035 \\
{[0.005]}\end{array}$ \\
\hline 2nd child & $\begin{array}{c}-0.200 \\
{[0.037]}\end{array}$ & $\begin{array}{c}-0.013 \\
{[0.006]}\end{array}$ & $\begin{array}{c}-0.095 \\
{[0.016]}\end{array}$ & $\begin{array}{c}-0.079 \\
{[0.004]}\end{array}$ & $\begin{array}{c}0.001 \\
{[0.012]}\end{array}$ & $\begin{array}{c}-0.004 \\
{[0.005]}\end{array}$ & $\begin{array}{c}-0.102 \\
{[0.031]}\end{array}$ & $\begin{array}{c}-0.001 \\
{[0.008]}\end{array}$ & $\begin{array}{c}-0.021 \\
{[0.006]}\end{array}$ & $\begin{array}{c}-0.041 \\
{[0.003]}\end{array}$ \\
\hline $3 \mathrm{rd}+$ child & $\begin{array}{c}-0.438 \\
{[0.042]}\end{array}$ & $\begin{array}{c}-0.026 \\
{[0.006]}\end{array}$ & $\begin{array}{c}-0.191 \\
{[0.017]}\end{array}$ & $\begin{array}{c}-0.121 \\
{[0.005]}\end{array}$ & $\begin{array}{c}-0.026 \\
{[0.013]}\end{array}$ & $\begin{array}{c}-0.016 \\
{[0.007]}\end{array}$ & $\begin{array}{l}-0.205 \\
{[0.037]}\end{array}$ & $\begin{array}{c}-0.019 \\
{[0.008]}\end{array}$ & $\begin{array}{c}-0.032 \\
{[0.007]}\end{array}$ & $\begin{array}{c}-0.067 \\
{[0.003]}\end{array}$ \\
\hline Africa mean of outcome & 3.871 & 0.616 & 1.407 & 0.466 & 0.323 & 0.134 & 6.142 & 0.433 & 0.159 & 0.377 \\
\hline India mean of outcome & 3.494 & 0.661 & 1.863 & 0.389 & 0.083 & 0.046 & 6.419 & 0.122 & 0.108 & 0.297 \\
\hline Age \& other controls & Yes & Yes & Yes & Yes & Yes & Yes & Yes & Yes & Yes & Yes \\
\hline Observations & 115,364 & 117,707 & 117,219 & 167,405 & 35,902 & 91,964 & 122,922 & 79,122 & 68,303 & 167,752 \\
\hline
\end{tabular}

Notes: Standard errors are clustered by mother and appear in brackets. Please consider the notes in Table 2.8 for further explanations. Source: Adapted from J+P using data from DHS (Heger Boyle \& Sobek, 2019)

Table B.70: Child Health Inputs (2011-2017): Weighted Macro-Determinants

\begin{tabular}{|c|c|c|c|c|c|c|c|c|c|c|}
\hline & \multicolumn{4}{|c|}{ Prenatal inputs } & \multicolumn{3}{|c|}{ Postnatal inputs } & \multirow[b]{2}{*}{$\begin{array}{c}\text { Average } \\
\text { pooled } \\
\text { inputs } \\
(8)\end{array}$} & \multicolumn{2}{|c|}{ Animal sourced foods } \\
\hline & $\begin{array}{c}\text { Total } \\
\text { prenatal } \\
\text { visits } \\
(1)\end{array}$ & $\begin{array}{l}\text { Mother } \\
\text { took iron } \\
\text { supple- } \\
\text { ments } \\
\text { (2) }\end{array}$ & $\begin{array}{l}\text { Mother's } \\
\text { total } \\
\text { tetanus } \\
\text { shots } \\
\text { (3) }\end{array}$ & $\begin{array}{c}\text { Delivery } \\
\text { at health } \\
\text { facility } \\
\text { (4) }\end{array}$ & $\begin{array}{c}\text { Postnatal } \\
\text { check } \\
\text { within } 2 \\
\text { months } \\
\text { (5) }\end{array}$ & $\begin{array}{c}\text { Child } \\
\text { taking } \\
\text { iron pills } \\
(6)\end{array}$ & $\begin{array}{c}\text { Child's } \\
\text { total vac- } \\
\text { cinations } \\
\text { (7) }\end{array}$ & & $\begin{array}{l}\text { Meat or } \\
\text { eggs } \\
\text { consumed } \\
\text { (9) }\end{array}$ & $\begin{array}{c}\text { Dairy } \\
\text { products } \\
\text { consumed } \\
\quad(10)\end{array}$ \\
\hline India $\times 2$ nd child & $\begin{array}{c}-0.162 \\
{[0.048]}\end{array}$ & $\begin{array}{c}-0.006 \\
{[0.006]}\end{array}$ & $\begin{array}{c}0.047 \\
{[0.016]}\end{array}$ & $\begin{array}{c}0.010 \\
{[0.004]}\end{array}$ & $\begin{array}{c}0.006 \\
{[0.007]}\end{array}$ & $\begin{array}{c}-0.003 \\
{[0.004]}\end{array}$ & $\begin{array}{c}0.113 \\
{[0.058]}\end{array}$ & $\begin{array}{c}0.035 \\
{[0.009]}\end{array}$ & $\begin{array}{c}0.049 \\
{[0.009]}\end{array}$ & $\begin{array}{c}-0.000 \\
{[0.003]}\end{array}$ \\
\hline India $\times 3$ rd + child & $\begin{array}{c}-0.353 \\
{[0.055]}\end{array}$ & $\begin{array}{c}-0.022 \\
{[0.007]}\end{array}$ & $\begin{array}{c}0.088 \\
{[0.018]}\end{array}$ & $\begin{array}{c}0.003 \\
{[0.006]}\end{array}$ & $\begin{array}{c}0.016 \\
{[0.008]}\end{array}$ & $\begin{array}{c}-0.016 \\
{[0.005]}\end{array}$ & $\begin{array}{c}0.052 \\
{[0.070]}\end{array}$ & $\begin{array}{c}0.043 \\
{[0.010]}\end{array}$ & $\begin{array}{c}0.063 \\
{[0.010]}\end{array}$ & $\begin{array}{c}-0.005 \\
{[0.003]}\end{array}$ \\
\hline 2nd child & $\begin{array}{c}-0.279 \\
{[0.034]}\end{array}$ & $\begin{array}{c}-0.016 \\
{[0.005]}\end{array}$ & $\begin{array}{c}-0.127 \\
{[0.014]}\end{array}$ & $\begin{array}{c}-0.078 \\
{[0.004]}\end{array}$ & $\begin{array}{c}-0.014 \\
{[0.006]}\end{array}$ & $\begin{array}{c}-0.002 \\
{[0.003]}\end{array}$ & $\begin{array}{l}-0.232 \\
{[0.055]}\end{array}$ & $\begin{array}{c}-0.004 \\
{[0.008]}\end{array}$ & $\begin{array}{c}-0.023 \\
{[0.007]}\end{array}$ & $\begin{array}{c}-0.043 \\
{[0.002]}\end{array}$ \\
\hline $3 \mathrm{rd}+$ child & $\begin{array}{l}-0.565 \\
{[0.038]}\end{array}$ & $\begin{array}{c}-0.027 \\
{[0.006]}\end{array}$ & $\begin{array}{c}-0.207 \\
{[0.016]}\end{array}$ & $\begin{array}{c}-0.135 \\
{[0.005]}\end{array}$ & $\begin{array}{c}-0.028 \\
{[0.007]}\end{array}$ & $\begin{array}{c}-0.002 \\
{[0.004]}\end{array}$ & $\begin{array}{c}-0.380 \\
{[0.065]}\end{array}$ & $\begin{array}{l}-0.017 \\
{[0.008]}\end{array}$ & $\begin{array}{c}-0.041 \\
{[0.008]}\end{array}$ & $\begin{array}{c}-0.071 \\
{[0.003]}\end{array}$ \\
\hline Africa mean of outcome & 3.993 & 0.742 & 1.410 & 0.582 & 0.448 & 0.078 & 4.982 & 0.304 & 0.202 & 0.382 \\
\hline India mean of outcome & 4.631 & 0.783 & 1.933 & 0.795 & 0.376 & 0.251 & 7.431 & 0.140 & 0.135 & 0.475 \\
\hline Age \& other controls & Yes & Yes & Yes & Yes & Yes & Yes & Yes & Yes & Yes & Yes \\
\hline Observations & 287,302 & 282,486 & 281,157 & 397,406 & 272,650 & 374,185 & 215,976 & 146,828 & 146,823 & 397,636 \\
\hline
\end{tabular}

Notes: Standard errors are clustered by mother and appear in brackets. Please consider the notes in Table 2.8 for further explanations. Source: Adapted from J+P using data from IPUMS DHS (ICF, 2004) and DHS (Heger Boyle \& Sobek, 2019) 


\subsection{Child Gender and the Birth Order Gradient in Height}

Table B.71: Child Gender and the Birth Order Gradient in Height (2004-2010): Weighted 3 Macro-Determinants

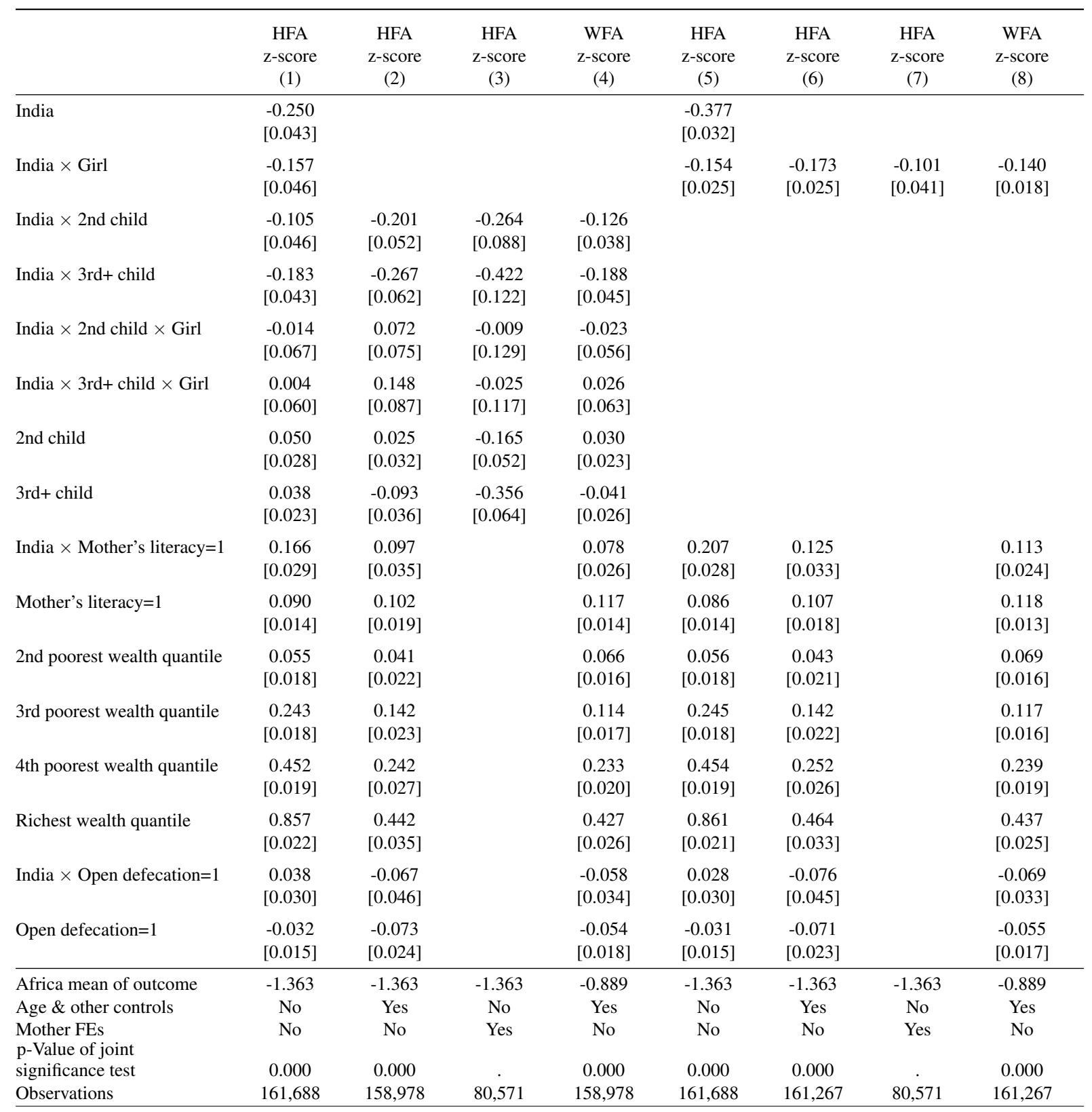

Notes: Standard errors are clustered by mother and appear in brackets. Please consider the notes in Table 2.10 for further explanations.

Source: Adapted from J+P using data from DHS (Heger Boyle \& Sobek, 2019) 
Table B.72: Child Gender and the Birth Order Gradient in Height (2010-2017): Weighted 3 Macro-Determinants

\begin{tabular}{|c|c|c|c|c|c|c|c|c|}
\hline & $\begin{array}{c}\text { HFA } \\
\text { z-score } \\
\text { (1) }\end{array}$ & $\begin{array}{c}\text { HFA } \\
\text { z-score } \\
\text { (2) }\end{array}$ & $\begin{array}{c}\text { HFA } \\
\text { z-score } \\
(3)\end{array}$ & $\begin{array}{c}\text { WFA } \\
\text { z-score } \\
(4)\end{array}$ & $\begin{array}{c}\text { HFA } \\
\text { Z-score } \\
(5)\end{array}$ & $\begin{array}{c}\text { HFA } \\
\text { z-score } \\
(6)\end{array}$ & $\begin{array}{c}\text { HFA } \\
\text { z-score } \\
(7)\end{array}$ & $\begin{array}{c}\text { WFA } \\
\text { z-score } \\
(8)\end{array}$ \\
\hline India & $\begin{array}{c}-0.186 \\
{[0.026]}\end{array}$ & & & & $\begin{array}{c}-0.297 \\
{[0.019]}\end{array}$ & & & \\
\hline India $\times$ Girl & $\begin{array}{c}-0.078 \\
{[0.029]}\end{array}$ & & & & $\begin{array}{c}-0.091 \\
{[0.015]}\end{array}$ & $\begin{array}{c}-0.097 \\
{[0.015]}\end{array}$ & $\begin{array}{c}-0.093 \\
{[0.025]}\end{array}$ & $\begin{array}{c}-0.064 \\
{[0.011]}\end{array}$ \\
\hline India $\times 2$ nd child & $\begin{array}{c}-0.062 \\
{[0.029]}\end{array}$ & $\begin{array}{c}-0.006 \\
{[0.033]}\end{array}$ & $\begin{array}{l}-0.145 \\
{[0.055]}\end{array}$ & $\begin{array}{c}-0.041 \\
{[0.025]}\end{array}$ & & & & \\
\hline India $\times 3$ rd + child & $\begin{array}{c}-0.159 \\
{[0.027]}\end{array}$ & $\begin{array}{c}-0.006 \\
{[0.039]}\end{array}$ & $\begin{array}{c}-0.371 \\
{[0.078]}\end{array}$ & $\begin{array}{c}-0.054 \\
{[0.029]}\end{array}$ & & & & \\
\hline India $\times 2$ nd child $\times$ Girl & $\begin{array}{c}-0.053 \\
{[0.042]}\end{array}$ & $\begin{array}{c}-0.112 \\
{[0.047]}\end{array}$ & $\begin{array}{c}-0.030 \\
{[0.076]}\end{array}$ & $\begin{array}{c}-0.088 \\
{[0.035]}\end{array}$ & & & & \\
\hline India $\times$ 3rd + child $\times$ Girl & $\begin{array}{c}-0.058 \\
{[0.037]}\end{array}$ & $\begin{array}{c}-0.188 \\
{[0.055]}\end{array}$ & $\begin{array}{c}-0.010 \\
{[0.073]}\end{array}$ & $\begin{array}{c}-0.136 \\
{[0.040]}\end{array}$ & & & & \\
\hline 2nd child & $\begin{array}{c}0.016 \\
{[0.023]}\end{array}$ & $\begin{array}{c}-0.083 \\
{[0.027]}\end{array}$ & $\begin{array}{c}-0.211 \\
{[0.042]}\end{array}$ & $\begin{array}{c}-0.012 \\
{[0.020]}\end{array}$ & & & & \\
\hline 3rd + child & $\begin{array}{c}0.043 \\
{[0.020]}\end{array}$ & $\begin{array}{c}-0.156 \\
{[0.030]}\end{array}$ & $\begin{array}{c}-0.295 \\
{[0.055]}\end{array}$ & $\begin{array}{c}-0.061 \\
{[0.022]}\end{array}$ & & & & \\
\hline India $\times$ Mother's literacy $=1$ & $\begin{array}{c}-0.001 \\
{[0.017]}\end{array}$ & $\begin{array}{c}0.073 \\
{[0.022]}\end{array}$ & & $\begin{array}{c}0.077 \\
{[0.016]}\end{array}$ & $\begin{array}{c}0.044 \\
{[0.017]}\end{array}$ & $\begin{array}{c}0.081 \\
{[0.020]}\end{array}$ & & $\begin{array}{c}0.081 \\
{[0.015]}\end{array}$ \\
\hline Mother's literacy $=1$ & $\begin{array}{c}0.246 \\
{[0.012]}\end{array}$ & $\begin{array}{c}0.111 \\
{[0.017]}\end{array}$ & & $\begin{array}{c}0.088 \\
{[0.013]}\end{array}$ & $\begin{array}{c}0.242 \\
{[0.012]}\end{array}$ & $\begin{array}{c}0.127 \\
{[0.016]}\end{array}$ & & $\begin{array}{c}0.101 \\
{[0.012]}\end{array}$ \\
\hline 2 nd poorest wealth quantile & $\begin{array}{c}0.126 \\
{[0.013]}\end{array}$ & $\begin{array}{c}0.094 \\
{[0.015]}\end{array}$ & & $\begin{array}{c}0.080 \\
{[0.011]}\end{array}$ & $\begin{array}{c}0.125 \\
{[0.013]}\end{array}$ & $\begin{array}{c}0.093 \\
{[0.014]}\end{array}$ & & $\begin{array}{c}0.080 \\
{[0.011]}\end{array}$ \\
\hline 3rd poorest wealth quantile & $\begin{array}{c}0.284 \\
{[0.013]}\end{array}$ & $\begin{array}{c}0.180 \\
{[0.017]}\end{array}$ & & $\begin{array}{c}0.154 \\
{[0.013]}\end{array}$ & $\begin{array}{c}0.288 \\
{[0.013]}\end{array}$ & $\begin{array}{c}0.187 \\
{[0.017]}\end{array}$ & & $\begin{array}{c}0.159 \\
{[0.012]}\end{array}$ \\
\hline 4 th poorest wealth quantile & $\begin{array}{c}0.507 \\
{[0.014]}\end{array}$ & $\begin{array}{c}0.338 \\
{[0.021]}\end{array}$ & & $\begin{array}{c}0.266 \\
{[0.015]}\end{array}$ & $\begin{array}{c}0.514 \\
{[0.014]}\end{array}$ & $\begin{array}{c}0.347 \\
{[0.019]}\end{array}$ & & $\begin{array}{c}0.276 \\
{[0.014]}\end{array}$ \\
\hline Richest wealth quantile & $\begin{array}{c}0.830 \\
{[0.016]}\end{array}$ & $\begin{array}{c}0.526 \\
{[0.025]}\end{array}$ & & $\begin{array}{c}0.450 \\
{[0.019]}\end{array}$ & $\begin{array}{c}0.844 \\
{[0.016]}\end{array}$ & $\begin{array}{c}0.554 \\
{[0.024]}\end{array}$ & & $\begin{array}{c}0.472 \\
{[0.018]}\end{array}$ \\
\hline India $\times$ Open defecation $=1$ & $\begin{array}{c}-0.084 \\
{[0.019]}\end{array}$ & $\begin{array}{c}0.004 \\
{[0.028]}\end{array}$ & & $\begin{array}{c}-0.030 \\
{[0.021]}\end{array}$ & $\begin{array}{c}-0.089 \\
{[0.019]}\end{array}$ & $\begin{array}{c}-0.013 \\
{[0.027]}\end{array}$ & & $\begin{array}{c}-0.041 \\
{[0.020]}\end{array}$ \\
\hline Open defecation $=1$ & $\begin{array}{c}0.041 \\
{[0.014]}\end{array}$ & $\begin{array}{c}-0.070 \\
{[0.021]}\end{array}$ & & $\begin{array}{c}-0.052 \\
{[0.016]}\end{array}$ & $\begin{array}{c}0.043 \\
{[0.014]}\end{array}$ & $\begin{array}{c}-0.069 \\
{[0.020]}\end{array}$ & & $\begin{array}{c}-0.049 \\
{[0.015]}\end{array}$ \\
\hline Africa mean of outcome & -1.163 & -1.163 & -1.163 & -0.838 & -1.163 & -1.163 & -1.163 & -0.838 \\
\hline Age \& other controls & No & Yes & No & Yes & No & Yes & No & Yes \\
\hline $\begin{array}{l}\text { Mother FEs } \\
\text { p-Value of joint }\end{array}$ & No & No & Yes & No & No & No & Yes & No \\
\hline $\begin{array}{l}\text { significance test } \\
\text { Observations }\end{array}$ & $\begin{array}{c}0.000 \\
384,190\end{array}$ & $\begin{array}{c}0.000 \\
374,909\end{array}$ & 183,299 & $\begin{array}{c}0.000 \\
374,909\end{array}$ & $\begin{array}{c}0.000 \\
384,190\end{array}$ & $\begin{array}{c}0.000 \\
383,034\end{array}$ & 183,299 & $\begin{array}{c}0.000 \\
383,034\end{array}$ \\
\hline
\end{tabular}

Notes: Standard errors are clustered by mother and appear in brackets. Please consider the notes in table 2.10 for further explanations. Source: Adapted from J+P using data from IPUMS DHS (ICF, 2004) and DHS (Heger Boyle \& Sobek, 2019) 


\subsection{Impact on Average Height - Accounting exercise}

Table B.73: Accounting Exercise Part 1: Sample Comparison (2004-2010): Weighted 3 MacroDeterminants

\begin{tabular}{|c|c|c|c|}
\hline & & $\begin{array}{l}\text { Accounting } \\
\text { Exercise } 1\end{array}$ & $\begin{array}{c}\text { Accounting } \\
\text { Exercise } 2\end{array}$ \\
\hline & $\begin{array}{c}\text { HFA z-score } \\
\text { (1) }\end{array}$ & $\begin{array}{c}\text { HFA z-score } \\
\text { (2) }\end{array}$ & $\begin{array}{c}\text { HFA z-score } \\
\text { (3) }\end{array}$ \\
\hline India & $\begin{array}{l}-0.342 \\
{[0.020]}\end{array}$ & & \\
\hline Gradient proxy & & $\begin{array}{c}0.037 \\
{[0.073]}\end{array}$ & $\begin{array}{c}0.206 \\
{[0.138]}\end{array}$ \\
\hline Mother's literacy $=1$ & & $\begin{array}{c}0.067 \\
{[0.017]}\end{array}$ & $\begin{array}{c}0.066 \\
{[0.017]}\end{array}$ \\
\hline 2 nd poorest wealth quantile & & $\begin{array}{c}0.066 \\
{[0.024]}\end{array}$ & $\begin{array}{c}0.066 \\
{[0.024]}\end{array}$ \\
\hline 3 rd poorest wealth quantile & & $\begin{array}{c}0.251 \\
{[0.025]}\end{array}$ & $\begin{array}{c}0.250 \\
{[0.025]}\end{array}$ \\
\hline 4 th poorest wealth quantile & & $\begin{array}{c}0.450 \\
{[0.027]}\end{array}$ & $\begin{array}{c}0.448 \\
{[0.026]}\end{array}$ \\
\hline Richest wealth quantile & & $\begin{array}{c}0.859 \\
{[0.031]}\end{array}$ & $\begin{array}{c}0.859 \\
{[0.031]}\end{array}$ \\
\hline Open defecation $=1$ & & $\begin{array}{c}-0.029 \\
{[0.020]}\end{array}$ & $\begin{array}{c}-0.027 \\
{[0.020]}\end{array}$ \\
\hline \multicolumn{4}{|l|}{ Mean of gradient proxy } \\
\hline India & & -0.324 & -0.236 \\
\hline Africa & & -0.068 & -0.040 \\
\hline Kerala \& Northeast & & -0.214 & -0.184 \\
\hline Rest of India & & -0.324 & -0.234 \\
\hline Log GDP per capita & Yes & Yes & Yes \\
\hline Sample & Full & Africa & Africa \\
\hline Observations & 168,135 & 122,567 & 122,567 \\
\hline
\end{tabular}

Notes: Standard errors are clustered by PSU and appear in brackets. Please consider the notes in Table 2.12 for further explanations. Source: Adapted from J+P using data from DHS (Heger Boyle \& Sobek, 2019) 
Table B.74: Accounting Exercise Part 1: Sample Comparison (2011-2017): Weighted 3 MacroDeterminants

\begin{tabular}{|c|c|c|c|}
\hline & & $\begin{array}{l}\text { Accounting } \\
\text { Exercise } 1\end{array}$ & $\begin{array}{c}\text { Accounting } \\
\text { Exercise } 2\end{array}$ \\
\hline & $\begin{array}{c}\text { HFA z-score } \\
\text { (1) }\end{array}$ & $\begin{array}{c}\text { HFA z-score } \\
\text { (2) }\end{array}$ & $\begin{array}{c}\text { HFA z-score } \\
\text { (3) }\end{array}$ \\
\hline India & $\begin{array}{l}-0.119 \\
{[0.021]}\end{array}$ & & \\
\hline Gradient proxy & & $\begin{array}{l}-0.627 \\
{[0.132]}\end{array}$ & $\begin{array}{l}-1.146 \\
{[0.233]}\end{array}$ \\
\hline Mother's literacy $=1$ & & $\begin{array}{c}0.218 \\
{[0.017]}\end{array}$ & $\begin{array}{c}0.213 \\
{[0.018]}\end{array}$ \\
\hline 2 nd poorest wealth quantile & & $\begin{array}{c}0.105 \\
{[0.019]}\end{array}$ & $\begin{array}{c}0.104 \\
{[0.019]}\end{array}$ \\
\hline 3 rd poorest wealth quantile & & $\begin{array}{c}0.292 \\
{[0.023]}\end{array}$ & $\begin{array}{c}0.291 \\
{[0.023]}\end{array}$ \\
\hline 4th poorest wealth quantile & & $\begin{array}{c}0.603 \\
{[0.023]}\end{array}$ & $\begin{array}{c}0.602 \\
{[0.023]}\end{array}$ \\
\hline Richest wealth quantile & & $\begin{array}{c}0.991 \\
{[0.029]}\end{array}$ & $\begin{array}{c}0.990 \\
{[0.029]}\end{array}$ \\
\hline Open defecation $=1$ & & $\begin{array}{c}0.055 \\
{[0.021]}\end{array}$ & $\begin{array}{c}0.055 \\
{[0.021]}\end{array}$ \\
\hline \multicolumn{4}{|l|}{ Mean of gradient proxy } \\
\hline India & & -0.281 & -0.222 \\
\hline Africa & & -0.130 & -0.077 \\
\hline Kerala \& Northeast & & -0.215 & -0.182 \\
\hline Rest of India & & -0.281 & -0.222 \\
\hline Log GDP per capita & Yes & Yes & Yes \\
\hline Sample & Full & Africa & Africa \\
\hline Observations & 398,710 & 167,173 & 167,173 \\
\hline
\end{tabular}

Notes: Standard errors are clustered by PSU and appear in brackets. Please consider the notes in Table 2.12 for further explanations. Source: Adapted from J+P using data from IPUMS DHS (ICF, 2004) and DHS (Heger Boyle \& Sobek, 2019) 
Table B.75: Accounting Exercise Part 2: Sample Comparison (2004-2010): Weighted 3 MacroDeterminants

\begin{tabular}{lll} 
& $\begin{array}{l}\text { Accounting } \\
\text { Exercise 1 }\end{array}$ & $\begin{array}{l}\text { Accounting } \\
\text { Exercise 2 }\end{array}$ \\
\hline & -0.256 & -0.196 \\
Calculation 1: Share explained by birth order gradient & -0.040 \\
- India-Africa gap in birth order gradient & $3 \%$ & $12 \%$ \\
- India-Africa gap in birth order gradient $\times$ Gradient coeff & $95 \%$ \\
- Birth order explained share of India-Africa level gap in height (shown in column 1) & $125 \%$ \\
- Macro-determinants explained share of India-Africa level gap in height (shown in column 1) & -0.050 \\
Calculation 2: Share explained by birth order gradient rooted in eldest son preference & -0.0110 \\
- Rest of India - Kerala \& NE gap in birth order gradient & -0.010 & -0.010 \\
- Rest of India - Kerala \& NE gap in birth order gradient $\times$ Gradient coff & $3 \%$ \\
- Birth order explained share of India-Africa level gap in height (shown in column 1) & $1 \%$
\end{tabular}

Table B.76: Accounting Exercise Part 2: Sample Comparison (2010-2017): Adjusted Methodology and 3 Macro-Determinants with Data from the More Recent Time Period

Accounting Accounting

Exercise 1 Exercise 2

Calculation 1: Share explained by birth order gradient

- India-Africa gap in birth order gradient

$-0.151 \quad-0.145$

- India-Africa gap in birth order gradient $\times$ Gradient coeff

$0.095 \quad 0.166$

- Birth order explained share of India-Africa level gap in height (shown in column 1) $-80 \%$

$-140 \%$

- Macro-determinants explained share of India-Africa level gap in height (shown in column 1)

$287 \%$

$275 \%$

Calculation 2: Share explained by birth order gradient rooted in eldest son preference

- Rest of India - Kerala \& NE gap in birth order gradient

$-0.066-0.040$

- Rest of India - Kerala \& NE gap in birth order gradient $\times$ Gradient coff

0.041

0.046

- Birth order explained share of India-Africa level gap in height (shown in column 1)

$-35 \% \quad-39 \%$

Source: Adapted from J+P using data from IPUMS DHS (ICF, 2004) and DHS (Heger Boyle \& Sobek, 2019) 
6 Replicated Results (2004-2010) and Replicated Results (20112017): Adjusted Methodology and Four Macro-Determinants with Data from the More Recent Time Period

6.1 India's Differential Birth Order Gradient in Child Height and Related Outcomes 
Table B.77: India's Differential Birth Order Gradient in Child Height and Related Outcomes (2004-2010): Weighted 4 Macro-Determinants

\begin{tabular}{|c|c|c|c|c|c|c|c|c|c|}
\hline & $\begin{array}{c}\text { HFA } \\
\text { z- } \\
\text { score } \\
(1) \\
\end{array}$ & $\begin{array}{c}\text { HFA } \\
\text { z- } \\
\text { score } \\
(2)\end{array}$ & $\begin{array}{c}\text { HFA } \\
\text { z- } \\
\text { score } \\
(3)\end{array}$ & $\begin{array}{c}\text { HFA } \\
\text { z- } \\
\text { score } \\
(4)\end{array}$ & $\begin{array}{c}\text { HFA } \\
\text { z- } \\
\text { score } \\
(5) \\
\end{array}$ & $\begin{array}{c}\text { Stunted } \\
\text { (6) }\end{array}$ & $\begin{array}{c}\text { WFA } \\
\text { z- } \\
\text { score } \\
(7) \\
\end{array}$ & $\begin{array}{c}\mathrm{Hb} \\
\text { level } \\
(8) \\
\end{array}$ & $\begin{array}{l}\text { Deceasec } \\
(9) \\
\end{array}$ \\
\hline India & $\begin{array}{l}-0.158 \\
{[0.036]}\end{array}$ & $\begin{array}{l}-0.142 \\
{[0.057]}\end{array}$ & & & & & & & \\
\hline India $\times 2$ nd child & & $\begin{array}{l}-0.117 \\
{[0.052]}\end{array}$ & $\begin{array}{l}-0.179 \\
{[0.060]}\end{array}$ & $\begin{array}{l}-0.732 \\
{[0.605]}\end{array}$ & $\begin{array}{c}0.000 \\
{[.]}\end{array}$ & $\begin{array}{c}0.051 \\
{[0.015]}\end{array}$ & $\begin{array}{l}-0.184 \\
{[0.043]}\end{array}$ & $\begin{array}{l}-0.085 \\
{[0.072]}\end{array}$ & $\begin{array}{c}0.003 \\
{[0.002]}\end{array}$ \\
\hline India $\times 3$ rd + child & & $\begin{array}{l}-0.170 \\
{[0.048]}\end{array}$ & $\begin{array}{l}-0.222 \\
{[0.070]}\end{array}$ & $\begin{array}{l}-1.374 \\
{[0.775]}\end{array}$ & $\begin{array}{c}0.000 \\
{[.]}\end{array}$ & $\begin{array}{c}0.065 \\
{[0.018]}\end{array}$ & $\begin{array}{l}-0.161 \\
{[0.050]}\end{array}$ & $\begin{array}{l}-0.121 \\
{[0.083]}\end{array}$ & $\begin{array}{c}0.006 \\
{[0.003]}\end{array}$ \\
\hline 2nd child & & $\begin{array}{c}0.092 \\
{[0.033]}\end{array}$ & $\begin{array}{c}0.052 \\
{[0.039]}\end{array}$ & $\begin{array}{l}1.500 \\
{[0.351]}\end{array}$ & $\begin{array}{c}0.000 \\
{[.]}\end{array}$ & $\begin{array}{l}-0.005 \\
{[0.009]}\end{array}$ & $\begin{array}{l}0.079 \\
{[0.028]}\end{array}$ & $\begin{array}{l}0.046 \\
{[0.055]}\end{array}$ & $\begin{array}{c}0.002 \\
{[0.001]}\end{array}$ \\
\hline $3 r d+$ child & & $\begin{array}{c}0.055 \\
{[0.028]}\end{array}$ & $\begin{array}{l}-0.048 \\
{[0.044]}\end{array}$ & $\begin{array}{l}2.426 \\
{[0.531]}\end{array}$ & $\begin{array}{c}0.000 \\
{[.]}\end{array}$ & $\begin{array}{c}0.014 \\
{[0.010]}\end{array}$ & $\begin{array}{l}-0.003 \\
{[0.031]}\end{array}$ & $\begin{array}{c}0.033 \\
{[0.062]}\end{array}$ & $\begin{array}{c}0.002 \\
{[0.001]}\end{array}$ \\
\hline India $\times$ Mother's literacy $=1$ & $\begin{array}{c}0.157 \\
{[0.034]}\end{array}$ & $\begin{array}{c}0.154 \\
{[0.043]}\end{array}$ & $\begin{array}{c}0.081 \\
{[0.052]}\end{array}$ & $\begin{array}{l}-0.026 \\
{[0.084]}\end{array}$ & $\begin{array}{c}0.000 \\
{[.]}\end{array}$ & $\begin{array}{l}-0.025 \\
{[0.014]}\end{array}$ & $\begin{array}{l}0.094 \\
{[0.037]}\end{array}$ & $\begin{array}{l}0.001 \\
{[0.061]}\end{array}$ & $\begin{array}{c}0.003 \\
{[0.002]}\end{array}$ \\
\hline Mother's literacy $=1$ & $\begin{array}{c}0.100 \\
{[0.019]}\end{array}$ & $\begin{array}{c}0.082 \\
{[0.023]}\end{array}$ & $\begin{array}{c}0.082 \\
{[0.031]}\end{array}$ & $\begin{array}{l}0.151 \\
{[0.061]}\end{array}$ & $\begin{array}{c}0.000 \\
{[.]}\end{array}$ & $\begin{array}{l}-0.023 \\
{[0.007]}\end{array}$ & $\begin{array}{l}0.123 \\
{[0.021]}\end{array}$ & $\begin{array}{l}0.098 \\
{[0.045]}\end{array}$ & $\begin{array}{l}-0.003 \\
{[0.001]}\end{array}$ \\
\hline 2 nd poorest wealth quantile & $\begin{array}{c}0.077 \\
{[0.025]}\end{array}$ & $\begin{array}{c}0.017 \\
{[0.030]}\end{array}$ & $\begin{array}{c}0.018 \\
{[0.036]}\end{array}$ & $\begin{array}{l}-0.016 \\
{[0.062]}\end{array}$ & $\begin{array}{c}0.000 \\
{[.]}\end{array}$ & $\begin{array}{l}-0.012 \\
{[0.009]}\end{array}$ & $\begin{array}{l}0.061 \\
{[0.025]}\end{array}$ & $\begin{array}{l}0.027 \\
{[0.044]}\end{array}$ & $\begin{array}{l}-0.001 \\
{[0.001]}\end{array}$ \\
\hline 3 rd poorest wealth quantile & $\begin{array}{c}0.229 \\
{[0.025]}\end{array}$ & $\begin{array}{c}0.184 \\
{[0.029]}\end{array}$ & $\begin{array}{c}0.140 \\
{[0.038]}\end{array}$ & $\begin{array}{l}0.175 \\
{[0.064]}\end{array}$ & $\begin{array}{c}0.000 \\
{[.]}\end{array}$ & $\begin{array}{l}-0.030 \\
{[0.010]}\end{array}$ & $\begin{array}{l}0.110 \\
{[0.026]}\end{array}$ & $\begin{array}{c}0.014 \\
{[0.046]}\end{array}$ & $\begin{array}{l}-0.001 \\
{[0.001]}\end{array}$ \\
\hline 4th poorest wealth quantile & $\begin{array}{c}0.363 \\
{[0.025]}\end{array}$ & $\begin{array}{c}0.314 \\
{[0.029]}\end{array}$ & $\begin{array}{c}0.188 \\
{[0.043]}\end{array}$ & $\begin{array}{l}0.295 \\
{[0.071]}\end{array}$ & $\begin{array}{c}0.000 \\
{[.]}\end{array}$ & $\begin{array}{l}-0.057 \\
{[0.011]}\end{array}$ & $\begin{array}{l}0.217 \\
{[0.030]}\end{array}$ & $\begin{array}{l}0.066 \\
{[0.052]}\end{array}$ & $\begin{array}{l}-0.000 \\
{[0.001]}\end{array}$ \\
\hline Richest wealth quantile & $\begin{array}{c}0.690 \\
{[0.028]}\end{array}$ & $\begin{array}{c}0.672 \\
{[0.034]}\end{array}$ & $\begin{array}{c}0.401 \\
{[0.056]}\end{array}$ & $\begin{array}{l}0.570 \\
{[0.092]}\end{array}$ & $\begin{array}{c}0.000 \\
{[.]}\end{array}$ & $\begin{array}{l}-0.107 \\
{[0.014]}\end{array}$ & $\begin{array}{l}0.413 \\
{[0.039]}\end{array}$ & $\begin{array}{l}0.264 \\
{[0.070]}\end{array}$ & $\begin{array}{c}0.001 \\
{[0.002]}\end{array}$ \\
\hline India $\times$ Open defecation $=1$ & $\begin{array}{l}-0.205 \\
{[0.035]}\end{array}$ & $\begin{array}{l}-0.073 \\
{[0.044]}\end{array}$ & $\begin{array}{l}-0.116 \\
{[0.068]}\end{array}$ & $\begin{array}{l}-0.019 \\
{[0.106]}\end{array}$ & $\begin{array}{c}0.000 \\
{[.]}\end{array}$ & $\begin{array}{c}0.038 \\
{[0.018]}\end{array}$ & $\begin{array}{l}-0.086 \\
{[0.048]}\end{array}$ & $\begin{array}{l}0.009 \\
{[0.077]}\end{array}$ & $\begin{array}{c}0.002 \\
{[0.003]}\end{array}$ \\
\hline Open defecation $=1$ & $\begin{array}{c}0.050 \\
{[0.021]}\end{array}$ & $\begin{array}{c}0.004 \\
{[0.025]}\end{array}$ & $\begin{array}{l}-0.061 \\
{[0.038]}\end{array}$ & $\begin{array}{l}0.002 \\
{[0.074]}\end{array}$ & $\begin{array}{c}0.000 \\
{[.]}\end{array}$ & $\begin{array}{c}0.009 \\
{[0.009]}\end{array}$ & $\begin{array}{l}-0.060 \\
{[0.027]}\end{array}$ & $\begin{array}{l}-0.076 \\
{[0.053]}\end{array}$ & $\begin{array}{l}-0.002 \\
{[0.002]}\end{array}$ \\
\hline India $\times$ Meat or eggs consumed $=1$ & $\begin{array}{c}0.059 \\
{[0.037]}\end{array}$ & $\begin{array}{c}0.068 \\
{[0.048]}\end{array}$ & $\begin{array}{c}0.092 \\
{[0.060]}\end{array}$ & $\begin{array}{l}0.167 \\
{[0.095]}\end{array}$ & $\begin{array}{c}0.000 \\
{[.]}\end{array}$ & $\begin{array}{l}-0.027 \\
{[0.017]}\end{array}$ & $\begin{array}{l}0.026 \\
{[0.044]}\end{array}$ & $\begin{array}{l}0.158 \\
{[0.066]}\end{array}$ & $\begin{array}{c}0.000 \\
{[0.002]}\end{array}$ \\
\hline Meat or eggs consumed $=1$ & $\begin{array}{c}0.199 \\
{[0.020]}\end{array}$ & $\begin{array}{l}0.204 \\
{[0.024]}\end{array}$ & $\begin{array}{c}0.134 \\
{[0.030]}\end{array}$ & $\begin{array}{l}0.094 \\
{[0.061]}\end{array}$ & $\begin{array}{c}0.000 \\
{[.]}\end{array}$ & $\begin{array}{l}-0.029 \\
{[0.007]}\end{array}$ & $\begin{array}{l}0.120 \\
{[0.020]}\end{array}$ & $\begin{array}{l}0.031 \\
{[0.039]}\end{array}$ & $\begin{array}{l}-0.000 \\
{[0.001]}\end{array}$ \\
\hline India $\times$ Dairy products consumed $=1$ & $\begin{array}{l}0.048 \\
{[0.044]}\end{array}$ & $\begin{array}{l}-0.020 \\
{[0.056]}\end{array}$ & $\begin{array}{l}-0.058 \\
{[0.067]}\end{array}$ & $\begin{array}{l}0.165 \\
{[0.108]}\end{array}$ & $\begin{array}{c}0.000 \\
{[.]}\end{array}$ & $\begin{array}{l}-0.005 \\
{[0.018]}\end{array}$ & $\begin{array}{l}0.058 \\
{[0.048]}\end{array}$ & $\begin{array}{l}-0.075 \\
{[0.072]}\end{array}$ & $\begin{array}{c}0.001 \\
{[0.002]}\end{array}$ \\
\hline Dairy products consumed $=1$ & $\begin{array}{c}0.101 \\
{[0.025]}\end{array}$ & $\begin{array}{c}0.126 \\
{[0.030]}\end{array}$ & $\begin{array}{c}0.126 \\
{[0.038]}\end{array}$ & $\begin{array}{l}-0.025 \\
{[0.078]}\end{array}$ & $\begin{array}{c}0.000 \\
{[.]}\end{array}$ & $\begin{array}{l}-0.030 \\
{[0.009]}\end{array}$ & $\begin{array}{c}0.080 \\
{[0.027]}\end{array}$ & $\begin{array}{c}0.135 \\
{[0.047]}\end{array}$ & $\begin{array}{l}-0.002 \\
{[0.001]}\end{array}$ \\
\hline Africa mean of outcome & -1.363 & -1.363 & -1.363 & -1.363 & -1.363 & 0.381 & -0.889 & 10.107 & 0.074 \\
\hline Child's age dummies $\times$ India & No & No & Yes & Yes & Yes & Yes & Yes & Yes & Yes \\
\hline Mother's age at birth $\times$ India & No & No & Yes & Yes & No & Yes & Yes & Yes & Yes \\
\hline PSU FEs & No & No & Yes & Yes & No & Yes & Yes & Yes & Yes \\
\hline Mother FEs & No & No & No & No & Yes & No & No & No & No \\
\hline $\begin{array}{l}\text { Completed fertility sample } \\
\text { p-Value of joint }\end{array}$ & No & No & No & Yes & No & No & No & No & No \\
\hline significance te & 0.000 & 0.000 & 0.000 & 0.000 & & 0.000 & 0.000 & 0.000 & 0.437 \\
\hline Observations & 64,785 & 64,785 & 63,635 & 24,638 & 1,376 & 63,635 & 63,635 & 28,297 & 47,835 \\
\hline
\end{tabular}

Notes: Standard errors are clustered by mother and appear in brackets. Please consider the notes in Table 2.6 for further explanations.

Source: Adapted from J+P using data from DHS (Heger Boyle \& Sobek, 2019) 
Table B.78: India's Differential Birth Order Gradient in Child Height and Related Outcomes (2011-2017): Weighted 4 Macro-Determinants

\begin{tabular}{|c|c|c|c|c|c|c|c|c|c|}
\hline & $\begin{array}{l}\text { HFA } \\
\text { Z- } \\
\text { score } \\
(1)\end{array}$ & $\begin{array}{l}\text { HFA } \\
\text { Z- } \\
\text { score } \\
(2)\end{array}$ & $\begin{array}{l}\text { HFA } \\
\text { Z- } \\
\text { score } \\
(3)\end{array}$ & $\begin{array}{l}\text { HFA } \\
\text { Z- } \\
\text { score } \\
(4)\end{array}$ & $\begin{array}{l}\text { HFA } \\
\text { z- } \\
\text { score } \\
(5)\end{array}$ & $\begin{array}{l}\text { Stunted } \\
\text { (6) }\end{array}$ & $\begin{array}{l}\text { WFA } \\
\text { Z- } \\
\text { score } \\
(7)\end{array}$ & $\begin{array}{l}\mathrm{Hb} \\
\text { level } \\
(8)\end{array}$ & $\begin{array}{l}\text { Deceased } \\
\text { (9) }\end{array}$ \\
\hline India & $\begin{array}{l}-0.309 \\
{[0.021]}\end{array}$ & $\begin{array}{l}-0.202 \\
{[0.040]}\end{array}$ & & & & & & & \\
\hline India $\times 2$ nd child & & $\begin{array}{l}-0.076 \\
{[0.037]}\end{array}$ & $\begin{array}{l}-0.098 \\
{[0.044]}\end{array}$ & $\begin{array}{l}0.231 \\
{[0.781]}\end{array}$ & $\begin{array}{c}0.000 \\
{[.]}\end{array}$ & $\begin{array}{l}0.023 \\
{[0.010]}\end{array}$ & $\begin{array}{l}-0.059 \\
{[0.032]}\end{array}$ & $\begin{array}{l}-0.104 \\
{[0.051]}\end{array}$ & $\begin{array}{l}0.001 \\
{[0.001]}\end{array}$ \\
\hline India $\times 3$ rd + child & & $\begin{array}{l}-0.166 \\
{[0.034]}\end{array}$ & $\begin{array}{l}-0.187 \\
{[0.051]}\end{array}$ & $\begin{array}{l}-0.128 \\
{[0.900]}\end{array}$ & $\begin{array}{c}0.000 \\
{[.]}\end{array}$ & $\begin{array}{l}0.040 \\
{[0.012]}\end{array}$ & $\begin{array}{l}-0.123 \\
{[0.037]}\end{array}$ & $\begin{array}{l}-0.030 \\
{[0.057]}\end{array}$ & $\begin{array}{c}0.002 \\
{[0.001]}\end{array}$ \\
\hline 2nd child & & $\begin{array}{l}0.068 \\
{[0.029]}\end{array}$ & $\begin{array}{l}0.033 \\
{[0.035]}\end{array}$ & $\begin{array}{l}0.604 \\
{[0.638]}\end{array}$ & $\begin{array}{c}0.000 \\
{[.]}\end{array}$ & $\begin{array}{l}-0.006 \\
{[0.008]}\end{array}$ & $\begin{array}{l}0.035 \\
{[0.025]}\end{array}$ & $\begin{array}{l}0.064 \\
{[0.044]}\end{array}$ & $\begin{array}{l}-0.002 \\
{[0.001]}\end{array}$ \\
\hline $3 r d+$ child & & $\begin{array}{l}0.077 \\
{[0.024]}\end{array}$ & $\begin{array}{c}0.012 \\
{[0.039]}\end{array}$ & $\begin{array}{c}1.183 \\
{[0.716]}\end{array}$ & $\begin{array}{c}0.000 \\
{[.]}\end{array}$ & $\begin{array}{l}0.000 \\
{[0.009]}\end{array}$ & $\begin{array}{l}0.003 \\
{[0.028]}\end{array}$ & $\begin{array}{l}-0.022 \\
{[0.048]}\end{array}$ & $\begin{array}{l}-0.002 \\
{[0.001]}\end{array}$ \\
\hline India $\times$ Mother's literacy=1 & $\begin{array}{l}0.102 \\
{[0.021]}\end{array}$ & $\begin{array}{l}0.073 \\
{[0.029]}\end{array}$ & $\begin{array}{l}0.082 \\
{[0.038]}\end{array}$ & $\begin{array}{l}0.052 \\
{[0.081]}\end{array}$ & $\begin{array}{c}0.000 \\
{[.]}\end{array}$ & $\begin{array}{l}-0.024 \\
{[0.009]}\end{array}$ & $\begin{array}{l}0.087 \\
{[0.027]}\end{array}$ & $\begin{array}{l}0.041 \\
{[0.042]}\end{array}$ & $\begin{array}{l}-0.002 \\
{[0.001]}\end{array}$ \\
\hline Mother's literacy=1 & $\begin{array}{c}0.122 \\
{[0.014]}\end{array}$ & $\begin{array}{l}0.167 \\
{[0.020]}\end{array}$ & $\begin{array}{l}0.104 \\
{[0.028]}\end{array}$ & $\begin{array}{l}0.119 \\
{[0.068]}\end{array}$ & $\begin{array}{c}0.000 \\
{[.]}\end{array}$ & $\begin{array}{l}-0.018 \\
{[0.007]}\end{array}$ & $\begin{array}{l}0.085 \\
{[0.021]}\end{array}$ & $\begin{array}{l}0.083 \\
{[0.034]}\end{array}$ & $\begin{array}{l}0.002 \\
{[0.001]}\end{array}$ \\
\hline 2nd poorest wealth quantile & $\begin{array}{l}0.096 \\
{[0.016]}\end{array}$ & $\begin{array}{l}0.086 \\
{[0.021]}\end{array}$ & $\begin{array}{l}0.051 \\
{[0.026]}\end{array}$ & $\begin{array}{l}0.132 \\
{[0.052]}\end{array}$ & $\begin{array}{c}0.000 \\
{[.]}\end{array}$ & $\begin{array}{l}-0.013 \\
{[0.006]}\end{array}$ & $\begin{array}{l}0.052 \\
{[0.019]}\end{array}$ & $\begin{array}{l}0.048 \\
{[0.030]}\end{array}$ & $\begin{array}{l}0.000 \\
{[0.001]}\end{array}$ \\
\hline 3rd poorest wealth quantile & $\begin{array}{l}0.225 \\
{[0.016]}\end{array}$ & $\begin{array}{l}0.217 \\
{[0.022]}\end{array}$ & $\begin{array}{l}0.113 \\
{[0.031]}\end{array}$ & $\begin{array}{l}0.183 \\
{[0.060]}\end{array}$ & $\begin{array}{c}0.000 \\
{[.]}\end{array}$ & $\begin{array}{l}-0.023 \\
{[0.007]}\end{array}$ & $\begin{array}{l}0.109 \\
{[0.022]}\end{array}$ & $\begin{array}{l}0.119 \\
{[0.034]}\end{array}$ & $\begin{array}{l}0.001 \\
{[0.001]}\end{array}$ \\
\hline 4th poorest wealth quantile & $\begin{array}{l}0.410 \\
{[0.017]}\end{array}$ & $\begin{array}{l}0.400 \\
{[0.023]}\end{array}$ & $\begin{array}{l}0.270 \\
{[0.036]}\end{array}$ & $\begin{array}{l}0.326 \\
{[0.069]}\end{array}$ & $\begin{array}{c}0.000 \\
{[.]}\end{array}$ & $\begin{array}{l}-0.065 \\
{[0.009]}\end{array}$ & $\begin{array}{l}0.223 \\
{[0.026]}\end{array}$ & $\begin{array}{l}0.168 \\
{[0.039]}\end{array}$ & $\begin{array}{l}0.001 \\
{[0.001]}\end{array}$ \\
\hline Richest wealth quantile & $\begin{array}{l}0.655 \\
{[0.019]}\end{array}$ & $\begin{array}{l}0.690 \\
{[0.028]}\end{array}$ & $\begin{array}{l}0.461 \\
{[0.047]}\end{array}$ & $\begin{array}{l}0.522 \\
{[0.085]}\end{array}$ & $\begin{array}{c}0.000 \\
{[.]}\end{array}$ & $\begin{array}{l}-0.100 \\
{[0.011]}\end{array}$ & $\begin{array}{l}0.416 \\
{[0.032]}\end{array}$ & $\begin{array}{l}0.269 \\
{[0.047]}\end{array}$ & $\begin{array}{l}0.001 \\
{[0.001]}\end{array}$ \\
\hline India $\times$ Open defecation $=1$ & $\begin{array}{l}-0.180 \\
{[0.023]}\end{array}$ & $\begin{array}{l}-0.151 \\
{[0.032]}\end{array}$ & $\begin{array}{l}0.010 \\
{[0.048]}\end{array}$ & $\begin{array}{l}-0.147 \\
{[0.099]}\end{array}$ & $\begin{array}{c}0.000 \\
{[.]}\end{array}$ & $\begin{array}{l}0.008 \\
{[0.011]}\end{array}$ & $\begin{array}{l}-0.086 \\
{[0.035]}\end{array}$ & $\begin{array}{l}-0.013 \\
{[0.054]}\end{array}$ & $\begin{array}{l}-0.002 \\
{[0.001]}\end{array}$ \\
\hline Open defecation $=1$ & $\begin{array}{l}0.084 \\
{[0.017]}\end{array}$ & $\begin{array}{l}0.122 \\
{[0.023]}\end{array}$ & $\begin{array}{l}-0.030 \\
{[0.035]}\end{array}$ & $\begin{array}{l}0.134 \\
{[0.083]}\end{array}$ & $\begin{array}{c}0.000 \\
{[.]}\end{array}$ & $\begin{array}{l}0.005 \\
{[0.008]}\end{array}$ & $\begin{array}{l}-0.003 \\
{[0.027]}\end{array}$ & $\begin{array}{l}-0.056 \\
{[0.045]}\end{array}$ & $\begin{array}{l}0.001 \\
{[0.001]}\end{array}$ \\
\hline India $\times$ Meat or eggs consumed $=1$ & $\begin{array}{c}0.009 \\
{[0.025]}\end{array}$ & $\begin{array}{l}-0.059 \\
{[0.037]}\end{array}$ & $\begin{array}{l}0.011 \\
{[0.047]}\end{array}$ & $\begin{array}{l}-0.069 \\
{[0.093]}\end{array}$ & $\begin{array}{c}0.000 \\
{[.]}\end{array}$ & $\begin{array}{l}-0.018 \\
{[0.011]}\end{array}$ & $\begin{array}{l}0.031 \\
{[0.033]}\end{array}$ & $\begin{array}{l}0.074 \\
{[0.046]}\end{array}$ & $\begin{array}{l}-0.000 \\
{[0.001]}\end{array}$ \\
\hline Meat or eggs consumed $=1$ & $\begin{array}{l}0.183 \\
{[0.015]}\end{array}$ & $\begin{array}{l}0.187 \\
{[0.022]}\end{array}$ & $\begin{array}{l}0.134 \\
{[0.027]}\end{array}$ & $\begin{array}{l}0.123 \\
{[0.067]}\end{array}$ & $\begin{array}{c}0.000 \\
{[.]}\end{array}$ & $\begin{array}{l}-0.027 \\
{[0.007]}\end{array}$ & $\begin{array}{l}0.089 \\
{[0.019]}\end{array}$ & $\begin{array}{l}0.002 \\
{[0.031]}\end{array}$ & $\begin{array}{l}0.000 \\
{[0.001]}\end{array}$ \\
\hline India $\times$ Dairy products consumed $=1$ & $\begin{array}{l}-0.050 \\
{[0.026]}\end{array}$ & $\begin{array}{l}-0.058 \\
{[0.038]}\end{array}$ & $\begin{array}{l}0.037 \\
{[0.046]}\end{array}$ & $\begin{array}{l}0.128 \\
{[0.093]}\end{array}$ & $\begin{array}{c}0.000 \\
{[.]}\end{array}$ & $\begin{array}{l}-0.000 \\
{[0.011]}\end{array}$ & $\begin{array}{l}0.006 \\
{[0.034]}\end{array}$ & $\begin{array}{l}0.006 \\
{[0.046]}\end{array}$ & $\begin{array}{l}0.003 \\
{[0.001]}\end{array}$ \\
\hline Dairy products consumed=1 & $\begin{array}{l}0.209 \\
{[0.017]}\end{array}$ & $\begin{array}{l}0.174 \\
{[0.024]}\end{array}$ & $\begin{array}{l}0.095 \\
{[0.030]}\end{array}$ & $\begin{array}{l}0.105 \\
{[0.074]}\end{array}$ & $\begin{array}{c}0.000 \\
{[.]}\end{array}$ & $\begin{array}{l}-0.016 \\
{[0.007]}\end{array}$ & $\begin{array}{l}0.095 \\
{[0.022]}\end{array}$ & $\begin{array}{l}-0.018 \\
{[0.035]}\end{array}$ & $\begin{array}{l}-0.002 \\
{[0.001]}\end{array}$ \\
\hline Africa me & -1.163 & -1.163 & -1.163 & -1.163 & -1.163 & 0.311 & -0.838 & 10.439 & 0.050 \\
\hline Child's age dummies $\times$ India & No & No & Yes & Yes & Yes & Yes & Yes & Yes & Yes \\
\hline Mother's age at birth $\times$ India & No & No & Yes & Yes & No & Yes & Yes & Yes & Yes \\
\hline PSU FEs & No & No & Yes & Yes & No & Yes & Yes & Yes & Yes \\
\hline Mother FEs & No & No & No & No & Yes & No & No & No & No \\
\hline $\begin{array}{l}\text { Completed fertility sample } \\
\text { p-Value of joint }\end{array}$ & No & No & No & Yes & No & No & No & No & No \\
\hline & 0.000 & 0.000 & 0.000 & 0.000 & & 0.000 & 0.000 & 0.000 & 0.029 \\
\hline Observations & 145,957 & 145,957 & 139,245 & 43,381 & 2,781 & 139,245 & 139,245 & 84,690 & 75,570 \\
\hline
\end{tabular}

Notes: Standard errors are clustered by mother and appear in brackets. Please consider the notes in Table 2.6 for further explanations.

Source: Adapted from J+P using data from IPUMS DHS (ICF, 2004) and DHS (Heger Boyle \& Sobek, 2019) 


\subsection{Child Gender and the Birth Order Gradient in Height}

Table B.79: Child Gender and the Birth Order Gradient in Height (2004-2010): Weighted 4 Macro-Determinants

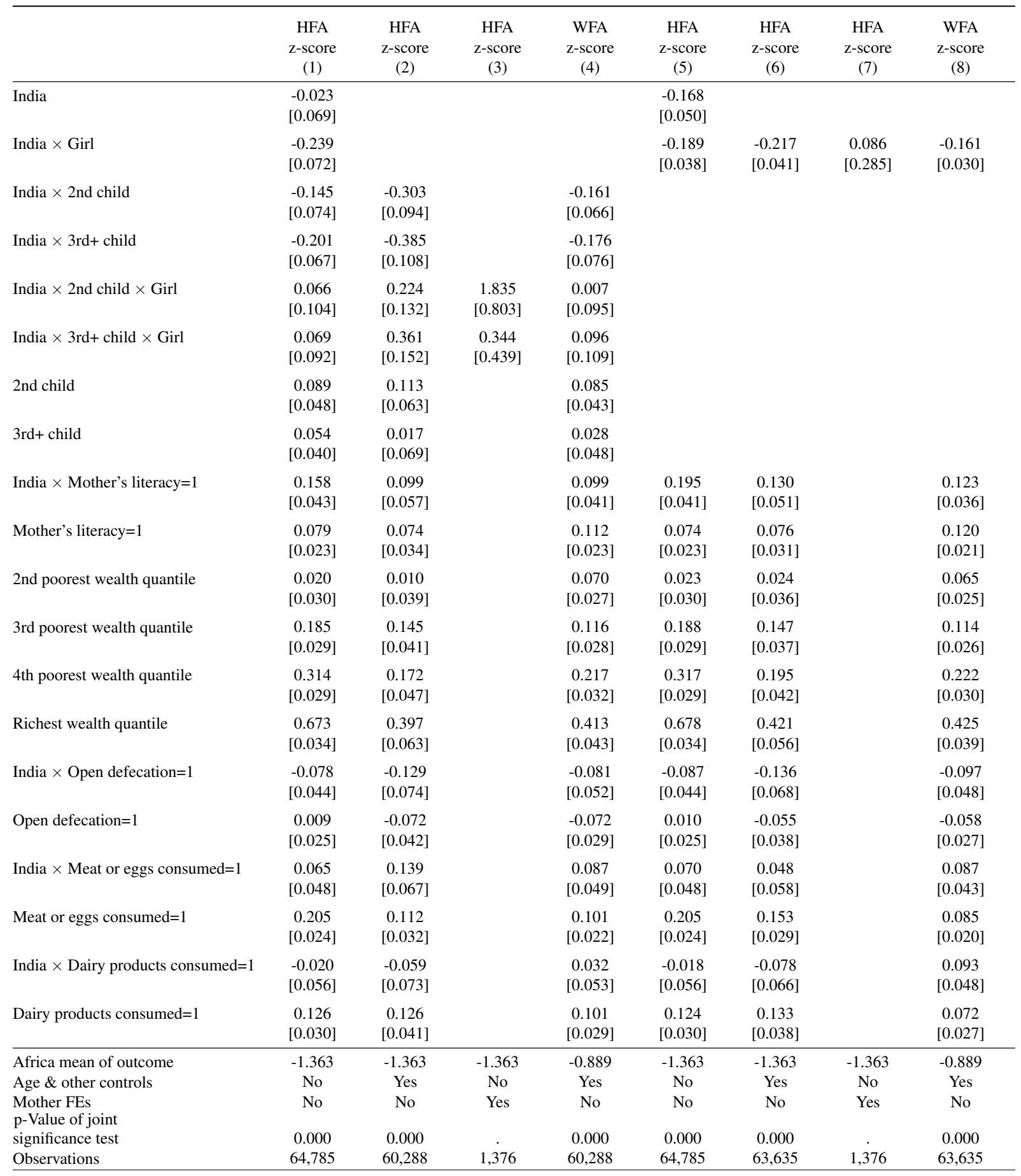

Notes: Standard errors are clustered by mother and appear in brackets. Please consider the notes in Table 2.10 for further explanations.

Source: Adapted from J+P using data from DHS (Heger Boyle \& Sobek, 2019) 
Table B.80: Child Gender and the Birth Order Gradient in Height (2010-2017): Weighted 4 Macro-Determinants

\begin{tabular}{|c|c|c|c|c|c|c|c|c|}
\hline & $\begin{array}{c}\text { HFA } \\
\text { z-score } \\
\text { (1) }\end{array}$ & $\begin{array}{c}\text { HFA } \\
\text { z-score } \\
(2)\end{array}$ & $\begin{array}{c}\text { HFA } \\
\text { z-score } \\
\text { (3) }\end{array}$ & $\begin{array}{c}\text { WFA } \\
\text { z-score } \\
(4)\end{array}$ & $\begin{array}{c}\text { HFA } \\
\text { z-score } \\
(5)\end{array}$ & $\begin{array}{c}\text { HFA } \\
\text { z-score } \\
(6)\end{array}$ & $\begin{array}{c}\text { HFA } \\
\text { z-score } \\
(7)\end{array}$ & $\begin{array}{c}\text { WFA } \\
\text { z-score } \\
(8)\end{array}$ \\
\hline India & $\begin{array}{c}-0.200 \\
{[0.048]}\end{array}$ & & & & $\begin{array}{c}-0.285 \\
{[0.033]}\end{array}$ & & & \\
\hline India $\times$ Girl & $\begin{array}{c}-0.000 \\
{[0.051]}\end{array}$ & & & & $\begin{array}{c}-0.047 \\
{[0.027]}\end{array}$ & $\begin{array}{c}-0.033 \\
{[0.029]}\end{array}$ & $\begin{array}{c}-0.369 \\
{[0.171]}\end{array}$ & $\begin{array}{c}-0.075 \\
{[0.021]}\end{array}$ \\
\hline India $\times 2$ nd child & $\begin{array}{l}-0.014 \\
{[0.053]}\end{array}$ & $\begin{array}{l}-0.045 \\
{[0.071]}\end{array}$ & & $\begin{array}{l}-0.053 \\
{[0.050]}\end{array}$ & & & & \\
\hline India $\times 3$ rd + child & $\begin{array}{l}-0.130 \\
{[0.048]}\end{array}$ & $\begin{array}{l}-0.120 \\
{[0.082]}\end{array}$ & & $\begin{array}{l}-0.092 \\
{[0.057]}\end{array}$ & & & & \\
\hline India $\times 2$ nd child $\times$ Girl & $\begin{array}{l}-0.115 \\
{[0.074]}\end{array}$ & $\begin{array}{c}-0.167 \\
{[0.100]}\end{array}$ & $\begin{array}{l}-0.333 \\
{[0.425]}\end{array}$ & $\begin{array}{l}-0.054 \\
{[0.072]}\end{array}$ & & & & \\
\hline India $\times 3$ rd + child $\times$ Girl & $\begin{array}{l}-0.066 \\
{[0.065]}\end{array}$ & $\begin{array}{l}-0.172 \\
{[0.115]}\end{array}$ & $\begin{array}{c}0.098 \\
{[0.329]}\end{array}$ & $\begin{array}{l}-0.068 \\
{[0.082]}\end{array}$ & & & & \\
\hline 2nd child & $\begin{array}{c}0.036 \\
{[0.041]}\end{array}$ & $\begin{array}{c}0.001 \\
{[0.057]}\end{array}$ & & $\begin{array}{c}0.056 \\
{[0.040]}\end{array}$ & & & & \\
\hline 3rd + child & $\begin{array}{c}0.080 \\
{[0.034]}\end{array}$ & $\begin{array}{c}-0.024 \\
{[0.063]}\end{array}$ & & $\begin{array}{c}-0.008 \\
{[0.044]}\end{array}$ & & & & \\
\hline India $\times$ Mother's literacy $=1$ & $\begin{array}{c}0.073 \\
{[0.029]}\end{array}$ & $\begin{array}{c}0.053 \\
{[0.043]}\end{array}$ & & $\begin{array}{c}0.077 \\
{[0.030]}\end{array}$ & $\begin{array}{c}0.110 \\
{[0.029]}\end{array}$ & $\begin{array}{c}0.103 \\
{[0.037]}\end{array}$ & & $\begin{array}{c}0.087 \\
{[0.026]}\end{array}$ \\
\hline Mother's literacy $=1$ & $\begin{array}{c}0.168 \\
{[0.020]}\end{array}$ & $\begin{array}{c}0.113 \\
{[0.032]}\end{array}$ & & $\begin{array}{c}0.080 \\
{[0.023]}\end{array}$ & $\begin{array}{c}0.155 \\
{[0.020]}\end{array}$ & $\begin{array}{c}0.104 \\
{[0.028]}\end{array}$ & & $\begin{array}{c}0.095 \\
{[0.020]}\end{array}$ \\
\hline 2 nd poorest wealth quantile & $\begin{array}{c}0.087 \\
{[0.021]}\end{array}$ & $\begin{array}{c}0.051 \\
{[0.029]}\end{array}$ & & $\begin{array}{c}0.039 \\
{[0.021]}\end{array}$ & $\begin{array}{c}0.087 \\
{[0.021]}\end{array}$ & $\begin{array}{c}0.055 \\
{[0.026]}\end{array}$ & & $\begin{array}{c}0.059 \\
{[0.019]}\end{array}$ \\
\hline 3 rd poorest wealth quantile & $\begin{array}{c}0.217 \\
{[0.022]}\end{array}$ & $\begin{array}{c}0.099 \\
{[0.035]}\end{array}$ & & $\begin{array}{c}0.102 \\
{[0.024]}\end{array}$ & $\begin{array}{c}0.218 \\
{[0.022]}\end{array}$ & $\begin{array}{c}0.118 \\
{[0.031]}\end{array}$ & & $\begin{array}{c}0.118 \\
{[0.022]}\end{array}$ \\
\hline 4 th poorest wealth quantile & $\begin{array}{c}0.403 \\
{[0.023]}\end{array}$ & $\begin{array}{c}0.270 \\
{[0.041]}\end{array}$ & & $\begin{array}{c}0.218 \\
{[0.029]}\end{array}$ & $\begin{array}{c}0.405 \\
{[0.023]}\end{array}$ & $\begin{array}{c}0.280 \\
{[0.036]}\end{array}$ & & $\begin{array}{c}0.235 \\
{[0.025]}\end{array}$ \\
\hline Richest wealth quantile & $\begin{array}{c}0.691 \\
{[0.028]}\end{array}$ & $\begin{array}{c}0.460 \\
{[0.052]}\end{array}$ & & $\begin{array}{c}0.412 \\
{[0.036]}\end{array}$ & $\begin{array}{c}0.696 \\
{[0.028]}\end{array}$ & $\begin{array}{c}0.478 \\
{[0.047]}\end{array}$ & & $\begin{array}{c}0.438 \\
{[0.032]}\end{array}$ \\
\hline India $\times$ Open defecation $=1$ & $\begin{array}{c}-0.153 \\
{[0.032]}\end{array}$ & $\begin{array}{c}0.007 \\
{[0.053]}\end{array}$ & & $\begin{array}{c}-0.084 \\
{[0.038]}\end{array}$ & $\begin{array}{l}-0.157 \\
{[0.032]}\end{array}$ & $\begin{array}{c}0.000 \\
{[0.048]}\end{array}$ & & $\begin{array}{c}-0.089 \\
{[0.035]}\end{array}$ \\
\hline Open defecation $=1$ & $\begin{array}{c}0.123 \\
{[0.023]}\end{array}$ & $\begin{array}{c}-0.015 \\
{[0.039]}\end{array}$ & & $\begin{array}{c}0.007 \\
{[0.029]}\end{array}$ & $\begin{array}{c}0.124 \\
{[0.023]}\end{array}$ & $\begin{array}{c}-0.027 \\
{[0.035]}\end{array}$ & & $\begin{array}{c}-0.003 \\
{[0.027]}\end{array}$ \\
\hline India $\times$ Meat or eggs consumed $=1$ & $\begin{array}{c}-0.064 \\
{[0.037]}\end{array}$ & $\begin{array}{c}0.059 \\
{[0.055]}\end{array}$ & & $\begin{array}{c}0.042 \\
{[0.038]}\end{array}$ & $\begin{array}{c}-0.062 \\
{[0.037]}\end{array}$ & $\begin{array}{c}0.035 \\
{[0.045]}\end{array}$ & & $\begin{array}{c}0.180 \\
{[0.032]}\end{array}$ \\
\hline Meat or eggs consumed $=1$ & $\begin{array}{c}0.189 \\
{[0.022]}\end{array}$ & $\begin{array}{c}0.110 \\
{[0.031]}\end{array}$ & & $\begin{array}{c}0.081 \\
{[0.022]}\end{array}$ & $\begin{array}{c}0.189 \\
{[0.022]}\end{array}$ & $\begin{array}{c}0.113 \\
{[0.026]}\end{array}$ & & $\begin{array}{c}-0.019 \\
{[0.019]}\end{array}$ \\
\hline India $\times$ Dairy products consumed $=1$ & $\begin{array}{c}-0.059 \\
{[0.038]}\end{array}$ & $\begin{array}{c}0.046 \\
{[0.053]}\end{array}$ & & $\begin{array}{c}0.012 \\
{[0.038]}\end{array}$ & $\begin{array}{c}-0.056 \\
{[0.038]}\end{array}$ & $\begin{array}{c}0.054 \\
{[0.045]}\end{array}$ & & $\begin{array}{c}0.093 \\
{[0.033]}\end{array}$ \\
\hline Dairy products consumed $=1$ & $\begin{array}{c}0.174 \\
{[0.024]}\end{array}$ & $\begin{array}{c}0.084 \\
{[0.034]}\end{array}$ & & $\begin{array}{c}0.085 \\
{[0.025]}\end{array}$ & $\begin{array}{c}0.171 \\
{[0.024]}\end{array}$ & $\begin{array}{c}0.082 \\
{[0.030]}\end{array}$ & & $\begin{array}{c}0.046 \\
{[0.022]}\end{array}$ \\
\hline Africa mean of outcome & -1.163 & -1.163 & -1.163 & -0.838 & -1.163 & -1.163 & -1.163 & -0.838 \\
\hline Age \& other controls & No & Yes & No & Yes & No & Yes & No & Yes \\
\hline $\begin{array}{l}\text { Mother FEs } \\
\text { p-Value of joint }\end{array}$ & No & No & Yes & No & No & No & Yes & No \\
\hline significance test & 0.000 & 0.000 & - & 0.000 & 0.000 & 0.000 & & 0.000 \\
\hline Observations & 145,957 & 122,102 & 2,781 & 122,102 & 145,957 & 139,245 & 2,781 & 139,245 \\
\hline
\end{tabular}

Notes: Standard errors are clustered by mother and appear in brackets. Please consider the notes in Table 2.10 for further explanations. Source: Adapted from J+P using data from IPUMS DHS (ICF, 2004) and DHS (Heger Boyle \& Sobek, 2019) 


\subsection{Impact on Average Height - Accounting exercise}

Table B.81: Accounting Exercise Part 1: Sample Comparison (2004-2010): Weighted 4 MacroDeterminants

\begin{tabular}{|c|c|c|c|}
\hline & & $\begin{array}{l}\text { Accounting } \\
\text { Exercise } 1\end{array}$ & $\begin{array}{l}\text { Accounting } \\
\text { Exercise } 2\end{array}$ \\
\hline & $\begin{array}{c}\text { HFA z-score } \\
\text { (1) }\end{array}$ & $\begin{array}{c}\text { HFA z-score } \\
(2)\end{array}$ & $\begin{array}{c}\text { HFA z-score } \\
\text { (3) }\end{array}$ \\
\hline India & $\begin{array}{c}-0.342 \\
{[0.020]}\end{array}$ & & \\
\hline Gradient proxy & & $\begin{array}{c}0.124 \\
{[0.120]}\end{array}$ & $\begin{array}{c}0.316 \\
{[0.218]}\end{array}$ \\
\hline Mother's literacy=1 & & $\begin{array}{c}0.080 \\
{[0.026]}\end{array}$ & $\begin{array}{c}0.081 \\
{[0.026]}\end{array}$ \\
\hline 2nd poorest wealth quantile & & $\begin{array}{c}0.039 \\
{[0.039]}\end{array}$ & $\begin{array}{c}0.040 \\
{[0.039]}\end{array}$ \\
\hline 3rd poorest wealth quantile & & $\begin{array}{c}0.208 \\
{[0.040]}\end{array}$ & $\begin{array}{c}0.209 \\
{[0.040]}\end{array}$ \\
\hline 4th poorest wealth quantile & & $\begin{array}{c}0.335 \\
{[0.040]}\end{array}$ & $\begin{array}{c}0.335 \\
{[0.040]}\end{array}$ \\
\hline Richest wealth quantile & & $\begin{array}{c}0.664 \\
{[0.047]}\end{array}$ & $\begin{array}{c}0.665 \\
{[0.047]}\end{array}$ \\
\hline Open defecation=1 & & $\begin{array}{c}0.002 \\
{[0.031]}\end{array}$ & $\begin{array}{c}0.003 \\
{[0.031]}\end{array}$ \\
\hline Meat or eggs consumed $=1$ & & $\begin{array}{c}0.187 \\
{[0.027]}\end{array}$ & $\begin{array}{c}0.186 \\
{[0.027]}\end{array}$ \\
\hline Dairy products consumed $=1$ & & $\begin{array}{c}0.122 \\
{[0.031]}\end{array}$ & $\begin{array}{c}0.124 \\
{[0.031]}\end{array}$ \\
\hline \multicolumn{4}{|l|}{ Mean of gradient proxy } \\
\hline India & & -0.324 & -0.236 \\
\hline Africa & & -0.068 & -0.040 \\
\hline Kerala \& Northeast & & -0.214 & -0.184 \\
\hline Rest of India & & -0.324 & -0.234 \\
\hline Log GDP per capita & Yes & Yes & Yes \\
\hline Sample & Full & Africa & Africa \\
\hline Observations & 168,135 & 44,392 & 44,392 \\
\hline
\end{tabular}

Notes: Standard errors are clustered by PSU and appear in brackets. Please consider the notes in Table 2.12 for further explanations. Source: Adapted from J+P using data from DHS (Heger Boyle \& Sobek, 2019) 
Table B.82: Accounting Exercise Part 1: Sample Comparison (2011-2017): Weighted 4 MacroDeterminants

\begin{tabular}{|c|c|c|c|}
\hline & & $\begin{array}{l}\text { Accounting } \\
\text { Exercise } 1\end{array}$ & $\begin{array}{c}\text { Accounting } \\
\text { Exercise } 2\end{array}$ \\
\hline & $\begin{array}{c}\text { HFA z-score } \\
\text { (1) }\end{array}$ & $\begin{array}{c}\text { HFA z-score } \\
\text { (2) }\end{array}$ & $\begin{array}{c}\text { HFA z-score } \\
\text { (3) }\end{array}$ \\
\hline India & $\begin{array}{l}-0.119 \\
{[0.021]}\end{array}$ & & \\
\hline Gradient proxy & & $\begin{array}{l}-0.627 \\
{[0.132]}\end{array}$ & $\begin{array}{l}-1.146 \\
{[0.233]}\end{array}$ \\
\hline Mother's literacy $=1$ & & $\begin{array}{c}0.218 \\
{[0.017]}\end{array}$ & $\begin{array}{c}0.213 \\
{[0.018]}\end{array}$ \\
\hline 2 nd poorest wealth quantile & & $\begin{array}{c}0.105 \\
{[0.019]}\end{array}$ & $\begin{array}{c}0.104 \\
{[0.019]}\end{array}$ \\
\hline 3 rd poorest wealth quantile & & $\begin{array}{c}0.292 \\
{[0.023]}\end{array}$ & $\begin{array}{c}0.291 \\
{[0.023]}\end{array}$ \\
\hline 4th poorest wealth quantile & & $\begin{array}{c}0.603 \\
{[0.023]}\end{array}$ & $\begin{array}{c}0.602 \\
{[0.023]}\end{array}$ \\
\hline Richest wealth quantile & & $\begin{array}{c}0.991 \\
{[0.029]}\end{array}$ & $\begin{array}{c}0.990 \\
{[0.029]}\end{array}$ \\
\hline Open defecation $=1$ & & $\begin{array}{c}0.055 \\
{[0.021]}\end{array}$ & $\begin{array}{c}0.055 \\
{[0.021]}\end{array}$ \\
\hline \multicolumn{4}{|l|}{ Mean of gradient proxy } \\
\hline India & & -0.281 & -0.222 \\
\hline Africa & & -0.130 & -0.077 \\
\hline Kerala \& Northeast & & -0.215 & -0.182 \\
\hline Rest of India & & -0.281 & -0.222 \\
\hline Log GDP per capita & Yes & Yes & Yes \\
\hline Sample & Full & Africa & Africa \\
\hline Observations & 398,710 & 167,173 & 167,173 \\
\hline
\end{tabular}

Notes: Standard errors are clustered by PSU and appear in brackets. Please consider the notes in table 2.12 for further explanations. Source: Adapted from J+P using data from IPUMS DHS (ICF, 2004) and DHS (Heger Boyle \& Sobek, 2019) 
Table B.83: Accounting Exercise Part 2: Sample Comparison (2004-2010): Weighted 4 MacroDeterminants

\begin{tabular}{lll} 
& $\begin{array}{l}\text { Accounting } \\
\text { Exercise 1 }\end{array}$ & $\begin{array}{l}\text { Accounting } \\
\text { Exercise 2 }\end{array}$ \\
\hline & -0.256 & -0.196 \\
Calculation 1: Share explained by birth order gradient & -0.062 \\
- India-Africa gap in birth order gradient & -0.032 & $18 \%$ \\
- India-Africa gap in birth order gradient $\times$ Gradient coeff & $9 \%$ & $94 \%$ \\
- Birth order explained share of India-Africa level gap in height (shown in column 1) & $122 \%$ & -0.050 \\
- Macro-determinants explained share of India-Africa level gap in height (shown in column 1) & -0.016 \\
Calculation 2: Share explained by birth order gradient rooted in eldest son preference & -0.110 \\
- Rest of India - Kerala \& NE gap in birth order gradient & -0.014 & $5 \%$ \\
- Rest of India - Kerala \& NE gap in birth order gradient $\times$ Gradient coff & $4 \%$ & \\
- Birth order explained share of India-Africa level gap in height (shown in column 1) & \\
Source: Adapted from J+P using data from DHS (Heger Boyle \& Sobek, 2019) &
\end{tabular}

Table B.84: Accounting Exercise Part 2: Sample Comparison (2011-2017): Weighted 4 MacroDeterminants

Accounting Accounting

Exercise 1 Exercise 2

Calculation 1: Share explained by birth order gradient

- India-Africa gap in birth order gradient

$-0.151 \quad-0.145$

- India-Africa gap in birth order gradient $\times$ Gradient coeff

$0.141 \quad 0.196$

- Birth order explained share of India-Africa level gap in height (shown in column 1)

$-119 \% \quad-165 \%$

- Macro-determinants explained share of India-Africa level gap in height (shown in column 1)

$267 \%$

$256 \%$

Calculation 2: Share explained by birth order gradient rooted in eldest son preference

- Rest of India - Kerala \& NE gap in birth order gradient

$-0.066-0.040$

- Rest of India - Kerala \& NE gap in birth order gradient $\times$ Gradient coff

$0.062 \quad 0.054$

- Birth order explained share of India-Africa level gap in height (shown in column 1)

$-52 \% \quad-45 \%$

Source: Adapted from J+P using data from IPUMS DHS (ICF, 2004) and DHS (Heger Boyle \& Sobek, 2019) 


\section{Additional Descriptive Evidence}

\subsection{Summary Statistics: Assets of Wealth Index}

Table B.85: Wealth Index Summary Statistics (2004-2010): Unweighted

\begin{tabular}{|c|c|c|c|c|c|}
\hline & $\begin{array}{c}\text { India } \\
\text { subsample }\end{array}$ & $\begin{array}{c}\text { Africa } \\
\text { subsample }\end{array}$ & & $\begin{array}{c}\text { India } \\
\text { subsample }\end{array}$ & $\begin{array}{c}\text { Africa } \\
\text { subsample }\end{array}$ \\
\hline Electricity & $\begin{array}{c}0.72 \\
{[0.45]}\end{array}$ & $\begin{array}{c}0.20 \\
{[0.40]}\end{array}$ & Flush toilet & $\begin{array}{c}0.43 \\
{[0.49]}\end{array}$ & $\begin{array}{c}0.07 \\
{[0.26]}\end{array}$ \\
\hline Radio & $\begin{array}{c}0.33 \\
{[0.47]}\end{array}$ & $\begin{array}{c}0.64 \\
{[0.48]}\end{array}$ & Improved Pit latrine (ventilated, with slab, composting, etc.) & $\begin{array}{c}0.06 \\
{[0.24]}\end{array}$ & $\begin{array}{c}0.21 \\
{[0.41]}\end{array}$ \\
\hline TV & $\begin{array}{c}0.48 \\
{[0.50]}\end{array}$ & $\begin{array}{c}0.19 \\
{[0.39]}\end{array}$ & Traditional pit latrine without slab & $\begin{array}{c}0.05 \\
{[0.21]}\end{array}$ & $\begin{array}{c}0.36 \\
{[0.48]}\end{array}$ \\
\hline Phone & $\begin{array}{c}0.26 \\
{[0.44]}\end{array}$ & $\begin{array}{c}0.25 \\
{[0.43]}\end{array}$ & No facility/bush/field; also stream/water & $\begin{array}{c}0.46 \\
{[0.50]}\end{array}$ & $\begin{array}{c}0.32 \\
{[0.47]}\end{array}$ \\
\hline Refridgerator & $\begin{array}{c}0.17 \\
{[0.38]}\end{array}$ & $\begin{array}{c}0.08 \\
{[0.27]}\end{array}$ & Other type of toilet/latrine & $\begin{array}{c}0.00 \\
{[0.05]}\end{array}$ & $\begin{array}{c}0.00 \\
{[0.05]}\end{array}$ \\
\hline Bicycle & $\begin{array}{c}0.47 \\
{[0.50]}\end{array}$ & $\begin{array}{c}0.31 \\
{[0.46]}\end{array}$ & Piped into own dwelling/yard/plot/residency & $\begin{array}{c}0.26 \\
{[0.44]}\end{array}$ & $\begin{array}{c}0.10 \\
{[0.30]}\end{array}$ \\
\hline Motorcycle/scooter & $\begin{array}{c}0.19 \\
{[0.40]}\end{array}$ & $\begin{array}{c}0.11 \\
{[0.31]}\end{array}$ & Public tap/standpipe & $\begin{array}{c}0.15 \\
{[0.36]}\end{array}$ & $\begin{array}{c}0.16 \\
{[0.37]}\end{array}$ \\
\hline Car/truck & $\begin{array}{c}0.04 \\
{[0.18]}\end{array}$ & $\begin{array}{c}0.04 \\
{[0.20]}\end{array}$ & Tube well/borehole and dug well (open/protected) & $\begin{array}{c}0.37 \\
{[0.48]}\end{array}$ & $\begin{array}{c}0.08 \\
{[0.27]}\end{array}$ \\
\hline Mud/Clay/Earth/Sand/Dung floor & $\begin{array}{c}0.47 \\
{[0.50]}\end{array}$ & $\begin{array}{c}0.62 \\
{[0.49]}\end{array}$ & Protected well & $\begin{array}{c}0.03 \\
{[0.16]}\end{array}$ & $\begin{array}{c}0.17 \\
{[0.38]}\end{array}$ \\
\hline Other type of floor & $\begin{array}{c}0.00 \\
{[0.04]}\end{array}$ & $\begin{array}{c}0.00 \\
{[0.05]}\end{array}$ & Unprotected well & $\begin{array}{c}0.10 \\
{[0.30]}\end{array}$ & $\begin{array}{c}0.22 \\
{[0.41]}\end{array}$ \\
\hline Rudimentary material of floor & $\begin{array}{c}0.01 \\
{[0.11]}\end{array}$ & $\begin{array}{c}0.01 \\
{[0.12]}\end{array}$ & Surface water-river, lake, spring, etc. & $\begin{array}{c}0.03 \\
{[0.18]}\end{array}$ & $\begin{array}{c}0.24 \\
{[0.43]}\end{array}$ \\
\hline Finished material of floor & $\begin{array}{c}0.46 \\
{[0.50]}\end{array}$ & $\begin{array}{c}0.29 \\
{[0.45]}\end{array}$ & Rainwater & $\begin{array}{c}0.00 \\
{[0.05]}\end{array}$ & $\begin{array}{c}0.00 \\
{[0.07]}\end{array}$ \\
\hline Electricity for cooking & $\begin{array}{c}0.01 \\
{[0.07]}\end{array}$ & $\begin{array}{c}0.02 \\
{[0.15]}\end{array}$ & Bottled water & $\begin{array}{c}0.00 \\
{[0.05]}\end{array}$ & $\begin{array}{c}0.00 \\
{[0.06]}\end{array}$ \\
\hline LPG/bottled gas/ natural gas for cooking & $\begin{array}{c}0.26 \\
{[0.44]}\end{array}$ & $\begin{array}{c}0.02 \\
{[0.14]}\end{array}$ & Other water source & $\begin{array}{c}0.01 \\
{[0.11]}\end{array}$ & $\begin{array}{c}0.02 \\
{[0.12]}\end{array}$ \\
\hline Biogas for cooking & $\begin{array}{c}0.00 \\
{[0.06]}\end{array}$ & $\begin{array}{c}0.00 \\
{[0.03]}\end{array}$ & Scores for factor 1 & $\begin{array}{c}0.56 \\
{[1.18]}\end{array}$ & $\begin{array}{l}-0.12 \\
{[0.90]}\end{array}$ \\
\hline Kerosene/Paraffin for cooking & $\begin{array}{c}0.03 \\
{[0.18]}\end{array}$ & $\begin{array}{c}0.03 \\
{[0.18]}\end{array}$ & wealth $_{c} a t==$ Poorestwealthquantile & $\begin{array}{c}0.14 \\
{[0.35]}\end{array}$ & $\begin{array}{c}0.23 \\
{[0.42]}\end{array}$ \\
\hline Coal/lignite for cooking & $\begin{array}{c}0.02 \\
{[0.13]}\end{array}$ & $\begin{array}{c}0.00 \\
{[0.06]}\end{array}$ & wealth $_{c} a t==2$ ndpoorestwealthquantile & $\begin{array}{c}0.07 \\
{[0.25]}\end{array}$ & $\begin{array}{c}0.23 \\
{[0.42]}\end{array}$ \\
\hline Charcoal for cooking & $\begin{array}{c}0.01 \\
{[0.08]}\end{array}$ & $\begin{array}{c}0.12 \\
{[0.32]}\end{array}$ & wealth $_{c} a t==3$ rdpoorestwealthquantile & $\begin{array}{c}0.18 \\
{[0.38]}\end{array}$ & $\begin{array}{c}0.20 \\
{[0.40]}\end{array}$ \\
\hline Wood/straw/grass/dung/agricultural residue for cooking & $\begin{array}{c}0.68 \\
{[0.47]}\end{array}$ & $\begin{array}{c}0.73 \\
{[0.44]}\end{array}$ & wealth $_{c} a t==4$ thpoorestwealthquantile & $\begin{array}{c}0.23 \\
{[0.42]}\end{array}$ & $\begin{array}{c}0.19 \\
{[0.39]}\end{array}$ \\
\hline Other material for cooking & $\begin{array}{c}0.00 \\
{[0.02]}\end{array}$ & $\begin{array}{c}0.00 \\
{[0.03]}\end{array}$ & wealth $_{c} a t==$ Richestwealthquantile & $\begin{array}{c}0.38 \\
{[0.49]}\end{array}$ & $\begin{array}{c}0.15 \\
{[0.36]}\end{array}$ \\
\hline
\end{tabular}

Notes: The means of the specified variables are calculated separately for the India and Africa subsamples. Standard deviations appear in brackets.

Source: Own calculations using data from DHS (Heger Boyle \& Sobek, 2019) 
Table B.86: Wealth Index Summary Statistics (2011-2017): Unweighted

\begin{tabular}{|c|c|c|c|c|c|}
\hline & $\begin{array}{c}\text { India } \\
\text { subsample }\end{array}$ & $\begin{array}{c}\text { Africa } \\
\text { subsample }\end{array}$ & & $\begin{array}{c}\text { India } \\
\text { subsample }\end{array}$ & $\begin{array}{c}\text { Africa } \\
\text { subsample }\end{array}$ \\
\hline Electricity & $\begin{array}{c}0.85 \\
{[0.36]}\end{array}$ & $\begin{array}{c}0.30 \\
{[0.46]}\end{array}$ & Flush toilet & $\begin{array}{c}0.44 \\
{[0.50]}\end{array}$ & $\begin{array}{c}0.12 \\
{[0.32]}\end{array}$ \\
\hline Radio & $\begin{array}{c}0.09 \\
{[0.28]}\end{array}$ & $\begin{array}{c}0.58 \\
{[0.49]}\end{array}$ & Improved Pit latrine (ventilated, with slab, composting, etc.) & $\begin{array}{c}0.08 \\
{[0.27]}\end{array}$ & $\begin{array}{c}0.33 \\
{[0.47]}\end{array}$ \\
\hline TV & $\begin{array}{c}0.58 \\
{[0.49]}\end{array}$ & $\begin{array}{c}0.29 \\
{[0.45]}\end{array}$ & Traditional pit latrine without slab & $\begin{array}{c}0.03 \\
{[0.17]}\end{array}$ & $\begin{array}{c}0.29 \\
{[0.45]}\end{array}$ \\
\hline Phone & $\begin{array}{c}0.92 \\
{[0.27]}\end{array}$ & $\begin{array}{c}0.73 \\
{[0.44]}\end{array}$ & No facility/bush/field; also stream/water & $\begin{array}{c}0.45 \\
{[0.50]}\end{array}$ & $\begin{array}{c}0.26 \\
{[0.44]}\end{array}$ \\
\hline Refridgerator & $\begin{array}{c}0.24 \\
{[0.43]}\end{array}$ & $\begin{array}{c}0.11 \\
{[0.31]}\end{array}$ & Other type of toilet/latrine & $\begin{array}{c}0.00 \\
{[0.04]}\end{array}$ & $\begin{array}{c}0.00 \\
{[0.04]}\end{array}$ \\
\hline Bicycle & $\begin{array}{c}0.49 \\
{[0.50]}\end{array}$ & $\begin{array}{c}0.26 \\
{[0.44]}\end{array}$ & Piped into own dwelling/yard/plot/residency & $\begin{array}{c}0.25 \\
{[0.43]}\end{array}$ & $\begin{array}{c}0.12 \\
{[0.33]}\end{array}$ \\
\hline Motorcycle/scooter & $\begin{array}{c}0.36 \\
{[0.48]}\end{array}$ & $\begin{array}{c}0.16 \\
{[0.37]}\end{array}$ & Public tap/standpipe & $\begin{array}{c}0.13 \\
{[0.33]}\end{array}$ & $\begin{array}{c}0.14 \\
{[0.35]}\end{array}$ \\
\hline Car/truck & $\begin{array}{c}0.06 \\
{[0.23]}\end{array}$ & $\begin{array}{c}0.05 \\
{[0.21]}\end{array}$ & Tube well/borehole and dug well (open/protected) & $\begin{array}{c}0.46 \\
{[0.50]}\end{array}$ & $\begin{array}{c}0.17 \\
{[0.38]}\end{array}$ \\
\hline Mud/Clay/Earth/Sand/Dung floor & $\begin{array}{c}0.46 \\
{[0.50]}\end{array}$ & $\begin{array}{c}0.57 \\
{[0.50]}\end{array}$ & Protected well & $\begin{array}{c}0.03 \\
{[0.17]}\end{array}$ & $\begin{array}{c}0.09 \\
{[0.28]}\end{array}$ \\
\hline Other type of floor & $\begin{array}{c}0.00 \\
{[0.03]}\end{array}$ & $\begin{array}{c}0.00 \\
{[0.05]}\end{array}$ & Unprotected well & $\begin{array}{c}0.06 \\
{[0.24]}\end{array}$ & $\begin{array}{c}0.16 \\
{[0.37]}\end{array}$ \\
\hline Rudimentary material of floor & $\begin{array}{c}0.01 \\
{[0.11]}\end{array}$ & $\begin{array}{c}0.00 \\
{[0.06]}\end{array}$ & Surface water-river, lake, spring, etc. & $\begin{array}{c}0.04 \\
{[0.21]}\end{array}$ & $\begin{array}{c}0.22 \\
{[0.42]}\end{array}$ \\
\hline Finished material of floor & $\begin{array}{c}0.47 \\
{[0.50]}\end{array}$ & $\begin{array}{c}0.00 \\
{[0.00]}\end{array}$ & Rainwater & $\begin{array}{c}0.00 \\
{[0.05]}\end{array}$ & $\begin{array}{c}0.01 \\
{[0.08]}\end{array}$ \\
\hline Electricity for cooking & $\begin{array}{c}0.01 \\
{[0.09]}\end{array}$ & $\begin{array}{c}0.02 \\
{[0.14]}\end{array}$ & Bottled water & $\begin{array}{c}0.01 \\
{[0.11]}\end{array}$ & $\begin{array}{c}0.01 \\
{[0.10]}\end{array}$ \\
\hline LPG/bottled gas/ natural gas for cooking & $\begin{array}{c}0.28 \\
{[0.45]}\end{array}$ & $\begin{array}{c}0.03 \\
{[0.17]}\end{array}$ & Other water source & $\begin{array}{c}0.02 \\
{[0.15]}\end{array}$ & $\begin{array}{c}0.02 \\
{[0.14]}\end{array}$ \\
\hline Biogas for cooking & $\begin{array}{c}0.00 \\
{[0.07]}\end{array}$ & $\begin{array}{c}0.00 \\
{[0.03]}\end{array}$ & Scores for factor 1 & $\begin{array}{c}0.45 \\
{[1.02]}\end{array}$ & $\begin{array}{l}-0.39 \\
{[0.78]}\end{array}$ \\
\hline Kerosene/Paraffin for cooking & $\begin{array}{c}0.01 \\
{[0.09]}\end{array}$ & $\begin{array}{c}0.03 \\
{[0.17]}\end{array}$ & wealth $_{c} a t==$ Poorestwealthquantile & $\begin{array}{c}0.06 \\
{[0.24]}\end{array}$ & $\begin{array}{c}0.36 \\
{[0.48]}\end{array}$ \\
\hline Coal/lignite for cooking & $\begin{array}{c}0.01 \\
{[0.11]}\end{array}$ & $\begin{array}{c}0.05 \\
{[0.21]}\end{array}$ & wealth $_{c} a t==2 n$ dpoorestwealthquantile & $\begin{array}{c}0.17 \\
{[0.38]}\end{array}$ & $\begin{array}{c}0.20 \\
{[0.40]}\end{array}$ \\
\hline Charcoal for cooking & $\begin{array}{c}0.01 \\
{[0.08]}\end{array}$ & $\begin{array}{c}0.13 \\
{[0.34]}\end{array}$ & wealth $_{c} a t==3$ rdpoorestwealthquantile & $\begin{array}{c}0.20 \\
{[0.40]}\end{array}$ & $\begin{array}{c}0.19 \\
{[0.39]}\end{array}$ \\
\hline Wood/straw/grass/dung/agricultural residue for cooking & $\begin{array}{c}0.68 \\
{[0.47]}\end{array}$ & $\begin{array}{c}0.73 \\
{[0.44]}\end{array}$ & wealth $_{c} a t==4$ thpoorestwealthquantile & $\begin{array}{c}0.23 \\
{[0.42]}\end{array}$ & $\begin{array}{c}0.16 \\
{[0.37]}\end{array}$ \\
\hline Other material for cooking & $\begin{array}{c}0.00 \\
{[0.02]}\end{array}$ & $\begin{array}{c}0.00 \\
{[0.03]}\end{array}$ & wealth $_{c} a t==$ Richestwealthquantile & $\begin{array}{c}0.34 \\
{[0.47]}\end{array}$ & $\begin{array}{c}0.09 \\
{[0.29]}\end{array}$ \\
\hline
\end{tabular}

Notes: The means of the specified variables are calculated separately for the India and Africa subsamples. Standard deviations appear in brackets.

Source: Own calculations using data from IPUMS DHS (ICF, 2004) 


\subsection{Summary Statistics: Child Survival}

Table B.87: Share of Ever Born Children and Survival Rate by Gender, Birth Order, Country, and Time: Weighted

\begin{tabular}{|c|c|c|c|c|}
\hline & \multicolumn{2}{|l|}{$2004-2010$} & \multicolumn{2}{|l|}{$2011-2017$} \\
\hline & India subsample & Africa subsample & India subsample & Africa subsample \\
\hline \multicolumn{5}{|c|}{ Panel A: All ever born children age 13 to 59 months } \\
\hline Birth order: 1 & 0.30 & 0.21 & 0.39 & 0.22 \\
\hline Birth order: 2 & 0.27 & 0.19 & 0.32 & 0.19 \\
\hline Birth order: 3 & 0.43 & 0.60 & 0.29 & 0.59 \\
\hline Girl \& Birth order: 1 & 0.15 & 0.10 & 0.19 & 0.11 \\
\hline Girl \& Birth order: 2 & 0.13 & 0.09 & 0.15 & 0.09 \\
\hline Girl \& Birth order: 3 & 0.20 & 0.30 & 0.14 & 0.29 \\
\hline Boy \& Birth order: 1 & 0.15 & 0.11 & 0.20 & 0.11 \\
\hline Boy \& Birth order: 2 & 0.14 & 0.09 & 0.16 & 0.10 \\
\hline Boy \& Birth order: 3 & 0.23 & 0.30 & 0.15 & 0.29 \\
\hline \multicolumn{5}{|c|}{ Panel B: Survival rate of all ever born children age 13 to 59 months } \\
\hline Birth order: 1 & 0.93 & 0.91 & 0.96 & 0.94 \\
\hline Birth order: 2 & 0.95 & 0.93 & 0.97 & 0.95 \\
\hline Birth order: 3 & 0.94 & 0.93 & 0.95 & 0.95 \\
\hline Girl \& Birth order: 1 & 0.94 & 0.92 & 0.96 & 0.95 \\
\hline Girl \& Birth order: 2 & 0.95 & 0.94 & 0.97 & 0.96 \\
\hline Girl \& Birth order: 3 & 0.94 & 0.93 & 0.95 & 0.96 \\
\hline Boy \& Birth order: 1 & 0.93 & 0.90 & 0.95 & 0.94 \\
\hline Boy \& Birth order: 2 & 0.96 & 0.93 & 0.97 & 0.95 \\
\hline Boy \& Birth order: 3 & 0.95 & 0.92 & 0.96 & 0.95 \\
\hline
\end{tabular}

Source: Own calculations using data from IPUMS DHS (ICF, 2004) and DHS (Heger Boyle \& Sobek, 2019) 


\subsection{Child Inputs by Birth Order, Gender, Time, and Country}

Table B.88: Summary Statistics of Inputs by Birth Order: Weighted Means

\begin{tabular}{|c|c|c|c|c|}
\hline & \multicolumn{2}{|l|}{$2004-2010$} & \multicolumn{2}{|l|}{$2011-2017$} \\
\hline & India subsample & Africa subsample & India subsample & Africa subsample \\
\hline \multicolumn{5}{|l|}{ Panel A: First born children } \\
\hline Total prenatal visits & 4.93 & 4.47 & 5.54 & 4.41 \\
\hline Mother took iron supplements & 0.77 & 0.66 & 0.84 & 0.78 \\
\hline Mother's total tetanus shots & 2.11 & 1.66 & 2.01 & 1.64 \\
\hline Delivery at health facility & 0.58 & 0.60 & 0.89 & 0.73 \\
\hline Postnatal check within 2 months & 0.11 & 0.35 & 0.40 & 0.50 \\
\hline Child taking iron pills & 0.06 & 0.17 & 0.27 & 0.08 \\
\hline Child's total vaccinations & 7.18 & 6.49 & 7.72 & 5.45 \\
\hline Average pooled inputs & 0.38 & 0.43 & 0.54 & 0.49 \\
\hline Meat or eggs consumed & 0.21 & 0.61 & 0.14 & 0.33 \\
\hline Dairy products consumed & 0.17 & 0.23 & 0.13 & 0.23 \\
\hline Child's HFA z-score & -1.72 & -1.64 & -1.09 & -1.06 \\
\hline \multicolumn{5}{|l|}{ Panel B: Second born children } \\
\hline Total prenatal visits & 4.41 & 4.34 & 5.03 & 4.27 \\
\hline Mother took iron supplements & 0.74 & 0.65 & 0.82 & 0.77 \\
\hline Mother's total tetanus shots & 2.02 & 1.58 & 1.94 & 1.51 \\
\hline Delivery at health facility & 0.45 & 0.52 & 0.82 & 0.65 \\
\hline Postnatal check within 2 months & 0.10 & 0.37 & 0.39 & 0.49 \\
\hline Child taking iron pills & 0.05 & 0.15 & 0.27 & 0.08 \\
\hline Child's total vaccinations & 6.86 & 6.39 & 7.59 & 5.18 \\
\hline Average pooled inputs & 0.33 & 0.38 & 0.50 & 0.45 \\
\hline Meat or eggs consumed & 0.21 & 0.60 & 0.16 & 0.33 \\
\hline Dairy products consumed & 0.17 & 0.20 & 0.16 & 0.22 \\
\hline Child's HFA z-score & -1.84 & -1.65 & -1.20 & -1.07 \\
\hline \multicolumn{5}{|c|}{ Panel B: Third or higher birth order children } \\
\hline Total prenatal visits & 2.28 & 3.74 & 3.22 & 3.76 \\
\hline Mother took iron supplements & 0.54 & 0.60 & 0.68 & 0.72 \\
\hline Mother's total tetanus shots & 1.67 & 1.35 & 1.84 & 1.30 \\
\hline Delivery at health facility & 0.21 & 0.40 & 0.65 & 0.51 \\
\hline Postnatal check within 2 months & 0.07 & 0.33 & 0.34 & 0.42 \\
\hline Child taking iron pills & 0.03 & 0.12 & 0.21 & 0.08 \\
\hline Child's total vaccinations & 5.61 & 5.95 & 6.88 & 4.79 \\
\hline Average pooled inputs & 0.19 & 0.32 & 0.39 & 0.37 \\
\hline Meat or eggs consumed & 0.14 & 0.54 & 0.12 & 0.29 \\
\hline Dairy products consumed & 0.12 & 0.18 & 0.11 & 0.18 \\
\hline Child's HFA z-score & -2.22 & -1.77 & -1.55 & -1.23 \\
\hline
\end{tabular}

Notes: The means of the specified variables are calculated separately for the India and Africa subsamples.

Source: Own calculations using data from IPUMS DHS (ICF, 2004) and DHS (Heger Boyle \& Sobek, 2019) 
Table B.89: Summary Statistics of Inputs by Birth Order for Girls: Weighted Means

\begin{tabular}{|c|c|c|c|c|}
\hline & \multicolumn{2}{|l|}{$2004-2010$} & \multicolumn{2}{|l|}{$2011-2017$} \\
\hline & India subsample & Africa subsample & India subsample & Africa subsample \\
\hline \multicolumn{5}{|l|}{ Panel A: First born children } \\
\hline Total prenatal visits & 4.94 & 4.49 & 5.59 & 4.43 \\
\hline Mother took iron supplements & 0.76 & 0.65 & 0.84 & 0.79 \\
\hline Mother's total tetanus shots & 2.11 & 1.64 & 2.01 & 1.64 \\
\hline Delivery at health facility & 0.57 & 0.60 & 0.89 & 0.72 \\
\hline Postnatal check within 2 months & 0.09 & 0.35 & 0.40 & 0.51 \\
\hline Child taking iron pills & 0.06 & 0.17 & 0.27 & 0.08 \\
\hline Child's total vaccinations & 7.11 & 6.56 & 7.70 & 5.49 \\
\hline Average pooled inputs & 0.37 & 0.43 & 0.54 & 0.49 \\
\hline Meat or eggs consumed & 0.21 & 0.62 & 0.14 & 0.32 \\
\hline Dairy products consumed & 0.17 & 0.24 & 0.13 & 0.23 \\
\hline Child's HFA z-score & -1.72 & -1.57 & -1.05 & -0.96 \\
\hline \multicolumn{5}{|l|}{ Panel B: Second born children } \\
\hline Total prenatal visits & 4.38 & 4.39 & 5.09 & 4.24 \\
\hline Mother took iron supplements & 0.75 & 0.65 & 0.82 & 0.77 \\
\hline Mother's total tetanus shots & 2.01 & 1.60 & 1.94 & 1.51 \\
\hline Delivery at health facility & 0.42 & 0.52 & 0.81 & 0.64 \\
\hline Postnatal check within 2 months & 0.11 & 0.35 & 0.39 & 0.49 \\
\hline Child taking iron pills & 0.05 & 0.16 & 0.26 & 0.08 \\
\hline Child's total vaccinations & 6.80 & 6.37 & 7.56 & 5.02 \\
\hline Average pooled inputs & 0.31 & 0.38 & 0.50 & 0.45 \\
\hline Meat or eggs consumed & 0.22 & 0.59 & 0.17 & 0.32 \\
\hline Dairy products consumed & 0.17 & 0.20 & 0.16 & 0.22 \\
\hline Child's HFA z-score & -1.87 & -1.57 & -1.16 & -0.96 \\
\hline \multicolumn{5}{|c|}{ Panel B: Third or higher birth order children } \\
\hline Total prenatal visits & 2.19 & 3.73 & 3.19 & 3.76 \\
\hline Mother took iron supplements & 0.54 & 0.60 & 0.68 & 0.72 \\
\hline Mother's total tetanus shots & 1.63 & 1.34 & 1.84 & 1.30 \\
\hline Delivery at health facility & 0.20 & 0.40 & 0.63 & 0.51 \\
\hline Postnatal check within 2 months & 0.07 & 0.33 & 0.33 & 0.42 \\
\hline Child taking iron pills & 0.03 & 0.12 & 0.21 & 0.08 \\
\hline Child's total vaccinations & 5.45 & 5.95 & 6.85 & 4.79 \\
\hline Average pooled inputs & 0.18 & 0.32 & 0.39 & 0.37 \\
\hline Meat or eggs consumed & 0.15 & 0.54 & 0.12 & 0.28 \\
\hline Dairy products consumed & 0.11 & 0.17 & 0.12 & 0.18 \\
\hline Child's HFA z-score & -2.23 & -1.70 & -1.56 & -1.16 \\
\hline
\end{tabular}

Notes: The means of the specified variables are calculated separately for the India and Africa subsamples.

Source: Own calculations using data from IPUMS DHS (ICF, 2004) and DHS (Heger Boyle \& Sobek, 2019) 
Table B.90: Summary Statistics of Inputs by Birth Order for Boys: Weighted Means

\begin{tabular}{|c|c|c|c|c|}
\hline & \multicolumn{2}{|l|}{$2004-2010$} & \multicolumn{2}{|l|}{$2011-2017$} \\
\hline & India subsample & Africa subsample & India subsample & Africa subsample \\
\hline \multicolumn{5}{|l|}{ Panel A: First born children } \\
\hline Total prenatal visits & 4.92 & 4.45 & 5.50 & 4.40 \\
\hline Mother took iron supplements & 0.79 & 0.66 & 0.84 & 0.78 \\
\hline Mother's total tetanus shots & 2.11 & 1.68 & 2.02 & 1.65 \\
\hline Delivery at health facility & 0.59 & 0.61 & 0.89 & 0.73 \\
\hline Postnatal check within 2 months & 0.12 & 0.35 & 0.39 & 0.50 \\
\hline Child taking iron pills & 0.07 & 0.17 & 0.27 & 0.08 \\
\hline Child's total vaccinations & 7.24 & 6.42 & 7.74 & 5.42 \\
\hline Average pooled inputs & 0.39 & 0.43 & 0.54 & 0.49 \\
\hline Meat or eggs consumed & 0.21 & 0.60 & 0.13 & 0.33 \\
\hline Dairy products consumed & 0.16 & 0.23 & 0.13 & 0.24 \\
\hline Child's HFA z-score & -1.72 & -1.71 & -1.14 & -1.16 \\
\hline \multicolumn{5}{|l|}{ Panel B: Second born children } \\
\hline Total prenatal visits & 4.44 & 4.29 & 4.97 & 4.30 \\
\hline Mother took iron supplements & 0.73 & 0.65 & 0.81 & 0.78 \\
\hline Mother's total tetanus shots & 2.02 & 1.56 & 1.94 & 1.51 \\
\hline Delivery at health facility & 0.48 & 0.52 & 0.82 & 0.65 \\
\hline Postnatal check within 2 months & 0.10 & 0.38 & 0.39 & 0.50 \\
\hline Child taking iron pills & 0.06 & 0.15 & 0.27 & 0.08 \\
\hline Child's total vaccinations & 6.92 & 6.41 & 7.61 & 5.33 \\
\hline Average pooled inputs & 0.34 & 0.39 & 0.50 & 0.45 \\
\hline Meat or eggs consumed & 0.21 & 0.60 & 0.16 & 0.33 \\
\hline Dairy products consumed & 0.17 & 0.20 & 0.16 & 0.22 \\
\hline Child's HFA z-score & -1.81 & -1.73 & -1.23 & -1.18 \\
\hline \multicolumn{5}{|c|}{ Panel B: Third or higher birth order children } \\
\hline Total prenatal visits & 2.35 & 3.76 & 3.24 & 3.76 \\
\hline Mother took iron supplements & 0.55 & 0.60 & 0.68 & 0.72 \\
\hline Mother's total tetanus shots & 1.70 & 1.36 & 1.83 & 1.30 \\
\hline Delivery at health facility & 0.22 & 0.41 & 0.67 & 0.51 \\
\hline Postnatal check within 2 months & 0.07 & 0.33 & 0.34 & 0.41 \\
\hline Child taking iron pills & 0.03 & 0.13 & 0.22 & 0.08 \\
\hline Child's total vaccinations & 5.74 & 5.96 & 6.91 & 4.78 \\
\hline Average pooled inputs & 0.19 & 0.32 & 0.40 & 0.37 \\
\hline Meat or eggs consumed & 0.13 & 0.55 & 0.12 & 0.29 \\
\hline Dairy products consumed & 0.12 & 0.18 & 0.11 & 0.18 \\
\hline Child's HFA z-score & -2.20 & -1.84 & -1.54 & -1.30 \\
\hline
\end{tabular}

Notes: The means of the specified variables are calculated separately for the India and Africa subsamples.

Source: Own calculations using data from IPUMS DHS (ICF, 2004) and DHS (Heger Boyle \& Sobek, 2019) 


\section{C $\mid$ Essay 2}

\section{Background}

\subsection{India's School-Feeding Program}

The MDM provides lunch free of cost for 100 million school children from first to seventh grade at 1.15 million government and government aided schools in India every day except school holidays (Department of School Education and Literacy \& Ministry of Human Resource and Development, 2015; Ministry of Human Resource Development, 2015). Its purpose aligns with the considered outcomes of this study because it aims at reducing hunger, increasing nutrition, and improving enrolment, attendance, and academic achievements (Bihar Government, 2017). Further, it wants to contribute to overcoming caste discrimination and gender inequity (Bihar Government, 2017).

One meal contains $450 \mathrm{kcal}$ for primary school children and $700 \mathrm{kcal}$ for upper primary school children (Bihar Government, 2017). The menu and the content of grains, pulses, vegetables, oils and fats, salt and spices is predefined (Bihar Government, 2017; Midday Meal Scheme, 2017). ${ }^{1}$ The meal is prepared mainly decentralized at the schools itself with special kitchens constructed for it (Midday Meal Scheme, 2017). Apart from rice schools have to purchase all ingredients (Midday Meal Scheme, 2017). ${ }^{2}$ Their budget depends on the number of students they are serving lunch (Midday Meal Scheme, 2017). ${ }^{3}$ The costs are shared by the central and the state government (Midday Meal Scheme, 2017).

The potential of the MDM to counter malnutrition is not unknown. The Ministry of Women and Child Development has announced the mandatory use of DFS in government nutrition programs like the MDM in a directive with the goal to reduce iron deficiency in school children. Never-

\footnotetext{
${ }^{1}$ The MDM for children in primary school should contain 100 grams of grains, 20 grams of pulses, 50 grams of vegetables, 5 grams of oils and fats, and salt and spices (Bihar Government, 2017; Midday Meal Scheme, 2017). The MDM for children in upper primary school should include 150 grams of grains, 30 grams of pulses, 75 grams of vegetables, 7.5 grams of oils and fats, and salt and spices.

${ }^{2}$ The Food Corporation of India delivers the rice directly to the schools (Midday Meal Scheme, 2017).

${ }^{3}$ Schools receive Rs. 3.59 (USD 0.05) for one primary child and Rs. 5.38 (USD 0.07) for every upper primary child per day (Midday Meal Scheme, 2017)
} 
theless, this is hardly implemented due to constraints in supply (Ministry of Human Resource Development, 2017; Krämer et al., 2020).

\subsection{Prevalence, Causes, and Consequences of Iron Deficiency in India}

Using DFS in the MDM provides a unique chance to overcome iron deficiency because 15 to 80 percent of school aged children (5 to 15 years of age) in India are anemic (Alvarez-Uria et al., 2014). Half of the cases of anemia are due to iron deficiency because low-income households in India consume a diet with little bioavailable iron (Allen et al., 2006). In particular girls and children from tribes have a high prevalence of this illness (Choudhary et al., 2006; Rao et al., 2007; Malhotra \& Passi, 2007).

Iron deficiency with or without anemia for children 6 to 16 years is associated with higher risk to score below average compared to children without deficiency according to Halterman et al. (2001) who examine the US National Health and Nutrition Examination Survey III (19881994) . Li et al. (2018) also find that fourth grade students with anemia or a low hemoglobin level in 25 primary schools in central China are more likely to perform poorly on standardized mathematics exams compared to their healthy peers. Ji et al. (2017) add that early adolescents (around age 12) with iron deficiency are associated with reduced neurocognitive performance compared to children with a normal iron status in their age group.

In a review article Falkingham et al. (2010) show that iron supplementation improves attention, concentration, intelligence quotient, memory, psychomotor skills, and scholastic achievement for iron-deficient children aged 6 and above, adolescents, and women. Cognitive functions might in turn affect the academic achievement of children and so human capital acquisition of later life (Zhao et al., 2019). Supplementation with iron is also associated with an increase in attendance for preschool children (Bobonis, 2009) and in test scores for children in fourth grade in China Luo et al. (2012).

Deficiencies in nutrients like iron impair the development of the brain and so cognitive functions because the frontal lobes that are assumed to be responsible for executive cognitive activities develop throughout childhood (Bryan et al., 2004; Hudspeth \& Pribram, 1990). The overview article by Bryan et al. (2004) confirms that in case of iron "there is reasonable evidence for the beneficial effects of longer-term iron supplementation on the cognitive performance of older children", in particular adolescents. 


\section{Study Design and Data}

\subsection{Causal Pathway of the Intervention}

Our DFS nutrition sensitive intervention helps to close a supply chain gap and so implement the government directive of the use of DFS in the MDM. In the following we present the underlying causal pathway using categories of a logical framework of results based management (Figure C.1). The objective of the study is improved development of children in early adolescents. The project delivers outputs such as the timely available and adequate amount of DFS to the treatment schools and creates awareness of the use and storage of DFS in the school personal. For this, we directly purchase the DFS from Indian private companies with on average $0.86 \mathrm{mg}$ of iron per gram of salt. The purpose of DFS is to prevent iron deficiency but not to cure cases that would need therapeutic attention, i.e. severe anemia cases, (Sivakumar \& Nair, 2002). Changes in hemoglobin should only be expected after a consumption of over a 2 year period whereas changes in prevalence of anemia can be expected earlier according to Sivakumar \& Nair (2002). The low content of iron in DFS mitigates the chance of over-consumption of iron and so potential negative treatment effects.

We deliver it to the treatment and later also control schools once or twice every month or depending on the needs of the schools. We sold the DFS to the schools for a similar price as non-DFS salt, INR 12 (0.18 USD) per kg, by subsidizing it. Due to the lack of production, we had to switch the supplier to a less known and so less accepted company by the schools for about 4 months in 2018.

The short term outcomes are the adequate storage of DFS and the fortification of the MDM with DFS that in turn leads to an increase of iron in the MDM consumed by the school children. The mid-term outcomes consist of the greater absorption of iron in school children increasing their health, in particular their nutritional status. It provides improved conditions for the development of the frontal lobes that are assumed to be responsible for executive cognitive activities (Bryan et al., 2004). Healthy children are supposed to attend school more often due to lack of illness and have improved cognitive ability. Both attribute to greater educational achievements.

For this project we focus particular on the long-term outcomes: health is measured as hemoglobin level and iron deficiency anemia, henceforth anemia, in children. We measure cognitive ability with different types of tests, attendance with the school records of missed days, and academic 
Figure C.1: Logical Framework of DFS Intervention

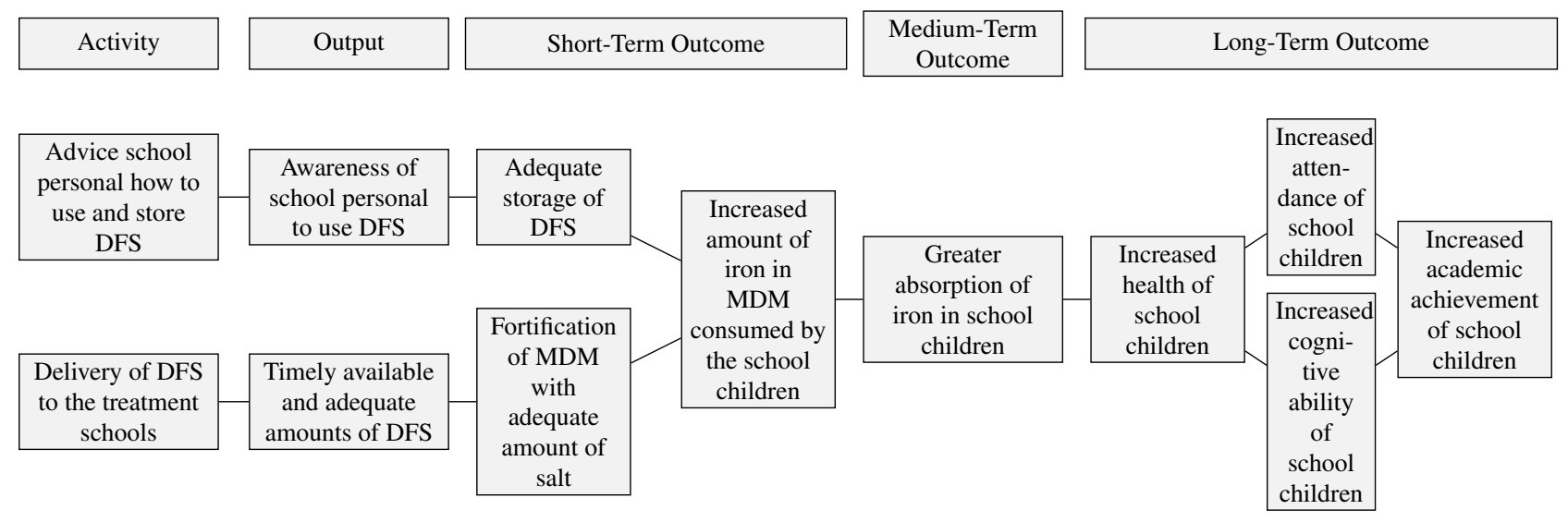

Source: Own data.

achievements with a reading and math test. 


\subsection{School Types Across Survey Waves}

Table C.1: Frequency and Treatment Periods of Schools Included at the Three Data Collection Waves

\begin{tabular}{lccc}
\hline School Type & $\begin{array}{c}\text { Frequency } \\
\text { Wave I } \\
(11 / 2014-01 / 2015)\end{array}$ & $\begin{array}{c}\text { Frequency } \\
\text { Wave II } \\
(08-10 / 2016)\end{array}$ & $\begin{array}{c}\text { Frequency } \\
\text { Wave III } \\
(01-07 / 2019)\end{array}$ \\
\hline Type 1: PS Early & 31 & 31 & 20 \\
Type 2: MS Early & 23 & 23 & 23 \\
Type 3: PS Late & 32 & 32 & 0 \\
Type 4: MS Late & 21 & 21 & 21 \\
Type 5: MS New & - & - & 16 \\
Type 6: Other governmental & - & - & $>0$ \\
Type 7: Private & - & - & $>1$ \\
\hline
\end{tabular}

Notes: Early indicates a start of the DFS supply in 2015 and Late in 2017. Source: Own data. 


\subsection{Measures}

\subsubsection{Outcomes}

Figure C.2: Frequency of Age of School Children by Survey Wave

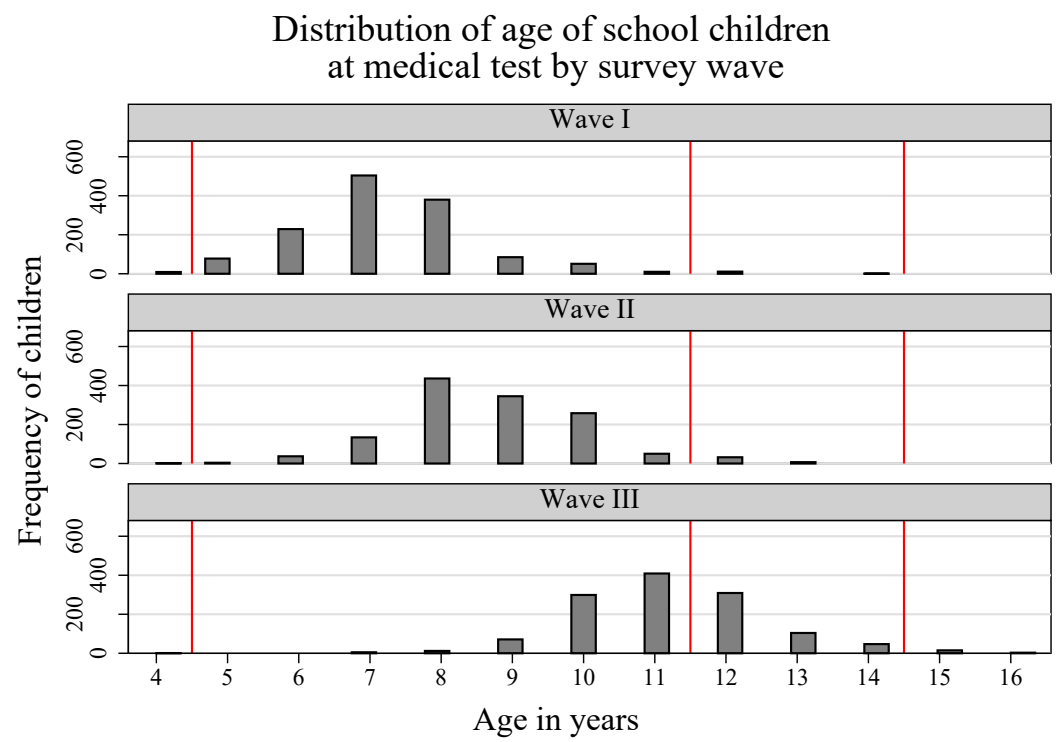

Notes: The red lines mark the next age group with different anemia thresholds.

Source: Own Data.

Table C.2: Number of Anemia Cases by Treatment and Survey Wave

\begin{tabular}{|c|c|c|c|c|c|c|c|c|c|c|c|c|}
\hline \multirow[b]{2}{*}{ Group } & \multicolumn{4}{|c|}{$\begin{array}{c}\text { Wave I } \\
(11 / 2014-01 / 2015)\end{array}$} & \multicolumn{4}{|c|}{$\begin{array}{c}\text { Wave II } \\
(08-10 / 2016)\end{array}$} & \multicolumn{4}{|c|}{$\begin{array}{c}\text { Wave III } \\
(01-07 / 2019)\end{array}$} \\
\hline & Always & Early & Late & Hardly & Always & Early & Late & Hardly & Always & Early & Late & Hardly \\
\hline Severe Anemia & 7 & 1 & 3 & 0 & 1 & 0 & 0 & 0 & 2 & 1 & 0 & 0 \\
\hline Moderate Anemia & 169 & 55 & 92 & 55 & 85 & 18 & 57 & 34 & 45 & 12 & 22 & 25 \\
\hline Mild Anemia & 121 & 39 & 78 & 42 & 77 & 19 & 50 & 33 & 75 & 26 & 58 & 33 \\
\hline Any Anemia & 297 & 95 & 173 & 97 & 163 & 37 & 107 & 67 & 122 & 39 & 80 & 58 \\
\hline Observations & 594 & 194 & 391 & 254 & 560 & 173 & 361 & 235 & 566 & 165 & 350 & 215 \\
\hline
\end{tabular}

Notes: Mild and any anemia are values adjusted by age and gender.

Source: Own data. 
Table C.3: Sources Used for Cognitive Tests in Wave III

\begin{tabular}{|c|c|c|}
\hline Test & Wave I \& Wave II & Wave III \\
\hline Block design & $\begin{array}{l}\text { Malin (1969) } \\
\text { (less pattern pictures) }\end{array}$ & $\begin{array}{l}\text { Malin (1969) } \\
\text { (additional two pattern pictures) }\end{array}$ \\
\hline Digit span forwards & Malin (1969) & unchanged \\
\hline Digit span backwards & Malin (1969) & unchanged \\
\hline $\begin{array}{l}\text { Raven's Colored Pro- } \\
\text { gressive Matrices }\end{array}$ & Raven et al. (1998) & matrices changed \\
\hline Stroop & $\begin{array}{l}\text { Stroop-like day-and-night test } \\
\text { Gerstadt et al. (1994) }\end{array}$ & $\begin{array}{l}\text { Fruit/vegetable stroop } \\
\text { (Röthlisberger et al., 2010) }\end{array}$ \\
\hline
\end{tabular}

Source: Adapted from Krämer et al. (2018). 
Conduction and Calculation of Stroop Scores Instead of the Stroop like "Day-Night" test by Gerstadt et al. (1994) used in the first two survey waves to measure the ability of inhibition control, we use an adapted version of the fruit/vegetable Stroop by Röthlisberger et al. (2010). This test has been conducted with the help of Prof. Dr. Claudia Mähler from the Institute for Psychology, University of Hildesheim. In the test, four different sets of cards are presented. In set 1 (colored squares) and set 2 (colored fruits and vegetables), the children are asked to name the printed color of the shapes or eatables. In set 3 (black and white outlines of fruits and vegetables) and set 4 (incorrectly colored fruits and vegetables), the children are asked to name the colors which the fruits and vegetables would actually have. The number of the correct answers, self-corrected answers, mistakes and the amount of time needed to complete each set are recorded. To measure inhibition, we follow the approach by Archibald \& Kerns (1999) using the measured times needed for naming all objects in the sets:

$$
\text { time }_{\text {set } 4}-\frac{\text { time }_{\text {set } 1} \times t i m e_{\text {set } 3}}{\text { time }_{\text {set } 1}+\text { time }_{\text {set } 3}}
$$

Higher values indicate less inhibition. Compared to the original version by Röthlisberger et al. (2010) of the fruits/vegtables Stroop test the chosen fruits and vegetables have been adapted to the context in India. Following fruits and vegetables are used with the correct color in brackets: banana (yellow), tomato (red), orange (orange), and lettuce (green).

For the direct comparison of the Stroop test in the different periods, we calculate 13 quantiles based on the inhibition scores of the children. The quantile representing the lowest inhibition scores are assigned zero points, whereas the 13th quantile is assigned 12 points. In the same way all other quantiles are assigned points. This conversion into points is not used for the calculation of the cognition index.

\subsubsection{Covariates}


Table C.4: Overview Covariates

\begin{tabular}{|c|c|c|c|}
\hline & Health Outcomes & Cognition Outcomes & Education Outcomes \\
\hline \multicolumn{4}{|l|}{ Socioeconomic } \\
\hline Household rural or urban & Yes & Yes & Yes \\
\hline Block & Yes & Yes & Yes \\
\hline Wealth index & Yes & Yes & Yes \\
\hline Parental education level (years of schooling) & Yes & Yes & Yes \\
\hline Caste & Yes & Yes & Yes \\
\hline Household religion & Yes & Yes & Yes \\
\hline Number of household members & Yes & Yes & Yes \\
\hline \multicolumn{4}{|l|}{ Food intake } \\
\hline Child's dietary diversity score & Yes & Yes & Yes \\
\hline Indicator for household food security & Yes & Yes & Yes \\
\hline Number of meals child eats every day & Yes & Yes & Yes \\
\hline Average calorie intake from the MDM at survey day per child & Yes & Yes & Yes \\
\hline Indicator for maternal health knowledge & Yes & Yes & Yes \\
\hline Dummy if the child consumes any meat, poultry or fish & Yes & Yes* & Yes* \\
\hline Dummy if the child gets iron supplements & Yes & Yes* & Yes* \\
\hline Average iron intake from the MDM at survey day per child & Yes & Yes* & Yes* \\
\hline Dummy if the child gets iron supplements & Yes & Yes* & Yes* \\
\hline Days child exposed to IFA tablets at school & Only for wave III & Only for wave III & Only for wave III \\
\hline \multicolumn{4}{|l|}{ Health care } \\
\hline Dummy for institutional delivery & Yes & Yes & Yes \\
\hline Dummy for health insurance coverage & Yes & Yes & Yes \\
\hline \multicolumn{4}{|l|}{ Morbidity } \\
\hline Diarrhea incidence of child (in last 30 days) & Yes & Yes & Yes \\
\hline Improved sanitation facilities & Yes & Yes & Yes \\
\hline \multicolumn{4}{|l|}{ Biological factors } \\
\hline Sex of child & Yes & Yes & Yes \\
\hline \multicolumn{4}{|l|}{$\underline{\text { Interaction and psychosocial stimuli }}$} \\
\hline If the mother helps the child with its homework & No & Yes & Yes \\
\hline Time the mother spends on giving physical care to the child & No & Yes & Yes \\
\hline Parental participation in parent-teacher meetings & No & Yes & Yes \\
\hline Father lives in household & No & Yes & Yes \\
\hline \multicolumn{4}{|l|}{ Test administration } \\
\hline Interviewer ID & No & Yes & Yes (No for attendance) \\
\hline \multicolumn{4}{|l|}{ Quality of schooling } \\
\hline Total school enrollment & Yes* & Yes* & Yes \\
\hline Number of children in second grade & Yes* & Yes* & Yes \\
\hline Distance to school & Yes* & Yes* & Yes \\
\hline Student teacher ratio (school level) & Yes* & Yes* & Yes \\
\hline If child drops out after fifth grade & Only for wave III & Only for wave III & Only for wave III \\
\hline If child attends private school only after fifth grade & Only for wave III & Only for wave III & Only for wave III \\
\hline
\end{tabular}

Note: If not other specified the baseline value of the variable is used as a covariate in the analysis for the data ollection wave II and III outcomes. * indicates a change to the strategy by Krämer et al. (2018), either inclusion or exclusion.

Source: Adapted from Krämer et al. (2018). 


\section{Internal Validity Threats}

\subsection{Attrition}

\subsubsection{Illustration of Attrition over Time Using the Health Outcomes Sample}

Exemplary, Figure C.3 illustrates the attrition at different points in time for the health outcomes sample. The original randomized sample comprises of 107 schools and 1,990 children. We have not collected data for the health outcome variables for all of these. We have missed 86 children at the wave I. The analytical wave I sample consists of 1,904 children.

Figure C.3: Flowchart of School and Child Attrition over Time for Health Outcomes
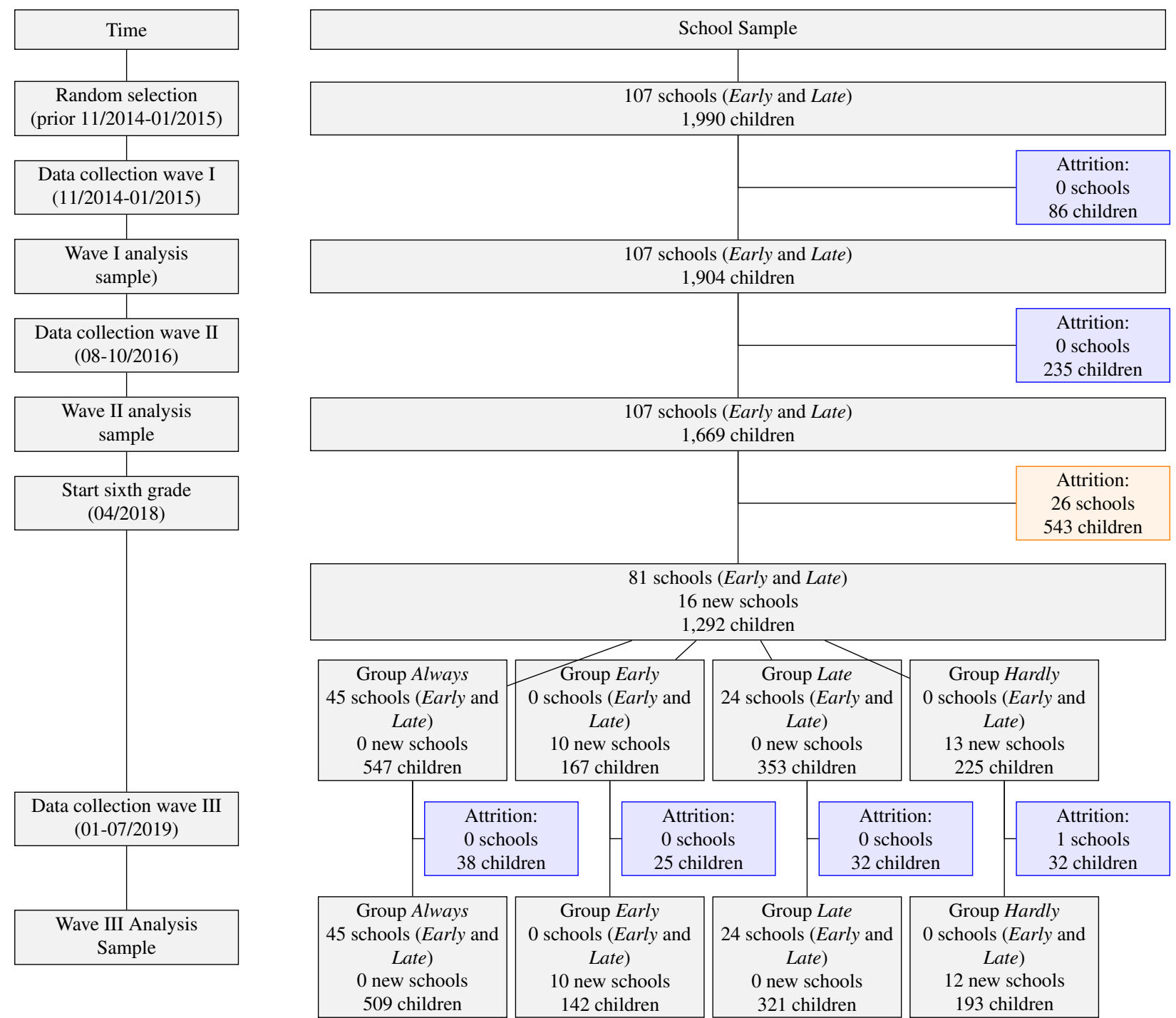

Notes: Blue shaded boxes indicate attrition due to missing outcome variables. Orange shaded boxes indicate attrition due to missing or contradictory information about attended schools or attendance of private and public school at the same time.

Source: Own data.

At wave II, the information for health outcomes of 235 children is missing. The analytical wave 
II sample reduces to 1,669 children. We have data for the children for both wave I and wave II. After completion of the fifth grade, children at PS are forced to go to another school to attend the next highest grade. This and the critical age of the child increase the attrition rate by large. We can not determine the attended school of 543 children. 26 PS are no longer visited by the children in our sample. Due to the change in school, we are left with 1,292 children and 81 sample schools for the wave III data collection. However, the school change also introduces 16 new MS that sample children attend after fifth grade.

After the school change, we are able to show the different exposure groups of our study. Group Always consists of 45 sample schools and 547 children, group Early of 10 new schools and 167 children, group Late of 24 sample schools and 353 children, and group Hardly of 13 new schools and 225 children. Group Early and group Hardly also contain children that have dropped out of school or only attend private schools.

At wave III the information for health outcomes is missing for 38 children in group Always. We are left with observations from 509 children. 25 children are lost in group Early and 32 children each in group Late and Hardly. There are now 142 children in group Early, 321 children in group Late, and 193 children in group Hardly.

\subsubsection{Examining Correlation between Attrition and DFS Exposure}

Further, we assess the attrition rate and the correlation between attrition and DFS exposure. We report statistically significant differences at least at the 10 percent level. The attrition rate is higher at wave III compared to the wave II for all considered outcome samples using wave I data (column 2, 3, 5, 6, 8, and 9 in Table C.5). For the sample considering health outcomes the attrition varies between 16.7 percent in group Always to 29.4 percent in group Early (column 2). Groups Early and Hardly have larger attrition rates than groups Always and Late. This holds also for cognition and education samples and for the attendance outcome sample at wave III using wave I data. We have greatest attrition for the sample of the attendance outcome, 59.2 percent in group Early at wave III (column 9). At wave II there are no significant differences in attrition of the different exposure groups for cognition and education and attendance outcomes at the 10 percent significance level (column 2, 5, and 8). At wave III we find significant differences in attrition for all samples using wave I or wave II data.

In column 4, 7, and 10 we assess the additional attrition from wave II to wave III data. The overall attrition rate is lower between wave II and wave III than between wave I and wave II 


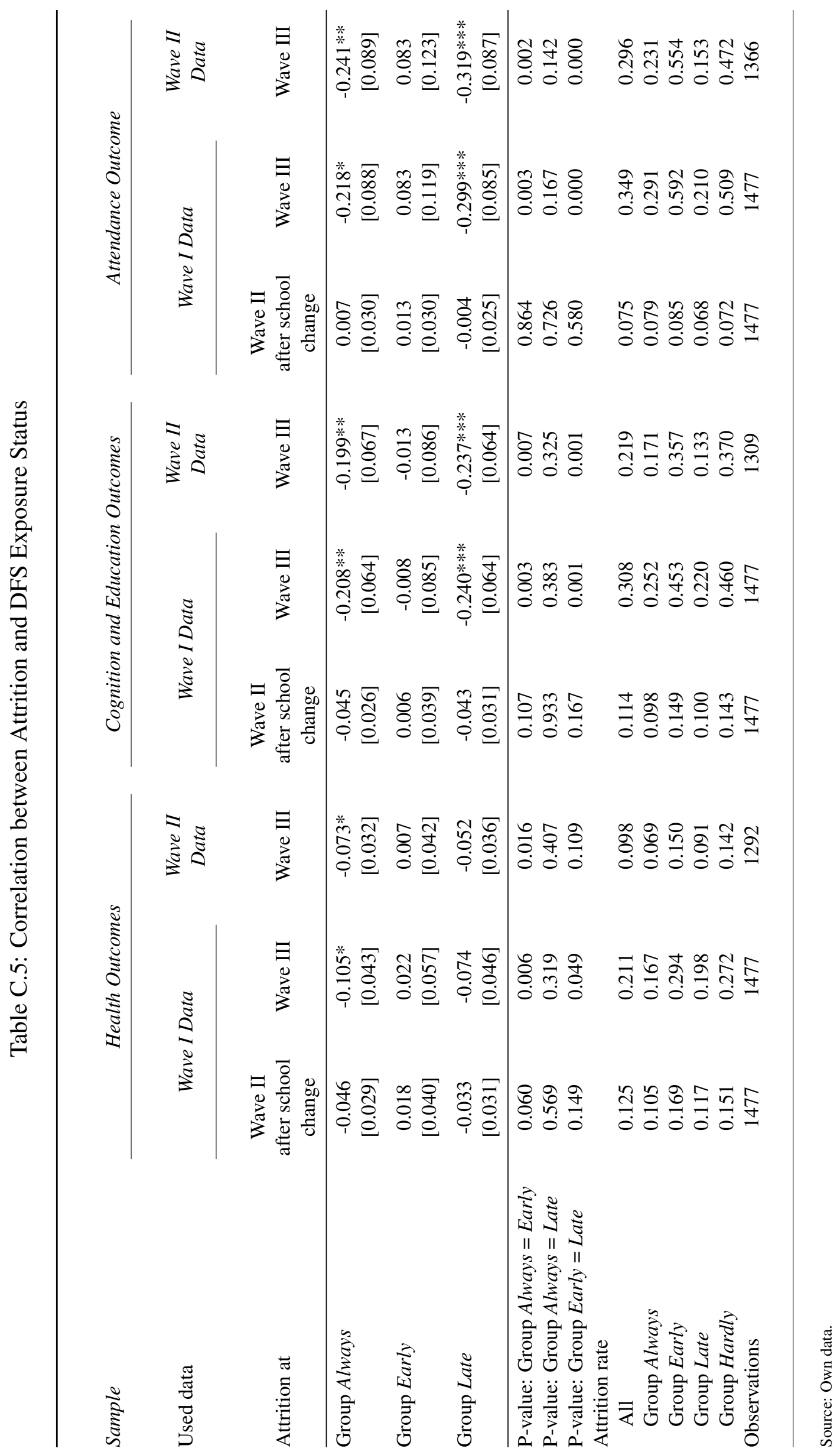


for the health outcomes sample, 9.8 percent compared to 12.5 percent. For the cognition and attendance sample the overall attrition rate is higher for the time period between wave II and wave III than between wave I and wave II.

There are significant differences between the exposure groups related to attrition. For the health outcome samples the difference between group Always and Hardly, Always and Early, and Early and Late are statistically significant at the 5 percent significance level using wave I data. The difference between group Early and Late loses its significance when only considering the attrition between wave II and wave III. For the other samples at wave III there are statistically significant difference at least at the 10 percent significance level between group Always and Early, Always and Hardly, Early and Late, and Late and Hardly. This pattern reveals that attrition seems to be different in group Early and Hardly that transition out of the school with DFS supply due to school change compared to group Always and Late that mainly remain at schools with DFS supply. Overall, attrition of participants is correlated with the exposure group and so threatens internal validity.

\subsubsection{Balancing Tables by Attrition Status Using wave I Data}




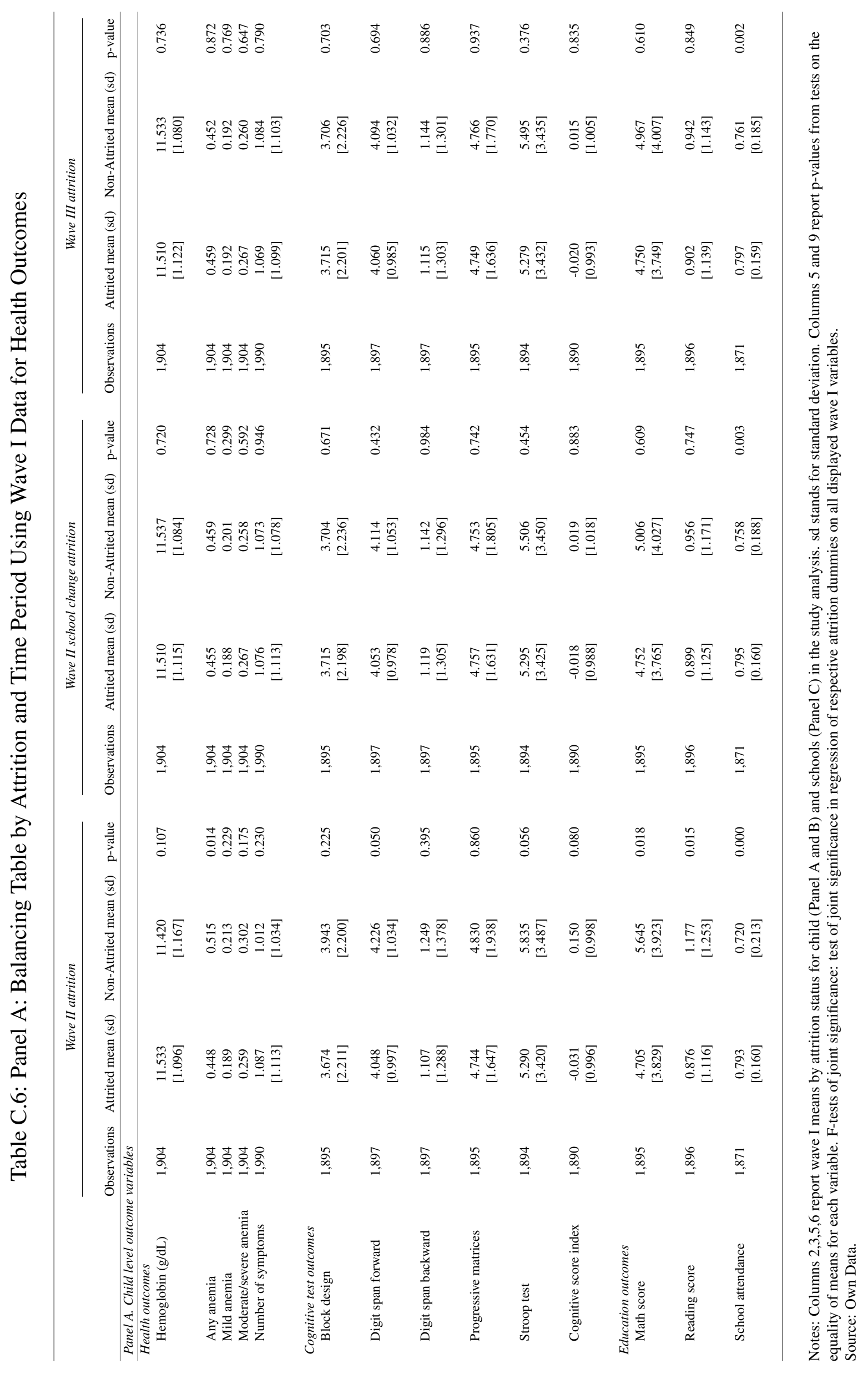




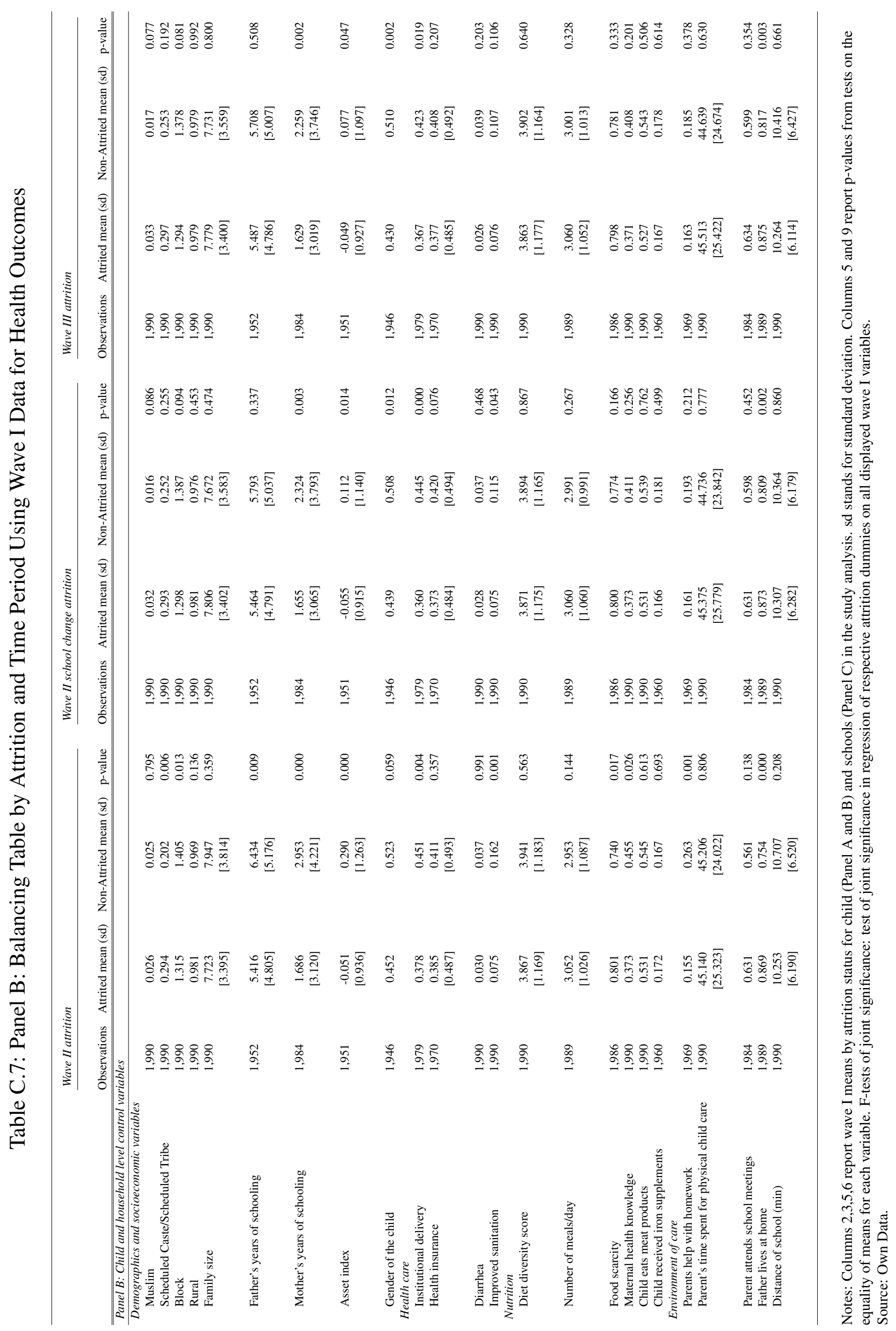




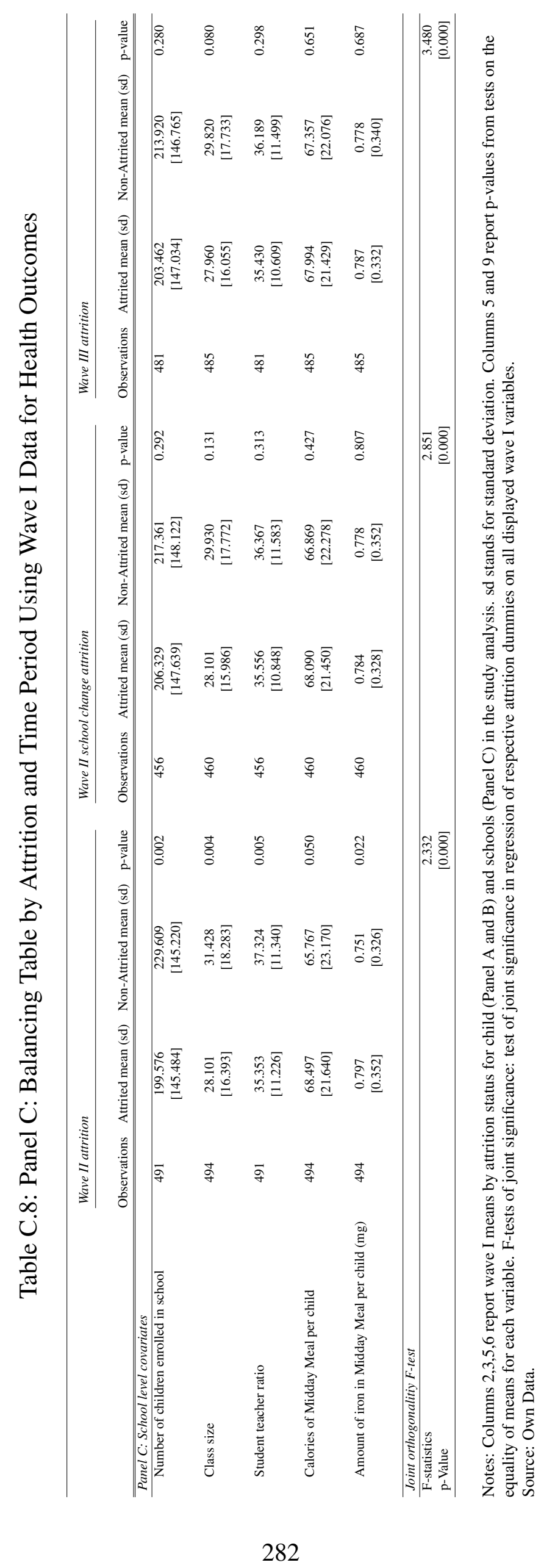




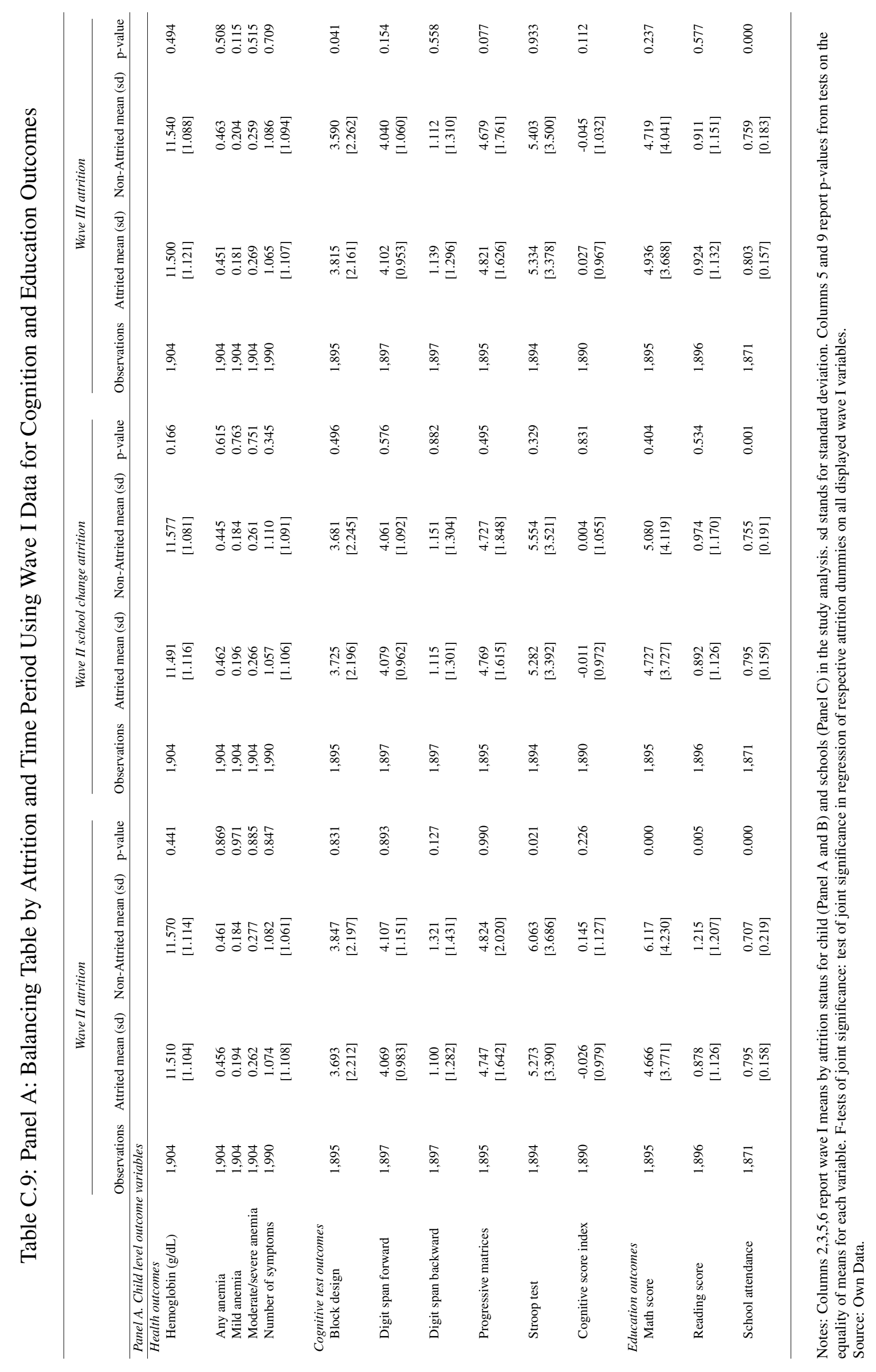




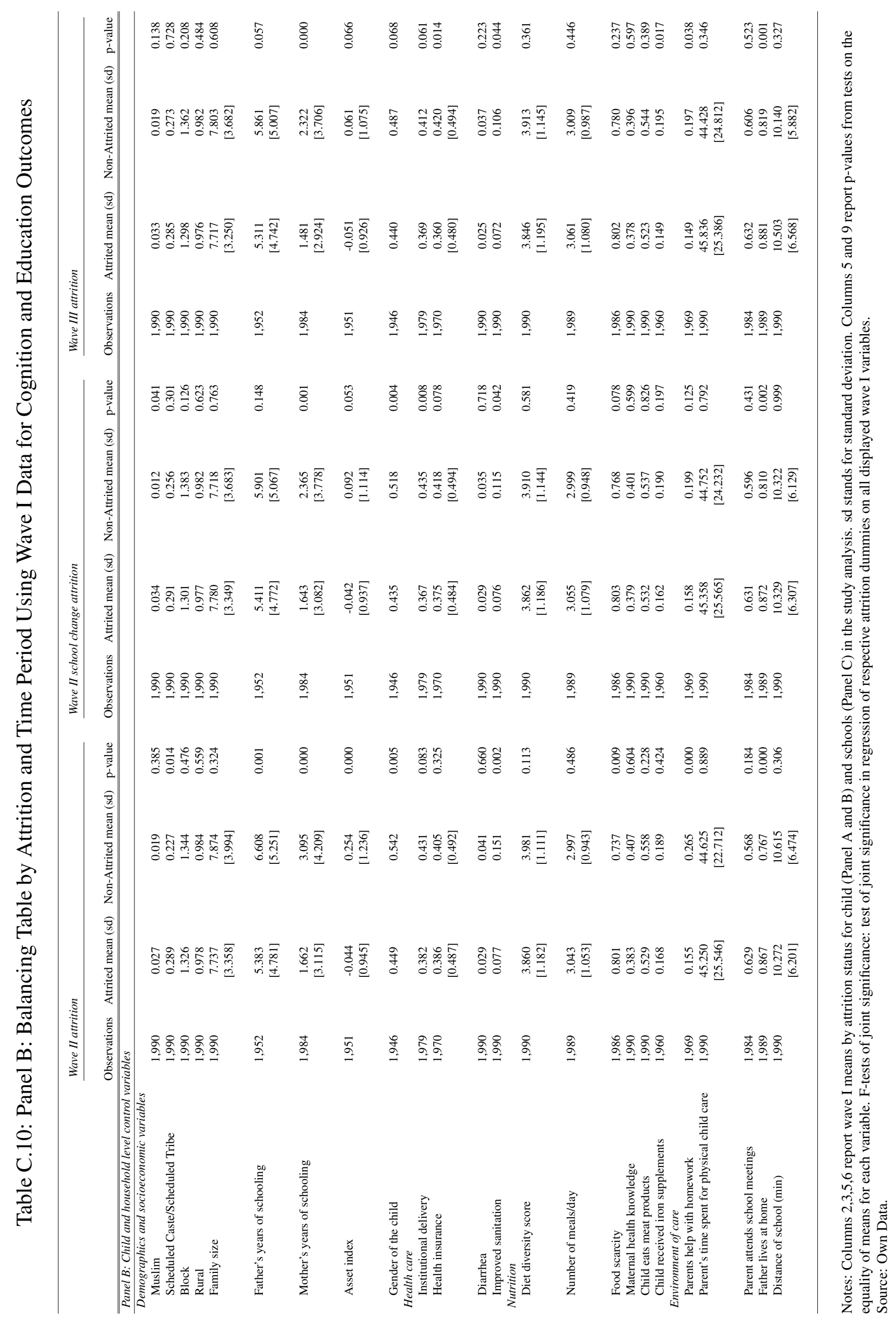




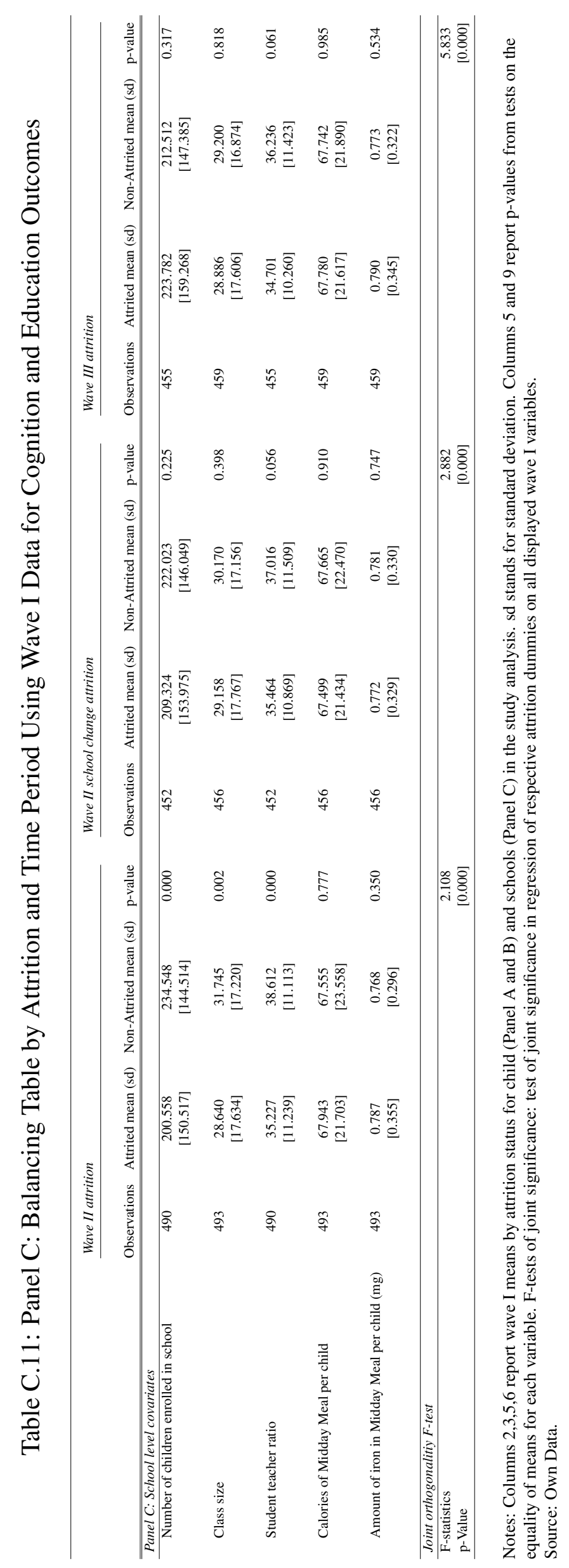




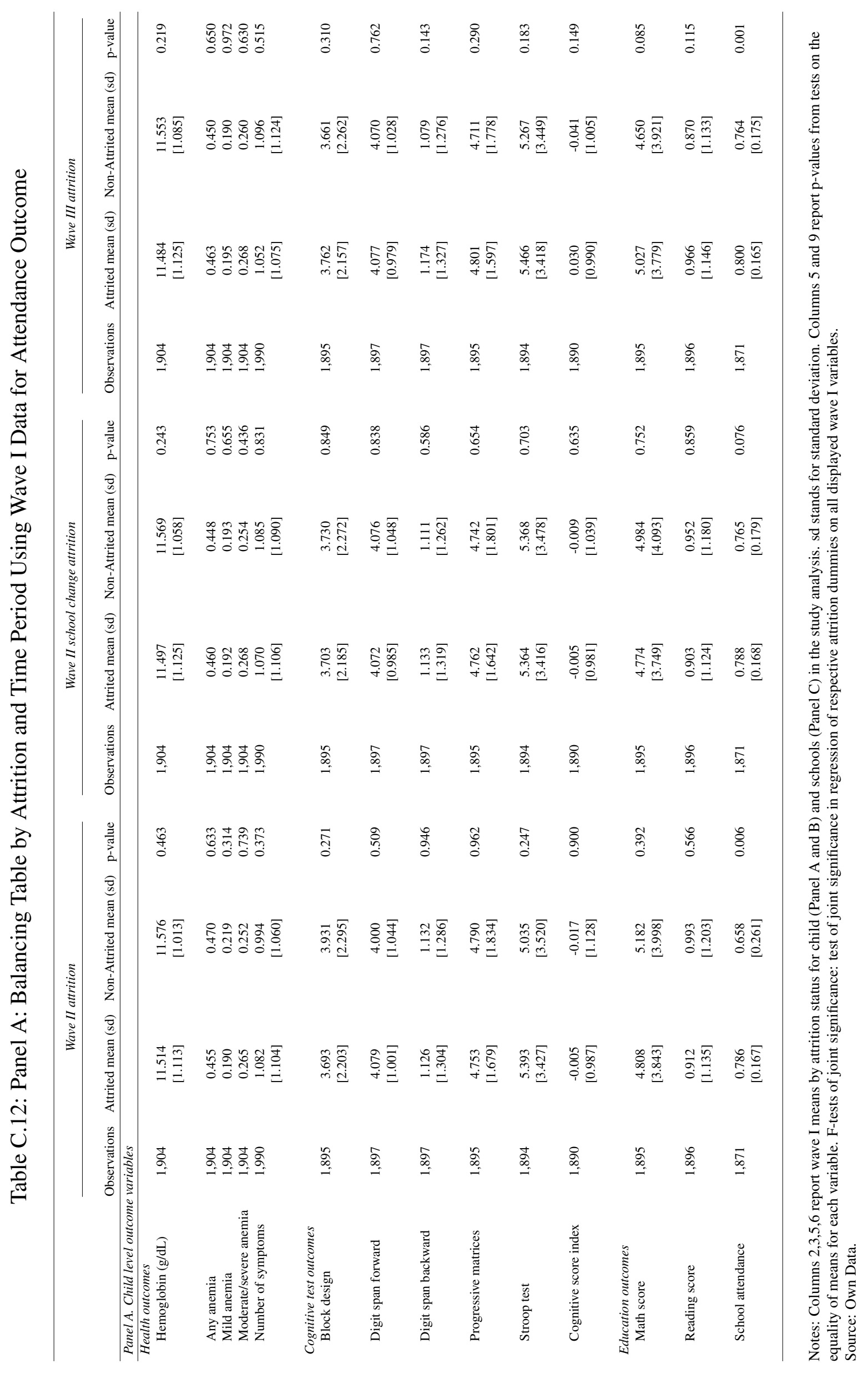




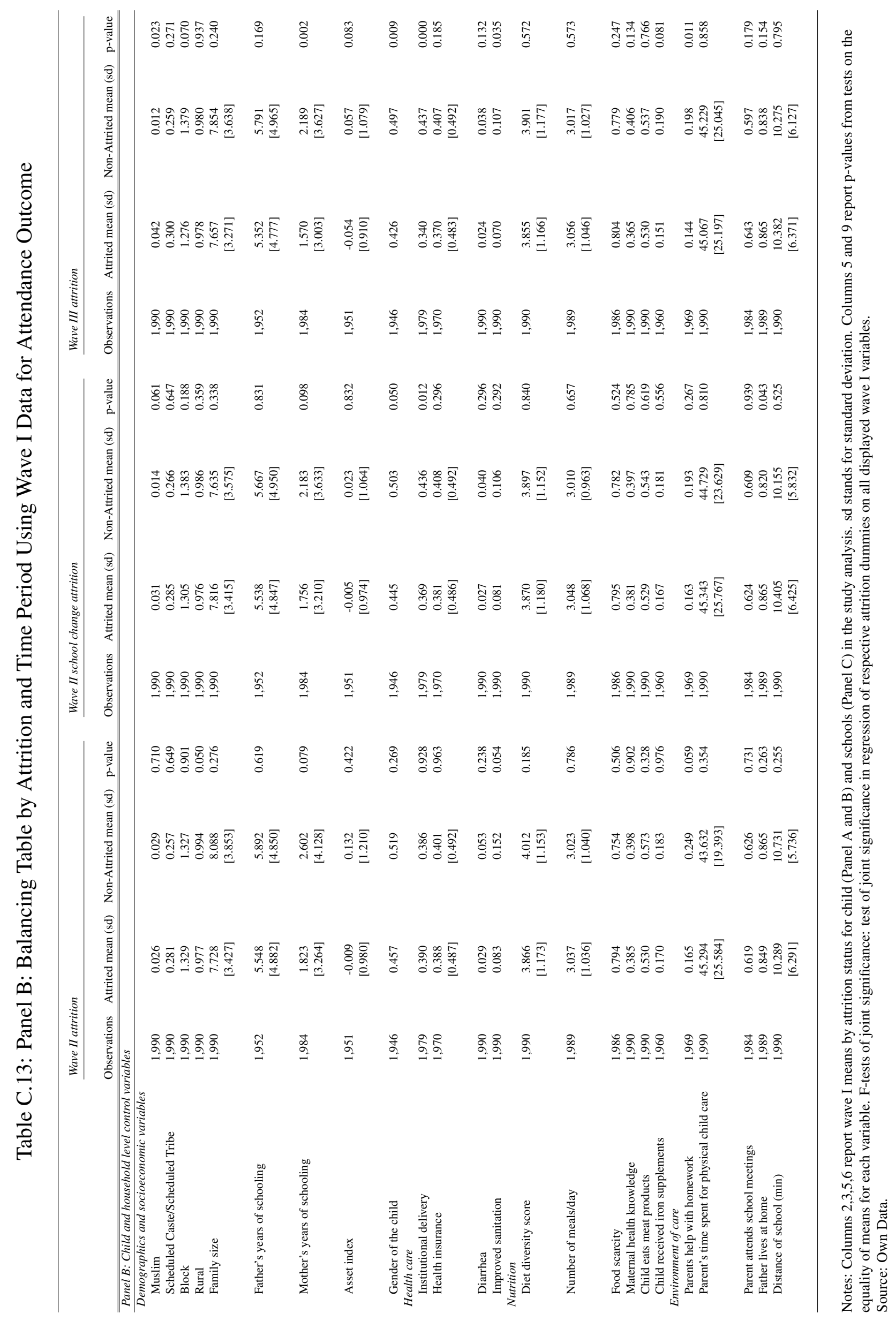




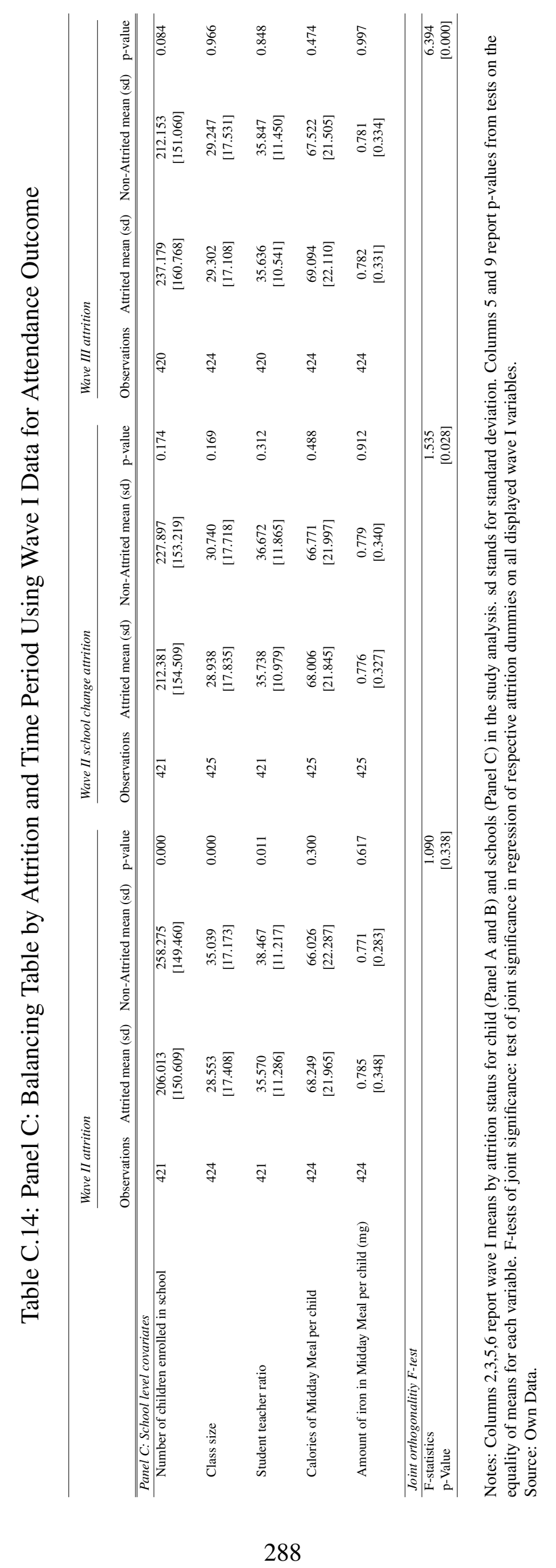


3.1.4 Balancing Tables by Attrition Status Using Data of Previous Time Period Data 


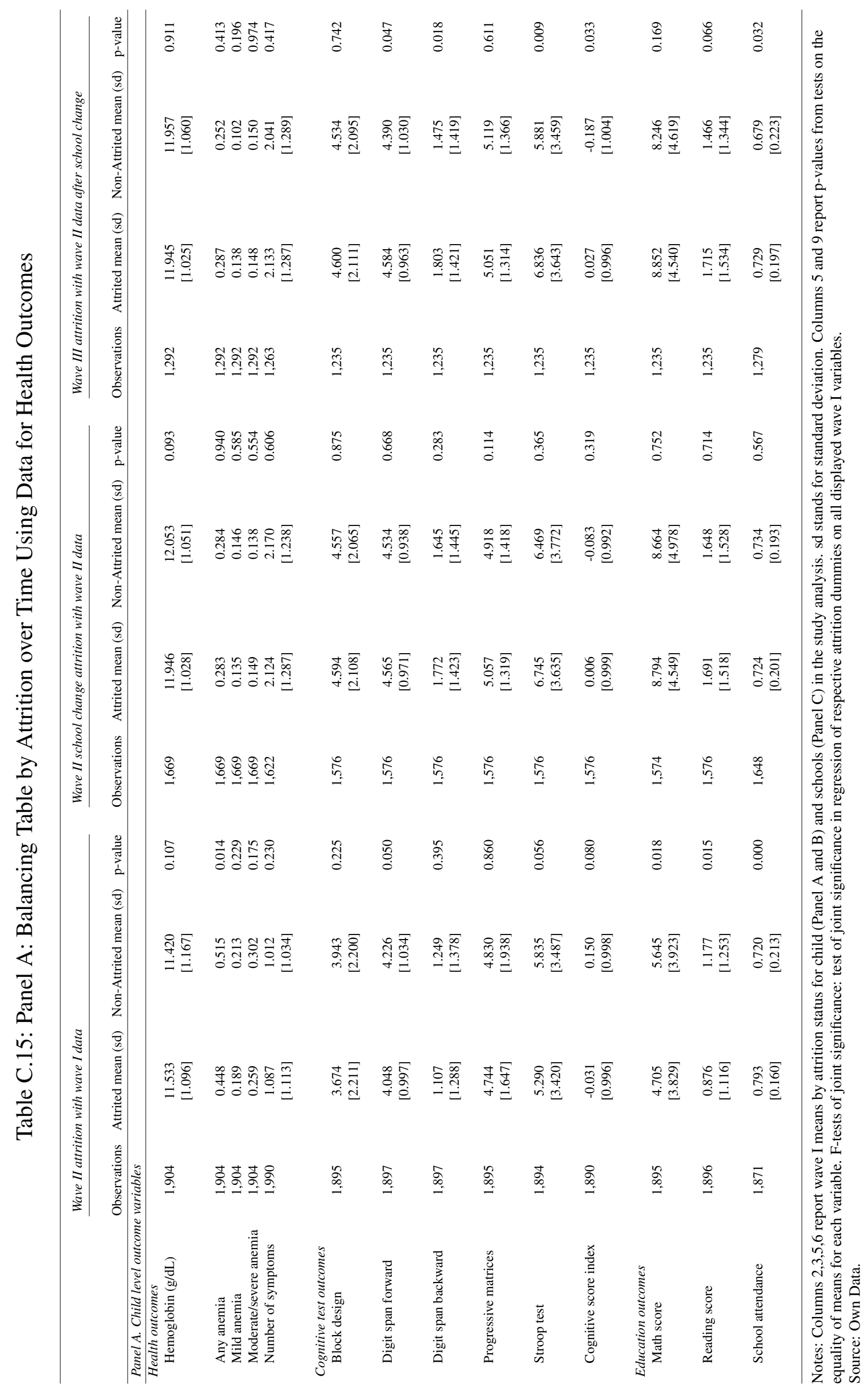




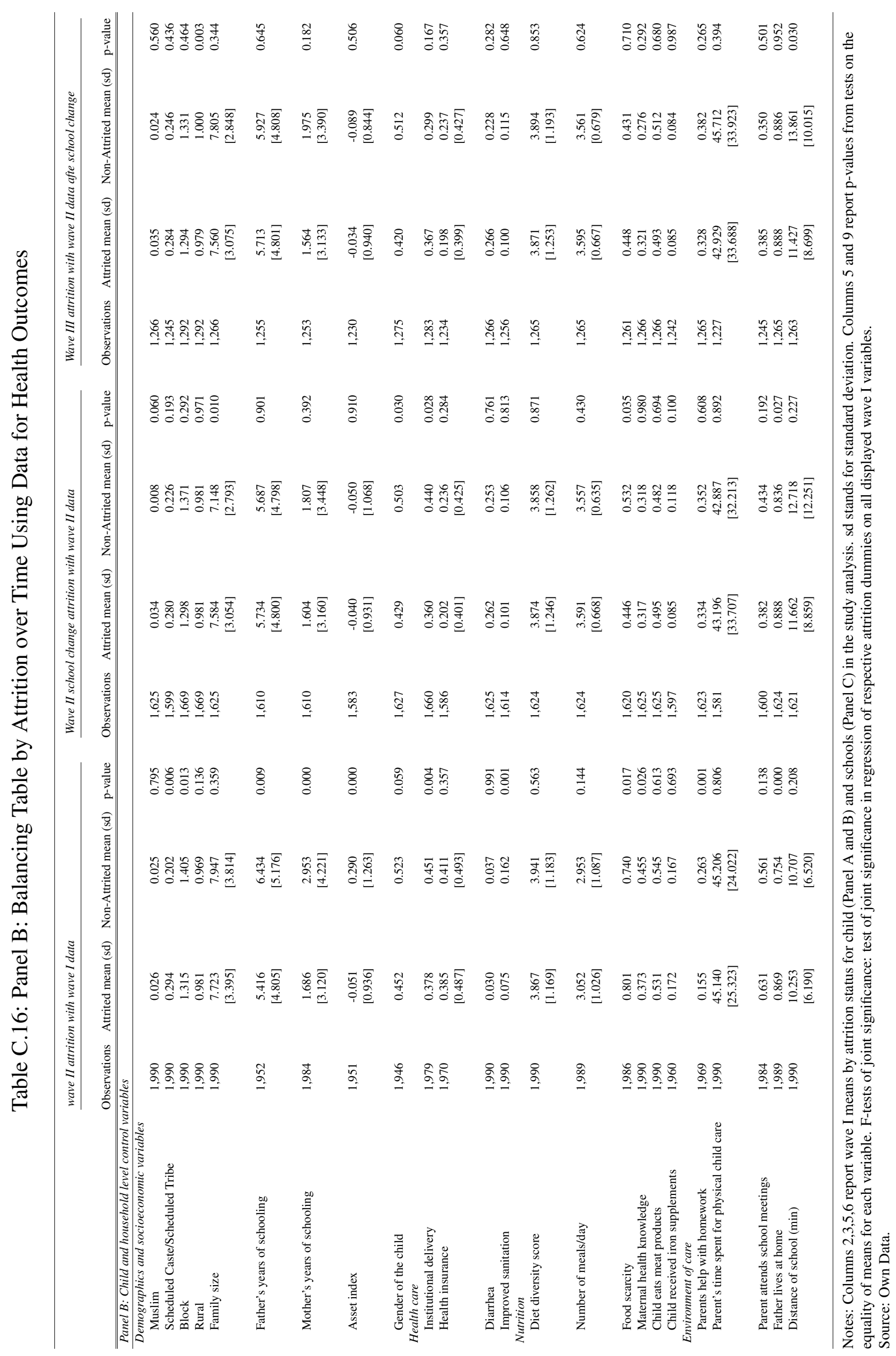




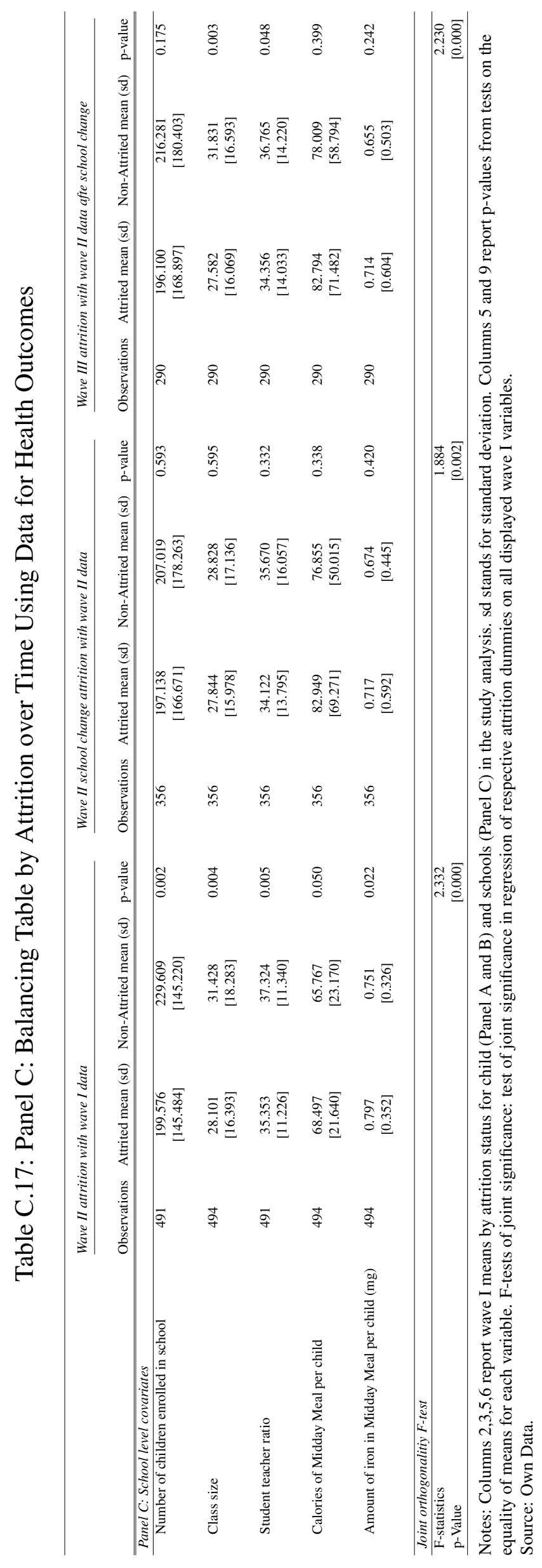




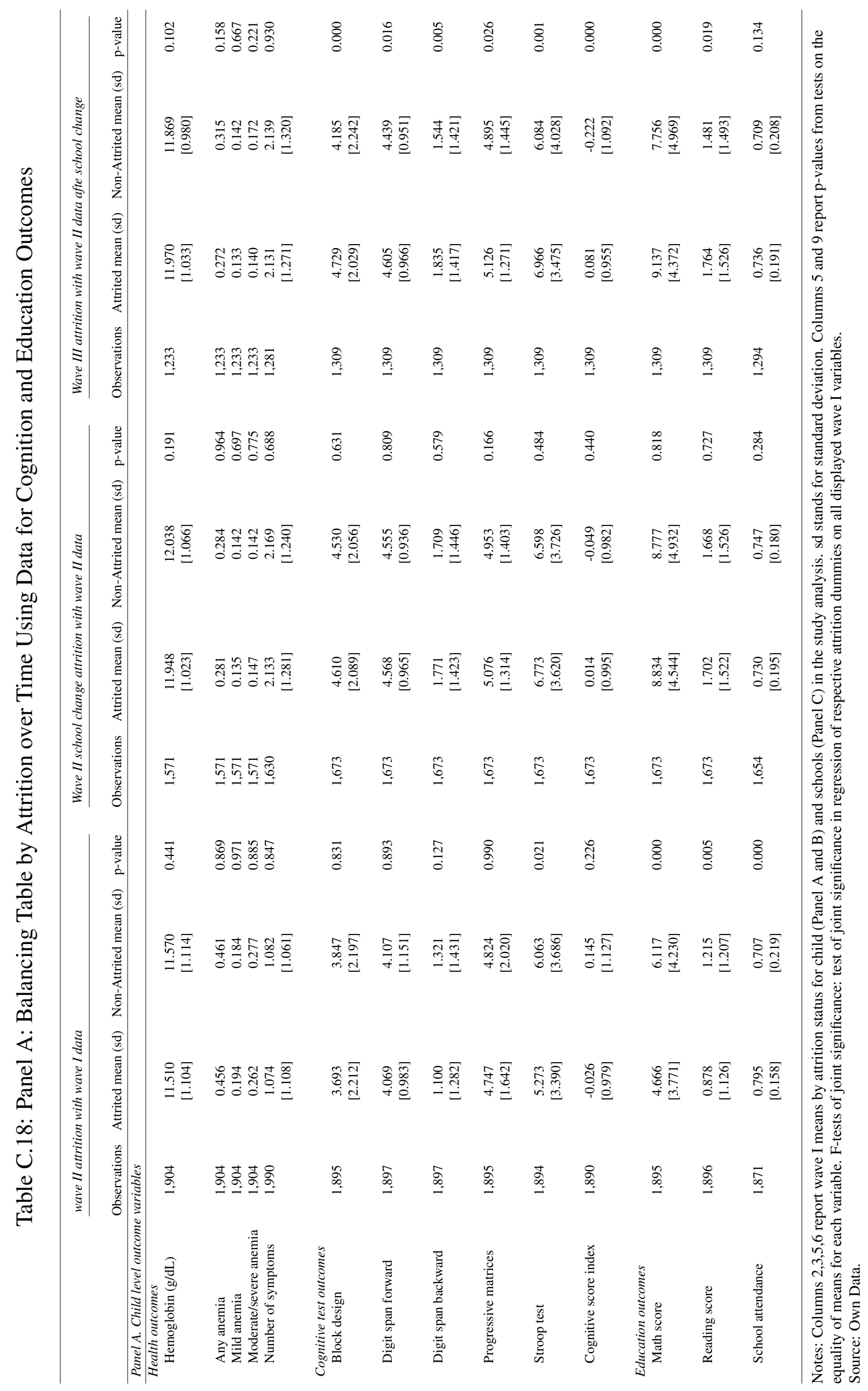




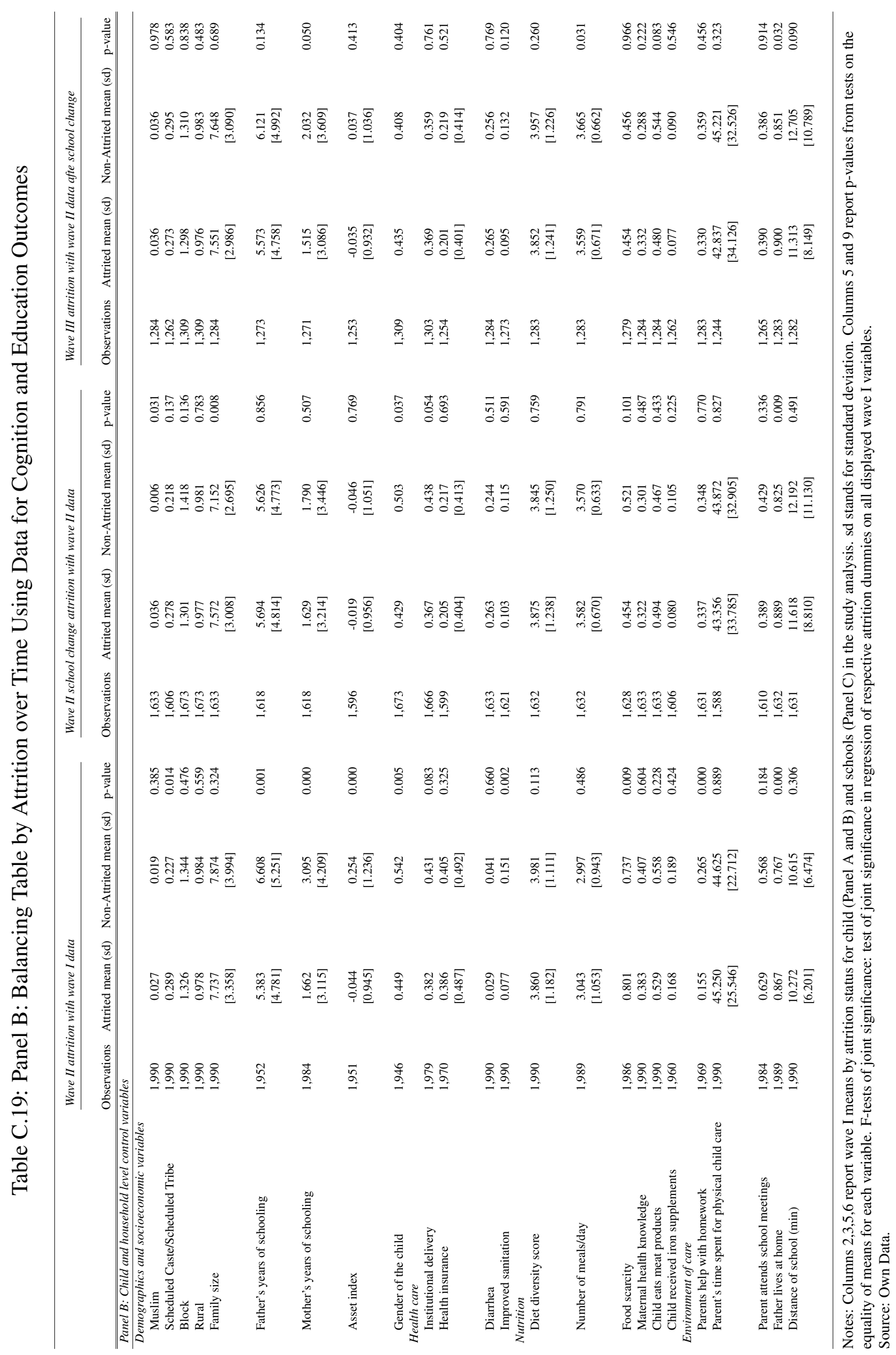




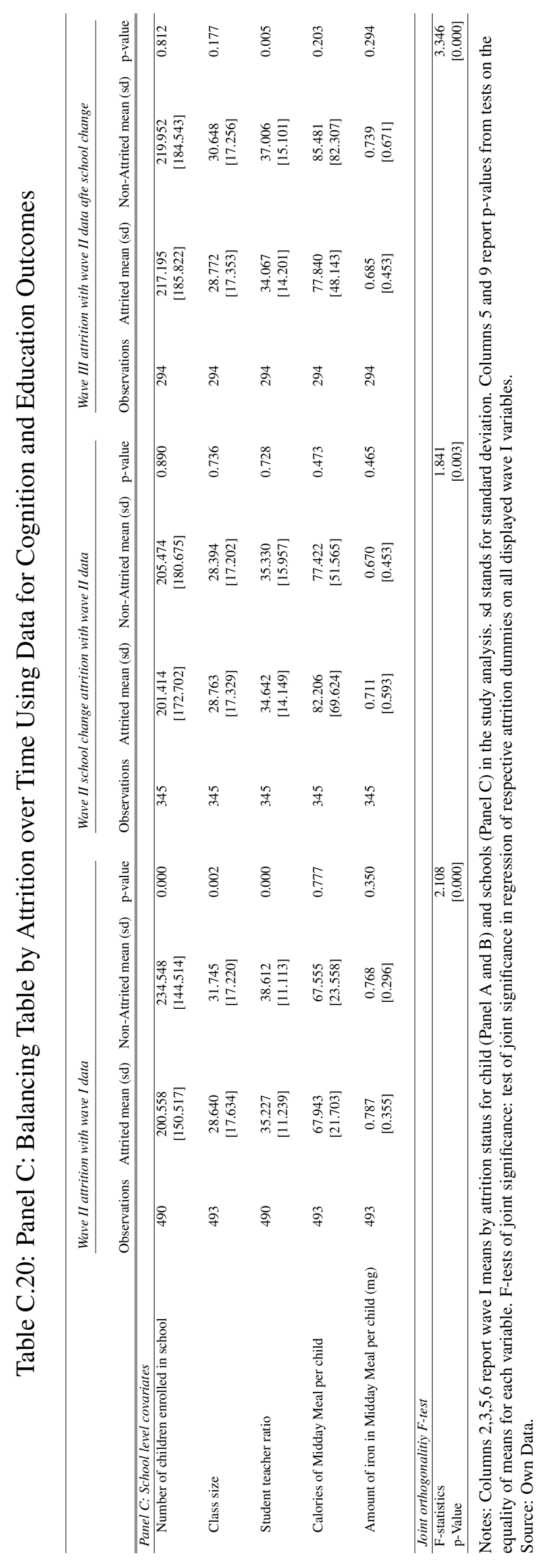




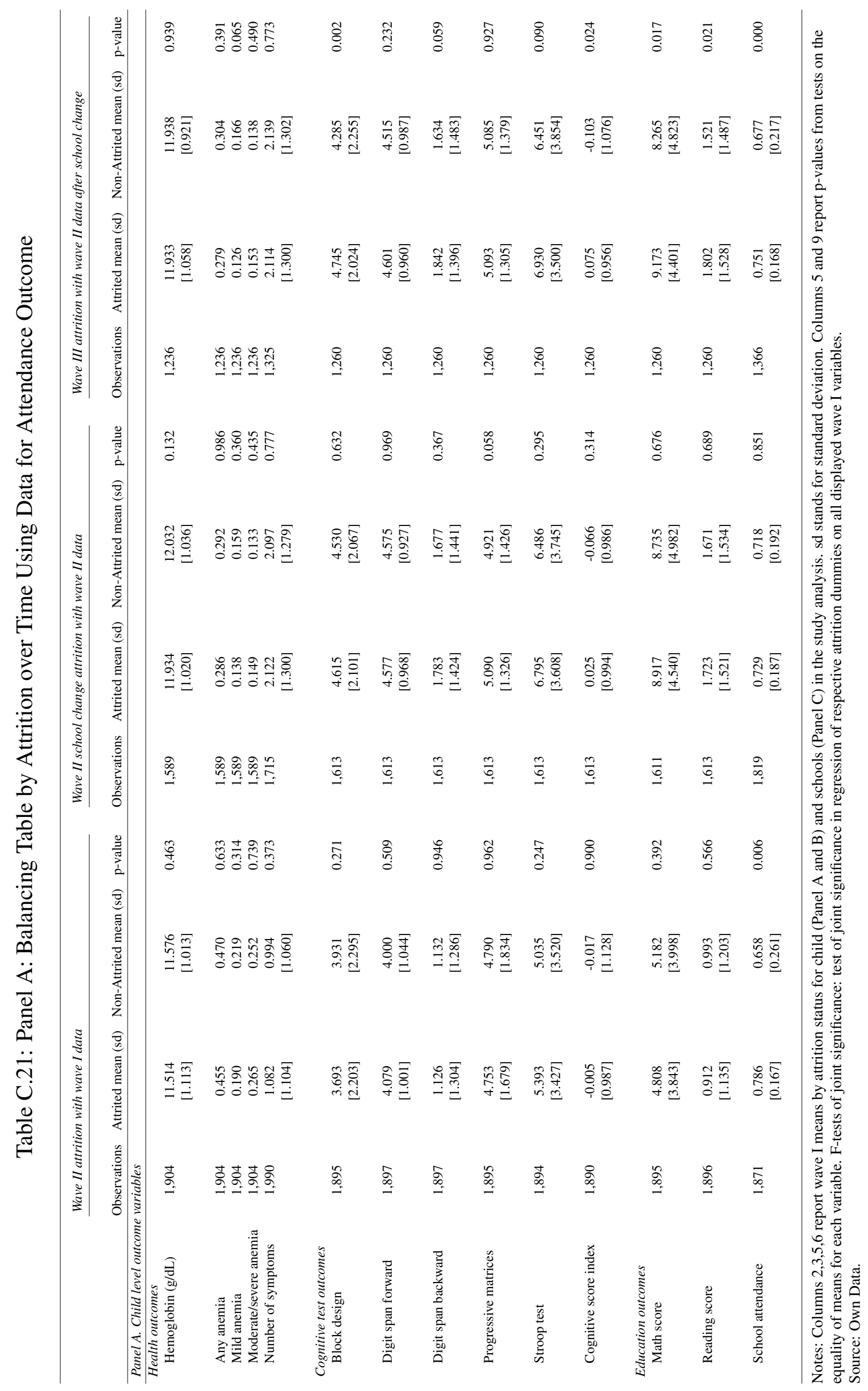




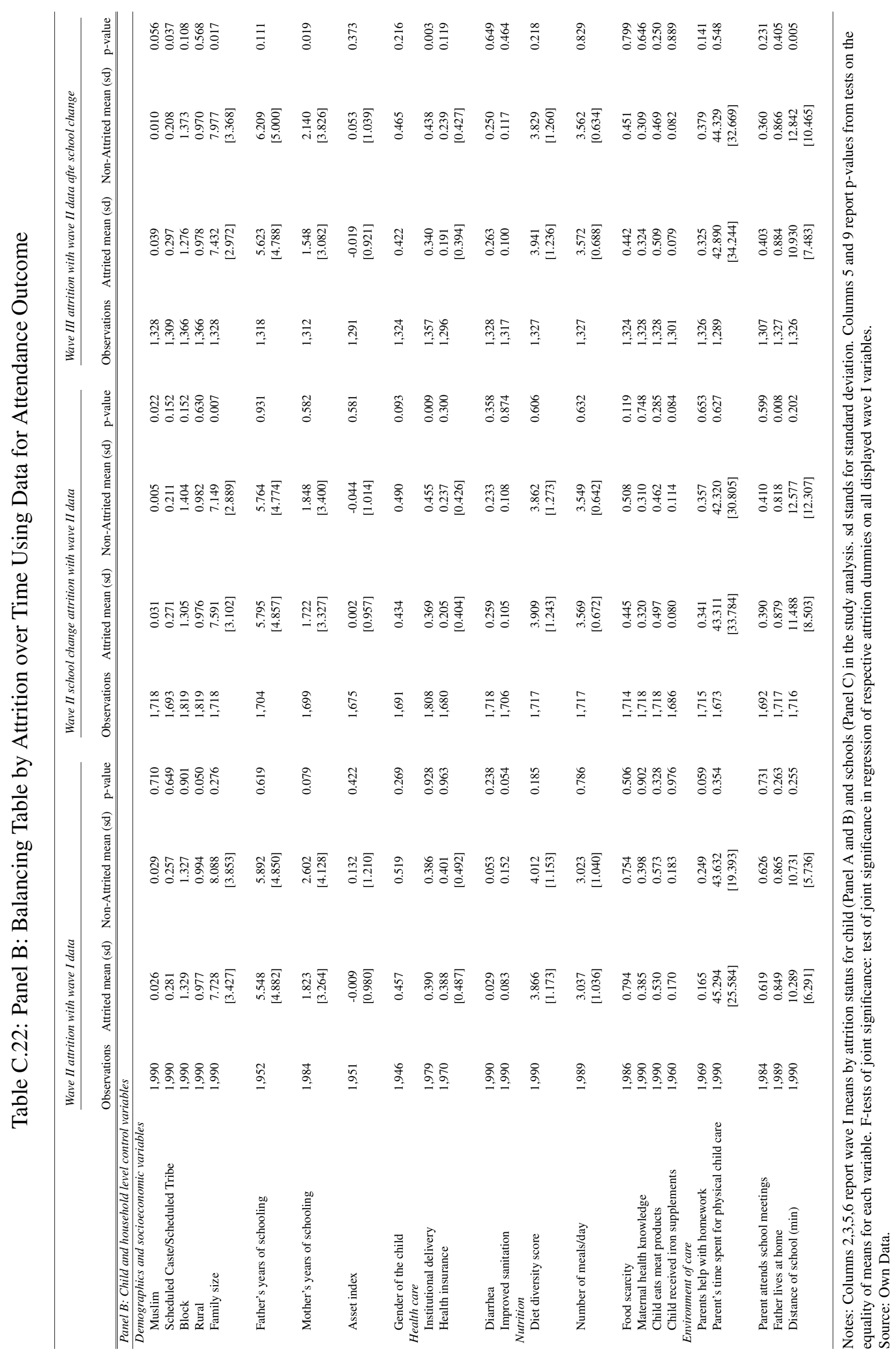




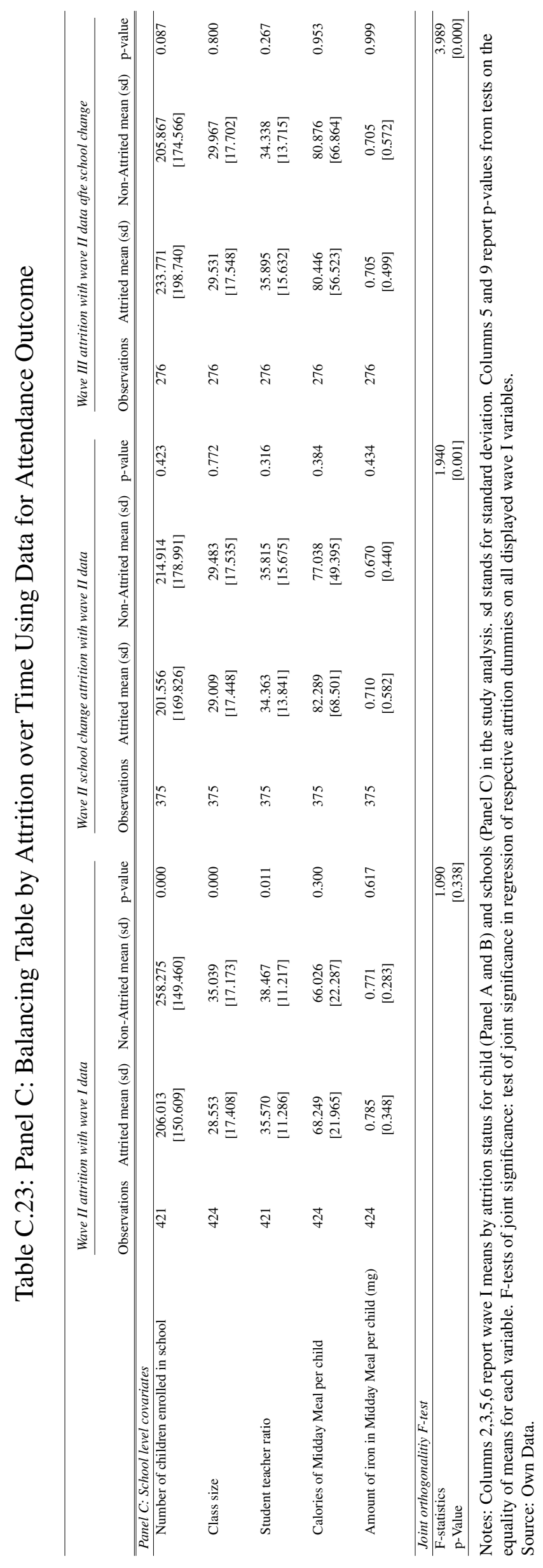




\subsubsection{Balancing Tables of Attrited by Exposure Group}

wave II after school change using wave I data 
Table C.24: Balancing Table of Attrited Members of Exposure Group Using Wave I Data for Health Outcomes

\begin{tabular}{|c|c|c|c|c|c|c|c|c|c|c|c|}
\hline & \multirow[b]{2}{*}{ Observations } & \multicolumn{4}{|c|}{ Means [Standard Deviations] } & \multicolumn{6}{|c|}{$p$-value of difference } \\
\hline & & Group Always & Early & Late & Hardly & Always-Early & Always-Late & Always-Hardly & Early-Late & Early-Hardly & Late-Hardly \\
\hline \multicolumn{12}{|l|}{ Panel A. Child level outcome variables } \\
\hline $\begin{array}{l}\text { Health outcomes } \\
\text { Hemoglobin }(\mathrm{g} / \mathrm{dL})\end{array}$ & 612 & $\begin{array}{l}11.334 \\
{[1.107]}\end{array}$ & $\begin{array}{l}11.337 \\
{[1.653]}\end{array}$ & $\begin{array}{l}11.584 \\
{[0.816]}\end{array}$ & $\begin{array}{l}11.528 \\
{[0.915]}\end{array}$ & 0.993 & 0.224 & 0.413 & 0.484 & 0.608 & 0.788 \\
\hline Any anemia & 612 & 0.553 & 0.519 & 0.500 & 0.517 & 0.778 & 0.637 & 0.753 & 0.892 & 0.993 & 0.893 \\
\hline Mild anemia & 612 & 0.213 & 0.222 & 0.342 & 0.276 & 0.927 & 0.226 & 0.551 & 0.308 & 0.646 & 0.580 \\
\hline Moderate/severe anemia & 612 & 0.340 & 0.296 & 0.158 & 0.241 & 0.717 & 0.076 & 0.375 & 0.230 & 0.658 & 0.420 \\
\hline Number of symptoms & 698 & $\begin{array}{c}1.016 \\
{[1.000]}\end{array}$ & $\begin{array}{c}0.853 \\
{[0.925]}\end{array}$ & $\begin{array}{c}1.021 \\
{[1.132]}\end{array}$ & $\begin{array}{c}1.075 \\
{[1.118]}\end{array}$ & 0.437 & 0.980 & 0.795 & 0.454 & 0.333 & 0.825 \\
\hline \multicolumn{12}{|l|}{ Cognitive test outcomes } \\
\hline Block design & 632 & $\begin{array}{c}3.870 \\
{[2.120]}\end{array}$ & $\begin{array}{c}2.929 \\
{[2.356]}\end{array}$ & $\begin{array}{c}3.762 \\
{[2.128]}\end{array}$ & $\begin{array}{c}3.568 \\
{[2.243]}\end{array}$ & 0.060 & 0.815 & 0.515 & 0.146 & 0.262 & 0.720 \\
\hline Digit span forward & 632 & $\begin{array}{c}4.000 \\
{[1.099]}\end{array}$ & $\begin{array}{c}4.357 \\
{[0.989]}\end{array}$ & $\begin{array}{c}4.286 \\
{[0.891]}\end{array}$ & $\begin{array}{c}3.973 \\
{[1.118]}\end{array}$ & 0.133 & 0.222 & 0.903 & 0.777 & 0.119 & 0.197 \\
\hline Digit span backward & 632 & $\begin{array}{c}1.222 \\
{[1.423]}\end{array}$ & $\begin{array}{c}1.143 \\
{[1.297]}\end{array}$ & $\begin{array}{c}1.452 \\
{[1.418]}\end{array}$ & $\begin{array}{c}0.865 \\
{[1.251]}\end{array}$ & 0.814 & 0.476 & 0.222 & 0.392 & 0.403 & 0.068 \\
\hline Progressive matrices & 631 & $\begin{array}{c}4.593 \\
{[1.879]}\end{array}$ & $\begin{array}{c}4.429 \\
{[2.332]}\end{array}$ & $\begin{array}{c}5.143 \\
{[1.475]}\end{array}$ & $\begin{array}{c}4.622 \\
{[2.046]}\end{array}$ & 0.700 & 0.164 & 0.950 & 0.111 & 0.702 & 0.277 \\
\hline Stroop test & 631 & $\begin{array}{c}5.343 \\
{[3.298]}\end{array}$ & $\begin{array}{c}5.554 \\
{[2.954]}\end{array}$ & $\begin{array}{c}5.488 \\
{[3.627]}\end{array}$ & $\begin{array}{c}5.608 \\
{[3.852]}\end{array}$ & 0.752 & 0.846 & 0.699 & 0.936 & 0.943 & 0.885 \\
\hline Cognitive score index & 630 & $\begin{array}{l}-0.011 \\
{[0.962]}\end{array}$ & $\begin{array}{l}-0.065 \\
{[0.903]}\end{array}$ & $\begin{array}{c}0.210 \\
{[1.084]}\end{array}$ & $\begin{array}{l}-0.116 \\
{[1.150]}\end{array}$ & 0.798 & 0.372 & 0.628 & 0.304 & 0.831 & 0.230 \\
\hline \multicolumn{12}{|l|}{ Education outcomes } \\
\hline Math score & 631 & $\begin{array}{l}4.556 \\
{[3.606]}\end{array}$ & $\begin{array}{c}4.714 \\
{[4.108]}\end{array}$ & $\begin{array}{c}5.619 \\
{[3.800]}\end{array}$ & $\begin{array}{c}5.216 \\
{[3.823]}\end{array}$ & 0.865 & 0.195 & 0.403 & 0.384 & 0.621 & 0.655 \\
\hline Reading score & 632 & $\begin{array}{c}0.870 \\
{[1.029]}\end{array}$ & $\begin{array}{c}0.750 \\
{[1.041]}\end{array}$ & $\begin{array}{c}1.095 \\
{[1.144]}\end{array}$ & $\begin{array}{c}0.811 \\
{[1.076]}\end{array}$ & 0.643 & 0.318 & 0.788 & 0.235 & 0.832 & 0.266 \\
\hline School attendance & 639 & $\begin{array}{c}0.740 \\
{[0.223]}\end{array}$ & $\begin{array}{c}0.678 \\
{[0.248]}\end{array}$ & $\begin{array}{c}0.723 \\
{[0.220]} \\
\end{array}$ & $\begin{array}{c}0.724 \\
{[0.205]} \\
\end{array}$ & 0.288 & 0.738 & 0.749 & 0.461 & 0.433 & 0.978 \\
\hline \multirow{2}{*}{\multicolumn{12}{|c|}{$\begin{array}{l}\text { Panel B: Child and household level control variables } \\
\text { Demographics and socioeconomic variables }\end{array}$}} \\
\hline & & & & & & & & & & & \\
\hline Muslim & 698 & 0.031 & 0.000 & 0.064 & 0.025 & 0.135 & 0.527 & 0.848 & 0.180 & 0.325 & 0.469 \\
\hline Scheduled Caste/Scheduled Tribe & 698 & 0.266 & 0.206 & 0.149 & 0.200 & 0.562 & 0.182 & 0.479 & 0.551 & 0.953 & 0.543 \\
\hline Block & 698 & 1.422 & 1.500 & 1.234 & 1.300 & 0.609 & 0.281 & 0.400 & 0.107 & 0.132 & 0.671 \\
\hline Rural & 698 & 0.969 & 0.912 & 0.979 & 0.950 & 0.301 & 0.744 & 0.654 & 0.224 & 0.535 & 0.488 \\
\hline Family size & 698 & $\begin{array}{c}8.359 \\
{[4.025]}\end{array}$ & $\begin{array}{c}8.618 \\
{[3.869]}\end{array}$ & $\begin{array}{c}8.298 \\
{[4.308]}\end{array}$ & $\begin{array}{c}7.200 \\
{[2.719]}\end{array}$ & 0.756 & 0.946 & 0.097 & 0.745 & 0.076 & 0.207 \\
\hline Father's years of schooling & 677 & $\begin{array}{c}6.750 \\
{[4.778]}\end{array}$ & $\begin{array}{c}7.367 \\
{[5.592]}\end{array}$ & $\begin{array}{c}4.745 \\
{[5.024]}\end{array}$ & $\begin{array}{c}5.579 \\
{[5.218]}\end{array}$ & 0.625 & 0.086 & 0.323 & 0.041 & 0.167 & 0.478 \\
\hline Mother's years of schooling & 697 & $\begin{array}{c}2.500 \\
{[3.809]}\end{array}$ & $\begin{array}{c}3.441 \\
{[5.064]}\end{array}$ & $\begin{array}{c}2.277 \\
{[4.137]}\end{array}$ & $\begin{array}{c}2.825 \\
{[4.181]}\end{array}$ & 0.396 & 0.779 & 0.702 & 0.293 & 0.589 & 0.514 \\
\hline Asset index & 684 & $\begin{array}{c}0.142 \\
{[1.038]}\end{array}$ & $\begin{array}{c}0.486 \\
{[1.430]}\end{array}$ & $\begin{array}{c}0.287 \\
{[1.355]}\end{array}$ & $\begin{array}{c}0.407 \\
{[1.428]}\end{array}$ & 0.252 & 0.561 & 0.329 & 0.547 & 0.820 & 0.693 \\
\hline $\begin{array}{l}\text { Gender of the child } \\
\text { Health care }\end{array}$ & 659 & 0.429 & 0.531 & 0.478 & 0.649 & 0.364 & 0.579 & 0.030 & 0.656 & 0.355 & 0.113 \\
\hline Institutional delivery & 696 & 0.406 & 0.588 & 0.489 & 0.450 & 0.102 & 0.363 & 0.649 & 0.391 & 0.247 & 0.697 \\
\hline Health insurance & 686 & $\begin{array}{c}0.438 \\
{[0.500]}\end{array}$ & $\begin{array}{c}0.375 \\
{[0.492]}\end{array}$ & $\begin{array}{c}0.468 \\
{[0.504]}\end{array}$ & $\begin{array}{c}0.450 \\
{[0.504]}\end{array}$ & 0.601 & 0.774 & 0.915 & 0.428 & 0.555 & 0.875 \\
\hline Diarrhea & 698 & 0.047 & 0.059 & 0.021 & 0.025 & 0.804 & 0.440 & 0.536 & 0.427 & 0.487 & 0.912 \\
\hline Improved sanitation & 698 & 0.094 & 0.235 & 0.128 & 0.150 & 0.126 & 0.602 & 0.409 & 0.278 & 0.398 & 0.771 \\
\hline \multicolumn{12}{|l|}{ Nutrition } \\
\hline Diet diversity score & 698 & $\begin{array}{c}3.813 \\
{[1.125]}\end{array}$ & $\begin{array}{c}4.118 \\
{[1.094]}\end{array}$ & $\begin{array}{c}4.000 \\
{[1.285]}\end{array}$ & $\begin{array}{c}3.975 \\
{[1.291]}\end{array}$ & 0.212 & 0.378 & 0.526 & 0.646 & 0.627 & 0.926 \\
\hline Number of meals/day & 698 & $\begin{array}{c}3.125 \\
{[1.076]}\end{array}$ & $\begin{array}{c}3.176 \\
{[1.114]}\end{array}$ & $\begin{array}{c}2.660 \\
{[1.290]}\end{array}$ & $\begin{array}{l}2.750 \\
{[1.235]}\end{array}$ & 0.831 & 0.068 & 0.156 & 0.077 & 0.155 & 0.768 \\
\hline Food scarcity & 696 & 0.746 & 0.735 & 0.761 & 0.775 & 0.918 & 0.869 & 0.764 & 0.783 & 0.689 & 0.867 \\
\hline Maternal health knowledge & 698 & 0.438 & 0.500 & 0.404 & 0.425 & 0.568 & 0.696 & 0.900 & 0.408 & 0.553 & 0.845 \\
\hline Child eats meat products & 698 & 0.563 & 0.676 & 0.532 & 0.525 & 0.286 & 0.693 & 0.732 & 0.130 & 0.217 & 0.944 \\
\hline Child received iron supplements & 690 & 0.127 & 0.088 & 0.196 & 0.237 & 0.566 & 0.389 & 0.165 & 0.198 & 0.073 & 0.654 \\
\hline \multicolumn{12}{|l|}{ Environment of care } \\
\hline Parents help with homework & 685 & 0.250 & 0.147 & 0.174 & 0.225 & 0.272 & 0.387 & 0.794 & 0.749 & 0.399 & 0.555 \\
\hline Parent's time spent for physical child care & 698 & $\begin{array}{c}46.250 \\
{[24.527]}\end{array}$ & $\begin{array}{c}47.206 \\
{[23.651]}\end{array}$ & $\begin{array}{c}46.702 \\
{[22.824]}\end{array}$ & $\begin{array}{l}40.200 \\
{[18.969]}\end{array}$ & 0.854 & 0.939 & 0.172 & 0.937 & 0.158 & 0.257 \\
\hline Parent attends school meetings & 696 & 0.563 & 0.441 & 0.638 & 0.600 & 0.295 & 0.517 & 0.737 & 0.103 & 0.167 & 0.740 \\
\hline Father lives at home & 697 & 0.844 & 0.765 & 0.851 & 0.825 & 0.393 & 0.926 & 0.802 & 0.408 & 0.550 & 0.769 \\
\hline Distance of school (min) & 698 & $\begin{array}{l}11.359 \\
{[8.232]}\end{array}$ & $\begin{array}{l}10.676 \\
{[5.907]}\end{array}$ & $\begin{array}{l}12.128 \\
{[6.678]}\end{array}$ & $\begin{array}{l}10.850 \\
{[5.600]}\end{array}$ & 0.662 & 0.619 & 0.732 & 0.332 & 0.903 & 0.367 \\
\hline \multicolumn{12}{|l|}{ Panel C: School level covariates } \\
\hline Number of children enrolled in school & 272 & $\begin{array}{c}298.548 \\
{[152.913]}\end{array}$ & $\begin{array}{c}183.759 \\
{[105.657]}\end{array}$ & $\begin{array}{c}323.429 \\
{[153.558]}\end{array}$ & $\begin{array}{l}206.500 \\
{[163.307]}\end{array}$ & 0.001 & 0.568 & 0.024 & 0.001 & 0.517 & 0.011 \\
\hline Class size & 274 & $\begin{array}{c}33.258 \\
{[11.225]}\end{array}$ & $\begin{array}{l}26.345 \\
{[9.868]}\end{array}$ & $\begin{array}{c}35.333 \\
{[26.766]}\end{array}$ & $\begin{array}{c}35.844 \\
{[24.562]}\end{array}$ & 0.014 & 0.737 & 0.591 & 0.147 & 0.048 & 0.944 \\
\hline Student teacher ratio & 272 & $\begin{array}{c}37.264 \\
{[10.083]}\end{array}$ & $\begin{array}{l}33.095 \\
{[8.800]}\end{array}$ & $\begin{array}{c}39.670 \\
{[10.884]}\end{array}$ & $\begin{array}{c}39.971 \\
{[13.489]}\end{array}$ & 0.093 & 0.423 & 0.370 & 0.027 & 0.021 & 0.929 \\
\hline Calories of MDM per child & 274 & $\begin{array}{c}62.284 \\
{[20.131]}\end{array}$ & $\begin{array}{c}59.721 \\
{[21.248]}\end{array}$ & $\begin{array}{c}70.219 \\
{[23.282]}\end{array}$ & $\begin{array}{c}67.852 \\
{[22.786]}\end{array}$ & 0.634 & 0.208 & 0.308 & 0.109 & 0.154 & 0.716 \\
\hline Amount of iron in MDM per child (mg) & 274 & $\begin{array}{c}0.696 \\
{[0.233]}\end{array}$ & $\begin{array}{c}0.635 \\
{[0.224]}\end{array}$ & $\begin{array}{c}0.789 \\
{[0.330]}\end{array}$ & $\begin{array}{c}0.840 \\
{[0.439]}\end{array}$ & 0.309 & 0.269 & 0.107 & 0.071 & 0.023 & 0.630 \\
\hline \multicolumn{12}{|l|}{ Joint orthogonalitiy F-test } \\
\hline F-statistics & & 2.402 & 1.352 & 1.962 & 1.352 & 2.526 & 3.705 & 2.998 & 10.376 & 4.137 & 11.377 \\
\hline $\mathrm{p}$-Value & & [0.000] & {$[0.097]$} & {$[0.002]$} & {$[0.097]$} & {$[0.000]$} & {$[0.000]$} & {$[0.000]$} & {$[0.000]$} & {$[0.000]$} & {$[0.000]$} \\
\hline
\end{tabular}

Notes: Columns 2-5 report wave I means by intervention arm for child (Panel A and B) and schools (Panel C) in the study analysis. Columns 6-11 report p-values from tests on the equality of means for each variable. F-tests of joint significance: test of joint significance in regression of respective treatment dummies on all displayed wave I variables.

Source: Own Data. 
Table C.25: Balancing Table of Attrited Members of Exposure Group Using Wave I Data for Health Outcomes

\begin{tabular}{|c|c|c|c|c|c|c|c|c|c|c|c|}
\hline & \multirow[b]{2}{*}{ Observations } & \multicolumn{4}{|c|}{ Means [Standard Deviations] } & \multicolumn{6}{|c|}{$p$-value of difference } \\
\hline & & Group Always & Early & Late & Hardly & Always-Early & Always-Late & Always-Hardly & Early-Late & Early-Hardly & Late-Hardly \\
\hline \multicolumn{12}{|l|}{ Panel A. Child level outcome variables } \\
\hline \multicolumn{12}{|l|}{ Health outcomes } \\
\hline Hemoglobin $(\mathrm{g} / \mathrm{dL})$ & 739 & $\begin{array}{l}11.398 \\
{[1.114]}\end{array}$ & $\begin{array}{l}11.423 \\
{[1.393]}\end{array}$ & $\begin{array}{l}11.480 \\
{[1.015]}\end{array}$ & $\begin{array}{l}11.628 \\
{[0.849]}\end{array}$ & 0.905 & 0.644 & 0.148 & 0.801 & 0.332 & 0.397 \\
\hline Any anemia & 739 & 0.494 & 0.481 & 0.500 & 0.410 & 0.869 & 0.944 & 0.296 & 0.837 & 0.435 & 0.333 \\
\hline Mild anemia & 739 & 0.176 & 0.192 & 0.271 & 0.197 & 0.834 & 0.200 & 0.779 & 0.310 & 0.954 & 0.317 \\
\hline Moderate/severe anemia & 739 & 0.318 & 0.288 & 0.229 & 0.213 & 0.723 & 0.201 & 0.184 & 0.420 & 0.362 & 0.824 \\
\hline Number of symptoms & 825 & $\begin{array}{c}1.069 \\
{[1.119]}\end{array}$ & $\begin{array}{c}1.085 \\
{[1.208]}\end{array}$ & $\begin{array}{c}1.025 \\
{[1.121]}\end{array}$ & $\begin{array}{c}1.056 \\
{[1.099]}\end{array}$ & 0.941 & 0.829 & 0.950 & 0.772 & 0.891 & 0.876 \\
\hline \multicolumn{12}{|l|}{ Cognitive test outcomes } \\
\hline Block design & 758 & $\begin{array}{c}3.870 \\
{[2.001]}\end{array}$ & $\begin{array}{c}3.019 \\
{[2.390]}\end{array}$ & $\begin{array}{c}4.041 \\
{[2.176]}\end{array}$ & $\begin{array}{c}3.449 \\
{[2.193]}\end{array}$ & 0.049 & 0.667 & 0.273 & 0.028 & 0.331 & 0.157 \\
\hline Digit span forward & 758 & $\begin{array}{c}3.870 \\
{[0.986]}\end{array}$ & $\begin{array}{c}4.189 \\
{[0.921]}\end{array}$ & $\begin{array}{c}4.370 \\
{[0.921]}\end{array}$ & $\begin{array}{c}3.928 \\
{[1.034]}\end{array}$ & 0.042 & 0.002 & 0.690 & 0.304 & 0.121 & 0.010 \\
\hline Digit span backward & 758 & $\begin{array}{c}1.185 \\
{[1.350]}\end{array}$ & $\begin{array}{c}0.962 \\
{[1.240]}\end{array}$ & $\begin{array}{c}1.466 \\
{[1.415]}\end{array}$ & $\begin{array}{c}1.000 \\
{[1.328]}\end{array}$ & 0.318 & 0.243 & 0.408 & 0.047 & 0.872 & 0.066 \\
\hline Progressive matrices & 756 & $\begin{array}{c}4.565 \\
{[1.673]}\end{array}$ & $\begin{array}{c}4.423 \\
{[2.080]}\end{array}$ & $\begin{array}{c}5.110 \\
{[1.638]}\end{array}$ & $\begin{array}{c}4.928 \\
{[1.752]}\end{array}$ & 0.645 & 0.068 & 0.224 & 0.059 & 0.163 & 0.601 \\
\hline Stroop test & 757 & $\begin{array}{c}5.571 \\
{[3.281]}\end{array}$ & $\begin{array}{c}4.745 \\
{[3.159]}\end{array}$ & $\begin{array}{c}5.918 \\
{[3.387]}\end{array}$ & $\begin{array}{c}5.384 \\
{[3.724]}\end{array}$ & 0.136 & 0.531 & 0.729 & 0.056 & 0.282 & 0.371 \\
\hline Cognitive score index & 755 & $\begin{array}{l}-0.041 \\
{[0.888]}\end{array}$ & $\begin{array}{l}-0.211 \\
{[0.908]}\end{array}$ & $\begin{array}{c}0.310 \\
{[1.047]}\end{array}$ & $\begin{array}{c}-0.086 \\
{[1.059]}\end{array}$ & 0.300 & 0.046 & 0.782 & 0.010 & 0.498 & 0.044 \\
\hline \multicolumn{12}{|l|}{ Education outcomes } \\
\hline Math score & 757 & $\begin{array}{c}4.348 \\
{[3.611]}\end{array}$ & $\begin{array}{c}4.415 \\
{[3.703]}\end{array}$ & $\begin{array}{c}5.904 \\
{[3.913]}\end{array}$ & $\begin{array}{c}4.971 \\
{[4.018]}\end{array}$ & 0.921 & 0.022 & 0.350 & 0.044 & 0.446 & 0.196 \\
\hline Reading score & 758 & $\begin{array}{c}0.739 \\
{[0.888]}\end{array}$ & $\begin{array}{c}0.755 \\
{[0.959]}\end{array}$ & $\begin{array}{c}1.164 \\
{[1.131]}\end{array}$ & $\begin{array}{c}0.884 \\
{[1.132]}\end{array}$ & 0.933 & 0.015 & 0.417 & 0.057 & 0.555 & 0.174 \\
\hline School attendance & 759 & $\begin{array}{c}0.758 \\
{[0.199]}\end{array}$ & $\begin{array}{c}0.727 \\
{[0.220]}\end{array}$ & $\begin{array}{c}0.726 \\
{[0.217]}\end{array}$ & $\begin{array}{c}0.760 \\
{[0.182]}\end{array}$ & 0.473 & 0.422 & 0.935 & 0.979 & 0.392 & 0.332 \\
\hline \multicolumn{12}{|c|}{ Panel B: Child and household level control variables } \\
\hline Demographics and socioeconomic variables & & & & & & & & & & & \\
\hline Muslim & 825 & 0.039 & 0.000 & 0.051 & 0.014 & 0.070 & 0.762 & 0.324 & 0.105 & 0.324 & 0.281 \\
\hline Scheduled Caste/Scheduled Tribe & 825 & 0.275 & 0.271 & 0.127 & 0.250 & 0.970 & 0.057 & 0.764 & 0.075 & 0.803 & 0.091 \\
\hline Block & 825 & 1.382 & 1.492 & 1.203 & 1.347 & 0.411 & 0.239 & 0.784 & 0.041 & 0.205 & 0.286 \\
\hline Rural & 825 & 0.980 & 0.949 & 0.987 & 0.972 & 0.339 & 0.713 & 0.737 & 0.236 & 0.516 & 0.520 \\
\hline Family size & 825 & $\begin{array}{c}8.402 \\
{[3.842]}\end{array}$ & $\begin{array}{c}8.068 \\
{[3.428]}\end{array}$ & $\begin{array}{c}8.544 \\
{[4.293]}\end{array}$ & $\begin{array}{c}7.236 \\
{[2.635]}\end{array}$ & 0.608 & 0.848 & 0.038 & 0.519 & 0.133 & 0.048 \\
\hline Father's years of schooling & 804 & $\begin{array}{c}5.990 \\
{[4.806]}\end{array}$ & $\begin{array}{l}6.036 \\
{[5.564]}\end{array}$ & $\begin{array}{c}4.873 \\
{[4.842]}\end{array}$ & $\begin{array}{c}6.100 \\
{[5.074]}\end{array}$ & 0.962 & 0.233 & 0.910 & 0.199 & 0.946 & 0.177 \\
\hline Mother's years of schooling & 823 & $\begin{array}{c}2.029 \\
{[3.379]}\end{array}$ & $\begin{array}{c}3.172 \\
{[4.776]}\end{array}$ & $\begin{array}{c}1.810 \\
{[3.641]}\end{array}$ & $\begin{array}{c}2.806 \\
{[4.171]}\end{array}$ & 0.126 & 0.685 & 0.256 & 0.068 & 0.664 & 0.143 \\
\hline Asset index & 809 & $\begin{array}{c}0.012 \\
{[0.977]}\end{array}$ & $\begin{array}{c}0.104 \\
{[1.221]}\end{array}$ & $\begin{array}{c}0.121 \\
{[1.145]}\end{array}$ & $\begin{array}{c}0.328 \\
{[1.225]}\end{array}$ & 0.659 & 0.529 & 0.118 & 0.940 & 0.351 & 0.321 \\
\hline Institutional delivery & \multicolumn{7}{|c|}{ Health care } & & & & \\
\hline Health insurance & 812 & $\begin{array}{c}0.363 \\
{[0.483]}\end{array}$ & $\begin{array}{c}0.351 \\
{[0.481]}\end{array}$ & $\begin{array}{c}0.397 \\
{[0.493]}\end{array}$ & $\begin{array}{c}0.486 \\
{[0.503]}\end{array}$ & 0.893 & 0.655 & 0.154 & 0.631 & 0.194 & 0.349 \\
\hline Diarrhea & 825 & 0.069 & 0.034 & 0.025 & 0.028 & 0.312 & 0.145 & 0.189 & 0.770 & 0.843 & 0.923 \\
\hline Improved sanitation & 825 & 0.078 & 0.136 & 0.101 & 0.139 & 0.332 & 0.621 & 0.260 & 0.580 & 0.961 & 0.510 \\
\hline \multicolumn{12}{|l|}{ Nutrition } \\
\hline Diet diversity score & 825 & $\begin{array}{c}3.873 \\
{[1.158]}\end{array}$ & $\begin{array}{c}3.915 \\
{[1.134]}\end{array}$ & $\begin{array}{c}4.025 \\
{[1.165]}\end{array}$ & $\begin{array}{c}4.000 \\
{[1.278]}\end{array}$ & 0.835 & 0.390 & 0.524 & 0.595 & 0.708 & 0.900 \\
\hline Number of meals/day & 825 & $\begin{array}{c}3.069 \\
{[1.110]}\end{array}$ & $\begin{array}{c}3.203 \\
{[1.013]}\end{array}$ & $\begin{array}{c}2.924 \\
{[1.238]}\end{array}$ & $\begin{array}{c}2.750 \\
{[1.242]}\end{array}$ & 0.445 & 0.490 & 0.129 & 0.216 & 0.045 & 0.488 \\
\hline Food scarcity & 822 & 0.792 & 0.776 & 0.782 & 0.764 & 0.846 & 0.883 & 0.717 & 0.928 & 0.879 & 0.767 \\
\hline Maternal health knowledge & 825 & 0.382 & 0.458 & 0.418 & 0.444 & 0.340 & 0.591 & 0.431 & 0.613 & 0.883 & 0.735 \\
\hline Child eats meat products & 825 & 0.578 & 0.559 & 0.557 & 0.569 & 0.827 & 0.723 & 0.915 & 0.976 & 0.917 & 0.866 \\
\hline Child received iron supplements & 816 & 0.150 & 0.085 & 0.205 & 0.186 & 0.251 & 0.486 & 0.577 & 0.120 & 0.101 & 0.814 \\
\hline \multicolumn{12}{|l|}{ 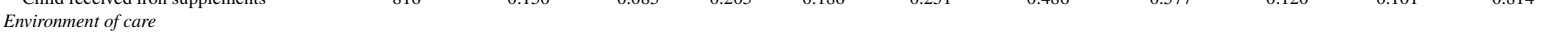 } \\
\hline Parents help with homework & 812 & 0.186 & 0.186 & 0.128 & 0.222 & 0.998 & 0.331 & 0.617 & 0.366 & 0.637 & 0.154 \\
\hline Parent's time spent for physical child care & 825 & $\begin{array}{c}41.373 \\
{[23.454]}\end{array}$ & $\begin{array}{c}50.695 \\
{[26.556]}\end{array}$ & $\begin{array}{c}46.266 \\
{[22.339]}\end{array}$ & $\begin{array}{c}43.097 \\
{[29.591]}\end{array}$ & 0.034 & 0.323 & 0.698 & 0.420 & 0.134 & 0.569 \\
\hline Parent attends school meetings & 823 & 0.588 & 0.475 & 0.608 & 0.639 & 0.196 & 0.833 & 0.521 & 0.171 & 0.054 & 0.724 \\
\hline Father lives at home & 824 & 0.863 & 0.831 & 0.823 & 0.833 & 0.604 & 0.536 & 0.597 & 0.919 & 0.967 & 0.881 \\
\hline Distance of school (min) & 825 & $\begin{array}{l}10.353 \\
{[7.211]}\end{array}$ & $\begin{array}{l}10.949 \\
{[5.917]}\end{array}$ & $\begin{array}{l}12.608 \\
{[8.484]}\end{array}$ & $\begin{array}{l}10.486 \\
{[6.537]}\end{array}$ & 0.585 & 0.171 & 0.904 & 0.327 & 0.695 & 0.213 \\
\hline \multicolumn{12}{|l|}{ Panel C: School level covariates } \\
\hline Number of children enrolled in school & 318 & $\begin{array}{c}253.634 \\
{[156.768]}\end{array}$ & $\begin{array}{c}198.581 \\
{[122.355]}\end{array}$ & $\begin{array}{c}305.560 \\
{[160.043]}\end{array}$ & $\begin{array}{c}206.620 \\
{[152.779]}\end{array}$ & 0.077 & 0.201 & 0.153 & 0.005 & 0.779 & 0.012 \\
\hline Class size & 320 & $\begin{array}{c}29.951 \\
{[12.093]}\end{array}$ & $\begin{array}{c}27.698 \\
{[11.277]}\end{array}$ & $\begin{array}{c}34.920 \\
{[25.402]}\end{array}$ & $\begin{array}{c}34.780 \\
{[23.329]}\end{array}$ & 0.380 & 0.361 & 0.207 & 0.181 & 0.060 & 0.982 \\
\hline Student teacher ratio & 318 & $\begin{array}{c}35.789 \\
{[10.140]}\end{array}$ & $\begin{array}{l}33.773 \\
{[9.590]}\end{array}$ & $\begin{array}{c}39.382 \\
{[10.912]}\end{array}$ & $\begin{array}{c}39.550 \\
{[12.687]}\end{array}$ & 0.352 & 0.186 & 0.120 & 0.036 & 0.014 & 0.953 \\
\hline Calories of MDM per child & 320 & $\begin{array}{c}65.545 \\
{[21.910]}\end{array}$ & $\begin{array}{c}61.363 \\
{[21.041]}\end{array}$ & $\begin{array}{c}71.122 \\
{[21.365]}\end{array}$ & $\begin{array}{l}67.839 \\
{[21.422]}\end{array}$ & 0.375 & 0.311 & 0.617 & 0.072 & 0.146 & 0.531 \\
\hline Amount of iron in MDM per child (mg) & 320 & $\begin{array}{c}0.738 \\
{[0.253]}\end{array}$ & $\begin{array}{c}0.658 \\
{[0.225]}\end{array}$ & $\begin{array}{c}0.802 \\
{[0.303]}\end{array}$ & $\begin{array}{c}0.813 \\
{[0.387]}\end{array}$ & 0.131 & 0.383 & 0.273 & 0.043 & 0.019 & 0.893 \\
\hline \multicolumn{12}{|l|}{ Joint orthogonalitiy F-test } \\
\hline F-statistics & & 2.402 & 1.352 & 1.962 & 1.352 & 2.526 & $\begin{array}{l}3.705 \\
50001\end{array}$ & 2.998 & 10.376 & 4.137 & 11.377 \\
\hline
\end{tabular}

Notes: Columns 2-5 report wave I means by intervention arm for child (Panel A and B) and schools (Panel C) in the study analysis. Columns 6-11 report p-values from tests on the equality of means for each variable. F-tests of joint significance: test of joint significance in regression of respective treatment dummies on all displayed wave I variables.

Source: Own Data. 
Table C.26: Balancing Table of Attrited Members of Exposure Group Using Wave II Data for Health Outcomes

\begin{tabular}{|c|c|c|c|c|c|c|c|c|c|c|c|}
\hline & \multirow[b]{2}{*}{ Observations } & \multicolumn{4}{|c|}{ Means [Standard Deviations] } & \multicolumn{6}{|c|}{$p$-value of difference } \\
\hline & & Group Always & Early & Late & Hardly & Always-Early & Always-Late & Always-Hardly & Early-Late & Early-Hardly & Late-Hardly \\
\hline \multirow{2}{*}{\multicolumn{12}{|c|}{ Panel A. Child level outcome variables }} \\
\hline \multicolumn{11}{|l|}{ Health outcomes } & \\
\hline Hemoglobin $(\mathrm{g} / \mathrm{dL})$ & 504 & $\begin{array}{c}12.068 \\
{[1.003]}\end{array}$ & $\begin{array}{c}12.016 \\
{[1.270]}\end{array}$ & $\begin{array}{c}11.744 \\
{[0.971]}\end{array}$ & $\begin{array}{l}11.991 \\
{[1.052]}\end{array}$ & 0.878 & 0.234 & 0.779 & 0.395 & 0.937 & 0.324 \\
\hline Any anemia & 504 & 0.184 & 0.240 & 0.313 & 0.281 & 0.627 & 0.260 & 0.368 & 0.543 & 0.717 & 0.780 \\
\hline Mild anemia & 504 & 0.079 & 0.040 & 0.094 & 0.188 & 0.505 & 0.811 & 0.177 & 0.378 & 0.066 & 0.253 \\
\hline Moderate/severe anemia & 504 & 0.105 & 0.200 & 0.219 & 0.094 & 0.346 & 0.229 & 0.885 & 0.861 & 0.266 & 0.159 \\
\hline Number of symptoms & 482 & $\begin{array}{c}2.184 \\
{[1.205]}\end{array}$ & $\begin{array}{c}2.174 \\
{[1.302]}\end{array}$ & $\begin{array}{c}2.067 \\
{[1.337]}\end{array}$ & $\begin{array}{c}1.750 \\
{[1.344]}\end{array}$ & 0.974 & 0.669 & 0.163 & 0.742 & 0.234 & 0.327 \\
\hline \multicolumn{12}{|l|}{ Cognitive test outcomes } \\
\hline Block design & 459 & $\begin{array}{c}4.361 \\
{[2.257]}\end{array}$ & $\begin{array}{c}4.083 \\
{[2.244]}\end{array}$ & $\begin{array}{c}4.867 \\
{[1.814]}\end{array}$ & $\begin{array}{c}4.786 \\
{[2.043]}\end{array}$ & 0.642 & 0.320 & 0.431 & 0.164 & 0.233 & 0.869 \\
\hline Digit span forward & 459 & $\begin{array}{c}4.139 \\
{[0.931]}\end{array}$ & $\begin{array}{c}4.583 \\
{[0.881]}\end{array}$ & $\begin{array}{c}4.667 \\
{[0.922]}\end{array}$ & $\begin{array}{c}4.250 \\
{[1.295]}\end{array}$ & 0.048 & 0.016 & 0.686 & 0.734 & 0.272 & 0.164 \\
\hline Digit span backward & 459 & $\begin{array}{c}1.389 \\
{[1.315]}\end{array}$ & $\begin{array}{c}1.542 \\
{[1.444]}\end{array}$ & $\begin{array}{c}1.633 \\
{[1.426]}\end{array}$ & $\begin{array}{c}1.357 \\
{[1.569]}\end{array}$ & 0.666 & 0.434 & 0.931 & 0.800 & 0.653 & 0.462 \\
\hline Progressive matrices & 459 & $\begin{array}{c}4.750 \\
{[1.339]}\end{array}$ & $\begin{array}{c}4.625 \\
{[1.245]}\end{array}$ & $\begin{array}{c}5.267 \\
{[1.363]}\end{array}$ & $\begin{array}{c}5.857 \\
{[1.208]}\end{array}$ & 0.705 & 0.106 & 0.002 & 0.075 & 0.002 & 0.102 \\
\hline Stroop test & 459 & $\begin{array}{c}5.444 \\
{[3.913]}\end{array}$ & $\begin{array}{c}5.750 \\
{[2.836]}\end{array}$ & $\begin{array}{c}7.017 \\
{[2.996]}\end{array}$ & $\begin{array}{c}5.339 \\
{[3.674]}\end{array}$ & 0.741 & 0.114 & 0.918 & 0.156 & 0.659 & 0.093 \\
\hline Cognitive score index & 459 & $\begin{array}{l}-0.400 \\
{[1.057]}\end{array}$ & $\begin{array}{l}-0.267 \\
{[0.904]}\end{array}$ & $\begin{array}{c}0.099 \\
{[0.889]}\end{array}$ & $\begin{array}{l}-0.151 \\
{[1.102]}\end{array}$ & 0.594 & 0.040 & 0.367 & 0.137 & 0.678 & 0.357 \\
\hline \multicolumn{12}{|l|}{ Education outcomes } \\
\hline Math score & 457 & $\begin{array}{c}7.139 \\
{[4.800]}\end{array}$ & $\begin{array}{c}7.875 \\
{[4.767]}\end{array}$ & $\begin{array}{c}9.900 \\
{[3.933]}\end{array}$ & $\begin{array}{c}8.214 \\
{[4.670]}\end{array}$ & 0.563 & 0.016 & 0.418 & 0.103 & 0.812 & 0.190 \\
\hline Reading score & 459 & $\begin{array}{c}1.111 \\
{[1.166]}\end{array}$ & $\begin{array}{c}1.542 \\
{[1.474]}\end{array}$ & $\begin{array}{c}1.900 \\
{[1.373]}\end{array}$ & $\begin{array}{c}1.393 \\
{[1.343]}\end{array}$ & 0.241 & 0.040 & 0.430 & 0.401 & 0.716 & 0.229 \\
\hline School attendance & 495 & $\begin{array}{c}0.727 \\
{[0.199]}\end{array}$ & $\begin{array}{c}0.557 \\
{[0.290]}\end{array}$ & $\begin{array}{c}0.683 \\
{[0.207]}\end{array}$ & $\begin{array}{c}0.717 \\
{[0.176]}\end{array}$ & 0.035 & 0.524 & 0.869 & 0.099 & 0.020 & 0.539 \\
\hline \multicolumn{12}{|c|}{ Panel B: Child and household level control variables } \\
\hline \multicolumn{12}{|l|}{ Demographics and socioeconomic variables } \\
\hline Muslim & 482 & 0.053 & 0.000 & 0.033 & 0.000 & 0.294 & 0.746 & 0.292 & 0.309 & & 0.306 \\
\hline Scheduled Caste/Scheduled Tribe & 476 & 0.263 & 0.348 & 0.133 & 0.258 & 0.553 & 0.330 & 0.970 & 0.159 & 0.554 & 0.382 \\
\hline Block & 504 & 1.316 & 1.480 & 1.156 & 1.406 & 0.326 & 0.310 & 0.568 & 0.031 & 0.617 & 0.071 \\
\hline Rural & 504 & 1.000 & 1.000 & 1.000 & 1.000 & & & & & & \\
\hline Family size & 482 & $\begin{array}{c}8.184 \\
{[3.030]}\end{array}$ & $\begin{array}{c}7.783 \\
{[2.923]}\end{array}$ & $\begin{array}{c}8.200 \\
{[3.221]}\end{array}$ & $\begin{array}{c}7.000 \\
{[2.048]}\end{array}$ & 0.586 & 0.983 & 0.055 & 0.593 & 0.232 & 0.072 \\
\hline Father's years of schooling & 478 & $\begin{array}{c}6.237 \\
{[4.239]}\end{array}$ & $\begin{array}{c}5.087 \\
{[4.889]}\end{array}$ & $\begin{array}{c}4.633 \\
{[5.176]}\end{array}$ & $\begin{array}{c}7.375 \\
{[4.804]}\end{array}$ & 0.414 & 0.191 & 0.416 & 0.732 & 0.130 & 0.042 \\
\hline Mother's years of schooling & 479 & $\begin{array}{c}1.395 \\
{[2.814]}\end{array}$ & $\begin{array}{c}2.696 \\
{[3.925]}\end{array}$ & $\begin{array}{c}1.500 \\
{[2.991]}\end{array}$ & $\begin{array}{c}2.613 \\
{[3.896]}\end{array}$ & 0.176 & 0.868 & 0.180 & 0.221 & 0.943 & 0.227 \\
\hline Asset index & 473 & $\begin{array}{c}-0.269 \\
{[0.812]}\end{array}$ & $\begin{array}{l}-0.302 \\
{[0.580]}\end{array}$ & $\begin{array}{l}-0.066 \\
{[0.699]}\end{array}$ & $\begin{array}{c}0.280 \\
{[1.066]}\end{array}$ & 0.870 & 0.323 & 0.031 & 0.219 & 0.017 & 0.155 \\
\hline \multicolumn{12}{|l|}{ Health care } \\
\hline Health insurance & 470 & $\begin{array}{c}0.171 \\
{[0.382]}\end{array}$ & $\begin{array}{c}0.391 \\
{[0.499]}\end{array}$ & $\begin{array}{c}0.107 \\
{[0.315]}\end{array}$ & $\begin{array}{c}0.313 \\
{[0.471]}\end{array}$ & 0.105 & 0.508 & 0.201 & 0.048 & 0.595 & 0.082 \\
\hline Diarrhea & 482 & 0.237 & 0.174 & 0.300 & 0.188 & 0.526 & 0.542 & 0.595 & 0.277 & 0.897 & 0.307 \\
\hline Improved sanitation & 480 & 0.053 & 0.043 & 0.133 & 0.226 & 0.871 & 0.313 & 0.071 & 0.287 & 0.068 & 0.415 \\
\hline \multicolumn{12}{|l|}{ Nutrition } \\
\hline Diet diversity score & 482 & $\begin{array}{c}4.053 \\
{[1.161]}\end{array}$ & $\begin{array}{c}3.826 \\
{[1.154]}\end{array}$ & $\begin{array}{c}3.733 \\
{[1.172]}\end{array}$ & $\begin{array}{c}3.906 \\
{[1.304]}\end{array}$ & 0.476 & 0.326 & 0.668 & 0.786 & 0.823 & 0.634 \\
\hline Number of meals/day & 482 & $\begin{array}{c}3.605 \\
{[0.679]}\end{array}$ & $\begin{array}{c}3.261 \\
{[0.619]}\end{array}$ & $\begin{array}{c}3.633 \\
{[0.718]}\end{array}$ & $\begin{array}{c}3.656 \\
{[0.653]}\end{array}$ & 0.079 & 0.886 & 0.773 & 0.064 & 0.029 & 0.899 \\
\hline Food scarcity & 482 & 0.526 & 0.565 & 0.367 & 0.281 & 0.790 & 0.196 & 0.040 & 0.170 & 0.044 & 0.449 \\
\hline Maternal health knowledge & 482 & 0.289 & 0.304 & 0.200 & 0.313 & 0.903 & 0.348 & 0.835 & 0.409 & 0.953 & 0.328 \\
\hline Child eats meat products & 482 & 0.526 & 0.522 & 0.400 & 0.594 & 0.974 & 0.274 & 0.589 & 0.346 & 0.600 & 0.088 \\
\hline Child received iron supplements & 474 & 0.143 & 0.043 & 0.103 & 0.031 & 0.306 & 0.729 & 0.225 & 0.489 & 0.821 & 0.371 \\
\hline \multicolumn{12}{|l|}{ Environment of care } \\
\hline Parents help with homework & 481 & 0.289 & 0.348 & 0.500 & 0.406 & 0.635 & 0.075 & 0.322 & 0.265 & 0.669 & 0.473 \\
\hline Parent's time spent for physical child care & 472 & $\begin{array}{c}51.944 \\
{[30.502]}\end{array}$ & $\begin{array}{c}41.739 \\
{[17.491]}\end{array}$ & $\begin{array}{c}42.750 \\
{[45.646]}\end{array}$ & $\begin{array}{c}44.097 \\
{[35.118]}\end{array}$ & 0.119 & 0.424 & 0.338 & 0.926 & 0.746 & 0.910 \\
\hline Parent attends school meetings & 475 & 0.324 & 0.364 & 0.310 & 0.406 & 0.790 & 0.925 & 0.539 & 0.732 & 0.762 & 0.499 \\
\hline Father lives at home & 482 & 0.947 & 0.870 & 0.900 & 0.813 & 0.329 & 0.449 & 0.097 & 0.721 & 0.565 & 0.311 \\
\hline Distance of school (min) & 480 & $\begin{array}{c}13.658 \\
{[10.520]}\end{array}$ & $\begin{array}{c}12.391 \\
{[8.100]}\end{array}$ & $\begin{array}{c}16.333 \\
{[11.592]}\end{array}$ & $\begin{array}{l}12.806 \\
{[9.005]}\end{array}$ & 0.613 & 0.458 & 0.731 & 0.267 & 0.860 & 0.315 \\
\hline \multicolumn{12}{|l|}{ Panel C: School level covariates } \\
\hline Number of children enrolled in school & 227 & $\begin{array}{c}246.565 \\
{[272.077]}\end{array}$ & $\begin{array}{c}196.522 \\
{[123.255]}\end{array}$ & $\begin{array}{c}306.467 \\
{[167.239]}\end{array}$ & $\begin{array}{l}159.321 \\
{[99.392]}\end{array}$ & 0.426 & 0.406 & 0.150 & 0.034 & 0.248 & 0.003 \\
\hline Class size & 227 & $\begin{array}{c}27.913 \\
{[14.694]}\end{array}$ & $\begin{array}{c}30.304 \\
{[12.928]}\end{array}$ & $\begin{array}{c}38.933 \\
{[23.252]}\end{array}$ & $\begin{array}{c}32.500 \\
{[16.167]}\end{array}$ & 0.561 & 0.109 & 0.294 & 0.196 & 0.592 & 0.342 \\
\hline Student teacher ratio & 227 & $\begin{array}{c}36.057 \\
{[18.231]}\end{array}$ & $\begin{array}{l}32.485 \\
{[9.645]}\end{array}$ & $\begin{array}{c}42.450 \\
{[10.924]}\end{array}$ & $\begin{array}{c}37.818 \\
{[14.675]}\end{array}$ & 0.411 & 0.185 & 0.710 & 0.006 & 0.126 & 0.247 \\
\hline Calories of MDM per child & 227 & $\begin{array}{c}82.692 \\
{[102.666]}\end{array}$ & $\begin{array}{c}75.627 \\
{[29.895]}\end{array}$ & $\begin{array}{l}85.364 \\
{[44.620]}\end{array}$ & $\begin{array}{c}72.178 \\
{[28.783]}\end{array}$ & 0.753 & 0.913 & 0.635 & 0.460 & 0.678 & 0.303 \\
\hline Amount of iron in MDM per child (mg) & 227 & $\begin{array}{c}0.773 \\
{[0.810]}\end{array}$ & $\begin{array}{c}0.670 \\
{[0.382]}\end{array}$ & $\begin{array}{c}0.692 \\
{[0.393]}\end{array}$ & $\begin{array}{c}0.527 \\
{[0.246]}\end{array}$ & 0.584 & 0.685 & 0.165 & 0.864 & 0.126 & 0.142 \\
\hline \multicolumn{12}{|l|}{ Joint orthogonalitiy F-test } \\
\hline F-statistics & & 2.402 & 1.352 & 1.962 & 1.352 & 2.526 & 3.705 & 2.998 & 10.376 & 4.137 & 11.377 \\
\hline
\end{tabular}

Notes: Columns 2-5 report wave I means by intervention arm for child (Panel A and B) and schools (Panel C) in the study analysis. Columns 6-11 report p-values from tests on the equality of means for each variable. F-tests of joint significance: test of joint significance in regression of respective treatment dummies on all displayed wave I variables.

Source: Own Data. 
Table C.27: Balancing Table of Attrited Members of Exposure Group Using Wave I Data for Cognition and Education Outcomes

\begin{tabular}{|c|c|c|c|c|c|c|c|c|c|c|c|}
\hline & \multirow[b]{2}{*}{ Observations } & \multicolumn{4}{|c|}{ Means [Standard Deviations] } & \multicolumn{6}{|c|}{$p$-value of difference } \\
\hline & & Group Always & Early & Late & Hardly & Always-Early & Always-Late & Always-Hardly & Early-Late & Early-Hardly & Late-Hardly \\
\hline \multicolumn{12}{|l|}{ Panel A. Child level outcome variables } \\
\hline \multicolumn{12}{|l|}{ Health outcomes } \\
\hline Hemoglobin (g/dL) & 620 & $\begin{array}{l}11.578 \\
{[1.081]}\end{array}$ & $\begin{array}{l}11.693 \\
{[1.319]}\end{array}$ & $\begin{array}{l}11.539 \\
{[1.116]}\end{array}$ & $\begin{array}{l}11.691 \\
{[1.015]}\end{array}$ & 0.686 & 0.861 & 0.601 & 0.616 & 0.995 & 0.533 \\
\hline Any anemia & 620 & 0.481 & 0.444 & 0.500 & 0.406 & 0.736 & 0.858 & 0.475 & 0.662 & 0.766 & 0.446 \\
\hline Mild anemia & 620 & 0.185 & 0.222 & 0.222 & 0.125 & 0.699 & 0.663 & 0.471 & 1.000 & 0.321 & 0.265 \\
\hline Moderate/severe anemia & 620 & 0.296 & 0.222 & 0.278 & 0.281 & 0.470 & 0.815 & 0.878 & 0.580 & 0.612 & 0.971 \\
\hline Number of symptoms & 681 & $\begin{array}{l}1.183 \\
{[1.127]}\end{array}$ & $\begin{array}{c}1.067 \\
{[1.015]}\end{array}$ & $\begin{array}{l}1.175 \\
{[1.174]}\end{array}$ & $\begin{array}{c}1.105 \\
{[1.060]}\end{array}$ & 0.626 & 0.972 & 0.736 & 0.671 & 0.875 & 0.778 \\
\hline \multicolumn{12}{|l|}{ Cognitive test outcomes } \\
\hline Block design & 586 & $\begin{array}{c}2.943 \\
{[2.182]}\end{array}$ & $\begin{array}{c}3.700 \\
{[2.055]}\end{array}$ & $\begin{array}{c}3.000 \\
{[1.941]}\end{array}$ & $\begin{array}{c}4.212 \\
{[2.408]}\end{array}$ & 0.265 & 0.925 & 0.050 & 0.273 & 0.438 & 0.045 \\
\hline Digit span forward & 588 & $\begin{array}{c}3.595 \\
{[1.212]}\end{array}$ & $\begin{array}{l}4.250 \\
{[0.851]}\end{array}$ & $\begin{array}{c}3.741 \\
{[1.196]}\end{array}$ & $\begin{array}{l}4.061 \\
{[1.321]}\end{array}$ & 0.016 & 0.641 & 0.119 & 0.113 & 0.524 & 0.352 \\
\hline Digit span backward & 588 & $\begin{array}{c}0.946 \\
{[1.268]}\end{array}$ & $\begin{array}{c}1.700 \\
{[1.559]}\end{array}$ & $\begin{array}{c}1.222 \\
{[1.450]}\end{array}$ & $\begin{array}{c}1.333 \\
{[1.472]}\end{array}$ & 0.070 & 0.423 & 0.258 & 0.297 & 0.417 & 0.778 \\
\hline Progressive matrices & 586 & $\begin{array}{c}4.000 \\
{[2.108]}\end{array}$ & $\begin{array}{c}4.842 \\
{[2.292]}\end{array}$ & $\begin{array}{c}4.667 \\
{[1.797]}\end{array}$ & $\begin{array}{l}4.970 \\
{[2.298]}\end{array}$ & 0.132 & 0.180 & 0.073 & 0.761 & 0.834 & 0.585 \\
\hline Stroop test & 585 & $\begin{array}{c}4.214 \\
{[3.035]}\end{array}$ & $\begin{array}{c}6.275 \\
{[3.458]}\end{array}$ & $\begin{array}{c}6.426 \\
{[4.153]}\end{array}$ & $\begin{array}{c}6.364 \\
{[4.059]}\end{array}$ & 0.040 & 0.029 & 0.019 & 0.890 & 0.930 & 0.951 \\
\hline Cognitive score index & 581 & $\begin{array}{l}-0.542 \\
{[1.219]}\end{array}$ & $\begin{array}{c}0.304 \\
{[0.758]}\end{array}$ & $\begin{array}{l}-0.101 \\
{[1.192]}\end{array}$ & $\begin{array}{c}0.231 \\
{[1.298]}\end{array}$ & 0.006 & 0.214 & 0.022 & 0.205 & 0.801 & 0.341 \\
\hline \multicolumn{12}{|l|}{ Education outcomes } \\
\hline Math score & 586 & $\begin{array}{c}4.000 \\
{[3.923]}\end{array}$ & $\begin{array}{c}5.900 \\
{[3.684]}\end{array}$ & $\begin{array}{c}6.423 \\
{[4.429]}\end{array}$ & $\begin{array}{c}5.818 \\
{[4.231]}\end{array}$ & 0.082 & 0.058 & 0.095 & 0.669 & 0.937 & 0.620 \\
\hline Reading score & 587 & $\begin{array}{c}0.703 \\
{[0.812]}\end{array}$ & $\begin{array}{c}1.053 \\
{[0.970]}\end{array}$ & $\begin{array}{c}1.037 \\
{[1.018]}\end{array}$ & $\begin{array}{c}1.152 \\
{[1.253]}\end{array}$ & 0.207 & 0.142 & 0.107 & 0.955 & 0.755 & 0.677 \\
\hline School attendance & 617 & $\begin{array}{c}0.694 \\
{[0.256]}\end{array}$ & $\begin{array}{c}0.730 \\
{[0.260]}\end{array}$ & $\begin{array}{c}0.659 \\
{[0.235]}\end{array}$ & $\begin{array}{c}0.753 \\
{[0.175]}\end{array}$ & 0.622 & 0.561 & 0.296 & 0.287 & 0.713 & 0.049 \\
\hline \multicolumn{12}{|c|}{ Panel B: Child and household level control variables } \\
\hline \multicolumn{12}{|c|}{ Demographics and socioeconomic variables } \\
\hline Muslim & 681 & 0.017 & 0.000 & 0.050 & 0.000 & 0.315 & 0.393 & 0.314 & 0.161 & & 0.160 \\
\hline Scheduled Caste/Scheduled Tribe & 681 & 0.283 & 0.233 & 0.150 & 0.184 & 0.645 & 0.203 & 0.322 & 0.414 & 0.614 & 0.710 \\
\hline Block & 681 & 1.367 & 1.400 & 1.250 & 1.368 & 0.820 & 0.487 & 0.990 & 0.374 & 0.818 & 0.459 \\
\hline Rural & 681 & 1.000 & 0.933 & 0.975 & 1.000 & 0.159 & 0.324 & & 0.437 & 0.159 & 0.324 \\
\hline Family size & 681 & $\begin{array}{c}8.167 \\
{[4.251]}\end{array}$ & $\begin{array}{l}10.433 \\
{[4.732]}\end{array}$ & $\begin{array}{c}8.225 \\
{[4.406]}\end{array}$ & $\begin{array}{c}7.237 \\
{[2.794]}\end{array}$ & 0.025 & 0.951 & 0.160 & 0.069 & 0.002 & 0.290 \\
\hline Father's years of schooling & 665 & $\begin{array}{c}5.933 \\
{[5.048]}\end{array}$ & $\begin{array}{l}7.533 \\
{[5.191]}\end{array}$ & $\begin{array}{c}6.425 \\
{[5.472]}\end{array}$ & $\begin{array}{l}6.784 \\
{[5.287]}\end{array}$ & 0.177 & 0.675 & 0.460 & 0.403 & 0.564 & 0.782 \\
\hline Mother's years of schooling & 680 & $\begin{array}{c}2.050 \\
{[3.116]}\end{array}$ & $\begin{array}{l}3.800 \\
{[5.142]}\end{array}$ & $\begin{array}{c}2.975 \\
{[4.481]}\end{array}$ & $\begin{array}{c}3.395 \\
{[4.378]}\end{array}$ & 0.109 & 0.264 & 0.078 & 0.496 & 0.727 & 0.651 \\
\hline Asset index & 670 & $\begin{array}{c}0.014 \\
{[1.081]}\end{array}$ & $\begin{array}{c}0.695 \\
{[1.391]}\end{array}$ & $\begin{array}{c}0.069 \\
{[1.101]}\end{array}$ & $\begin{array}{c}0.387 \\
{[1.273]}\end{array}$ & 0.031 & 0.795 & 0.159 & 0.050 & 0.378 & 0.237 \\
\hline $\begin{array}{l}\text { Gender of the child } \\
\text { Health care }\end{array}$ & 637 & 0.508 & 0.714 & 0.474 & 0.548 & 0.036 & 0.709 & 0.711 & 0.032 & 0.177 & 0.533 \\
\hline Institutional delivery & 676 & 0.431 & 0.433 & 0.475 & 0.378 & 0.985 & 0.714 & 0.628 & 0.756 & 0.658 & 0.417 \\
\hline Health insurance & 668 & $\begin{array}{c}0.407 \\
{[0.495]}\end{array}$ & $\begin{array}{c}0.393 \\
{[0.497]}\end{array}$ & $\begin{array}{c}0.450 \\
{[0.504]}\end{array}$ & $\begin{array}{c}0.474 \\
{[0.506]}\end{array}$ & 0.909 & 0.678 & 0.555 & 0.654 & 0.549 & 0.841 \\
\hline Diarrhea & 681 & 0.033 & 0.033 & 0.050 & 0.000 & 1.000 & 0.681 & 0.151 & 0.726 & 0.323 & 0.137 \\
\hline Improved sanitation & 681 & 0.117 & 0.233 & 0.100 & 0.158 & 0.206 & 0.799 & 0.561 & 0.173 & 0.454 & 0.455 \\
\hline \multicolumn{12}{|l|}{ Nutrition } \\
\hline Diet diversity score & 681 & $\begin{array}{c}3.833 \\
{[1.152]}\end{array}$ & $\begin{array}{l}4.267 \\
{[1.112]}\end{array}$ & $\begin{array}{c}4.025 \\
{[1.000]}\end{array}$ & $\begin{array}{c}4.132 \\
{[1.119]}\end{array}$ & 0.124 & 0.402 & 0.256 & 0.345 & 0.635 & 0.650 \\
\hline Number of meals/day & 681 & $\begin{array}{c}3.100 \\
{[0.969]}\end{array}$ & $\begin{array}{c}2.800 \\
{[1.186]}\end{array}$ & $\begin{array}{c}2.825 \\
{[1.152]}\end{array}$ & $\begin{array}{c}3.000 \\
{[0.986]}\end{array}$ & 0.218 & 0.261 & 0.609 & 0.936 & 0.466 & 0.525 \\
\hline Food scarcity & 680 & 0.783 & 0.700 & 0.744 & 0.632 & 0.441 & 0.662 & 0.148 & 0.685 & 0.565 & 0.282 \\
\hline Maternal health knowledge & 681 & 0.417 & 0.433 & 0.300 & 0.447 & 0.883 & 0.200 & 0.778 & 0.227 & 0.911 & 0.165 \\
\hline Child eats meat products & 681 & 0.517 & 0.667 & 0.500 & 0.632 & 0.168 & 0.856 & 0.299 & 0.120 & 0.774 & 0.226 \\
\hline Child received iron supplements & 673 & 0.169 & 0.167 & 0.175 & 0.286 & 0.973 & 0.952 & 0.206 & 0.936 & 0.254 & 0.319 \\
\hline \multicolumn{12}{|l|}{ Environment of care } \\
\hline Parents help with homework & 668 & 0.200 & 0.267 & 0.231 & 0.263 & 0.546 & 0.731 & 0.529 & 0.730 & 0.975 & 0.728 \\
\hline Parent's time spent for physical child care & 681 & $\begin{array}{c}45.667 \\
{[28.796]}\end{array}$ & $\begin{array}{c}37.833 \\
{[14.895]}\end{array}$ & $\begin{array}{l}48.625 \\
{[23.479]}\end{array}$ & $\begin{array}{c}47.316 \\
{[23.016]}\end{array}$ & 0.074 & 0.651 & 0.732 & 0.091 & 0.037 & 0.843 \\
\hline Parent attends school meetings & 679 & 0.533 & 0.400 & 0.675 & 0.605 & 0.292 & 0.244 & 0.536 & 0.037 & 0.102 & 0.558 \\
\hline Father lives at home & 680 & 0.883 & 0.900 & 0.775 & 0.763 & 0.842 & 0.226 & 0.152 & 0.239 & 0.176 & 0.910 \\
\hline Distance of school (min) & 681 & $\begin{array}{l}11.017 \\
{[7.503]}\end{array}$ & $\begin{array}{l}11.400 \\
{[6.605]}\end{array}$ & $\begin{array}{l}12.250 \\
{[6.898]}\end{array}$ & $\begin{array}{l}10.421 \\
{[5.717]}\end{array}$ & 0.821 & 0.404 & 0.693 & 0.574 & 0.526 & 0.160 \\
\hline \multicolumn{12}{|l|}{ Panel C: School level covariates } \\
\hline Number of children enrolled in school & 267 & $\begin{array}{c}296.867 \\
{[153.711]}\end{array}$ & $\begin{array}{c}215.231 \\
{[107.100]}\end{array}$ & $\begin{array}{c}346.158 \\
{[141.320]}\end{array}$ & $\begin{array}{c}208.212 \\
{[146.357]}\end{array}$ & 0.024 & 0.255 & 0.023 & 0.001 & 0.832 & 0.002 \\
\hline Class size & 269 & $\begin{array}{c}33.867 \\
{[11.890]}\end{array}$ & $\begin{array}{c}31.962 \\
{[11.276]}\end{array}$ & $\begin{array}{c}36.579 \\
{[27.911]}\end{array}$ & $\begin{array}{l}31.303 \\
{[19.875]}\end{array}$ & 0.541 & 0.689 & 0.533 & 0.498 & 0.873 & 0.470 \\
\hline Student teacher ratio & 267 & $\begin{array}{l}37.799 \\
{[9.877]}\end{array}$ & $\begin{array}{l}37.703 \\
{[8.959]}\end{array}$ & $\begin{array}{c}38.522 \\
{[11.026]}\end{array}$ & $\begin{array}{c}41.125 \\
{[12.815]}\end{array}$ & 0.970 & 0.816 & 0.251 & 0.791 & 0.233 & 0.443 \\
\hline Calories of MDM per child & 269 & $\begin{array}{l}67.187 \\
{[23.944]}\end{array}$ & $\begin{array}{c}56.903 \\
{[21.385]}\end{array}$ & $\begin{array}{c}70.115 \\
{[24.234]}\end{array}$ & $\begin{array}{c}68.615 \\
{[20.501]}\end{array}$ & 0.095 & 0.680 & 0.801 & 0.064 & 0.038 & 0.821 \\
\hline Amount of iron in MDM per child (mg) & 269 & $\begin{array}{c}0.726 \\
{[0.257]}\end{array}$ & $\begin{array}{c}0.641 \\
{[0.199]}\end{array}$ & $\begin{array}{c}0.770 \\
{[0.327]}\end{array}$ & $\begin{array}{c}0.812 \\
{[0.283]}\end{array}$ & 0.172 & 0.616 & 0.209 & 0.133 & 0.009 & 0.641 \\
\hline \multicolumn{12}{|l|}{ Joint orthogonalitiy F-test } \\
\hline F-statistics & & 2.402 & 1.352 & 1.962 & 1.352 & 2.526 & 3.705 & 2.998 & 10.376 & 4.137 & 11.377 \\
\hline
\end{tabular}

Notes: Columns 2-5 report wave I means by intervention arm for child (Panel A and B) and schools (Panel C) in the study analysis. Columns 6-11 report p-values from tests on the equality of means for each variable. F-tests of joint significance: test of joint significance in regression of respective treatment dummies on all displayed wave I variables.

Source: Own Data. 
Table C.28: Balancing Table of Attrited Members of Exposure Group Using Wave I Data for Health Outcomes

\begin{tabular}{|c|c|c|c|c|c|c|c|c|c|c|c|}
\hline & \multirow[b]{2}{*}{ Observations } & \multicolumn{4}{|c|}{ Means [Standard Deviations] } & \multicolumn{6}{|c|}{$p$-value of difference } \\
\hline & & Group Always & Early & Late & Hardly & Always-Early & Always-Late & Always-Hardly & Early-Late & Early-Hardly & Late-Hardly \\
\hline \multicolumn{12}{|l|}{ Panel A. Child level outcome variables } \\
\hline \multicolumn{12}{|l|}{ Health outcomes } \\
\hline Hemoglobin $(\mathrm{g} / \mathrm{dL})$ & 901 & $\begin{array}{c}11.412 \\
{[1.050]}\end{array}$ & $\begin{array}{l}11.508 \\
{[1.097]}\end{array}$ & $\begin{array}{l}11.410 \\
{[1.338]}\end{array}$ & $\begin{array}{l}11.725 \\
{[0.974]}\end{array}$ & 0.528 & 0.987 & 0.016 & 0.576 & 0.156 & 0.045 \\
\hline Any anemia & 901 & 0.524 & 0.489 & 0.518 & 0.420 & 0.595 & 0.937 & 0.094 & 0.707 & 0.315 & 0.189 \\
\hline Mild anemia & 901 & 0.204 & 0.250 & 0.253 & 0.223 & 0.445 & 0.375 & 0.699 & 0.964 & 0.671 & 0.609 \\
\hline Moderate/severe anemia & 901 & 0.320 & 0.239 & 0.265 & 0.196 & 0.184 & 0.350 & 0.017 & 0.693 & 0.485 & 0.237 \\
\hline Number of symptoms & 968 & $\begin{array}{c}1.045 \\
{[1.105]}\end{array}$ & $\begin{array}{c}1.121 \\
{[1.143]}\end{array}$ & $\begin{array}{c}1.034 \\
{[1.108]}\end{array}$ & $\begin{array}{c}1.090 \\
{[1.068]}\end{array}$ & 0.689 & 0.949 & 0.789 & 0.617 & 0.851 & 0.708 \\
\hline \multicolumn{12}{|l|}{ Cognitive test outcomes } \\
\hline Block design & 873 & $\begin{array}{c}3.132 \\
{[2.112]}\end{array}$ & $\begin{array}{c}3.407 \\
{[2.474]}\end{array}$ & $\begin{array}{c}3.627 \\
{[2.253]}\end{array}$ & $\begin{array}{c}3.607 \\
{[2.285]}\end{array}$ & 0.452 & 0.116 & 0.179 & 0.542 & 0.613 & 0.954 \\
\hline Digit span forward & 875 & $\begin{array}{c}3.817 \\
{[1.066]}\end{array}$ & $\begin{array}{c}4.148 \\
{[0.989]}\end{array}$ & $\begin{array}{c}3.880 \\
{[0.999]}\end{array}$ & $\begin{array}{c}4.043 \\
{[1.109]}\end{array}$ & 0.022 & 0.680 & 0.144 & 0.113 & 0.532 & 0.359 \\
\hline Digit span backward & 875 & $\begin{array}{c}0.969 \\
{[1.370]}\end{array}$ & $\begin{array}{c}1.148 \\
{[1.433]}\end{array}$ & $\begin{array}{c}1.213 \\
{[1.328]}\end{array}$ & $\begin{array}{c}1.120 \\
{[1.301]}\end{array}$ & 0.427 & 0.225 & 0.488 & 0.777 & 0.907 & 0.673 \\
\hline Progressive matrices & 873 & $\begin{array}{c}4.160 \\
{[1.607]}\end{array}$ & $\begin{array}{c}4.588 \\
{[1.833]}\end{array}$ & $\begin{array}{c}4.733 \\
{[1.655]}\end{array}$ & $\begin{array}{c}4.940 \\
{[1.821]}\end{array}$ & 0.077 & 0.028 & 0.001 & 0.625 & 0.208 & 0.482 \\
\hline Stroop test & 872 & $\begin{array}{c}4.702 \\
{[3.500]}\end{array}$ & $\begin{array}{c}5.012 \\
{[3.497]}\end{array}$ & $\begin{array}{c}6.127 \\
{[3.513]}\end{array}$ & $\begin{array}{c}5.526 \\
{[3.571]}\end{array}$ & 0.605 & 0.015 & 0.109 & 0.065 & 0.342 & 0.238 \\
\hline Cognitive score index & 868 & $\begin{array}{c}-0.354 \\
{[1.040]}\end{array}$ & $\begin{array}{l}-0.076 \\
{[0.984]}\end{array}$ & $\begin{array}{c}0.010 \\
{[1.061]}\end{array}$ & $\begin{array}{c}0.012 \\
{[1.059]}\end{array}$ & 0.080 & 0.020 & 0.031 & 0.594 & 0.614 & 0.989 \\
\hline \multicolumn{12}{|l|}{ Education outcomes } \\
\hline Math score & 873 & $\begin{array}{c}3.229 \\
{[3.693]}\end{array}$ & $\begin{array}{c}4.667 \\
{[3.821]}\end{array}$ & $\begin{array}{c}5.257 \\
{[4.135]}\end{array}$ & $\begin{array}{c}4.940 \\
{[3.905]}\end{array}$ & 0.026 & 0.006 & 0.012 & 0.447 & 0.707 & 0.692 \\
\hline Reading score & 874 & $\begin{array}{c}0.588 \\
{[0.935]}\end{array}$ & $\begin{array}{c}0.813 \\
{[1.092]}\end{array}$ & $\begin{array}{c}1.027 \\
{[1.078]}\end{array}$ & $\begin{array}{c}1.000 \\
{[1.189]}\end{array}$ & 0.188 & 0.011 & 0.016 & 0.270 & 0.334 & 0.889 \\
\hline School attendance & 885 & $\begin{array}{c}0.744 \\
{[0.202]}\end{array}$ & $\begin{array}{c}0.750 \\
{[0.192]}\end{array}$ & $\begin{array}{c}0.725 \\
{[0.215]}\end{array}$ & $\begin{array}{c}0.764 \\
{[0.169]}\end{array}$ & 0.862 & 0.652 & 0.559 & 0.523 & 0.634 & 0.321 \\
\hline \multicolumn{12}{|c|}{ Panel B: Child and household level control variables } \\
\hline Demographics and socioeconomic variables & & & & & & & & & & & \\
\hline Muslim & 968 & 0.026 & 0.000 & 0.080 & 0.016 & 0.038 & 0.225 & 0.573 & 0.061 & 0.160 & 0.150 \\
\hline Scheduled Caste/Scheduled Tribe & 968 & 0.338 & 0.308 & 0.182 & 0.254 & 0.716 & 0.062 & 0.317 & 0.107 & 0.494 & 0.358 \\
\hline Block & 968 & 1.273 & 1.407 & 1.170 & 1.434 & 0.228 & 0.366 & 0.164 & 0.042 & 0.813 & 0.030 \\
\hline Rural & 968 & 1.000 & 0.956 & 0.977 & 0.984 & 0.104 & 0.146 & 0.161 & 0.495 & 0.347 & 0.744 \\
\hline Family size & 968 & $\begin{array}{c}8.104 \\
{[3.938]}\end{array}$ & $\begin{array}{l}8.297 \\
{[3.650]}\end{array}$ & $\begin{array}{c}8.682 \\
{[4.782]}\end{array}$ & $\begin{array}{c}7.680 \\
{[3.160]}\end{array}$ & 0.744 & 0.393 & 0.394 & 0.575 & 0.231 & 0.101 \\
\hline Father's years of schooling & 947 & $\begin{array}{c}5.039 \\
{[4.867]}\end{array}$ & $\begin{array}{c}6.898 \\
{[5.128]}\end{array}$ & $\begin{array}{c}6.103 \\
{[5.095]}\end{array}$ & $\begin{array}{c}6.683 \\
{[4.871]}\end{array}$ & 0.012 & 0.148 & 0.030 & 0.289 & 0.780 & 0.454 \\
\hline Mother's years of schooling & 965 & $\begin{array}{c}1.542 \\
{[2.872]}\end{array}$ & $\begin{array}{c}3.189 \\
{[4.479]}\end{array}$ & $\begin{array}{c}2.818 \\
{[3.906]}\end{array}$ & $\begin{array}{c}2.844 \\
{[3.996]}\end{array}$ & 0.005 & 0.011 & 0.006 & 0.576 & 0.594 & 0.963 \\
\hline Asset index & 953 & $\begin{array}{c}-0.159 \\
{[0.863]}\end{array}$ & $\begin{array}{c}0.328 \\
{[1.264]}\end{array}$ & $\begin{array}{c}0.072 \\
{[0.974]}\end{array}$ & $\begin{array}{c}0.202 \\
{[1.177]}\end{array}$ & 0.011 & 0.068 & 0.024 & 0.182 & 0.557 & 0.421 \\
\hline \multicolumn{12}{|l|}{ Health care } \\
\hline Health insurance & 954 & $\begin{array}{c}0.412 \\
{[0.494]}\end{array}$ & $\begin{array}{l}0.416 \\
{[0.496]}\end{array}$ & $\begin{array}{c}0.471 \\
{[0.502]}\end{array}$ & $\begin{array}{c}0.426 \\
{[0.497]}\end{array}$ & 0.962 & 0.403 & 0.841 & 0.513 & 0.903 & 0.536 \\
\hline Diarrhea & 968 & 0.045 & 0.011 & 0.057 & 0.033 & 0.106 & 0.700 & 0.599 & 0.078 & 0.263 & 0.394 \\
\hline Improved sanitation & 968 & 0.071 & 0.132 & 0.114 & 0.131 & 0.157 & 0.322 & 0.177 & 0.708 & 0.989 & 0.727 \\
\hline \multicolumn{12}{|l|}{ Nutrition } \\
\hline Diet diversity score & 968 & $\begin{array}{c}3.864 \\
{[1.061]}\end{array}$ & $\begin{array}{c}3.890 \\
{[1.178]}\end{array}$ & $\begin{array}{c}3.920 \\
{[1.157]}\end{array}$ & $\begin{array}{c}4.156 \\
{[1.164]}\end{array}$ & 0.880 & 0.737 & 0.085 & 0.874 & 0.164 & 0.203 \\
\hline Number of meals/day & 968 & $\begin{array}{c}3.162 \\
{[0.967]}\end{array}$ & $\begin{array}{c}3.121 \\
{[0.964]}\end{array}$ & $\begin{array}{c}2.795 \\
{[1.195]}\end{array}$ & $\begin{array}{c}2.877 \\
{[1.140]}\end{array}$ & 0.731 & 0.006 & 0.037 & 0.038 & 0.126 & 0.624 \\
\hline Food scarcity & 966 & 0.837 & 0.758 & 0.816 & 0.689 & 0.202 & 0.684 & 0.013 & 0.350 & 0.311 & 0.034 \\
\hline Maternal health knowledge & 968 & 0.351 & 0.451 & 0.330 & 0.434 & 0.111 & 0.736 & 0.214 & 0.071 & 0.819 & 0.141 \\
\hline Child eats meat products & 968 & 0.584 & 0.516 & 0.500 & 0.615 & 0.303 & 0.162 & 0.653 & 0.813 & 0.198 & 0.110 \\
\hline Child received iron supplements & 958 & 0.222 & 0.165 & 0.172 & 0.229 & 0.323 & 0.438 & 0.911 & 0.909 & 0.299 & 0.403 \\
\hline \multicolumn{12}{|l|}{ Environment of care } \\
\hline Parents help with homework & 951 & 0.131 & 0.225 & 0.244 & 0.262 & 0.082 & 0.038 & 0.016 & 0.757 & 0.551 & 0.774 \\
\hline Parent's time spent for physical child care & 968 & $\begin{array}{c}43.994 \\
{[27.785]}\end{array}$ & $\begin{array}{c}43.846 \\
{[26.014]}\end{array}$ & $\begin{array}{c}43.295 \\
{[20.593]}\end{array}$ & $\begin{array}{c}45.680 \\
{[25.483]}\end{array}$ & 0.971 & 0.868 & 0.678 & 0.902 & 0.673 & 0.593 \\
\hline Parent attends school meetings & 965 & 0.610 & 0.500 & 0.693 & 0.607 & 0.157 & 0.257 & 0.957 & 0.024 & 0.195 & 0.264 \\
\hline Father lives at home & 967 & 0.857 & 0.890 & 0.795 & 0.803 & 0.485 & 0.253 & 0.282 & 0.098 & 0.105 & 0.895 \\
\hline Distance of school (min) & 968 & $\begin{array}{c}9.974 \\
{[5.935]}\end{array}$ & $\begin{array}{l}10.330 \\
{[6.039]}\end{array}$ & $\begin{array}{l}11.420 \\
{[6.430]}\end{array}$ & $\begin{array}{c}9.795 \\
{[5.288]}\end{array}$ & 0.692 & 0.101 & 0.828 & 0.237 & 0.539 & 0.057 \\
\hline \multicolumn{12}{|l|}{ Panel C: School level covariates } \\
\hline Number of children enrolled in school & 347 & $\begin{array}{c}249.545 \\
{[150.475]}\end{array}$ & $\begin{array}{c}193.983 \\
{[117.046]}\end{array}$ & $\begin{array}{c}324.148 \\
{[181.564]}\end{array}$ & $\begin{array}{c}197.780 \\
{[147.681]}\end{array}$ & 0.045 & 0.077 & 0.085 & 0.001 & 0.878 & 0.002 \\
\hline Class size & 349 & $\begin{array}{c}30.886 \\
{[12.029]}\end{array}$ & $\begin{array}{c}28.069 \\
{[11.829]}\end{array}$ & $\begin{array}{c}33.556 \\
{[25.044]}\end{array}$ & $\begin{array}{l}30.847 \\
{[20.144]}\end{array}$ & 0.241 & 0.605 & 0.990 & 0.279 & 0.364 & 0.621 \\
\hline Student teacher ratio & 347 & $\begin{array}{l}36.322 \\
{[9.818]}\end{array}$ & $\begin{array}{l}35.047 \\
{[9.212]}\end{array}$ & $\begin{array}{c}40.301 \\
{[11.684]}\end{array}$ & $\begin{array}{c}37.978 \\
{[12.807]}\end{array}$ & 0.506 & 0.143 & 0.459 & 0.042 & 0.158 & 0.407 \\
\hline Calories of MDM per child & 349 & $\begin{array}{c}66.206 \\
{[22.464]}\end{array}$ & $\begin{array}{c}62.802 \\
{[21.574]}\end{array}$ & $\begin{array}{c}69.431 \\
{[21.499]}\end{array}$ & $\begin{array}{c}69.591 \\
{[19.919]}\end{array}$ & 0.442 & 0.548 & 0.429 & 0.188 & 0.080 & 0.974 \\
\hline Amount of iron in MDM per child (mg) & 349 & $\begin{array}{c}0.712 \\
{[0.251]}\end{array}$ & $\begin{array}{c}0.691 \\
{[0.226]}\end{array}$ & $\begin{array}{c}0.782 \\
{[0.312]}\end{array}$ & $\begin{array}{c}0.815 \\
{[0.317]}\end{array}$ & 0.676 & 0.326 & 0.067 & 0.179 & 0.016 & 0.643 \\
\hline \multicolumn{12}{|l|}{ Joint orthogonalitiy F-test } \\
\hline F-statistics & & 2.402 & 1.352 & 1.962 & 1.352 & 2.526 & $\begin{array}{r}3.705 \\
50001\end{array}$ & 2.998 & 10.376 & 4.137 & 11.377 \\
\hline
\end{tabular}

Notes: Columns 2-5 report wave I means by intervention arm for child (Panel A and B) and schools (Panel C) in the study analysis. Columns 6-11 report p-values from tests on the equality of means for each variable. F-tests of joint significance: test of joint significance in regression of respective treatment dummies on all displayed wave I variables.

Source: Own Data. 
Table C.29: Balancing Table of Attrited Members of Exposure Group Using Wave II Data for Health Outcomes

\begin{tabular}{|c|c|c|c|c|c|c|c|c|c|c|c|}
\hline & \multirow[b]{2}{*}{ Observations } & \multicolumn{4}{|c|}{ Means [Standard Deviations] } & \multicolumn{6}{|c|}{$p$-value of difference } \\
\hline & & Group Always & Early & Late & Hardly & Always-Early & Always-Late & Always-Hardly & Early-Late & Early-Hardly & Late-Hardly \\
\hline \multicolumn{12}{|l|}{ Panel A. Child level outcome variables } \\
\hline \multicolumn{12}{|l|}{ Health outcomes } \\
\hline Hemoglobin (g/dL) & 605 & $\begin{array}{l}11.946 \\
{[1.062]}\end{array}$ & $\begin{array}{l}11.951 \\
{[0.977]}\end{array}$ & $\begin{array}{l}11.476 \\
{[0.996]}\end{array}$ & $\begin{array}{l}11.930 \\
{[0.824]}\end{array}$ & 0.974 & 0.009 & 0.898 & 0.025 & 0.900 & 0.014 \\
\hline Any anemia & 605 & 0.330 & 0.200 & 0.452 & 0.303 & 0.071 & 0.164 & 0.680 & 0.015 & 0.217 & 0.127 \\
\hline Mild anemia & 605 & 0.160 & 0.091 & 0.143 & 0.158 & 0.213 & 0.784 & 0.974 & 0.421 & 0.227 & 0.807 \\
\hline Moderate/severe anemia & 605 & 0.170 & 0.109 & 0.310 & 0.145 & 0.329 & 0.060 & 0.669 & 0.009 & 0.561 & 0.025 \\
\hline Number of symptoms & 630 & $\begin{array}{c}2.140 \\
{[1.273]}\end{array}$ & $\begin{array}{c}2.281 \\
{[1.485]}\end{array}$ & $\begin{array}{c}2.063 \\
{[1.156]}\end{array}$ & $\begin{array}{c}2.084 \\
{[1.354]}\end{array}$ & 0.549 & 0.775 & 0.780 & 0.458 & 0.392 & 0.934 \\
\hline \multicolumn{12}{|l|}{ Cognitive test outcomes } \\
\hline Block design & 651 & $\begin{array}{c}3.819 \\
{[2.355]}\end{array}$ & $\begin{array}{c}4.656 \\
{[2.198]}\end{array}$ & $\begin{array}{c}4.000 \\
{[2.269]}\end{array}$ & $\begin{array}{c}4.357 \\
{[2.081]}\end{array}$ & 0.028 & 0.599 & 0.059 & 0.117 & 0.414 & 0.286 \\
\hline Digit span forward & 651 & $\begin{array}{c}4.309 \\
{[1.037]}\end{array}$ & $\begin{array}{c}4.541 \\
{[0.923]}\end{array}$ & $\begin{array}{c}4.438 \\
{[0.823]}\end{array}$ & $\begin{array}{c}4.512 \\
{[0.938]}\end{array}$ & 0.195 & 0.441 & 0.219 & 0.552 & 0.865 & 0.641 \\
\hline Digit span backward & 651 & $\begin{array}{c}1.351 \\
{[1.350]}\end{array}$ & $\begin{array}{c}1.738 \\
{[1.537]}\end{array}$ & $\begin{array}{c}1.542 \\
{[1.414]}\end{array}$ & $\begin{array}{c}1.619 \\
{[1.413]}\end{array}$ & 0.143 & 0.436 & 0.242 & 0.475 & 0.648 & 0.748 \\
\hline Progressive matrices & 651 & $\begin{array}{c}4.809 \\
{[1.505]}\end{array}$ & $\begin{array}{c}4.869 \\
{[1.489]}\end{array}$ & $\begin{array}{c}4.854 \\
{[1.271]}\end{array}$ & $\begin{array}{c}5.036 \\
{[1.452]}\end{array}$ & 0.820 & 0.860 & 0.366 & 0.958 & 0.542 & 0.496 \\
\hline Stroop test & 651 & $\begin{array}{c}5.473 \\
{[3.869]}\end{array}$ & $\begin{array}{c}6.910 \\
{[4.119]}\end{array}$ & $\begin{array}{c}5.646 \\
{[4.290]}\end{array}$ & $\begin{array}{c}6.417 \\
{[3.912]}\end{array}$ & 0.063 & 0.821 & 0.174 & 0.113 & 0.492 & 0.285 \\
\hline Cognitive score index & 651 & $\begin{array}{l}-0.421 \\
{[1.103]}\end{array}$ & $\begin{array}{l}-0.015 \\
{[1.140]}\end{array}$ & $\begin{array}{l}-0.294 \\
{[1.066]}\end{array}$ & $\begin{array}{l}-0.109 \\
{[1.035]}\end{array}$ & 0.051 & 0.491 & 0.082 & 0.198 & 0.655 & 0.329 \\
\hline \multicolumn{12}{|l|}{ Education outcomes } \\
\hline Math score & 651 & $\begin{array}{c}6.234 \\
{[5.169]}\end{array}$ & $\begin{array}{l}8.164 \\
{[5.050]}\end{array}$ & $\begin{array}{c}8.417 \\
{[4.589]}\end{array}$ & $\begin{array}{c}8.786 \\
{[4.552]}\end{array}$ & 0.070 & 0.020 & 0.007 & 0.801 & 0.539 & 0.671 \\
\hline Reading score & 651 & $\begin{array}{c}1.138 \\
{[1.404]}\end{array}$ & $\begin{array}{c}1.656 \\
{[1.504]}\end{array}$ & $\begin{array}{c}1.729 \\
{[1.469]}\end{array}$ & $\begin{array}{c}1.595 \\
{[1.553]}\end{array}$ & 0.053 & 0.033 & 0.106 & 0.804 & 0.843 & 0.667 \\
\hline School attendance & 644 & $\begin{array}{c}0.724 \\
{[0.205]}\end{array}$ & $\begin{array}{c}0.649 \\
{[0.273]}\end{array}$ & $\begin{array}{c}0.736 \\
{[0.152]}\end{array}$ & $\begin{array}{c}0.721 \\
{[0.177]}\end{array}$ & 0.159 & 0.777 & 0.934 & 0.080 & 0.133 & 0.660 \\
\hline \multicolumn{12}{|c|}{ Panel B: Child and household level control variables } \\
\hline \multicolumn{12}{|l|}{ Demographics and socioeconomic variables } \\
\hline Muslim & 630 & 0.032 & 0.000 & 0.104 & 0.024 & 0.077 & 0.206 & 0.742 & 0.055 & 0.161 & 0.157 \\
\hline Scheduled Caste/Scheduled Tribe & 622 & 0.370 & 0.281 & 0.239 & 0.253 & 0.400 & 0.201 & 0.227 & 0.667 & 0.761 & 0.872 \\
\hline Block & 651 & 1.213 & 1.410 & 1.104 & 1.464 & 0.101 & 0.250 & 0.045 & 0.010 & 0.699 & 0.004 \\
\hline Rural & 651 & 1.000 & 0.967 & 0.979 & 0.976 & 0.166 & 0.321 & 0.161 & 0.705 & 0.757 & 0.912 \\
\hline Family size & 630 & $\begin{array}{c}7.699 \\
{[3.448]}\end{array}$ & $\begin{array}{c}7.491 \\
{[2.653]}\end{array}$ & $\begin{array}{c}7.479 \\
{[2.666]}\end{array}$ & $\begin{array}{c}7.795 \\
{[3.215]}\end{array}$ & 0.717 & 0.702 & 0.870 & 0.980 & 0.538 & 0.525 \\
\hline Father's years of schooling & 625 & $\begin{array}{c}4.891 \\
{[4.505]}\end{array}$ & $\begin{array}{c}6.684 \\
{[5.471]}\end{array}$ & $\begin{array}{c}5.708 \\
{[4.981]}\end{array}$ & $\begin{array}{c}7.337 \\
{[4.910]}\end{array}$ & 0.059 & 0.335 & 0.008 & 0.291 & 0.504 & 0.069 \\
\hline Mother's years of schooling & 627 & $\begin{array}{l}1.183 \\
{[2.766]}\end{array}$ & $\begin{array}{l}2.544 \\
{[4.192]}\end{array}$ & $\begin{array}{c}2.298 \\
{[3.413]}\end{array}$ & $\begin{array}{c}2.482 \\
{[3.995]}\end{array}$ & 0.048 & 0.088 & 0.037 & 0.758 & 0.936 & 0.804 \\
\hline Asset index & 618 & $\begin{array}{l}-0.301 \\
{[0.819]}\end{array}$ & $\begin{array}{c}0.262 \\
{[1.184]}\end{array}$ & $\begin{array}{c}0.048 \\
{[0.893]}\end{array}$ & $\begin{array}{c}0.253 \\
{[1.130]}\end{array}$ & 0.017 & 0.115 & 0.010 & 0.421 & 0.973 & 0.408 \\
\hline \multicolumn{12}{|l|}{ Health care } \\
\hline Institutional delivery & 650 & 0.309 & 0.410 & 0.333 & 0.393 & 0.218 & 0.788 & 0.279 & 0.440 & 0.842 & 0.533 \\
\hline Health insurance & 619 & $\begin{array}{c}0.182 \\
{[0.388]}\end{array}$ & $\begin{array}{c}0.281 \\
{[0.453]}\end{array}$ & $\begin{array}{c}0.170 \\
{[0.380]}\end{array}$ & $\begin{array}{c}0.244 \\
{[0.432]}\end{array}$ & 0.174 & 0.874 & 0.344 & 0.176 & 0.619 & 0.328 \\
\hline Diarrhea & 630 & 0.290 & 0.298 & 0.250 & 0.193 & 0.921 & 0.670 & 0.168 & 0.614 & 0.143 & 0.512 \\
\hline Improved sanitation & 628 & 0.054 & 0.193 & 0.170 & 0.157 & 0.023 & 0.082 & 0.058 & 0.786 & 0.624 & 0.864 \\
\hline \multicolumn{12}{|l|}{ Nutrition } \\
\hline Diet diversity score & 629 & $\begin{array}{c}3.839 \\
{[1.191]}\end{array}$ & $\begin{array}{c}3.982 \\
{[1.261]}\end{array}$ & $\begin{array}{c}4.191 \\
{[1.116]}\end{array}$ & $\begin{array}{c}3.940 \\
{[1.301]}\end{array}$ & 0.580 & 0.100 & 0.665 & 0.437 & 0.881 & 0.301 \\
\hline Number of meals/day & 630 & $\begin{array}{c}3.806 \\
{[0.664]}\end{array}$ & $\begin{array}{c}3.509 \\
{[0.630]}\end{array}$ & $\begin{array}{c}3.813 \\
{[0.673]}\end{array}$ & $\begin{array}{c}3.530 \\
{[0.631]}\end{array}$ & 0.011 & 0.960 & 0.015 & 0.018 & 0.852 & 0.023 \\
\hline Food scarcity & 630 & 0.430 & 0.439 & 0.583 & 0.422 & 0.927 & 0.128 & 0.921 & 0.153 & 0.843 & 0.087 \\
\hline Maternal health knowledge & 630 & 0.161 & 0.368 & 0.396 & 0.313 & 0.008 & 0.002 & 0.047 & 0.739 & 0.515 & 0.311 \\
\hline Child eats meat products & 630 & 0.527 & 0.491 & 0.625 & 0.554 & 0.697 & 0.293 & 0.770 & 0.148 & 0.495 & 0.451 \\
\hline Child received iron supplements & 621 & 0.144 & 0.018 & 0.128 & 0.060 & 0.014 & 0.786 & 0.128 & 0.013 & 0.194 & 0.162 \\
\hline \multicolumn{12}{|l|}{ Environment of care } \\
\hline Parents help with homework & 629 & 0.269 & 0.351 & 0.458 & 0.410 & 0.371 & 0.054 & 0.092 & 0.332 & 0.550 & 0.637 \\
\hline Parent's time spent for physical child care & 615 & $\begin{array}{c}52.191 \\
{[29.290]}\end{array}$ & $\begin{array}{c}42.222 \\
{[25.415]}\end{array}$ & $\begin{array}{c}42.872 \\
{[38.515]}\end{array}$ & $\begin{array}{c}40.926 \\
{[35.550]}\end{array}$ & 0.061 & 0.159 & 0.030 & 0.925 & 0.816 & 0.775 \\
\hline Parent attends school meetings & 625 & 0.446 & 0.368 & 0.375 & 0.337 & 0.416 & 0.523 & 0.213 & 0.954 & 0.734 & 0.726 \\
\hline Father lives at home & 630 & 0.860 & 0.860 & 0.854 & 0.831 & 0.993 & 0.917 & 0.599 & 0.938 & 0.675 & 0.702 \\
\hline Distance of school (min) & 630 & $\begin{array}{l}12.871 \\
{[9.249]}\end{array}$ & $\begin{array}{c}13.544 \\
{[13.092]}\end{array}$ & $\begin{array}{l}10.354 \\
{[6.518]}\end{array}$ & $\begin{array}{c}13.301 \\
{[12.490]}\end{array}$ & 0.752 & 0.125 & 0.824 & 0.132 & 0.918 & 0.124 \\
\hline \multicolumn{12}{|l|}{ Panel C: School level covariates } \\
\hline Number of children enrolled in school & 275 & $\begin{array}{c}267.289 \\
{[234.032]}\end{array}$ & $\begin{array}{c}168.238 \\
{[109.844]}\end{array}$ & $\begin{array}{c}334.182 \\
{[205.308]}\end{array}$ & $\begin{array}{c}170.186 \\
{[146.926]}\end{array}$ & 0.020 & 0.252 & 0.030 & 0.001 & 0.945 & 0.001 \\
\hline Class size & 275 & $\begin{array}{c}30.895 \\
{[15.002]}\end{array}$ & $\begin{array}{c}27.405 \\
{[12.335]}\end{array}$ & $\begin{array}{c}34.727 \\
{[24.310]}\end{array}$ & $\begin{array}{c}31.512 \\
{[18.938]}\end{array}$ & 0.262 & 0.504 & 0.871 & 0.187 & 0.238 & 0.588 \\
\hline Student teacher ratio & 275 & $\begin{array}{c}37.178 \\
{[18.291]}\end{array}$ & $\begin{array}{l}32.802 \\
{[9.931]}\end{array}$ & $\begin{array}{c}42.950 \\
{[11.993]}\end{array}$ & $\begin{array}{c}37.921 \\
{[16.788]}\end{array}$ & 0.194 & 0.146 & 0.850 & 0.001 & 0.090 & 0.169 \\
\hline Calories of MDM per child & 275 & $\begin{array}{c}93.928 \\
{[109.730]}\end{array}$ & $\begin{array}{c}96.199 \\
{[104.679]}\end{array}$ & $\begin{array}{c}81.366 \\
{[38.314]}\end{array}$ & $\begin{array}{c}69.654 \\
{[27.273]}\end{array}$ & 0.925 & 0.525 & 0.188 & 0.416 & 0.115 & 0.204 \\
\hline Amount of iron in MDM per child (mg) & 275 & $\begin{array}{c}0.831 \\
{[0.873]}\end{array}$ & $\begin{array}{c}0.813 \\
{[0.851]}\end{array}$ & $\begin{array}{c}0.786 \\
{[0.385]}\end{array}$ & $\begin{array}{c}0.560 \\
{[0.205]}\end{array}$ & 0.926 & 0.783 & 0.065 & 0.860 & 0.065 & 0.012 \\
\hline \multicolumn{12}{|l|}{ Joint orthogonalitiy F-test } \\
\hline F-statistics & & 2.402 & 1.352 & 1.962 & 1.352 & 2.526 & 3.705 & 2.998 & 10.376 & 4.137 & 11.377 \\
\hline $\mathrm{p}$-Value & & {$[0.000]$} & [0.097] & [0.002] & {$[0.097]$} & {$[0.000]$} & [0.000] & {$[0.000]$} & {$[0.000]$} & {$[0.000]$} & {$[0.000]$} \\
\hline
\end{tabular}

Notes: Columns 2-5 report wave I means by intervention arm for child (Panel A and B) and schools (Panel C) in the study analysis. Columns 6-11 report p-values from tests on the equality of means for each variable. F-tests of joint significance: test of joint significance in regression of respective treatment dummies on all displayed wave I variables.

Source: Own Data. 
Table C.30: Balancing Table of Attrited Members of Exposure Group Using Baseline Data for Attendance Outcome

\begin{tabular}{|c|c|c|c|c|c|c|c|c|c|c|c|}
\hline & \multirow[b]{2}{*}{ Observations } & \multicolumn{4}{|c|}{ Means [Standard Deviations] } & \multicolumn{6}{|c|}{$p$-value of difference } \\
\hline & & Group Always & Early & Late & Hardly & Always-Early & Always-Late & Always-Hardly & Early-Late & Early-Hardly & Late-Hardly \\
\hline \multicolumn{12}{|l|}{ Panel A. Child level outcome variables } \\
\hline \multicolumn{12}{|l|}{ Health outcomes } \\
\hline Hemoglobin $(\mathrm{g} / \mathrm{dL})$ & 574 & $\begin{array}{l}11.566 \\
{[0.976]}\end{array}$ & $\begin{array}{l}11.460 \\
{[1.198]}\end{array}$ & $\begin{array}{l}11.342 \\
{[0.967]}\end{array}$ & $\begin{array}{l}12.118 \\
{[0.780]}\end{array}$ & 0.751 & 0.278 & 0.017 & 0.738 & 0.079 & 0.004 \\
\hline Any anemia & 574 & 0.489 & 0.667 & 0.583 & 0.176 & 0.212 & 0.471 & 0.010 & 0.616 & 0.003 & 0.008 \\
\hline Mild anemia & 574 & 0.234 & 0.400 & 0.250 & 0.118 & 0.191 & 0.884 & 0.220 & 0.318 & 0.047 & 0.287 \\
\hline Moderate/severe anemia & 574 & 0.255 & 0.267 & 0.333 & 0.059 & 0.931 & 0.487 & 0.032 & 0.650 & 0.115 & 0.018 \\
\hline Number of symptoms & 624 & $\begin{array}{c}0.896 \\
{[1.036]}\end{array}$ & $\begin{array}{c}0.706 \\
{[0.920]}\end{array}$ & $\begin{array}{c}1.519 \\
{[1.252]}\end{array}$ & $\begin{array}{c}0.895 \\
{[0.994]}\end{array}$ & 0.503 & 0.028 & 0.997 & 0.018 & 0.557 & 0.051 \\
\hline \multicolumn{12}{|l|}{ Cognitive test outcomes } \\
\hline Block design & 567 & $\begin{array}{c}3.432 \\
{[2.472]}\end{array}$ & $\begin{array}{c}4.214 \\
{[2.225]}\end{array}$ & $\begin{array}{c}3.667 \\
{[2.517]}\end{array}$ & $\begin{array}{c}4.000 \\
{[2.208]}\end{array}$ & 0.309 & 0.757 & 0.454 & 0.503 & 0.791 & 0.680 \\
\hline Digit span forward & 567 & $\begin{array}{c}3.659 \\
{[1.010]}\end{array}$ & $\begin{array}{c}4.357 \\
{[1.008]}\end{array}$ & $\begin{array}{c}3.905 \\
{[0.768]}\end{array}$ & $\begin{array}{c}4.235 \\
{[0.970]}\end{array}$ & 0.023 & 0.345 & 0.073 & 0.104 & 0.705 & 0.264 \\
\hline Digit span backward & 567 & $\begin{array}{c}0.727 \\
{[1.107]}\end{array}$ & $\begin{array}{c}1.000 \\
{[1.240]}\end{array}$ & $\begin{array}{l}1.238 \\
{[1.261]}\end{array}$ & $\begin{array}{c}1.588 \\
{[1.278]}\end{array}$ & 0.415 & 0.258 & 0.037 & 0.617 & 0.176 & 0.502 \\
\hline Progressive matrices & 565 & $\begin{array}{c}4.250 \\
{[2.179]}\end{array}$ & $\begin{array}{c}4.538 \\
{[2.106]}\end{array}$ & $\begin{array}{c}4.762 \\
{[1.729]}\end{array}$ & $\begin{array}{c}5.471 \\
{[1.231]}\end{array}$ & 0.727 & 0.513 & 0.054 & 0.797 & 0.199 & 0.285 \\
\hline Stroop test & 566 & $\begin{array}{c}4.114 \\
{[3.476]}\end{array}$ & $\begin{array}{c}5.250 \\
{[3.567]}\end{array}$ & $\begin{array}{c}4.619 \\
{[3.844]}\end{array}$ & $\begin{array}{c}5.559 \\
{[3.107]}\end{array}$ & 0.331 & 0.681 & 0.198 & 0.615 & 0.784 & 0.436 \\
\hline Cognitive score index & 564 & $\begin{array}{l}-0.449 \\
{[1.156]}\end{array}$ & $\begin{array}{c}0.111 \\
{[1.175]}\end{array}$ & $\begin{array}{l}-0.101 \\
{[1.090]}\end{array}$ & $\begin{array}{c}0.318 \\
{[0.979]}\end{array}$ & 0.203 & 0.454 & 0.059 & 0.649 & 0.597 & 0.328 \\
\hline \multicolumn{12}{|l|}{ Education outcomes } \\
\hline Math score & 566 & $\begin{array}{c}4.159 \\
{[4.215]}\end{array}$ & $\begin{array}{c}5.500 \\
{[3.956]}\end{array}$ & $\begin{array}{c}5.238 \\
{[3.767]}\end{array}$ & $\begin{array}{c}5.824 \\
{[3.909]}\end{array}$ & 0.335 & 0.305 & 0.208 & 0.843 & 0.833 & 0.637 \\
\hline Reading score & 567 & $\begin{array}{c}0.682 \\
{[0.959]}\end{array}$ & $\begin{array}{c}0.786 \\
{[1.311]}\end{array}$ & $\begin{array}{c}0.952 \\
{[1.117]}\end{array}$ & $\begin{array}{c}1.118 \\
{[0.993]}\end{array}$ & 0.817 & 0.313 & 0.160 & 0.716 & 0.492 & 0.600 \\
\hline School attendance & 505 & $\begin{array}{c}0.746 \\
{[0.254]}\end{array}$ & $\begin{array}{c}0.628 \\
{[0.314]}\end{array}$ & $\begin{array}{c}0.614 \\
{[0.226]}\end{array}$ & $\begin{array}{c}0.713 \\
{[0.135]}\end{array}$ & 0.444 & 0.267 & 0.738 & 0.920 & 0.508 & 0.186 \\
\hline \multicolumn{12}{|c|}{ Panel B: Child and household level control variables } \\
\hline \multicolumn{12}{|l|}{ Demographics and socioeconomic variables } \\
\hline Muslim & 624 & 0.000 & 0.000 & 0.111 & 0.053 & & 0.122 & 0.301 & 0.124 & 0.304 & 0.502 \\
\hline Scheduled Caste/Scheduled Tribe & 624 & 0.396 & 0.235 & 0.037 & 0.263 & 0.262 & 0.002 & 0.379 & 0.083 & 0.859 & 0.072 \\
\hline Block & 624 & 1.313 & 1.471 & 1.333 & 1.211 & 0.518 & 0.935 & 0.653 & 0.539 & 0.174 & 0.547 \\
\hline Rural & 624 & 1.000 & 1.000 & 1.000 & 1.000 & & & & & & \\
\hline Family size & 624 & $\begin{array}{c}8.333 \\
{[4.402]}\end{array}$ & $\begin{array}{c}9.176 \\
{[5.053]}\end{array}$ & $\begin{array}{c}8.259 \\
{[3.300]}\end{array}$ & $\begin{array}{c}7.158 \\
{[2.167]}\end{array}$ & 0.581 & 0.948 & 0.247 & 0.537 & 0.152 & 0.242 \\
\hline Father's years of schooling & 607 & $\begin{array}{c}5.362 \\
{[4.594]}\end{array}$ & $\begin{array}{c}5.000 \\
{[5.534]}\end{array}$ & $\begin{array}{c}5.538 \\
{[4.150]}\end{array}$ & $\begin{array}{c}6.579 \\
{[5.178]}\end{array}$ & 0.836 & 0.883 & 0.452 & 0.750 & 0.432 & 0.503 \\
\hline Mother's years of schooling & 623 & $\begin{array}{c}1.563 \\
{[2.873]}\end{array}$ & $\begin{array}{c}3.824 \\
{[5.615]}\end{array}$ & $\begin{array}{c}1.667 \\
{[2.774]}\end{array}$ & $\begin{array}{c}2.737 \\
{[4.227]}\end{array}$ & 0.177 & 0.901 & 0.306 & 0.202 & 0.555 & 0.359 \\
\hline Asset index & 613 & $\begin{array}{l}-0.300 \\
{[0.691]}\end{array}$ & $\begin{array}{c}0.379 \\
{[1.555]}\end{array}$ & $\begin{array}{l}-0.053 \\
{[1.013]}\end{array}$ & $\begin{array}{c}0.096 \\
{[0.962]}\end{array}$ & 0.123 & 0.287 & 0.072 & 0.348 & 0.528 & 0.564 \\
\hline Gender of the child & 588 & 0.417 & 0.733 & 0.423 & 0.500 & 0.050 & 0.962 & 0.623 & 0.057 & 0.224 & 0.652 \\
\hline \multicolumn{12}{|l|}{ Health care } \\
\hline Institutional delivery & 622 & 0.417 & 0.529 & 0.296 & 0.579 & 0.439 & 0.319 & 0.246 & 0.171 & 0.785 & 0.088 \\
\hline Health insurance & 612 & $\begin{array}{c}0.391 \\
{[0.493]}\end{array}$ & $\begin{array}{c}0.471 \\
{[0.514]}\end{array}$ & $\begin{array}{c}0.296 \\
{[0.465]}\end{array}$ & $\begin{array}{c}0.421 \\
{[0.507]}\end{array}$ & 0.648 & 0.419 & 0.857 & 0.294 & 0.806 & 0.424 \\
\hline Diarrhea & 624 & 0.063 & 0.059 & 0.074 & 0.000 & 0.957 & 0.846 & 0.059 & 0.846 & 0.331 & 0.148 \\
\hline Improved sanitation & 624 & 0.083 & 0.235 & 0.148 & 0.000 & 0.276 & 0.455 & 0.103 & 0.555 & 0.076 & 0.043 \\
\hline \multicolumn{12}{|l|}{ Nutrition } \\
\hline Diet diversity score & 624 & $\begin{array}{c}3.750 \\
{[1.101]}\end{array}$ & $\begin{array}{c}4.471 \\
{[1.231]}\end{array}$ & $\begin{array}{c}3.889 \\
{[1.050]}\end{array}$ & $\begin{array}{c}4.421 \\
{[1.121]}\end{array}$ & 0.031 & 0.397 & 0.031 & 0.086 & 0.905 & 0.092 \\
\hline Number of meals/day & 624 & $\begin{array}{c}3.229 \\
{[0.994]}\end{array}$ & $\begin{array}{c}3.118 \\
{[0.928]}\end{array}$ & $\begin{array}{c}2.963 \\
{[1.255]}\end{array}$ & $\begin{array}{l}2.368 \\
{[1.535]}\end{array}$ & 0.691 & 0.226 & 0.022 & 0.604 & 0.079 & 0.120 \\
\hline Food scarcity & 624 & 0.833 & 0.647 & 0.852 & 0.684 & 0.274 & 0.882 & 0.328 & 0.214 & 0.840 & 0.251 \\
\hline Maternal health knowledge & 624 & 0.354 & 0.412 & 0.370 & 0.421 & 0.712 & 0.869 & 0.631 & 0.799 & 0.961 & 0.728 \\
\hline Child eats meat products & 624 & 0.542 & 0.765 & 0.556 & 0.737 & 0.069 & 0.891 & 0.126 & 0.092 & 0.844 & 0.159 \\
\hline Child received iron supplements & 618 & 0.149 & 0.059 & 0.111 & 0.278 & 0.228 & 0.630 & 0.273 & 0.558 & 0.086 & 0.196 \\
\hline \multicolumn{12}{|l|}{ Environment of care } \\
\hline Parents help with homework & 610 & 0.170 & 0.294 & 0.154 & 0.368 & 0.428 & 0.881 & 0.138 & 0.371 & 0.666 & 0.109 \\
\hline Parent's time spent for physical child care & 624 & $\begin{array}{c}45.521 \\
{[19.712]}\end{array}$ & $\begin{array}{c}37.235 \\
{[17.782]}\end{array}$ & $\begin{array}{c}47.407 \\
{[24.937]}\end{array}$ & $\begin{array}{c}50.263 \\
{[18.445]}\end{array}$ & 0.144 & 0.786 & 0.270 & 0.233 & 0.047 & 0.707 \\
\hline Parent attends school meetings & 622 & 0.563 & 0.647 & 0.741 & 0.526 & 0.564 & 0.212 & 0.793 & 0.535 & 0.416 & 0.139 \\
\hline Father lives at home & 623 & 0.917 & 0.882 & 0.889 & 0.895 & 0.676 & 0.703 & 0.769 & 0.950 & 0.906 & 0.952 \\
\hline Distance of school (min) & 624 & $\begin{array}{l}11.063 \\
{[6.200]}\end{array}$ & $\begin{array}{c}8.824 \\
{[3.909]}\end{array}$ & $\begin{array}{l}11.778 \\
{[6.375]}\end{array}$ & $\begin{array}{l}10.421 \\
{[4.087]}\end{array}$ & 0.101 & 0.638 & 0.638 & 0.053 & 0.229 & 0.368 \\
\hline \multicolumn{12}{|l|}{ Panel C: School level covariates } \\
\hline Number of children enrolled in school & 215 & $\begin{array}{c}360.500 \\
{[145.421]}\end{array}$ & $\begin{array}{l}233.429 \\
{[99.556]}\end{array}$ & $\begin{array}{c}374.917 \\
{[204.130]}\end{array}$ & $\begin{array}{c}208.813 \\
{[111.519]}\end{array}$ & 0.012 & 0.840 & 0.004 & 0.038 & 0.528 & 0.016 \\
\hline Class size & 217 & $\begin{array}{c}37.929 \\
{[13.315]}\end{array}$ & $\begin{array}{c}33.429 \\
{[10.479]}\end{array}$ & $\begin{array}{c}37.667 \\
{[29.525]}\end{array}$ & $\begin{array}{c}34.500 \\
{[11.978]}\end{array}$ & 0.329 & 0.978 & 0.467 & 0.640 & 0.796 & 0.727 \\
\hline Student teacher ratio & 215 & $\begin{array}{l}41.298 \\
{[11.141]}\end{array}$ & $\begin{array}{l}35.160 \\
{[8.183]}\end{array}$ & $\begin{array}{c}39.003 \\
{[12.626]}\end{array}$ & $\begin{array}{l}41.761 \\
{[14.263]}\end{array}$ & 0.108 & 0.630 & 0.921 & 0.374 & 0.126 & 0.593 \\
\hline Calories of MDM per child & 217 & $\begin{array}{c}54.839 \\
{[14.822]}\end{array}$ & $\begin{array}{c}58.350 \\
{[20.480]}\end{array}$ & $\begin{array}{c}67.763 \\
{[25.479]}\end{array}$ & $\begin{array}{c}65.578 \\
{[19.495]}\end{array}$ & 0.608 & 0.134 & 0.098 & 0.314 & 0.332 & 0.806 \\
\hline Amount of iron in MDM per child (mg) & 217 & $\begin{array}{c}0.632 \\
{[0.151]}\end{array}$ & $\begin{array}{c}0.661 \\
{[0.176]} \\
\end{array}$ & $\begin{array}{c}0.734 \\
{[0.367]} \\
\end{array}$ & $\begin{array}{c}0.818 \\
{[0.282]}\end{array}$ & 0.638 & 0.374 & 0.030 & 0.534 & 0.075 & 0.515 \\
\hline \multicolumn{12}{|l|}{ Joint orthogonalitiy F-test } \\
\hline F-statistics & & $\begin{array}{ll}2.402 \\
{[0.0001}\end{array}$ & $\begin{array}{ll}1.352 \\
{[0.0971}\end{array}$ & $\begin{array}{c}1.962 \\
{[0.002]}\end{array}$ & $\begin{array}{c}1.352 \\
{[0.097]}\end{array}$ & $\begin{array}{c}2.526 \\
{[0.000]}\end{array}$ & $\begin{array}{c}3.705 \\
{[0.000]}\end{array}$ & $\begin{array}{c}2.998 \\
{[0.000]}\end{array}$ & $\begin{array}{l}10.376 \\
\end{array}$ & $\begin{array}{c}4.137 \\
{[0.000]}\end{array}$ & $\begin{array}{l}11.377 \\
\lceil 0.0001\end{array}$ \\
\hline
\end{tabular}

Notes: Columns 2-5 report wave I means by intervention arm for child (Panel A and B) and schools (Panel C) in the study analysis. Columns 6-11 report p-values from tests on the equality of means for each variable. F-tests of joint significance: test of joint significance in regression of respective treatment dummies on all displayed wave I variables.

Source: Own Data. 
Table C.31: Balancing Table of Attrited Members of Exposure Group Using Wave I Data for Health Outcomes

\begin{tabular}{|c|c|c|c|c|c|c|c|c|c|c|c|}
\hline & \multirow[b]{2}{*}{ Observations } & \multicolumn{4}{|c|}{ Means [Standard Deviations] } & \multicolumn{6}{|c|}{$p$-value of difference } \\
\hline & & Group Always & Early & Late & Hardly & Always-Early & Always-Late & Always-Hardly & Early-Late & Early-Hardly & Late-Hardly \\
\hline \multicolumn{12}{|l|}{ Panel A. Child level outcome variables } \\
\hline \multicolumn{12}{|l|}{ Health outcomes } \\
\hline Hemoglobin $(\mathrm{g} / \mathrm{dL})$ & 964 & $\begin{array}{l}11.431 \\
{[1.120]}\end{array}$ & $\begin{array}{l}11.507 \\
{[1.073]}\end{array}$ & $\begin{array}{l}11.586 \\
{[1.263]}\end{array}$ & $\begin{array}{l}11.691 \\
{[0.973]}\end{array}$ & 0.595 & 0.359 & 0.051 & 0.649 & 0.187 & 0.525 \\
\hline Any anemia & 964 & 0.480 & 0.491 & 0.463 & 0.406 & 0.850 & 0.817 & 0.204 & 0.715 & 0.173 & 0.462 \\
\hline Mild anemia & 964 & 0.168 & 0.223 & 0.225 & 0.195 & 0.270 & 0.326 & 0.545 & 0.978 & 0.606 & 0.629 \\
\hline Moderate/severe anemia & 964 & 0.312 & 0.268 & 0.237 & 0.211 & 0.413 & 0.200 & 0.042 & 0.649 & 0.338 & 0.672 \\
\hline Number of symptoms & 1,029 & $\begin{array}{c}0.966 \\
{[1.134]}\end{array}$ & $\begin{array}{c}1.118 \\
{[1.187]}\end{array}$ & $\begin{array}{c}1.333 \\
{[1.255]}\end{array}$ & $\begin{array}{c}1.089 \\
{[1.089]}\end{array}$ & 0.357 & 0.082 & 0.427 & 0.293 & 0.847 & 0.216 \\
\hline \multicolumn{12}{|l|}{ Cognitive test outcomes } \\
\hline Block design & 957 & $\begin{array}{c}3.452 \\
{[2.127]}\end{array}$ & $\begin{array}{c}3.586 \\
{[2.410]}\end{array}$ & $\begin{array}{c}3.701 \\
{[2.519]}\end{array}$ & $\begin{array}{c}3.700 \\
{[2.198]}\end{array}$ & 0.700 & 0.550 & 0.454 & 0.790 & 0.747 & 0.998 \\
\hline Digit span forward & 957 & $\begin{array}{c}3.917 \\
{[1.011]}\end{array}$ & $\begin{array}{c}4.198 \\
{[0.903]}\end{array}$ & $\begin{array}{c}3.857 \\
{[1.085]}\end{array}$ & $\begin{array}{c}4.146 \\
{[0.973]}\end{array}$ & 0.032 & 0.767 & 0.084 & 0.087 & 0.685 & 0.149 \\
\hline Digit span backward & 957 & $\begin{array}{c}0.935 \\
{[1.194]}\end{array}$ & $\begin{array}{c}1.072 \\
{[1.380]}\end{array}$ & $\begin{array}{c}1.013 \\
{[1.262]}\end{array}$ & $\begin{array}{c}1.138 \\
{[1.310]}\end{array}$ & 0.463 & 0.721 & 0.270 & 0.804 & 0.747 & 0.594 \\
\hline Progressive matrices & 955 & $\begin{array}{c}4.399 \\
{[1.751]}\end{array}$ & $\begin{array}{c}4.873 \\
{[1.828]}\end{array}$ & $\begin{array}{c}4.299 \\
{[1.702]}\end{array}$ & $\begin{array}{c}5.023 \\
{[1.767]}\end{array}$ & 0.049 & 0.760 & 0.013 & 0.079 & 0.535 & 0.030 \\
\hline Stroop test & 956 & $\begin{array}{c}4.443 \\
{[3.237]}\end{array}$ & $\begin{array}{c}5.104 \\
{[3.395]}\end{array}$ & $\begin{array}{c}4.961 \\
{[3.332]}\end{array}$ & $\begin{array}{c}5.754 \\
{[3.635]}\end{array}$ & 0.187 & 0.329 & 0.006 & 0.793 & 0.179 & 0.124 \\
\hline Cognitive score index & 954 & $\begin{array}{l}-0.270 \\
{[0.997]}\end{array}$ & $\begin{array}{l}-0.001 \\
{[0.956]}\end{array}$ & $\begin{array}{l}-0.204 \\
{[1.020]}\end{array}$ & $\begin{array}{c}0.093 \\
{[0.966]}\end{array}$ & 0.078 & 0.752 & 0.018 & 0.321 & 0.519 & 0.148 \\
\hline \multicolumn{12}{|l|}{ Education outcomes } \\
\hline Math score & 956 & $\begin{array}{c}3.589 \\
{[3.647]}\end{array}$ & $\begin{array}{c}4.820 \\
{[3.723]}\end{array}$ & $\begin{array}{c}4.195 \\
{[3.580]}\end{array}$ & $\begin{array}{c}4.862 \\
{[3.702]}\end{array}$ & 0.033 & 0.389 & 0.030 & 0.393 & 0.946 & 0.367 \\
\hline Reading score & 957 & $\begin{array}{c}0.607 \\
{[0.967]}\end{array}$ & $\begin{array}{c}0.892 \\
{[1.155]}\end{array}$ & $\begin{array}{c}0.740 \\
{[1.056]}\end{array}$ & $\begin{array}{c}0.885 \\
{[1.046]}\end{array}$ & 0.099 & 0.440 & 0.042 & 0.473 & 0.968 & 0.429 \\
\hline School attendance & 910 & $\begin{array}{c}0.757 \\
{[0.192]}\end{array}$ & $\begin{array}{c}0.740 \\
{[0.190]}\end{array}$ & $\begin{array}{c}0.735 \\
{[0.164]}\end{array}$ & $\begin{array}{c}0.782 \\
{[0.156]}\end{array}$ & 0.590 & 0.599 & 0.425 & 0.896 & 0.084 & 0.199 \\
\hline \multicolumn{12}{|c|}{ Panel B: Child and household level control variables } \\
\hline Demographics and socioeconomic variables & & & & & & & & & & & \\
\hline Muslim & 1,029 & 0.006 & 0.000 & 0.048 & 0.015 & 0.316 & 0.148 & 0.439 & 0.094 & 0.158 & 0.278 \\
\hline Scheduled Caste/Scheduled Tribe & 1,029 & 0.303 & 0.261 & 0.095 & 0.274 & 0.605 & 0.007 & 0.733 & 0.009 & 0.857 & 0.008 \\
\hline Block & 1,029 & 1.365 & 1.420 & 1.310 & 1.341 & 0.667 & 0.744 & 0.846 & 0.472 & 0.441 & 0.837 \\
\hline Rural & 1,029 & 0.978 & 0.966 & 1.000 & 0.970 & 0.685 & 0.217 & 0.759 & 0.107 & 0.875 & 0.048 \\
\hline Family size & 1,029 & $\begin{array}{c}8.388 \\
{[3.927]}\end{array}$ & $\begin{array}{c}8.286 \\
{[3.869]}\end{array}$ & $\begin{array}{c}8.286 \\
{[3.910]}\end{array}$ & $\begin{array}{c}7.837 \\
{[3.348]}\end{array}$ & 0.857 & 0.866 & 0.273 & 1.000 & 0.374 & 0.410 \\
\hline Father's years of schooling & 1,004 & $\begin{array}{c}5.260 \\
{[4.713]}\end{array}$ & $\begin{array}{c}6.626 \\
{[5.199]}\end{array}$ & $\begin{array}{c}5.088 \\
{[4.694]}\end{array}$ & $\begin{array}{c}6.567 \\
{[4.980]}\end{array}$ & 0.047 & 0.838 & 0.057 & 0.089 & 0.937 & 0.101 \\
\hline Mother's years of schooling & 1,025 & $\begin{array}{c}1.503 \\
{[2.859]}\end{array}$ & $\begin{array}{c}3.060 \\
{[4.312]}\end{array}$ & $\begin{array}{c}1.321 \\
{[2.698]}\end{array}$ & $\begin{array}{c}2.859 \\
{[4.105]}\end{array}$ & 0.005 & 0.639 & 0.006 & 0.004 & 0.760 & 0.005 \\
\hline Asset index & 1,013 & $\begin{array}{c}-0.193 \\
{[0.798]}\end{array}$ & $\begin{array}{c}0.320 \\
{[1.330]}\end{array}$ & $\begin{array}{c}-0.137 \\
{[0.892]}\end{array}$ & $\begin{array}{c}0.331 \\
{[1.176]}\end{array}$ & 0.005 & 0.635 & 0.000 & 0.016 & 0.954 & 0.003 \\
\hline Institutional delivery & \multicolumn{7}{|c|}{ Health care } & & & & \\
\hline Health insurance & 1,014 & $\begin{array}{c}0.371 \\
{[0.485]}\end{array}$ & $\begin{array}{c}0.419 \\
{[0.495]}\end{array}$ & $\begin{array}{c}0.381 \\
{[0.489]}\end{array}$ & $\begin{array}{c}0.437 \\
{[0.498]}\end{array}$ & 0.526 & 0.905 & 0.354 & 0.658 & 0.814 & 0.495 \\
\hline Diarrhea & 1,029 & 0.039 & 0.017 & 0.071 & 0.037 & 0.248 & 0.299 & 0.918 & 0.064 & 0.313 & 0.270 \\
\hline Improved sanitation & 1,029 & 0.073 & 0.143 & 0.083 & 0.141 & 0.121 & 0.809 & 0.114 & 0.239 & 0.967 & 0.237 \\
\hline \multicolumn{12}{|l|}{ Nutrition } \\
\hline Diet diversity score & 1,029 & $\begin{array}{c}3.848 \\
{[1.122]}\end{array}$ & $\begin{array}{c}3.882 \\
{[1.158]}\end{array}$ & $\begin{array}{c}3.690 \\
{[1.317]}\end{array}$ & $\begin{array}{c}4.222 \\
{[1.214]}\end{array}$ & 0.833 & 0.350 & 0.017 & 0.275 & 0.037 & 0.002 \\
\hline Number of meals/day & 1,029 & $\begin{array}{c}3.034 \\
{[1.119]}\end{array}$ & $\begin{array}{c}3.118 \\
{[1.027]}\end{array}$ & $\begin{array}{c}3.024 \\
{[1.280]}\end{array}$ & $\begin{array}{c}2.919 \\
{[1.146]}\end{array}$ & 0.554 & 0.959 & 0.432 & 0.629 & 0.181 & 0.594 \\
\hline Food scarcity & 1,028 & 0.780 & 0.765 & 0.905 & 0.704 & 0.807 & 0.013 & 0.174 & 0.018 & 0.338 & 0.000 \\
\hline Maternal health knowledge & 1,029 & 0.360 & 0.471 & 0.381 & 0.444 & 0.097 & 0.781 & 0.218 & 0.256 & 0.711 & 0.432 \\
\hline Child eats meat products & 1,029 & 0.545 & 0.504 & 0.476 & 0.630 & 0.499 & 0.300 & 0.169 & 0.698 & 0.067 & 0.038 \\
\hline Child received iron supplements & 1,021 & 0.215 & 0.185 & 0.095 & 0.227 & 0.591 & 0.014 & 0.818 & 0.086 & 0.469 & 0.011 \\
\hline \multicolumn{12}{|l|}{ Environment of care } \\
\hline Parents help with homework & 1,013 & 0.158 & 0.220 & 0.146 & 0.304 & 0.229 & 0.811 & 0.005 & 0.223 & 0.178 & 0.010 \\
\hline Parent's time spent for physical child care & 1,029 & $\begin{array}{c}44.303 \\
{[23.044]}\end{array}$ & $\begin{array}{c}45.874 \\
{[24.797]}\end{array}$ & $\begin{array}{c}49.524 \\
{[31.524]}\end{array}$ & $\begin{array}{c}45.763 \\
{[26.387]}\end{array}$ & 0.588 & 0.416 & 0.625 & 0.579 & 0.974 & 0.570 \\
\hline Parent attends school meetings & 1,025 & 0.582 & 0.551 & 0.595 & 0.615 & 0.662 & 0.890 & 0.630 & 0.658 & 0.385 & 0.842 \\
\hline Father lives at home & 1,028 & 0.882 & 0.874 & 0.893 & 0.844 & 0.856 & 0.790 & 0.410 & 0.691 & 0.569 & 0.320 \\
\hline Distance of school (min) & 1,029 & $\begin{array}{l}10.635 \\
{[5.967]}\end{array}$ & $\begin{array}{l}11.059 \\
{[7.344]}\end{array}$ & $\begin{array}{l}10.310 \\
{[6.008]}\end{array}$ & $\begin{array}{l}10.059 \\
{[6.209]}\end{array}$ & 0.650 & 0.687 & 0.463 & 0.459 & 0.314 & 0.774 \\
\hline \multicolumn{12}{|l|}{ Panel C: School level covariates } \\
\hline Number of children enrolled in school & 361 & $\begin{array}{c}232.022 \\
{[147.989]}\end{array}$ & $\begin{array}{c}196.438 \\
{[119.941]}\end{array}$ & $\begin{array}{c}328.042 \\
{[187.504]}\end{array}$ & $\begin{array}{c}207.559 \\
{[169.987]}\end{array}$ & 0.181 & 0.032 & 0.417 & 0.002 & 0.663 & 0.006 \\
\hline Class size & 364 & $\begin{array}{c}28.761 \\
{[12.315]}\end{array}$ & $\begin{array}{c}27.859 \\
{[11.654]}\end{array}$ & $\begin{array}{c}35.250 \\
{[25.378]}\end{array}$ & $\begin{array}{c}31.072 \\
{[22.691]}\end{array}$ & 0.699 & 0.239 & 0.483 & 0.169 & 0.301 & 0.474 \\
\hline Student teacher ratio & 361 & $\begin{array}{l}34.942 \\
{[9.586]}\end{array}$ & $\begin{array}{l}34.787 \\
{[9.440]}\end{array}$ & $\begin{array}{c}40.341 \\
{[12.337]}\end{array}$ & $\begin{array}{c}36.830 \\
{[13.053]}\end{array}$ & 0.933 & 0.065 & 0.375 & 0.047 & 0.303 & 0.238 \\
\hline Calories of MDM per child & 364 & $\begin{array}{c}62.679 \\
{[20.149]}\end{array}$ & $\begin{array}{c}63.208 \\
{[20.949]}\end{array}$ & $\begin{array}{l}71.587 \\
{[21.162]}\end{array}$ & $\begin{array}{c}71.057 \\
{[21.480]}\end{array}$ & 0.894 & 0.093 & 0.035 & 0.099 & 0.035 & 0.916 \\
\hline Amount of iron in MDM per child (mg) & 364 & $\begin{array}{c}0.707 \\
{[0.255]}\end{array}$ & $\begin{array}{c}0.702 \\
{[0.231]}\end{array}$ & $\begin{array}{c}0.805 \\
{[0.309]}\end{array}$ & $\begin{array}{c}0.852 \\
{[0.375]}\end{array}$ & 0.926 & 0.186 & 0.015 & 0.141 & 0.006 & 0.539 \\
\hline \multicolumn{12}{|l|}{ Joint orthogonalitiy F-test } \\
\hline F-statistics & & 2.402 & 1.352 & 1.962 & 1.352 & 2.526 & $\begin{array}{l}3.705 \\
50001\end{array}$ & 2.998 & 10.376 & 4.137 & 11.377 \\
\hline
\end{tabular}

Notes: Columns 2-5 report wave I means by intervention arm for child (Panel A and B) and schools (Panel C) in the study analysis. Columns 6-11 report p-values from tests on the equality of means for each variable. F-tests of joint significance: test of joint significance in regression of respective treatment dummies on all displayed wave I variables.

Source: Own Data. 
Table C.32: Balancing Table of Attrited Members of Exposure Group Using Wave II Data for Health Outcomes

\begin{tabular}{|c|c|c|c|c|c|c|c|c|c|c|c|}
\hline & \multirow[b]{2}{*}{ Observations } & \multicolumn{4}{|c|}{ Means [Standard Deviations] } & \multicolumn{6}{|c|}{$p$-value of difference } \\
\hline & & Group Always & Early & Late & Hardly & Always-Early & Always-Late & Always-Hardly & Early-Late & Early-Hardly & Late-Hardly \\
\hline \multicolumn{12}{|l|}{ Panel A. Child level outcome variables } \\
\hline $\begin{array}{l}\text { Health outcomes } \\
\text { Hemoglobin }(\mathrm{g} / \mathrm{dL})\end{array}$ & 708 & $\begin{array}{l}11.946 \\
{[0.970]}\end{array}$ & $\begin{array}{l}12.011 \\
{[0.870]}\end{array}$ & $\begin{array}{l}12.100 \\
{[1.007]}\end{array}$ & $\begin{array}{l}11.777 \\
{[0.841]}\end{array}$ & 0.591 & 0.337 & 0.157 & 0.593 & 0.069 & 0.053 \\
\hline Any anemia & 708 & 0.309 & 0.200 & 0.275 & 0.406 & 0.066 & 0.581 & 0.115 & 0.289 & 0.003 & 0.071 \\
\hline Mild anemia & 708 & 0.171 & 0.106 & 0.157 & 0.219 & 0.158 & 0.808 & 0.366 & 0.385 & 0.040 & 0.338 \\
\hline Moderate/severe anemia & 708 & 0.138 & 0.094 & 0.118 & 0.188 & 0.327 & 0.735 & 0.296 & 0.701 & 0.053 & 0.269 \\
\hline Number of symptoms & 778 & $\begin{array}{c}2.070 \\
{[1.317]}\end{array}$ & $\begin{array}{c}2.383 \\
{[1.304]}\end{array}$ & $\begin{array}{c}2.071 \\
{[1.189]}\end{array}$ & $\begin{array}{c}2.045 \\
{[1.330]}\end{array}$ & 0.074 & 0.996 & 0.885 & 0.168 & 0.078 & 0.908 \\
\hline \multicolumn{12}{|l|}{ Cognitive test outcomes } \\
\hline Block design & 708 & $\begin{array}{c}4.025 \\
{[2.424]}\end{array}$ & $\begin{array}{c}4.670 \\
{[2.066]}\end{array}$ & $\begin{array}{c}4.037 \\
{[2.257]}\end{array}$ & $\begin{array}{c}4.407 \\
{[2.165]}\end{array}$ & 0.062 & 0.980 & 0.214 & 0.197 & 0.386 & 0.426 \\
\hline Digit span forward & 708 & $\begin{array}{c}4.336 \\
{[0.976]}\end{array}$ & $\begin{array}{c}4.682 \\
{[0.977]}\end{array}$ & $\begin{array}{c}4.481 \\
{[1.094]}\end{array}$ & $\begin{array}{c}4.615 \\
{[0.916]}\end{array}$ & 0.046 & 0.462 & 0.067 & 0.324 & 0.675 & 0.472 \\
\hline Digit span backward & 708 & $\begin{array}{c}1.541 \\
{[1.397]}\end{array}$ & $\begin{array}{c}1.909 \\
{[1.580]}\end{array}$ & $\begin{array}{c}1.352 \\
{[1.456]}\end{array}$ & $\begin{array}{c}1.659 \\
{[1.492]}\end{array}$ & 0.161 & 0.476 & 0.621 & 0.054 & 0.342 & 0.249 \\
\hline Progressive matrices & 708 & $\begin{array}{c}4.967 \\
{[1.477]}\end{array}$ & $\begin{array}{c}5.148 \\
{[1.386]}\end{array}$ & $\begin{array}{c}4.944 \\
{[1.352]}\end{array}$ & $\begin{array}{c}5.264 \\
{[1.246]}\end{array}$ & 0.394 & 0.928 & 0.127 & 0.431 & 0.564 & 0.191 \\
\hline Stroop test & 708 & $\begin{array}{c}5.857 \\
{[3.658]}\end{array}$ & $\begin{array}{c}7.233 \\
{[3.725]}\end{array}$ & $\begin{array}{c}5.444 \\
{[4.032]}\end{array}$ & $\begin{array}{c}7.088 \\
{[3.919]}\end{array}$ & 0.013 & 0.552 & 0.029 & 0.018 & 0.814 & 0.031 \\
\hline Cognitive score index & 708 & $\begin{array}{c}-0.283 \\
{[1.078]}\end{array}$ & $\begin{array}{c}0.139 \\
{[1.095]}\end{array}$ & $\begin{array}{c}-0.322 \\
{[1.056]}\end{array}$ & $\begin{array}{c}0.033 \\
{[1.013]}\end{array}$ & 0.020 & 0.865 & 0.051 & 0.062 & 0.555 & 0.127 \\
\hline Education outcomes & & & & & & & & & & & \\
\hline Math score & 706 & $\begin{array}{c}7.377 \\
{[5.018]}\end{array}$ & $\begin{array}{c}9.114 \\
{[4.726]}\end{array}$ & $\begin{array}{c}7.574 \\
{[4.677]}\end{array}$ & $\begin{array}{c}9.044 \\
{[4.529]}\end{array}$ & 0.031 & 0.826 & 0.040 & 0.111 & 0.936 & 0.130 \\
\hline Reading score & 708 & $\begin{array}{c}1.246 \\
{[1.410]}\end{array}$ & $\begin{array}{c}1.727 \\
{[1.514]}\end{array}$ & $\begin{array}{c}1.370 \\
{[1.508]}\end{array}$ & $\begin{array}{c}1.780 \\
{[1.497]}\end{array}$ & 0.039 & 0.661 & 0.023 & 0.253 & 0.841 & 0.191 \\
\hline School attendance & 858 & $\begin{array}{c}0.690 \\
{[0.220]} \\
\end{array}$ & $\begin{array}{c}0.657 \\
{[0.234]}\end{array}$ & $\begin{array}{c}0.656 \\
{[0.191]} \\
\end{array}$ & $\begin{array}{c}0.692 \\
{[0.210]} \\
\end{array}$ & 0.450 & 0.428 & 0.962 & 0.985 & 0.329 & 0.296 \\
\hline \multirow{2}{*}{\multicolumn{12}{|c|}{$\begin{array}{l}\text { Panel B: Child and household level control variables } \\
\text { Demographics and socioeconomic variables }\end{array}$}} \\
\hline & & & & & & & & & & & \\
\hline Muslim & 778 & 0.008 & 0.000 & 0.018 & 0.018 & 0.321 & 0.614 & 0.491 & 0.329 & 0.158 & 0.988 \\
\hline Scheduled Caste/Scheduled Tribe & 768 & 0.236 & 0.215 & 0.073 & 0.239 & 0.823 & 0.063 & 0.981 & 0.031 & 0.764 & 0.017 \\
\hline Block & 858 & 1.385 & 1.412 & 1.298 & 1.362 & 0.827 & 0.621 & 0.856 & 0.490 & 0.651 & 0.698 \\
\hline Rural & 858 & 0.969 & 0.961 & 1.000 & 0.966 & 0.805 & 0.213 & 0.901 & 0.107 & 0.873 & 0.048 \\
\hline Family size & 778 & $\begin{array}{c}8.047 \\
{[3.434]}\end{array}$ & $\begin{array}{c}8.553 \\
{[3.812]}\end{array}$ & $\begin{array}{c}8.018 \\
{[3.042]}\end{array}$ & $\begin{array}{c}7.382 \\
{[2.971]}\end{array}$ & 0.370 & 0.960 & 0.155 & 0.405 & 0.034 & 0.255 \\
\hline Father's years of schooling & 773 & $\begin{array}{c}5.703 \\
{[4.743]}\end{array}$ & $\begin{array}{c}6.617 \\
{[5.446]}\end{array}$ & $\begin{array}{c}4.732 \\
{[4.692]}\end{array}$ & $\begin{array}{c}7.211 \\
{[4.854]}\end{array}$ & 0.227 & 0.292 & 0.031 & 0.065 & 0.463 & 0.012 \\
\hline Mother's years of schooling & 772 & $\begin{array}{c}1.583 \\
{[3.356]}\end{array}$ & $\begin{array}{c}2.883 \\
{[4.250]}\end{array}$ & $\begin{array}{c}0.982 \\
{[2.604]}\end{array}$ & $\begin{array}{c}2.750 \\
{[4.263]}\end{array}$ & 0.018 & 0.168 & 0.042 & 0.001 & 0.844 & 0.004 \\
\hline Asset index & 765 & $\begin{array}{l}-0.222 \\
{[0.903]}\end{array}$ & $\begin{array}{c}0.198 \\
{[1.125]}\end{array}$ & $\begin{array}{c}-0.270 \\
{[0.717]}\end{array}$ & $\begin{array}{c}0.430 \\
{[1.120]}\end{array}$ & 0.021 & 0.748 & 0.000 & 0.012 & 0.245 & 0.000 \\
\hline $\begin{array}{l}\text { Gender of the child } \\
\text { Health care }\end{array}$ & 739 & 0.405 & 0.543 & 0.400 & 0.505 & 0.054 & 0.951 & 0.167 & 0.071 & 0.606 & 0.189 \\
\hline Institutional delivery & 853 & 0.395 & 0.510 & 0.509 & 0.386 & 0.123 & 0.141 & 0.892 & 0.990 & 0.102 & 0.117 \\
\hline Health insurance & 765 & $\begin{array}{c}0.220 \\
{[0.416]}\end{array}$ & $\begin{array}{c}0.298 \\
{[0.460]}\end{array}$ & $\begin{array}{c}0.148 \\
{[0.359]}\end{array}$ & $\begin{array}{c}0.255 \\
{[0.438]}\end{array}$ & 0.265 & 0.441 & 0.587 & 0.126 & 0.543 & 0.255 \\
\hline Diarrhea & 778 & 0.211 & 0.319 & 0.304 & 0.209 & 0.101 & 0.194 & 0.976 & 0.824 & 0.074 & 0.160 \\
\hline Improved sanitation & 774 & 0.055 & 0.149 & 0.071 & 0.187 & 0.046 & 0.688 & 0.008 & 0.149 & 0.518 & 0.038 \\
\hline \multicolumn{12}{|l|}{ Nutrition } \\
\hline Diet diversity score & 777 & $\begin{array}{c}3.648 \\
{[1.214]}\end{array}$ & $\begin{array}{c}3.872 \\
{[1.211]}\end{array}$ & $\begin{array}{c}3.818 \\
{[1.263]}\end{array}$ & $\begin{array}{c}4.009 \\
{[1.338]}\end{array}$ & 0.293 & 0.437 & 0.074 & 0.808 & 0.508 & 0.368 \\
\hline Number of meals/day & 778 & $\begin{array}{c}3.594 \\
{[0.581]}\end{array}$ & $\begin{array}{c}3.553 \\
{[0.598]}\end{array}$ & $\begin{array}{c}3.625 \\
{[0.676]}\end{array}$ & $\begin{array}{c}3.500 \\
{[0.701]}\end{array}$ & 0.651 & 0.762 & 0.354 & 0.498 & 0.609 & 0.281 \\
\hline Food scarcity & 778 & 0.531 & 0.457 & 0.464 & 0.345 & 0.353 & 0.451 & 0.019 & 0.933 & 0.107 & 0.137 \\
\hline Maternal health knowledge & 778 & 0.219 & 0.383 & 0.268 & 0.373 & 0.010 & 0.486 & 0.025 & 0.123 & 0.886 & 0.183 \\
\hline Child eats meat products & 778 & 0.414 & 0.457 & 0.464 & 0.545 & 0.598 & 0.555 & 0.093 & 0.933 & 0.237 & 0.294 \\
\hline Child received iron supplements & 764 & 0.065 & 0.054 & 0.109 & 0.111 & 0.816 & 0.435 & 0.297 & 0.306 & 0.158 & 0.970 \\
\hline \multicolumn{12}{|l|}{ Environment of care } \\
\hline Parents help with homework & 777 & 0.328 & 0.436 & 0.214 & 0.473 & 0.183 & 0.159 & 0.055 & 0.013 & 0.659 & 0.002 \\
\hline Parent's time spent for physical child care & 761 & $\begin{array}{l}48.150 \\
{[32.311]}\end{array}$ & $\begin{array}{c}44.341 \\
{[33.418]}\end{array}$ & $\begin{array}{l}42.182 \\
{[35.782]}\end{array}$ & $\begin{array}{l}40.788 \\
{[30.637]}\end{array}$ & 0.430 & 0.386 & 0.101 & 0.758 & 0.448 & 0.836 \\
\hline Parent attends school meetings & 771 & 0.373 & 0.351 & 0.321 & 0.373 & 0.778 & 0.464 & 0.997 & 0.680 & 0.771 & 0.440 \\
\hline Father lives at home & 778 & 0.883 & 0.840 & 0.857 & 0.873 & 0.419 & 0.682 & 0.815 & 0.814 & 0.553 & 0.809 \\
\hline Distance of school (min) & 777 & $\begin{array}{l}13.109 \\
{[9.191]}\end{array}$ & $\begin{array}{c}13.340 \\
{[12.106]}\end{array}$ & $\begin{array}{c}9.839 \\
{[6.158]}\end{array}$ & $\begin{array}{l}13.642 \\
{[11.871]}\end{array}$ & 0.891 & 0.013 & 0.740 & 0.031 & 0.871 & 0.014 \\
\hline \multicolumn{12}{|l|}{ Panel C: School level covariates } \\
\hline Number of children enrolled in school & 330 & $\begin{array}{c}223.049 \\
{[223.735]}\end{array}$ & $\begin{array}{r}174.000 \\
{[112.744]}\end{array}$ & $\begin{array}{c}304.150 \\
{[194.235]}\end{array}$ & $\begin{array}{c}193.017 \\
{[171.690]}\end{array}$ & 0.197 & 0.149 & 0.470 & 0.005 & 0.477 & 0.024 \\
\hline Class size & 330 & $\begin{array}{c}28.854 \\
{[15.567]}\end{array}$ & $\begin{array}{c}27.817 \\
{[13.127]}\end{array}$ & $\begin{array}{c}34.600 \\
{[21.269]}\end{array}$ & $\begin{array}{c}31.356 \\
{[21.481]}\end{array}$ & 0.727 & 0.283 & 0.501 & 0.178 & 0.281 & 0.555 \\
\hline Student teacher ratio & 330 & $\begin{array}{c}34.955 \\
{[17.427]}\end{array}$ & $\begin{array}{l}31.223 \\
{[9.181]}\end{array}$ & $\begin{array}{c}39.588 \\
{[11.369]}\end{array}$ & $\begin{array}{c}35.298 \\
{[14.909]}\end{array}$ & 0.211 & 0.218 & 0.919 & 0.003 & 0.076 & 0.181 \\
\hline Calories of MDM per child & 330 & $\begin{array}{c}83.242 \\
{[78.782]}\end{array}$ & $\begin{array}{c}89.192 \\
{[89.207]}\end{array}$ & $\begin{array}{c}72.940 \\
{[31.121]}\end{array}$ & $\begin{array}{c}73.463 \\
{[30.857]}\end{array}$ & 0.725 & 0.469 & 0.451 & 0.231 & 0.200 & 0.948 \\
\hline Amount of iron in MDM per child (mg) & 330 & $\begin{array}{c}0.752 \\
{[0.656]}\end{array}$ & $\begin{array}{c}0.760 \\
{[0.725]}\end{array}$ & $\begin{array}{c}0.704 \\
{[0.373]}\end{array}$ & $\begin{array}{c}0.619 \\
{[0.348]}\end{array}$ & 0.954 & 0.718 & 0.238 & 0.656 & 0.179 & 0.370 \\
\hline \multicolumn{12}{|l|}{ Joint orthogonalitiy F-test } \\
\hline F-statistics & & 2.402 & 1.352 & 1.962 & 1.352 & 2.526 & 3.705 & 2.998 & 10.376 & 4.137 & 11.377 \\
\hline $\mathrm{p}$-Value & & [0.000] & {$[0.097]$} & [0.002] & [0.097] & [0.000] & [0.000] & {$[0.000]$} & {$[0.000]$} & {$[0.000]$} & {$[0.000]$} \\
\hline
\end{tabular}

Notes: Columns 2-5 report wave I means by intervention arm for child (Panel A and B) and schools (Panel C) in the study analysis. Columns 6-11 report p-values from tests on the equality of means for each variable. F-tests of joint significance: test of joint significance in regression of respective treatment dummies on all displayed wave I variables.

Source: Own Data. 
3.2 Additional Balancing Tables by Exposure Groups 
Table C.33: Baseline Mean Characteristics by Exposure Groups - Sample for Health Outcomes

\begin{tabular}{|c|c|c|c|c|c|c|c|c|c|c|c|}
\hline & \multirow[b]{2}{*}{ Observations } & \multicolumn{4}{|c|}{ Means [Standard Deviations] } & \multicolumn{6}{|c|}{$p$-value of difference } \\
\hline & & Group Always & Early & Late & Hardly & Always-Early & Always-Late & Always-Hardly & Early-Late & Early-Hardly & Late-Hardly \\
\hline \multicolumn{12}{|l|}{ Panel A. Child level outcome variables } \\
\hline \multicolumn{12}{|l|}{ Health outcomes } \\
\hline Hemoglobin $(\mathrm{g} / \mathrm{dL})$ & 1,165 & $\begin{array}{l}11.401 \\
{[1.107]}\end{array}$ & $\begin{array}{l}11.458 \\
{[1.091]}\end{array}$ & $\begin{array}{l}11.586 \\
{[1.177]}\end{array}$ & $\begin{array}{l}11.709 \\
{[1.058]}\end{array}$ & 0.654 & 0.037 & 0.001 & 0.330 & 0.059 & 0.198 \\
\hline Any anemia & 1,165 & 0.501 & 0.493 & 0.430 & 0.373 & 0.887 & 0.033 & 0.002 & 0.271 & 0.052 & 0.161 \\
\hline Mild anemia & 1,165 & 0.208 & 0.204 & 0.184 & 0.155 & 0.907 & 0.289 & 0.135 & 0.559 & 0.268 & 0.427 \\
\hline Moderate/severe anemia & 1,165 & 0.293 & 0.289 & 0.246 & 0.218 & 0.943 & 0.157 & 0.024 & 0.451 & 0.210 & 0.400 \\
\hline Number of symptoms & 1,165 & $\begin{array}{l}1.110 \\
{[1.124]}\end{array}$ & $\begin{array}{c}0.979 \\
{[1.075]}\end{array}$ & $\begin{array}{c}1.093 \\
{[1.100]}\end{array}$ & $\begin{array}{c}0.984 \\
{[1.048]}\end{array}$ & 0.291 & 0.884 & 0.272 & 0.381 & 0.966 & 0.369 \\
\hline \multicolumn{12}{|l|}{ Cognitive test outcomes } \\
\hline Block design & 1,137 & $\begin{array}{c}3.725 \\
{[2.184]}\end{array}$ & $\begin{array}{c}3.928 \\
{[2.153]}\end{array}$ & $\begin{array}{c}3.691 \\
{[2.193]}\end{array}$ & $\begin{array}{c}3.576 \\
{[2.295]}\end{array}$ & 0.496 & 0.890 & 0.630 & 0.431 & 0.323 & 0.711 \\
\hline Digit span forward & 1,139 & $\begin{array}{c}4.071 \\
{[1.016]}\end{array}$ & $\begin{array}{c}4.080 \\
{[0.905]}\end{array}$ & $\begin{array}{c}3.990 \\
{[0.937]}\end{array}$ & $\begin{array}{l}4.131 \\
{[1.035]}\end{array}$ & 0.932 & 0.398 & 0.589 & 0.476 & 0.712 & 0.279 \\
\hline Digit span backward & 1,139 & $\begin{array}{c}1.151 \\
{[1.299]}\end{array}$ & $\begin{array}{c}1.254 \\
{[1.425]}\end{array}$ & $\begin{array}{c}0.975 \\
{[1.251]}\end{array}$ & $\begin{array}{c}1.152 \\
{[1.295]}\end{array}$ & 0.599 & 0.143 & 0.997 & 0.158 & 0.647 & 0.272 \\
\hline Progressive matrices & 1,139 & $\begin{array}{c}4.667 \\
{[1.671]}\end{array}$ & $\begin{array}{c}4.906 \\
{[1.669]}\end{array}$ & $\begin{array}{c}4.704 \\
{[1.516]}\end{array}$ & $\begin{array}{c}4.921 \\
{[1.701]}\end{array}$ & 0.305 & 0.817 & 0.246 & 0.410 & 0.956 & 0.349 \\
\hline Stroop test & 1,137 & $\begin{array}{c}5.112 \\
{[3.329]}\end{array}$ & $\begin{array}{c}5.591 \\
{[3.526]}\end{array}$ & $\begin{array}{c}5.428 \\
{[3.488]}\end{array}$ & $\begin{array}{c}5.241 \\
{[3.532]}\end{array}$ & 0.234 & 0.376 & 0.723 & 0.710 & 0.428 & 0.640 \\
\hline Cognitive score index & 1,135 & $\begin{array}{l}-0.034 \\
{[1.009]}\end{array}$ & $\begin{array}{c}0.099 \\
{[0.950]}\end{array}$ & $\begin{array}{l}-0.071 \\
{[0.976]}\end{array}$ & $\begin{array}{c}0.013 \\
{[1.012]}\end{array}$ & 0.365 & 0.740 & 0.730 & 0.280 & 0.622 & 0.569 \\
\hline \multicolumn{12}{|l|}{ Education outcomes } \\
\hline Math score & 1,138 & $\begin{array}{c}4.506 \\
{[3.841]}\end{array}$ & $\begin{array}{c}5.101 \\
{[3.657]}\end{array}$ & $\begin{array}{l}4.920 \\
{[3.679]}\end{array}$ & $\begin{array}{l}4.848 \\
{[3.675]}\end{array}$ & 0.372 & 0.427 & 0.527 & 0.797 & 0.724 & 0.902 \\
\hline Reading score & 1,138 & $\begin{array}{c}0.815 \\
{[1.118]}\end{array}$ & $\begin{array}{c}1.058 \\
{[1.205]}\end{array}$ & $\begin{array}{c}0.949 \\
{[1.166]}\end{array}$ & $\begin{array}{c}0.937 \\
{[1.089]}\end{array}$ & 0.099 & 0.273 & 0.441 & 0.498 & 0.525 & 0.945 \\
\hline School attendance & 1,112 & $\begin{array}{c}0.781 \\
{[0.172]}\end{array}$ & $\begin{array}{c}0.817 \\
{[0.138]}\end{array}$ & $\begin{array}{c}0.801 \\
{[0.157]}\end{array}$ & $\begin{array}{c}0.819 \\
{[0.139]}\end{array}$ & 0.124 & 0.363 & 0.116 & 0.395 & 0.921 & 0.361 \\
\hline \multicolumn{12}{|c|}{ Panel B: Child and household level control variables } \\
\hline \multicolumn{12}{|c|}{ Demographics and socioeconomic variables } \\
\hline Muslim & 1,165 & 0.041 & 0.000 & 0.050 & 0.005 & 0.022 & 0.816 & 0.054 & 0.126 & 0.313 & 0.175 \\
\hline Scheduled Caste/Scheduled Tribe & 1,165 & 0.344 & 0.303 & 0.218 & 0.301 & 0.642 & 0.071 & 0.551 & 0.328 & 0.979 & 0.243 \\
\hline Block & 1,165 & 1.334 & 1.387 & 1.146 & 1.368 & 0.684 & 0.100 & 0.802 & 0.059 & 0.894 & 0.092 \\
\hline Rural & 1,165 & 0.986 & 0.972 & 0.978 & 0.964 & 0.559 & 0.649 & 0.287 & 0.814 & 0.783 & 0.545 \\
\hline Family size & 1,165 & $\begin{array}{c}7.739 \\
{[3.422]}\end{array}$ & $\begin{array}{c}7.732 \\
{[3.385]}\end{array}$ & $\begin{array}{l}7.788 \\
{[3.385]}\end{array}$ & $\begin{array}{c}7.902 \\
{[3.401]}\end{array}$ & 0.987 & 0.869 & 0.558 & 0.899 & 0.688 & 0.728 \\
\hline Father's years of schooling & 1,148 & $\begin{array}{c}5.002 \\
{[4.696]}\end{array}$ & $\begin{array}{c}6.371 \\
{[4.828]}\end{array}$ & $\begin{array}{c}5.588 \\
{[4.842]}\end{array}$ & $\begin{array}{c}5.948 \\
{[4.790]}\end{array}$ & 0.032 & 0.225 & 0.096 & 0.249 & 0.567 & 0.560 \\
\hline Mother's years of schooling & 1,161 & $\begin{array}{c}1.295 \\
{[2.673]}\end{array}$ & $\begin{array}{c}2.142 \\
{[3.496]}\end{array}$ & $\begin{array}{c}1.809 \\
{[3.051]}\end{array}$ & $\begin{array}{c}1.834 \\
{[3.361]}\end{array}$ & 0.030 & 0.043 & 0.078 & 0.395 & 0.471 & 0.934 \\
\hline Asset index & 1,142 & $\begin{array}{l}-0.146 \\
{[0.869]}\end{array}$ & $\begin{array}{c}0.223 \\
{[1.174]}\end{array}$ & $\begin{array}{l}-0.082 \\
{[0.834]}\end{array}$ & $\begin{array}{c}0.066 \\
{[0.976]}\end{array}$ & 0.004 & 0.512 & 0.088 & 0.023 & 0.302 & 0.257 \\
\hline $\begin{array}{l}\text { Gender of the child } \\
\text { Health care }\end{array}$ & 1,162 & 0.448 & 0.486 & 0.383 & 0.421 & 0.448 & 0.076 & 0.576 & 0.043 & 0.274 & 0.431 \\
\hline Institutional delivery & 1,156 & 0.348 & 0.454 & 0.330 & 0.414 & 0.038 & 0.654 & 0.182 & 0.018 & 0.496 & 0.096 \\
\hline Health insurance & 1,158 & $\begin{array}{c}0.364 \\
{[0.482]}\end{array}$ & $\begin{array}{c}0.415 \\
{[0.495]}\end{array}$ & $\begin{array}{c}0.353 \\
{[0.479]}\end{array}$ & $\begin{array}{c}0.420 \\
{[0.495]}\end{array}$ & 0.465 & 0.830 & 0.387 & 0.408 & 0.961 & 0.339 \\
\hline Diarrhea & 1,165 & 0.026 & 0.007 & 0.037 & 0.021 & 0.053 & 0.281 & 0.692 & 0.010 & 0.281 & 0.229 \\
\hline Improved sanitation & 1,165 & 0.083 & 0.085 & 0.078 & 0.052 & 0.949 & 0.875 & 0.266 & 0.838 & 0.287 & 0.368 \\
\hline \multicolumn{12}{|l|}{ Nutrition } \\
\hline Diet diversity score & 1,165 & $\begin{array}{c}3.827 \\
{[1.158]}\end{array}$ & $\begin{array}{c}3.838 \\
{[1.140]}\end{array}$ & $\begin{array}{c}3.841 \\
{[1.236]}\end{array}$ & $\begin{array}{c}4.010 \\
{[1.150]}\end{array}$ & 0.938 & 0.909 & 0.244 & 0.983 & 0.325 & 0.295 \\
\hline Number of meals/day & 1,164 & $\begin{array}{c}2.996 \\
{[1.070]}\end{array}$ & $\begin{array}{c}3.169 \\
{[1.003]}\end{array}$ & $\begin{array}{c}3.081 \\
{[1.065]}\end{array}$ & $\begin{array}{c}3.114 \\
{[1.014]}\end{array}$ & 0.143 & 0.404 & 0.262 & 0.464 & 0.652 & 0.760 \\
\hline Food scarcity & 1,164 & 0.799 & 0.782 & 0.832 & 0.751 & 0.672 & 0.354 & 0.246 & 0.262 & 0.539 & 0.071 \\
\hline Maternal health knowledge & 1,165 & 0.373 & 0.430 & 0.349 & 0.358 & 0.205 & 0.546 & 0.770 & 0.091 & 0.227 & 0.879 \\
\hline Child eats meat products & 1,165 & 0.519 & 0.507 & 0.526 & 0.565 & 0.845 & 0.859 & 0.474 & 0.761 & 0.467 & 0.577 \\
\hline Child received iron supplements & 1,144 & 0.147 & 0.214 & 0.150 & 0.213 & 0.101 & 0.949 & 0.089 & 0.170 & 0.975 & 0.162 \\
\hline \multicolumn{12}{|l|}{ Environment of care } \\
\hline Parents help with homework & 1,157 & 0.124 & 0.216 & 0.170 & 0.219 & 0.046 & 0.137 & 0.014 & 0.310 & 0.954 & 0.194 \\
\hline Parent's time spent for physical child care & 1,165 & $\begin{array}{c}46.953 \\
{[25.404]}\end{array}$ & $\begin{array}{c}44.901 \\
{[25.588]}\end{array}$ & $\begin{array}{l}41.576 \\
{[21.016]}\end{array}$ & $\begin{array}{c}48.715 \\
{[30.849]}\end{array}$ & 0.587 & 0.045 & 0.653 & 0.364 & 0.413 & 0.063 \\
\hline Parent attends school meetings & 1,161 & 0.622 & 0.645 & 0.639 & 0.648 & 0.754 & 0.797 & 0.689 & 0.945 & 0.978 & 0.914 \\
\hline Father lives at home & 1,165 & 0.864 & 0.873 & 0.903 & 0.855 & 0.789 & 0.088 & 0.760 & 0.375 & 0.647 & 0.134 \\
\hline Distance of school (min) & 1,165 & $\begin{array}{l}10.670 \\
{[6.203]}\end{array}$ & $\begin{array}{c}9.528 \\
{[6.853]}\end{array}$ & $\begin{array}{l}10.530 \\
{[5.958]}\end{array}$ & $\begin{array}{c}9.290 \\
{[5.412]}\end{array}$ & 0.246 & 0.823 & 0.050 & 0.334 & 0.825 & 0.109 \\
\hline \multicolumn{12}{|l|}{ Panel C: School level covariates } \\
\hline Number of children enrolled in school & 199 & $\begin{array}{c}218.877 \\
{[145.401]}\end{array}$ & $\begin{array}{l}165.732 \\
{[96.096]}\end{array}$ & $\begin{array}{c}317.607 \\
{[181.501]}\end{array}$ & $\begin{array}{c}169.638 \\
{[143.566]}\end{array}$ & 0.024 & 0.014 & 0.070 & 0.000 & 0.864 & 0.000 \\
\hline Class size & 201 & $\begin{array}{c}27.789 \\
{[12.305]}\end{array}$ & $\begin{array}{l}25.804 \\
{[10.537]}\end{array}$ & $\begin{array}{c}32.759 \\
{[24.410]}\end{array}$ & $\begin{array}{l}27.814 \\
{[18.266]}\end{array}$ & 0.359 & 0.303 & 0.993 & 0.145 & 0.469 & 0.335 \\
\hline Student teacher ratio & 199 & $\begin{array}{l}34.447 \\
{[9.587]}\end{array}$ & $\begin{array}{l}33.864 \\
{[8.012]}\end{array}$ & $\begin{array}{c}40.540 \\
{[11.536]}\end{array}$ & $\begin{array}{c}35.440 \\
{[12.628]}\end{array}$ & 0.726 & 0.017 & 0.635 & 0.007 & 0.426 & 0.065 \\
\hline Calories of MDM per child & 201 & $\begin{array}{c}67.783 \\
{[22.467]}\end{array}$ & $\begin{array}{c}64.121 \\
{[20.617]}\end{array}$ & $\begin{array}{c}69.222 \\
{[20.931]}\end{array}$ & $\begin{array}{c}71.269 \\
{[21.341]}\end{array}$ & 0.368 & 0.769 & 0.394 & 0.286 & 0.070 & 0.668 \\
\hline Amount of iron in MDM per child (mg) & 201 & $\begin{array}{c}0.737 \\
{[0.260]}\end{array}$ & $\begin{array}{c}0.734 \\
{[0.232]} \\
\end{array}$ & $\begin{array}{c}0.776 \\
{[0.300]} \\
\end{array}$ & $\begin{array}{c}0.892 \\
{[0.451]}\end{array}$ & 0.951 & 0.551 & 0.024 & 0.511 & 0.019 & 0.154 \\
\hline \multicolumn{12}{|l|}{ Joint orthogonalitiy F-test } \\
\hline $\begin{array}{l}\text { F-statistics } \\
\text { p-Value }\end{array}$ & & $\begin{array}{c}2.402 \\
{[0.000]}\end{array}$ & $\begin{array}{c}1.352 \\
{[0.097]}\end{array}$ & $\begin{array}{c}1.962 \\
{[0.002]}\end{array}$ & $\begin{array}{c}1.352 \\
{[0.097]}\end{array}$ & $\begin{array}{c}2.526 \\
{[0.000]}\end{array}$ & $\begin{array}{c}3.705 \\
{[0.000]}\end{array}$ & $\begin{array}{c}2.998 \\
{[0.000]}\end{array}$ & $\begin{array}{l}10.376 \\
{[0.000]}\end{array}$ & $\begin{array}{c}4.137 \\
{[0.000]}\end{array}$ & $\begin{array}{l}11.377 \\
{[0.000]}\end{array}$ \\
\hline
\end{tabular}

Notes: Columns 2-5 report baseline means by intervention arm for child (Panel A and B) and schools (Panel C) in the study analysis. Columns 6-11 report p-values from tests on the equality of means for each variable. F-tests of joint significance: test of joint significance in regression of respective treatment dummies on all displayed baseline variables.

Source: Own Data. 
Table C.34: Baseline Mean Characteristics by Exposure Groups - Sample for Cognition and Education Outcomes

\begin{tabular}{|c|c|c|c|c|c|c|c|c|c|c|c|}
\hline & \multirow[b]{2}{*}{ Observations } & \multicolumn{4}{|c|}{ Means [Standard Deviations] } & \multicolumn{6}{|c|}{$p$-value of difference } \\
\hline & & Group Always & Early & Late & Hardly & Always-Early & Always-Late & Always-Hardly & Early-Late & Early-Hardly & Late-Hardly \\
\hline \multicolumn{12}{|l|}{ Panel A. Child level outcome variables } \\
\hline \multicolumn{12}{|l|}{ Health outcomes } \\
\hline Hemoglobin $(\mathrm{g} / \mathrm{dL})$ & 1,003 & $\begin{array}{l}11.396 \\
{[1.126]}\end{array}$ & $\begin{array}{l}11.399 \\
{[1.241]}\end{array}$ & $\begin{array}{l}11.610 \\
{[1.091]}\end{array}$ & $\begin{array}{l}11.662 \\
{[1.042]}\end{array}$ & 0.987 & 0.021 & 0.009 & 0.214 & 0.133 & 0.633 \\
\hline Any anemia & 1,003 & 0.492 & 0.491 & 0.422 & 0.352 & 0.980 & 0.059 & 0.001 & 0.293 & 0.041 & 0.105 \\
\hline Mild anemia & 1,003 & 0.204 & 0.160 & 0.185 & 0.120 & 0.280 & 0.411 & 0.016 & 0.529 & 0.387 & 0.053 \\
\hline Moderate/severe anemia & 1,003 & 0.289 & 0.330 & 0.237 & 0.232 & 0.519 & 0.124 & 0.136 & 0.160 & 0.153 & 0.907 \\
\hline Number of symptoms & 1,022 & $\begin{array}{c}1.123 \\
{[1.129]}\end{array}$ & $\begin{array}{c}0.918 \\
{[1.085]}\end{array}$ & $\begin{array}{c}1.093 \\
{[1.103]}\end{array}$ & $\begin{array}{c}0.930 \\
{[1.052]}\end{array}$ & 0.111 & 0.803 & 0.157 & 0.181 & 0.935 & 0.238 \\
\hline \multicolumn{12}{|l|}{ Cognitive test outcomes } \\
\hline Block design & 1,022 & $\begin{array}{c}3.921 \\
{[2.138]}\end{array}$ & $\begin{array}{c}3.873 \\
{[2.064]}\end{array}$ & $\begin{array}{c}3.788 \\
{[2.179]}\end{array}$ & $\begin{array}{c}3.490 \\
{[2.254]}\end{array}$ & 0.898 & 0.574 & 0.211 & 0.823 & 0.398 & 0.381 \\
\hline Digit span forward & 1,022 & $\begin{array}{c}4.103 \\
{[0.989]}\end{array}$ & $\begin{array}{c}4.082 \\
{[0.847]}\end{array}$ & $\begin{array}{c}4.106 \\
{[0.927]}\end{array}$ & $\begin{array}{c}4.105 \\
{[0.977]}\end{array}$ & 0.856 & 0.973 & 0.985 & 0.840 & 0.868 & 0.994 \\
\hline Digit span backward & 1,022 & $\begin{array}{c}1.210 \\
{[1.284]}\end{array}$ & $\begin{array}{c}1.191 \\
{[1.344]}\end{array}$ & $\begin{array}{c}1.032 \\
{[1.288]}\end{array}$ & $\begin{array}{c}1.105 \\
{[1.309]}\end{array}$ & 0.928 & 0.161 & 0.541 & 0.461 & 0.725 & 0.675 \\
\hline Progressive matrices & 1,022 & $\begin{array}{c}4.792 \\
{[1.663]}\end{array}$ & $\begin{array}{c}4.909 \\
{[1.769]}\end{array}$ & $\begin{array}{c}4.792 \\
{[1.521]}\end{array}$ & $\begin{array}{c}4.909 \\
{[1.623]}\end{array}$ & 0.679 & 0.998 & 0.637 & 0.687 & 1.000 & 0.649 \\
\hline Stroop test & 1,022 & $\begin{array}{c}5.321 \\
{[3.263]}\end{array}$ & $\begin{array}{c}5.609 \\
{[3.393]}\end{array}$ & $\begin{array}{c}5.375 \\
{[3.449]}\end{array}$ & $\begin{array}{c}5.077 \\
{[3.583]}\end{array}$ & 0.469 & 0.879 & 0.555 & 0.580 & 0.260 & 0.495 \\
\hline Cognitive score index & 1,022 & $\begin{array}{c}0.053 \\
{[0.959]}\end{array}$ & $\begin{array}{c}0.080 \\
{[0.916]}\end{array}$ & $\begin{array}{l}-0.001 \\
{[0.986]}\end{array}$ & $\begin{array}{c}-0.034 \\
{[0.997]}\end{array}$ & 0.878 & 0.599 & 0.552 & 0.650 & 0.581 & 0.827 \\
\hline \multicolumn{12}{|l|}{ Education outcomes } \\
\hline Math score & 1,022 & $\begin{array}{l}4.840 \\
{[3.763]}\end{array}$ & $\begin{array}{c}5.091 \\
{[3.567]}\end{array}$ & $\begin{array}{c}5.071 \\
{[3.645]}\end{array}$ & $\begin{array}{c}4.832 \\
{[3.654]}\end{array}$ & 0.747 & 0.656 & 0.988 & 0.980 & 0.752 & 0.681 \\
\hline Reading score & 1,022 & $\begin{array}{c}0.864 \\
{[1.118]}\end{array}$ & $\begin{array}{c}1.091 \\
{[1.177]}\end{array}$ & $\begin{array}{c}0.981 \\
{[1.181]}\end{array}$ & $\begin{array}{c}0.860 \\
{[1.018]}\end{array}$ & 0.124 & 0.317 & 0.979 & 0.471 & 0.229 & 0.475 \\
\hline School attendance & 986 & $\begin{array}{c}0.787 \\
{[0.166]}\end{array}$ & $\begin{array}{c}0.825 \\
{[0.141]}\end{array}$ & $\begin{array}{c}0.802 \\
{[0.157]}\end{array}$ & $\begin{array}{c}0.835 \\
{[0.132]}\end{array}$ & 0.142 & 0.529 & 0.039 & 0.311 & 0.655 & 0.097 \\
\hline \multicolumn{12}{|c|}{ Panel B: Child and household level control variables } \\
\hline \multicolumn{12}{|l|}{ Demographics and socioeconomic variables } \\
\hline Muslim & 1,022 & 0.046 & 0.000 & 0.042 & 0.000 & 0.026 & 0.907 & 0.025 & 0.179 & & 0.179 \\
\hline Scheduled Caste/Scheduled Tribe & 1,022 & 0.330 & 0.282 & 0.205 & 0.315 & 0.625 & 0.066 & 0.832 & 0.426 & 0.745 & 0.121 \\
\hline Block & 1,022 & 1.365 & 1.427 & 1.154 & 1.301 & 0.689 & 0.092 & 0.662 & 0.074 & 0.460 & 0.311 \\
\hline Rural & 1,022 & 0.980 & 0.973 & 0.981 & 0.951 & 0.804 & 0.980 & 0.327 & 0.796 & 0.576 & 0.327 \\
\hline Family size & 1,022 & $\begin{array}{c}7.764 \\
{[3.341]}\end{array}$ & $\begin{array}{c}7.445 \\
{[3.129]}\end{array}$ & $\begin{array}{l}7.728 \\
{[3.152]}\end{array}$ & $\begin{array}{c}7.755 \\
{[3.281]}\end{array}$ & 0.400 & 0.909 & 0.978 & 0.483 & 0.431 & 0.934 \\
\hline Father's years of schooling & 1,005 & $\begin{array}{c}5.212 \\
{[4.680]}\end{array}$ & $\begin{array}{c}5.766 \\
{[4.921]}\end{array}$ & $\begin{array}{c}5.254 \\
{[4.762]}\end{array}$ & $\begin{array}{c}5.406 \\
{[4.786]}\end{array}$ & 0.446 & 0.938 & 0.728 & 0.509 & 0.646 & 0.806 \\
\hline Mother's years of schooling & 1,019 & $\begin{array}{c}1.376 \\
{[2.795]}\end{array}$ & $\begin{array}{c}1.826 \\
{[3.302]}\end{array}$ & $\begin{array}{c}1.523 \\
{[2.873]}\end{array}$ & $\begin{array}{c}1.462 \\
{[3.135]}\end{array}$ & 0.232 & 0.566 & 0.805 & 0.435 & 0.422 & 0.865 \\
\hline Asset index & 998 & $\begin{array}{l}-0.106 \\
{[0.898]}\end{array}$ & $\begin{array}{c}0.071 \\
{[1.109]}\end{array}$ & $\begin{array}{c}-0.074 \\
{[0.885]}\end{array}$ & $\begin{array}{c}0.082 \\
{[0.937]}\end{array}$ & 0.157 & 0.762 & 0.118 & 0.303 & 0.941 & 0.253 \\
\hline $\begin{array}{l}\text { Gender of the child } \\
\text { Health care }\end{array}$ & 1,022 & 0.451 & 0.445 & 0.410 & 0.469 & 0.930 & 0.297 & 0.763 & 0.569 & 0.762 & 0.334 \\
\hline Institutional delivery & 1,016 & 0.353 & 0.468 & 0.327 & 0.437 & 0.064 & 0.517 & 0.112 & 0.024 & 0.654 & 0.038 \\
\hline Health insurance & 1,016 & $\begin{array}{c}0.347 \\
{[0.477]}\end{array}$ & $\begin{array}{c}0.382 \\
{[0.488]}\end{array}$ & $\begin{array}{c}0.331 \\
{[0.471]}\end{array}$ & $\begin{array}{c}0.448 \\
{[0.499]}\end{array}$ & 0.660 & 0.741 & 0.179 & 0.548 & 0.516 & 0.150 \\
\hline Diarrhea & 1,022 & 0.028 & 0.018 & 0.029 & 0.014 & 0.494 & 0.971 & 0.220 & 0.508 & 0.800 & 0.258 \\
\hline Improved sanitation & 1,022 & 0.085 & 0.073 & 0.074 & 0.028 & 0.695 & 0.697 & 0.018 & 0.978 & 0.146 & 0.107 \\
\hline \multicolumn{12}{|l|}{ Nutrition } \\
\hline Diet diversity score & 1,022 & $\begin{array}{c}3.825 \\
{[1.188]}\end{array}$ & $\begin{array}{c}3.836 \\
{[1.105]}\end{array}$ & $\begin{array}{c}3.865 \\
{[1.243]}\end{array}$ & $\begin{array}{c}3.881 \\
{[1.190]}\end{array}$ & 0.943 & 0.747 & 0.760 & 0.860 & 0.834 & 0.933 \\
\hline Number of meals/day & 1,021 & $\begin{array}{c}2.956 \\
{[1.107]}\end{array}$ & $\begin{array}{c}3.227 \\
{[1.037]}\end{array}$ & $\begin{array}{c}3.122 \\
{[1.065]}\end{array}$ & $\begin{array}{c}3.133 \\
{[1.036]}\end{array}$ & 0.070 & 0.162 & 0.210 & 0.487 & 0.577 & 0.941 \\
\hline Food scarcity & 1,020 & 0.785 & 0.798 & 0.824 & 0.811 & 0.776 & 0.317 & 0.572 & 0.593 & 0.810 & 0.794 \\
\hline Maternal health knowledge & 1,022 & 0.383 & 0.427 & 0.372 & 0.336 & 0.365 & 0.775 & 0.433 & 0.278 & 0.184 & 0.560 \\
\hline Child eats meat products & 1,022 & 0.510 & 0.527 & 0.542 & 0.524 & 0.801 & 0.481 & 0.840 & 0.842 & 0.976 & 0.820 \\
\hline Child received iron supplements & 1,002 & 0.122 & 0.185 & 0.157 & 0.186 & 0.185 & 0.363 & 0.110 & 0.610 & 0.992 & 0.554 \\
\hline \multicolumn{12}{|l|}{ Environment of care } \\
\hline Parents help with homework & 1,018 & 0.136 & 0.193 & 0.139 & 0.183 & 0.323 & 0.926 & 0.268 & 0.319 & 0.874 & 0.240 \\
\hline Parent's time spent for physical child care & 1,022 & $\begin{array}{l}46.705 \\
{[24.201]}\end{array}$ & $\begin{array}{c}48.882 \\
{[25.782]}\end{array}$ & $\begin{array}{l}42.279 \\
{[21.570]}\end{array}$ & $\begin{array}{l}48.476 \\
{[34.340]}\end{array}$ & 0.610 & 0.111 & 0.653 & 0.126 & 0.937 & 0.120 \\
\hline Parent attends school meetings & 1,019 & 0.618 & 0.673 & 0.616 & 0.678 & 0.484 & 0.974 & 0.370 & 0.517 & 0.947 & 0.425 \\
\hline Father lives at home & 1,022 & 0.867 & 0.836 & 0.913 & 0.888 & 0.413 & 0.036 & 0.447 & 0.044 & 0.216 & 0.389 \\
\hline Distance of school (min) & 1,022 & $\begin{array}{l}10.834 \\
{[6.511]}\end{array}$ & $\begin{array}{c}9.627 \\
{[7.058]}\end{array}$ & $\begin{array}{l}10.804 \\
{[6.618]}\end{array}$ & $\begin{array}{c}9.462 \\
{[6.133]}\end{array}$ & 0.288 & 0.970 & 0.121 & 0.352 & 0.900 & 0.197 \\
\hline \multicolumn{12}{|l|}{ Panel C: School level covariates } \\
\hline Number of children enrolled in school & 147 & $\begin{array}{c}233.229 \\
{[153.259]}\end{array}$ & $\begin{array}{c}168.324 \\
{[102.268]}\end{array}$ & $\begin{array}{c}324.926 \\
{[180.699]}\end{array}$ & $\begin{array}{c}189.605 \\
{[162.414]}\end{array}$ & 0.024 & 0.029 & 0.208 & 0.000 & 0.504 & 0.003 \\
\hline Class size & 149 & $\begin{array}{c}27.792 \\
{[12.634]}\end{array}$ & $\begin{array}{l}24.912 \\
{[9.805]}\end{array}$ & $\begin{array}{l}32.714 \\
{[24.856]}\end{array}$ & $\begin{array}{c}30.949 \\
{[21.366]}\end{array}$ & 0.249 & 0.330 & 0.417 & 0.123 & 0.118 & 0.762 \\
\hline Student teacher ratio & 147 & $\begin{array}{l}33.739 \\
{[9.406]}\end{array}$ & $\begin{array}{l}31.515 \\
{[6.807]}\end{array}$ & $\begin{array}{l}39.820 \\
{[11.094]}\end{array}$ & $\begin{array}{l}35.128 \\
{[12.057]}\end{array}$ & 0.218 & 0.018 & 0.561 & 0.001 & 0.117 & 0.110 \\
\hline Calories of MDM per child & 149 & $\begin{array}{c}68.331 \\
{[21.856]}\end{array}$ & $\begin{array}{c}63.876 \\
{[19.833]}\end{array}$ & $\begin{array}{l}69.484 \\
{[21.267]}\end{array}$ & $\begin{array}{l}69.282 \\
{[23.403]}\end{array}$ & 0.340 & 0.822 & 0.846 & 0.291 & 0.289 & 0.971 \\
\hline Amount of iron in MDM per child (mg) & 149 & $\begin{array}{c}0.747 \\
{[0.264]}\end{array}$ & $\begin{array}{c}0.751 \\
{[0.234]}\end{array}$ & $\begin{array}{c}0.782 \\
{[0.303]} \\
\end{array}$ & $\begin{array}{c}0.883 \\
{[0.502]}\end{array}$ & 0.949 & 0.612 & 0.130 & 0.655 & 0.145 & 0.310 \\
\hline \multicolumn{12}{|l|}{ Joint orthogonalitiy F-test } \\
\hline $\begin{array}{l}\text { F-statistics } \\
\text { p-Value }\end{array}$ & & $\begin{array}{c}2.402 \\
{[0.000]}\end{array}$ & $\begin{array}{c}1.352 \\
{[0.097]}\end{array}$ & $\begin{array}{c}1.962 \\
{[0.002]}\end{array}$ & $\begin{array}{c}1.352 \\
{[0.097]}\end{array}$ & $\begin{array}{c}2.526 \\
{[0.000]}\end{array}$ & $\begin{array}{c}3.705 \\
{[0.000]}\end{array}$ & $\begin{array}{c}2.998 \\
{[0.000]}\end{array}$ & $\begin{array}{l}10.376 \\
{[0.000]}\end{array}$ & $\begin{array}{c}4.137 \\
{[0.000]}\end{array}$ & $\begin{array}{l}11.377 \\
{[0.000]}\end{array}$ \\
\hline
\end{tabular}

Notes: Columns 2-5 report baseline means by intervention arm for child (Panel A and B) and schools (Panel C) in the study analysis. Columns 6-11 report p-values from tests on the equality of means for each variable. F-tests of joint significance: test of joint significance in regression of respective treatment dummies on all displayed baseline variables.

Source: Own Data. 
Table C.35: Baseline Mean Characteristics by Exposure Groups - Sample for Attendance Outcome

\begin{tabular}{|c|c|c|c|c|c|c|c|c|c|c|c|}
\hline & \multirow[b]{2}{*}{ Observations } & \multicolumn{4}{|c|}{ Means [Standard Deviations] } & \multicolumn{6}{|c|}{$p$-value of difference } \\
\hline & & Group Always & Early & Late & Hardly & Always-Early & Always-Late & Always-Hardly & Early-Late & Early-Hardly & Late-Hardly \\
\hline \multicolumn{12}{|l|}{ Panel A. Child level outcome variables } \\
\hline \multicolumn{12}{|l|}{ Health outcomes } \\
\hline Hemoglobin $(\mathrm{g} / \mathrm{dL})$ & 940 & $\begin{array}{l}11.388 \\
{[1.102]}\end{array}$ & $\begin{array}{c}11.368 \\
{[1.306]}\end{array}$ & $\begin{array}{c}11.562 \\
{[1.120]}\end{array}$ & $\begin{array}{l}11.688 \\
{[1.052]}\end{array}$ & 0.930 & 0.049 & 0.007 & 0.390 & 0.182 & 0.279 \\
\hline Any anemia & 940 & 0.508 & 0.488 & 0.437 & 0.357 & 0.803 & 0.036 & 0.002 & 0.542 & 0.152 & 0.088 \\
\hline Mild anemia & 940 & 0.219 & 0.171 & 0.193 & 0.135 & 0.197 & 0.279 & 0.056 & 0.543 & 0.491 & 0.179 \\
\hline Moderate/severe anemia & 940 & 0.290 & 0.317 & 0.244 & 0.222 & 0.734 & 0.190 & 0.070 & 0.368 & 0.255 & 0.542 \\
\hline Number of symptoms & 961 & $\begin{array}{c}1.159 \\
{[1.114]}\end{array}$ & $\begin{array}{c}0.854 \\
{[0.983]}\end{array}$ & $\begin{array}{c}1.013 \\
{[1.051]}\end{array}$ & $\begin{array}{c}0.915 \\
{[1.027]}\end{array}$ & 0.031 & 0.258 & 0.088 & 0.253 & 0.682 & 0.490 \\
\hline \multicolumn{12}{|l|}{ Cognitive test outcomes } \\
\hline Block design & 938 & $\begin{array}{c}3.866 \\
{[2.158]}\end{array}$ & $\begin{array}{c}3.800 \\
{[2.021]}\end{array}$ & $\begin{array}{c}3.771 \\
{[2.106]}\end{array}$ & $\begin{array}{c}3.385 \\
{[2.327]}\end{array}$ & 0.894 & 0.668 & 0.247 & 0.952 & 0.494 & 0.335 \\
\hline Digit span forward & 940 & $\begin{array}{c}4.088 \\
{[1.010]}\end{array}$ & $\begin{array}{c}3.987 \\
{[0.907]}\end{array}$ & $\begin{array}{c}4.113 \\
{[0.901]}\end{array}$ & $\begin{array}{c}4.008 \\
{[1.096]}\end{array}$ & 0.577 & 0.756 & 0.562 & 0.491 & 0.926 & 0.453 \\
\hline Digit span backward & 940 & $\begin{array}{c}1.245 \\
{[1.339]}\end{array}$ & $\begin{array}{c}1.313 \\
{[1.374]}\end{array}$ & $\begin{array}{c}1.081 \\
{[1.306]}\end{array}$ & $\begin{array}{c}1.085 \\
{[1.300]}\end{array}$ & 0.822 & 0.173 & 0.417 & 0.442 & 0.508 & 0.984 \\
\hline Progressive matrices & 940 & $\begin{array}{c}4.752 \\
{[1.628]}\end{array}$ & $\begin{array}{c}4.638 \\
{[1.759]}\end{array}$ & $\begin{array}{c}4.900 \\
{[1.483]}\end{array}$ & $\begin{array}{c}4.823 \\
{[1.654]}\end{array}$ & 0.788 & 0.377 & 0.820 & 0.550 & 0.720 & 0.812 \\
\hline Stroop test & 938 & $\begin{array}{c}5.482 \\
{[3.315]}\end{array}$ & $\begin{array}{c}5.706 \\
{[3.496]}\end{array}$ & $\begin{array}{c}5.660 \\
{[3.494]}\end{array}$ & $\begin{array}{c}4.804 \\
{[3.468]}\end{array}$ & 0.644 & 0.605 & 0.133 & 0.924 & 0.124 & 0.063 \\
\hline Cognitive score index & 936 & $\begin{array}{c}0.060 \\
{[0.973]}\end{array}$ & $\begin{array}{c}0.036 \\
{[0.938]}\end{array}$ & $\begin{array}{c}0.052 \\
{[0.989]}\end{array}$ & $\begin{array}{l}-0.120 \\
{[1.072]}\end{array}$ & 0.927 & 0.936 & 0.330 & 0.951 & 0.613 & 0.357 \\
\hline \multicolumn{12}{|l|}{ Education outcomes } \\
\hline Math score & 939 & $\begin{array}{c}4.838 \\
{[3.811]}\end{array}$ & $\begin{array}{c}5.037 \\
{[3.623]}\end{array}$ & $\begin{array}{c}5.333 \\
{[3.749]}\end{array}$ & $\begin{array}{c}4.900 \\
{[3.835]}\end{array}$ & 0.860 & 0.335 & 0.924 & 0.797 & 0.911 & 0.522 \\
\hline Reading score & 939 & $\begin{array}{c}0.881 \\
{[1.120]}\end{array}$ & $\begin{array}{c}1.089 \\
{[1.134]}\end{array}$ & $\begin{array}{c}1.052 \\
{[1.179]}\end{array}$ & $\begin{array}{c}0.962 \\
{[1.151]}\end{array}$ & 0.245 & 0.177 & 0.711 & 0.840 & 0.623 & 0.686 \\
\hline School attendance & 961 & $\begin{array}{c}0.783 \\
{[0.170]}\end{array}$ & $\begin{array}{c}0.861 \\
{[0.100]}\end{array}$ & $\begin{array}{c}0.796 \\
{[0.173]}\end{array}$ & $\begin{array}{c}0.823 \\
{[0.148]}\end{array}$ & 0.008 & 0.553 & 0.156 & 0.012 & 0.221 & 0.263 \\
\hline \multicolumn{12}{|c|}{ Panel B: Child and household level control variables } \\
\hline \multicolumn{12}{|c|}{ Demographics and socioeconomic variables } \\
\hline Muslim & 961 & 0.055 & 0.000 & 0.051 & 0.000 & 0.017 & 0.906 & 0.017 & 0.144 & & 0.142 \\
\hline Scheduled Caste/Scheduled Tribe & 961 & 0.344 & 0.341 & 0.228 & 0.300 & 0.984 & 0.111 & 0.632 & 0.395 & 0.777 & 0.427 \\
\hline Block & 961 & 1.333 & 1.415 & 1.117 & 1.385 & 0.677 & 0.079 & 0.771 & 0.122 & 0.898 & 0.122 \\
\hline Rural & 961 & 0.988 & 0.963 & 0.975 & 0.962 & 0.532 & 0.508 & 0.371 & 0.790 & 0.969 & 0.690 \\
\hline Family size & 961 & $\begin{array}{c}7.628 \\
{[3.289]}\end{array}$ & $\begin{array}{c}7.171 \\
{[2.423]}\end{array}$ & $\begin{array}{c}7.845 \\
{[3.500]}\end{array}$ & $\begin{array}{c}7.600 \\
{[3.089]}\end{array}$ & 0.201 & 0.475 & 0.914 & 0.082 & 0.227 & 0.407 \\
\hline Father's years of schooling & 948 & $\begin{array}{c}5.131 \\
{[4.735]}\end{array}$ & $\begin{array}{c}5.775 \\
{[4.776]}\end{array}$ & $\begin{array}{c}5.535 \\
{[4.885]}\end{array}$ & $\begin{array}{c}5.388 \\
{[4.671]}\end{array}$ & 0.489 & 0.438 & 0.705 & 0.795 & 0.707 & 0.825 \\
\hline Mother's years of schooling & 959 & $\begin{array}{c}1.383 \\
{[2.797]}\end{array}$ & $\begin{array}{c}1.561 \\
{[3.123]}\end{array}$ & $\begin{array}{c}1.939 \\
{[3.278]}\end{array}$ & $\begin{array}{c}1.308 \\
{[2.833]}\end{array}$ & 0.558 & 0.057 & 0.825 & 0.241 & 0.498 & 0.082 \\
\hline Asset index & 938 & $\begin{array}{l}-0.089 \\
{[0.923]}\end{array}$ & $\begin{array}{l}-0.004 \\
{[0.911]}\end{array}$ & $\begin{array}{l}-0.015 \\
{[0.910]}\end{array}$ & $\begin{array}{l}-0.063 \\
{[0.872]}\end{array}$ & 0.457 & 0.485 & 0.846 & 0.927 & 0.690 & 0.732 \\
\hline Gender of the child & 957 & 0.447 & 0.366 & 0.403 & 0.453 & 0.322 & 0.271 & 0.926 & 0.651 & 0.390 & 0.474 \\
\hline \multicolumn{12}{|l|}{ Health care } \\
\hline Institutional delivery & 955 & 0.334 & 0.346 & 0.316 & 0.415 & 0.831 & 0.681 & 0.147 & 0.607 & 0.306 & 0.094 \\
\hline Health insurance & 956 & $\begin{array}{c}0.360 \\
{[0.481]}\end{array}$ & $\begin{array}{c}0.366 \\
{[0.485]}\end{array}$ & $\begin{array}{c}0.357 \\
{[0.480]}\end{array}$ & $\begin{array}{c}0.438 \\
{[0.498]}\end{array}$ & 0.959 & 0.942 & 0.397 & 0.932 & 0.587 & 0.395 \\
\hline Diarrhea & 961 & 0.030 & 0.012 & 0.025 & 0.008 & 0.223 & 0.668 & 0.029 & 0.398 & 0.762 & 0.121 \\
\hline Improved sanitation & 961 & 0.085 & 0.037 & 0.082 & 0.008 & 0.064 & 0.913 & 0.001 & 0.072 & 0.098 & 0.001 \\
\hline \multicolumn{12}{|l|}{ Nutrition } \\
\hline Diet diversity score & 961 & $\begin{array}{c}3.829 \\
{[1.172]}\end{array}$ & $\begin{array}{c}3.829 \\
{[1.109]}\end{array}$ & $\begin{array}{c}3.927 \\
{[1.194]}\end{array}$ & $\begin{array}{c}3.785 \\
{[1.114]}\end{array}$ & 0.999 & 0.424 & 0.827 & 0.593 & 0.857 & 0.477 \\
\hline Number of meals/day & 960 & $\begin{array}{c}2.998 \\
{[1.060]}\end{array}$ & $\begin{array}{c}3.268 \\
{[0.969]}\end{array}$ & $\begin{array}{c}3.057 \\
{[1.051]}\end{array}$ & $\begin{array}{c}3.115 \\
{[1.024]}\end{array}$ & 0.091 & 0.597 & 0.406 & 0.203 & 0.416 & 0.693 \\
\hline Food scarcity & 958 & 0.806 & 0.802 & 0.800 & 0.808 & 0.955 & 0.888 & 0.968 & 0.964 & 0.937 & 0.884 \\
\hline Maternal health knowledge & 961 & 0.381 & 0.390 & 0.358 & 0.315 & 0.852 & 0.528 & 0.359 & 0.524 & 0.356 & 0.563 \\
\hline Child eats meat products & 961 & 0.522 & 0.549 & 0.547 & 0.500 & 0.751 & 0.562 & 0.807 & 0.988 & 0.679 & 0.604 \\
\hline Child received iron supplements & 939 & 0.120 & 0.163 & 0.179 & 0.183 & 0.349 & 0.196 & 0.147 & 0.777 & 0.717 & 0.942 \\
\hline \multicolumn{12}{|l|}{ Environment of care } \\
\hline Parents help with homework & 956 & 0.125 & 0.188 & 0.166 & 0.132 & 0.287 & 0.226 & 0.858 & 0.698 & 0.362 & 0.349 \\
\hline Parent's time spent for physical child care & 961 & $\begin{array}{c}46.727 \\
{[25.968]}\end{array}$ & $\begin{array}{c}47.659 \\
{[27.645]}\end{array}$ & $\begin{array}{c}40.636 \\
{[17.268]}\end{array}$ & $\begin{array}{c}48.669 \\
{[34.403]}\end{array}$ & 0.875 & 0.035 & 0.730 & 0.217 & 0.893 & 0.135 \\
\hline Parent attends school meetings & 959 & 0.630 & 0.659 & 0.643 & 0.677 & 0.786 & 0.847 & 0.525 & 0.888 & 0.871 & 0.670 \\
\hline Father lives at home & 961 & 0.857 & 0.841 & 0.886 & 0.854 & 0.718 & 0.255 & 0.929 & 0.332 & 0.808 & 0.391 \\
\hline Distance of school (min) & 961 & $\begin{array}{l}10.610 \\
{[6.545]}\end{array}$ & $\begin{array}{c}8.329 \\
{[4.982]}\end{array}$ & $\begin{array}{l}11.108 \\
{[6.716]}\end{array}$ & $\begin{array}{c}9.154 \\
{[5.218]}\end{array}$ & 0.046 & 0.538 & 0.119 & 0.030 & 0.536 & 0.071 \\
\hline \multicolumn{12}{|l|}{ Panel C: School level covariates } \\
\hline Number of children enrolled in school & 95 & $\begin{array}{c}256.675 \\
{[156.874]}\end{array}$ & $\begin{array}{l}126.667 \\
{[43.423]}\end{array}$ & $\begin{array}{c}324.926 \\
{[180.699]}\end{array}$ & $\begin{array}{l}123.250 \\
{[38.968]}\end{array}$ & 0.000 & 0.114 & 0.000 & 0.000 & 0.831 & 0.000 \\
\hline Class size & 96 & $\begin{array}{c}30.225 \\
{[13.302]}\end{array}$ & $\begin{array}{l}21.500 \\
{[6.667]}\end{array}$ & $\begin{array}{c}32.714 \\
{[24.856]}\end{array}$ & $\begin{array}{c}26.875 \\
{[13.033]}\end{array}$ & 0.003 & 0.629 & 0.388 & 0.034 & 0.168 & 0.313 \\
\hline Student teacher ratio & 95 & $\begin{array}{l}34.946 \\
{[9.873]}\end{array}$ & $\begin{array}{l}29.574 \\
{[6.376]}\end{array}$ & $\begin{array}{l}39.820 \\
{[11.094]}\end{array}$ & $\begin{array}{c}34.850 \\
{[11.698]}\end{array}$ & 0.029 & 0.069 & 0.977 & 0.001 & 0.139 & 0.176 \\
\hline Calories of MDM per child & 96 & $\begin{array}{c}70.322 \\
{[22.670]}\end{array}$ & $\begin{array}{c}64.373 \\
{[20.607]}\end{array}$ & $\begin{array}{l}69.484 \\
{[21.267]}\end{array}$ & $\begin{array}{c}68.882 \\
{[24.742]}\end{array}$ & 0.388 & 0.877 & 0.840 & 0.476 & 0.603 & 0.935 \\
\hline Amount of iron in MDM per child (mg) & 96 & $\begin{array}{c}0.748 \\
{[0.259]}\end{array}$ & $\begin{array}{c}0.713 \\
{[0.203]} \\
\end{array}$ & $\begin{array}{c}0.782 \\
{[0.303]} \\
\end{array}$ & $\begin{array}{c}0.915 \\
{[0.547]} \\
\end{array}$ & 0.621 & 0.626 & 0.241 & 0.399 & 0.187 & 0.373 \\
\hline \multicolumn{12}{|l|}{ Joint orthogonalitiy F-test } \\
\hline $\begin{array}{l}\text { F-statistics } \\
\text { p-Value }\end{array}$ & & 2.402 & $\begin{array}{l}1.352 \\
1.35971\end{array}$ & 1.962 & $\begin{array}{l}1.352 \\
10.0971\end{array}$ & 2.526 & $\begin{array}{l}3.705 \\
50.000\end{array}$ & 2.998 & 10.376 & 4.137 & 11.377 \\
\hline
\end{tabular}

Notes: Columns 2-5 report baseline means by intervention arm for child (Panel A and B) and schools (Panel C) in the study analysis. Columns 6-11 report p-values from tests on the equality of means for each variable. F-tests of joint significance: test of joint significance in regression of respective treatment dummies on all displayed baseline variables.

Source: Own Data. 
3.3 Inverse Probability Weighting

3.3.1 Health Outcomes 


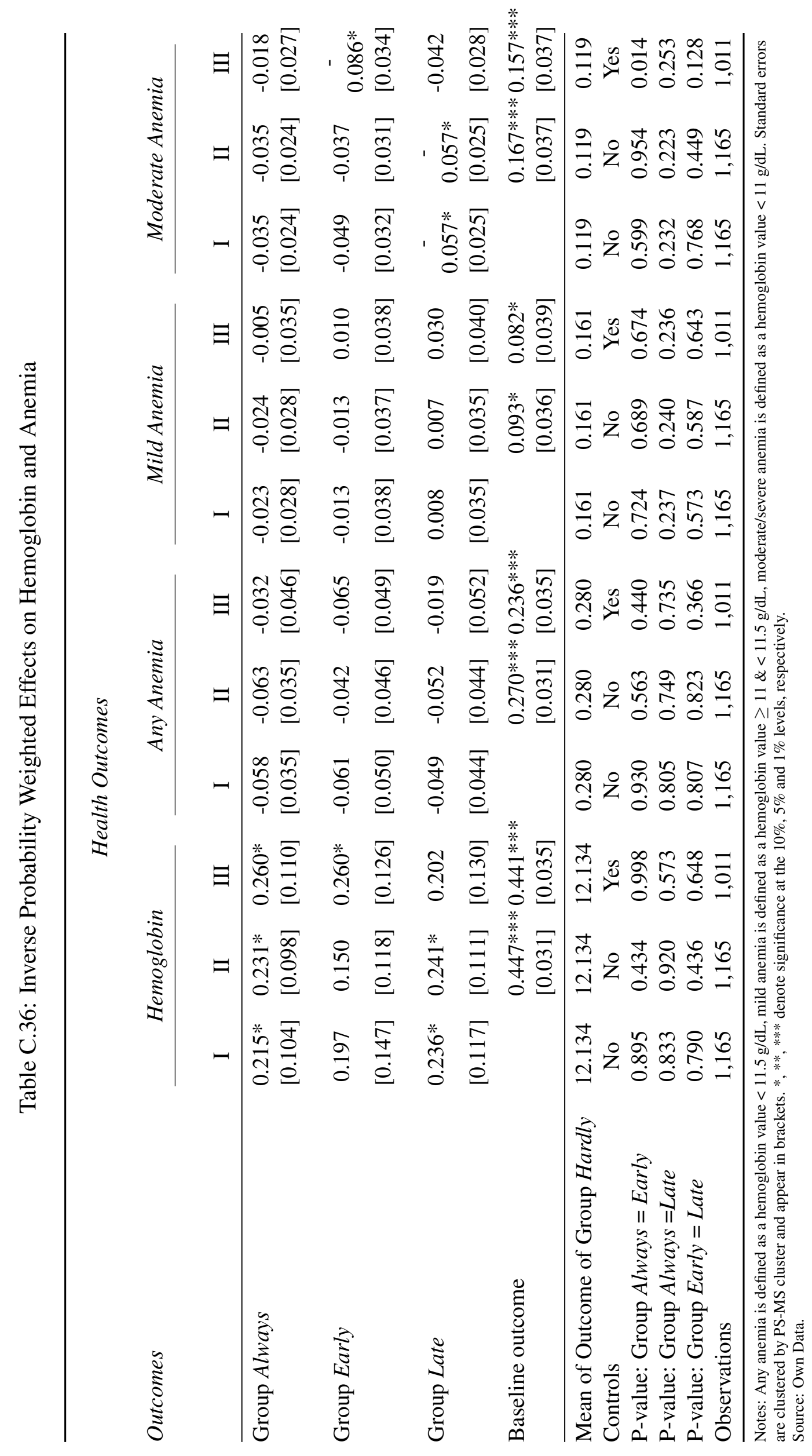




\subsubsection{Cognition Outcomes}




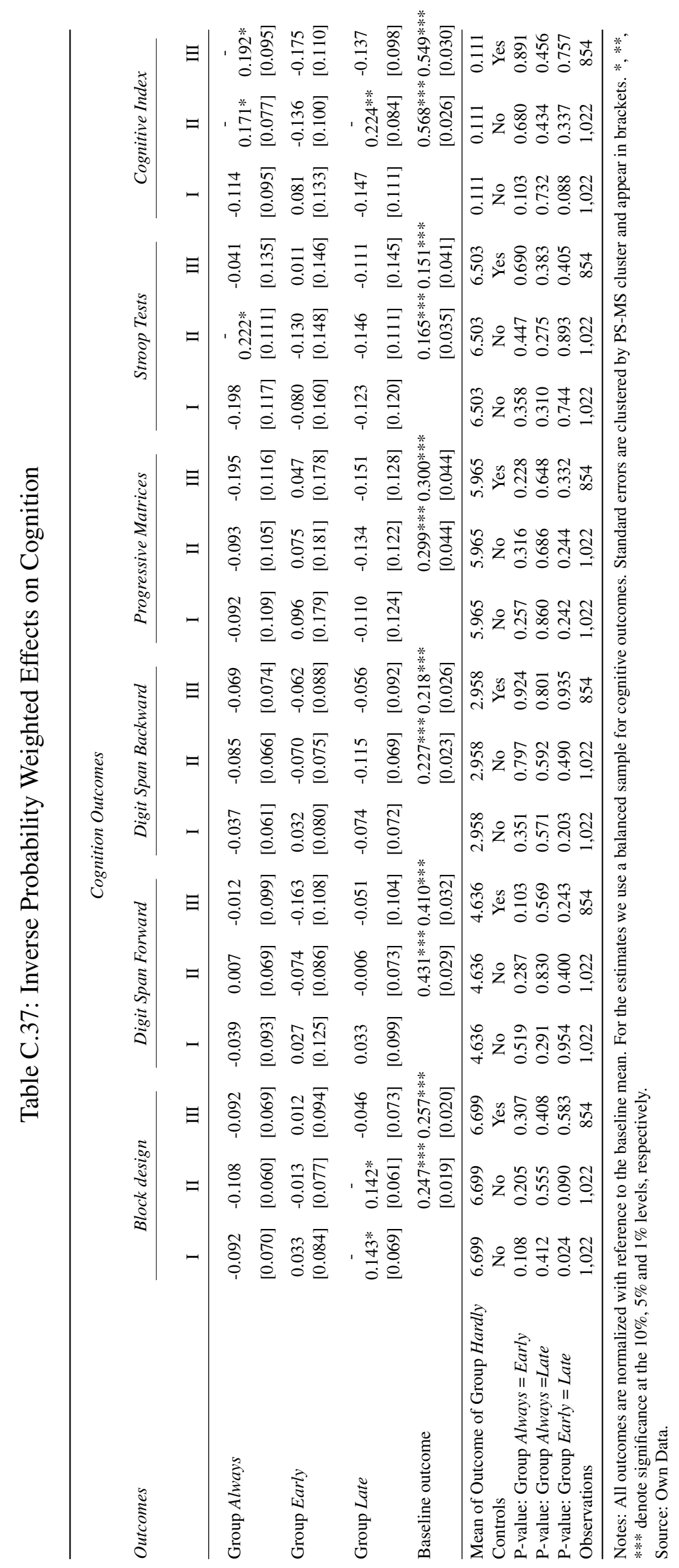




\subsubsection{Education Outcomes}




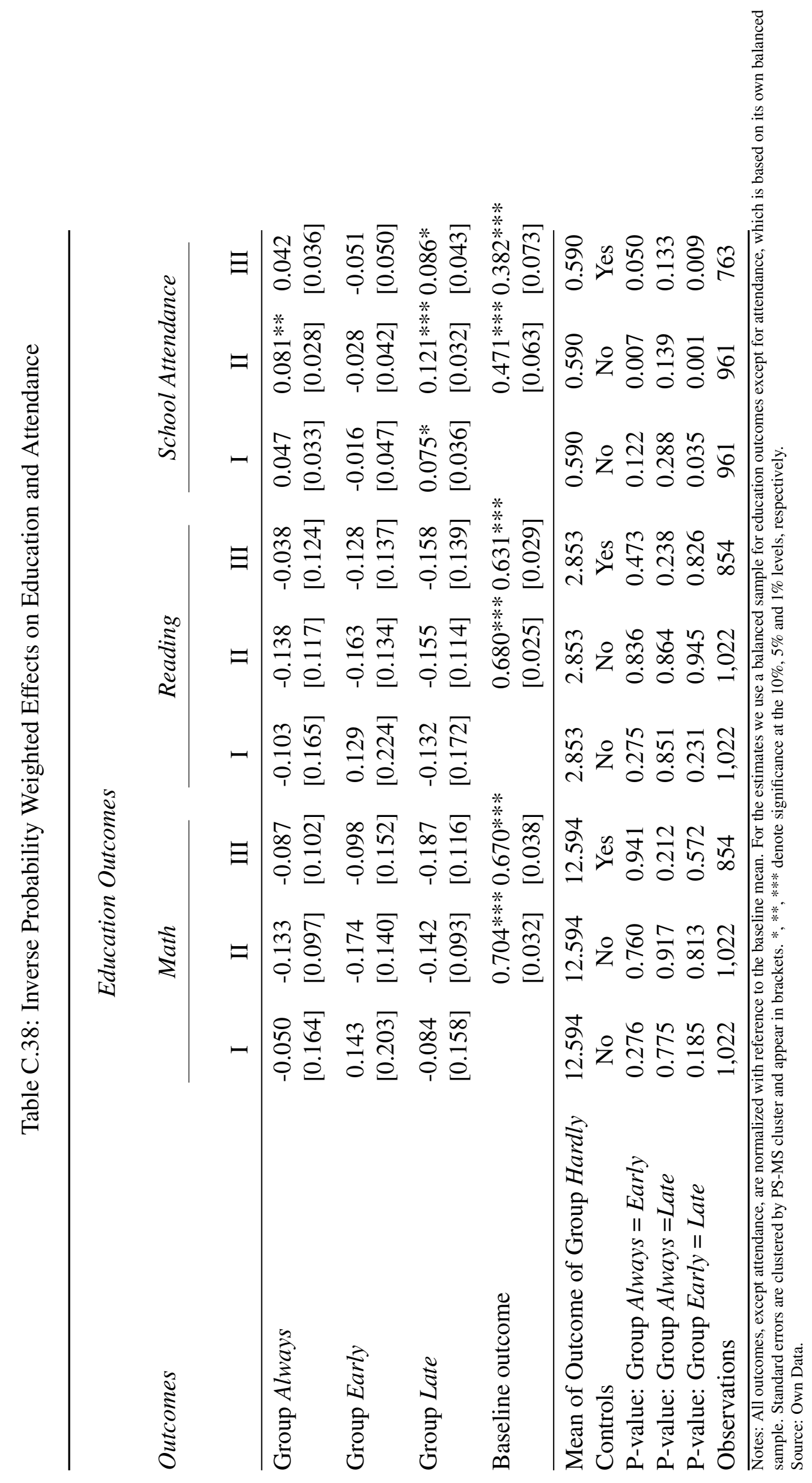




\subsection{Lee Bounds for Outcomes}

\subsubsection{Health Outcomes}

Table C.39: Hemoglobin (g/dL)

I

II

\begin{tabular}{cccccccc}
\cline { 2 - 4 } \cline { 5 - 7 } & & & & & & & \\
& OLS & Lower & Upper & ANCOVA & Lower & Upper \\
\hline Group Always & 0.204 & -0.035 & 0.528 & 0.224 & 0.052 & 0.449 \\
& {$[0.088]$} & {$[0.108]$} & {$[0.107]$} & {$[0.082]$} & {$[0.106]$} & {$[0.104]$}
\end{tabular}

Observations $\quad 702$

702

$\begin{array}{ccccccc}\text { Group Early } & 0.147 & 0.120 & 0.248 & 0.125 & 0.153 & 0.183 \\ & {[0.109]} & {[0.173]} & {[0.174]} & {[0.108]} & {[0.174]} & {[0.169]}\end{array}$

Observations 335

\begin{tabular}{lcccccc}
\hline Group Late & 0.226 & 0.076 & 0.463 & 0.221 & 0.098 & 0.411 \\
& {$[0.088]$} & {$[0.116]$} & {$[0.111]$} & {$[0.085]$} & {$[0.112]$} & {$[0.108]$}
\end{tabular}

Observations

514

514

Baseline mean 11.945

11.945

Notes: The coefficient of each group has been estimated separately, relative to Hardly using OLS or ANCOVA. In model I, there are no control variables and the bounds are classic Lee (2009) bounds. Model II includes the baseline outcome as control and employs the terciles of the baseline outcome to tighten the Lee bounds.The estimation of Lee bounds uses the Stata command by Tauchmann (2014).Standard errors in parenthesis.

Source: Own Data.

Table C.40: Any anemia

I

II

\begin{tabular}{lcccccc} 
& OLS & Lower & Upper & ANCOVA & Lower & Upper \\
\hline Group Always & -0.054 & -0.170 & -0.026 & -0.058 & -0.143 & -0.036 \\
& {$[0.034]$} & {$[0.054]$} & {$[0.040]$} & {$[0.033]$} & {$[0.049]$} & {$[0.041]$} \\
Observations & 702 & & & 702 & & \\
\hline Group Early & -0.033 & -0.070 & -0.039 & -0.035 & -0.042 & -0.042 \\
& {$[0.045]$} & {$[0.051]$} & {$[0.065]$} & {$[0.045]$} & {$[0.050]$} & {$[0.060]$} \\
Observations & 335 & & & 335 & & \\
\hline Group Late & -0.041 & -0.128 & -0.026 & -0.042 & -0.115 & -0.033 \\
& {$[0.037]$} & {$[0.056]$} & {$[0.043]$} & {$[0.038]$} & {$[0.052]$} & {$[0.043]$} \\
Observations & 514 & & & 514 & & \\
\hline \hline Baseline mean & 0.287 & & \multicolumn{5}{c}{0.287} \\
\hline
\end{tabular}

Notes: The coefficient of each group has been estimated separately, relative to Hardly using OLS or ANCOVA. In model I, there are no control variables and the bounds are classic Lee (2009) bounds. Model II includes the baseline outcome as control and employs the terciles of the baseline outcome to tighten the Lee bounds.The estimation of Lee bounds uses the Stata command by Tauchmann (2014).Standard errors in parenthesis.

Source: Own Data. 
Table C.41: Mild anemia

\begin{tabular}{|c|c|c|c|c|c|c|}
\hline & \multicolumn{3}{|c|}{ I } & \multicolumn{3}{|c|}{ II } \\
\hline & OLS & Lower & Upper & ANCOVA & Lower & Upper \\
\hline \multirow[t]{2}{*}{ Group Always } & -0.021 & -0.147 & -0.003 & -0.021 & -0.111 & -0.008 \\
\hline & [0.028] & {$[0.052]$} & [0.032] & [0.029] & [0.042] & [0.032] \\
\hline Observations & 702 & & & 702 & & \\
\hline \multirow[t]{2}{*}{ Group Early } & 0.004 & -0.018 & 0.013 & -0.011 & -0.009 & -0.006 \\
\hline & [0.038] & {$[0.042]$} & [0.065] & [0.039] & [0.041] & [0.060] \\
\hline Observations & 335 & & & 335 & & \\
\hline \multirow[t]{2}{*}{ Group Late } & 0.012 & -0.077 & 0.025 & 0.013 & -0.061 & 0.022 \\
\hline & [0.032] & {$[0.054]$} & [0.036] & [0.033] & [0.047] & [0.036] \\
\hline Observations & 514 & & & 514 & & \\
\hline Baseline mean & 0.138 & & & 0.138 & & \\
\hline
\end{tabular}

Notes: The coefficient of each group has been estimated separately, relative to Hardly using OLS or ANCOVA. In model I, there are no control variables and the bounds are classic Lee (2009) bounds. Model II includes the baseline outcome as control and employs the terciles of the baseline outcome to tighten the Lee bounds. The estimation of Lee bounds uses the Stata command by Tauchmann (2014).Standard errors in parenthesis.

Source: Own Data.

Table C.42: Moderate/severe anemia

\begin{tabular}{|c|c|c|c|c|c|c|}
\hline & \multicolumn{3}{|c|}{ I } & \multicolumn{3}{|c|}{ II } \\
\hline & OLS & Lower & Upper & ANCOVA & Lower & Upper \\
\hline Group Always & $\begin{array}{l}-0.033 \\
{[0.023]}\end{array}$ & $\begin{array}{c}-0.119 \\
{[0.023]}\end{array}$ & $\begin{array}{c}-0.023 \\
{[0.028]}\end{array}$ & $\begin{array}{c}-0.033 \\
{[0.023]}\end{array}$ & $\begin{array}{c}-0.089 \\
{[0.027]}\end{array}$ & $\begin{array}{l}-0.028 \\
{[0.028]}\end{array}$ \\
\hline Observations & 702 & & & 702 & & \\
\hline Group Early & $\begin{array}{c}-0.037 \\
{[0.031]}\end{array}$ & $\begin{array}{c}-0.052 \\
{[0.033]}\end{array}$ & $\begin{array}{c}-0.022 \\
{[0.063]}\end{array}$ & $\begin{array}{c}-0.036 \\
{[0.032]}\end{array}$ & $\begin{array}{c}-0.041 \\
{[0.034]}\end{array}$ & $\begin{array}{l}-0.044 \\
{[0.052]}\end{array}$ \\
\hline Observations & 335 & & & 335 & & \\
\hline Group Late & $\begin{array}{c}-0.053 \\
{[0.024]}\end{array}$ & $\begin{array}{c}-0.119 \\
{[0.023]}\end{array}$ & $\begin{array}{c}-0.051 \\
{[0.028]}\end{array}$ & $\begin{array}{c}-0.054 \\
{[0.024]}\end{array}$ & $\begin{array}{c}-0.090 \\
{[0.028]}\end{array}$ & $\begin{array}{c}-0.054 \\
{[0.028]}\end{array}$ \\
\hline Observations & 514 & & & 514 & & \\
\hline
\end{tabular}

Notes: The coefficient of each group has been estimated separately, relative to Hardly using OLS or ANCOVA. In model I, there are no control variables and the bounds are classic Lee (2009) bounds. Model II includes the baseline outcome as control and employs the terciles of the baseline outcome to tighten the Lee bounds.The estimation of Lee bounds uses the Stata command by Tauchmann (2014).Standard errors in parenthesis.

Source: Own Data. 


\subsubsection{Cognition Outcomes}

Table C.43: Block design

\begin{tabular}{|c|c|c|c|c|c|c|}
\hline & \multicolumn{3}{|c|}{ I } & \multicolumn{3}{|c|}{ II } \\
\hline & OLS & Lower & Upper & ANCOVA & Lower & Upper \\
\hline \multirow[t]{2}{*}{ Group Always } & -0.087 & -0.092 & 0.163 & -0.102 & -0.267 & 0.068 \\
\hline & [0.057] & {$[0.076]$} & [0.065] & [0.054] & [0.083] & [0.082] \\
\hline Observations & 600 & & & 600 & & \\
\hline \multirow[t]{2}{*}{ Group Early } & 0.058 & 0.033 & 0.051 & -0.001 & 0.016 & -0.061 \\
\hline & [0.072] & [0.089] & [0.132] & {$[0.068]$} & [0.098] & [0.108] \\
\hline Observations & 253 & & & 253 & & \\
\hline \multirow[t]{2}{*}{ Group Late } & -0.124 & -0.586 & 0.092 & -0.138 & -0.421 & 0.060 \\
\hline & {$[0.058]$} & {$[0.080]$} & [0.065] & [0.057] & [0.080] & [0.071] \\
\hline Observations & 455 & & & 455 & & \\
\hline Baseline mean & 4.729 & & & 4.729 & & \\
\hline
\end{tabular}

Notes: The coefficient of each group has been estimated separately, relative to Hardly using OLS or ANCOVA. In model I, there are no control variables and the bounds are classic Lee (2009) bounds. Model II includes the baseline outcome as control and employs the terciles of the baseline outcome to tighten the Lee bounds.The estimation of Lee bounds uses the Stata command by Tauchmann (2014).Standard errors in parenthesis.

Source: Own Data.

Table C.44: Digit span forward

\begin{tabular}{lccccccc} 
& \multicolumn{3}{c}{ I } & & \multicolumn{3}{c}{ II } \\
\cline { 2 - 3 } \cline { 6 - 8 } & OLS & Lower & Upper & ANCOVA & Lower & Upper \\
\hline Group Always & -0.050 & -0.366 & 0.315 & & 0.022 & -0.215 & 0.281 \\
& {$[0.079]$} & {$[0.093]$} & {$[0.102]$} & {$[0.070]$} & {$[0.118]$} & {$[0.108]$} \\
Observations & 600 & & & 600 & & \\
\hline Group Early & 0.084 & -0.001 & 0.070 & -0.005 & 0.034 & 0.003 \\
& {$[0.102]$} & {$[0.158]$} & {$[0.177]$} & {$[0.094]$} & {$[0.188]$} & {$[0.287]$} \\
Observations & 253 & & & 253 & & \\
\hline Group Late & 0.052 & -0.376 & 0.464 & -0.001 & -0.293 & 0.324 \\
& {$[0.088]$} & {$[0.099]$} & {$[0.118]$} & {$[0.076]$} & {$[0.114]$} & {$[0.120]$} \\
Observations & 455 & & & 455 & & \\
\hline \hline Baseline mean & 4.605 & & \multicolumn{5}{c}{4.605} \\
\hline
\end{tabular}

Notes: The coefficient of each group has been estimated separately, relative to Hardly using OLS or ANCOVA. In model I, there are no control variables and the bounds are classic Lee (2009) bounds. Model II includes the baseline outcome as control and employs the terciles of the baseline outcome to tighten the Lee bounds. The estimation of Lee bounds uses the Stata command by Tauchmann (2014).Standard errors in parenthesis.

Source: Own Data. 
Table C.45: Digit span backward

\begin{tabular}{lccccccc} 
& \multicolumn{3}{c}{ I } & & \multicolumn{3}{c}{ II } \\
\cline { 2 - 3 } \cline { 6 - 8 } & OLS & Lower & Upper & ANCOVA & Lower & Upper \\
\hline Group Always & -0.046 & -1.063 & 0.273 & & -0.086 & -0.945 & 0.135 \\
& {$[0.067]$} & {$[0.108]$} & {$[0.059]$} & {$[0.065]$} & {$[0.110]$} & {$[0.071]$} \\
Observations & 600 & & & 600 & & \\
\hline Group Early & 0.056 & 0.032 & 0.065 & -0.038 & 0.012 & -0.179 \\
& {$[0.078]$} & {$[0.156]$} & {$[0.216]$} & {$[0.075]$} & {$[0.136]$} & {$[0.168]$} \\
Observations & 253 & & & 253 & & \\
\hline Group Late & -0.054 & -1.102 & 0.281 & -0.122 & -0.983 & 0.150 \\
& {$[0.072]$} & {$[0.122]$} & {$[0.061]$} & {$[0.070]$} & {$[0.132]$} & {$[0.079]$} \\
Observations & 455 & & & 455 & & \\
\hline \hline Baseline mean & 1.835 & & \multicolumn{5}{c}{1.835} \\
\hline
\end{tabular}

Notes: The coefficient of each group has been estimated separately, relative to Hardly using OLS or ANCOVA. In model I, there are no control variables and the bounds are classic Lee (2009) bounds. Model II includes the baseline outcome as control and employs the terciles of the baseline outcome to tighten the Lee bounds. The estimation of Lee bounds uses the Stata command by Tauchmann (2014).Standard errors in parenthesis.

Source: Own Data.

Table C.46: Progressive matrices

\begin{tabular}{|c|c|c|c|c|c|c|}
\hline & \multicolumn{3}{|c|}{ I } & \multicolumn{3}{|c|}{ II } \\
\hline & OLS & Lower & Upper & ANCOVA & Lower & Upper \\
\hline \multirow[t]{2}{*}{ Group Always } & -0.095 & -0.698 & 0.346 & -0.072 & -0.584 & 0.255 \\
\hline & [0.098] & [0.131] & [0.120] & [0.100] & {$[0.134]$} & [0.130] \\
\hline Observations & 600 & & & 600 & & \\
\hline \multirow[t]{2}{*}{ Group Early } & 0.121 & 0.047 & 0.131 & 0.102 & 0.166 & 0.051 \\
\hline & {$[0.137]$} & {$[0.341]$} & {$[0.264]$} & [0.140] & {$[0.312]$} & [0.248] \\
\hline Observations & 253 & & & 253 & & \\
\hline \multirow[t]{2}{*}{ Group Late } & -0.099 & -0.661 & 0.238 & -0.123 & -0.645 & 0.191 \\
\hline & [0.097] & [0.109] & {$[0.121]$} & [0.099] & {$[0.127]$} & [0.129] \\
\hline Observations & 455 & & & 455 & & \\
\hline Baseline mean & $\overline{5.126}$ & & & $\overline{5.126}$ & & \\
\hline
\end{tabular}

Notes: The coefficient of each group has been estimated separately, relative to Hardly using OLS or ANCOVA. In model I, there are no control variables and the bounds are classic Lee (2009) bounds. Model II includes the baseline outcome as control and employs the terciles of the baseline outcome to tighten the Lee bounds.The estimation of Lee bounds uses the Stata command by Tauchmann (2014).Standard errors in parenthesis.

Source: Own Data. 
Table C.47: Stroop test

\begin{tabular}{|c|c|c|c|c|c|c|}
\hline & \multicolumn{3}{|c|}{ I } & \multicolumn{3}{|c|}{ II } \\
\hline & OLS & Lower & Upper & ANCOVA & Lower & Upper \\
\hline Group Always & $\begin{array}{c}-0.154 \\
{[0.098]}\end{array}$ & $\begin{array}{c}-0.554 \\
{[0.133]}\end{array}$ & $\begin{array}{c}0.324 \\
{[0.135]}\end{array}$ & $\begin{array}{c}-0.181 \\
{[0.100]}\end{array}$ & $\begin{array}{c}-0.525 \\
{[0.138]}\end{array}$ & $\begin{array}{c}0.182 \\
{[0.137]}\end{array}$ \\
\hline Observations & 600 & & & 600 & & \\
\hline Group Early & $\begin{array}{c}-0.056 \\
{[0.133]}\end{array}$ & $\begin{array}{c}-0.104 \\
{[0.205]}\end{array}$ & $\begin{array}{c}0.101 \\
{[0.222]}\end{array}$ & $\begin{array}{c}-0.076 \\
{[0.137]}\end{array}$ & $\begin{array}{c}-0.049 \\
{[0.199]}\end{array}$ & $\begin{array}{c}0.114 \\
{[0.208]}\end{array}$ \\
\hline Observations & 253 & & & 253 & & \\
\hline Group Late & $\begin{array}{c}-0.086 \\
{[0.102]}\end{array}$ & $\begin{array}{c}-0.715 \\
{[0.133]}\end{array}$ & $\begin{array}{c}0.457 \\
{[0.136]}\end{array}$ & $\begin{array}{c}-0.127 \\
{[0.105]}\end{array}$ & $\begin{array}{c}-0.554 \\
{[0.138]}\end{array}$ & $\begin{array}{c}0.303 \\
{[0.141]}\end{array}$ \\
\hline Observations & 455 & & & 455 & & \\
\hline
\end{tabular}

Notes: The coefficient of each group has been estimated separately, relative to Hardly using OLS or ANCOVA. In model I, there are no control variables and the bounds are classic Lee (2009) bounds. Model II includes the baseline outcome as control and employs the terciles of the baseline outcome to tighten the Lee bounds. The estimation of Lee bounds uses the Stata command by Tauchmann (2014).Standard errors in parenthesis.

Source: Own Data.

Table C.48: Cognitive score index

\begin{tabular}{|c|c|c|c|c|c|c|}
\hline & \multicolumn{3}{|c|}{ I } & \multicolumn{3}{|c|}{ II } \\
\hline & OLS & Lower & Upper & ANCOVA & Lower & Upper \\
\hline Group Always & $\begin{array}{l}-0.159 \\
{[0.089]}\end{array}$ & $\begin{array}{c}-0.567 \\
{[0.105]}\end{array}$ & $\begin{array}{c}0.318 \\
{[0.105]}\end{array}$ & $\begin{array}{c}-0.194 \\
{[0.071]}\end{array}$ & $\begin{array}{c}-0.452 \\
{[0.101]}\end{array}$ & $\begin{array}{c}0.148 \\
{[0.105]}\end{array}$ \\
\hline Observations & 600 & & & 600 & & \\
\hline Group Early & $\begin{array}{c}0.107 \\
{[0.109]}\end{array}$ & $\begin{array}{c}0.047 \\
{[0.220]}\end{array}$ & $\begin{array}{c}0.105 \\
{[0.239]}\end{array}$ & $\begin{array}{c}-0.117 \\
{[0.087]}\end{array}$ & $\begin{array}{c}-0.142 \\
{[0.193]}\end{array}$ & $\begin{array}{l}-0.169 \\
{[0.183]}\end{array}$ \\
\hline Observations & 253 & & & 253 & & \\
\hline Group Late & $\begin{array}{c}-0.145 \\
{[0.088]}\end{array}$ & $\begin{array}{c}-0.609 \\
{[0.100]}\end{array}$ & $\begin{array}{c}0.282 \\
{[0.109]}\end{array}$ & $\begin{array}{c}-0.246 \\
{[0.070]}\end{array}$ & $\begin{array}{c}-0.515 \\
{[0.102]}\end{array}$ & $\begin{array}{c}0.090 \\
{[0.106]}\end{array}$ \\
\hline Observations & 455 & & & 455 & & \\
\hline
\end{tabular}

Notes: The coefficient of each group has been estimated separately, relative to Hardly using OLS or ANCOVA. In model I, there are no control variables and the bounds are classic Lee (2009) bounds. Model II includes the baseline outcome as control and employs the terciles of the baseline outcome to tighten the Lee bounds.The estimation of Lee bounds uses the Stata command by Tauchmann (2014).Standard errors in parenthesis.

Source: Own Data. 


\subsubsection{Education Outcomes}

Table C.49: Math score

\begin{tabular}{|c|c|c|c|c|c|c|}
\hline & \multicolumn{3}{|c|}{ I } & \multicolumn{3}{|c|}{ II } \\
\hline & OLS & Lower & Upper & ANCOVA & Lower & Upper \\
\hline \multirow[t]{2}{*}{ Group Always } & -0.056 & -0.050 & 0.622 & -0.149 & -0.154 & 0.194 \\
\hline & {$[0.113]$} & {$[0.128]$} & {$[0.121]$} & [0.084] & {$[0.135]$} & {$[0.147]$} \\
\hline Observations & 600 & & & 600 & & \\
\hline \multirow[t]{2}{*}{ Group Early } & 0.212 & 0.143 & 0.186 & -0.213 & -0.070 & -0.202 \\
\hline & {$[0.140]$} & {$[0.152]$} & [0.287] & [0.102] & {$[0.184]$} & {$[0.229]$} \\
\hline Observations & 253 & & & 253 & & \\
\hline \multirow[t]{2}{*}{ Group Late } & -0.043 & -0.084 & 0.593 & -0.163 & -0.380 & 0.274 \\
\hline & {$[0.114]$} & {$[0.136]$} & {$[0.124]$} & [0.083] & {$[0.140]$} & {$[0.139]$} \\
\hline Observations & 455 & & & 455 & & \\
\hline Baseline mean & 9.137 & & & 9.137 & & \\
\hline
\end{tabular}

Notes: The coefficient of each group has been estimated separately, relative to Hardly using OLS or ANCOVA. In model I, there are no control variables and the bounds are classic Lee (2009) bounds. Model II includes the baseline outcome as control and employs dummies indicating values below and above the median of the baseline outcome to tighten the Lee bounds.The estimation of Lee bounds uses the Stata command by Tauchmann (2014).Standard errors in parenthesis.

Source: Own Data.

Table C.50: Reading score

\begin{tabular}{|c|c|c|c|c|c|c|}
\hline & \multicolumn{3}{|c|}{ I } & \multicolumn{3}{|c|}{ II } \\
\hline & OLS & Lower & Upper & ANCOVA & Lower & Upper \\
\hline Group Always & $\begin{array}{c}-0.094 \\
{[0.123]}\end{array}$ & $\begin{array}{c}-0.103 \\
{[0.144]}\end{array}$ & $\begin{array}{c}0.730 \\
{[0.194]}\end{array}$ & & & \\
\hline Observations & 600 & & & & & \\
\hline Group Early & $\begin{array}{c}0.185 \\
{[0.155]}\end{array}$ & $\begin{array}{c}0.129 \\
{[0.179]}\end{array}$ & $\begin{array}{c}0.166 \\
{[0.280]}\end{array}$ & & & \\
\hline Observations & 253 & & & & & \\
\hline Group Late & $\begin{array}{c}-0.090 \\
{[0.124]}\end{array}$ & $\begin{array}{c}-0.132 \\
{[0.153]}\end{array}$ & $\begin{array}{c}0.673 \\
{[0.152]}\end{array}$ & & & \\
\hline Observations & 455 & & & & & \\
\hline Baseline mean & 1.764 & & & 1.764 & & \\
\hline
\end{tabular}

Notes: The coefficient of each group has been estimated separately, relative to Hardly using OLS or ANCOVA. In model I, there are no control variables and the bounds are classic Lee (2009) bounds. Model II includes the baseline outcome as control and employs dummies indicating values below and above the median of the baseline outcome to tighten the Lee bounds. The estimation of Lee bounds uses the Stata command by Tauchmann (2014).Standard errors in parenthesis.

Source: Own Data. 
Table C.51: School attendance

\begin{tabular}{lccccccc} 
& \multicolumn{3}{c}{ I } & & \multicolumn{3}{c}{ II } \\
\cline { 2 - 3 } \cline { 6 - 8 } & OLS & Lower & Upper & ANCOVA & Lower & Upper \\
\hline Group Always & 0.042 & -0.053 & 0.178 & & 0.075 & -0.034 & 0.185 \\
& {$[0.023]$} & {$[0.028]$} & {$[0.025]$} & {$[0.021]$} & {$[0.028]$} & {$[0.024]$} \\
Observations & 563 & & & 563 & & \\
\hline Group Early & -0.010 & -0.079 & 0.040 & -0.021 & -0.064 & -0.005 \\
& {$[0.028]$} & {$[0.039]$} & {$[0.040]$} & {$[0.026]$} & {$[0.050]$} & {$[0.040]$} \\
Observations & 212 & & & 212 & & \\
\hline Group Late & 0.078 & -0.051 & 0.225 & 0.118 & -0.015 & 0.234 \\
& {$[0.023]$} & {$[0.030]$} & {$[0.023]$} & {$[0.022]$} & {$[0.029]$} & {$[0.022]$} \\
Observations & 446 & & & 446 & & \\
\hline \hline Baseline mean & 0.751 & & \multicolumn{5}{c}{0.751} \\
\hline
\end{tabular}

Notes: The coefficient of each group has been estimated separately, relative to Hardly using OLS or ANCOVA. In model I, there are no control variables and the bounds are classic Lee (2009) bounds. Model II includes the baseline outcome as control and employs the quartiles of the baseline outcome to tighten the Lee bounds. The estimation of Lee bounds uses the Stata command by Tauchmann (2014).Standard errors in parenthesis.

Source: Own Data. 


\subsection{Multiple Hypothesis Corrected Sharpened q-Values}

\subsubsection{Health Outcomes}

Table C.52: Multiple Hypothesis Corrected Sharpened q-Values for Inverse Probability Weighted Effects on Hemoglobin and Anemia

Health Outcomes

\begin{tabular}{lcccc} 
Outcomes & Hemoglobin & Any Anemia & Mild Anemia & $\begin{array}{c}\text { Moderate } \\
\text { Anemia }\end{array}$ \\
& III & III & III & III \\
\hline Group Always & $0.260^{*}$ & -0.032 & -0.005 & -0.018 \\
& {$[0.110]$} & {$[0.046]$} & {$[0.035]$} & {$[0.027]$} \\
& $(0.019)$ & $(0.493)$ & $(0.895)$ & $(0.493)$ \\
Group Early & $0.260^{*}$ & -0.065 & 0.010 & $-0.086^{*}$ \\
& {$[0.126]$} & {$[0.049]$} & {$[0.038]$} & {$[0.034]$} \\
Group Late & $(0.040)$ & $(0.192)$ & $(0.787)$ & $(0.013)$ \\
& 0.202 & -0.019 & 0.030 & -0.042 \\
Baseline outcome & {$[0.130]$} & {$[0.052]$} & {$[0.040]$} & {$[0.028]$} \\
& $(0.124)$ & $(0.717)$ & $(0.455)$ & $(0.141)$ \\
\hline Mean of Outcome of Group Hardly & 12.134 & 0.280 & 0.161 & $0.157^{* * *}$ \\
Controls & Yes & Yes & Yes & Yes \\
Observations & 1,011 & 1,011 & 1,011 & 1,011 \\
\hline
\end{tabular}

Notes: Any anemia is defined as a hemoglobin value $<11.5 \mathrm{~g} / \mathrm{dL}$, mild anemia is defined as a hemoglobin value $\geq 11 \&<11.5 \mathrm{~g} / \mathrm{dL}$, moderate/severe anemia is defined as a hemoglobin value $<11 \mathrm{~g} / \mathrm{dL}$. Standard errors are clustered by PS-MS cluster and appear in brackets. Multiple hypothesis corrected sharpened q-values are in square brackets. $*$, **, $* * *$ denote significance at the $10 \%, 5 \%$ and $1 \%$ levels, respectively.

Source: Own Data. 


\subsubsection{Cognition Outcomes}

Table C.53: Multiple Hypothesis Corrected Sharpened q-Values for Inverse Probability Weighted Effects on Cognition Outcomes

\begin{tabular}{|c|c|c|c|c|c|c|}
\hline \multirow[b]{2}{*}{ Outcomes } & \multicolumn{3}{|c|}{ Cognition Outcomes } & \multirow[b]{2}{*}{$\begin{array}{c}\text { Progressive } \\
\text { Matrices } \\
\text { III }\end{array}$} & \multirow[b]{2}{*}{$\begin{array}{c}\text { Stroop Tests } \\
\text { III }\end{array}$} & \multirow[b]{2}{*}{$\begin{array}{c}\text { Cognitive } \\
\text { Index } \\
\text { III }\end{array}$} \\
\hline & $\begin{array}{c}\text { Block design } \\
\text { III }\end{array}$ & $\begin{array}{l}\text { Digit Span } \\
\text { Forward } \\
\text { III }\end{array}$ & $\begin{array}{c}\text { Digit Span } \\
\text { Backward } \\
\text { III }\end{array}$ & & & \\
\hline Group Always & $\begin{array}{c}-0.092 \\
{[0.069]} \\
(0.397)\end{array}$ & $\begin{array}{c}-0.012 \\
{[0.099]} \\
(0.820)\end{array}$ & $\begin{array}{l}-0.069 \\
{[0.074]} \\
(0.533)\end{array}$ & $\begin{array}{c}-0.195 \\
{[0.116]} \\
(0.373)\end{array}$ & $\begin{array}{c}-0.041 \\
{[0.135]} \\
(0.820)\end{array}$ & $\begin{array}{l}-0.192 * \\
{[0.095]} \\
(0.373)\end{array}$ \\
\hline Group Early & $\begin{array}{c}0.012 \\
{[0.094]} \\
(1.000)\end{array}$ & $\begin{array}{l}-0.163 \\
{[0.108]} \\
(0.670)\end{array}$ & $\begin{array}{l}-0.062 \\
{[0.088]} \\
(1.000)\end{array}$ & $\begin{array}{c}0.047 \\
{[0.178]} \\
(1.000)\end{array}$ & $\begin{array}{c}0.011 \\
{[0.146]} \\
(1.000)\end{array}$ & $\begin{array}{l}-0.175 \\
{[0.110]} \\
(0.670)\end{array}$ \\
\hline Group Late & $\begin{array}{c}-0.046 \\
{[0.073]} \\
(1.000)\end{array}$ & $\begin{array}{l}-0.051 \\
{[0.104]} \\
(1.000)\end{array}$ & $\begin{array}{l}-0.056 \\
{[0.092]} \\
(1.000)\end{array}$ & $\begin{array}{c}-0.151 \\
{[0.128]} \\
(1.000)\end{array}$ & $\begin{array}{l}-0.111 \\
{[0.145]} \\
(1.000)\end{array}$ & $\begin{array}{c}-0.137 \\
{[0.098]} \\
(1.000)\end{array}$ \\
\hline Baseline outcome & $\begin{array}{c}0.257 * * * \\
{[0.020]}\end{array}$ & $\begin{array}{c}0.410 * * * \\
{[0.032]}\end{array}$ & $\begin{array}{c}0.218 * * * \\
{[0.026]}\end{array}$ & $\begin{array}{c}0.300 * * * \\
{[0.044]}\end{array}$ & $\begin{array}{c}0.151 * * * \\
{[0.041]}\end{array}$ & $\begin{array}{c}0.549 * * * \\
{[0.030]}\end{array}$ \\
\hline Mean of Outcome of Group Hardly & 6.699 & 4.636 & 2.958 & 5.965 & 6.503 & 0.111 \\
\hline Controls & Yes & Yes & Yes & Yes & Yes & Yes \\
\hline Observations & 854 & 854 & 854 & 854 & 854 & 854 \\
\hline
\end{tabular}

Notes: Any anemia is defined as a hemoglobin value $<11.5 \mathrm{~g} / \mathrm{dL}$, mild anemia is defined as a hemoglobin value $\geq 11 \&<11.5 \mathrm{~g} / \mathrm{dL}$, moderate/severe anemia is defined as a hemoglobin value $<11 \mathrm{~g} / \mathrm{dL}$. Standard errors are clustered by PS-MS cluster and appear in brackets. Multiple hypothesis corrected sharpened q-values are in round brackets. *, **, *** denote significance at the $10 \%, 5 \%$ and $1 \%$ levels, respectively.

Source: Own Data. 


\subsubsection{Education Outcomes}

Table C.54: Multiple Hypothesis Corrected Sharpened q-Values for Inverse Probability Weighted Effects on Education Outcomes

Education Outcomes

\begin{tabular}{lccc} 
Outcomes & Math & Reading & $\begin{array}{c}\text { School } \\
\text { Attendance } \\
\text { III }\end{array}$ \\
\hline Group Always & III & III & 0.042 \\
& -0.087 & -0.038 & {$[0.036]$} \\
& {$[0.102]$} & {$[0.124]$} & $(1.000)$ \\
Group Early & $(1.000)$ & $(1.000)$ & -0.051 \\
& -0.098 & -0.128 & {$[0.050]$} \\
& {$[0.152]$} & {$[0.137]$} & $(1.000)$ \\
Group Late & $(1.000)$ & $(1.000)$ & $0.086 *$ \\
& -0.187 & -0.158 & {$[0.043]$} \\
Baseline outcome & {$[0.116]$} & {$[0.139]$} & $(0.165)$ \\
& $(0.165)$ & $(0.192)$ & $0.382^{* * *}$ \\
Mean of Outcome of Group Hardly & 12.594 & 2.853 & 0.590 \\
Controls & Yes & Yes & Yes \\
Observations & 854 & 854 & 763 \\
\hline
\end{tabular}

Notes: Any anemia is defined as a hemoglobin value $<11.5 \mathrm{~g} / \mathrm{dL}$, mild anemia is defined as a hemoglobin value $\geq 11 \&<11.5 \mathrm{~g} / \mathrm{dL}$, moderate/severe anemia is defined as a hemoglobin value $<11 \mathrm{~g} / \mathrm{dL}$. Standard errors are clustered by PS-MS cluster and appear in brackets. Multiple hypothesis corrected sharpened q-values are in round brackets. *, **, *** denote significance at the $10 \%, 5 \%$ and $1 \%$ levels, respectively.

Source: Own Data. 


\subsection{Ceiling Effects}

Figure C.4: Frequency of Math Score of School Children by Survey Wave

Distribution of math scores of school children at cognition test by survey wave

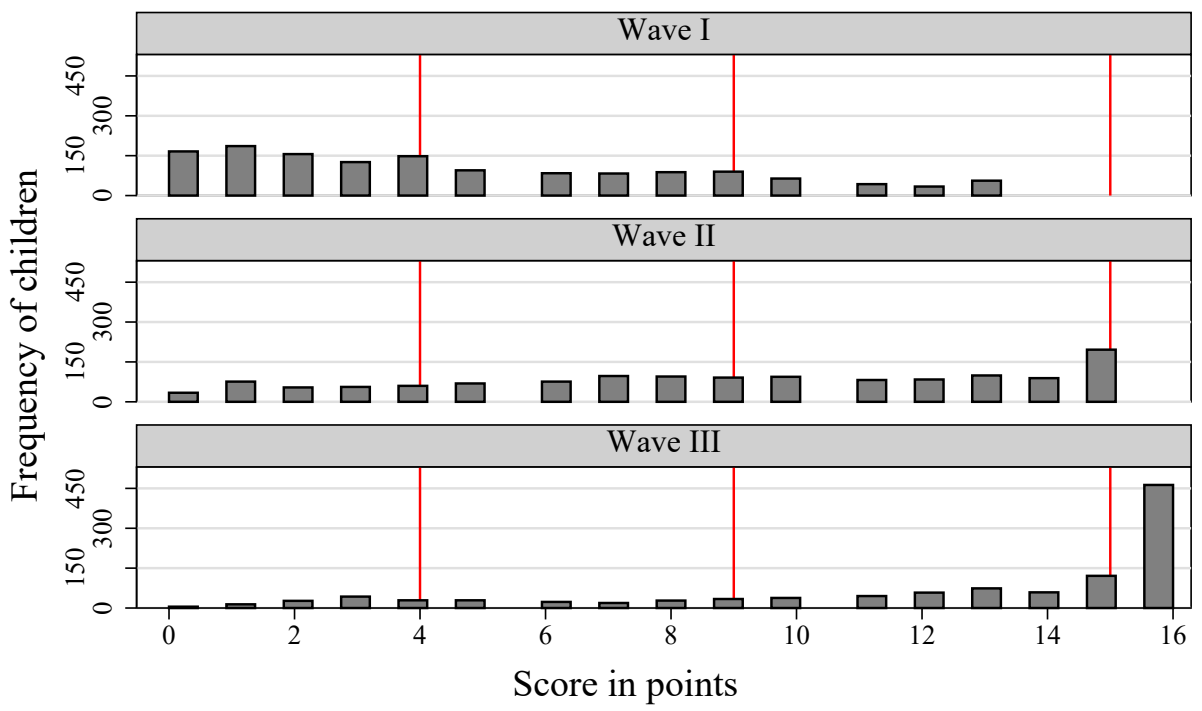

Notes: The red lines mark the increasing median over the three waves (4 at wave I, 9 at wave II, and 15 at wave III).

Source: Own Data.

Figure C.5: Frequency of Reading Score of School Children by Survey Wave

Distribution of reading scores of school children at cognition test by survey wave

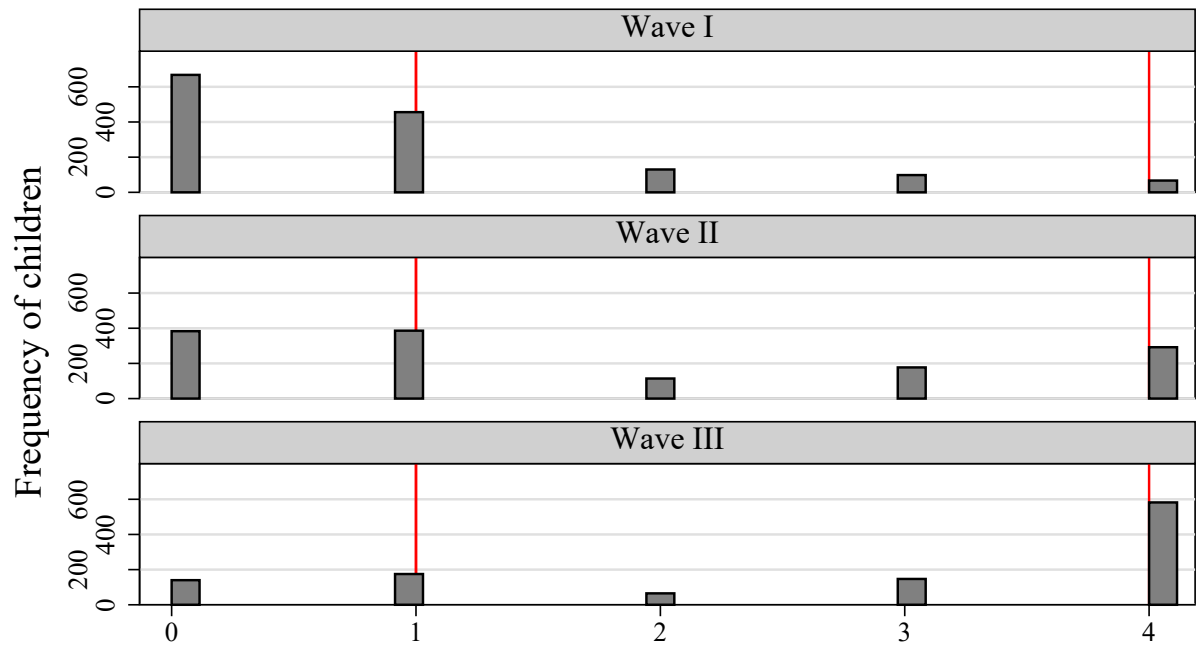

Reading ability from 0 (Cannot read any letter) to 4 (Can read story fluently) Notes: The red lines mark the increasing median over the three waves ( 1 at wave I and at wave II; 4 at wave III).

Source: Own Data. 


\section{Heterogeneous Effects}

\subsection{Attendance}

\subsubsection{Health Outcomes}

Figure C.6: Marginal Affects for Hemoglobin by Level of Attendance

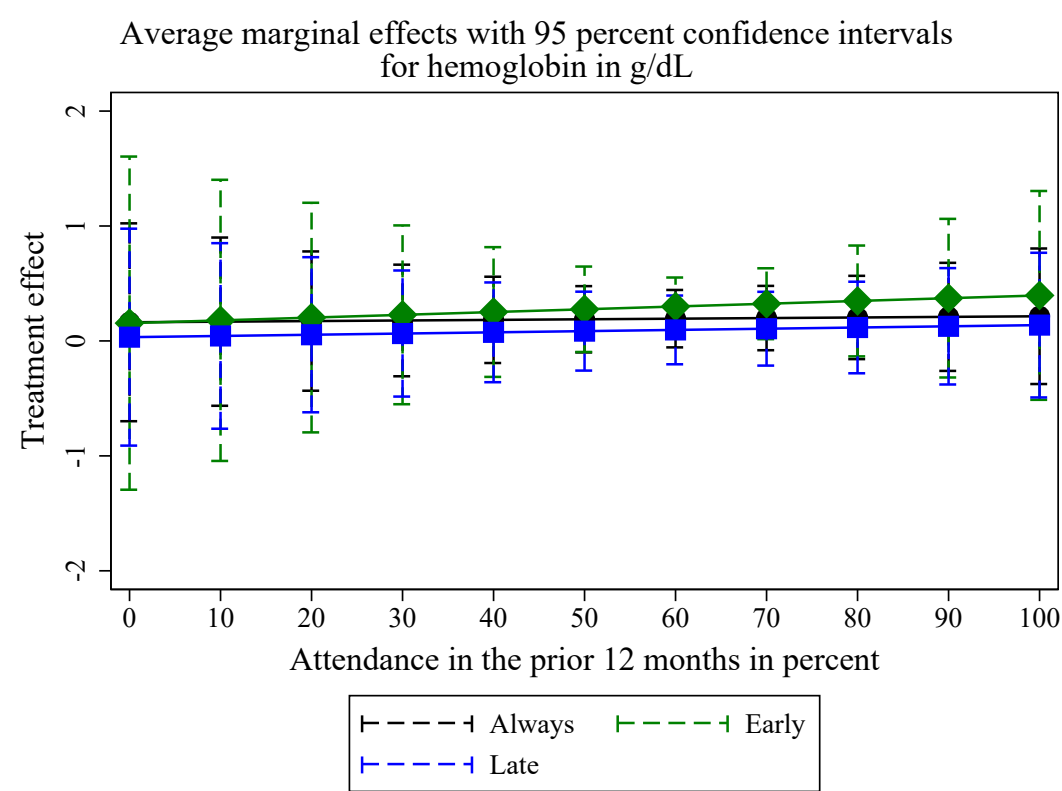

Figure C.7: Marginal Affects for Any Anemia by Level of Attendance

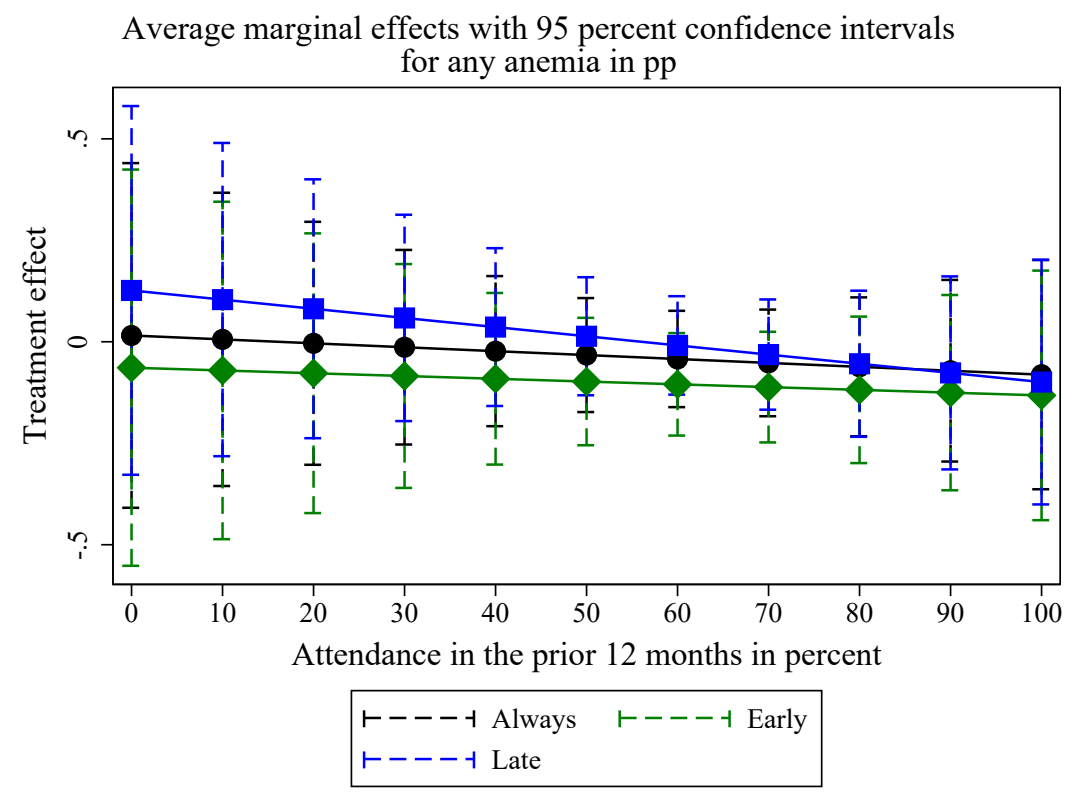


Figure C.8: Marginal Affects for Mild Anemia by Level of Attendance

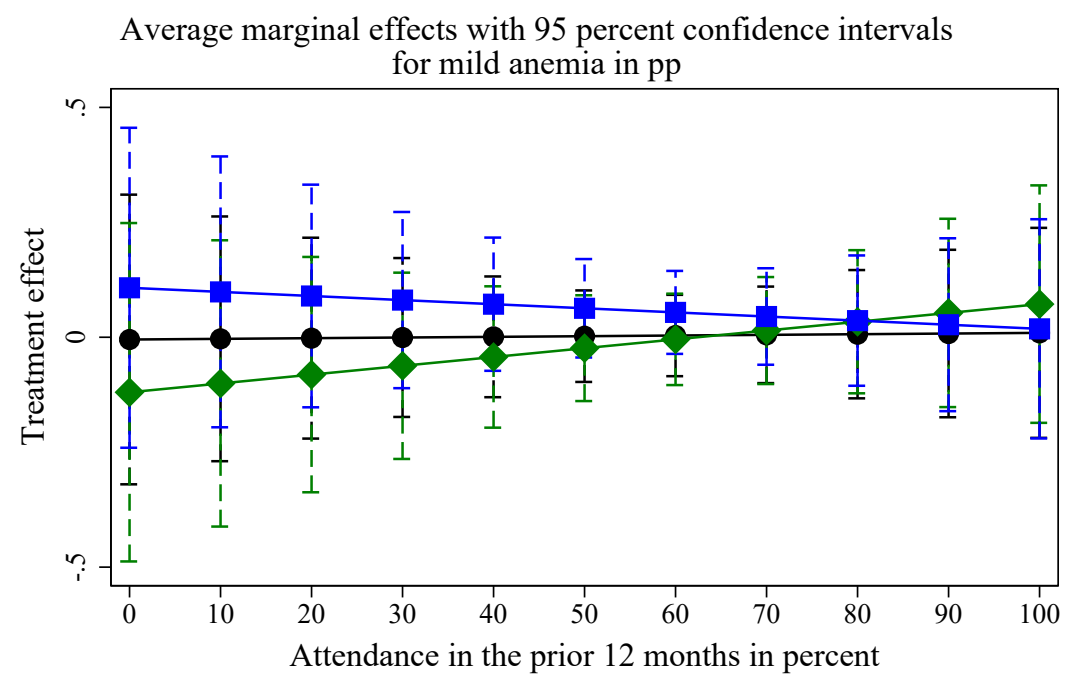

$\vdash ー-ー \dashv$ Always $\vdash---\dashv$ Early
$\vdash---\dashv$ Late

Figure C.9: Marginal Affects for Moderate and Severe Anemia by Level of Attendance

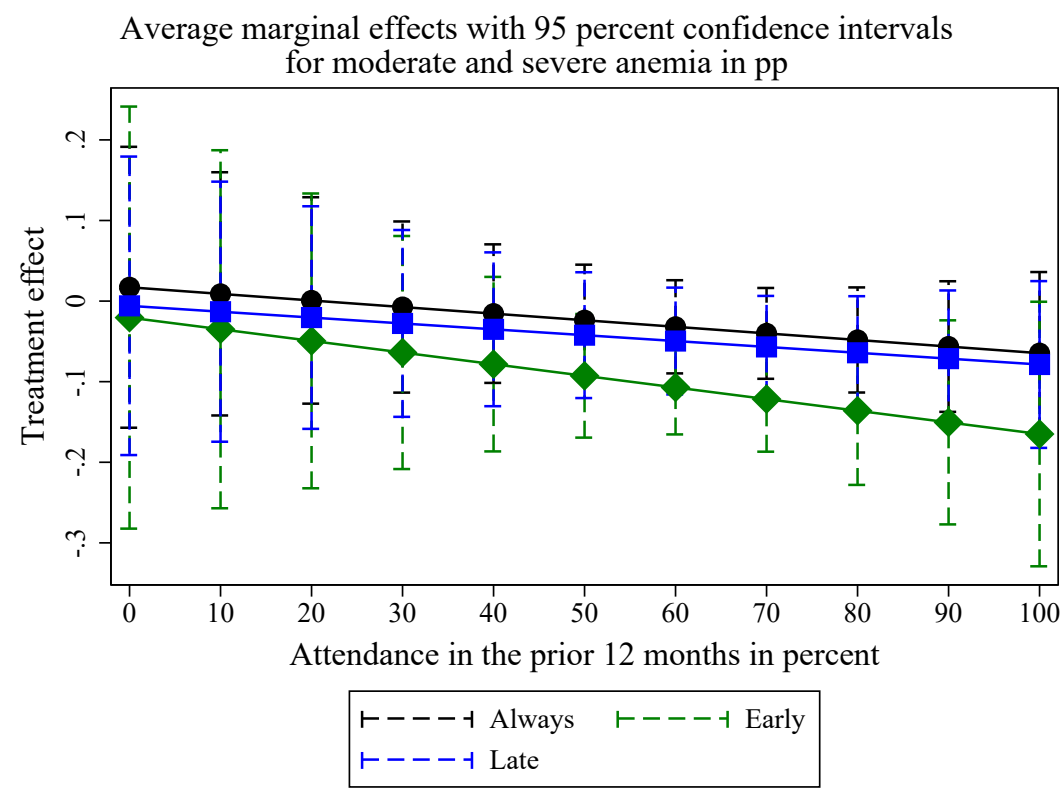




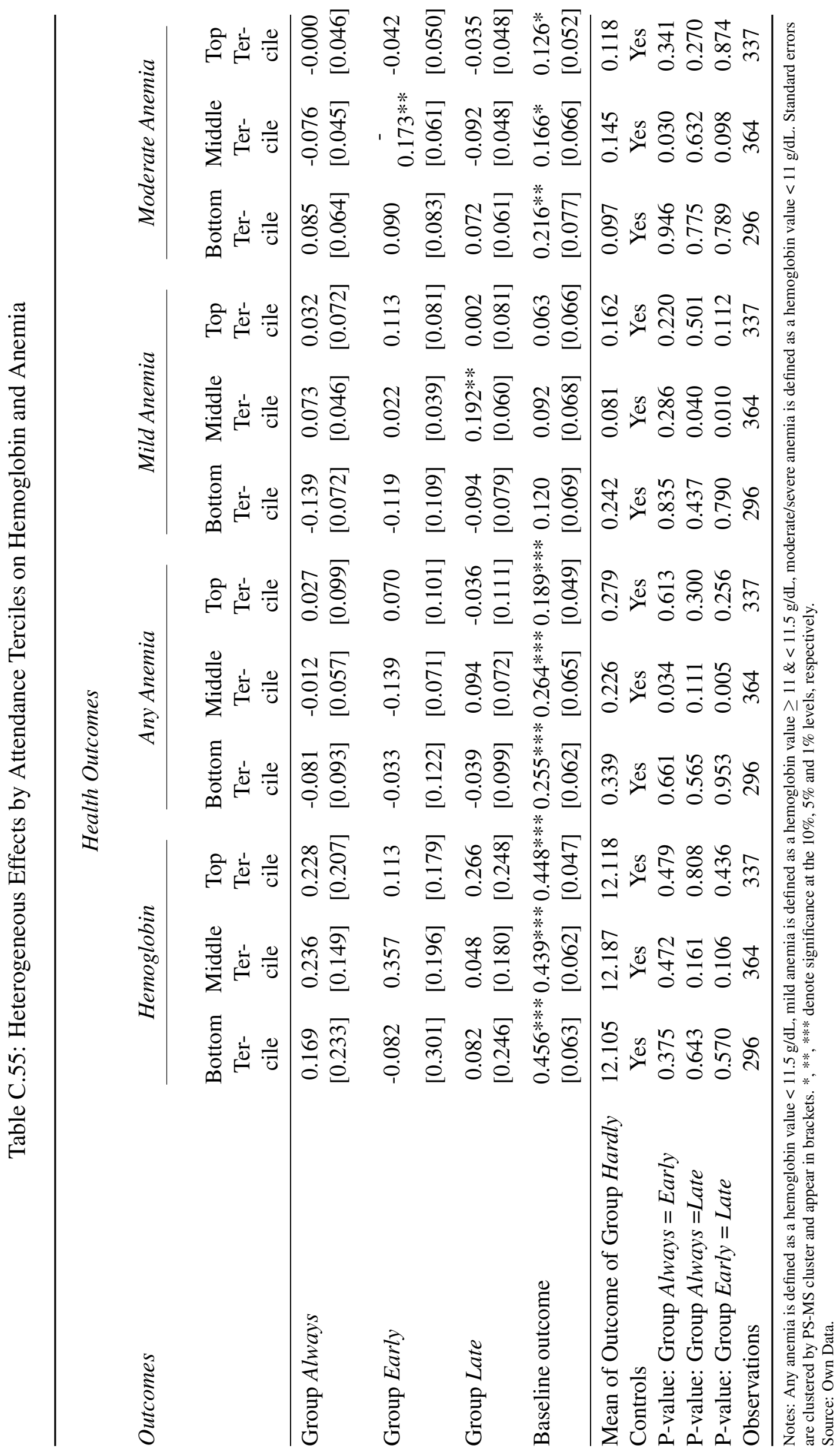




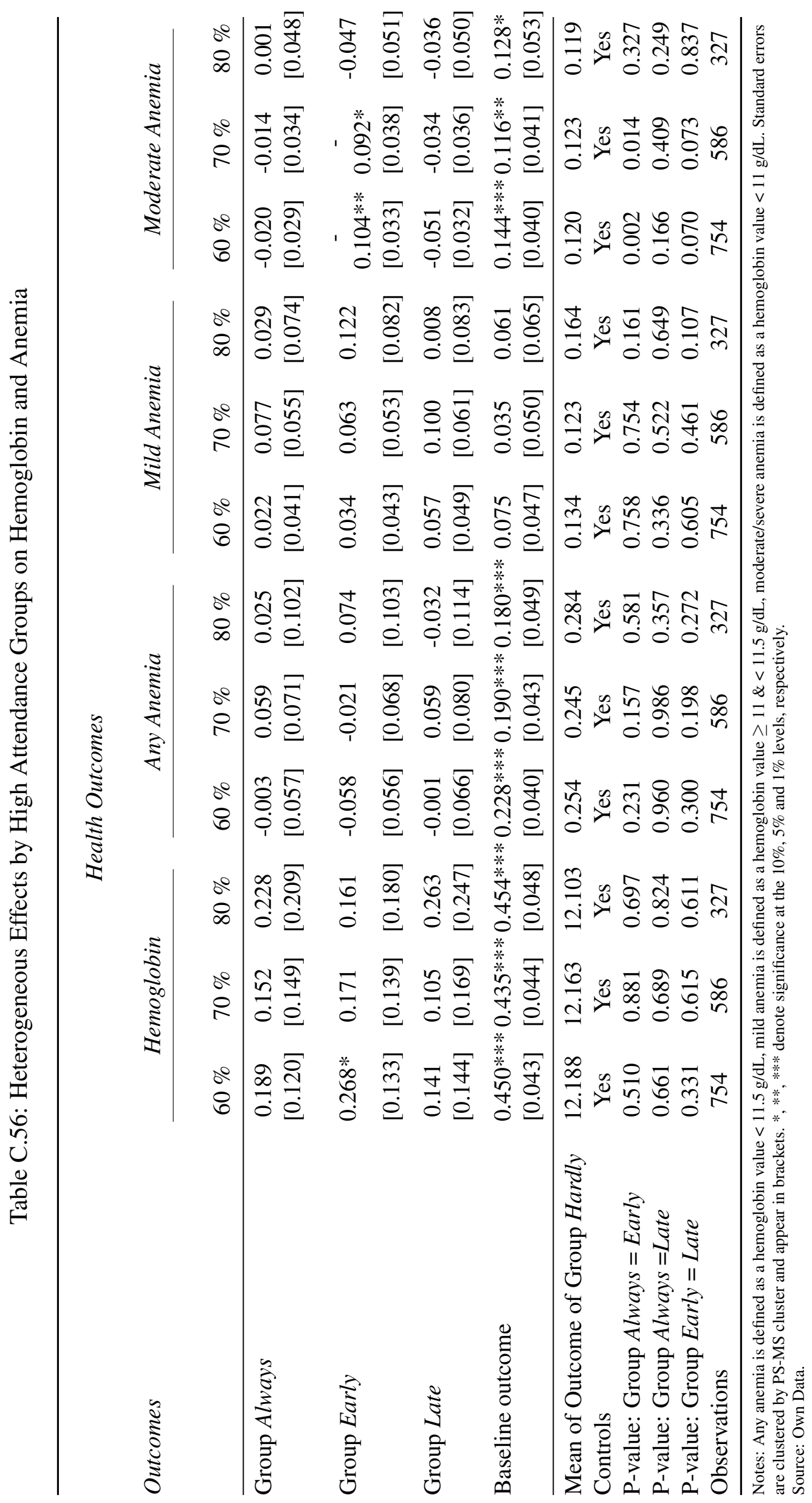




\subsubsection{Cognition Outcomes}

Figure C.10: Marginal Affects for Block Design by Level of Attendance

Average marginal effects with 95 percent confidence intervals for block design score in sd

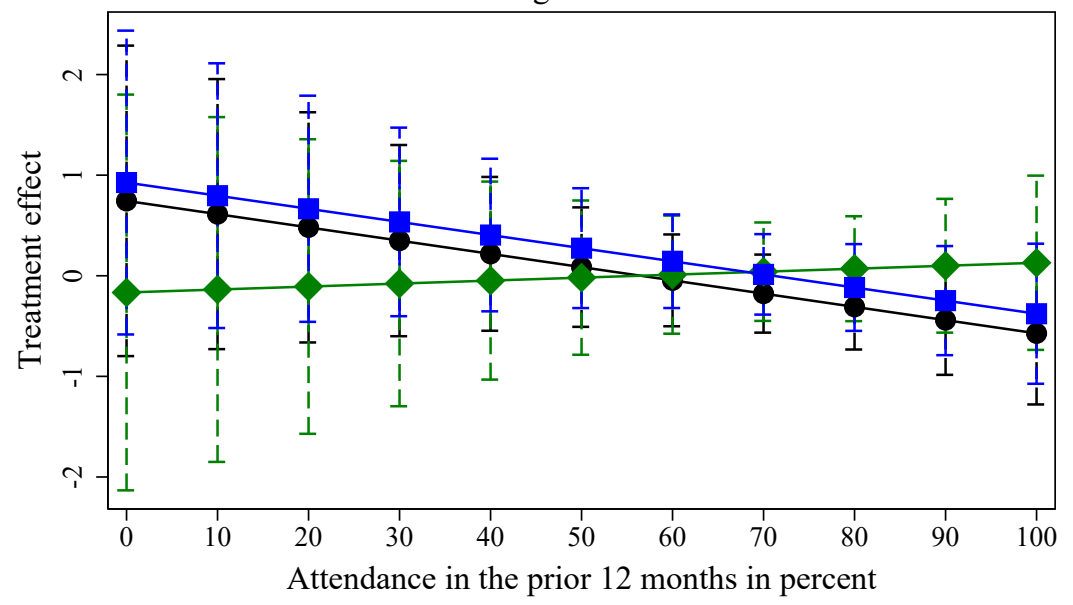

$\vdash---\dashv$ Always $\vdash---\dashv$ Early

$\vdash---\dashv$ Late

Figure C.11: Marginal Affects for Digit Span Forward by Level of Attendance

Average marginal effects with 95 percent confidence intervals for digit span forward score in sd

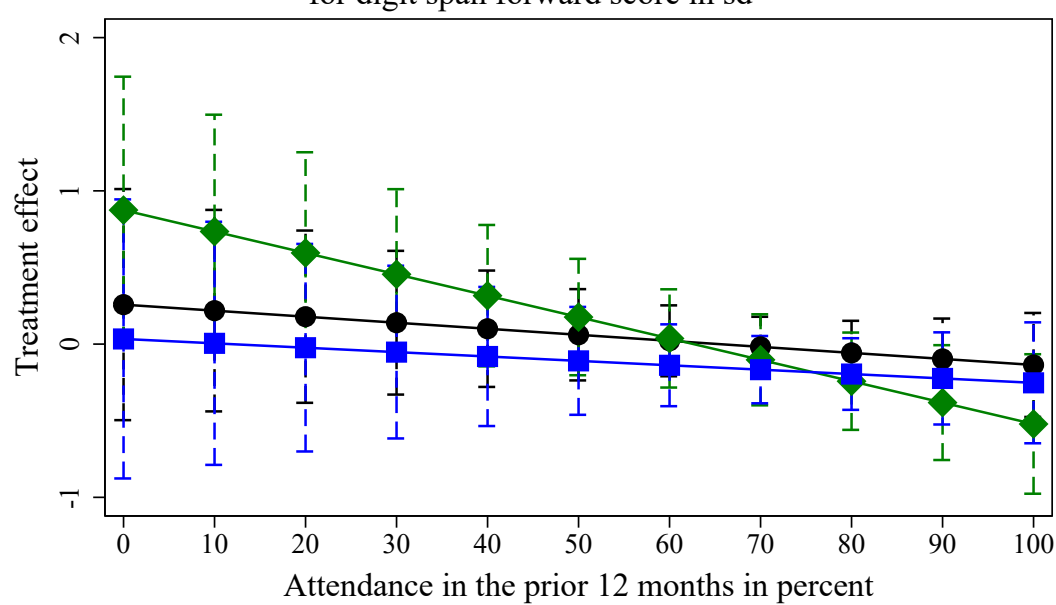

$\vdash---\dashv$ Always $\vdash---\dashv$ Early

$\vdash--\dashv$ Late 
Figure C.12: Marginal Affects for Digit Span Backward by Level of Attendance

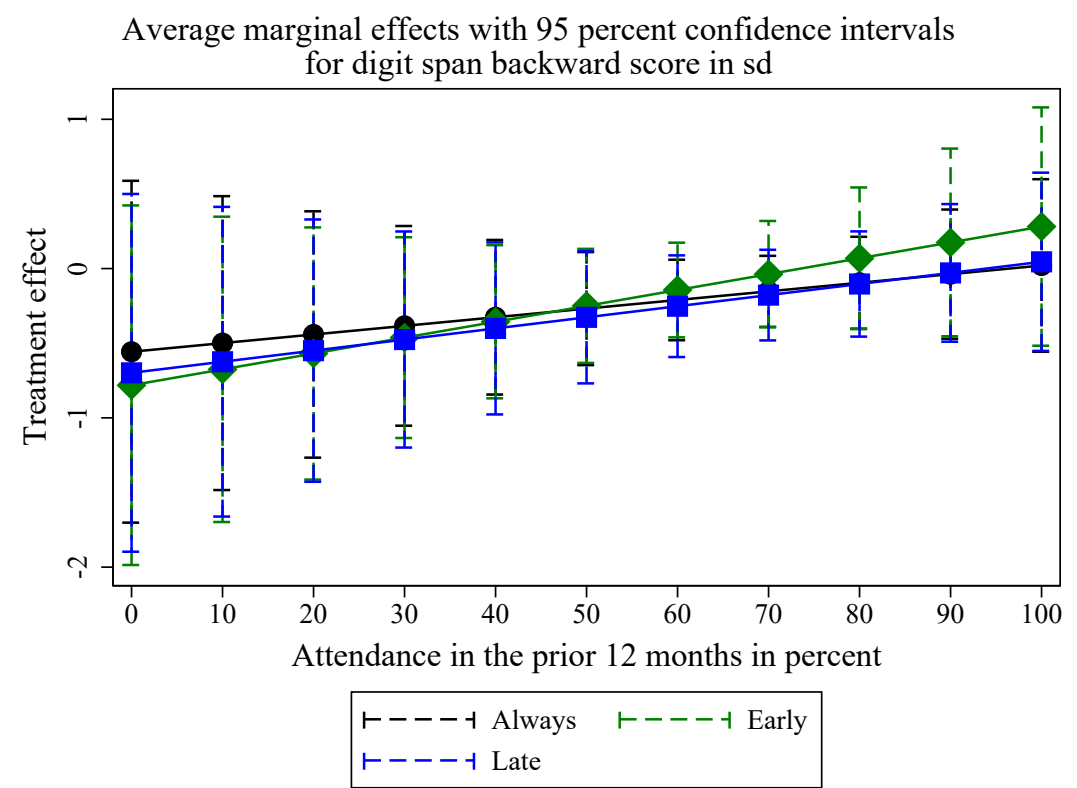

Figure C.13: Marginal Affects for Raven's Progressive Matrices by Level of Attendance

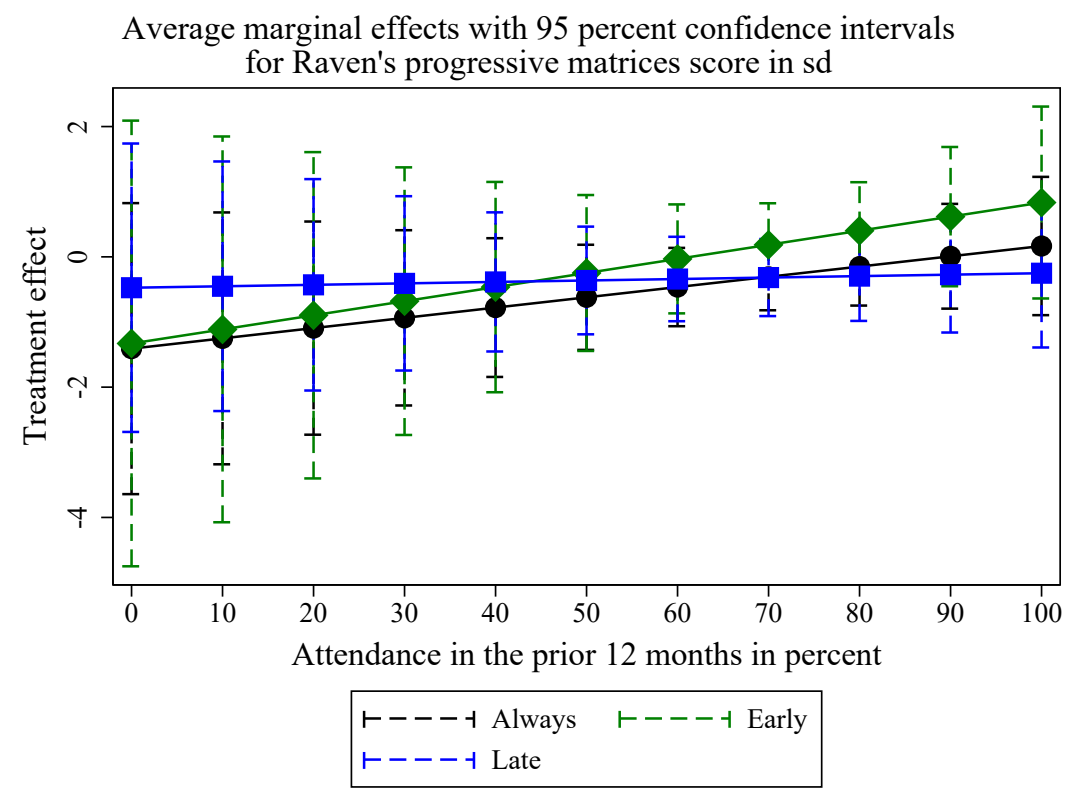


Figure C.14: Marginal Affects for Stroop Test by Level of Attendance

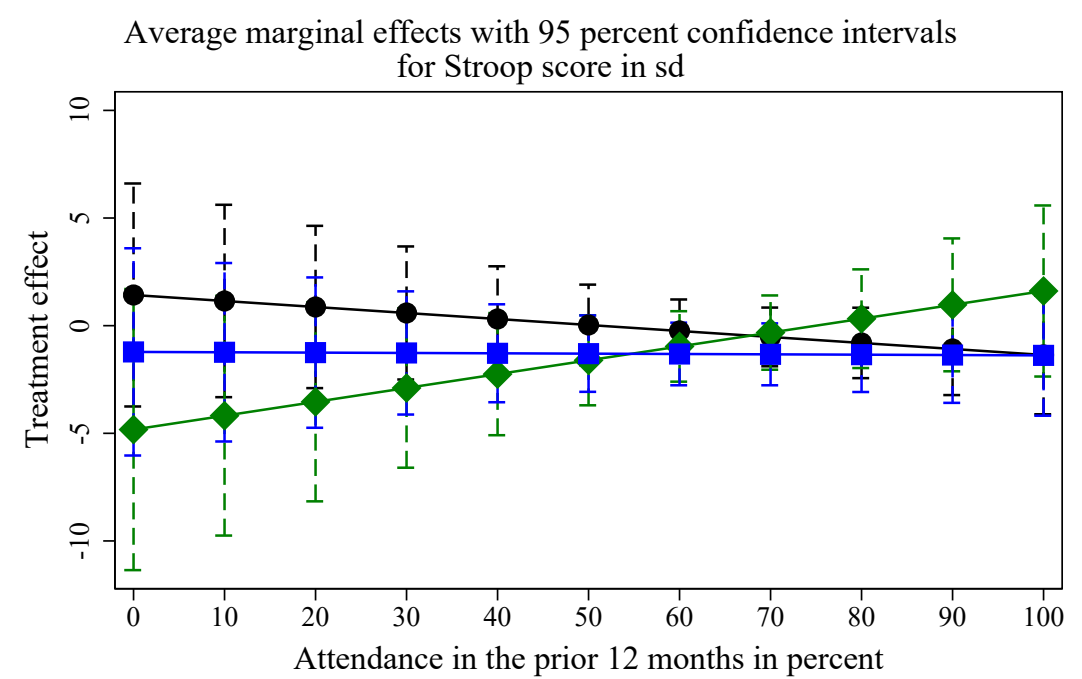

$\vdash ー-ー \dashv$ Always $\vdash---\dashv$ Early
$\vdash---\dashv$ Late

Figure C.15: Marginal Affects for Cognition Index by Level of Attendance

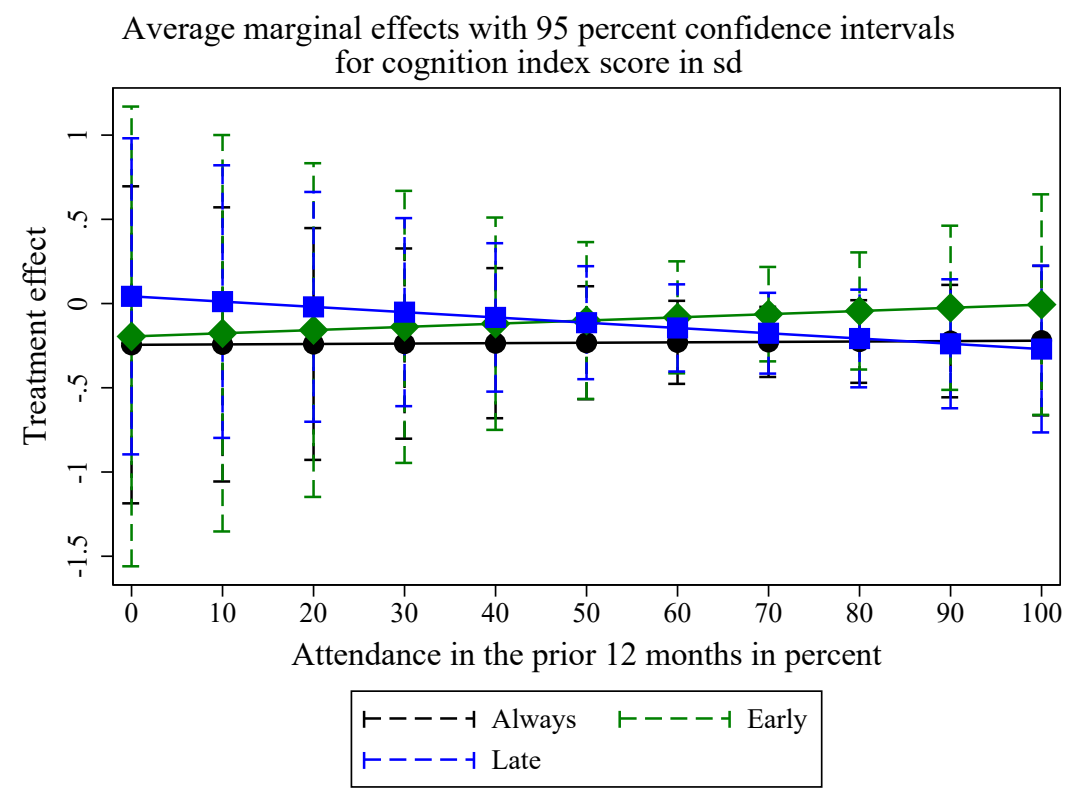




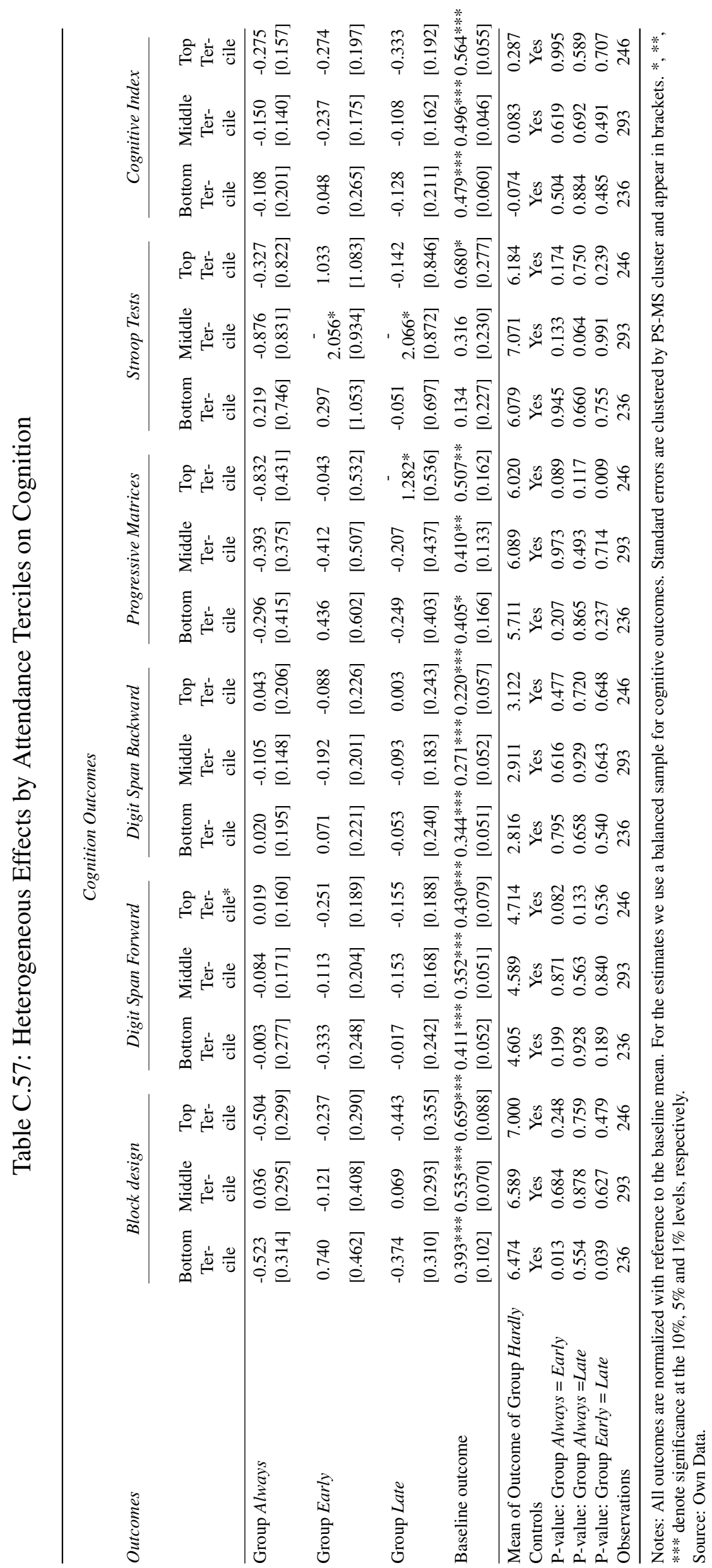




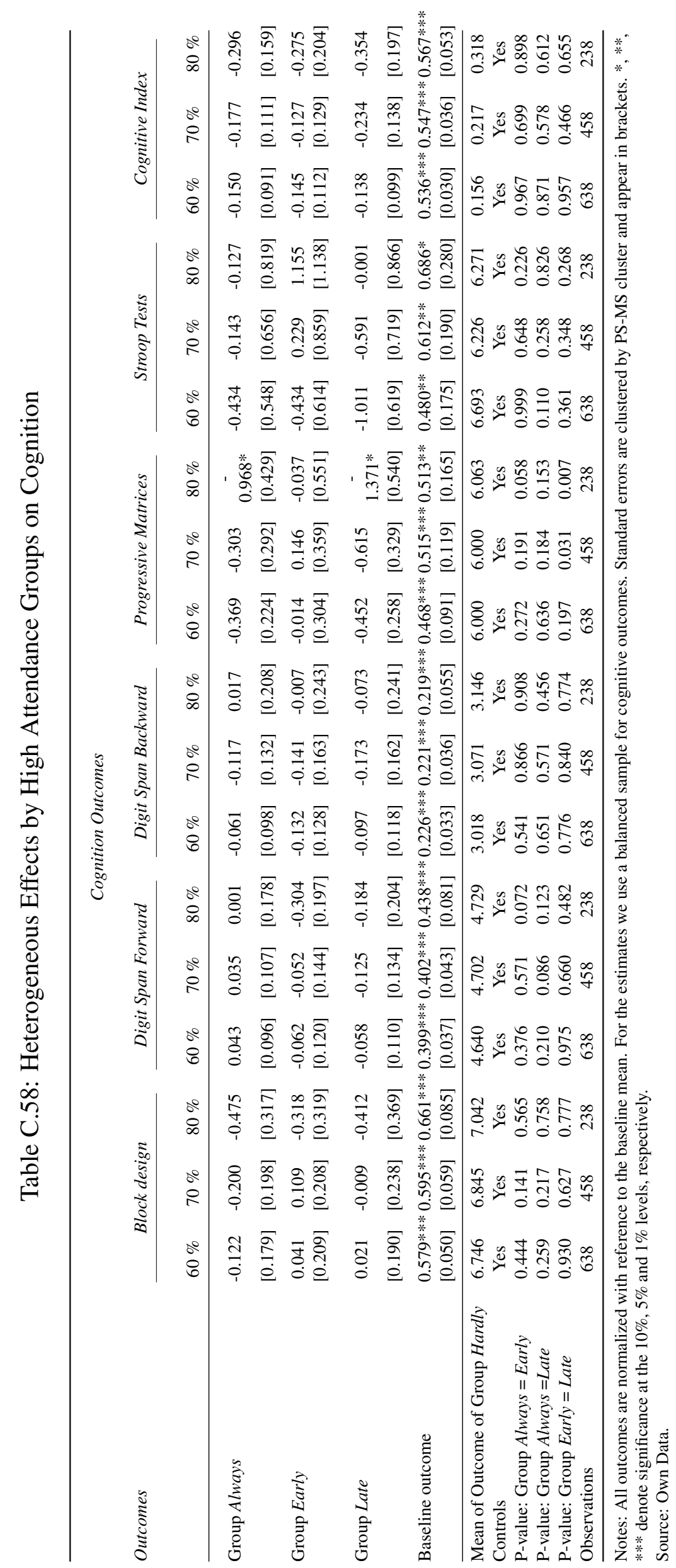




\subsubsection{Education Outcomes}

Figure C.16: Marginal Affects for Math Score by Level of Attendance

Average marginal effects with 95 percent confidence intervals

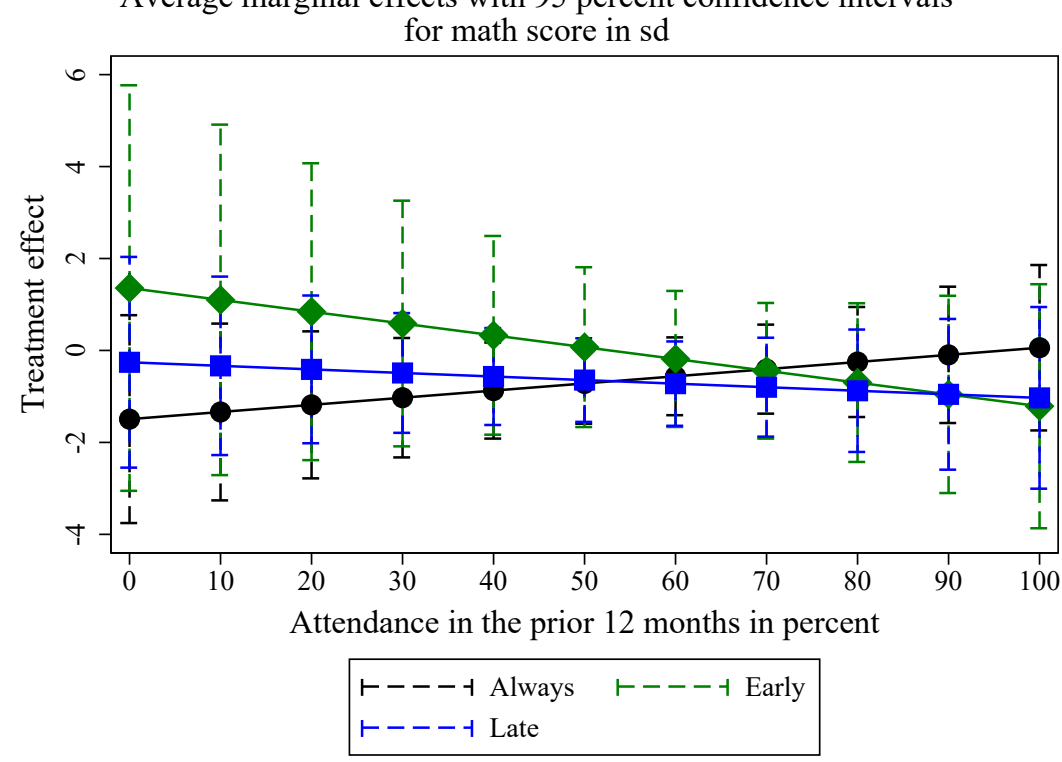

Figure C.17: Marginal Affects for Reading Score by Level of Attendance

Average marginal effects with 95 percent confidence intervals for reading score in sd

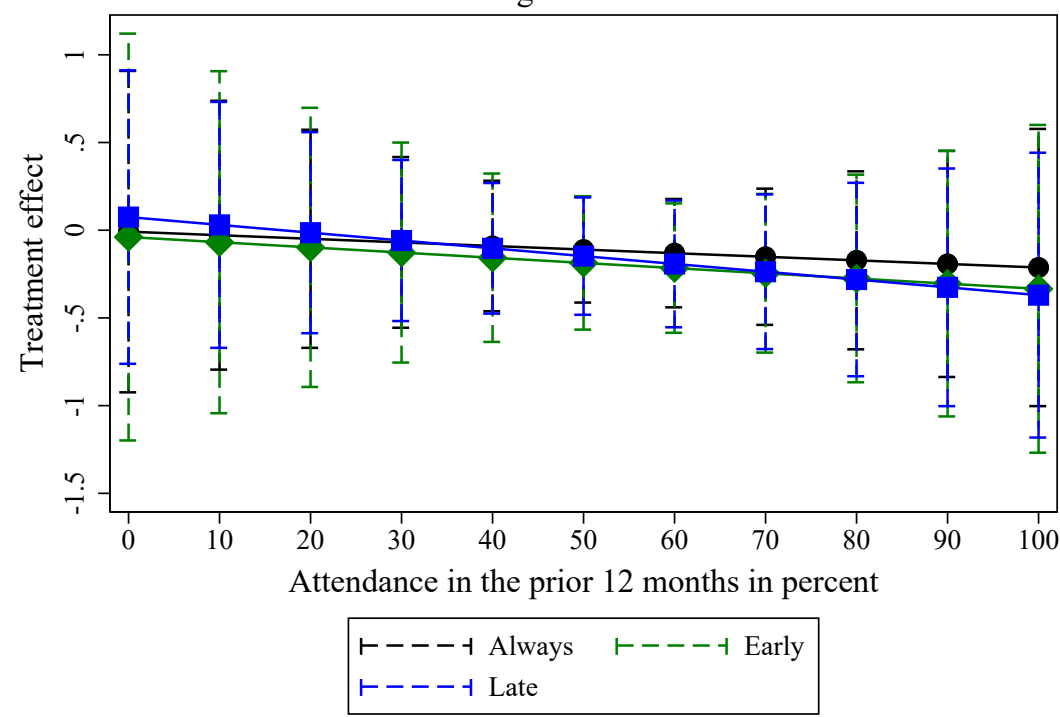


Table C.59: Heterogeneous Effects by Attendance Terciles on Education and Attendance

Education Outcomes

\begin{tabular}{|c|c|c|c|c|c|c|}
\hline \multirow[t]{2}{*}{ Outcomes } & \multicolumn{3}{|c|}{ Math } & \multicolumn{3}{|c|}{ Reading } \\
\hline & $\begin{array}{l}\text { Bottom } \\
\text { Ter- } \\
\text { cile }\end{array}$ & $\begin{array}{l}\text { Middle } \\
\text { Ter- } \\
\text { cile }\end{array}$ & $\begin{array}{l}\text { Top } \\
\text { Ter- } \\
\text { cile }\end{array}$ & $\begin{array}{c}\text { Bottom } \\
\text { Ter- } \\
\text { cile }\end{array}$ & $\begin{array}{l}\text { Middle } \\
\text { Ter- } \\
\text { cile }\end{array}$ & $\begin{array}{l}\text { Top } \\
\text { Ter- } \\
\text { cile }\end{array}$ \\
\hline Group Always & $\begin{array}{l}-0.896 \\
{[1.058]}\end{array}$ & $\begin{array}{c}0.326 \\
{[0.876]}\end{array}$ & $\begin{array}{l}0.502 \\
{[0.703]}\end{array}$ & $\begin{array}{c}0.147 \\
{[0.239]}\end{array}$ & $\begin{array}{c}0.233 \\
{[0.252]}\end{array}$ & $\begin{array}{l}-0.240 \\
{[0.375]}\end{array}$ \\
\hline Group Early & $\begin{array}{c}0.386 \\
{[1.233]}\end{array}$ & $\begin{array}{c}0.555 \\
{[0.930]}\end{array}$ & $\begin{array}{c}0.459 \\
{[0.688]}\end{array}$ & $\begin{array}{c}0.002 \\
{[0.274]}\end{array}$ & $\begin{array}{c}0.051 \\
{[0.264]}\end{array}$ & $\begin{array}{l}-0.070 \\
{[0.335]}\end{array}$ \\
\hline Group Late & $\begin{array}{l}-1.174 \\
{[0.940]}\end{array}$ & $\begin{array}{l}-0.236 \\
{[0.876]}\end{array}$ & $\begin{array}{l}-0.164 \\
{[0.830]}\end{array}$ & $\begin{array}{l}-0.142 \\
{[0.202]}\end{array}$ & $\begin{array}{l}-0.034 \\
{[0.268]}\end{array}$ & $\begin{array}{l}-0.227 \\
{[0.425]}\end{array}$ \\
\hline Baseline outcome & $\begin{array}{l}2.736 * * \\
{[0.241]}\end{array}$ & $\begin{array}{l}2.345 * * * \\
{[0.248]}\end{array}$ & $\begin{array}{l}2.522 * * \\
{[0.241]}\end{array}$ & $\begin{array}{l}0.839 * * \\
{[0.068]}\end{array}$ & $\begin{array}{l}0.711 * * * \\
{[0.046]}\end{array}$ & $\begin{array}{l}0.568 * * \\
{[0.060]}\end{array}$ \\
\hline Mean of Outcome of Group Hardly & 11.500 & 12.679 & 13.347 & 2.211 & 2.964 & 3.224 \\
\hline Controls & Yes & Yes & Yes & Yes & Yes & Yes \\
\hline P-value: Group Always = Early & 0.257 & 0.771 & 0.930 & 0.595 & 0.416 & 0.482 \\
\hline P-value: Group Always =Late & 0.683 & 0.293 & 0.169 & 0.109 & 0.148 & 0.949 \\
\hline P-value: Group Early = Late & 0.189 & 0.358 & 0.314 & 0.603 & 0.735 & 0.586 \\
\hline Observations & 236 & 293 & 246 & 236 & 293 & 246 \\
\hline
\end{tabular}

Notes: All outcomes, except attendance, are normalized with reference to the baseline mean. For the estimates we use a balanced sample for education outcomes except for attendance, which is based on its own balanced sample. Standard errors are clustered by PS-MS cluster and appear in brackets. *, **,*** denote significance at the $10 \%, 5 \%$ and $1 \%$ levels, respectively.

Source: Own Data. 
Table C.60: Heterogeneous Effects by High Attendance Groups on Education and Attendance Education Outcomes

\begin{tabular}{|c|c|c|c|c|c|c|}
\hline \multirow[t]{2}{*}{ Outcomes } & \multicolumn{3}{|c|}{ Math } & \multicolumn{3}{|c|}{ Reading } \\
\hline & $60 \%$ & $70 \%$ & $80 \%$ & $60 \%$ & $70 \%$ & $80 \%$ \\
\hline Group Always & $\begin{array}{l}-0.071 \\
{[0.493]}\end{array}$ & $\begin{array}{l}-0.223 \\
{[0.547]}\end{array}$ & $\begin{array}{c}0.501 \\
{[0.665]}\end{array}$ & $\begin{array}{l}-0.007 \\
{[0.175]}\end{array}$ & $\begin{array}{l}-0.304 \\
{[0.221]}\end{array}$ & $\begin{array}{l}-0.270 \\
{[0.366]}\end{array}$ \\
\hline Group Early & $\begin{array}{l}-0.374 \\
{[0.661]}\end{array}$ & $\begin{array}{l}-0.568 \\
{[0.809]}\end{array}$ & $\begin{array}{c}0.265 \\
{[0.677]}\end{array}$ & $\begin{array}{l}-0.204 \\
{[0.189]}\end{array}$ & $\begin{array}{l}-0.270 \\
{[0.232]}\end{array}$ & $\begin{array}{l}-0.036 \\
{[0.338]}\end{array}$ \\
\hline Group Late & $\begin{array}{l}-0.607 \\
{[0.549]}\end{array}$ & $\begin{array}{l}-0.856 \\
{[0.680]}\end{array}$ & $\begin{array}{l}-0.309 \\
{[0.806]}\end{array}$ & $\begin{array}{l}-0.155 \\
{[0.199]}\end{array}$ & $\begin{array}{l}-0.341 \\
{[0.261]}\end{array}$ & $\begin{array}{l}-0.319 \\
{[0.405]}\end{array}$ \\
\hline Baseline outcome & $\begin{array}{l}2.387 * * * \\
{[0.169]}\end{array}$ & $\begin{array}{l}2.408 * * * \\
{[0.207]}\end{array}$ & $\begin{array}{l}2.506 * * * \\
{[0.238]}\end{array}$ & $\begin{array}{l}0.666 * * * \\
{[0.038]}\end{array}$ & $\begin{array}{c}0.628 * * * \\
{[0.044]}\end{array}$ & $\begin{array}{l}0.567 * * \\
{[0.063]}\end{array}$ \\
\hline Mean of Outcome of Group Hardly & 13.000 & 13.119 & 13.563 & 3.035 & 3.202 & 3.292 \\
\hline Controls & Yes & Yes & Yes & Yes & Yes & Yes \\
\hline P-value: Group Always = Early & 0.621 & 0.631 & 0.658 & 0.234 & 0.863 & 0.360 \\
\hline P-value: Group Always = Late & 0.123 & 0.180 & 0.096 & 0.273 & 0.829 & 0.809 \\
\hline P-value: Group Early = Late & 0.718 & 0.714 & 0.377 & 0.787 & 0.746 & 0.334 \\
\hline Observations & 638 & 458 & 238 & 638 & 458 & 238 \\
\hline
\end{tabular}

Notes: All outcomes, except attendance, are normalized with reference to the baseline mean. For the estimates we use a balanced sample for education outcomes except for attendance, which is based on its own balanced sample. Standard errors are clustered by PS-MS cluster and appear in brackets. *,**,*** denote significance at the $10 \%, 5 \%$ and $1 \%$ levels, respectively.

Source: Own Data. 


\section{D $\mid$ Essay 3}

\section{Comparison Believed and Measured Probabilities of Com- petitors}

Table D.1: Mean Comparison of Believed and Measured Values by Number of Solved Task for Competing Child Without Known Gender

\begin{tabular}{|c|c|c|c|c|c|c|}
\hline $\begin{array}{l}\text { Number of } \\
\text { Solved Tasks }\end{array}$ & Observations & $\begin{array}{l}\text { Believed } \\
\text { mean [sd] }\end{array}$ & $\begin{array}{l}\text { Measured } \\
\text { mean [sd] }\end{array}$ & $\begin{array}{l}\text { t-test } \\
\text { p-value }\end{array}$ & $\begin{array}{l}\text { Wilcoxon } \\
\text { p-value }\end{array}$ & $\begin{array}{l}\text { Sign test } \\
\text { p-value }\end{array}$ \\
\hline 0 & 92 & $\begin{array}{c}0.079 \\
{[0.087]}\end{array}$ & $\begin{array}{c}0.027 \\
{[0.047]}\end{array}$ & 0.000 & 0.000 & 0.000 \\
\hline 1 & 92 & $\begin{array}{c}0.137 \\
{[0.102]}\end{array}$ & $\begin{array}{c}0.155 \\
{[0.078]}\end{array}$ & 0.158 & 0.114 & 0.208 \\
\hline 2 & 92 & $\begin{array}{c}0.163 \\
{[0.147]}\end{array}$ & $\begin{array}{c}0.227 \\
{[0.095]}\end{array}$ & 0.000 & 0.000 & 0.000 \\
\hline 3 & 92 & $\begin{array}{c}0.138 \\
{[0.092]}\end{array}$ & $\begin{array}{c}0.221 \\
{[0.124]}\end{array}$ & 0.000 & 0.000 & 0.001 \\
\hline 4 & 92 & $\begin{array}{c}0.153 \\
{[0.094]}\end{array}$ & $\begin{array}{c}0.164 \\
{[0.107]}\end{array}$ & 0.439 & 0.533 & 0.602 \\
\hline 5 & 92 & $\begin{array}{c}0.145 \\
{[0.127]}\end{array}$ & $\begin{array}{c}0.143 \\
{[0.068]}\end{array}$ & 0.908 & 0.347 & 0.246 \\
\hline 6 & 92 & $\begin{array}{c}0.185 \\
{[0.182]}\end{array}$ & $\begin{array}{c}0.063 \\
{[0.078]}\end{array}$ & 0.000 & 0.000 & 0.000 \\
\hline
\end{tabular}

Notes: All tests are two-tailed. The abbreviation sd stands for standard deviation. 
Table D.2: Mean Comparison of Believed and Measured Values by Number of Solved Task for Competing Girl

\begin{tabular}{|c|c|c|c|c|c|c|}
\hline $\begin{array}{l}\text { Number of } \\
\text { Solved Tasks }\end{array}$ & Observations & $\begin{array}{l}\text { Believed } \\
\text { mean [sd] }\end{array}$ & $\begin{array}{l}\text { Measured } \\
\text { mean [sd] }\end{array}$ & $\begin{array}{l}\text { t-test } \\
\text { p-value }\end{array}$ & $\begin{array}{l}\text { Wilcoxon } \\
\text { p-value }\end{array}$ & $\begin{array}{l}\text { Sign test } \\
\text { p-value }\end{array}$ \\
\hline 0 & 83 & $\begin{array}{c}0.094 \\
{[0.105]}\end{array}$ & $\begin{array}{c}0.014 \\
{[0.050]}\end{array}$ & 0.000 & 0.000 & 0.000 \\
\hline 1 & 83 & $\begin{array}{c}0.137 \\
{[0.079]}\end{array}$ & $\begin{array}{c}0.119 \\
{[0.097]}\end{array}$ & 0.157 & 0.122 & 0.910 \\
\hline 2 & 83 & $\begin{array}{c}0.141 \\
{[0.086]}\end{array}$ & $\begin{array}{c}0.228 \\
{[0.115]}\end{array}$ & 0.000 & 0.000 & 0.000 \\
\hline 3 & 83 & $\begin{array}{c}0.169 \\
{[0.092]}\end{array}$ & $\begin{array}{c}0.235 \\
{[0.104]}\end{array}$ & 0.000 & 0.000 & 0.000 \\
\hline 4 & 83 & $\begin{array}{c}0.161 \\
{[0.093]}\end{array}$ & $\begin{array}{c}0.217 \\
{[0.144]}\end{array}$ & 0.003 & 0.004 & 0.075 \\
\hline 5 & 83 & $\begin{array}{c}0.153 \\
{[0.105]}\end{array}$ & $\begin{array}{c}0.144 \\
{[0.095]}\end{array}$ & 0.512 & 0.693 & 0.822 \\
\hline 6 & 83 & $\begin{array}{c}0.145 \\
{[0.114]}\end{array}$ & $\begin{array}{c}0.043 \\
{[0.066]}\end{array}$ & 0.000 & 0.000 & 0.000 \\
\hline
\end{tabular}

Notes: All tests are two-tailed. The abbreviation sd stands for standard deviation.

Source: Own Data.

Table D.3: Mean Comparison of Believed and Measured Values by Number of Solved Task for Competing Boy

\begin{tabular}{|c|c|c|c|c|c|c|}
\hline $\begin{array}{l}\text { Number of } \\
\text { Solved Tasks }\end{array}$ & Observations & $\begin{array}{l}\text { Believed } \\
\text { mean [sd] }\end{array}$ & $\begin{array}{l}\text { Measured } \\
\text { mean [sd] }\end{array}$ & $\begin{array}{l}\text { t-test } \\
\text { p-value }\end{array}$ & $\begin{array}{l}\text { Wilcoxon } \\
\text { p-value }\end{array}$ & $\begin{array}{l}\text { Sign test } \\
\text { p-value }\end{array}$ \\
\hline 0 & 91 & $\begin{array}{c}0.089 \\
{[0.116]}\end{array}$ & $\begin{array}{c}0.036 \\
{[0.082]}\end{array}$ & 0.001 & 0.001 & 0.001 \\
\hline 1 & 91 & $\begin{array}{c}0.120 \\
{[0.088]}\end{array}$ & $\begin{array}{c}0.171 \\
{[0.186]}\end{array}$ & 0.018 & 0.066 & 0.434 \\
\hline 2 & 91 & $\begin{array}{c}0.143 \\
{[0.087]}\end{array}$ & $\begin{array}{c}0.144 \\
{[0.083]}\end{array}$ & 0.912 & 0.619 & 0.668 \\
\hline 3 & 91 & $\begin{array}{c}0.158 \\
{[0.127]}\end{array}$ & $\begin{array}{c}0.203 \\
{[0.158]}\end{array}$ & 0.034 & 0.061 & 0.050 \\
\hline 4 & 91 & $\begin{array}{c}0.159 \\
{[0.112]}\end{array}$ & $\begin{array}{c}0.171 \\
{[0.150]}\end{array}$ & 0.533 & 0.657 & 1.000 \\
\hline 5 & 91 & $\begin{array}{c}0.147 \\
{[0.120]}\end{array}$ & $\begin{array}{c}0.199 \\
{[0.165]}\end{array}$ & 0.014 & 0.040 & 1.000 \\
\hline 6 & 91 & $\begin{array}{c}0.184 \\
{[0.163]}\end{array}$ & $\begin{array}{c}0.077 \\
{[0.106]}\end{array}$ & 0.000 & 0.000 & 0.000 \\
\hline
\end{tabular}

Notes: All tests are two-tailed. The abbreviation sd stands for standard deviation. 
2 Robustness Checks: Regressions 


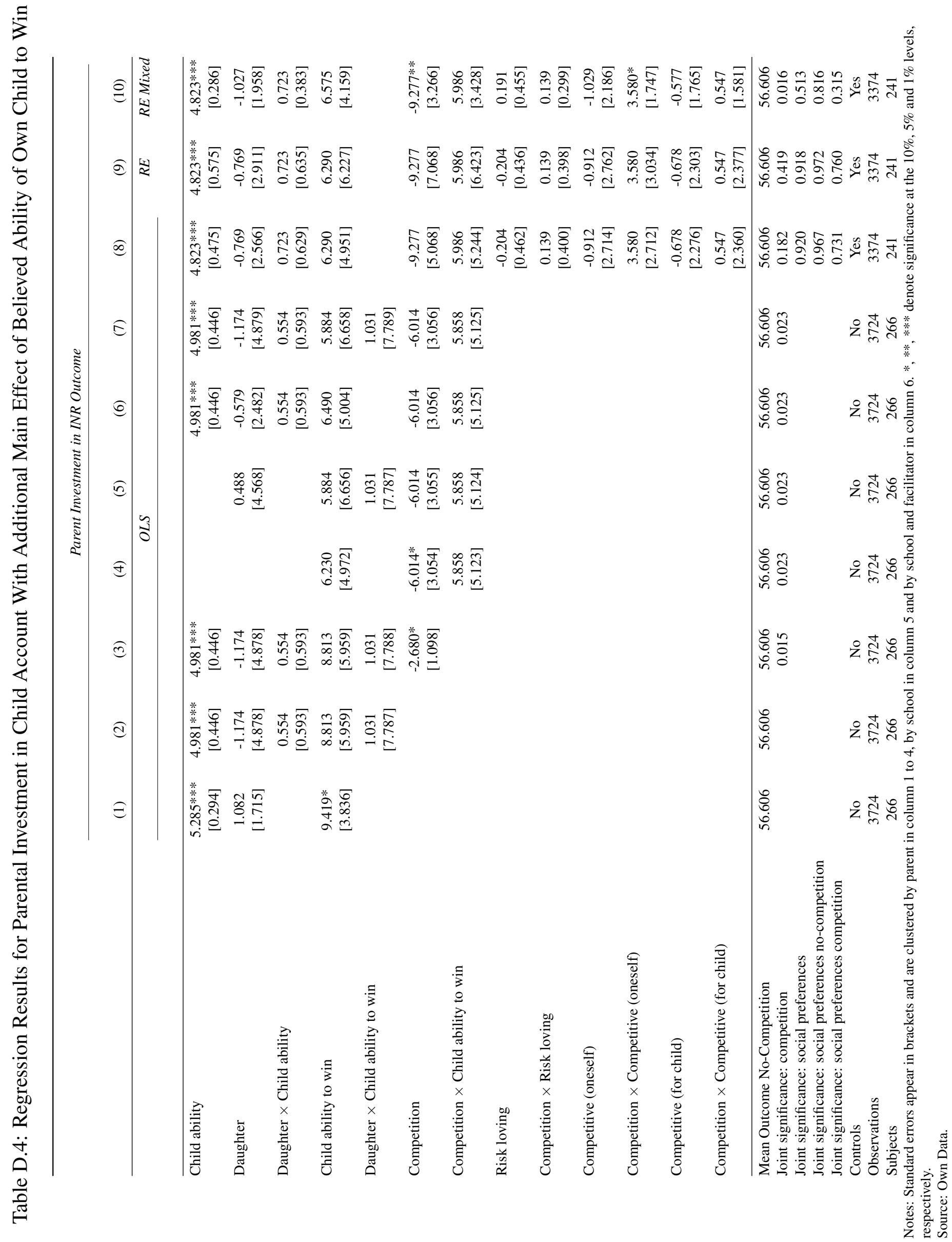

